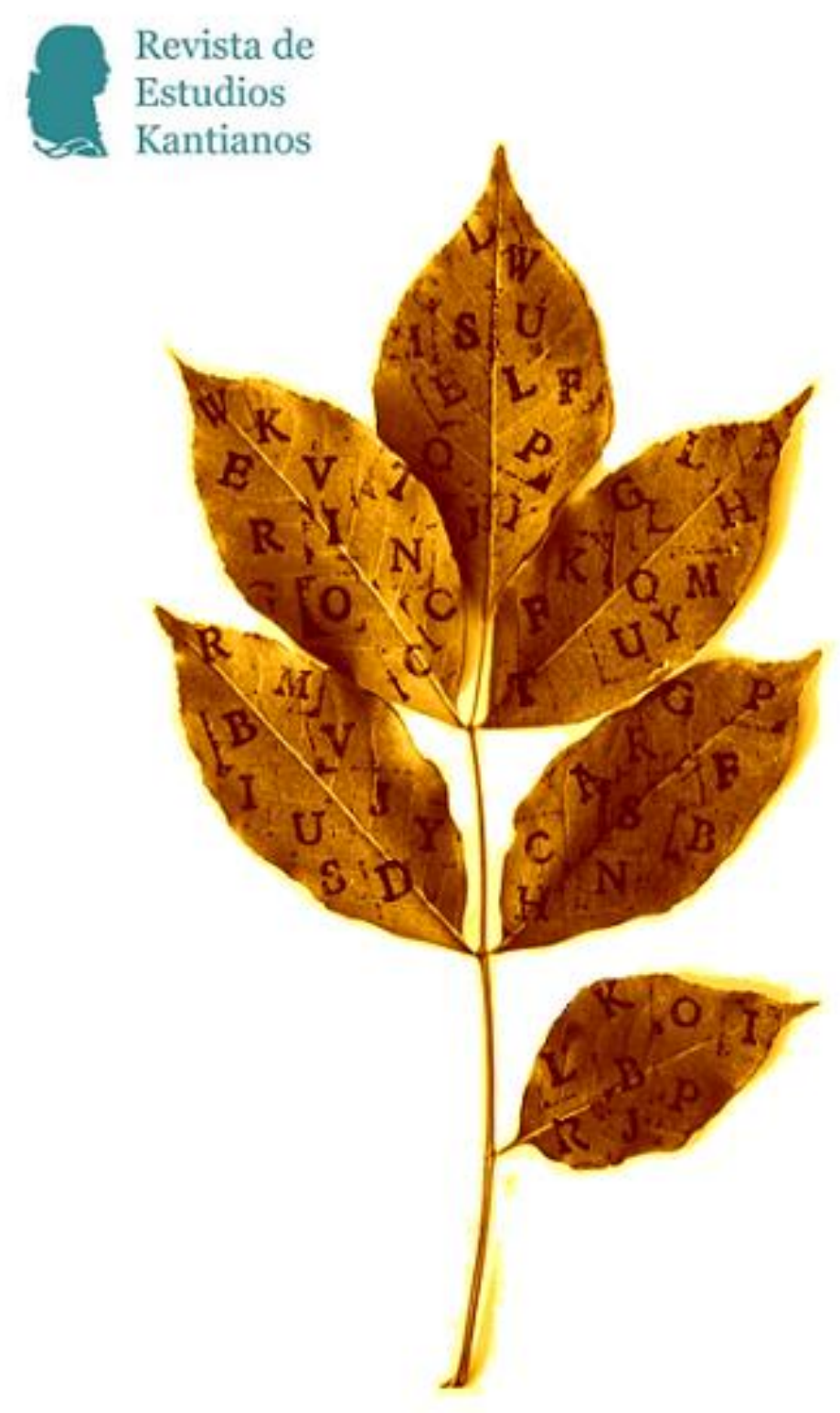




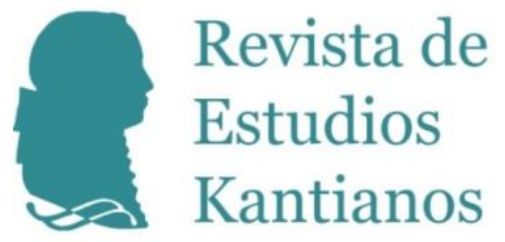




\section{Revista de Estudios Kantianos}

Publicación internacional de la Sociedad de Estudios Kantianos en Lengua Española Internationale Zeitschrift der Gesellschaft für Kant-Studien in Spanischer Sprache

International Journal of the Society of Kantian Studies in the Spanish Language

Número 4.2, año 2019

\section{Dirección}

Fernando Moledo, FernUniversität in Hagen

fernando.moledo@fernuni-hagen.de

Hernán Pringe, CONICET-Universidad de Buenos Aires/

Universidad Diego Portales, Santiago de Chile

hpringe@gmail.com

\section{Secretario de edición}

Óscar Cubo Ugarte, Universitat de València

oscar.cubo@uv.es

\section{Secretaria de calidad}

Alba Jiménez Rodríguez, Universidad Complutense de Madrid

albjim04@ucm.es

\section{Editores científicos}

Jacinto Rivera de Rosales, UNED, Madrid

Claudia Jáuregui, Universidad de Buenos Aires

Vicente Durán, Pontificia Universidad Javeriana, Bogotá

Julio del Valle, Pontificia Universidad Católica del Perú, Lima

Jesús Conill, Universitat de València

Gustavo Leyva, Universidad Autónoma de México, México D. F.

María Xesús Vázquez Lobeiras, Universidade de Santiago de Compostela

Wilson Herrera, Universidad del Rosario, Bogotá

Pablo Oyarzun, Universidad de Chile, Santiago de Chile

Paula Órdenes Azúa, Universität Heidelberg 


\section{Comité científico}

Juan Arana, Universidad de Sevilla

Reinhardt Brandt, Philipps-Universität Marburg

Mario Caimi, Universidad de Buenos Aires

Monique Castillo, Université de Paris-Est

Adela Cortina, Universitat de València

Bernd Dörflinger, Universität Trier

Norbert Fischer, Universität Eichstätt-Ingolstadt

Miguel Giusti, Pontificia Universidad Católica del Perú

Dulce María Granja, Universidad Nacional Autónoma de México

Christian Hamm, Universidad Federal de Santa María, Brasil

Dietmar Heidemann, Université du Luxembourg

Otfried Höffe, Universität Tübingen

Claudio La Rocca, Università degli Studi di Genova

Juan Manuel Navarro Cordón, Universidad Complutense, Madrid

Carlos Pereda, Universidad Nacional Autónoma de México

Gustavo Pereira, Universidad de la República, Uruguay

Ubirajara Rancan de Azevedo, Universidade Estadual Paulista, Brasil

Margit Ruffing, Johannes Gutenberg-Universität Mainz

Gustavo Sarmiento, Universidad Simón Bolívar, Venezuela

Sergio Sevilla, Universitat de València

Roberto Torretti, Universidad Diego Portales, Santiago de Chile

Violetta Waibel, Universität Wien

Howard Williams, University of Aberystwyth

Allen W. Wood, Indiana University

Diseño, revisión de estilo, corrector y maqueta

Josefa Ros Velasco, Harvard University, Cambridge (MA)

\section{Entidades colaboradoras}

Sociedad de Estudios Kantianos en Lengua Española (SEKLE)

Departament de Filosofia de la Universitat de València

Instituto de Humanidades, Universidad Diego Portales

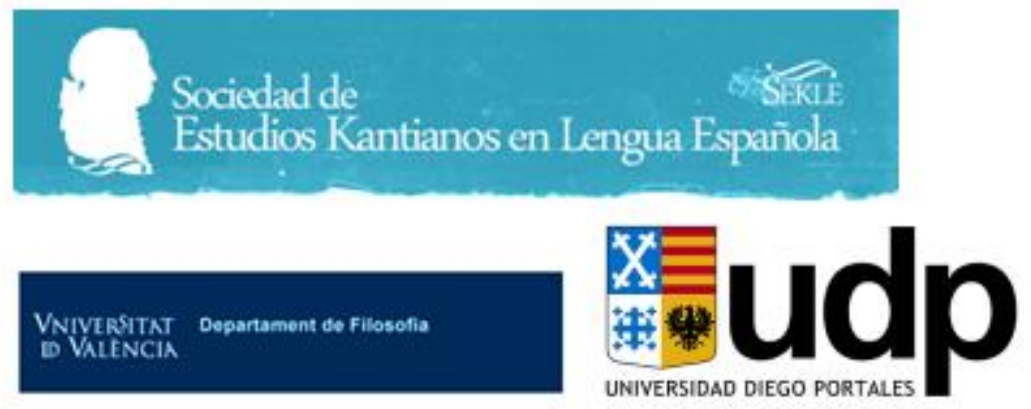




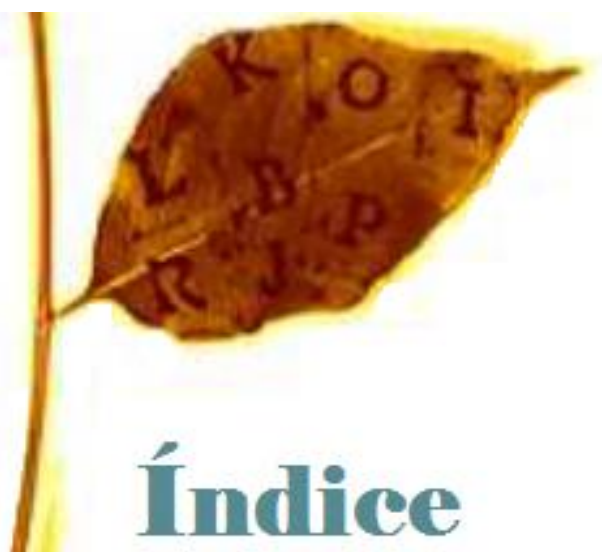

\section{Artículos}

193 Phänomenologie oder Kritizismus? Zur Ausenandersetzung zwischen Eugen Fink und Rudolf Zocher

Christian Krijnen

DOI 10.7203/REK.4.2.13750

221 Una interpretación de la Stufenleiter de A320/B376. Contribución a la determinación precisa del carácter de la distinción entre intuiciones y conceptos

Luis Placencia; Javier Fuentes

DOI 10.7203/REK.4.2.15537

Número monográfico: La actualidad de la Crítica de la razón pura: Parte Teórica

245 Presentación de los editores al número monográfico. La actualidad de la Crítica de la razón pura: Parte Teórica

David Hereza; Óscar Cubo

DOI 10.7203/REK.4.2.15571

249 "Los primeros pensamientos de Copérnico" $(\mathrm{KrV}, \mathrm{Bxvi})$

Gonzalo Serrano Escallón

DOI 10.7203/REK.4.2.13930

270 El espacio en cuanto forma de los fenómenos y la tesis de la receptividad: mutua implicación

Diana Gloria Contreras Gallegos

DOI 10.7203/REK.4.2.14005

293 La idealidad del tiempo, Gödel y la relatividad Gilberto Castrejón

DOI 10.7203/REK.4.2.13825 
319 Synthetische und analytische Einheit der Apperzeption. Über ein nach wie vor aktuelles und missverständliches Problem der „Kritik der reinen Vernunft“

Carsten Olk

DOI 10.7203/REK.4.2.13784

338 Una defensa de la actualidad de la Crítica de la razón pura

Alejandro Lanchas Sánchez.

DOI 10.7203/REK.4.2.13840

352 Substancia, cambio y materia en las Analogías de la experiencia de la Crítica de la razón pura de Kant

Jacinto Rivera de Rosales

DOI 10.7203/REK.4.2.15752

382 La refutación kantiana del idealismo y el realismo ingenuo reconsiderado

Manuel Amado

DOI 10.7203/REK.4.2.13963

397 La concepción kantiana de la verdad: Entre la correspondencia y la argumentación Ana María Andaluz Romanillos

DOI 10.7203/REK.4.2.14094

423 Die konzeptualistische und die nicht-konzeptualistische Interpretation der

Kooperationsthese

Sophia Maddalena Fazio

DOI 10.7203/REK.4.2.13996

434 Geist im Sinnlichen. Eine Deutung der transzendentalen Ideen im Ausgang von Kants

Anthropologie

Margit Ruffing

DOI 10.7203/REK.4.2.14336

452 La deducción metafísica de las ideas a partir de las formas del silogismo

Mario Pedro Miguel Caimi

DOI 10.7203/REK.4.2.14015

476 The epistemological interpretation of transcendental idealism and its unavoidable slide into compatibilism

Daniel Dal Monte

DOI 10.7203/REK.4.2.13939

508 Estructura argumentativa, unidad temática y coherencia doctrinal en los Progresos de la metafísica de Immanuel Kant

Marcos Thisted

DOI 10.7203/REK.4.2.14102

525 Sentido y límites de la filosofía transcendental en el proyecto kantiano

Salvi Turró

DOI 10.7203/REK.4.2.13919 


\section{Recensiones}

546 Gualtiero Lorini y Robert B. Louden (Eds.): Knowledge, Morals and Practice in Kant's Anthropology. Nueva York, Palgrave Macmillan, 2018, 171 pp. ISBN: 978-3-319-98726-2 Natalia Andrea Lerussi DOI 10.7203/REK.4.2.15773

552 Paula Órdenes y Anna Pickhan (Eds.): Teleologische Reflexion in Kants Philosophie. Weisbaden, Springer, 2019, 310 pp. ISBN: 978-3-658-23693-9

Rafael Reyna Fortes

DOI 10.7203/REK.4.2.15851

\section{Traducción}

556 Los Aforismos sobre religión y deísmo de J. G. Fichte. Presentación, debates abiertos y traducción

María Jimena Solé

DOI 10.7203/REK.4.2.15772

\section{Eventos y normas para autores}

583 Normas para autores

DOI 10.7203/REK.4.2.15906 


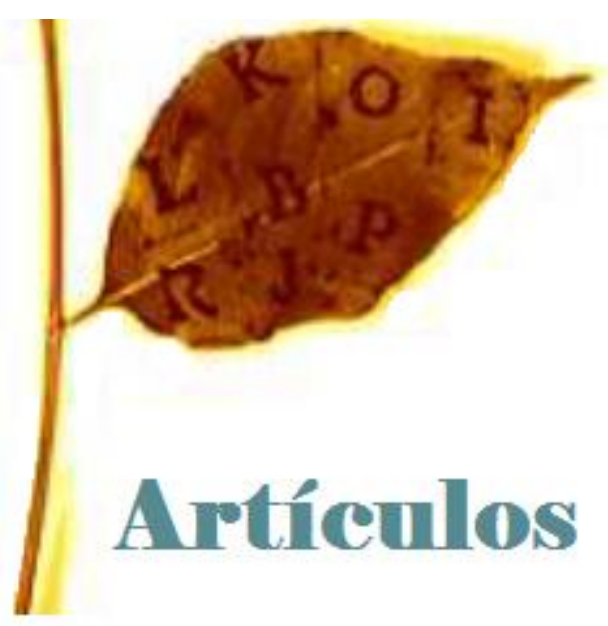




\title{
Phänomenologie oder Kritizismus? Zur Auseinandersetzung zwischen Eugen Fink und Rudolf Zocher
}

\author{
CHRISTIAN KRIJNEN
}

\begin{abstract}
Inhaltsangabe
Die Frage ,Phänomenologie oder Kritizismus?‘ als Frage nach dem Profil der Philosophie wurde nicht zuletzt durch Rudolf Zocher (1932) und Eugen Fink (1933) in Angriff genommen. Inwiefern ist Finks Auseinandersetzung mit dem Kritizismus ertragreich und inwiefern wird Zochers Kritik der Phänomenologie durch Finks Replik aus den Angeln gehoben? Es stellt sich nicht nur heraus, daß es Finks Grenzziehung zwischen Kritizismus und Phänomenologie an zureichender Bestimmtheit mangelt, sondern auch, daß er auf Zochers Kernargument nur unzureichend eingeht. Das durch die Geschicke der Zeit unterbrochene Gespräch über die aufgeworfene Frage sollte mit erhöhter Intensität fortgesetzt werden. Zochers Studie verdiente dabei besondere Beachtung.
\end{abstract}

Schlüsselwörter: Sinn, Sein, Geltung, Transzendentalphilosophie, Evidenz, Ontologie, Intuitionismus, Ursprung

\section{¿Fenomenología o crítica? La discusión entre Eugen Fink y Rudolf Zocher}

\begin{abstract}
Resumen
La pregunta '¿fenomenología o criticismo?' como cuestión en torno al perfil de la filosofía no fue, por última vez, abordada por Rudolf Zocher (1932) y Eugen Finl (1933). ¿En qué medida es estratégico el análisis de Fink del criticismo? Y, ¿en qué medida la respuesta de Fink está sacando de contexto la crítica de Zocher a la fenomenología? Se pondrá de manifiesto no solo que la diferenciación de Fink entre criticismo y fenomenología carece de una determinación suficiente, sino también que penetra de forma insuficiente en el argumento principal de Zocher. Este diálogo interrumpido sobre las preguntas planteadas debe ser continuado con más intesidad; por ello merece especial antención el estudio de Zocher.
\end{abstract}

Palabras clave: sentido, ser, validez, filosofía trascendental, evidencia, ontología, institucionismo, origen

1 Vrije Universiteit Amsterdam. Kontakt: c.h.krijnen@vu.nl. 
1. Ein erster Gesprächsversuch und seine Schwierigkeiten

Auf Philosophen, die für Transzendentalphilosophie aufgelegt sind, hat die Diskussion zwischen Kritizismus, d.h. Neukantianismus, und Phänomenologie immer eine gewisse Faszination ausgeübt. Allerdings wurde diese Diskussion durch die verheerenden Ereignisse 1933-1945 jäh abgebrochen, ohne daß sie sich in der gebotenen Form hätte entfalten können. Die Faszination ist verständlich. Immerhin haben der Kritizismus des Marburger Neukantianismus (Cohen, Natorp, Cassirer et al.) und des südwestdeutschen Neukantianismus (Windelband, Rickert, Lask, Bauch u. a.) wie die von Husserl inaugurierte phänomenologische Bewegung versucht, die Exklusivität der Philosophie und der Erkenntnistheorie als prima philosophia subjekttheoretisch zu begreifen. Für beide Philosopheme gilt, daß die Subjektivität Objektivität (Gegenständlichkeit) begründet, das Transzendentale dem Empirischen logisch vorhergeht. Da es in puncto Objektivitätsbegründung jedoch ganz gravierende methodische und infolgedessen auch thematische Unterschiede zwischen Kritizismus und Phänomenologie gibt, stehen beide zugleich in einem fundamentalphilosophischen Konkurrenzverhältnis.

Retrospektiv gesehen, repräsentiert die philosophische Problemlage, so wie sie um 1930 vorlag, einen Höhepunkt deutscher systematischer Philosophie. In der Nachkriegszeit indes schrumpfte Philosophie, jedenfalls dominanterweise, zurück auf einen Metatheoretizismus logischer Analyse der Wissenschaften bzw. auf historisierend-hermeneutische Thematisierung von Vorverständnissen und Verständigungsbedingungen. Insofern ist die damalige Debatte nach wie vor aktuell (auch wenn die intensiven Bemühungen, Hegel im Zuge der gegenwärtigen Diskussion um ,Anerkennung' zu rehabilitieren (Schmidt am Busch; Zurn 2010; Krijnen 2014b), eine Neubewertung Hegels erforderlich machen, die über den damaligen Diskussionsstand hinausgeht).

Die Frage ,Phänomenologie oder Kritizismus?‘ als Frage nach dem Profil der Philosophie wurde, von gelegentlichen Bemerkungen der Meister selbst abgesehen, zunächst in Angriff genommen in den Schülerarbeiten von Kreis (1930) und Zocher (1932) seitens des südwestdeutschen Neukantianismus sowie Fink (1933) von seiten der Phänomenologen. Nach 1945 gab es dann zwar noch vereinzelte Fortsetzungen der Diskussion, allerdings im angedeuteten veränderten geistig-philosophischen Klima 
(Wagner 1980abc; Seebohm 1962; Kern 1964; Brelage 1965; Orth 1967; Marx 1987; Flach 1994). In jüngster Zeit erfreut sie sich erneuter Aufmerksamkeit (Bermes 1997; Makkreel; Luft 2010; Fabbianelli; Luft 2014; Staiti 2014).

Die Kontroverse zwischen Fink und Zocher ist dabei nach wie vor unterbeleuchtet. Dies ist um so bedauerlicher, als Zocher gerade jenes Problem in den Vordergrund rückt, welches als das Kernanliegen des Kritizismus gelten darf: das Geltungsproblem, d.i. das Problem der Geltungsbestimmtheit eines jedweden gegenständlichen Sinns, und Husserl in einem Vorwort zum Aufsatz seines Assistenten und Vertrauten Fink dessen Stellungnahme zudem als seine, Husserls, Position autorisiert hat. Da nicht nur die Kritizisten, sondern auch die dieser Tradition systematisch positiv verbundenen Transzendentalphilosophen der Nachkriegszeit gerade in Sachen Letztbegründung des Sinns der kritizistischen Profilierung der Philosophie deren methodisch-thematischen Konzentration auf die Geltung wegen entscheidende prinzipientheoretische Vorzüge zuschreiben, fragt sich: Wie ist Finks Stellungnahme zu Zochers Kritik diesbezüglich zu beurteilen? Zwar wirft auch Kreis, gewiß in simplifizierender Weise, Husserl vor, das Problem der Geltung methodisch unzureichend gerecht zu werden (1930: 59ff.), Zochers Husserl-Buch ist jedoch erheblich kenntnisreicher, eingehender, umsichtiger und so insgesamt wesentlich gehaltvoller als die Kreissche Arbeit.

Allerdings ist die Rolle, die Zochers Kritik bei den Protagonisten und Antagonisten spielt, überaus merkwürdig: Schon Fink, der sich nur ganz allgemein auf Zocher bezieht, ist der Meinung, die kritizistischen Kritiker würden »nicht ausreichend « auf Husserls 1929 erschienene Formale und transzendentale Logik (Husserl 1929) eingehen (Fink 1933: 322, Anm.). Wagner, der Zochers Schrift zwar als »weitaus wichtiger « als die von Kreis beurteilt (1980b: 362), schreibt wohl unter dem Einfluß von Fink, Zocher befasse sich schon nicht mehr mit Husserls Formale und transzendentale Logik, geschweige denn mit späteren Schriften (1980b: 363). Dabei weist Zocher nicht nur darauf hin, daß er die Niederschrift seiner Arbeit 1930 abgeschlossen hat und Husserls Vorbemerkungen zur englischen Übersetzung der »Ideen« von 1930 nicht mehr berücksichtigen konnte (1932: 8), sondern an vielen, und zwar auch entscheidenden Stellen seines Husserl-Buches bezieht er sich ausdrücklich auf die Formale und 
transzendentale Logik.2 Angesichts der Tatsache, daß Zochers Buch nicht nur durch seine sorgfältige Argumentation besticht, sondern zugleich durch eine beeindruckende Fülle von Einzelanalysen auf der Grundlage eines eingehenden Husserl-Studiums, müssen solche Einschätzungen Finks und Wagners befremden. Während Wagner den Nukleus von Zochers Kritik wenigstens systematisch integriert,3 geht Finks Replik auf die kritizistische Kritik an jenem Kernargument gänzlich vorbei.4 Zocher selbst, der im übrigen der Arbeit von Kreis durchaus kritisch gegenübersteht, 5 scheint eine Antwort auf Fink formuliert zu haben, die, wie es heißt, von den KantStudien nicht in »sinngemäßer Frist « gedruckt wurde; der »Plan der KantStudien«, die Aussprache über Sinn und Recht der phänomenologischen Philosophie fortzusetzen, sei wohl aufgegeben (1939: 24, Anm. 2). Davon ist in der Anmerkung, in der Zocher diesen Sachverhalt erwähnt, nur noch der Hinweis übriggeblieben, seine Ausführungen stützten sich durchaus auf Husserls Texte. Mit diesem Bezug auf Husserl selbst hat es jedoch eine besondere Bewandtnis.

Laut Wagner ist Finks mangelnde Kenntnisnahme des Zocherschen Werkes dadurch bedingt, daß es ihm auf eine »allgemeine Abwehr des ,Kritizismus" « ankam (1980b: 363). Dem ist zweifelsohne so. Wie zuletzt jedoch angedeutet, spielen auch andere Faktoren eine Rolle. In erster Linie ist da an die eigentümliche Stellung zu denken, die dem Fink-Aufsatz zukommt. Er kennzeichnet sich nämlich durch eine doppelte Frontstellung.

2 Vgl. Zocher (1932: 101, Anm. 4), wo er ihre Stellung qualifiziert (1932: 110ff.), wo er ihre LogikKonzeption einbezieht (oder 1932: 223ff., u. ö).

3 Vgl. Wagner (1980b: 375f). Hier unterscheidet Wagner die phänomenologische Reduktion von der »klassischen Transzendentalphilosophie«, und zwar so, daß diese eine Reflexion auf die »Prinzipien« bietet, die das Noema in seiner »Geltung « aufbauen, während jene mit einer Reflexion aufwartet, welche die Noesen in den Blick bringt, in denen das Noema in seiner Struktur erwächst. Die phänomenologische Reflexionsform führt Wagner zufolge, ganz im Sinne Zochers, zu einem »Zweisphärentheorem« von Grund und Begründetem, in der der Grund alles Geltens doch wieder »in der Art des Seienden« gedacht wird, so daß das Zweisphärentheorem eine philosophisch ganz »unmögliche« Gestalt annimmt. Wie Wagner dann pauschal schreibt, ist Husserl in diesem Punkt von Platon, Kant, Fichte und Hegel unbelehrt geblieben. Wir werden sehen, daß es sich hierbei eben auch um das Kernargument Zochers handelt. Die Differenz von klassisch-idealistischer und phänomenologischer Reflexionsform hat Wagner ausführlich unter dem Titel einer noematischen Konstitutionstheorie und einer noematischen Geltungstheorie ausgearbeitet. Vgl. dazu Wagner (1980c: §6f., 30). Vgl. auch Wagner (1980d). Zu Wagner, der das Husserl-Bild der kantianisierenden Transzendentalphilosophie erheblich beeinflußt hat, vgl. neuerdings Krijnen und Zeidler (2017).

4 Für Scherbel (1999: 176, inkl. Anm. 294) birgt Finks Argumentationsmuster ebenfalls die Gefahr, daß »unversehens« auch berechtigte Einwände zurückgewiesen werden könnten. Ein »wirkliches Eingehen « auf Zochers Kritik des phänomenologischen Noemas fehle. Scherbel verweist dabei auch auf Wagner (1980b).

5 Vgl. Zocher (1932: 27, Anm. 12 mit 245 Anm. 7). Er sehe das Problem »komplizierter«; die Sache liege »wohl nicht ganz einfach«. 
Zum einen, und prima facie, agiert Fink gegen die Einwendungen des durch »Rickert und seine Schule« vertretenen Kritizismus (1933: 321), gegen den südwestdeutschen Neukantianismus also. Zum anderen aber, secunda facie, operiert Fink gegen die bis dahin vorliegende Lehre Husserls. Er weist geradezu unermüdlich auf relativierende Aspekte hin: eine »gewisse Motivation für diese [die kritizistische, ck] Deutung der Entwicklung der Phänomenologie« lasse sich nicht in Abrede stellen (1933: 327), die Zurückweisung der kritizistischen Kritik würde ein »intensives Eingehen auf die verborgene Motivationsgeschichtlichkeit der Husserlschen Entwicklung « erfordern (1933: 328), gelegentlich überbetone Husserl die »Seinsselbständigkeit des ,Idealen“" (1933: 329), die methodische Struktur der im zweiten Band der Logischen Untersuchungen einsetzenden Phänomenologie sei noch »undurchsichtig und verhüllt« (1933: 331), die Ideen ließen den Unterschied des psychologischen und transzendentalen Noemas »ohne eingehende Erörterung « (1933: 364), so daß die phänomenologische Analytik der Subjektivität sich streckenweise in einer »Doppeldeutigkeit« bewege (1933: 365), die formale Struktur der Epoché habe Husserl in den Ideen »nicht differenziert genug « entfaltet (1933: 354), und hier, wie »fast in allen publizierten Schriften Husserls«, sei die Eigenart der konstitutiven Analytik »nicht zur expliziten Darstellung « gekommen (1933: 371), Husserls Unterscheidung von »,sensueller ${ }^{6}$ und ,intentionaler Morphé" « könne nur bei ausdrücklicher Beachtung ihrer »Vorläufigkeit« verstanden werden (1933: 375), usw.

Die doppelte Frontstellung gibt Finks Polemik die ihr eigentümliche Note. Zocher kann sich insofern durchaus mit Recht auf Husserl berufen. Tatsächlich ist es mittlerweile in der Husserl-Forschung gut bekannt, daß der Husserl-Mitarbeiter Fink weniger Husserls Rahmen folgt als vielmehr versucht - in intensiver Kooperation mit Husserl freilich - Husserls Phänomenologie in ihren Voraussetzungen und Konsequenzen zu durchdenken und entsprechend zu systematisieren. Bruzina spricht nicht zu Unrecht von Finks Aufsatz als einer Arbeit, die eine Trennlinie zwischen Husserls Phänomenologie und dem Neukantianismus zieht

aus der Perspektive von Finks eigener Zurechtlegung (sic!) des Husserlschen Programms jenseits des in vielerlei Hinsicht neukantianisch anmutenden Schemas der Ideen I. [...] Fink übernimmt die kritischen Punkte seiner Forschungsnotizen um zu erklären, wie man, über das „Ideen-Projekt“ hinausgehend und auf eine 
verzeitlichung-fundierte Neukonzeptionalisierung der phänomenologischen Reduktion ausgerichtet, zu einem besseren Verständnis nicht nur der grundsätzlichen Verschiedenheit von transzendentaler Phänomenologie und Neukantianismus gelangen kann, sondern auch davon, wie das Versprechen der Radikalität, das die Phänomenologie einst mit der Reduktion abgab, eingelöst werden kann jenseits der mundanen Begriffe und Schemata samt ihres vorläufigen Status, den sie in den bekanntesten Werken Husserls haben (2013: 245, Übers. CK). 6

Bei Finks Grenzziehung zwischen Phänomenologie und Kritizismus fällt noch ein Drittes auf: Während Zocher sich mit seiner Husserl-Studie zugleich als Forscher ausweist, der über gründliche und umfassende Kenntnis von Husserls Schriften verfügt, spricht schon die äußere Form des Fink-Textes eine andere Sprache. Obwohl vielfach die Rede von ,Kritizismus' ist, fehlen Bezüge auf Primärtexte bzw. eine Darlegung der Position mit deren Hilfe. Vielmehr bietet Fink ein Gemisch von Kreis und Zocher. Dabei ist es umso bedauerlicher, daß besonders Kreis Fink durch den Terminus ,transzendentale Apperzeption' eine Brücke baut, obwohl es sich hierbei um ein Kantisches Lehrstück handelt, das im südwestdeutschen Neukantianismus einer einschneidenden werttheoretischen Transformation unterliegt,7 woraus sich geradezu neue Fragen nach der Stellung des konkreten Subjekts und seines Verhältnisses zum reinen Subjekt ergeben (vgl. Krijnen 2001a; 2014a; 2016). Finks primäres Interesse gilt offenbar der Phänomenologie Husserls. Allerdings rächen sich Finks im Vergleich mit seinen Husserl-Kenntnissen weit unterentwickelte Kenntnisse des Kritizismus in mehrfacher Hinsicht. Speziell Zochers überaus abstrakte, geradezu formelhafte und vielfach wiederholte Wendungen, die Fink übrigens konzise wiedergibt, erhalten ihren vollen Sinn erst vor dem Hintergrund der Lehren des südwestdeutschen Neukantianismus, vor allem der Philosophie Rickerts (Fink selbst macht für ein adäquates Verständnis

\footnotetext{
6 "from the vantage-point of Fink's own reframing [sic!] of Husserl's program beyond the, in many respects, Neo-Kantian-seeming schema of Ideen I. [...] Fink adopts the critical points expressed in his research notes to explain how, in moving beyond the "Ideen-project" and focusing on a temporalization-grounded reconception of the phenomenological reduction, one comes to a clearer idea not only of how transcendental phenomenology is fundamentally unlike Neo-Kantianism, but also of how one can fulfill the promise of radicality for phenomenology's initial thrust of reduction beyond the mundane notions and schemata that can remain in the pre-ultimate status of Husserl's best-known writings",

7 Vgl. den Titel des 5. „Abschnitts der Arbeit Kreis“ (1930: 50): »Phänomenologische Epoché und transzendentale Apperzeption«. Kreis weist freilich auf den Kantischen Charakter hin (1930: 20f.).
} 
seiner Ausführungen über die Phänomenologie eingehende HusserlKenntnisse zur Bedingung). 8 Auf das Kernargument Zochers geht Fink gar nicht adäquat ein; dabei hat es noch in bezug auf Husserls Spätschriften Bestand. Das sachliche Kenntnisdefizit führt zudem dazu, daß die Grenzziehung zwischen (südwestdeutschem) Kritizismus und Phänomenologie, um die sich Fink so sehr bemüht, fehlschlägt: Finks Grenzziehung mangelt es an zureichender Bestimmtheit. — Jedenfalls sind dies die beiden Thesen, die ich im Folgenden zu plausibilisieren versuche.

\section{Transzendentalphilosophie als Ursprungsphilosophie}

Da Fink zufolge die »fundamentale« oder »fundierende« Voraussetzung der kritizistischen Kritik die Identifizierung der kritizistischen und phänomenologischen Idee von Transzendentalphilosophie ist (1933: 332f., 336f.), schickt er sich zunächst an, die prinzipielle Differenz von Phänomenologie und Kritizismus durch eine Bestimmung des jeweiligen »Grundproblems « herauszuarbeiten (1933: 337). Er kommt dabei zu einer Kontrastierung, die die Sachlage eher entstellt als sie ins rechte Licht zu rücken.

Die »Grundfrage« der Phänomenologie, in der sich ihr »radikaler Gegensatz« zum Kritizismus offenbare, sei die nach dem »Ursprung der Welt“ (Fink 1933: 338, vgl. 338-345). Der Kritizismus indes frage nach »jener Sinnsphäre, die Voraussetzung alles Seienden« sei (1933: 337). Da es sich hierbei um eine »apriorische Weltform « handle, eigne dem Kritizismus ein »mundaner « Charakter; dies sei für die Unterscheidung von Phänomenologie und Kritizismus von »entscheidender« Bedeutung (1933: 338). Die Problemstellung des Kritizismus bleibe grundsätzlich »auf dem Boden der Welt«; seine Interpretation des Weltproblems »weltimmanent« durch den Rückgang auf die apriorische Weltform. Kurioserweise kontrastiert Fink diesen Gedanken der Begründung des »Seienden« bzw. der Welt mit der Phänomenologie dahingehend, daß diese nach dem »Ursprung der Welt « frage (1933: 338). Dies ist deshalb kurios, weil der Sinn von Kants transzendentaler Wende gerade darin besteht, die Bedingungen der Möglichkeit von Ermöglichtem, von Welt, mit Fink gesprochen, durch den

8 Finks Auffassungen vom Verstehen einer Philosophie (vgl. 1933: 322, u. ö.) bedürften einer gesonderten Betrachtung. Hier würden erneut Differenzen zutage treten. 
Rückgang auf einen Inbegriff von Prinzipien zu erklären, der das Ausgangsfaktum der philosophischen Analyse, d. i. die Welt, das ,fruchtbare Bathos der Erfahrung' (Kant), begreiflich machen soll. Transzendentalphilosophie kritizistischer Prägung ist sozusagen Ursprungserklärung (Krijnen 2008b). Sie bringt das Denken als Prinzip jedweder Gegenständlichkeit auf seinen Begriff und bestimmt damit das Denken in seiner prinzipiellen Gestalt als Grund oder Ursprung seiner selbst in seiner konkreten Gestalt. Der Kritizismus verwirft dabei mitnichten, wie Fink (1933: 339f.) es sich zurechtlegt, das Problem der Metaphysik als Problem des Ursprungs der Welt, sondern vollzieht mit Kant eine sog. Kopernikanische Revolution im Denken der Philosophie. Gemäß Kants kopernikanischer Revolution kann nur auf transzendentalem Weg Selbstvergewisserung der Erkenntnis erreicht werden. Hier erweist sich, um den griffigen, gängigen (wenn auch nicht-kantischen) Terminus zu verwenden, die ,Subjektivität‘ als Prinzip möglichen Gegenstandsbezugs und damit als Grund von Objektivität (wobei ,Subjektivität' der Titel ist für den Inbegriff der weder naturalistisch noch kulturalistisch zu verstehenden ,Erkenntnisvermögen“ des Subjekts). Die transzendentale Erkenntnis der Erkenntnis führt sodann auf einen Inbegriff von Geltungsgründen, der nicht wie in der tradierten Metaphysik und im Empirismus durch den Rückgang auf ein Seiendes außerhalb der Erkenntnisrelation begriffen wird, sondern durch einen Rückgang auf die Erkenntnisrelation selbst, d. h. auf die Anschauungs- und Denkrelation, die sie ist. Die objektive Gültigkeit konkreter, paradigmatisch: direkt-intentionaler Sinnleistungen des erkennenden Subjekts findet ihren Grund in einem Inbegriff von Geltungsprinzipien. Deren objektive Gültigkeit wird wiederum dadurch legitimiert, daß sie sich in einem obliquen, reflexiven Verfahren als Geltungsbedingungen der Erkenntnis ausweisen lassen. Die Pointe der transzendentalen Wende ist also, daß die Subjektivität objektive (weil Gegenständlichkeit begründende) Bedingung für die Möglichkeit von Erkenntnis ist. Gegenständlichkeit steht von Anfang an unter der Bedingung der Subjektivität.

Jenseits dieser Subjektivität gibt es nichts, weil sie selbst noch das definiens von Sein ist. Eine Ursprungsfrage jenseits ihrer ist daher schlechterdings unbegreiflich (bzw. ,vorkritisch'). Gerade für Rickert (und seine Schule) ist Philosophie nicht Erkenntnis- oder Wissenschaftstheorie, 
sondern Philosophie des »Weltganzen«.9 Eben jene Qualifikationen, die Fink für die Phänomenologie beansprucht, sind durchaus geläufig als Beschreibung — des Kritizismus: »die Welt aus dem letzten Grunde ihres Seins her, in allen ihren realen und ideellen Bestimmtheiten, begreiflich zu machen«, und zwar in der Form einer »strengen Wissenschaft« (Fink 1933: 340). Entsprechend macht nicht bloß die Phänomenologie, sondern eben auch der Kritizismus, entgegen Finks freischwebender Behauptung, den Weltgrund zum Gegenstand, zwar nicht in einer theoretischen »Erfahrung « (1933: 340) (darin hat Fink recht, denn für den Kritizismus sind, aus logischen Gründen, Möglichkeitsbedingungen von Erfahrung selbst nicht erfahrbar; erfahrbar ist immer nur Ermöglichtes (Konstituiertes)), sehr wohl jedoch als Gegenstand einer »theoretischen Erkenntnis« (1933: 340). Während die nicht-philosophische Erkenntnis nur Erkenntnis aus den Prinzipien des Denkens bietet, ist die Philosophie zugleich Erkenntnis der Prinzipien des Denkens und ihres Prinzipiierens. Der philosophische Gegenstandsgedanke kritizistischer Prägung zielt entsprechend auf die dem Denken immanente Selbstbezogenheit (Reflexivität) bei all seiner Bezogenheit auf mögliche Gegenstände: das Voll-Endliche, wie Rickert sagt, ist der Grund für jeglichen Gegenstandsbezug des Denkens; es ist die immer vorausgesetzte Einheit der Erkenntnis in der Mannigfaltigkeit ihrer gegenständlichen Differenzierungen. Wie Fink für die Phänomenologie eine »genuine Methodik« zwecks Erkenntnis des Weltgrundes reklamiert, so auch der Kritizismus: die Geltungsreflexion. Indem das Denken sich selbst geltungsreflexiv versteht, überwindet es seine direkt-gegenständliche Bedingtheit und begreift sich selbst als den voll-endlichen und damit positiv-unendlichen Grund für das von ihm Begründete: Die Geltungsreflexion ist ein Rückgang in den Ursprung aller Bestimmtheit und legt in diesem Rückgang die ursprüngliche Bestimmtheit (die Eigenbestimmtheit) des Denkens frei, und zwar hinsichtlich dessen Ermöglichungsstruktur (Prinzipien). Dieser Ursprung ist das positiv-unendliche Ganze; es ist der selbst nicht mehr durch anderes bedingte (,unbedingte') Geltungsgrund möglicher Gegenständlichkeit. Die fundamentale Unendlichkeit des Denkens muß sich hier zuletzt als der ursprüngliche Sinn von Bestimmtheit selbst erweisen: die Geltungsreflexion

9 Vgl. etwa Rickert (1910: 1f.; 1921: 14ff.; 1930: 8; 1931: 24ff.; 1934a: V, lff.; 1934b: 139ff.; 1939c: 96; 1939a: 97). Vgl. dazu eingehend Krijnen (2001b: Kap. 3.2.1). 
ist nichts Geringeres als Unendlichkeitsdenken; sie bestimmt die Struktur der prinzipiellen Unendlichkeit des Denkens als des Ursprungs.

Während Fink in seinem Aufsatz eingehend die »Erkenntnismethode« der Phänomenologie als »phänomenologische Reduktion« erörtert und eine Differenz zur kritizistischen Methode dahingehend meint ausmachen zu müssen, daß das »Welt-Transzendieren, das im Vollzug der phänomenologischen Reduktion geschieht«, nicht »aus der Welt « herausführt, sondern als »Eröffnung der transzendentalen Subjektivität« zugleich die »Einbehaltung der Welt in das freigelegte Universum des absoluten ,Seins'" ist (1933: 341ff., vgl. 374f.) — läßt sich auch diese Qualifikation für die kritizistische Geltungsreflexion in Anspruch nehmen. Auch in letzterer bleibt die Welt dem »Absoluten« »immanent «, wird als »im Absoluten liegende « entdeckt; auch der Kritizismus erkennt das ", konstitutive Werden" der Welt aus dem Transzendentalen; auch ihm sind Welt und Ursprung, das, was sie sind, nur ,aufeinander hin'" (1933: 342). Die Bestimmung der »entscheidenden Differenz« am »Grundproblem«, so wie Fink sie mit seinen »massiven Begriffen« (1933: 342) vornimmt, schlägt also erneut fehl. Es ist ein wesentlich höheres Maß an Bestimmtheit der Differenzen vonnöten, als Fink zu bieten hat!

Bei Fink heißt es im Kontext seiner Ausführungen zur phänomenologischen Reduktion: Die Welt ist uns als ein »Universum von Geltungen « gegeben, ein »Geltungsgefüge«, das in seinem »inneren Aufbau « zu begreifen ist (1933: 348f.); in der »Entdeckung der Welt als eines transzendentalen Geltungsuniversums durch die Epoché« wird eine Problematik möglich, die nicht selbst »auf dem Boden der Welt, d. h. in der Weltbefangenheit der natürlichen Einstellung steht «, so daß nach dem »Sein der Welt« gefragt werden kann. Fink bezieht das Sein der Welt zuück auf die »transzendentale Subjektivität«; die Frage nach dem Sein der Welt verwandelt sich in die nach dem »Wesen der transzendentalen Subjektivität« (1933: 353). Damit aber rennt er, ungeachtet aller durchaus erheblichen Differenzen im Begriff von Subjektivität, bei ,Rickert und seiner Schule' in puncto Fundierungssinn von Subjektivität nur offene Türen ein. Wie für die Phänomenologie, so gilt auch für den Kritizismus, daß er die Welt nicht ausschaltet, »um sich von ihr abzukehren und einer anderen philosophischen Thematik zuzuwenden«, sondern um zu wissen, 
»was die Welt sei« (1933: 355). Er befriedigt dieses Wissen durch die Methodik der transzendentalen Reflexion als Geltungsreflexion.

Gerade mit Blick auf Finks Ausführungen zum Grundproblem, zur Epoché und zur Konstitution scheint es angebracht, einige Aspekte der Rickertschen Methodik philosophischer Erkenntnis der Erkenntnis hervorzukehren, die cum grano salis auch für seine ,Schule" maßgebend geworden sind und die die intrinsische Beziehung von ,Ursprung und Welt ${ }^{\star}$ geradezu methodisch artikulieren. Dann wird auch klar, daß Finks Differenzbestimmung, in der phänomenologischen Konstitution gebe es in Wahrheit keinen »Dualismus heterologischer Momente«, sondern nur »relative Stufen der einheitlichen konstitutiven Herkunftsenthüllung aus der Lebenstiefe der transzendentalen Subjektivität« (1933: 376), phänomenologischer Idealismus sei »konstitutiver Idealismus «, der die Welt im Rückgang auf den konstitutiven Ursprung einbegreife (1933: 377), wiederum eine recht präzise Beschreibung ist — der kritizistischen Konstitutionsidee.

Zunächst ist mit Blick auf Finks Floskel von der ,apriorischen Weltform' wichtig, daß es im Neukantianismus zu einer eingehenden Kritik an der Abstraktionstheorie des Begriffs gekommen ist. Bei Rickert hat dies zu einer differenzierten Auffassung der Allgemeinheit des Begriffs geführt, die etwa die generalisierende Abstraktion der Gattungsallgemeinheit von der, wie er sagt, isolierenden Abstraktion philosophischer Begriffsbildung als »generalisierender Erforschung der irrealen Sinngebilde« (1929: 597) wohl zu unterscheiden weiß (vgl. Krijnen 2001b: 179ff. mit 288ff.). Im Einklang mit seiner von Fink oft berufenen Heterologie, aus der hervorgeht, daß Inhalt selbst ein formaler Faktor der Erkenntnis ist, sind Begriffe im Sinne von Prinzipien nicht als abstrakte Allgemeinheiten und Produkte generalisierender Abstraktion zu denken, sondern als Konstituenten konkreter Gebilde; entsprechend sucht die Philosophie nicht den allgemeinen Begriff von Individuellem, sondern den eines Allgemeinen (Rickert 1939d: 27ff.). Methodisch geht sie dabei in der Weise der »isolierenden Abstraktion« (1939d: 29) vor, d. i. der Methodik der Geltungsreflexion. Sie ist auch für Rickerts erkenntnistheoretisches Hauptwerk Der Gegenstand der Erkenntnis (1928) maßgeblich. Entsprechend ermittelt Rickert in seinem Gegenstandsbuch im Ausgang von einem synthetischen Ausgangspunkt sinnanalytisch dessen Prinzipien in 
ihrer Bestimmtheit und Geltung. Näherhin führt diese geltungsreflexive Ermittlung zu einer zunehmenden prinzipientheoretischen Reinigung von Subjekt- und Objekt-Begriffen bzw. - Verhältnissen. Indem Rickert von dieser geltungsreflexiven Reduktion eben auch als von einer ,isolierenden Abstraktion", einer "zu Ende geführten Subtraktion« (1928: 41) oder »allmählichen Verminderung « (1928: 57) spricht, 10 sogar die Form des Subjekts bisweilen als »nur leere Form« (1928: 59, u. ö.) bestimmt, beschwört er (ganz entgegen seiner Intention und Durchführung) den von Grund auf verfehlten, gleichwohl populären ,Formalismusvorwurf ${ }^{*}$ und damit den einer bloßen ,Konstruktion' geradezu herauf. Indes ergibt sich im Zuge von Rickerts Heterologie, daß Inhalt selbst ein Bestandteil des Gegenstandmodells ist und damit ein formaler Faktor des theoretischen Gegenstandes überhaupt: Inhalt ist selbst eine Form des logischen Denkens, 11 das Bewußtsein ein »Inhaltsbewußtsein« (1939d: 26) und Wertgeltung keine ,abstrakte Allgemeinheit' (1924b: VIII).

In diesem Verfahren der Geltungsreflexion liegt des weiteren - und Rickerts Heterologie ist hier das für die südwestdeutsche Schule maßgebende Lehrstück - , daß Form und Inhalt bzw. Subjekt und Objekt nicht als Entitäten zu denken sind, die ,außerhalb ‘ der Erkenntnisbeziehung einen selbständigen Bestand hätten: sie haben ihren Sinn als Momente des Denkens, bestehen nur ,innerhalb ' der Erkenntniseinheit. Die kritizistische Erkenntnistheorie hat an ihrem Anfang nicht die Tatsache der Getrenntheit von Form und Inhalt, Subjekt und Objekt, sondern diese Getrenntheit erweist sich selbst als souveränes Werk objektiven, gegenstandsbezogenen, erkenntnisinteressierten Denkens. Dadurch, daß Inhalt sich als eine Form des Denkens herausstellt, ist die Inhaltsbezogenheit des Denkens garantiert und eine Mannigfaltigkeit von Inhalten ermöglicht. Es gibt daher im Horizont des Denkens strikte nichts radikal Denkfremdes, sondern bestenfalls Stufen relativer logischer Ursprünglichkeit (Stufen von Apriorität). Dies gilt nicht weniger für das Verhältnis von Wert und Wirklichkeit; sie werden nicht auseinandergerissen, sondern erkenntnistheoretisch rückgebunden und in ihrer internen Verschränkung expliziert (vgl. Krijnen 2001b: Kap. 6.3.3.3.1). Jedwedes denkbare Etwas,

10 Geglückter ist m. E. die Rede vom »Prinzip fortschreitender Desobjektivierung« (Rickert 1928: $55)$.

11 Rickert (1924a: 11ff.; 1921: 52f). Vgl. dazu Krijnen (2001b: Kap. 5.2.2.1; 2008b) und Flach (1959). 
der reale wie der irreale Gegenstand, besteht aus Form und Inhalt (Rickert 1921: 120f., 262); auch die Bestimmung des Sinns enthält für eine transzendentalphilosophische Erkenntnistheorie ein »Formproblem«; auch in bezug auf den Sinn geht es um die Bestimmung der »Form des Sinnes«, um die »Wertformen des Sinnes« (Rickert 1909: 108; 1928: 268). Ontologisch gesehen besteht die als wahrnehmbar oder verstehbar gegebene Welt für Rickert aus sinnlichen Gegenständen, denen erkenntnistheoretisch gesehen sinnlicher Inhalt und unsinnliche Form eignet, sowie unsinnlichen Gegenständen (Sinngebilden), denen erkenntnistheoretisch gesehen unsinnlicher Inhalt und unsinnliche Form zukommt (1939a: 107, u. ö.; 1939b; 1934a).

Die Stufen relativer Ursprünglichkeit innerhalb der theoretischen Sphäre reichen bei Rickert von der Ursprungssynthesis des Denkens als Denkens eines theoretischen Gegenstandes überhaupt, wie im Gegenstandsmodell dargelegt, bis hin zur Konstitution des konkretgegenständlichen Sinns durch methodologische Erkenntnisformen, also vom Ursprungssinn der reinen Synthesis bis hin zum Sinn konkreter Gegenständlichkeit. Die Erkenntnisbeziehung wird somit prinzipientheoretisch konkretisiert. So wird im Kritizismus die Welt von ihrem Ursprung her philosophisch begriffen.12

12 Staiti (2014: Ch. 4) schätzt zwar einige kritische Bemerkungen Rickerts zu Husserl, Staitis Verteidigung Husserls stellt jedoch die methodische Struktur der Rickertschen Prinzipienforschung, wie Staiti mit Husserl sagen würde: der ,Wesenserkenntnis', nicht zureichend in Rechnung. Beispielsweise heißt es: »Bei Rickert fehlt ein robustes Verständnis der Grenzen, die die Erfahrung unserer Begriffsbildung auferlegt. Wir können nicht einfach irgendwelche Begriffe bilden, wenn wir Wesenserkenntnis über einen gegebenen Bereich der Wirklichkeit produzieren wollen. Wir müssen an der zugrunde liegenden eidetischen Intuition festhalten und unsere Konzeptualisierung an einer getreuen Artikulation des Wesens, wie es intuitiv gegeben ist, orientieren. [...] [N]icht jegliche Form begrifflicher Reorganisation ist gleichermaßen anwendbar auf jede Intuition. Falls wir Wesenserkenntnis erreichen wollen, müssen wir vielmehr unsere Begriffe gemäß der zugrunde liegenden Wesensintuition bilden; in Husserls Sprache: wir müssen dafür sorgen, daß die Verbindungen zwischen Begriffen, die wir verwenden um ein Wesen zu beschreiben, wirklich eine intuitive Erfüllung erhalten können « ["Rickert has no robust account of the boundaries imposed upon concept-formation by experience. We cannot form concepts of any sort if we intend to produce essential knowledge about a given sector of reality. We have to hold fast to an underlying eidetic intuition and orient our conceptualization to a faithful articulation of the essence as it is given intuitively [...]. [N]ot every form of conceptual reorganization is equally legitimate for every kind of intuition. If we want to attain essential knowledge, we rather have to mold our concepts according to an underlying essential intuition; in Husserlian language, we have to make sure that the connections of concepts that we use to describe an essence can really receive intuitive fulfillment" (121, Übers. CK). Offenbar operiert Staiti hiermit einer Argumentationsfigur, die der kritiztstischen Vorstellung einer transzendentalen Deduktion diametral entgegengesetzt ist. Die objektive Gültigkeit konkreter Sinnleistungen des erkennenden Subjekts findet ihren Grund in einem Inbegriff von Geltungsprinzipien, deren objektive Gültigkeit wiederum dadurch legitimiert wird, daß sie sich in 


\section{Ontologismus}

Worin besteht der prinzipientheoretische Kern von Zochers OntologismusKritik? Er besteht im Vorwurf einer »übergreifenden « Ontologiekonzeption von Sinn, freilich einer Krypto-Ontologie, wie Zochers systematische Husserl-Analyse ergibt. Zocher schreibt damit das Ergebnis eines durchaus dunklen Kantischen Lehrstücks fort, das nicht nur allgemein den »stolzen Namen einer Ontologie « durch den »bescheidenden« einer »Analytik des Verstandes « in ihrer Fundierungsfunktion ersetzt $(\mathrm{KrV}, \mathrm{B} 303), 13$ sondern innerhalb dieser Analytik des Verstandes, intragnoseologisch also, der »objektiven Deduktion« einen Primat vor der »subjektiven Deduktion« ( $K r V$, AXVIf.) angedeihen läßt,14 während Husserl die diesbezüglichen Fundierungsverhältnisse geradezu umkehrt, so daß sich der Sinn in seiner Geltung nur noch, um den von Kant wie von Zocher und Fink favorisierten Terminus zu verwenden, ,dogmatisch`absichern läßt.

Zunächst ist für das Verständnis von Zochers Kritik wichtig, daß Zocher den Terminus ,ontologisch' in einem prägnanten Sinne verwendet, der sich nur streckenweise mit Husserls Verwendung deckt. Bei Zocher fungiert er strikte als »Antithese « zu allem, was man als »semasiologisch«, d. h. als »bedeutungsmäßig« bezeichnen könnte (1932: 106ff., u. ö).15

einem reflexiven Verfahren als Geltungsbedingungen der Erkenntnis ausweisen lassen. Dabei ist der Bezug auf Inhalt selbst eines der Geltungsprinzipien. Das Analysandum der kritizistischen Geltungsreflexion ist das sog. ,Faktum der Kultur'. Gemäß ihrem Verständnis der transzendentalen Methode, d. i. der Geltungsreflexion als der Methodik der Philosophie, gehen die Neukantianer von einem Kulturfaktum aus - von einem Anspruch auf Geltung (auf Erkenntnis etwa). Sie sind daher von vornherein auf die Wirklichkeit, in der wir leben, bezogen, allerdings: bezogen auf die Wirklichkeit nicht als Geltungsgrund, sondern als Begründungsbedürftiges. Sie versuchen sodann, dieses Faktum, d. i. die Wirklichkeit eines Geltungsanspruchs (nicht die eines als gültig Fixierten), in seiner Möglichkeit, d. h. aus den ihn bestimmenden Geltungsprinzipien, zu begreifen. Indem sie dessen Objektivität würdigen, bestimmen sie zugleich die ihm zugrundeliegenden Prinzipien selbst in ihrer geltungsfunktionalen Bestimmtheit. Insofern ist, wie Bauch einmal einprägsam formuliert hat, Erfahrung Anfang und Ende der transzendentalen Methode - Anfang in ihrer Wirklichkeit, Ende in ihrer Möglichkeit (Bauch 1923b: 359f.; 1923a: 131f.); oder wie es bei Rickert heißt: Die Kultur ist einerseits das »empirisch gegebene ,Material'" und anderseits der »Gegenstand «, der mittels eines Wertsystems auf seinen Begriff gebracht werden soll (Rickert 1934a: 161). Daß der Materialbegriff dabei durchaus noch weiterer Reflexion bedarf, ist gerade ein Anliegen der Zocherschen HusserlStudie, wie er gleich zu Beginn darlegt (vgl. Zocher 1932: 21ff.). Er thematisiert zudem eingehend den phänomenologischen Erfüllungsbegriff (1932: Kap. VIf.).

13 Kant wird zitiert nach der Akademie-Ausgabe (Kant 1910ff.). $\mathrm{KrV}=$ Kritik der reinen Vernunft $(\mathrm{Bd}$. III = B, Bd. IV = A).

$14 \mathrm{Vgl}$. den letzten Paragraphen der vorliegenden Studie.

15 In seiner glänzenden Studie über Kant (Zocher 1959) spricht Zocher immer wieder von einer transzendentalen »Semantik«, wohl wissend, daß, gemäß Kants transzendentalisiertem Sinnbegriff, Sinn nicht linguistisch, sondern ,objektiv ${ }^{\star}$ thematisch ist, d. h., Sinn ist Kant gegenständlicher, auf 
Zocher betont entsprechend die charakteristische Eigenartdes »Bedeutungsgebiets « gegenüber allem »Ontologischen«. Gerade in Husserls Formale und transzendentale Logik werde die formale in der transzendentalen Logik fundiert und damit »ontologische « Gebilde in leistenden Tätigkeiten des Bewußtseins, in einer, wie Zocher sagt, Phänomenologie als »allbegründenden Wissenschaft«, die solche Gebilde als »Bewußtseinsgegebenheiten« zum Gegenstand hat, d. h. eine Analyse des »Intentionalen « ist (1932: 115). Husserl begründe Ontologie insofern in Semasiologie. Er führe diese Unterscheidung jedoch nicht scharf durch. Vielmehr gebe es eine die Sphäre des Fundierenden und des Fundierten »umgreifende« ontologische Charakterisierung (1932: 118), eine »nivellierende Tendenz« in der Lehre von der Reduktion des Seins auf Sinn (1932: 19). Damit gehe das eigentümliche Prius der Fundierungssphäre verloren: der ontologische Charakter der fundierten Sphäre greife auf die fundierende über (1932: 119f.). Husserls Idee der Phänomenologie als Eidetik tendiert laut Zocher zu einer »vortranszendentalen « Ontologisierung der transzendentalen Subjektivität (1932: 120).

Diese Ontologisierung besagt, daß Husserl die disparaten Sphären des Fundierenden und des Fundierten zuungunsten der ersteren nivelliert. Sein wird also letztlich doch nicht auf Sinn bzw. Geltung reduziert, sondern Sinn bzw. Geltung auf Sein. Dies hatte Kreis Husserl ebenfalls vorgeworfen. Gemäß der südwestdeutschen Schuldoktrin heißt es bei Kreis: Erkenntnis bedarf der »Anerkennung « des »Wertes der Wahrheit« (1930: 59f.). Es fungiert also nicht nur der Wert und damit ein Prinzipieninbegriff von Orientierungsdeterminanten für das theoretische Leisten des Subjekts als die Grundlage der Erkenntnis (allgemein: jedweder Gegenständlichkeit), sondern offenbar ist Erkenntnis (allgemein: jedwede Gegenständlichkeit) ein Geltungs- oder Sinnsachverhalt. Immer kommt eine ,Beziehung auf einen Gegenstand‘ (Kant) zustande. Auf diese Differenz von Geltung und Sein legt Zocher den Finger. Geltung lasse sich nicht auf Sein reduzieren; eine Ontologie als Grundlehre schlage fehl.

Um die Subjektivität als Grundlage von Objektivität philosophisch zu verstehen, kommt es für Zocher darauf an, sie selbst nicht zu fassen als etwas, das ,ist', sondern als etwas, das anderes als das, was es ist und wie es

Gegenstände bezogener und folglich geltungsreferenter Sinn. Philosophische Sinnanalyse ist für Kant daher transzendentale Geltungsreflexion. 
ist, fundiert, ,konstituiert' und damit dieses Fundieren in seiner Geltung reglementiert. Aus diesem Grund moniert Zocher, Husserl fasse das konstituierende oder sinngebende Bewußtsein qua Inbegriff der reinen Erlebnisse selbst, die fundierende Sphäre also, als »absolutes Sein« (1932: 125). Dieser »allgemeine« Ontologismus prägt sich nun, was Zocher zu zeigen versucht, als ein »spezieller« Ontologismus in Husserls Eidetik aus, d. h. in Husserls Konzeption der Philosophie als Wesenswissenschaft. Die fundierende Sphäre sei zwar eine Sphäre von Wesen, diese würden jedoch in der Art eines Seienden gefaßt (1932: 131f.).

Dabei handelt es sich keineswegs bloß um eine terminologische Angelegenheit. Bei Husserl hat sie Zocher zufolge nämlich die oben erwähnte sachliche Konsequenz, daß die Sphärendifferenz von Geltung und Sein nivelliert wird (1932: 169): Das »Sein des Wertes«, die »objektive Geltung des Wertes « (das Fundierende also) ist ein »Sein«, so wie irgendein konstituiertes Gebilde als Gegenstand ein Sein darstellt, während die Bewußtseinsleistung, die es konstituiert, eine gültige Leistung sein muß, wenn das Sein eines Gegenstandes denn als Sein soll anerkannt werden können. Zocher führt dabei eine Unterscheidung ein, die, wenn ich recht sehe, die durchaus wirkungsmächtige Unterscheidung Wagners von Reflexionstypen zumindest mit motiviert hat, ja, ihre entscheidende Kontrastierung vorwegnimmt. Faßte man Geltung nämlich als Sein, dann liefe die Konstitutionstheorie, wie es nach Wagner charakteristisch ist für den Husserlschen Reflexionstypus, auf eine, wie Zocher sagt, Phänomenologie von »Bewußtseinskonstituentien möglicher Gültigkeiten« hinaus (1932: 170); Wagner würde sagen: auf eine noematische Konstitutionstheorie, d. i. eine Theorie, in der das Noema hinsichtlich seiner Geleistetheit durch das Bewußtsein bzw. durch das Subjekt und dessen Aktleben thematisch wird. Nennt man beide Sphären - die der Geltung als Konstituierendes und die des Seins als Konstituiertes - unterschiedslos »Sein«, dann werden »wesentliche Unterschiede« verwischt. Sie hängen für Zocher und den Kritizismus am Begriff der Geltung bzw. an dem des Sinnes als eines solchen, das nicht bloß ist, sondern über sein Sein hinaus sich zugleich durch seine Geltungsqualifikation auszeichnet. In der Konstitution des Seins durch eine wahre Setzung, also durch eine Noesis, die ein gültiges Noema enthält, eignet sich das Bewußtsein das Sein an. Die Noesis ist ein Gebilde, »das gültig oder ungültig vollziehen kann«; die Noesis ist sozusagen »wesensmäßig« auf mögliche Gültigkeit bezogen, enthält nicht 
notwendig Gültigkeit, sondern ein Noema, das gültig sein kann (1932: 187). Von sich aus konstituiert die Noesis das Sein also nur »uneigentlich«; nur wenn sie ein gültiges Noema enthält, konstituiert sie es »eigentlich«, d. h. als gültige Setzung. Die transzendentale Begründungssphäre hat ihren »eigentlichen Charakter« als »Gültigkeit« (1932: 253).16 Dem Eidetischen indes eignet allenfalls, wie Zocher es nennt, die Dimension »neutraler Sinngebilde «, nicht die der »Gültigkeitsgebilde« im strikten Sinne (1932: 253). Das Eidetische »übergreift« gemäß Zochers Analyse die Grundlehre wie die fundierten Lehren (1939: 20). Durch die gemeinsame eidetische Struktur werden die »methodisch « disparaten Sphären der Fundierung und des Fundierten also »nivelliert« (1939: 21, Anm. 1).

\section{Intuitionismus}

Daher muß es trotz allem transzendentalen Idealismus Husserls auch einen ontologischen Zuschnitt der Lösung des ,Geltungsproblems' geben. Dieser ontologische Zuschnitt führt zum zweiten Kernbegriff der Zocherschen Kritik des »intuitionistischen Ontologismus « Husserls (Zocher 1932: Kap. II.2b, VI u. ö.): dem des »Intuitionismus«. Dieser hat eine »ontologische«, den »deskriptiven Bestand“ ausmachende Seite und eine die »Geltung « betreffende, »semasiologische, noematische Gültigkeit garantierende« Seite (so die prägnante Wendung Zochers [1932: 185]). Wie oben angedeutet, bildet für Zocher, von allen spezifisch ,ontologischen' Problemen noch abgesehen, das Geltungsproblem die Achillesferse des Philosophiekonzepts der Phänomenologie Husserls. Das Augenmerk bei der Behandlung des Intuitionismusvorwurfs muß sich daher auf die Verschränkung von Ontologismus und Intuitionismus richten, noch jenseits von Fragen nach der Berechtigung von Ontologie und Intuition.

Gemäß der Idee einer transzendentalen Fundierung wird, bewußtseinstheoretisch gesprochen, gegenständlicher Sinn auf ein fundierendes Bewußtsein qua Sinngebilde reduziert, und zwar dergestalt, daß, wie Zocher schreibt, es positiv gilt und dadurch seinen »Gegenstand « aneignet (1932: 26). Es ist dies ein fundierungsmethodischer Sachverhalt, d.h., die Aneignung des Gegenstandes durch die »Positivität« des

16 Vgl. auch Zocher (1939: 17f.), wo es heißt, es reiche nicht aus, die Fundierungssphäre durch »Reinheit« und »Allgemeinheit« zu qualifizieren, sondern erst die Idee der »Gültigkeit« helfe weiter. 
fundierenden Bewußtseins ist (für den Kritizismus) nur als »methodische Antizipation « zu nehmen. Der Intuitionsbegriff gehört zum einen diesem methodischen Sachverhalt zu. Er verselbständige sich jedoch leicht zu einem »sachlichen « Begriff, nämlich zum Begriff eines Gebildes, das von gewissen Strukturkomplikationen noch frei sein solle, sozusagen (vermeintlich) »deskriptive« Merkmale der Ursprünglichkeit zeige: die kritische Bewußtseinsidee werde $\mathrm{zu}$ einem ontologischen Begriff transformiert (Zocher 1939: 26f.). Diese allgemeine Beschreibung gewinnt spezifische Relevanz, wenn man sie auf die Fundierungsfunktion der Intuition für die philosophische Erkenntnis anwendet.

Der hierbei auschlaggebende Aspekt ist, daß der Rückgang auf das Bewußtsein ein Rückgang auf die reinen Erlebnisse ist, das Intuitive folglich eine fundierende Rolle erhält; alles Intentionale, so Zocher zu Recht, »reduziert sich auf einen Erlebnisbestand, in welchem sein Sinn sich letztlich legitimiert« (1932: 130). Dieses Motiv heißt bei Zocher »Intuitionismus«. Es steht, wie Zocher ebenfalls bemerkt, »in enger Verbindung « mit einem Ontologismus, der das reine Bewußtsein als (absolutes) »Sein« faßt (1932: 131). Wie oben angedeutet, prägt diese allgemeine Ontologie sich spezifisch als Eidetik aus. Dies ist deshalb wichtig, weil das Eidetische bei Husserl (anders als im Kritizismus) ein eigenes Feld der Erfahrung ausmacht. Prinzipien, Möglichkeitsbedingungen von Erfahrung sind demgemäß selbst erfahrbar. Da Zocher den Finger auf das Geltungsproblem legt, stellt sich also die Frage nach der Geltung ebendieser eidetischen Erfahrung. Diesbezüglich hebt Zocher die Rolle des Husserlschen Evidenztheorems hervor (1932: 172ff.). Er arbeitet dabei das Entscheidende heraus, nämlich, daß die originär gebende Anschauung als Geltungsquelle der Erkenntnis fungiert (1932: 175). Rücksichtlich der Gültigkeit koinzidieren somit Sein und Sinn. Die »Intuition« ist als »Garant« aller Art von Gültigkeit angesetzt (1932: 176). Offenbar ist die Konstitution dann so gedacht, daß sie Gültiges konstituiert, die Noesis folglich ein »gültiges Noem« enthält; Konstitution ist Konstitution der »wahren Setzung «; Sein fällt mit gültigem noematischem Sinn zusammen (1932: 181). Die Intuition hat damit sowohl einen ontologischen als auch einen semasiologischen Charakter: das Noema bildet einen deskriptiven Bestand (Ontologie) und fungiert zugleich als Garant der Geltung (Semasiologie); intuitive (erlebnismäßige, anschauliche) Gehalte sind also zum einen gegeben, zum anderen gewährleisten sie noematische Gültigkeit 
(1932: 185). Die semasiologische »Funktion« des Intuitiven wird nach dieser Zocherschen Deutung mit einem deskriptiv-ontologischen Charakter konfundiert (1932: 186), hat die Intuition doch den »Doppelsinn« des »funktionellen Geltungsgaranten« und des »deskriptiven Bestandes«. Dies heißt nun nichts anderes, als daß der Noesis als dem Noema Konstitutierenden, wie Zocher sagt, eine »,schlechte“ Dialektik» eigen ist. Das Bewußtsein eignet sich das Sein an, sofern die Noesis gültig vollzogen wird. Die Noesis ist auf Gültigkeit bezogen, enthält jedoch nicht notwendigerweise Gültigkeit. Zocher zufolge unterscheidet Husserl den semasiologischen Sinn des Intuitionsbegriffs unzureichend von seinem ontologischen Sinn; er wird ihm zum »Medium«, in dem die semasiologische Idee in die ontologische übergleitet (1932: 194).

In diesem Kontext geht Zocher bedeutsamerweise auf Husserls Begriff der Evidenz ein (1932: 194ff.). Ob eine auf Gültigkeit bezogene Noesis ihre Intention wirklich erfüllt, also Gültigkeit enthält, ist bei Husserl immerhin mit dem Evidenzbegriff verbunden. Gültigkeit muß intuitiv ausweisbar sein. Gibt es »Garantien« solcher Gültigkeit? Wie sieht man es einer Noesis an, ob sie eine gültige ist? Wie die Eidetik bleibe auch Husserls Evidenzlehre dem Ontologismus verhaftet (1932: 196). Zocher trifft offenbar den Punkt, wenn er dazu ausführt, Husserls Evidenzlehre müsse »ganz bestimmte deskriptive Charaktere der Evidenz« ausfindig machen, deren Geltung sich jedoch aus der Methode der Ableitung nicht rechtfertigen lasse. Ein Bewußtseinscharakter habe die Geltung in aller Gewißheit und Klarheit zu verbürgen, und zwar nicht diskursiv, sondern intuitiv (1932: 196f.). Obwohl Zocher, wenn ich recht sehe, darauf nicht eingeht, ist das Paradigma solcher Evidenz die »apodiktische«. Von den Logischen Untersuchungen (Hua XIX/2: §36ff.) 17 bis zu den Ideen I (Hua III/I: §136-145) und noch in den Cartesianischen Meditationen (Hua I: §5ff.) bildet sie ein zentrales Theorem. Daß Husserl - anders etwa als Scheler - spätestens seit den Ideen I die Erlebnistatsächlichkeit der Evidenz immer mehr durch deren Relations- und Synthesischarakter überformt (vgl. etwa Hua III/I: 346-350; I: §27ff. mit 17), was Zocher übrigens gesehen hat, spielt für die Beurteilung der Sachlage keine Rolle. Dasselbe gilt für den Versuch, theoretische und prädikative Erkenntnisse in vor-prädikativen und vor-theoretischen Evidenzen zu begründen (vgl. etwa

17 Hua = Husserliana (Husserl 1950ff.). 
Husserl 1948: $\$ 4$ mit 13; vgl. schon Hua IV: 90f., 4ff.). Im Rückgang vom Noema auf die Noesen kommt es begründungstheoretisch letztlich eben auf solche Noesen an, bei denen Geltung und Vollzug zusammenfallen, d. i. auf die sog. apodiktische Evidenz. Zocher stellt u. a. unter Berufung auf Husserls berühmte Floskel vom »Prinzip aller Prinzipien« auf die Kriterienoder Letztbegründungsfunktion der (originär gebenden) Anschauung ab (1932: 199). Völlig zu Recht, wie mir scheint. Denn Husserl hat zwar im Laufe seiner denkerischen Entwicklung das Evidenztheorem durchaus modifiziert, gleichwohl bleibt dabei die Anschaulichkeit, Erfahrbarkeit von Prinzipien immer vorausgesetzt. Die Gegenständlichkeit des Eidetischen ist also entscheidend: gemäß dem phänomenologischen »Prinzip aller Prinzipien « fungiert nur das unmittelbare Sehen, die »originär gebende Anschauung «,18 die originäre ,Evidenz ${ }^{6}$ als Geltungs- oder »Rechtsquelle « der Erkenntnis; entsprechend ist auch das Wesen als das Gegebene der Wesensanschauung ein ,Gegenstand' (Hua III/I: 51 mit I: 12, 65ff., 112; III/I: 14, 46; V: 142ff.; Husserl 1948: 421). Zocher selbst spricht diesbezüglich von der »Wesenserschauung « als begründender »Unterlage« der »Wesenserkenntnis « (1932: 205).

Erfahrbarkeit, Anschaulichkeit übergreifen als Grund das Reich der Wesenheiten wie das des Seins als Begründeten. Zocher versucht in seinen Ausführungen zur Evidenz- und Anschauungslehre fortwährend, diese Differenz herauszuarbeiten und dabei die »semasiologische« und »ontologische« Dimension zu unterscheiden. Stets wirkt sich ihm Husserls Intuitionismus »strukturnivellierend « aus (1932: 218, u. ö.). Zocher formuliert dies gelegentlich auch so, daß Husserls Anschauungslehre die Koinzidenz von Gegenstand und Sinn zu einer Koinzidenz von Gegenstand und Inhalt abschwächt. Er sieht nämlich bei Husserl einen Hyletismus wirksam, infolgedessen eine rein ontologisch faßbare Sinnunterlage mit dem Sinn verwechselt wird. Kurzum: erneut ist für Zochers Kritik die »intuitionistisch-ontologische Verschiebung « des transzendentalen Fundierungsgedankens leitend (1932: 233). Durch diese Verschiebung entsteht die Konzeption eines Bewußtseins, das seine Inhalte »,ontologisch ${ }^{`}$,

18 Das Problem der Anschauung ist in der Auseinandersetzung zwischen Phänomenologie und Neukantianismus besonders wichtig und daher von den Kontrahenten selbst schon in mehrfacher Hinsicht traktiert. Speziell mit Blick auf die Südwestdeutschen ist die Forschungslage eher dünn. Hier ist das Problem zunächst der Rickertschen Heterologie zugehörig, also der Thematik der Struktur des Denkens als Beziehung. Vgl. dazu Krijnen (2001b). 
in reiner Faktizität« aufbaut (1932: 234): es entsteht eine noematische Konstitutionstheorie, die nicht zugleich Geltungstheorie ist.

Zochers Argument, die transzendentale Begründungssphäre zeichne sich durch ihren Geltungscharakter aus, so daß es zu kurz greife, sie intuitivdeskriptiv-eidetisch zu konzipieren, da die entscheidende Strukturdifferenz eingeebnet werde (Sein - Geltung), besticht. Durch den intuitionistischen Einschlag der Grundlehre schrumpft der ,Inhalt' zum ,Gegenstand', schlägt Semasiologie in Ontologie um: aufs Ganze gesehen, kommt es zu einer ontologisierenden Fassung des konstituierenden Bewußtseins. Die fundierende Noesis wird, wie Zocher sagt, im Grunde doch nach dem Vorbild einer »Hylese « modelliert; die im »methodisch-fundierenden « Sinne, d. h. als Moment der Geltungsstruktur berechtigte »Intuition« erfährt eine »sachlich-intuitive« Wendung (1932: 269). Es liegt bei Husserl durchaus der Ansatz einer »Ontologisierung des transzendentalen Subjekts « (1932: 277) vor. In seinem 1939 erschienenen Buch Die philosophische Grundlehre betont Zocher im Abschnitt über die Phänomenologie, soweit er (auch) Husserl betrifft (16-25), just den eidetischen Charakter des Bewußtseins, den ontologischen Einschlag, die Eidetik des Apriorischen, die Einebnung der Differenz zwischen Fundierendem und Fundiertem durch die gemeinsame eidetische Struktur, den bewußtseinsontologischen Impetus, kurz: die diskutierten zentralen Elemente der Kritik seines Husserl(und Schuppe-) Buches aus 1932. Dagegen besteht er auf dem Geltungscharakter der Fundierungssphäre.

\section{Ein problemgeschichtlicher Schluß}

Bedauerlicherweise geht Fink auf die skizzierte fundamentalphilosophische Bedeutung von Zochers Kritik nicht ein. Der Zochersche Einwand bleibt also vorerst bestehen. Fink hätte allerdings schon aus problemgeschichtlichen Gründen Anlaß genug gehabt, das Ausgeführte nicht gleich mit einer phänomenologischen Brille zu lesen, sondern den Bogen, den Zocher selbst spannt, ob seiner Wirkungsmächtigkeit ernster zu nehmen, als er es faktisch tut.

Der unmittelbare Hintergrund von Zochers Arbeit ist, worauf Zocher auch immer wieder hinweist, die Wertphilosophie des südwestdeutschen Neukantianismus. Rickert hatte hier im Kontext einer von Lask 
angestoßenen Diskussion über den Sinn des ,Primates der praktischen Vernunft' (Lask 1923) eine Abhandlung geschrieben über ,Zwei Wege der Erkenntnistheorie“ (Rickert 1909). Sie klärt u. a. grundsätzlich das Verhältnis von Akt und Gegenstand, von Objektivität und Subjektivität der Erkenntnis, von Gegenstand der Erkenntnis und Erkenntnis des Gegenstandes und gelangt dabei $\mathrm{zu}$ einem sog. Primat des ,objektiven Weges', d.i. der geltungsnoematischen Geltungsreflexion vor einer jedweden noetischen, das Aktleben oder sonstige Tätigkeitmomente des Subjekts thematisierenden Reflexion.19 Dieser sog. ,subjektive" Weg ist Rickert nämlich mit einer petitio principii behaftet.

Rickert schreibt damit im Rahmen der kritizistischen Tradition in seiner Weise eine Argumentation fort, die schon Kant, wenn auch wenig elaboriert, in der ersten Auflage der Kritik der reinen Vernunft zur Unterscheidung einer objektiven von einer subjektiven Deduktion bewogen hat (vgl. Krijnen 2008a). Kant unterscheidet an seinem transzendentalen ,subjektivitätstheoretischen' Fundierungsgedanken einen objektiv-logischen und einen subjektiv-logischen Aspekt. Der objektiv-logische betrifft die Synthesis als Verbindung von reinem Verstand und reiner Sinnlichkeit, der subjektiv-logische das geltungsfunktionale Zustandekommen der Gegenstandskonstitution durch das Zusammenspiel von ,Erkenntniskräften“. Da es Kant nicht so sehr auf die Bestimmung dieses Erkenntnisvollzugs ankommt als vielmehr auf den Nachweis der objektiven Gültigkeit der den Vollzug und damit das erkennende Subjekt leitenden (weil Gegenständlichkeit selbst fundierenden) Begriffe, bezeichnet er nur die sog. objektive Deduktion, welche diese Aufgabe zu lösen hat (KrV, AXVI, 111, 128), als »wesentlich« für seine Aufgabe.20 In der subjektiven Erkenntnisleistung des ,Verstandes ${ }^{6}$ ist Kant zufolge objektive Urteilsgesetzlichkeit vorausgesetzt.

Zocher nun macht diesen Gedanken einer in aller subjektiven Geltungsbestimmtheit vorausgesetzten objektiven Geltungsstruktur für seine Husserl-Kritik fruchtbar. Er akzentuiert dieses Vorausgesetztsein bzw. die petitio principii des subjektiven Weges dahingehend, daß er die

19 Es ist durchaus erstaunlich, daß Kern (1964) in seinen Ausführungen zu Husserl und Rickert überhaupt nicht auf Zochers Analyse eingeht. Das wäre angesichts Kerns eher mangelhaften Verständnisses des Verhältnisses von Geltungsnoetik und Geltungsnoematik bei Rickert gewiß förderlich gewesen (vgl. zu jenem Verhältnis Krijnen [2001b: 352f., Anm. 102]).

20 - mag auch die subjektive Seite von »großer Wichtigkeit« sein (KrV, AXVIf.). 
vorausgesetzte Objektivität transgnoseologisch, wie er sagt: in einer ,sachlich-intuitiven', nach dem Vorbild einer Hylese, also einer vorgegebenen Gegenständlichkeit, d. i. des Eidos als eines Gegenstandes, in seinen Verästelungen bei Husserl ausarbeitet.

In der systematischen Tradition der Transzendentalphilosophie nach 1945 hat zunächst Hans Wagner in seiner ausführlichen und kritischen Besprechung von ,Husserls Nachlass“ das Zochersche Argument aufgegriffen und wie Zocher darauf hingewiesen, daß der phänomenologische Idealismus durch die Reduktion zwar eine Fundierungsdimension freilegt, diese jedoch als neue Erfahrungssphäre in Anspruch nimmt, also als durch Erfahrung zugänglich und beschreibbar, so daß Wagner wie Zocher moniert, daß die Erfahrungsstruktur Grund wie Begründetes übergreift, Grund und Begründetes in der Art des Seienden gedacht werden, mag es sich auch um den Seinssinn eines absoluten Seins handeln (Wagner 1980b). Folglich führt die Reduktion auch Wagner zufolge nicht $\mathrm{zu}$ jenen Prinzipien, die das Noema in seiner Geltung aufbauen, sondern zur noetischen Leistungsmannigfaltigkeit, in der es erwächst, mit Zocher gesprochen: zum Noema als einem ,neutralen Gebilde‘. Ebenso wie Zocher betont Wagner den geltungsfunktionalen Sinn der Husserlschen Evidenzlehre, wobei er besonders die Rolle der sog. ,apodiktischen Evidenz' artikuliert.

Damit haben Kant, Rickert, Zocher und Wagner Argumentationslinien gezeichnet, die bis heute für Kreise, die sich an der Transzendentalphilosophie Kants und des Kritizismus orientieren, richtungweisend sind in puncto Auseinandersetzung mit Husserl. Die noetisch-noematische Verschmelzung von Aktleben und Geltungsprinzipien, Kantisch gesprochen, die Kontamination der objektiven mit der subjektiven Deduktion, ist ein Sachverhalt, der in der Diskussion über das Verhältnis von Kritizismus und Phänomenologie nach wie vor der weiteren Aufhellung bedarf. Es wäre im Sinne Zochers und Finks, das durch die Geschicke der Zeit bedauerlicherweise unterbrochene und dann nur vereinzelt aufgegriffene Gespräch mit erhöhter Intensität fortzusetzen. Zochers Studie verdiente dabei gerade wegen ihrer weit ausholenden systematischen Erwägungen besondere Beachtung.21

21 Seebohm (1962: 166) folgt Fink in seiner Kritik, die neukantianische Kritik sei von zwei miteinander zusammenhängenden Vorurteilen getragen, will aber vor allem die Differenz der 


\section{Literaturverzeichnis}

BAUCH, B.: Immanuel Kant. 3. Aufl., Berlin/Leipzig, de Gruyter, 1923a. : Wahrheit, Wert und Wirklichkeit, Leipzig, Meiner, 1923b.

BERMES, C.: Bedeutung als Bestimmung und Bestimmbarkeit: Eine Studie zu Frege, Husserl, Cassirer und Hönigswald, Würzburg, Königshausen \& Neumann, 1997.

BRELAGE, M.: Studien zur Transzendentalphilosophie, Berlin, de Gruyter, 1965.

\section{FABBIANELLI, F.; LUFT, S.: Husserl und die klassische deutsche Philosophie: Husserl and Classical German Philosophy,} Cham/Heidelberg/New York/Dordrecht/London, Springer, 2014.

FINK, E.: „Die phänomenologische Philosophie Edmund Husserls in der gegenwärtigen Kritik: Mit einem Vorwort von Edmund Husserl“", KantStudien 38 (1933) 319-83.

FLACH, W.: Negation und Andersheit: Ein Beitrag zur Problematik der Letztimplikation, München/Basel, Schwabe, 1959.

: Grundzüge der Erkenntnislehre: Erkenntniskritik, Logik, Methodologie, Würzburg, Königshausen \& Neumann, 1994.

Methoden diskutieren. Er setzt sich dabei auch mit Zocher (Seebohm 1962: 168ff.) und Wagner (Seebohm 1962: 175ff.) auseinander. Leider liest Seebohm Zocher von vornhinein aus einer phänomenologischen Perspektive, so daß ihm der Sinn des von Zocher Gemeinten nur entstellt erscheint. Etwa, daß es im Kritizismus ,bezeichnenderweise' sinnvoll sein möge, »ein fixes Kriterium zu verlangen, das den Bereich transzendentaler Bedingungen der Möglichkeit von den ermöglichten Gegenständen trennt«, während ein »vorangestelltes Kriterium« für die transzendentale Phänomenologie eine »methodische Verirrung « sei, »da hier die Transzendentalität erst durch den Prozeß reflektiver, erfahrender Auslegung der Subjektivität entdeckt werden soll«, ist wenig sachgerecht. Das Geltungsproblem, das Zochers Argumentation wie einen roten Faden durchzieht, spielt auch in Seebohms Replik keine Rolle. Er stellt vielmehr auf eine Klärung des Bewußtseinsbegriffs $a b$, ohne in Rechnung zu stellen, daß es sich um das Bewußtsein qua Geltungsgrund gegenständlichen Sinns handeln muß, das Bewußtsein Geltungsursprung und Geltung Konstituierendes ist, Sein selbst eine Geltungsbestimmtheit ist, Ursprungsprobleme also Geltungsprobleme sind. Kants Philosophie wie die der Neukantianer ist keine Bewußtseinstheorie, sondern eine Geltungstheorie. Husserl bietet eine bewußtseinstheoretische Lösung des Geltungsproblems, um es mit einer seiner ,Spätschriften', den Cartesianische Meditationen, zu sagen: Die phänomenologische Epoché inihibiert die »Seinsgeltungs der objektiven Welt«; das philosophierende Ich setzt sich »als Geltungsgrund aller objektiven Geltungen und Gründe« (Hua I: 64f.). Seebohm ist verborgen geblieben, daß und wie Wagners Kritik des »Zweisphärentheorems « eine Reprise der Zocherschen Kritik ist, und er mißversteht zudem Wagners Ausführungen zur Implikationsstruktur (Seebohm 1962: 175f.). Wenn Seebohm schließlich eine »direkt aufweisend verfahrende Methode« propagiert, bleibt leider mehr als dunkel, wie das von Zocher und Wagner aufgeworfene Geltungsproblem damit bewältigt werden kann. 
HUSSERL, E.: Formale und transzendentale Logik: Versuch einer Kritik der logischen Vernunft, Halle/S., Max Niemeyer, 1929.

: Erfahrung und Urteil: Untersuchungen zur Genealogie der Logik, Hamburg, Meiner, 1948.

: Gesammelte Werke (Husserliana), Den Haag, Dordrecht, $1950 \mathrm{ff}$.

KANT, I.: Kants gesammelte Schriften: Bd. I-XXIX, Berlin, de Gruyter, $1910 \mathrm{ff}$.

KERN, I.: Husserl und Kant: Eine Untersuchung über Husserls Verhältnis zu Kant und zum Neukantianismus, Den Haag, Nijhoff, 1964.

KREIS, F.: Phänomenologie und Kritizismus, Tübingen, Mohr, 1930.

KRIJNEN, C.: „Fehlt die konkrete Subjektivität im Neukantianismus? Zur systematischen Bedeutung von $H$. Rickerts ,Zwei Wege der Erkenntnistheorie““, Zeitschrift für philosophische Forschung 55 (2001a) 409-430.

: Nachmetaphysischer Sinn: Eine problemgeschichtliche und systematische Studie zu den Prinzipien der Wertphilosophie Heinrich Rickerts, Würzburg, Königshausen \& Neumann, $2001 b$.

: „Kants Subjektstheorie und die Grundlegung einer philosophischen Anthropologie“, Zeitschrift für philosophische Forschung 62 (2008a) 254-273.

: Philosophie als System: Prinzipientheoretische Untersuchungen zum Systemgedanken bei Hegel, im Neukantianismus und in der Gegenwartsphilosophie, Würzburg, Königshausen \& Neumann, 2008b.

: „Gegenstandskonstitution bei Husserl und in der klassischen deutschen Philosophie: Eine problemgeschichtliche Deutungslinie", in FABBIANELLI, F.; LUFT, S. (Hgs.): Husserl und die klassische deutsche Philosophie: Husserl and Classical German Philosophy, Cham/Heidelberg/New York/Dordrecht/London, Springer, 115-131, 2014a.

: Recognition: German Idealism as an Ongoing Challenge, Leiden/Boston, BRILL, 2014b.

: "Subjectivity as the Foundation for Objectivity in Kant and Husserl: On Two Types of Transcendental Idealism", Meta: Research in 
Hermeneutics, Phenomenology, and Practical Philosophy VII (2016) 526549.

KRIJNEN, C.; ZEIDLER, K. W.: Reflexion und konkrete Subjektivität: Beiträge zum 100. Geburtstag von Hans Wagner (1917-2000), Wien, Ferstl \& Perz, 2017.

LASK, E.: „Gibt es einen ,Primat der praktischen Vernunft' in der Logik? (1908)“, in HERRIGEL, E. (Hg.): Gesammelte Schriften, 3. Bd., Tübingen, Mohr, 347-356, 1923.

MAKKREEL, R.; LUFT, S. (Hgs.): Neo-Kantianism in Contemporary Philosophy, Bloomington, Indiana University Press, 2010.

MARX, W. (Hg.): Zur Selbstbegründung der Philosophie seit Kant, Fráncfort del Meno, Klostermann, 1987.

ORTH, E. W.: Bedeutung, Sinn, Gegenstand: Studien zur Sprachphilosophie Edmund Husserls und Richard Hönigswalds, Bonn, Bouvier, 1967.

RICKERT, H.: „Zwei Wege der Erkenntnistheorie: Transcendentalpsychologie und Transcendentallogik“", Kant-Studien 14 (1909) 169-228.

: „Vom Begriff der Philosophie“, Logos 1 (1910) 1-34.

: System der Philosophie: Erster Teil: Allgemeine Grundlegung der Philosophie, Tübingen, Mohr, 1921.

: Das Eine, die Einheit und die Eins: Bemerkungen zur Logik des Zahlbegriffs. 2. umg. Aufl., Tübingen, Mohr, 1924a.

: Die Probleme der Geschichtsphilosophie. 3. umg. Aufl., Heidelberg, Winter, 1924b.

: Der Gegenstand der Erkenntnis: Einführung in die Transzendentalphilosophie. 6. verb. Aufl., Tübingen, Mohr, 1928.

: Die Grenzen der naturwissenschaftlichen Begriffsbildung: Eine logische Einleitung in die historischen Wissenschaften. 5. verb. u. erw. Aufl., Tübingen, Mohr, 1929.

: Die Logik des Prädikats und das Problem der Ontologie, Heidelberg, Winter, 1930. 
: „Geschichte und System der Philosophie“, Archiv für Geschichte der Philosophie 40, 7-46 u. (1931) 403-448.

: Grundprobleme der Philosophie: Methodologie, Ontologie, Anthropologie, Tübingen, Mohr, 1934a.

: „Kennen und Erkennen: Kritische Bemerkungen zum theoretischen Intuitionismus“, Kant-Studien 39 (1934b) 139-155.

: „Die Erkenntnis der intelligiblen Welt und das Problem der Metaphysik: Erster Teil (1927),“ in FAUST, A. (Hg.): Unmittelbarkeit und Sinndeutung: Aufsätze zur Ausgestaltung des Systems der Philosophie, Tübingen, Mohr, 97-138, 1939a.

: „Die Erkenntnis der intelligiblen Welt und das Problem der Metaphysik: Zweiter Teil (1929)“, in FAUST, A. (Hg.): Unmittelbarkeit und Sinndeutung: Aufsätze zur Ausgestaltung des Systems der Philosophie, Tübingen, Mohr, 139-185, 1939b.

: „Die Methode der Philosophie und das Unmittelbare. Eine Problemstellung (1923)“, in FAUST, A. (Hg.): Unmittelbarkeit und Sinndeutung: Aufsätze zur Ausgestaltung des Systems der Philosophie, Tübingen, Mohr, 51-96, 1939c.

: „Vom Anfang der Philosophie (1925)“, in FAUST, A. (Hg.):

Unmittelbarkeit und Sinndeutung: Aufsätze zur Ausgestaltung des Systems der Philosophie, Tübingen, Mohr, 9-50, 1939d.

SCHERBEL, M.: Phänomenologie als absolute Wissenschaft: Die systembildende Funktion des Zuschauers in Eugen Finks VI. Cartesianischer Meditation, Amsterdam, Rodopi, 1999.

SCHMIDT AM BUSCH, H.-C.; ZURN, C. (Hgs.): The Philosophy of Recognition: Historical and Contemporary Perspectives, Lanham, Rowman \& Littlefield, 2010.

SEEBOHM, T.: Die Bedingungen der Möglichkeit der TranszendentalPhilosophie: Edmund Husserls transzendental-phänomenologischer Ansatz, dargestellt im Anschluss an seine Kant-Kritik, Bonn, Bouvier, 1962.

STAITI, A.: Husserl's Transcendental Phenomenology: Nature, Spirit, and Life, Cambridge, Cambridge University Press, 2014. 
WAGNER, H.: „Husserls zweideutige Wissenschaftsphilosophie (1974)“, in BÄRTHLEIN, K.; FLACH, W. (Hgs.): Kritische Philosophie: Systematische und historische Abhandlungen, Würzburg, Königshausen \& Neumann, 397-408, 1980a.

: „Kritische Betrachtungen zu Husserls Nachlass (1953)“, in BÄRTHLEIN, K.; FLACH, W. (Hgs.): Kritische Philosophie: Systematische und historische Abhandlungen, Würzburg, Königshausen \& Neumann, 363-396, 1980b.

: Philosophie und Reflexion. 3. Aufl., München/Basel, Reinhardt, 1980c.

: „Reflexion (1973)“, in BÄRTHLEIN, K.; FLACH, W. (Hgs.):

Kritische Philosophie: Systematische und historische Abhandlungen, Würzburg, Königshausen \& Neumann, 57-63, 1980d.

ZOCHER, R.: Husserls Phänomenologie und Schuppes Logik: Ein Beitrag zur Kritik des intuitionistischen Ontologismus in der Immanenzidee, München, Reinhardt, 1932.

: Die philosophische Grundlehre: Eine Studie zur Kritik der Ontologie, Tübingen, Mohr, 1939.

: Kants Grundlehre, Erlangen, Universitätsbund, 1959. 


\title{
Una interpretación de la Stufenleiter de A320/B376. Contribución a la determinación precisa del carácter de la distinción entre intuiciones y conceptos
}

\author{
LUIS PLACENCIA 1 \\ JAVIER FUENTES 2
}

\begin{abstract}
Resumen
Comenzando desde el pasaje de la Stufenleiter (A320/B376), se constata que su lectura más recurrente en la literatura corresponde a un árbol porfiriano según el cual las representaciones se distinguirían como clases de cosas según géneros y especies. Rechazando esta interpretación, se considera entender las representaciones como distintas descripciones de un mismo objeto o como conjuntos de la lógica matemática. Mostrando también la insuficiencia de tales lecturas, se concluye que el modo más adecuado de interpretar la distinción entre representaciones es comprenderlas como diferentes momentos que constituyen el objeto de la experiencia, es decir, el fenómeno.
\end{abstract}

Palabras clave: Stufenleiter, intuición, concepto, distinción, momento

An interpretation of the Stufenleiter from A320/B376.

A contribution to the accurate determination of the character of the distinction between intuitions and concepts

\begin{abstract}
Starting from the Stufenleiter passage (A320/B376), it is observed that its usual reading in the literature corresponds to a Porfirian tree according to which representations would be distinguished as classes of things according to genera and species. Rejecting this interpretation, it is considered to understand representations as different descriptions of the same object or as sets from mathematical logic. Showing also the insufficiency of such readings, it is concluded that the most appropriate way to interpret the distinction between representations is to understand them as different moments which constitute the object of the experience, that is, the phenomenon.
\end{abstract}

Keywords: Stufenleiter, intuition, concept, distinction, moment

1 Universidad de Chile. Contacto: luisplacencia@gmail.com.

2 Universidad Andrés Bello, Chile. Contacto: jfuentesg10@gmail.com. 


\section{Introducción}

Uno de los fundamentos de la filosofía teórica de Kant consiste en las distinciones que hay entre las diversas representaciones, tales como las intuiciones y los conceptos. En efecto, son muchas las tesis kantianas que, al menos a primera vista, solo pueden ser comprendidas a cabalidad bajo el supuesto de que se haya captado de manera adecuada cuál es la naturaleza de estas distintas representaciones. Lo anterior parece ser, por ejemplo, lo que ocurre con la conocida idea kantiana según la cual, para que haya conocimiento, deben concurrir intuiciones y conceptos, tesis que es expresada del siguiente modo en un pasaje crucial de la introducción a la Lógica trascendental:

Si queremos llamar sensibilidad a la receptividad de nuestro ánimo para recibir representaciones en cuanto él es afectado de alguna manera, entonces es, por el contrario, el entendimiento la facultad de producir representaciones por uno mismo o espontaneidad del conocimiento. Nuestra naturaleza es tal que la intuición no puede nunca sino ser sensible, i.e. solo contiene el modo en que somos afectados por los objetos. Por el contrario, el entendimiento es la facultad de pensar el objeto de la intuición sensible. Ninguna de estas propiedades ha de ser preferida a la otra. Sin la sensibilidad no nos serían dados objetos y sin el entendimiento no podrían ser pensados. Pensamientos sin contenido son vacíos, intuiciones sin conceptos son ciegas [...] Solo del hecho de que ambas facultades se unifiquen puede surgir conocimiento. Por eso no se puede mezclar su contribución, sino que hay buenas razones para abstraer y diferenciar la una de la otra (A51/B75).3

El pasaje citado resume de modo notable una parte esencial de las enseñanzas de la $K r V$. Junto con ello, presenta un conjunto de ideas que han sido de enorme influencia en la filosofía hasta nuestros días. Pero también, como es bien sabido entre los especialistas, el texto citado presenta una serie de dificultades interpretativas que han concentrado el interés de los

\footnotetext{
3 Como es habitual entre los especialistas, citamos las obras de Kant recurriendo a la edición comenzada por la Academia Prusiana de Ciencias y continuada desde 1966 por la Academia de Ciencias de Gotinga, que identificamos, como es habitual, con las siglas AA, seguidas del volumen, página y línea de la misma. La única excepción a esta práctica la constituye la $K r V$ que citamos, como es costumbre entre los especialistas, remitiendo a la paginación de las ediciones primera y segunda, identificadas como A y B respectivamente. En el caso los restantes textos clásicos seguimos también las convenciones clásicas entre especialistas. Para mayores datos, se puede consultar la bibliografía al final. Todas las traducciones son de nuestra responsabilidad.
} 
intérpretes de modo creciente. Revisemos brevemente las tesis del texto para luego dar cuenta de algunos de sus problemas. En primer lugar, el pasaje recién presentado destaca la famosa tesis de la necesaria colaboración de intuiciones y conceptos para que haya conocimiento. En segundo lugar, pone de relieve el hecho de que la colaboración ya mencionada es necesaria en virtud del carácter heterogéneo de las facultades de las cuales este tipo de representaciones son actos, $s c$. sensibilidad y entendimiento, toda vez que ellas responden a formas de representar completamente diferentes. Mientras el entendimiento, nos dice Kant, es una facultad activa de conocimiento basada en la espontaneidad, la sensibilidad es una facultad pasiva de conocimientos, basada en la receptividad. La tesis que está detrás de la posición de Kant parece ser, entonces, que para que haya conocimiento es necesario el concurso de estos dos rendimientos, $s c$. intuiciones y conceptos. Así las cosas, intuiciones y conceptos serían condiciones sine quibus non para conocer, pues cada una proveería elementos necesarios para el conocimiento no provistos por la otra. Sin embargo, ellas serían, además, condiciones en algún sentido 'independientes'. Como bien es sabido, estas tesis han devenido un asunto de interés ya no solo para los especialistas en Kant, sino que incluso de modo creciente para scholars de otros ámbitos a partir de la publicación de Mind and World de J. McDowell, obra que a su vez ha generado un enorme debate y revitalizado el interés en el marco de los mismos estudios kantianos por la cuestión de la relación entre intuiciones y conceptos (1994: 3ss.).4 A partir de los trabajos de McDowell, que a su vez recogen la herencia de autores de enorme influencia en la tradición analítica como W. Sellars (1963) y D. Davidson (1974), la cuestión de las relaciones entre 'lo dado' (i.e. la intuición) y el ámbito conceptual ha sido releída a partir de Kant y a la vez ha influido en la interpretación de las ideas de este último. Tal discusión, sin embargo, no pocas veces entraña equívocos o lecturas extemporáneas, de suerte que se hace urgente, al menos a la luz de los estudios kantianos, el volver a revisar la cuestión atendiendo con el mayor cuidado posible a la base textual. No intentaremos aquí resolver en su totalidad la cuestión de la relación entre intuiciones y conceptos en Kant que, como se ha visto en la última nota de

\footnotetext{
4 El debate que ha originado el trabajo de McDowell ha influenciado una muy nutrida discusión en el ámbito de los estudios kantianos, como puede verse en los trabajos de Hanna (2005), Haag (2007), Ginsborg (2008), Allais (2009), Grünne (2009), Tolley (2013), Land (2015) y Schulting (2016), por nombrar algunos de los más influyentes. En el ámbito de habla hispana cabe destacar los aportes de Lazos (2014) y Stepanenko (2000; 2008; 2016).
} 
nuestro texto, es copiosa. Hacerlo supondría la comprensión plena de qué son intuiciones y conceptos, asunto que a su vez ha sido enormemente discutido y no es este el lugar para emprender una tarea de ese tipo. Con todo, es claro que tal comprensión es un desideratum y entraña no solo la identificación de aquellos aspectos o características que son propios de cada una de estas 'representaciones', tarea que ha interesado a la literatura reciente con bastante claridad, sino que también la comprensión de 'qué tipo de distinción' hay entre intuiciones y conceptos. Una manera habitual de entender esta distinción, común a muchos tratamientos de las nociones de intuición, concepto así como de sus relaciones, es la de comprender a intuiciones y conceptos como especies de un orden de géneros que tendrían como género supremo al de 'representación'. En este texto intentaremos proveer de razones para poner en duda esa interpretación y sugeriremos una lectura diferente de al menos un pasaje en que parece basarse esta lectura habitual. Con ello, estimamos, haremos una contribución, aunque sea pequeña, a la cuestión de la elucidación de la relación entre intuiciones y conceptos en Kant.

\section{La interpretación usual de la Stufenleiter}

Un conocido pasaje de la $K r V$ que citamos parcialmente a continuación ofrece la siguiente clasificación de las representaciones:

He aquí una escala (Stufenleiter) de las representaciones: El género es la representación sin más (raepresentatio). Bajo él están las representaciones con conciencia (perceptio). Una percepción que solo se refiere al sujeto como modificación de su estado es una sensación (Empfindung) (sensatio), una percepción objetiva es conocimiento. Este es o bien intuición o bien concepto (intuitus vel conceptus). La primera se refiere inmediatamente al objeto y es singular, la segunda mediatamente, por medio de una nota que puede ser común a más cosas. El concepto es o bien empírico o bien puro, y el concepto puro, en cuanto él tiene su origen solamente en el entendimiento, se llama noción. Un concepto a partir de nociones que sobrepasa la posibilidad de la experiencia, es la idea o el concepto de la razón (A320/B376-377).5

5 El esquema de esta Stufenleiter se puede encontrar también en Refl., AA 16: 538, 13-539, 8; R 2836. 
El pasaje en comento ha sido de enorme influencia en la interpretación de la obra de Kant y es sumamente habitual citarlo a la hora de dar cuenta de la caracterización que haría Kant de intuiciones y conceptos, así como de la distinción que habría entre ambas representaciones. De acuerdo con la lectura habitual de este pasaje, que E. Lazos ha dado en llamar recientemente 'pasaje clasificatorio', la Stufenleiter correspondería a una "taxonomía” de representaciones (Smit 2000: 235). Esta taxonomía suele ser comprendida explícita o implícitamente como una especie 'árbol de Porfirio' de las mismas, i.e. de una clasificación en géneros y especies, que incluye a la 'representación' como género supremo, bajo el cual caería la 'percepción' y así especies de este género, que serían identificadas a partir de la posesión de propiedades contradictorias (o contrarias o al menos excluyentes), propiedades que las harían 'distintas' entre sí.6 Todos los elementos identificados habrían de ser entonces tales que contuvieran bajo una definición unívoca al género del cual son especies. Así, bajo la noción de 'percepción' caerían como especies la sensación y el conocimiento, que serían por ello formas de 'percepción'. Estos géneros y especies habrían entonces de identificar clases distintas de representaciones y por ello entidades distintas entre sí. Así, por ejemplo, bajo el género 'conocimiento' caerían las especies 'intuición' y 'concepto', que serían 'conocimientos' (y no sensaciones), de modo que toda sensación no sería conocimiento y todo conocimiento no sería sensación. Esta lectura que da cuenta del pasaje en comento como presentando un 'árbol de Porfirio' (que llamaremos 'lectura del árbol') es asumida, como se indicaba más arriba, de modo más o menos explícito por muchos autores que dan cuenta de este pasaje apelando al repertorio de 'géneros' y 'especies' (Grüne 2009: 35ss.; Lazos 2014: 24; Natterer 2003: 160; Smit 2000: 244).7 Por otra parte, es muy habitual en la literatura introducir la idea de que Kant aquí presenta una 'clasificación', sin aclarar de modo preciso exactamente en qué tipo de clasificación se está

\footnotetext{
6 Porfirio presenta el tipo de relación de orden que llamamos 'árbol de Porfirio' en su Isagogé I 6. Como es bien sabido, la expresión 'árbol de Porfirio' no es empleada por el comentarista de Aristóteles mismo, sino que remonta probablemente a Pedro Hispano o incluso a Avicena. Para la noción de 'Árbol de Porfirio', $c f r$. Baumgartner (1980).

7 Véase Lazos (2014: 24): "Encontramos aquí un trayecto por pasos o niveles desde la clase más general - las representaciones - hasta la más específica - las ideas -.”. Natterer (2003: 160) denomina de manera explícita al Stufenleiter "árbol de conceptos" [Begriffsbaum]. Grüne, por su parte, presenta las caracterizaciones de la Stufenleiter como 'definiciones'. Con todo, especialmente tomando en cuenta el modo en que Kant mismo entiende este término, caben serias dudas de que las presentaciones de la Stufenleiter tengan el carácter de definiciones, al menos en sentido estricto.
} 
pensando. Con todo, es difícil comprender el sentido y alcance de la 'clasificación' si no deja en claro cuál es la forma de la misma.

3. Razones para sostener la lectura del árbol y buscar otra forma de clasificación

Comencemos, de todos modos, comprendiendo por qué parece ser razonable la lectura del árbol. Esta parece fundarse en razones textuales sólidas, como queda claro ya por el hecho de que el mismo Kant llama 'género' [Gattung] a la noción de 'representación sin más' [Vorstellung überhaupt]. Por otra parte, la expresión Stufenleiter parece sugerir la presentación de un orden sistemático (como queda claro en la entrada Stufenleiter del Wörterbuch de los hermanos Grimm), que bien podría coincidir - aunque no necesariamente - con el que se presenta en un 'árbol de Porfirio'. Tanto más plausible resulta esta idea si se apunta al hecho de que, al igual que el procedimiento presentado por Porfirio en la Isagogé, Kant parece presentar en el pasaje en comento una 'división' diádica de géneros en especies que continúa la 'cadena' divisoria siempre por un brazo de la misma, dejando el lado complementario sin analizar, tal como se puede apreciar fácilmente en la representación de la Stufenleiter en forma de tabla (cfr. Bondeli 2015: 2568).

Con todo, hay también buenas razones para poner en duda la forma de interpretar el pasaje según el árbol porfiriano. Una de ellas es que este, como se deja ver de modo claro a partir del contexto en que es introducido, no tiene por función el establecer una clasificación de las representaciones, sino más bien el presentar los conceptos que Kant llama 'ideas'. Recuérdese que el pasaje corresponde a la primera sección del primer libro de la Dialéctica trascendental, en concreto al título "De las ideas sin más" ["Von den Ideen überhaupt"]. Aunque esta función es compatible con la presentación de una clasificación o taxonomía de las representaciones e incluso puede suponerla, no parece, por otro lado, exigirla de suyo. Lo importante es, con todo, establecer que el sentido del pasaje no es, al menos a primera vista, el asentar una taxonomía de representaciones, sino más bien el aislar y presentar así el contraste entre un tipo de representación que a Kant interesa en el contexto del pasaje, $s c$. las ideas y las demás ya tratadas en el texto. A lo anterior se suma que, si se toma la clasificación recién referida como una propia de un 'árbol de Porfirio', surgen claras dudas respecto de la consistencia entre las afirmaciones de la pretendida 
'clasificación' y otros textos de la misma $\mathrm{KrV} .8$ La primera de ellas, y las más obvia, es que de ser correcto el 'árbol' pareciera en algún sentido que se contradice la doctrina sentada en el primer pasaje que citamos (A51/B75), toda vez que podría haber conocimientos que fueran conceptos y no intuiciones $\mathrm{y}$ viceversa, conocimientos que fueran intuiciones y no conceptos. Como es bien sabido, sin embargo, Kant reitera esta doctrina incluso hasta en textos escritos hacia el final de su vida (FM, AA 20: 235, 5-14). Parecen haber buenas razones, así, para buscar una lectura del pasaje que la haga compatible con la doctrina kantiana mencionada. Con todo, bien podría argüirse que la interpretación del árbol admite modificaciones que permiten resolver esta cuestión.9 Pero las razones contra la lectura del árbol no se agotan aquí. Junto con lo anterior, debe de mencionarse que la interpretación en comento genera otras inconsistencias. Así, por ejemplo, mientras la 'sensación' cae en el 'pasaje clasificatorio' del lado de la percepción que no se refiere al objeto, siendo las intuiciones y los conceptos percepciones 'objetivas', la caracterización que da el mismo Kant de la 'intuición empírica' en A20/B34, por otra, parece no identificar la sensación con un 'tipo de representación' distinto de la intuición, al menos de la intuición empírica, sino más bien como una parte componente, y por cierto necesaria, de la misma. En efecto, en el pasaje en cuestión sostiene Kant lo siguiente: "el efecto de un objeto en la capacidad representativa en cuanto somos afectados por él es la sensación. Aquella intuición que se refiere al objeto por medio de la sensación se llama intuición empírica" (A20/B34). Este pasaje afirma de modo claro que la "intuición empírica" refiere a objetos por medio de su contenido, sc. la sensación, de manera tal que la intuición empírica no podría caer meramente del lado de aquello que no es sensación, ni tampoco la sensación ser considerada sin más como carente de referencia a objetos y como constituyendo una "representación diferente" de la intuición. De este modo, nos parece claro que el pasaje de A20/B34 no parece calzar del todo con la lectura del árbol del 'pasaje clasificatorio'. Por otro lado, en el $\$ 1$ de la Estética trascendental, donde Kant caracteriza diversas nociones clave para tal sección de la $K r V$ y también para el resto

8 Las dificultades que prepara este pasaje han sido indicadas — al menos parcialmente - ya en la literatura (Wolff 1995: 62ss.).

9 La lectura que hacen tanto Klaus Reich como Michael Wolff del modo en que debe entenderse el que intuiciones y conceptos sean llamados 'conocimientos' en la Stufenleiter y pasajes afines parece ser compatible con la lectura del árbol, aunque esta nos parece que claramente no es imputable al menos a Wolff. Cfr. Reich (1948: 12) y Wolff (1995: 60-63). 
del texto, se encuentra el siguiente pasaje: "El objeto indeterminado de una intuición empírica se denomina fenómeno (Erscheinung)" (A20/B34).

De acuerdo con este pasaje, la intuición empírica tiene como objeto al fenómeno, no a una 'parte' de él. En caso de que el pasaje clasificatorio se refiriera a un árbol porfiriano, las clases que se identifican en este deberían ser disjuntas, en la medida en que tales clases quedan definidas sobre la base de diferencias específicas. De este modo, parece obtenerse siguiendo la lectura del árbol- que las intuiciones y los conceptos deberían tener como objeto partes disjuntas del fenómeno, y lo mismo debería suceder en el caso de las intuiciones puras y las empíricas. Sin embargo, la intuición empírica tiene como objeto el fenómeno, mientras que los conceptos y las intuiciones puras tienen como objeto 'partes' del fenómeno, de modo que los objetos de estas últimas representaciones están contenidos dentro del objeto de la primera y, por lo tanto, no hay una disyunción entre los objetos de estas representaciones, i.e. de intuiciones y conceptos, por un lado, y del fenómeno por otro.

Ahora bien, ¿en qué sentido los conceptos y las intuiciones puras tienen como objeto 'partes' o si se quiere - y para ser más precisosmomentos constituyentes del fenómeno? Siguiendo en el §1 de la Estética trascendental, Kant recurre a las nociones de materia y de forma, con el fin de introducir la de intuición pura: "En el fenómeno llamo materia del mismo a lo que corresponde a la sensación. Por otra parte, llamo forma del fenómeno a lo que hace que lo múltiple del mismo pueda ser ordenado en ciertas relaciones" (A20/B34). No es nuestro objetivo realizar una aclaración exhaustiva sobre el modo en que Kant entiende las nociones de materia y de forma, sino que nos basta con tomar ciertas indicaciones contenidas en el pasaje recién citado.10 En primera instancia, debe destacarse que en el pasaje citado Kant no habla de materia y de forma sin más, sino que aplica estos términos para el caso del fenómeno. De este modo, la materia del fenómeno es aquel elemento de este al cual refiere la sensación, mientras que la forma del fenómeno es el principio ordenador de lo múltiple de este. Aunque es correcto hablar de una distinción entre

10 La tarea de elucidar de modo preciso el significado de estos conceptos en la obra de Kant sigue siendo, según nuestro parecer y conocimiento, un desideratum de la Kant-Forschung. Un punto importante a tener en cuenta en una tarea como esta sería considerar que Kant identifica explícitamente "materia" y "forma" como "conceptos de reflexión" (A266/B322). Sobre tales conceptos, y en general sobre el rendimiento sistemático de la "Anfibología de los conceptos de reflexión", $c f r$. Vigo (2006). 
materia y forma del fenómeno, esta no es una según un árbol porfiriano, es decir, materia y forma no son dos especies de un mismo género dado que, al menos, ambas no son conjuntos de ítems, sino, más bien, distintos aspectos de un mismo ítem, i.e. formas en las que este ítem puede ser considerado según sus momentos constituyentes. Estos momentos no constituyen el fenómeno como un mero agregado de partes discretas, así como un montón de arroz se forma de una suma de granos de arroz o como del agregado de patas y tabla se forma la mesa sino que, más bien, son momentos necesarios para que haya fenómeno, pero que solo son identificables como tales en la medida en que reflexionamos sobre las condiciones necesarias para que este tenga lugar.11

Ahora bien, ¿qué alcance tiene esta consideración sobre la distinción entre intuición pura y empírica? Para resolver esta inquietud, conviene tomar en cuenta el siguiente pasaje, ubicado unas líneas después del anterior:

Llamo puras (en sentido trascendental) a todas las representaciones en las que no se encuentra nada perteneciente a la sensación. En consecuencia con lo anterior la forma pura de las intuiciones sensibles se encontrará a priori en el ánimo, [forma] en la cual todo múltiple de los fenómenos es intuido en ciertas relaciones. Esa forma pura de la sensibilidad se llamará también, ella misma, intuición pura (A20/B34-35).

En primer lugar, Kant caracteriza como puras a aquellas representaciones en las cuales no hay nada que remita la sensación, es decir, se trata de representaciones de las cuales se ha abstraído todo aquello que es material. En segundo lugar, Kant describe en particular la intuición pura como forma pura de la sensibilidad, asociando, de esta manera, a la intuición pura con un elemento formal del fenómeno. Por otro lado, se ha visto anteriormente que la intuición empírica tiene como objeto al fenómeno en su totalidad (A20/B34), de modo que la intuición empírica remite tanto a la materia como a la forma del fenómeno, dado que ambas son aspectos que lo constituyen. Luego, la intuición pura tiene como objeto un aspecto formal del objeto de la intuición empírica. Esta distinción entre intuición pura y empírica, en donde la primera remite a un aspecto formal de lo remitido por

11 Empleamos deliberadamente aquí esta noción husserliana. Cfr. Hua, XIX/1, 272. 
la última, es otra razón que fortalece la plausibilidad del rechazo de la interpretación de la Stufenleiter como un árbol de Porfirio.

Unos párrafos más adelante, dentro del mismo $\$ 1$ de la Estética trascendental, Kant realiza la siguiente aclaración sobre la intuición pura:

\begin{abstract}
Así, si abstraigo de la representación de un cuerpo aquello que el entendimiento piensa de este, como la sustancia, la fuerza, la divisibilidad, etc., y de la misma manera lo que de este pertenece a la sensación, tal como la impenetrabilidad, la dureza, el color, etc., entonces me queda algo todavía de esta intuición empírica, a saber la extensión y la figura. Estas pertenecen a la intuición pura, la cual tiene lugar a priori en el ánimo como una mera forma de la sensibilidad, incluso sin un objeto efectivamente real de los sentidos o de la sensación (A20-21/B35).
\end{abstract}

Más allá de que este pasaje tenga como fin precisar en qué consiste la intuición pura, el punto relevante para nuestra discusión radica en el modo en que esta se vincula con la intuición empírica y los conceptos. Este pasaje es uno de aquellos lugares en los que Kant explica ciertas nociones por medio del empleo de un proceso de abstracción [Absonderung].12 Es importante enfatizar aquello que en este pasaje corresponde al punto de partida de este proceso abstractivo, a saber, la representación de un cuerpo. De esta se separa aquello que 'el entendimiento piensa', es decir, el contenido conceptual, ya sea puro (las categorías) o empírico. A continuación, se separa de esta aquello que pertenece a la sensación, quedando como resultado aquello que corresponde a la intuición pura. Cabe destacar que en este último paso abstractivo Kant menciona que se retira lo que queda todavía de esta intuición empírica, a propósito de lo cual podemos notar dos cosas: i) esta intuición empírica no es una parte más que, junto con otras, compone el objeto representado, sino que, más bien, dentro de esta, o si se quiere a partir de esta, se encuentran como sus momentos tanto los conceptos, ya sean puros o empíricos, como la intuición pura. De la mano con esto, podemos notar que ii) la intuición empírica representa aquello desde lo cual se comenzó este proceso abstractivo, es decir, la percepción de un cierto cuerpo a través de sensaciones. En otras palabras, la

12 Sobre este proceso de "abstracción", cfr. Placencia (2007: 140). Es de destacar que G. Bird lo vincula explícitamente a la "tópica trascendental", tratada en la "Anfibología de los conceptos de reflexión”, sección en que son tematizados, además, los conceptos de materia y forma (2006: 106). 
intuición empírica representa al fenómeno y no meramente a una parte de este, tal como se vio en el pasaje anterior.

Existen otros pasajes que son favorables para nuestra interpretación. Así, por ejemplo, podemos mencionar aquellos donde Kant se refiere al papel que la intuición, ya sea pura o empírica, desempeña dentro del conocimiento matemático. De hecho, como se verá en el siguiente análisis, una comprensión de la clasificación de las representaciones, en particular de las intuiciones, del tipo porfiriana, da origen a inconsistencias en los planteamientos de Kant, las cuales son fácilmente evitables a partir de una comprensión de tal clasificación según el modo que planteamos nosotros.

El primer pasaje de estos que deseamos abordar corresponde a aquel de "La disciplina de la razón pura en el uso dogmático" en donde Kant caracteriza la noción de construcción, caracterización que se inserta dentro del contexto de la distinción entre el conocimiento filosófico y el matemático:

El conocimiento filosófico es el conocimiento racional por conceptos; el matemático por construcción de los conceptos. Ahora bien, construir un concepto quiere decir exhibir a priori la intuición que le corresponde. Por lo tanto, se requiere para la construcción de un concepto una intuición no empírica. Por consiguiente, ella es un objeto singular (en tanto intuición). Sin embargo, en tanto construcción de un concepto (de una representación universal) debe expresar en la representación validez universal para todas las intuiciones posibles que están subordinadas al mismo concepto. Así, construyo un triángulo exhibiendo el objeto que corresponde a ese concepto mediante mera imaginación en la intuición pura, o bien de acuerdo con ella también en el papel, en la intuición empírica. Pero en ambos casos lo hago enteramente a priori, sin haber tomado de alguna experiencia el patrón para ello. La figura singular dibujada es empírica y sirve, sin embargo, para expresar el concepto sin perjuicio de la universalidad de este último, porque en esta intuición empírica se considera siempre solo la acción de construcción del concepto, para el cual muchas determinaciones son enteramente indiferentes (v.gr. las del tamaño, de los lados y de los ángulos); y por lo tanto se hace abstracción de estas diferencias, que no modifican el concepto del triángulo (A713-714/B741742).

La comprensión cabal de este pasaje requiere más desarrollo del que podemos ofrecer aquí, pues ella exige, entre otras cosas, una interpretación adecuada de la compleja noción de construcción. No obstante, ese no es el 
asunto central de nuestro texto. Lo que nos interesa acá más bien es destacar el modo en el cual se vinculan la intuición pura y la empírica dentro de la construcción, en la medida en que aquello repercute en la comprensión de la Stufenleiter. Consideremos entonces el pasaje desde ese ángulo. A simple vista, parece haber una contradicción en las afirmaciones contenidas en este texto. En efecto, al comienzo, Kant sostiene que la construcción de un concepto requiere de una intuición no empírica mientras que, hacia el final del mismo, afirma que la construcción puede llevarse a cabo sobre el papel, por medio de una intuición empírica. ¿Cómo se resuelve esta aparente contradicción? Para lograrlo se debe apuntar hacia el supuesto de base que da surgimiento a esta, el cual no es otro que un falso dilema en la última afirmación. Este falso dilema supone que la disyunción entre intuición pura y empírica es exclusiva, supuesto que también está a la base de la comprensión porfiriana de la Stufenleiter, i.e. se supone que para toda intuición $x$, si $x$ pertenece al género intuición empírica, entonces no pertenece al género intuición pura y viceversa. Bajo este supuesto, cuando en la construcción de un concepto se emplea una intuición empírica, no se estaría también empleando una intuición pura, lo cual llevaría a la contradicción con la primera afirmación de Kant. Sin embargo, tal contradicción aparente desaparece una vez que se elimina este supuesto. Con todo, lo anterior también exige dar una explicación del vínculo entre intuición empírica e intuición pura. La clave para tal explicación ya la hemos considerado antes, pero también aparece en este mismo pasaje. Se ha observado anteriormente que la intuición pura es un momento constitutivo de la intuición empírica, de modo que la intuición pura que la construcción requiere también puede encontrarse en una intuición empírica. Ahora bien, el modo por medio del cual puede identificarse la intuición pura correspondiente a una intuición empírica es descrito por Kant hacia el final del pasaje citado. Este modo corresponde a un proceso de abstracción [abstrahieren], i.e. el mismo tipo de procedimiento al que Kant parece haber apelado a la hora de la determinación del objeto de la Estética trascendental. Este proceso también debe ser entendido de la manera correcta. En efecto, esta abstracción no consiste en la separación de unos elementos de otros como quien distingue entre diferentes clases de cosas (digamos, como quien separa el trigo de la cizaña), sino, más bien, en la consideración de ciertos elementos constitutivos de un determinado objeto sin tomar en cuenta los demás elementos que lo constituyen. En este caso específico, tal como 
expone Kant, el matemático se focaliza solo en elementos intuitivos a priori que contienen una intuición empírica y, mediante aquello, logra obtener un cierto conocimiento matemático.

El segundo de los pasajes que aborda el papel de la intuición dentro del conocimiento matemático se encuentra en la Introducción B de la $\mathrm{KrV}$. Para algunos intérpretes (por ejemplo, Frege 1972), este pasaje es tristemente célebre por los ejemplos que emplea Kant a la hora de explicar que la aritmética contiene juicios sintéticos a priori: "Porque tomo en primer lugar el número $7 \mathrm{y}$, tomando como ayuda para el concepto de 5 los dedos de mi mano como intuición, añado ahora de a poco al número 7, en aquella imagen mía, las unidades que tomé antes para el número 5, y veo así surgir el número 12" (B15-16; cfr. Prol., AA 04: 269, 1-6). Al igual que en el caso anterior sobre el triángulo, no parece a primera vista claro por qué Kant menciona los dedos como intuición para explicar que los juicios de la aritmética son sintéticos a priori, puesto que los dedos, si se los quiere considerar como una intuición, parecen corresponder a una intuición empírica, de modo que estos no serían los indicados para fundar un juicio $a$ priori. Sin embargo, tal malentendido se funda nuevamente en que la intuición empírica excluye a la intuición pura, lo cual se resuelve tomando en cuenta lo que ha sido expuesto en los párrafos anteriores, a saber, que la intuición empírica tiene como momento constitutivo a la intuición pura. De este modo, incluso si se toma en cuenta una intuición empírica como los dedos, tal consideración debe focalizarse solo en los aspectos intuitivos $a$ priori que esta posee, pues solo en esa medida puede ser tal intuición un fundamento de un determinado juicio sintético a priori.

\section{Distintas formas de clasificación}

A continuación revisaremos tres formas usuales de clasificación, con el objetivo de determinar si alguna de estas se ajusta a la clasificación de la Stufenleiter. Nuestra idea es mostrar que ninguna de estas tres formas, a pesar de ser muy recurrentes, se ajusta a ella. Debido a esto, será necesario buscar otro modo de comprender tal clasificación, el cual corresponde a la cuarta forma aquí presentada. 


\section{1. Árbol porfiriano}

La clasificación según un árbol porfiriano se caracteriza por las siguientes notas: i) aquello que se clasifica corresponde, en última instancia, a individuos, de modo que las distintas clases de esta clasificación corresponden a conjuntos de tales individuos; ii) se comienza con un conjunto, del cual se determinan subconjuntos, proceso que puede ser iterado para cada uno de estos últimos, lo cual brinda a este tipo de clasificación una estructura arbórea; iii) todos los subconjuntos de un determinado conjunto son disjuntos entre sí, dado que estos quedan definidos sobre la base de diferencias específicas que se agregan al género próximo.

Según lo discutido en la sección anterior, nos parece que la Stufenleiter no se ajusta a un árbol porfiriano. En primer lugar, lo que se está distinguiendo en ella no son individuos, sino que se realizan distinciones sobre la representación del fenómeno. En segundo lugar, las clases establecidas dentro de la Stufenleiter no son disjuntas, dado que algunas de ellas son momentos constitutivos de otras, como la intuición pura de la intuición empírica. Como se hizo ver con anterioridad, tener en cuenta estos puntos permite resolver aparentes inconsistencias de Kant.

\subsection{Distintas descripciones de un mismo objeto}

Para caracterizar este modo de clasificar recurriremos a un ejemplo de la filosofía antigua, específicamente de la filosofía estoica, el cual también fue motivo de malentendidos. El siguiente fragmento describe los así llamados 'géneros' de los estoicos:

\footnotetext{
Los estoicos consideran adecuado reducir a una cantidad menor el número de los géneros primeros [de lo ente o de lo corpóreo] e incluyen algunos [de estos géneros], con modificaciones, en esa cantidad menor. En efecto, hacen la división en cuatro [géneros], [a saber,] en sustrato (hypokeímenon), en cualificado (poión), en lo que se encuentra de cierto modo (pōs échon) y en lo que se encuentra de cierto modo en relación a algo (prós tí pos échon) (Simplicio, In Ar. Cat. 66.3267.2, SVF 2.369/LS 27F/BS 3.1).
} 
Solo a partir de este pasaje, no es claro cómo debe entenderse la clasificación que los estoicos establecen dentro de lo ente o de lo corpóreo. El siguiente fragmento ofrece una pista al respecto:

El individuo peculiarmente cualificado (idíos poiós) y la sustancia (ousía) de la cual este está hecho no son lo mismo, pero tampoco son distintos, sino solo no lo mismo, dado que la sustancia es una parte [de este] y ocupa el mismo lugar [que este], pero es necesario que lo que se dice "distinto de otro" esté separado en cuanto al lugar y que no se lo considere como parte (Estobeo, Ecl. I 178, 21-179, 5, LS 28D9/BS 3.6, 22-27).

No podemos hacer en este lugar una explicación detallada de la doctrina estoica de los géneros ( $v$. Duhot 1991; Menn 1999; Brunschwig 2003), sino que solo nos interesa mencionar esta como ejemplo para comprender otra forma de clasificación. Lo que destaca del pasaje anterior es que Estobeo menciona que el individuo peculiarmente cualificado y la sustancia no son ni distintos ni lo mismo. Si aquello no es contradictorio, se debe asumir que en un sentido son lo mismo, pero que en un cierto otro sentido no lo son. Una forma de entender ambos sentidos es que se trata de un mismo objeto bajo distintas descripciones.13 De este modo, estos géneros serían distintos en la medida en que se trata de distintas descripciones, pero serían lo mismo en la medida en que tales descripciones lo son de un mismo objeto.

Sin embargo, no todos comprendieron esta clasificación de este modo, sino que ya en la misma antigüedad hubo malentendidos en torno a ella. Uno de ellos es el siguiente, por parte de Plutarco, quien quizás deliberadamente no quiso hacer una interpretación caritativa de esta doctrina, en la medida en que consideraba a los estoicos como una escuela rival: "Pero estoy haciendo su doctrina más simple, puesto que hacen cuádruple los sustratos en relación a cada uno, más bien, [hacen] cuádruple

13 Sedley (1982: 259-260) se refiere este modo de entender las distinciones dentro de los géneros estoicos del siguiente modo: "Un objeto ostensiblemente unitario puede, bajo diferentes descriptiones, contener cosas diferentes e incluso incompatibles que se digan sobre él. Esta idea no es nueva, sino que el esquema de Crisipo ya es un primer intento de obtener una clasificación formal de los niveles de descripción disponibles" ["[A]n ostensibly unitary object may under different descriptions have different and even incompatible things truly said of it. The insight was not in itself a new one, but Chrysippus' scheme is the first attempt to derive from it a formal classification of the levels of description available"]. De modo análogo, Boeri y Salles (2014: 9) sostienen: "[H]ay razones para creer que "sustrato", "cualificado", "dispuesto de cierto modo" y "dispuesto de cierto modo respecto de algo" no son más que diferentes descripciones o aspectos del mismo objeto". 
a cada uno de nosotros" (Plutarco, Comm. not. 1083e6-8, LS 28A6/BS 3.5, 39-41). Según Plutarco, los cuatro géneros de lo ente o de lo corpóreo de los estoicos corresponden a una clasificación según un árbol porfiriano, en la medida en que se están distinguiendo individuos distintos. En caso de que esta interpretación de Plutarco haya sido sincera, es probable que su error radique en asumir de antemano que esta clasificación sería una según un árbol porfiriano debido a que en general son las recurrentes dentro de la tradición filosófica. Consideramos que un error similar se ha presentado en la mayoría de las lecturas del pasaje de la Stufenleiter.

Ahora bien, tampoco pensamos que la Stufenleiter establezca una clasificación según distintas descripciones de un mismo objeto, al modo como los estoicos clasifican los géneros de lo ente o de lo corpóreo. La razón fundamental consiste en que los conceptos y las intuiciones no tienen como objeto a lo mismo, al menos no en un sentido total, pues cada una de estas representaciones se refiere a un momento del fenómeno en la medida en que lo constituye, aunque en el caso de la intuición empírica se trata de 'una parte impropia', pues su referencia coincide con el fenómeno completo. Por otra parte, en el caso de la intuición pura se trata de una parte o momento que es condición para todos los fenómenos, pero que no constituye por sí sola al fenómeno.

\subsection{Conjuntos y subconjuntos}

Otra opción que puede considerarse para comprender la Stufenleiter es que se trate de una clasificación según conjuntos y subconjuntos al modo de la teoría matemática que ha formalizado estas estructuras. La idea de que haya 'partes' del fenómeno parece sugerir, en alguna medida, esta lectura.Veamos qué tan factible es realizar una interpretación como esta.

Tomemos, como ha sido usual hasta ahora, el caso de la intuición empírica y la intuición pura. La primera dificultad que encontramos es que, en caso de que cada una de estas fuera un conjunto, entonces cada uno de estos conjuntos tendría un solo elemento, por ejemplo, ie y ip respectivamente. Ahora bien, ¿esos elementos son idénticos o no, es decir, $i e=i p$ o no? La respuesta debiera ser negativa, dado que ip es un momento constitutivo de $e$. No obstante, si $i e \neq i p$, entonces los conjuntos a los cuales pertenecen, por ejemplo IE y IP, serían disjuntos, es decir, IE $\cap$ IP $=\phi$, pero esta es precisamente una de las razones por las cuales hemos rechazado la clasificación según un árbol porfiriano, ya que ie y ip sí tienen algo en 
común. ¿Cómo podría solucionarse esto? Una alternativa es considerar que ie está compuesto por ip y algo más, por ejemplo, $r$, de modo que $i e=$ $\{i p\} \cup\{r\}$. Siendo más preciso, esta $r$ debería representar los aspectos conceptuales de $i e$ y si estos se dividen en empíricos y puros, por ejemplo, ce y $c p$ respectivamente, entonces $\{r\}=\{c e\} \cup\{c p\}$, con lo cual ie= $\{i p\} \cup\{c e\} \cup\{c p\}$. Sin embargo, ahora surge otro problema, pues bajo esta comprensión la intuición empírica se reduce a una unión de las demás representaciones, pero aquello no puede ser, ya que se estaría excluyendo el papel que juega la sensación al proveer la materia del fenómeno. Si aquello no fuera así, entonces Kant no incluiría dentro del proceso abstractivo analizado anteriormente aquel paso donde se retira de la intuición empírica lo correspondiente a la sensación. Este paso, junto con el retiro de aquello que corresponde al entendimiento, daba como resultado aquello que corresponde a la intuición pura. Pero, si ie $=\{i p\} \cup\{c e\} \cup\{c p\}$, entonces bastaría con este último paso, es decir, con la abstracción de lo intelectual, para obtener lo relativo a la intuición pura.

De este modo, se muestra que la teoría de conjuntos, al menos en su versión básica, no es suficiente para interpretar correctamente la Stufenleiter. En la sección que viene presentaremos brevemente nuestra propuesta, que según nos parece, no ha sido defendida hasta ahora en la literatura. 14

\subsection{Momentos constitutivos de un objeto}

La distinción según momentos constitutivos ya ha sido adelantada dentro del texto. Para contribuir un poco más a su esclarecimiento, es conveniente abordar el modo en que Kant comprende la abstracción [Absonderung], puesto que tal comprensión repercute también en el modo en que están relacionados aquellos elementos que son abstraídos en ese proceso, por ejemplo, si es que tales elementos son disjuntos o no. Para tratar este punto, es útil a una distinción que realiza Tomás de Aquino entre dos modos de abstraer:

14 Podría considerarse que M. Wolff constituye una excepción (1995: 63). Con todo, él meramente parece sugerir que la interpretación del pasaje no puede corresponder a la del árbol (y probablemente a ninguna de las otras opciones hasta aquí analizadas) en la medida en que caracteriza a intuiciones y conceptos como teniendo parte [Anteil] en el conocimiento. Lamentablemente, Wolff no desarrolla esta idea más allá de esta indicación, del todo fructífera a nuestro modo de ver. 


\begin{abstract}
A lo primero, por lo tanto, hay que decir que abstraer se da de dos modos. De un modo, por composición y división, como cuando entendemos que algo no está en otro o bien que está separado de este. De otro modo, por consideración simple y absoluta, como cuando entendemos una cosa sin considerar nada de otra. Abstraer, por lo tanto, por el entendimiento aquello que según la cosa no está abstraído, según el primer modo de abstraer, no se da sin error. Pero abstraer, según el segundo modo, por el entendimiento aquello que no está abstraído según la cosa no tiene falsedad, como aparece de modo manifiesto en las cosas sensibles. En efecto, si entendiéramos o dijéramos que el color no está en un cuerpo coloreado, o bien que está separado de este, habría falsedad en la opinión o en la oración. En cambio, si consideráramos el color y sus propiedades, considerando para nada la manzana coloreada, o bien expresásemos con la palabra lo que así entendemos, no habría error ni en la opinión ni en la oración (ST I, q. 85, a. 1, ad. 1).
\end{abstract}

Uno de los modos de abstracción considerados en este pasaje consiste en separar dos cosas. Este modo de abstraer no corresponde al que emplea Kant en el pasaje de la Stufenleiter, puesto que los distintos elementos que constituyen al fenómeno, a saber, intuiciones y conceptos, no se presentan de modo separado, sino de modo conjunto en el fenómeno como momentos constitutivos de este. El otro modo de abstracción abordado en este pasaje consiste en considerar separadamente dos cosas, pero sin separarlas de hecho. En este caso, la abstracción se trata, más que de una separación, de una focalización en aquellos aspectos que se desea abordar de un objeto, dejando de lado los demás aspectos de este. Este modo de abstraer sí corresponde al que emplea Kant en el pasaje anteriormente mencionado, puesto que en este se identifican los momentos constitutivos del fenómeno sin separar uno del otro, ya que si se llevara a cabo un proceso así, entonces incluso las intuiciones y conceptos dejarían de ser tales.

Estos modos de abstracción tienen una vinculación directa con las distintas maneras en que se puede clasificar ciertos objetos. La abstracción según separación se ajusta a un árbol porfiriano, en la medida en que los objetos clasificados están separados de hecho, mientras que la abstracción según focalización se ajusta, desde nuestro punto de vista, a la Stufenleiter, dado que en esta lo que se está clasificando no está separado de hecho, sino que solo es considerado como distinto, aunque en rigor no es independiente de los otros momentos.

En lo que sigue presentaremos algunas conclusiones que estimamos que se pueden extraer a partir de lo dicho hasta acá. 


\section{Conclusión}

Parece claro que más que clases, géneros y especies de cosas, Kant parece, tanto en A20/B34 como en A320/B376-377, estar más bien distinguiendo entre momentos de una única realidad y no entre entidades diferentes, como parece sugerir la lectura del árbol. No hay en A320/B376-377, de este modo, una "clasificación de las representaciones" identificando "géneros y especies" de las mismas, sino más bien la identificación de diferentes momentos de la experiencia que tenemos del mundo; momentos que pueden ser identificados por referencia a diversos 'aspectos' de la representación, según ella sea considerada desde diferentes puntos de vista (como dependiente de la sensibilidad, como derivando su contenido de la experiencia o no, etc.), i.e. en la medida en que reflexionamos —en el sentido propio que Kant da a este término - sobre el contenido de nuestra experiencia. Es de destacar, de hecho, que un árbol de Porfirio distingue clases de entes, mientras que no toda clasificación con forma de árbol debería entenderse inmediatamente como siendo una clasificación de entes en clases. De este modo, el carácter clasificatorio del pasaje puede eventualmente mantenerse, pero sin considerar que los relata guardan entre sí el tipo de relaciones que guardan los elementos de un árbol de Porfirio. También puede mantenerse incluso el carácter 'arbóreo' de la clasificación, sin que ella sea una que presenta entidades individuales o bien ítems que sean interpretados como guardando entre sí las relaciones que guardan géneros y especies.

Más allá de la indiscutible relevancia que tiene para la filosofía de Kant comprender correctamente el pasaje clasificatorio, sobre todo a partir de lo que hemos expuesto en la introducción de este texto, el punto hecho acá también es relevante para la filosofía en general. Este punto general radica en que no siempre es claro a simple vista cómo debe entenderse una clasificación, sobre todo si esta tiene una estructura arbórea como la del pasaje clasificatorio. Lo más natural parece ser, para la mayoría de los lectores, sobre todo si se tiene presente la tradición filosófica, el asumir en una clasificación una comprensión porfiriana. Pero tal comprensión tiene a la base un modo determinado de acuerdo al cual se distingue lo que está siendo clasificado, a saber, como entes pertenecientes a clases disjuntas. No todas las entidades que interesa clasificar o distinguir en la filosofía tienen este modo de ser 'objetual'. Es cierto que la filosofía siempre supo de lo 
anterior, pero probablemente ha tendido a olvidarlo a la luz de la preeminencia que han adquirido los debates basados fundamentalmente en variaciones de problemas de 'referencia'. Dado que no siempre las distinciones o clasificaciones se realizan bajo tales circunstancias, conviene tener a la vista otros modos de acuerdo a los cuales estas se pueden llevar a cabo. En este texto hemos presentado algunos de esos modos y hemos intentado mostrar cuál de estos es el más apropiado para el caso del famoso pasaje clasificatorio.

\section{Referencias}

ALLAIS, L.: "Kant, Non-Conceptual Content and the Representation of Space”, Journal of the History of Philosophy 47, 3 (2009), 383-413.

ARNIM, H. v.: Stoicorum Veterum Fragmenta, Leipzig, Teubner, 19031905.

BAUMGARTNER, H. M.: „Arbor porphyriana, porphyrischer Baum“, en: Lexikon des Mittelalters, 1, München/Zürich: Artemis \& Winkler, 889-890, 1980.

BIRD, G.: The revolutionary Kant. A commentary on the Critique of pure reason, La Salle, Open Court, 2006.

BOERI, M.; SALLES, R.: Los filósofos estoicos. Ontología, lógica, física y ética, Sankt Augustin, Academia Verlag, 2014.

BONDELI, M.: „Vorstellung“, en: Kant-Lexikon, Berlín/Boston, Walter de Gruyter, 2565-2569, 2015.

BRUNSCHWIG, J.: "Stoic Metaphysics", en: INWOOD, B.: The Cambridge Companion to the Stoics, Cambridge: Cambridge University Press, 206-232, 2003.

DAVIDSON, D.: "On the very idea of a conceptual scheme", en: Inquires into truth and interpretation, Oxford, Oxford University Press, 183-198, 1974.

DUHOT, J.: "Y a-t-il des catégories stoïciennes?", Revue Internationale de Philosophie 178 (1991) 220-245. 
ESTOBEO: Ioannis Stobaei Anthologium, Berlín, Weidmann, 1884-1912.

FREGE, G.: Los fundamentos de la aritmética, Barcelona, Laia, 1972.

GINSBORG, H.: „Was Kant a nonconceptualist?“, Philosophical Studies 137 (2008) 65-77.

GRÜNE, S.: Blinde Anschauung, Fráncfort del Meno, Klostermann, 2009.

HAAG, J.: Erfahrung und Gegenstand. Das Verhältnis von Sinnlichkeit und Verstand, Fráncfort del Meno, Klostermann, 2007.

HANNA, R.: "Kant and nonconceptual content", European Journal of Philosophy, 13 (2005) 247-290.

HUSSERL, E.: Husserliana. Edmund Husserl Gesammelte Werke, Den Haag, Martinius Nijhoff, 1950ss.

KANT, I.: Gesammelte Schriften, Bd. 1-22, Preussische Akademie der Wissenschaften, 23, Deutsche Akademie der Wissenschaften zu Berlin, 24, Berlín, Akademie der Wissenschaften zu Göttingen,1900ss.

: Kritik der reinen Vernunft, Hamburgo, Felix Meiner, 1956 $[K r V]$.

: "Kant's Theory of Judgment", en: ZALTA, E. N.: The Stanford

Encyclopedia of Philosophy, 2018, https://plato.stanford.edu/archives/win2018/entries/kant-judgment/.

KERN, A.: „Anschauung, intellektuelle“, en: Kant-Lexikon, Berlín/Boston, Walter de Gruyter, 110-112, 2015.

LAND, T.: "Nonconceptual Readings of Kant and the Transcendental Deduction", Kantian Review 20 (2015) 25-51.

LAZOS, E.: Disonancias de la crítica, México, UNAM, 2014.

LONG, A.; SEDLEY, D.: The Hellenistic Philosophers, Cambridge: Cambridge University Press, 1987.

MENN, S.: "The Stoic theory of categories", Oxford Studies in Ancient Philosophy 17 (1999) 215-247.

NATTERER, P.: Systematischer Kommentar zur Kritik der reinen Vernunft, Berlín/Nueva York, Walter de Gruyter, 2003. 
PLACENCIA, L.: La ontología del espacio en Kant, Pamplona, Cuadernos de Anuario Filosófico, 2007.

: “¿Es la intuición lógicamente anterior a la intuición intelectual en Kant”, Mss, 2019.

PLUTARCO: Plutarchi moralia, vol. 6.2, Leipzig, Teubner, 1958.

PORFIRIO: Porphyrii Isagoge et in Aristotelis Categorias commentarium, en: Commentaria in Aristotelem Graeca, Berlín: Academia Litterarum Regia Borussica, IV (1-22), 1887.

PROCOLO: Procli Diadochi in primum Euclidis elementorum librum commentarii, Leipzig, Teubner, 1967.

REICH, K.: Die Vollständigkeit der kantischen Urteilstafel, Berlín, Richard Schoetz, 1948.

SCHULTING, D. (ed.): Kantian nonconceptualism, Londres/Nueva York, Palgrave Macmillan, 2016.

SEDLEY, D.: “The Stoic Criterion of Identity", Phronesis 27, 3 (1982) 255-275.

SELLARS, W.: "Empiricism and the philosophy of mind", en: Knowledge, Mind and the Given, Indianapolis/Cambridge, Hackett, 205-276, 2000.

SIMPLICIO: Simplicii in Aristotelis categorías commentarium (Commentaria in Aristotelis Graeca 8), Berlín, Reimer, 1097.

SMIT, H.: "Kant on marks and the inmediacy of intuition", The Philosophical Review 109 (2000) 235-266.

STEPANENKO, P.: Categorías y autoconciencia en Kant, México, UNAM, 2000 . : Unidad de la conciencia y objetividad, México, UNAM, 2008.

: "Contenidos no-conceptuales en la obra de Kant", Praxis filosófica 43 (2016) 225-242.

TOLLEY, C.: "The Non-Conceptuality of the Content of Intuitions: A New Approach", Kantian Review 18 (2013) 107-136.

VIGO, A.: "Reflexión y juicio", Dianoia 57 (2006) 27-64. 
WOLFF, M.: Die Vollständigkeit der Urteilstafel. Mit einem Essay über Freges Begriffsschrift, Fráncfort del Meno, Klostermann, 1995. 


\section{La actualidad de la}

\section{Crítica de la razón pura:}

Parte Teórica 


\title{
Presentación de los editores al número monográfico. La actualidad de la Crítica de la razón pura: Parte Teórica
}

\author{
DAVID HEREZA \\ ÓSCAR $\mathrm{CUBO}_{2}$
}

En 1790 Kant anunció que daba por concluida la totalidad de su "empresa crítica" [»Hiermit endige ich also mein ganzes kritisches Geschäft «] $(K U$, AA V: 170). A sus lectores le correspondería ahora la tarea de "aportar su parte" en el "sendero" allí trazado — como ya apuntó en 1781- para convertirlo en un "camino real" [»Heeresstraße«] $(\mathrm{KrV}$, A856/B884). Más de dos siglos después de aquella declaración, y cerca del tercer centenario del nacimiento de este pensador revolucionario, tal empresa, lejos de su consumación, aún sigue viva y nutriéndose de las aportaciones que surgen en los debates filosóficos contemporáneos. Ya sea como partidario o detractor, ya sea con la pretensión de reformular o superar, no hay duda de que a ningún filósofo le puede resultar indiferente el pensamiento de Kant, como él mismo señalaba respecto de las exigencias de la Razón ( $K r V, \mathrm{AX})$. Intentar trazar un mapa de esos debates, de su profundidad y de su concreta imbricación en el presente, fue el principal objetivo del IV Congreso Internacional de la Sociedad de Estudios Kantianos en Lengua Española (SEKLE), organizado por el Departamento de Filosofía de la Universitat de València del 15 al 19 de octubre del 2018 bajo el título La actualidad de la Crítica de la razón pura.

Durante esos días, investigadores de más de diez países intentaron responder a esta invitación desde los más diversos ámbitos y perspectivas. Prueba de ellos son las ciento cincuenta ponencias que se programaron dentro de los bloques confeccionados para la ocasión: "La Crítica en contexto", "Estructura de la Crítica", "Metafísica de la Naturaleza", "Metafísica de las costumbres" e "Historia de la recepción de la filosofía crítica". Así, aun teniendo su columna vertebral en la Crítica de la razón

1 Universitat de València. Contacto: david.hereza@uv.es.

2 Universitat de València. Contacto: oscar.cubo@uv.es. 
pura, durante el congreso no se vaciló en abordar los múltiples caminos abiertos a partir de sus fundamentos: desde los principios jurídicos hasta la filosofía de la historia, pasando por su vinculación con la física del siglo XX o por las distintas interpretaciones dadas en el trascurso de su recepción.

Una muestra de la productividad del intercambio científico de esas jornadas son los dos números monográficos que se van a publicar en la Revista de Estudios Kantianos. En ellos se recogen un nutrido grupo de trabajos que permiten ofrecer una panorámica general de las propuestas presentadas en el congreso. Estas han sido divididas en dos bloques según su objeto de estudio pertenezca a la vertiente teórica o práctica del pensamiento kantiano. Así, el número que aquí presentamos, el primero de los dos previstos, reúne contribuciones en torno al uso teórico de la Razón, al que seguirá otro monográfico dedicado a la filosofía práctica de Kant.

Sin embargo, más allá de atestiguar una enriquecedora actividad académica, los trabajos que aquí se presentan también ofrecen al lector una panorámica de algunos de los problemas que subyacen a la imponente arquitectura que presenta la Crítica de la razón pura. Mediante el análisis detallado de pasajes concretos o por vía de un enfoque transversal a lo largo de diversos textos, los artículos seleccionados para este monográfico son un buen despliegue de la variedad de temas contenidos en la obra principal de Kant, así como de los posibles modos de su abordaje. Por este motivo, el orden de lectura y, por tanto, la unidad de esta pluralidad de intervenciones, puede ser vista de muchas maneras. Aquí, siguiendo la articulación fundamental de las partes de la Crítica, hemos querido disponerla en analogía con las secciones esenciales que la estructuran.

El monográfico se abre con un interesante estudio de Gonzalo Serrano Escallón (Universidad Nacional de Colombia) en torno a la metáfora del heliocentrismo que Kant utiliza en el Prólogo de la segunda edición. A partir de esta famosa y siempre polémica figura del criticismo, el tema se traslada directamente a la Doctrina de los elementos, núcleo principal de la Crítica. En primer lugar, a la Estética trascendental y a sus dos conceptos fundamentales: espacio y tiempo. Estos son analizados por los artículos de Diana G. Contreras y Gilberto Castrejón (ambos autores de la Universidad Autónoma de México). Con un talante muy analítico, Contreras investiga la vinculación entre el espacio como forma de la intuición y la facultad de la receptividad y, del mismo modo, Castrejón 
aborda la relación entre las teorías científicas del siglo XX y la noción kantiana de tiempo. A estos les sigue otro grupo de cuatro estudios que esta vez tienen su punto de anclaje en la Analítica trascendental. El primero de ellos trata el manido problema de la apercepción que, como reza el título del artículo de Carsten Olk (Universidad de Trier), sigue siendo todavía uno de los lugares sistemáticos más complejos de la empresa crítica. A continuación, Alejandro Lanchas Sánchez (Universidad Complutense de Madrid) se adentra en la Analítica de los principios con una defensa de la actualidad de la Crítica que pivota en torno al concepto kantiano de 'anticipación'. A este respecto, Jacinto Rivera de Rosales (UNED, Madrid) realiza un exhaustivo análisis de algunas nociones claves para la comprensión de las Analogías de la Experiencia. Después, el lector podrá leer un examen detallado del polémico añadido de la segunda edición de la Crítica de la razón pura, la Refutación del Idealismo, realizado por Manuel A. Amado (Universidad Libre de Colombia).

Con la intención de seguir explorando el "terreno del intelecto puro" ( $K r V$, A235/B294), tal y como Kant se propone en la primera parte de la Lógica trascendental, a estas aportaciones se les suman otras de talante más transversal como las de Ana Andaluz (Universidad de Salamanca), sobre la concepción kantiana de la 'verdad', y la de Sophia M. Fazio (FriedrichWilhelms-Universität Bonn), que discute acerca de si la filosofía kantiana debe ser calificada o no como 'conceptualista'. Junto a ellas, M. Ruffing (Johannes Gutenberg-Universität Mainz) prosigue este modus operandi a la luz de un corpus textual más amplio y en referencia al concepto de espíritu [Geist], tan discutido por la filosofía de la mente contemporánea.

Dando inicio a un nuevo conjunto de contribuciones, Mario Caimi (CONICET) emprende la compleja tarea de adentrarse en el "inmenso y tempestuoso mar" de la Dialéctica trascendental ( $K r V$, A235/B294) y, de una forma ejemplar, intenta justificar la derivación de las tres 'Ideas' de la Razón a partir de los juicios de relación. Del mismo modo, en alusión a las antinomias y al concepto de "libertad" que allí se consigue por primera vez ( $K r V$, A444/B472), Daniel Dal Monte (Temple University Philadelphia) defiende el concepto kantiano de libertad en contraposición a las teorías compatibilistas fundamentales del debate anglosajón. Siguiendo en el horizonte de lo suprasensible, concretamente en referencia a la disputa de Kant frente al sistema leibniziano-wolffiano, Marcos Thised (Universidad 
de Buenos Aires) presenta un comentario crítico y conciso sobre la edición de los Progresos de la Metafísica, analizando las implicaciones que ciertas cuestiones filológicas pueden suponer para la comprensión filosófica del texto.

Finalmente, el volumen se cierra con el problema que la filosofía moral representa ya dentro de la Crítica de la razón pura, como muestra Salvi Turró (Universitat de Barcelona) en su análisis de un pasaje del Canon de la Razón pura, segundo capítulo de la Doctrina del Método. Con él se pone en evidencia una de las tensiones más importantes del proyecto presentado en este libro: la mirada hacia lo práctico, ámbito del que nos ocuparemos en el segundo monográfico dedicado a la actualidad de la filosofía práctica de Kant.

Estas líneas solo pretenden fungir como indicación de una de las posibilidades de lectura que ofrecen las diferentes contribuciones aquí reunidas. Ya sea en su conjunto o por separado, no hay duda de que el lector podrá enriquecerse con ellas y adentrarse en las grandes líneas interpretativas que actualmente se desarrollan alrededor de la filosofía teórica de Kant.

Por último, solo queda repetir el agradecimiento a todos los participantes del congreso que hicieron posible el intercambio de ideas, reflexiones y trabajos a lo largo de los días de su realización. También, al organizador principal que lo hizo posible, Pedro Jesús Teruel (Universitat de València), y a todas las personas que le ayudaron en su tarea, entre ellas, merecen un especial reconocimiento por su implicación Alba Jiménez (Universidad Complutense), Jesús Conill (Universitat de València), AnaCarolina Gutiérrez (Philipps-Universität Marburg), Fernando Moledo (Fernuniversität Hagen), Maria Caterina Marinelli (Università di Roma Tor Vergata) y Alberto Hilario (Universitat de València). Gracias a todos ellos porque sin su inestimable colaboración el presente monográfico no habría sido posible. 


\title{
"Los primeros pensamientos de Copérnico" (KrV, Bxvi)
}

\author{
GONZALO SERRANO ESCALLÓN 1
}

\begin{abstract}
Resumen
Aprovechando la ocasión de dos muy recientes artículos sobre el tema en español, quisiera discutir el rol que juega el heliocentrismo copernicano como único referente de la analogía propuesta por Kant, el cual, al sucumbir a la objeción de Alexander/Russell, termina por convertir la propuesta crítica de Kant en su contraria, análoga más bien al geocentrismo de Ptolomeo. Insistiré, primero, en que el heliocentrismo no es el término de la analogía propuesta por Kant, y por tanto la objeción queda desvirtuada; segundo, que un oportuno rastreo de los 'primeros pensamientos de Copérnico' en la obra del propio astrónomo nos libera de ese marco de oposición entre heliocentrismo y geocentrismo que tanto ha confundido, hasta malograrla, a la analogía; tercero, que la doctrina copernicana del movimiento de la tierra es el verdadero término de comparación y que ello se puede comprobar en la enorme fecundidad explicativa e interpretativa que brinda a la propuesta kantiana
\end{abstract}

Palabras clave: epistemología, filosofía de la ciencia, criticismo, Kant, Copérnico, Revolución Copernicana

\section{"The first thoughts of Copernicus" $(\mathrm{KrV}, \mathrm{Bxvi})$}

\begin{abstract}
Seizing the opportunity given by two recent papers in Spanish on the topic, I would like to discuss the role played by the heliocentric theory as the only referent for the analogy proposed by Kant with Copernicus. As we know, this referent succumbs to the Alexander / Russell objection and changes the idea of Kant in its contrary one, becoming so the analogy more akin to the geocentric theory of Ptolemy. I will insist, first, that heliocentric theory is not the term of the proposed

1 Universidad Nacional de Colombia. Contacto: gserranoe@unal.edu.co.

La presente contribución fue presentada en el IV Congreso de la Sociedad de Estudios Kantianos en Lengua Española (SEKLE) en Valencia (octubre de 2018) y hace parte de los resultados del proyecto de investigación sobre La deducción trascendental de Kant (código 7271) con el apoyo de la División de Investigación de la Sede Bogotá de la Universidad Nacional de Colombia; el proyecto está adscrito a las actividades del grupo de investigación Dialéctica y mos geometricus. Participantes en el seminario de posgrado Kant: Inversión copernicana e Idealismo trascendental, impartido en el segundo semestre de 2018, merecen mi agradecimiento con especial mención de Natalia Alejandra Chaparro por el gusto, la seriedad y la distancia crítica con que asumió la exposición de este mismo
\end{abstract} texto. 
analogy by Kant, and consequently the objection misses the point; second, that an appropriate tracking of the so called by Kant 'Copernicus' first thoughts' through the work of the astronomer himself would free us from this rigid frame of opposition between heliocentric and geocentric theories, which has made the analogy so confusing and misleading; third, that the Copernican doctrine of the movement of the earth is the most plausible term of the analogy and that this can be tested thanks to the fruitful explanations and interpretations it produces.

Keywords: epistemology, philosophy of science, criticism, Kant, Copernicus, Copernican Revolution

\section{Preliminar}

Ante la identificación de la referencia de Kant al giro de Copérnico como una referencia al paso del geocentrismo al heliocentrismo, muy pronto nos damos cuenta del inconveniente que genera y que ya ha sido denunciado hasta la saciedad por Alexander (1909: 49), Russell (1948: 9) y Bloch (1985): Kant, fallidamente, resultaría más ptolomeico que copernicano, más geocentrista que heliocentrista. A estas alturas muchos abandonan la analogía por contraproducente o por poco idónea para entender a Kant, mientras otros, sin cuestionar la identificación con el heliocentrismo, persisten en ella con reservas, enmiendas o desplazándose a aspectos distintos de los puramente astronómicos (metodológicos y demás); pero el común denominador entre unos y otros es que la analogía refiere al heliocentrismo copernicano. Por mi parte sigo pensando que lo copernicano en la analogía que Kant propone no es el heliocentrismo (Serrano Escallón 1999); y ello ahora no solo en virtud de la denuncia de inconsistencia ya mencionada, sino en razón del texto mismo y de la especificación que contiene la fórmula "los primeros pensamientos de Copérnico" ( $K r V$, BXVI). Reinhard Brandt (2007; 2015), enfrentándose a Blumenberg (1975), insiste en que sí se trata del heliocentrismo copernicano; que la rotación de la tierra sobre su propio eje allí ensayada entraña también su movimiento orbital: por tanto, el heliocentrismo. Nos queda, pues, la obligación de mostrar eso copernicano a lo que supuestamente se refiere Kant y que, a la vez, no es el heliocentrismo que ya, inmerecidamente, lo dejó tan mal librado. 
Por otra parte, debo especial reconocimiento a la conferencia del profesor Mario Caimi (2018: 6-24) en el pasado congreso de la SEKLE en la Ciudad de México, celebrado en septiembre de 2016, que me sirvió de estímulo para retomar el tema de la analogía copernicana. Igual reconocimiento debo a Fernando Moledo (2017), quien, entre tanto, publicaba su contribución sobre el tema. Ambos me exigieron ordenar mis ideas, identificar mejor a mis rivales y, por qué no, también a mis aliados. El meollo del asunto lo he identificado en la recurrencia al heliocentrismo en las interpretaciones de la analogía que Kant establece con Copérnico en el prefacio de 1787, en particular en $K r V$, BXVI. En ambos, aunque en distinta medida, está presente el heliocentrismo como término de la analogía, por lo que me veo en la obligación de actualizar y profundizar mi posición. Ryall (2017) es la muestra más reciente y consistente de lo lejos que puede llegar el malentendido que trato ahora de enfrentar.

En lo que sigue, me propongo brindar una lectura de la analogía en la que muestro, como diría Blumenberg (1975: 705), que el heliocentrismo en ese pasaje no tiene que ver con lo que quiere decir Kant. Pareciera a veces que la manera de eludir la objeción al subjetivismo o al antropocentrismo sea recurriendo al heliocentrismo. Mostraré, en cambio, que la relatividad terráquea en astronomía, al igual que la relatividad subjetiva o humana en epistemología o metafísica, es el término de la comparación que propone Kant con Copérnico, sin que por ello ninguno de los dos esté incurriendo en el antropocentrismo, el subjetivismo o el geocentrismo.

En lo que a Brandt respecta, baste por ahora reconocerle el mérito de haber llamado la atención recientemente sobre la complejidad de la analogía y de la unidad y coherencia de todo el prefacio. Sin embargo hay detalles que él mismo parece desdeñar precisamente por mor de la totalidad. Estoy de acuerdo con Caimi (2018: 13) en que la restricción de Copérnico a la intuición para delegar el concepto a la parte newtoniana de la analogía (Brandt 2015: 8, 17, 21) no se sostiene. Brandt también cree que el meollo de la analogía es el heliocentrismo y que detenerse demasiado en la letra y en el análisis parcial de la primera referencia a Copérnico es destrozar la unidad del pensamiento de Kant para, como él mismo dice, vender los pedazos al detal (2007: 223). Confieso que asumo esa responsabilidad, la de quedarme en ese detalle que Brandt pasa por alto, aunque me valga el mote 
de mercachifle al detal; ello no me impide apreciar sus aportes al panorama global de la analogía y emprender en otro lugar una interpretación integral.

\title{
2. Los textos: Kant y Copérinco \\ El pasaje de Kant en cuestión reza:
}

\begin{abstract}
Ocurre aquí lo mismo que con los primeros pensamientos de Copérnico, quien, al no poder adelantar bien con la explicación de los movimientos celestes cuando suponía que todas las estrellas giraban en torno del espectador, ensayó si no tendría mejor resultado si hiciera girar al espectador, y dejara, en cambio, en reposo a las estrellas $(K r V, \mathrm{BXVI}) .2$
\end{abstract}

Ateniéndonos a lo que el texto dice, los primeros pensamientos de Copérnico consisten en el intento [Versuch] del astrónomo de dar cuenta del giro del firmamento, tal como lo percibimos al mirar el cielo, con base en el supuesto de que es más bien el espectador el que gira (la tierra sobre su propio eje) mientras el firmamento está quieto. En otras palabras, nuestra percepción del giro de la bóveda celeste de oriente a poniente, experiencia que podemos tener cualquier noche estrellada, se puede explicar también, y probablemente mejor, si suponemos que la propia bóveda celeste está quieta y que es el espectador el que gira sobre su propio eje en la dirección inversa a la que percibe en el cielo, es decir, de poniente a oriente.

Hasta aquí Kant, en relación con los tales primeros pensamientos de Copérnico. Por lo pronto, sospecho que el movimiento celeste expuesto y su alternativa de invertirlo [intercambiarlo] en relación con el supuesto reposo del espectador, puede generar una comparación fructífera con su propuesta inmediatamente anterior y que da pie al pasaje que nos ocupa. En relación con la posibilidad del conocimiento a priori, si seguimos suponiendo que los conocimientos se rigen por los objetos, saber algo a priori de ellos

\footnotetext{
2 »Es ist hiermit ebenso, als mit den ersten Gedanken des Kopernikus bewandt, der, nachdem es mit der Erklärung der Himmelsbewegungen nicht gut fort wollte, wenn er annahm, das ganze Sternenheer drehe sich um den Zuschauer, versuchte, ob es nicht besser gelingen möchte, wenn er den Zuschauer sich drehen, und dagegen die Sterne in Ruhe ließ«. Me guío por la edición de $\mathrm{KrV}$ (Kant 1998) y por la traducción de M. Caimi (Kant 2006) siguiendo las exigencias de distinguir entre las dos ediciones de 1781 y 1787 mediante A y B respectivamente.
} 
resulta imposible; por ello, hay que intentar si, al contrario, más bien son los objetos los que se rigen por el conocimiento. 3

Pero veamos qué es lo que no funciona en ambos casos, el astronómico y el filosófico, con la asunción original y que obliga a invertir [umzuändern] (quiero insistir en 'inversión', 'vuelco' del modo de pensar, que se acerca más al concepto de revolución que el de mera modificación, cambio, variación) el modo de pensar. En astronomía, si se partía solo de los movimientos celestes aparentes en círculos concéntricos en torno a un observador en reposo, muy pronto nos encontrábamos con irregularidades y anomalías para las que difícilmente había explicación; menos aún un principio de movimiento que permitiera preverlos, determinarlos o hacerlos inteligibles. Además, entre los astrónomos había variadas propuestas de solución que se enfrentaban entre sí, pero no llegaban a una solución unívoca, como era el caso de las diversas hipótesis matemáticas (excéntricas, epiciclos y ecuantes) que probablemente resolvían casos particulares, pero que no alcanzaban generalidad ni sistematicidad alguna.

En filosofía, concretamente en metafísica, parece todavía imposible el conocimiento a priori si este ha de depender enteramente de su objeto; igual que pasaba en astronomía, al depender exclusivamente de las apariencias y de los objetos, no había manera de establecer regularidad,

\footnotetext{
3 Varios intérpretes de la analogía copernicana de Kant asumen un paralelo entre las fórmulas 'regirse por' (conocimientos y objetos) y 'girar alrededor de' (sol y tierra), sin percatarse de que estos últimos no son los términos adecuados ni los mencionados en el texto. Un reciente ejemplo de los problemas que resultan de este tratamiento es Ryall 2017. De ese errado tratamiento paralelo surgen las inconsistencias denunciadas que conducen a un Kant más geocentrista que heliocentrista, más ptolemaico que copernicano y más contrarrevolucionario que revolucionario (Alexander 1909; Russell 1948: 9). El temor a tales inconsistencias, resultado del propio error, ha suscitado reservas y enmiendas a la analogía que ya he señalado (Serrano 1999) y que aún persisten. E. Bloch se suma a esta denuncia de Alexander y Russell así: "Como Copérnico él intenta si se puede invertir de manera que, en vez de hacer que el sol gire alrededor de la tierra, más bien haga girar la tierra alrededor del sol. Kant ha hecho ciertamente una inversión Ptolomeica. Pues Copérnico hizo girar a la tierra alrededor del sol - siendo la tierra el sujeto y el sol el objeto. Y Kant haría girar al sol alrededor de la tierra, por tanto el objeto alrededor del sujeto. En el primer caso tienen ustedes la prevalencia del objeto, si tomo al sol por el objeto, en el otro caso la prevalencia del sujeto. En consecuencia, Kant ha eliminado la inversión copernicana del sano entendimiento común y la ha reemplazado con la ptolomeica, aunque lo que dice es lo contrario" (a. trad.) [»Wie Kopernikus versucht er, ob man es nicht umgekehrt machen kann, statt die Sonne sich um die Erde, die Erde sich um die Sonne drehen zu lassen. Kant hat nämlich die ptolemäische Wendung gemacht. Kopernikus ließ doch die Erde sich um die Sonne drehen - die Erde ist das Subjekt und die Sonne das Objekt. Und Kant läßt die Sonne sich um die Erde drehen, also das Objekt um das Subjekt. In dem ersten Fall haben Sie die Prävalenz des Objekts, wenn ich die Sonne als das Objekt nehme, in dem anderen die Prävalenz des Subjekts. Infolgedessen hat Kant die kopernikanische Wendung des gesunden Menschenverstands aufgehoben und ersetzt durch die ptolemäische, obwohl er das Gegenteil sagt «] (1985: 61). Debo esta referencia a Lemanski (2012: 452-453).
} 
necesidad y certeza acerca de ellos. Entre los metafísicos también hay propuestas enfrentadas, basadas probablemente también en soluciones parciales, por lo que, al carecer de unidad y sistematicidad, ninguna goza del consenso general. De ahí que en ambos casos la clave se intente ya no en la dirección de los objetos, sino en la del observador o sujeto cognoscente, según el caso.

No sobra explorar ahora cuál es el referente textual de lo que Kant entiende por los 'primeros pensamientos de Copérnico' y cuáles son sus fuentes.4 Si nos atenemos a la recepción común de la obra de Copérnico nos podemos llevar sorpresas por lo simplificada y superficial que se presenta, 5 por lo que creo que la mejor estrategia es dejar hablar al autor mismo, con especial atención en los pasajes que expresan el modo como se refiere a su propia obra, lo que piensa de ella, lo que lo llevó a ella, lo que ha pretendido hacer, lo que considera su mayor logro.

Frases como "que atribuyo al globo de la tierra algunos movimientos", "esta doctrina mía sobre el movimiento de la tierra", "poner por escrito mis pensamientos sobre el movimiento de la tierra", "que [...], contra el sentido común, me haya atrevido a imaginar algún movimiento de la tierra", "en consecuencia, aprovechando esta ocasión empecé yo también a pensar sobre la movilidad de la tierra" (Copérnico 2015: 5-9),6 denotan

4 J. Lemanski (2012: 457) afirma que la terminología usada por Kant, y con ello la metáfora propuesta, la del espectador y el ejército de estrellas [Zuschauer/Sternenheer] no es original de él, "sino que la toma de Lambert" [»sondern sie von Johann Heinrich Lambert übernimmt «], teniendo en cuenta que el libro de Lambert Cosmologische Briefe (1761) estaba en la biblioteca de Kant, según el listado de sus libros que nos ha sido legado. Sin embargo, esta tesis acerca de la dependencia de Kant de tal texto queda desvirtuada tan pronto verificamos que Kant usa ya en su temprana NTH (AA 01) (1755), seis años antes de la publicación de la obra de Lambert, las figuras del "ejército de estrellas" [»das ganze Heer derselben«] (AA 01: 250.12) y [»Himmelsheer«] (AA 01: 252.15), como también la figura del "espectador" [»Zuschauer«] (AA 01: 251.03) y del "observador" [»Beobachter «] (AA 01: 254.31). Por lo demás, creo que varias de las dependencias que Lemanski (2012: 458-462) cree descubrir en el texto de Kant respecto del de Lambert pierden fuerza y que son más bien coincidencias entre ellos que se justifican suficientemente solo porque ambos se nutren de una fuente común.

5 La recepción de Copérnico y el copernicanismo pasa por una variedad de vicisitudes que van desde su reducción a eslóganes y partidismos religiosos e ideológicos hasta la ignorancia sistemática en razón de su pronta obsolescencia al ser descubierto el telescopio; pasa también por un artificial antagonismo con Ptolomeo, con quien realmente tiene muchas afinidades, siendo en muchos aspectos más bien un sucesor suyo que un contradictor. Por último, su canonización como el revolucionario de la ciencia moderna es demasiado problemática y controvertida.

6 Todas estas frases se encuentran en el prefacio al papa: "terrae globo tribuere quosdam motus", "haec mea doctrina de terrae motu", "ut meas cogitationes de terrae motu etiam litteris committere", "contra communem sensum ausus fuerim imaginari aliquem motum terrae", "Inde igitur occasionem nactus coepi et ego de terrae mobilitate cogitare". Pero no hay que desconocer que estas referencias al movimiento de la tierra como principio explicativo de las apariencias celestes proliferan 
con precisión el concepto que el autor tenía de su obra, de su temática y, veremos más adelante, de su estructura y orden. Por otra parte, estas frases también aluden, directa o indirectamente, a la anterioridad cronológica y biográfica de tales pensamientos, al igual que el hecho de que figuren en el prefacio, se desarrollen en los primeros capítulos del primer libro y, además, se reiteren en la introducción de cada libro subsiguiente, a manera de principio de inteligibilidad de las apariencias en cuestión, denota una anterioridad en la exposición y una antecedencia sistemática.7 No se puede descartar que aludan estas frases también a pensamientos juveniles que ahora conocemos plasmados en el inédito Commentariolus. 8

Pero podemos adentrarnos en pasajes más allá de las frases sueltas y examinar el rol que el autor pretendía otorgar a tales pensamientos y a lo pensado en ellos:

Y yo, supuestos así los movimientos que más abajo en la obra atribuyo a la tierra, encontré con una larga y abundante información que, si se relacionan los movimientos de los demás astros errantes con el movimiento circular de la tierra, y si los movimientos se calculan con respecto a la revolución de cada astro, no solo de ahí se siguen los fenómenos de aquéllos, sino que también el orden y la magnitud de los astros y de todas las órbitas, e incluso el cielo mismo, se ponen en conexión; de tal modo que en ninguna parte puede cambiarse nada, sin la confusión de las otras partes y de todo el universo (Copérnico 1982: 94).9

explícitamente en el resto de la obra; por ejemplo, en el Libro I (caps. iv, v, viii, ix, x, xi, xii), en el Libro II (Introducción y caps. vii, xiii), en el Libro III (caps. i, iii xiii, xv, xxv), en el Libro IV (Introducción), en el Libro V (Introducción y caps. i, ii, iii, iv, ix, x, xv, xx, xxxii, xxxv, xxxvi) y en el Libro VI (Introducción y cap. i).

7 Schönecker et al. (2011: 502-505) hacen una excelente exposición de los varios motivos en que se funda tal anterioridad de los 'primeros pensamientos de Copérnico'. De destacar son también las correspondencias textuales encontradas entre el prefacio al Papa de Copérnico y el pasaje de Kant que nos concierne (2011: 503-504).

8 La redacción del Comentariolus antecede en más de 30 años a la publicación del De Revolutionibus, solo que como fue apenas descubierto a finales del siglo XIX, es difícil que Kant lo hubiera conocido, mas no imposible, pues, al fin y al cabo, vivían ambos en el mismo 'remoto rincón del mundo', a orillas del Vístula; no descartaría yo que una copia del inédito hubiera llegado de Frombork a Königsberg (Kaliningrado).

9 "Atque ita ego positis motibus, quos terrae infra in opere tribuo, multa \& longa obseruatione tandem repperi, quod si reliquorum syderum errantium motus, ad terrae circulationem conferantur \& supputentur pro cuiusque syderis reuolutione, non modo illorum phaenomena inde sequantur, sed et syderum atque orbium omnium ordines et magnitudines \& caelum ipsum ita connectantur, ut in nulla sui parte possit transponi aliquid, sine reliquarum partium ac totius uniuerfitatis confusione" (Copérnico 2015: 8, 24-30). 
Aquí se pone en evidencia una anterioridad que podríamos llamar condicional, o hipotética, pero que al término del párrafo se pretende como necesaria en virtud de su capacidad explicativa y su coherencia sistemática. A continuación, el autor hace un sumario de toda su obra que no deja dudas respecto del rol de sus pensamientos sobre el movimiento de la tierra en su teoría:

De ahí también, que haya seguido en el transcurso de la obra este orden, de modo que en el primer libro describiré todas las posiciones de las órbitas con los movimientos que le atribuyo a la tierra, de modo que ese libro contenga como la constitución común del universo. Después, en los restantes libros, relaciono los movimientos de los demás astros y de todas las órbitas con la movilidad de la tierra, para que de ahí pueda deducirse en qué medida los movimientos y apariencias de los demás astros y órbitas pueden salvarse, si se relacionan con el movimiento de la tierra (Copérnico 1982: 94).10

Otro elemento textual de la referencia a los primeros pensamientos de Copérnico se puede apreciar en la libertad de ensayar una hipótesis, como lo han hecho otros:

En consecuencia, aprovechando esa ocasión empecé yo también a pensar sobre la movilidad de la tierra. Y aunque la opinión parecía absurda, sin embargo, puesto que sabía que a otros se les había concedido tal libertad antes que a mí, de modo que representaban algunos círculos para demostrar los fenómenos de los astros, estimé que fácilmente se me permitiría experimentar, si, supuesto algún movimiento de la tierra, podrían encontrarse en la revolución de las órbitas celestes demostraciones más firmes que lo eran las de aquéllos (Copérnico 1982: 94).11

\footnotetext{
10 "Proinde quoque \& in progressu operis hunc secutus sum ordinem ut in primo libro describam omnes positiones orbium, cum terrae, quos ei tribuo, motibus, ut is liber contineat communem quasi constitutionem uniuersi. In reliquis uero libris postea confero reliquorum syderum atque omnium orbium motus cum terrae mobilitate, ut inde colligi possit, quatenus reliquorum syderum atque orbium motus \& apparentiae saluari possint, si ad terrae motus conferantur" (Copérnico 2015: 8, 31-9).

11 "Inde igitur occasionem nactus coepi \& ego de terrae mo bilitate cogitare. Et quamuis absurda opinio videbatur, ta men quia sciebam alijs ante me hanc concessam libertatem, ut quoslibet fingerent circulos ad demonstrandum phaenomena astrorum, existimaui mihi quoque facile perrmitti, tu experirer an posito terrae aliquo motu firmiores demonstrationes quam illorum essent, inueniri in reuolutione orbium caelestium possent" (Copérnico 2015: 8, 17-23).
} 


\section{Kant y Copérnico, la comparación en juego}

En Copérnico, Kant ve que los movimientos de la tierra propuestos y a la vez responsables en gran parte de las apariencias celestes se asemejan a las facultades de conocimiento del sujeto que también son responsables en gran parte de nuestra experiencia. Mientras Copérnico cree que los movimientos por él supuestos de la tierra se comportan como principios respecto de las apariencias celestes, Kant, por su parte, piensa que nuestras facultades de conceptos e intuiciones, el entendimiento y la sensibilidad, en cierto modo, se comportan también como principios (condiciones de posibilidad) de nuestra experiencia.

Copérnico pretende que con base en los tres movimientos de la tierra se pueda dar razón de los múltiples movimientos celestes que presenciamos desde la tierra; la duplicación de la tierra en esta formulación es intencional, no es redundante. Kant, de manera similar, pretende que con base en las estructuras intelectuales y sensibles del sujeto cognoscente se pueda dar razón de lo que es objeto para ese mismo sujeto. En ambos casos esto ha de significar que los movimientos de la tierra, así como las categorías y las formas de la sensibilidad, constituyen información a priori, universal y necesaria acerca, en un caso, de los movimientos celestes aparentes para el observador terreno, como en el otro caso, de nuestra humana experiencia.

Pero esto no significa que solo haya un lugar desde donde observar el cielo y los movimientos de sus astros, ni que solo haya una particular estructura subjetiva de facultades de conocimiento. Significa, más bien, que, tratándose del mismo cielo para todos, cualquiera que sea el lugar que se escoja para observar los astros, la inteligibilidad de los movimientos aparentes para ese lugar es posible solo por referencia a las condiciones particulares del lugar mismo, las cuales anteceden y configuran cualquier observación y apariencia; y tales condiciones solo serán determinantes para las apariencias y observaciones desde tal lugar. Por tanto, no se trata de una astronomía relativa a la tierra, o de un relativismo terrícola, más bien de una regla o principio general que cobija cualquier punto de vista. 12

12 A estas alturas no puedo por menos que asentir a la tesis de la abstracción de Lazos que llama la atención para no confundir "una regla con una aplicación particular de la misma" o, como concluye más adelante, distinguir "entre un determinado punto de vista acerca del mundo, por un lado, y la articulación conceptual requerida para tener cualquier punto de vista - la diferencia, si se quiere, entre un principio y los episodios en los que ese principio encuentra su aplicación" (2014: 219, 230). 
Esto es entonces lo que significa que "las condiciones de la posibilidad de la experiencia en general son, a la vez, condiciones de la posibilidad de los objetos de la experiencia" ( $K r V$, A158/B197). No se está diciendo aquí que la experiencia humana es la única que está siendo considerada, o que es exclusiva respecto de sus pretensiones de conocimiento a priori, sino que cualquiera que sea el caso se lo estudia bajo la máxima o regla general según la cual las condiciones que hacen posible la experiencia del caso (humano o no) son las mismas que hacen posible los objetos de tal caso de experiencia.

Lo que Kant vio de afinidad con Copérnico, y que alentó su analogía, fue precisamente el carácter de la relación o el vínculo entre las condiciones observacionales de los movimientos celestes y su apariencia misma; es decir, los movimientos celestes nos aparecen determinados por nuestras condiciones observacionales y, en general, aparecen en relación con las condiciones observacionales del observador, según donde quiera que esté y como quiera que se mueva. Esta posibilidad de generalización es la que impide que se le objete a Copérnico por relativista terrícola, o en algún sentido todavía geocentrista, y en otro aún de ptolomeico. Y esta generalización es también algo que Kant encuentra afín con su propuesta, por lo que podría ser utilizada contra la objeción que se le hace de subjetivista o de antropocentrista. De ahí la insistencia de Kant en la especial constitución del conocimiento humano, ese que él mismo caracteriza por la dualidad entre sensibilidad y entendimiento — dualidad de la que no adolecen otras posibles constituciones cognitivas-; y correspondiente con esa insistencia también está la que hace acerca del objeto en general y sus especificaciones, a saber, el fenómeno, el noúmeno, la cosa en sí, etc. [ente de razón, ens imaginarium].

La apariencia tiene en Copérnico cierta función fiscalizadora de las hipótesis, análoga a la que Kant otorga a la sensibilidad y a sus intuiciones, respecto del entendimiento. Las generalizaciones, leyes o regularidades que se propongan han de estar controladas por las apariencias, lo cual significa que estas se deben poder deducir de las primeras. Esto parece también valer para las hipótesis que conciernen a los movimientos de la tierra, los cuales no son ellos mismos aparentes, pero se someten a dar satisfacción a las apariencias, es decir, a ser condiciones de las apariencias para el observador terrícola. Eso significa que esa relación o vínculo entre movimientos 
celestes aparentes y condiciones observacionales que permiten determinar regularidades, leyes, y establecer pronósticos en el caso concreto de, digamos, la tierra, no brinda acceso sensible o aparente a otros movimientos celestes que no estén dentro de las condiciones observacionales establecidas.13 En otras palabras, no podemos presenciar la ruta de los planetas como se presenciarían desde, digamos, el sol, aunque sí la podamos seguir objetivamente y de manera verificable en las apariencias, ateniéndonos a nuestras condiciones observacionales de la tierra y haciendo las correspondientes conmutaciones entre nuestro movimiento (tierra) y el propio de los planetas (el llamado paralaje). Vale la pena preguntarnos ahora si la 'verdadera ruta' es 'conocida' objetivamente, hechas las conmutaciones correspondientes, aunque de manera indirecta, o es solo la ruta que hipotéticamente presenciaríamos desde el sol, supuesto su completo reposo. Lo que llamaríamos 'verdadera ruta' no es entonces otra cosa que la que verificaría absolutamente nuestra 'idea' del sistema solar heliocéntrico; pero esta es una mera 'idea', cuyo sentido no es verificable de manera sensible, o en nuestra experiencia, aunque tampoco se trata de una idea inocua.14 Esto nos conecta con el pasaje conocido de El Conflicto de las

13 En sentido estricto, las condiciones observacionales de la tierra difícilmente sirven para hacer aparente, por ejemplo, el movimiento del sol a lo largo de la galaxia; por tanto, tampoco para pretender ser una explicación de ello. Se requerirían lapsos de tiempo enormes para registrar diferencias mínimas.

14 Esto nos pone en una situación delicada una vez leemos la interpretación de Brandt $(2009 ; 2015)$, pues el sistema solar, desde el punto de vista heliocéntrico, es objeto de conocimiento científico verificado y demostrado por Newton; de manera que no puede ser una mera idea. Sin embargo, ateniéndonos a los primeros pensamientos de Copérnico, por tanto, a lo que Brandt llamaría lo primero, o el antecedente de lo que se ha de demostrar en Newton, permanecemos en una situación todavía de incertidumbre respecto de esa realidad por demostrar, mientras nos atenemos a las correlaciones espaciales y geométricas de los movimientos celestes; o, como el mismo Brandt dice, a la parte foronómica. Todavía no hay compromiso físico, solo hipótesis matemática; no hay cosmología, solo astronomía. Sabemos, retrospectivamente, y lo sabía Kant, según BXXII, que estos dos aspectos están vinculados, o que la tradicional separación ya no es sostenible, y que Copérnico y Newton terminan por constituir los extremos inicial y final, hipotético y conclusivo, de toda una gesta teórica que configura la noción moderna del mundo o universo. En conclusión, podría decirse que a la altura de los primeros pensamientos de Copérnico, en los que no hay compromiso cosmológico ni físico, lo que pueda preverse de un sistema heliocéntrico se mantiene como mera idea no verificable en el ámbito de las apariencias, las cuales son el objeto a explicar o conocer mediante los hipotéticos movimientos de la tierra. La tensión entre movimientos de la tierra y movimientos celestes aparentes se corresponde con la tensión kantiana entre condiciones subjetivas de conocimiento y mundo fenoménico, de manera que lo que en astronomía no está en conexión con las condiciones establecidas (movimiento de la tierra) no hace parte de lo que hay que explicar (apariencias celestes), igual que lo que no está en relación con nuestras estructuras cognitivas, no hace parte del mundo objetivo de los fenómenos. Lo cual no quiere decir que no haya algo más que apariencias celestes y fenómenos; solo que ello pertenece a la especulación cosmológica o metafísica. Ahora bien, la analogía se mueve, progresa, en el momento en que el movimiento de la tierra deja de ser mera hipótesis matemática explicativa que se justifica no por su realidad, sino por su éxito teórico respecto 
Facultades en el que Kant identifica el punto de vista del sol como punto de vista de la razón; es decir, como punto de vista ideal, en ningún caso como el verdadero y científico punto de vista, pues está claro que se trata de un punto de vista que no se somete al dictamen de la experiencia o, en términos copernicanos, que no da cuenta de las apariencias. He aquí el pasaje:

Los planetas, vistos desde la tierra, de pronto retroceden, de pronto se quedan quietos, de pronto avanzan. Pero tomando el punto de vista del Sol, según la hipótesis copernicana, que es algo que solo puede hacer la razón, prosiguen su marcha regular de manera constante (Kant 2003: 157).15

Se puede ver que el valor del sistema heliocéntrico es distinto del de las condiciones observacionales peculiares nuestras. La tesis del heliocentrismo, al igual que la del sistema planetario, contiene menos de astronomía y de apariencias que de especulación cosmológica; por eso, Kant habla aquí del punto de vista del sol que solo puede tomar la razón. Y por esto es que hay que tratar de manera diferente la referencia al heliocentrismo, o punto de vista del sol o de la razón, y la que se hace a los primeros pensamientos de Copérnico, o punto de vista de una tierra en movimiento pendiente de las apariencias, cuando de interpretar la analogía se trata; está claro que los dos pasajes no se pueden confundir, pues aluden a dos cosas distintas. Veamos.

de las apariencias celestes, y pasa a ser un hecho asumido físicamente (sin hablar todavía de la prueba empírica que habrá de esperar hasta mediados del siglo XIX). Entonces, la relación de la tierra con los astros ya no es de hipótesis explicativa de sus apariencias, sino de reciprocidad causal, por lo que se profundiza y se cualifica nuestra noción de lo que nos rodea como mundo. Podemos ahora pasar de una explicación foronómica o astronómica, con alcances de medición precisa y prognosis, a una teoría mecánica del universo que explica el comportamiento de los cuerpos celestes, incluida nuestra tierra, más allá de las apariencias visibles, en virtud de una ley universal para todos ellos, la gravitación.

$15 \gg$ Die Planeten, von der Erde aus gesehen, sind bald rückgängig, bald stillstehend, bald fortgängig. Den Standpunkt aber von der Sonne aus genommen, welches nur die Vernunft thun kann, gehen sie nach der Kopernikanischen Hypothese beständig ihren regelmäßigen Gang fort« (SF, AA 07: 83.2226). Esta cita se suele tomar como si el punto de vista del sol, que solo puede tomarse desde la razón, fuera el punto de vista de la razón, cuando el caso es que esta puede hacer lo mismo con cualquier otro punto de vista desde cualquier planeta, para empezar. Esto podría denunciarse como una recaída en el racionalismo, es decir, como si el punto de vista superior y logrado, el crítico, fuera el de la razón. De nuevo, que sea algo que solo pueda hacer la razón no quiere decir que sea lo único que ella tiene que hacer; gracias a la razón también podemos ponernos en el punto de vista de Júpiter o Saturno, o finalmente de la tierra, en la que sensiblemente estamos ubicados, pero que además podemos hacer inteligible por medio de la razón, es decir, ponernos con la razón en la posición de la tierra en la que ya estamos realmente (sensiblemente) ubicados. 
Para empezar la cita amerita explicación, en particular, para mostrar que no se la puede utilizar como sustituto del pasaje de BXVI que nos ocupa desde el comienzo; tampoco como soporte para su interpretación heliocéntrica. En esta cita de $S F$ la llamada hipótesis copernicana sí es ciertamente la heliocéntrica y es claro que alude a la estructura del cosmos y a la verdadera ruta de los planetas. La primera parte de la cita, referente a la perspectiva de la tierra, nos muestra la ruta aparente de los planetas y sus incomprensibles movimientos; pero lo que no está en la cita es que si tomamos esos movimientos y los conmutamos con los de la tierra se hacen comprensibles, acordes con su apariencia a la vez que con la hipótesis heliocéntrica, aunque no en el mismo sentido, según veremos. La cita procede, a diferencia del pasaje que nos interesa, a saltar a los verdaderos movimientos, a la estructura del sistema solar, no a hacer inteligible la apariencia que nos brinda el punto de vista de la tierra, en este caso.16

Los dos pasajes tienen algo en común, pero que no alcanza para confundirlos o tomarlos para el mismo propósito: ambos empiezan por referirse a dos apariencias distintas que se pueden verificar desde la tierra, a saber, el firmamento o bóveda celeste y los errantes planetas. Pero siguen dos caminos distintos: la apariencia de la bóveda celeste en movimiento se hace más comprensible por el movimiento de rotación de la tierra sobre su propio eje y, por tanto, no involucra al heliocentrismo. La apariencia de los planetas y sus extraños movimientos es contrapuesta a los verdaderos movimientos que solo se pueden establecer racionalmente, pero que no se pueden percibir salvo que tomemos el lugar del sol como centro de observación o que finjamos en nuestra imaginación o razón hacerlo: heliocentrismo. Esto nos muestra la independencia con que Kant maneja las dos cosas: por un lado, los primeros pensamientos de Copérnico relativos a la movilidad de la tierra; por otro lado, la hipótesis heliocéntrica. Esas dos cosas independientes convergen en lo relativo a los planetas, pues el movimiento de la tierra que los explica y hace comprensibles es el que ella

16 Estos dos pasajes de Newton parecen ser la fuente más cercana, bastante literal por cierto, a la manera de hablar de Kant en la referencia al heliocentrismo en $S F$ (AA 07: 83) que estamos analizando: "Pues desde la Tierra a veces parecen directos, a veces estacionarios y a veces retrógrados. Pero vistos desde el Sol son siempre directos, y avanzan con un movimiento casi uniforme, es decir, algo más veloz en el perihelio y algo más lento en el afelio, de forma que se mantiene una igualdad en la descripción de las áreas" (Newton 1982: 665-666). "En efecto, si Júpiter fuera visto desde el Sol, nunca parecería retrógrado ni estacionario, como a veces parece desde la Tierra, sino que siempre avanzaría con movimiento casi uniforme" (Newton 1982: 831, Sistema del Mundo, 8). 
hace alrededor del sol; pero ello no nos habilita a confundirlos, sustituirlos, ni a reducirlos a una sola hipótesis o, como diría Erdmann, a hablar de un único pensamiento, 'el primer pensamiento de Copérnico'.17

Finalmente, no se puede pasar por alto, sin embargo, que el supuesto movimiento de la tierra con el que se pretende explicar el movimiento aparente de los planetas, es decir, el movimiento anual alrededor del sol, es igualmente ideal, no solo por ser hipotético y punto de partida explicativo, sino porque tampoco es aparente o verificable sensiblemente. Además, es un movimiento que se define con base en el reposo ideal del sol (marco de referencia). Como decíamos arriba, la suposición del movimiento de la tierra tiene valor en la medida en que da cuenta de las apariencias, es decir, se soporta en su acuerdo con las apariencias, en ser hipótesis explicativas de tales apariencias. En cambio, cuando pasamos a hablar del sistema heliocéntrico estamos ya en un ámbito 'cosmológico', haciendo aseveraciones sobre la configuración real del universo, lo cual puede ciertamente provenir en algún sentido de las hipótesis 'astronómicas', pero en sus afirmaciones sobre la estructura del sistema solar y del universo parecen ya abandonar el terreno del necesario acuerdo con las apariencias.

Volviendo a la analogía, la idea está en retomar la tesis kantiana de la relación entre las facultades de conocimiento y su mutuo condicionamiento para hacerla corresponder con los movimientos de la tierra, en el primer caso, como configuradoras de la experiencia humana y, en el segundo, como configuradores de la apariencia astronómica. Esto implica una limitación que no siempre se explicita en ambos lados: para el

17 Erdmann, en su edición de la $K r V$ de 1878 (BXVI, línea 21), en lugar del dativo plural ,mit den ersten Gedanken...' ['con los primeros pensamientos'] sugiere leerlo en singular , mit dem ersten Gedanken' ['con el primer pensamiento']. Murray Miles (2006: 1, nota 1) asume por completo la enmienda de Erdmann. Pienso, por mi parte, que Miles está equivocado con respecto a la referencia de Kant a Copérnico. Su insistencia sobre 'el primer pensamiento de Copérnico', en singular, basado solo en la sugerencia de Erdmann, y convertido en 'el pensamiento inicial de Copérnico', incluso en 'su pensamiento original' (2006: 1) y reiterado por el mismo Miles (2006: 5, 7), para respaldar que lo que Kant quería significar con su referencia a Copérnico era la teoría heliocéntrica, no logra un mínimo de plausibilidad; y tampoco su nota 60 (2006: 28), dedicada a refutar a Paton y a KempSmith en relación con el mismo asunto. Primero, Copérnico mismo se refiere a sus pensamientos en plural al comienzo del De Revolutionibus (prefacio al Papa); habla de sus pensamientos acerca de la movilidad de la tierra, 'meas cogitationes de terrae motu'. Estoy seguro de que son esos los pensamientos a los que también se refiere Kant, a saber, los que conciernen a la movilidad de la tierra. Pero, si todavía hay duda sobre el contenido de tales pensamientos, de manera que el singular le fuera más favorable a la teoría heliocéntrica, en la misma página, líneas arriba, Copérnico habla de su doctrina sobre el movimiento de la tierra, 'haec mea doctrina de terrae motu' en singular. Así, pues, singular o plural, el mejor candidato para el contenido de tal o tales pensamientos es el movimiento de la tierra, no el heliocentrismo. 
caso de Kant, sabemos que aquellas condiciones estudiadas y propuestas, por las cuales estamos en capacidad de legitimar nuestras pretensiones de conocimiento a priori, nos restringen su aplicación al ámbito de la experiencia posible y nos inhiben cualquier ampliación hacia las cosas mismas, no susceptibles de experiencia, no condicionadas por la posibilidad de la experiencia. Sin embargo, para el caso de Copérnico, algunos autores ya extralimitan el ámbito de las apariencias y se involucran con la realidad cósmica. Para mantenernos en la correspondencia que comprometimos, y que consideramos que es lo que motiva la referencia de Kant a Copérnico, hemos de encontrar una diferencia, y su consabida restricción, también en este último, aunque no probablemente en su tan mentado heliocentrismo. Se trata entonces de apuntar a una lectura paralela de la analogía con Copérnico y la deducción trascendental. Encontramos para ello una clave en el propio Copérnico cuando nos exige controlar las hipótesis con las apariencias ["para que de ahí pueda deducirse en qué medida los movimientos y apariencias de los demás astros y órbitas pueden salvarse, si se relacionan con el movimiento de la tierra" (1982: 94)],18 con lo cual podríamos inferir que las hipótesis que no se sometan al control de las apariencias no se pueden arrogar el valor y la legitimidad de las que sí lo hacen. Algo similar a lo que muestra la deducción: que las condiciones de inteligibilidad de los objetos de la experiencia se establecen en la medida en que al mismo tiempo se demuestra que nuestras estructuras intelectuales solo hallan aplicación legítima en el mundo de la experiencia sensible.

En este sentido vale la pena retomar el pasaje de Copérnico que citamos arriba y que discierne entre la conexión o dependencia que hay entre hipótesis y apariencias, por un lado, y la que hay con otros elementos de nuestro conocimiento del mundo cuya fuerza radica más en su sistematicidad, coherencia y orden, que en su apariencia sensible, por otro. Esto apunta hacia que no todo lo que sabemos y creemos con certeza respecto del mundo y del cielo es lo que vemos, sino que también hay convicciones, prejuicios, supuestos que rigen el modo como interpretamos lo que vemos, pero que se prueba y se legitima más allá, o más acá, de lo que vemos. 'Más allá', cuando creemos depender de una realidad que nos dice cómo es, cómo nos la podemos representar (metafísica), o cuando apelamos a un creador de mente y voluntad insondables para nosotros. 'Más

18 "ut inde colligi possit, quatenus reliquorum syderum atque orbium motus \& apparentiae saluari possint, si ad terrae motus conferantur" (Copérnico 2015: 9, 5-7). 
acá', cuando sospechamos de nosotros mismos como en cierto sentido y hasta cierto punto condicionadores tanto de nuestras apariencias celestes como de nuestras artes (geometría y lógica), por las que buscamos el orden y la unidad del cielo y el mundo. 19

Por otro lado, la figura del empirismo y su punto de partida en la experiencia puede ser relacionada con la astronomía ptolomeica, geocéntrica y geoestática, también de cuño aristotélico, en la que se parte de las apariencias celestes y se trata de dar razón de ellas como si fueran un reflejo inmediato de la realidad. El lugar de los cálculos matemáticos y geométricos se considera como el arte de salvar las apariencias cuando ellas presentan dificultades en su comprensión e intelección (cuando infringen los principios de circularidad y uniformidad). Tal sería el sentido, en astronomía, de la famosa divisa, atribuida al aristotelismo, "nada hay en el entendimiento que no haya pasado primero por los sentidos" ["nihil est in intellectu quod prius non fuerit in sensu"]. Copérnico significa un enfrentamiento, probablemente a pesar de sí mismo, con esa tradición. Si bien Copérnico se mantiene en el respeto por las apariencias y los fenómenos, encuentra que es posible cuestionar esa relación tan directa con ellas y esa dependencia y subordinación a ellas. Las mismas dificultades y desacuerdos que hay en torno a la interpretación de los fenómenos y las apariencias celestes le llevan a pensar que el problema puede no estar en ellos como tales, como reflejos directos de la realidad celeste, sino sospechar que esté, más bien, en el incuestionado punto de partida de tales apariencias y observaciones, a saber, el 'reposo' de la tierra, el cual conecta, aunque no es idéntico, con la 'centralidad' de la tierra.

De ahí que Copérnico recurra a las antiguas opiniones acerca del movimiento de la tierra y empiece entonces él mismo a intentar relacionar las apariencias y sus dificultades con la movilidad de la tierra, es decir, con

\footnotetext{
19 Yo pensaría, por el talante de estas afirmaciones de Copérnico, que este tipo de conocimientos gozan de una mayor certidumbre que aquel tipo de los que él mismo atribuye a los 'fisiólogos' o filósofos naturales, que él mismo considera especulaciones. Y esa mayor certidumbre radica en el respeto por las apariencias y nuestra dependencia de ellas, de manera que tal sistematicidad y unidad se legitima en la tensión que en principio hay entre hipótesis y apariencia. Por otro lado, está la distinción entre astronomía y cosmología con su consabida correspondencia con la matemática y la metafísica, respectivamente. Podríamos pensar que se corresponde esta última distinción con la anterior entre fenómenos aparentes y sistematicidad y unidad; pero no es tan fácil, pues Copérnico parece tener confianza en cierta continuidad que hay para él entre su labor de astrónomo matemático y su búsqueda de sistematicidad y unidad, mientras que sus juicios sobre los fisiólogos no parecen reflejar esa confianza.
} 
un cambio en las condiciones del observador, hasta ahora inadvertidas e incuestionadas y, por defecto, consideradas como en 'reposo' y ocupando el 'centro' de todo lo observado.20 Esto hace que su relación con las apariencias cambie en un peculiar sentido, pues su respeto por ellas no radica en ser reflejo directo de la realidad, sino que se convierten ahora en verificadoras de las hipótesis alternas, de las cuales sí podemos decir ahora que se comportan como punto explícito de partida. Los movimientos de la tierra propuestos por Copérnico contra toda experiencia común y, en cierto sentido, contra la usual interpretación de la apariencia, se someten a ser coherentes con las apariencias y, algo tal vez más fuerte, a que las apariencias puedan ser deducidas de ellos. Y es en esto en lo que yo leo el propósito varias veces explícito de Copérnico en su obra: la movilidad de la tierra, en particular los tres movimientos propuestos, son principios explicativos de las apariencias y también principios resolutivos de las dificultades y problemas a los que ellas a lo largo de observaciones milenarias han conducido; en fin, los movimientos de la tierra son parte de lo que observamos en el cielo, son el supuesto que ordena y hace coherente las apariencias celestes.

\section{Conclusión}

'Copernicano', para el caso que nos ocupa, es lo relativo a los primeros pensamientos del astrónomo, los cuales consisten en la movilidad de la tierra como principio explicativo de las apariencias celestes. Esto puede parecer ambiguo, pues a la vez que privilegia la tierra, también la saca del centro (en el cual queda ahora el sol), en la medida en que le atribuye movimientos; y estas dos cosas aparentemente paradójicas, a saber, el

20 Los dos pasajes que siguen dan prueba de la conciencia de Copérnico acerca de las condiciones observacionales y de sus efectos en las observaciones astronómicas, no solo de las relativas a la perspectiva astronómica sino también a la perceptual humana: "Pero estos dos círculos que tienen el centro en la superficie de la tierra (me refiero al horizonte y al meridiano) siguen el movimiento de la tierra, según nuestro punto de mira. Pues el ojo toma siempre el papel de centro de la esfera de todo lo visible que le rodea. Además, todos los círculos tomados en la tierra producen en el cielo sus imágenes y las de los círculos semejantes a ellos, como se demuestra en Cosmografía y en lo relativo a las dimensiones de la tierra" (Copérnico 2015: 82.4-10; 1982: 163). Y combinada con esta otra cita: "Porque todo lo visible tiene alguna longitud dentro de una distancia, más allá de la cual no se ve, como se demuestra en Óptica. Pues, que desde el más alto de los astros errantes, Saturno, hasta la esfera de las estrellas fijas hay una gran distancia, lo demuestran sus destellantes luces. Por este indicio se distinguen sobre todo de los planetas, pues entre los que se mueven y los que no se mueven convenía que hubiera la máxima diferencia. Tan admirable es esta divina obra del Óptimo y Máximo [Hacedor]" (Copérnico 2015: 39.17-23; 1982: 119). 
descentramiento móvil y el observatorio privilegiado, atentan en conjunto contra la tradición geocentrista que postulaba el mismo privilegio pero en reposo y centrado (geoestatismo). En breve, privilegiar la tierra, con su descentramiento y movilidad, no es propiamente lo que se llama geocentrismo; este consistía, por cierto, en el mismo privilegio de la tierra, pero centrada e inmóvil. Ahora, tal centro inmóvil lo detentará el sol, pero sin el privilegio observacional.21 Igual que privilegiar la tierra, descentrada y móvil, no es relativismo astronómico, ni astronomía antropocéntrica, pues lo que vale para el punto de vista privilegiado de la tierra, descentrada y móvil, vale igual si, mutatis mutandis, se privilegia el punto de vista de Júpiter, Marte, Saturno o, incluso el del mismo sol que, sabemos, igual que Kant, también se mueve. Es decir, la generalidad aquí obtenida consiste simplemente en considerar la movilidad particular del punto de vista privilegiado y dar cuenta de los movimientos observados siempre en concordancia (o con las correspondientes 'conmutaciones', al decir de Copérnico) con ella. Entonces, las observaciones de las apariencias celestes se rigen y, por tanto, se explican por los movimientos de la tierra, en nuestro caso particular, y, en general, por las condiciones y movimientos del correspondiente punto de vista. Se puede así decir que los movimientos de la tierra constituyen información a priori acerca de los movimientos celestes observados desde la tierra; y, mutatis mutandis, los de cualquier otro punto de vista en relación con sus correspondientes observaciones. ¡Esto es lo copernicano! ¡Y probablemente también lo revolucionario!

Ahora bien, 'kantiano', en estricta analogía con lo copernicano establecido, es lo relativo en el ámbito del conocimiento a cierta precedencia de las representaciones (condiciones representativas), conceptos e intuiciones frente a lo representado por ellas, a saber, los fenómenos; así, las facultades del entendimiento y la sensibilidad tendrán la clave explicativa de la objetividad fenoménica, es decir, del conocimiento objetivo de los fenómenos. En breve, la dependencia de los objetos respecto de los conocimientos; son estos, pues, los que rigen a los objetos y no al contrario. Aquí parece repetirse legítimamente la ambigüedad que despejamos antes para la objeción de geocentrismo o de antropocentrismo:

21 Ya hablamos arriba sobre el punto de vista del sol como punto de vista de la razón; concluimos que no es propiamente un punto de vista astronómico, algo así como si se tratara del observatorio absoluto, el cual no existe, sino que corresponde a un centro ideal, de valor cosmológico, racional, que no tiene correspondiente real, del cual se puedan derivar apariencias sensibles del verdadero y único orden del cosmos. 
que se trata de un 'subjetivismo' que reñiría con la pretensión de conocimiento objetivo, es decir, de una relatividad al sujeto que diluye toda representación cognitiva en vivencias subjetivas particulares;22 mejor aún, de un conocimiento que no alcanza a la realidad misma que pretende conocer. Equivaldría, en términos copernicanos y astronómicos, a la imposibilidad de observar directamente lo que verdaderamente ocurre en el cielo y a tener que conformarnos con lo que vemos gracias a la mediación de un punto de vista que exige la 'conmutación' de lo observado con la movilidad del observador, es decir, que lo observado depende de, o se rige por, las condiciones del observador. Pero esa ambigüiedad, pensamos, es algo que podemos despejar en analogía con lo que hicimos antes: Copérnico, más que establecer una astronomía desde la tierra, nos brinda una regla para ejercer la astronomía desde cualquier parte.

De nuevo: 'kantiano', en analogía con lo 'copernicano', sería la precedencia de las condiciones cognitivas respecto del objeto de conocimiento o fenómeno; de modo tal que la particular configuración de la relación entre sensibilidad y entendimiento es responsable de la clase de representación objetiva de que somos capaces. Sin embargo, igual que se despeja en astronomía el sesgo de geocentrismo, también queda claro que no se trata de un antropocentrismo o de un privilegio particular de la manera humana de conocer. Más bien, se trata de que en asuntos de conocimiento, cualquiera que él sea, las condiciones específicas de conocer determinan en gran medida el objeto de conocimiento y, por ende, su objetividad. Lo humano del conocimiento es un caso específico entre otras posibilidades de conocimiento, igual que lo es la georreferencialidad en astronomía, que se puede replicar mutatis mutandis para cualquier otro planeta, o el sol, etc.

Hay muchos más detalles que se pueden seguir en paralelo entre el punto de vista copernicano y el kantiano, de manera que la analogía es aplicable y expandible a variados aspectos entre ambas teorías, imposibles de abarcar en una sola contribución. Todo lo anterior me permite concluir que la analogía propuesta por Kant, cotejada con Copérnico e interpretada tan textual y directamente como sea posible, es idónea y fructífera. También puedo concluir que muchas de las enmiendas y reservas que abundan en la literatura kantiana se deben a equívocos fundamentales tanto respecto de

22 M. Caimi (2018) se centra en aclarar la objeción de subjetivismo al proyecto kantiano; su recurso a la instancia impersonal del sujeto de conocimiento, con todo lo aparentemente paradójico que pueda ser hablar de un yo impersonal, me parece acertado. 
Kant como de Copérnico. Espero haber contribuido a despejar algunos de ellos.

\section{Referencias}

ALEXANDER, S.: "Ptolemaic and Copernican views of the place of Mind in the Universe", Hibbert Journal VIII (1909) 47-66.

BLOCH, E.: „Die kopernikanische Wende, in Wahrheit eine ptolemäische“, en: Leipziger Vorlesungen zur Geschichte der Philosophie (1950-1956), IV, Fráncfort del Meno, Suhrkamp, 61-62, 1985.

BLUMENBERG, H.: „Die Kopernikanische Konsequenz für den Zeitbegriff“, en DOBRZYCKI, J. (ed.): The Reception of Copernicus' Heliocentric Theory, Dordrecht, Springer, 57-77, 1972.

: Die Genesis der Kopernikanischen Welt, Fráncfort del Meno, Suhrkamp, 1975.

BRANDT, R.: „Kants Revolutionen“, Kant-Studien 106, 1 (2015) 3-35.

Verlag, 2007.

: Die Bestimmung des Menschen bei Kant, Hamburg, Meiner

CAIMI, M.: "La revolución copernicana del modo de pensar. Algunos problemas", en LEYVA, G.; PELÁEZ, A.; STEPANENKO, P. (eds.): Los Rostros de la razón: Immanuel Kant desde Hispanoamérica, Barcelona, Anthropos Editorial, 17-36, 2018.

COPÉRNICO, N.: De revolutionibus orbium coelestium / Des révolutions des orbes célestes, París, Les Belles Lettres, 2015.

: Sobre las Revoluciones de los orbes celestes, Madrid, Editora Nacional, 1982.

: "Comentariolus”, en COPÉRNICO, N.; GALILEI, G.; DIGGES, T.: Opúsculos sobre el movimiento de la tierra, Madrid, Alianza Editorial, 25-43, 1983.

DOBRZYCKI, J. (ed.): The Reception of Copernicus' Heliocentric Theory, Dordrecht, Springer, 1972. 
GINGERICH, O.: "From Copernicus to Kepler. Heliocentrism as model and as reality", Proceedings of the American Philosophical Society 117, 6 (1973) 513-522.

KANT, I.: Gesammelte Schriften, Bd. 1-22, Preussische Akademie der Wissenschaften, 23, Deutsche Akademie der Wissenschaften zu Berlin, 24, Berlín, Akademie der Wissenschaften zu Göttingen,1900ss.

: Kritik der reinen Vernunft, Hamburg, Meiner Verlag, 1998.

: Crítica de la razón pura, Buenos Aires, Colihue, 2007. : El Conflicto de las Facultades, Madrid, Alianza, 2003.

LAMBERT, J. H.: Cosmologische Briefe über die Einrichtung des Weltbaues (1761), Hildesheim, Olms, 2006.

LAZOS, E.: Disonancias de la Crítica: Variaciones sobre cuatro temas kantianos, México, UNAM Instituto de Investigaciones Filosóficas, 2014.

LEMANSKI, J.: „Die Königin der Revolution. Zur Rettung und Erhaltung der Kopernikanischen Wende“, Kant-Studien 103 (2012) 448-471.

MILES, M.: “Kant's 'Copernican Revolution': Toward Rehabilitation of a Concept and Provision of a Framework for the Interpretation of the Critique of Pure Reason", Kant-Studien 97 (2006) 1-32.

MOLEDO, F.: 'Kant y la 'revolución del modo de pensar' (KrV, B xi) el significado metodológico general y el significado metafísico específico analizados desde una perspectiva sistemática e histórico-evolutiva", Ideas y Valores LXVI, 164 (2017) 13-34.

NEWTON, I.: Principios Matemáticos de Filosofía Natural, Madrid, Editora Nacional, 1982.

RUSSELL, B.: Human Knowledge, Londres, Allen and Unwin, 1948.

SCHÖNECKER， D.; SCHULTING， D.; STROBACH， N.: „Kants kopernikanisch-newtonische Analogie“, DZPhil 59, 4 (2011) 497-518.

SERRANO ESCALLÓN, G.: "Apparientias salvare. Misunderstandings in Kant's Copernican Analogy, (KrV, Bxvi)", British Journal for the History of Philosophy, 7, 3 (1999) 475-490.

RYALL, J. T. W.: A Copernican Critique of Kantian Idealism, Londres, Palgrave Macmillan, 2017. 


\title{
El espacio en cuanto forma de los fenómenos y la tesis de la receptividad: mutua implicación
}

\author{
Diana Gloria Contreras Gallegos ${ }_{1}$
}

\begin{abstract}
Resumen
En este trabajo mostraré que existe un nexo de mutua implicación entre dos tesis kantianas: la tesis del espacio en cuanto forma de los fenómenos y la tesis de la receptividad. Ambas tesis se encuentran en la Estética trascendental de la Crítica de la razón pura desde el parágrafo introductorio (\$1) y, de manera específica, es posible apreciar el vínculo de mutua implicación que existe entre ellas en la segunda de las consecuencias que Kant deriva tras haber presentado sus argumentos en favor de la naturaleza a priori e intuitiva del espacio.
\end{abstract}

Palabras clave: espacio, receptividad, forma de los fenómenos, a priori, estética trascendental

\section{Space as the shape of phenomena and the thesis of receptivity: Mutual involvement}

\begin{abstract}
The purpose of this paper is to show that there is a mutual implication between two Kantian theses: the thesis of the space as a form of phenomena and the thesis of receptivity. Both can be found in the Transcendental Aesthetic of the Critique of Pure Reason from its introductory paragraph $(\S 1)$ and, specifically, it is possible to see the mutual implication that exists between them in the second consequence that Kant derives after the presentation of his arguments about the a priori and intuitive nature of space.
\end{abstract}

Keywords: space, receptivity, form of phenomena, a priori, Transcendental aesthetic

1 Universidad Autónoma de México. Contacto: ainda08@yahoo.com.mx. 


\section{Introducción}

En este trabajo mostraré que existe un nexo de mutua implicación entre dos tesis kantianas: la tesis del espacio en cuanto forma de los fenómenos y la tesis de la receptividad. Ambas tesis se encuentran en la Estética trascendental de la Crítica de la razón pura desde el parágrafo introductorio (§1) y, de manera específica, es posible apreciar el vínculo de mutua implicación que existe entre ellas en la segunda de las consecuencias que Kant deriva tras haber presentado sus argumentos en favor de la naturaleza a priori e intuitiva del espacio, es decir, en la consecuencia (b) (conocida como 'tesis de la subjetividad').

Para cumplir con el objetivo delineado líneas arriba, en este trabajo presento una reconstrucción del argumento que aparece en la consecuencia (b); hago notar que en él Kant parte de una premisa que alude explícitamente a la capacidad receptiva humana y de ella deriva que nos es posible entender dos notas del espacio en cuanto forma de los fenómenos: (i) su carácter a priori en el sentido de que antecede de manera estructural la percepción humana de todo particular; y (ii) su naturaleza relacional, en tanto que como intuición pura contiene a priori los principios que regulan las relaciones en y entre los particulares. Dado que en una primera lectura el argumento en cuestión resulta ser opaco en la medida en que no hay forma de saber cuál es el nexo teórico que Kant encuentra entre la capacidad receptiva humana, por una parte, y cada uno de los rasgos referidos del espacio, por otra, propongo incluir una premisa implícita en el argumento: el espacio es la forma de la capacidad receptiva humana; aserto que aparece en el parágrafo introductorio de la Estética trascendental. Con la inserción de esta premisa será posible apreciar con mayor claridad la mutua implicación que existe entre la tesis del espacio en cuanto forma de los fenómenos (TEF) y la tesis de la receptividad (TR).

Finalmente, muestro que un tratamiento cabal de la tesis de la receptividad implica la tesis del espacio en cuanto forma de los fenómenos; tesis que expresa el idealismo trascendental kantiano. Esta tesis en absoluto mina, o incluso aniquila, el compromiso del filósofo alemán con la realidad empírica del espacio y los objetos dados a los sentidos. Del mismo modo, considero que un estudio del espacio kantiano conforme a la Estética trascendental implica la tesis de la receptividad, lo que a su vez conduce a 
hablar de la capacidad receptiva humana.2 Esto, en el marco de la investigación trascendental kantiana dirigida a nuestra facultad de conocer objetos ( $c f r$. $K r V$, A26/B42; véase, por ejemplo, AA 04: 293). Vayamos, entonces, a la consecuencia (b).

2. Consecuencia (b): "El espacio no es más que la forma de todos los fenómenos de los sentidos externos, es decir, la condición subjetiva de la sensibilidad" ( $K r V$, A26/B42) (Tesis de la subjetividad del espacio).

En A26/B42, después de haber desplegado toda una argumentación en favor del espacio en cuanto intuición a priori en la Exposición metafísica, Kant deriva dos consecuencias; en la segunda de ellas, el filósofo concluye lo siguiente:

El espacio no es más que la forma de todos los fenómenos de los sentidos externos, es decir, la condición subjetiva de la sensibilidad. Solo bajo esta condición nos es posible la intuición externa. Ahora bien, dado que la receptividad del sujeto, cualidad consistente en poder ser afectado por los objetos, precede necesariamente a toda intuición de esos objetos, es posible entender cómo la forma

\footnotetext{
2 Es preciso tener presente una distinción quizá sutil pero sumamente importante en el contexto de la investigación kantiana sobre los límites de nuestro conocimiento empírico: la tesis epistemológica de la receptividad referida a que nuestro conocimiento depende de que seamos afectados por los objetos tiene su explicación en los rasgos estructurales de la capacidad receptiva humana, como veremos. En este sentido, el término 'receptividad', aplicado al análisis de la propuesta del filósofo alemán, corre el riesgo de ser ambiguo ya que puede aludir a la tesis epistemológica, o bien, a la explicación de esta. Para evitar esta ambigüedad, en el presente trabajo hablo de 'la capacidad receptiva humana' o hablo de 'nuestra receptividad' cuando Kant alude a la receptividad en cuanto capacidad del sujeto, por ejemplo, cuando el filósofo hace referencia a la sensibilidad humana y al espacio en cuanto a la forma de esta. Por otra parte, es conveniente tener presente la distinción entre la tesis epistemológica de la receptividad y su explicación, i.e., la posición de Kant sobre el espacio en cuanto forma de la receptividad, ya que es posible interpretar la propuesta kantiana sobre los límites de nuestro conocimiento objetivo recuperando solo la tesis de la receptividad, sin la explicación que el filósofo alemán da sobre ella a partir de la estructura de la capacidad receptiva humana, es decir, sin aludir a los rasgos inherentes a la facultad sensible de los seres humanos. La lectura 'austera' de P. F. Strawson es un ejemplo de este tipo de interpretación (véase Strawson 1966: 47-51). Otro ejemplo lo encontramos en Langton quien sostiene que nuestra ignorancia de las cosas en sí mismas (tesis de la humildad epistémica) se sigue de tres tesis kantianas: i) la tesis de la distinción entre las propiedades extrínsecas o relacionales de los objetos y las propiedades intrínsecas; ii) la tesis de la receptividad; y iii) la tesis de la irreductibilidad (las propiedades relacionales de los objetos no son reducibles a sus propiedades intrínsecas). Langton respalda la tesis de la humildad a partir de las tesis anteriores sin compromiso alguno con la idealidad trascendental del espacio (véase Langton 2001 [1998]). Como recién señalé, mi punto de vista es que un tratamiento cabal de la tesis de la receptividad (y también de la tesis de la irreductibilidad) implican necesariamente la idealidad trascendental del espacio (la tesis del espacio en cuanto forma del fenómeno); con ello adquiere pleno soporte teórico la tesis kantiana de la humildad epistémica.
} 
de los fenómenos puede darse en el psiquismo con anterioridad a toda percepción real, es decir, a priori, y cómo puede ella, en cuanto intuición pura en la que tienen que ser determinados todos los objetos, contener, previamente a toda experiencia, principios que regulen las relaciones de esos objetos.

Centremos nuestra atención en las dos primeras líneas de este pasaje y observemos que Kant identifica la — de por sí problemática- proposición acerca de que el espacio no es más que la forma de todos los fenómenos de los sentidos externos, con el enunciado respecto de que el espacio solo es la condición subjetiva de la sensibilidad. La pregunta que emerge es inminente: '¿por qué?'

Kant, como si adivinara el pasmo del lector, introduce enseguida una afirmación que da razón del carácter subjetivo del espacio en cuanto condición de la sensibilidad. Explica el filósofo: "Solo bajo esta condición nos es posible la intuición externa" ( $K r V$, A26/B42). El espacio es la única manera en que podemos recibir la intuición externa. Todo particular se presenta ante nosotros ordenado espacialmente. Notemos en esta explicación la referencia implícita a la receptividad humana: el espacio es el modo en que los seres humanos recibimos el material sensible; es un rasgo inherente a nuestras capacidades receptivas. La razón por la que el espacio, en cuanto forma de todos los fenómenos de los sentidos externos, constituye la condición subjetiva de la sensibilidad se entrelaza con la tesis referida a que la sensibilidad humana es receptiva: la manera necesariamente espacial en que recibimos la intuición externa es un rasgo inherente a nuestras capacidades receptivas, un rasgo estructural. Volvamos, de nuevo, a esta consecuencia y observemos que en ella Kant introduce un argumento cuya premisa alude explícitamente a la capacidad receptiva humana:

Ahora bien, dado que la receptividad del sujeto, cualidad consistente en poder ser afectado por los objetos, precede necesariamente a toda intuición de esos objetos, es posible entender cómo la forma de todos los fenómenos puede darse en la mente con anterioridad a toda percepción real, es decir, a priori, y cómo puede ella, en cuanto intuición pura en la que tienen que ser determinados todos los objetos, 
contener, previamente a toda experiencia, principios que regulen las relaciones de estos objetos (KrV, A26/B42).3

$\mathrm{Si}$ vemos de cerca la estructura del razonamiento, notaremos que Kant deriva de la premisa en torno a la receptividad humana dos consecuencias relacionadas con el espacio en cuanto "forma de todos los fenómenos":

\section{Dado que}

(1) la receptividad del sujeto, cualidad consistente en poder ser afectado por los objetos, precede necesariamente a toda intuición de esos objetos,

[Se sigue que]

(2) es posible entender cómo la forma de todos los fenómenos puede darse en la mente con anterioridad a toda percepción real, es decir, $a$ priori,

\section{$\mathrm{y}$}

(3) [es posible entender] cómo puede ella, en cuanto intuición pura en la que tienen que ser determinados todos los objetos, contener, previamente a toda experiencia, principios que regulen las relaciones de estos objetos.

Lo que a primera vista resalta en el argumento es el peso que Kant otorga a la capacidad receptiva humana, en particular, a la anterioridad necesaria de esta respecto de la intuición de cualquier objeto; de esta premisa se sigue que nos es posible comprender dos notas que definen el espacio en cuanto forma de los fenómenos: i) su carácter a priori, en el sentido de que antecede necesariamente - de manera estructural- la percepción humana de cualquier particular: "puede darse en la mente con anterioridad a toda percepción real” (conclusión [2]); y ii) su naturaleza

\footnotetext{
3 Anoto con cursivas la expresión "dado que", para hacer notar que actúa como indicador de la premisa referida a la receptividad humana dentro del argumento que Kant introduce en este pasaje, después de las tres primeras afirmaciones.
} 
relacional, ya que en cuanto intuición pura contiene a priori los principios que regulan las relaciones en y entre los particulares (conclusión [3]). Es indudable que Kant encuentra un vínculo entre la tesis referida a la receptividad humana y la tesis sobre el carácter a priori del espacio en cuanto forma de los fenómenos, de tal modo que propone partir de la tesis sobre nuestra capacidad receptiva para poder comprender el par de rasgos del espacio recién descritos; rasgos en los que — dicho sea de paso- quizá Kant advirtió la dificultad que entraña su comprensión (y tal vez también su aceptación), por lo que en este argumento propone tomar como base la receptividad humana para poder entenderlos. ¿Cuál es el vínculo que Kant establece entre ambas tesis, i.e., entre la tesis en torno a la capacidad receptiva humana y la del espacio en cuanto forma de los fenómenos? ¿Por qué es preciso partir de la antelación necesaria de nuestra capacidad receptiva respecto de toda intuición posible para poder entender que el espacio se halla a priori en nuestra mente y, asimismo, para comprender su carácter relacional? Estas preguntas nos obligan a penetrar en el argumento que Kant nos presenta aquí, en el cuerpo de la consecuencia (b).

Ahora bien, aunque es precisamente en este pasaje en el que encontramos de manera clara el enlace entre la tesis de la receptividad y la tesis del espacio en cuanto forma de la intuición, ambas se hallan desde el inicio de la Estética trascendental, en el parágrafo introductorio. A continuación me concentraré en el argumento que Kant nos presenta aquí y, a la par, haré notar el enlace entre el contenido de este y lo afirmado en el $\S 1$; con ello podremos apreciar que la tesis kantiana acerca de la subjetividad del espacio - cuya explicación para el filósofo se encuentra en la capacidad receptiva humana- constituye uno de los ejes argumentativos que atraviesan la Estética trascendental desde su inicio.

En primer término, es preciso observar que no obstante la presencia del indicador de premisa "dado que", quizá no resulta del todo fácil distinguir los componentes que estructuran el argumento de este pasaje. Esto se debe a que tanto en la conclusión (2) como en la (3) no aparece formulado de modo explícito el sujeto gramatical de cada oración, lo que obstaculiza el reconocimiento del papel que tales afirmaciones desempeñan como consecuencias del argumento. Por esta razón, es obligado realizar un trabajo previo de reformulación de cada una de las aseveraciones con el propósito de que su contenido exprese un pensamiento completo a través de 
un enunciado declarativo; ello, me parece, facilitará la comprensión cabal del razonamiento que Kant presenta en este sitio.

De este modo, con base en el contenido que aporta la premisa (1), la reconstrucción de (2) y de (3), respectivamente, queda de la siguiente manera:

(2) es posible entender cómo la forma de todos los fenómenos puede darse en la mente con anterioridad a toda percepción real, es decir, $a$ priori,

(3) el que la receptividad del sujeto preceda necesariamente a toda intuición de los objetos que pueden afectarlo, posibilita entender cómo puede la forma de todos los fenómenos - en cuanto intuición pura en la que tienen que ser determinados todos los objetoscontener, previamente a toda experiencia, principios que regulen las relaciones de esos objetos.

Una vez realizada la reformulación tanto de (2) como de (3), estamos en condiciones de analizar cada una de las afirmaciones que estructuran el argumento. Exploremos, entonces, la premisa en torno a la capacidad receptiva humana en el argumento que nos ocupa:

(1) la receptividad del sujeto, cualidad consistente en poder ser afectado por los objetos, precede necesariamente a toda intuición de esos objetos.

Lo primero que considero necesario destacar es que esta proposición alude a "la receptividad del sujeto" y Kant aborda dicha "receptividad" en cuanto cualidad humana, es decir, se trata de un rasgo inherente al aparato cognitivo de los seres humanos. De manera más precisa, constituye un rasgo estructural de nuestra sensibilidad. Podemos apreciar claramente esto a partir de la cláusula explicativa que el filósofo introduce a continuación: "cualidad consistente en poder ser afectado por los objetos". Esta cláusula, además de que nos aclara que la receptividad es un rasgo de nuestras 
capacidades sensibles, proporciona información relevante para comprender el argumento: dicho rasgo radica en que los seres humanos podemos ser afectados por los objetos. Notemos cómo en la explicación que Kant ofrece sobre nuestra capacidad receptiva humana se encuentra implícita la tesis epistemológica de la receptividad: el conocimiento humano depende de que seamos afectados por los objetos y esto es posible gracias a que nuestra sensibilidad tiene la cualidad de ser receptiva. Dicho de otro modo: en virtud de que la sensibilidad humana posee como rasgo inherente el ser receptiva es que podemos recibir intuiciones externas como resultado de los impactos de los objetos sobre nosotros. En este sentido, la receptividad humana antecede de modo necesario cualquier intuición posible. Podremos apreciar de manera más nítida esto si observamos de cerca la premisa en que nos encontramos; véase que contiene un argumento implícito cuya formulación puede ser la siguiente:

P: la receptividad del sujeto [es la] cualidad consistente en poder ser afectado por los objetos,

C: [la receptividad del sujeto] precede necesariamente a toda intuición de esos objetos [de los objetos que lo afectan].

En esta reconstrucción, la cláusula explicativa que aparece originalmente en el texto se convierte en la definición de lo que para Kant es la denominada 'receptividad del sujeto'. Mi interés al mostrar el argumento implícito en la premisa que nos ocupa radica en hacer evidente que lo afirmado por Kant en él, respecto de la receptividad humana, corresponde plenamente con lo que antes ha descrito en torno a la sensibilidad y al papel que esta desempeña en nuestro conocimiento en el parágrafo introductorio (§1) de la Estética trascendental. Kant inicia la investigación sobre la estructura de la sensibilidad humana presentando el significado de varios de los términos que emplea en dicho estudio. En este primer pasaje, Kant define la sensibilidad humana precisamente como 'receptividad', es decir, como la capacidad que tenemos los seres humanos de ser afectados por los objetos y, con ello, de recibir representaciones: "La capacidad (receptividad) 
de recibir representaciones, al ser afectados por los objetos, se llama sensibilidad" (KrV, A19/B33).4

Lo anterior es por completo afín al contenido de la premisa del argumento implícito que nos encontramos analizando. Pero no solo esto, también lo expresado en la conclusión de dicho argumento ("[la receptividad del sujeto] precede necesariamente a toda intuición de [los objetos que lo afectan]") ha sido afirmado por Kant desde el comienzo de la Estética trascendental, en el §1. En esta sección inicial, el filósofo caracteriza las intuiciones como aquellas representaciones que refieren inmediatamente a los objetos. Asimismo, subraya que solo podemos recibir intuiciones si los objetos nos son dados; y, para que ello sea posible, es preciso que tales cosas afecten "de alguna manera" nuestro aparato cognitivo. La receptividad, por tanto, es un rasgo constitutivo de la sensibilidad humana: "Pero este [el objeto], por su parte, solo nos puede ser dado [al menos a nosotros, los humanos] si afecta de alguna manera a nuestra mente" $(K r V, \mathrm{~A} 19 / \mathrm{B} 33) .5$

La sensibilidad, entonces, es la única capacidad humana que nos provee de intuiciones, sostiene el filósofo en el parágrafo introductorio: "Los objetos nos vienen, pues, dados mediante la sensibilidad y ella es la única que nos suministra intuiciones" ( $K r V$, A19/B33; las cursivas son del original. Véanse, de nuevo, A50/B74, A51/B75).

La receptividad humana, la capacidad que tenemos de recibir representaciones al ser afectados por los objetos, antecede necesariamente a toda intuición externa, tal y como señala la conclusión del argumento

\footnotetext{
4 Esta tesis también la encontramos en los primeros parágrafos con los que abre la Lógica trascendental, parte que sigue después de la Estética trascendental, dentro de la Doctrina trascendental de los elementos. En ella, Kant nos dice que: "Nuestro conocimiento surge básicamente de dos fuentes de la mente: la primera es la facultad de recibir representaciones (receptividad de las impresiones); la segunda es la facultad de conocer un objeto a través de tales representaciones (espontaneidad de los conceptos)" ( $K r V$, A50/B74). "Si llamamos sensibilidad a la receptividad que nuestra mente posee, siempre que sea afectada de alguna manera, en orden a recibir representaciones, llamaremos entendimiento a la capacidad de producirlas por sí mismo, es decir, a la espontaneidad del conocimiento" ( $\mathrm{KrV}, \mathrm{A} 51 / \mathrm{B} 75$; las cursivas son del original).

5 El corchete que contiene la cláusula explicativa "al menos a nosotros, los humanos", fue introducido por Kant. Este planteamiento corresponde plenamente con lo que el filósofo señala al inicio de la Lógica trascendental; en los primeros parágrafos de esta Kant, de manera clara, alude a nuestra constitución humana como la razón que explica por qué nuestra intuición es necesariamente sensible: "Nuestra naturaleza conlleva el que la intuición solo pueda ser sensible, es decir, que no contenga sino el modo según el cual somos afectados por los objetos" ( $K r V$, A51/B75; las cursivas son del original).
} 
implícito de la premisa (1). Veamos nuevamente esta en su formulación original:

(1) la receptividad del sujeto, cualidad consistente en poder ser afectado por los objetos, precede necesariamente a toda intuición de esos objetos.

Observemos que la tesis referida a la capacidad receptiva humana es de índole restrictivo: los seres humanos solo podemos tener intuiciones si los objetos nos afectan. El porqué de esta restricción se encuentra en la constitución cognitiva humana, en particular, en nuestra intuición: esta solo puede ser sensible (véase $K r V$, A51/B75). La receptividad de nuestra intuición es un rasgo inherente al aparato cognitivo de la especie humana, un rasgo eminentemente subjetivo.

Ahora bien, de la restricción impuesta por la naturaleza de nuestra intuición, Kant —en un salto que parece ser mortal- deriva que nos es posible entender dos rasgos del espacio en cuanto forma de los fenómenos: i) su aprioricidad, en tanto que antecede estructuralmente cualquier intuición externa (conclusión [1]); y ii) su carácter relacional (conclusión [2]). Esto nos obliga a revisar con mayor cercanía las consecuencias del razonamiento. A continuación llevaré a cabo esta tarea, a la par que mostraré cómo el contenido de cada conclusión corresponde con lo expresado inicialmente en la Estética trascendental en el parágrafo introductorio $(\S 1)$. Vayamos a la primera:

(2) el que la receptividad del sujeto preceda necesariamente a toda intuición de los objetos que pueden afectarlo, posibilita entender cómo la forma de todos los fenómenos puede darse en la mente con anterioridad a toda percepción real, es decir, a priori.

Lo primero que resalta es la afinidad temática entre i) la antelación necesaria de la receptividad humana frente a cualquier intuición externa y ii) la anterioridad necesaria - a priori- del espacio en cuanto forma de los fenómenos, respecto de cualquier 'percepción real'. Tanto la receptividad 
humana como el espacio, en cuanto forma de los fenómenos, anteceden de manera necesaria toda intuición externa. La razón de ello es de naturaleza estructural en ambos casos: la receptividad es un rasgo inherente a nuestra cognición —una cualidad, como señala la premisa del argumento- $\mathrm{y}$, de manera similar, el espacio en cuanto forma de los fenómenos "se da en la mente con anterioridad a toda percepción real", es decir, es un rasgo de nuestra estructura cognitiva. Es innegable que, en una primera mirada, esta última tesis es problemática; es posible aceptar (i) pero no ocurre lo mismo con (ii), es decir, cuesta trabajo conceder que el espacio entendido como "la forma de los fenómenos" se encuentre con anterioridad en la mente humana, a priori, y, en esa medida, constituya la condición de posibilidad de cualquier intuición externa, de "toda percepción real". Quizá Kant advirtió la dificultad que entraña la aceptación de (ii) y por ello propone partir de la primera tesis para poder comprender esta. Lo que sí es claro es que el filósofo encuentra un enlace entre la antelación necesaria inherente a nuestra receptividad (i) y la anterioridad estructuralmente necesaria - a priori- del espacio (ii). ¿Cuál es este nexo? Ciertamente, en la conclusión que nos encontramos analizando, no aparece de manera explícita la explicación del vínculo entre la tesis referida a la receptividad humana y el espacio en cuanto forma de los fenómenos. Con este interrogante en la mente, exploremos la segunda conclusión del argumento.

(3) el que la receptividad del sujeto preceda necesariamente a toda intuición de los objetos que pueden afectarlo, posibilita entender cómo puede la forma de todos los fenómenos - en cuanto intuición pura en la que tienen que ser determinados todos los objetoscontener, previamente a toda experiencia, principios que regulen las relaciones de esos objetos.

En esta consecuencia encontramos que Kant propone, de nuevo, partir de la anterioridad necesaria de la receptividad humana frente a cualquier intuición externa para comprender, en esta ocasión, que el espacio en cuanto forma de los fenómenos puede contener antes de cualquier experiencia los principios que regulan las relaciones entre los objetos. Esto, teniendo en cuenta que la forma de los fenómenos —en tanto que intuición pura - determina necesariamente todas las cosas. Véase en esta conclusión 
la referencia implícita a la naturaleza necesariamente relacional de nuestra experiencia de objetos externos a partir de que el espacio, en cuanto intuición pura, contiene a priori los principios que regulan las relaciones de los objetos y entre ellos y nosotros; planteamiento que, del mismo modo que los anteriores, también se encuentra en el parágrafo con el que abre la Estética trascendental, como veremos en breve.

Es importante observar que en la conclusión (3) nuevamente encontramos que, para Kant, existe un lazo entre nuestra capacidad receptiva y el espacio qua forma de los fenómenos y, aquí de manera específica, el carácter relacional de este último. Sin embargo, tal y como ocurre en la consecuencia (2), no aparece de manera explícita la explicación de este vínculo. Frente a esta opacidad, me parece indispensable consultar de nuevo el 'mapa' que el propio Kant nos proporciona en el §1. La primera pista que es preciso seguir, y que resulta verdaderamente crucial para iluminar el argumento que nos ocupa, es la tesis kantiana en torno al espacio en tanto que forma del fenómeno, es decir, en cuanto orden de presentación y disposición de la diversidad sensible del fenómeno.6 Vayamos, entonces, a esta sección introductoria.

En las primeras líneas de la Estética trascendental Kant plantea con claridad que la forma del fenómeno (el espacio) ordena y dispone en determinadas relaciones las sensaciones, esto es, la materia del fenómeno: "Llamo [...] forma del fenómeno aquello que hace que lo diverso del mismo pueda ser ordenado en ciertas relaciones" $(K r V$, A34/B20).

A su vez, en este parágrafo inicial, Kant traza la distinción entre la materia del fenómeno, las sensaciones y la forma de este, el espacio. Las primeras, al ser producto de los efectos que causan los objetos sobre nuestro aparato receptor ( $K r V$, A34/B20), son a posteriori. La 'forma del fenómeno' (el espacio), por el contrario, es la manera en que recibimos el material sensible y, en este sentido, para Kant, esta se encuentra $a$ priori en nuestra mente: las sensaciones solo pueden ser ordenadas y dispuestas en cierta

6 Para dar sustento a esta tesis, en el presente ensayo hablaré de manera indistinta del espacio como 'el orden de presentación de la diversidad sensible del fenómeno o de la intuición' con base en Falkenstein (1995) y del espacio como 'el orden de presentación de los particulares', a partir de lo argumentado por Lazos (2014). Sobre esta última tesis, el filósofo mexicano asevera lo siguiente: "Que sea un orden de presentación significa [...] que en el orden se incluye siempre un observador situado en un punto determinado de ese orden. Y que sea el orden de los particulares significa que todo lo que es un particular se nos presenta a los humanos ordenado espacialmente, i.e., con una localización determinada" (2014: 94). 
forma en algo que no puede ser, a su vez, sensación. Por ello, la materia de todo fenómeno nos viene dada únicamente a posteriori. Por el contrario, la forma del fenómeno debe estar completamente a priori dispuesta para el conjunto de las sensaciones en la mente.

Es aquí donde, por fin, hallamos lo que nos faltaba en el argumento que nos ocupa: la explicación del vínculo que Kant encuentra entre nuestra capacidad receptiva humana y el espacio qua forma de los fenómenos. El espacio es la forma en que recibimos el material sensible del fenómeno. Independientemente de cuáles sean, en particular, las sensaciones recibidas, la ordenación y disposición de estas será necesariamente espacial. Esto ocurre en cada episodio intuitivo: intuimos la diversidad sensible en relaciones de orden espacial. La manera específica de recibir las intuiciones sensibles bajo una ordenación espacial es un rasgo estructural de nuestra cognición. Esta tesis es expresada por Kant con mayor claridad líneas más adelante en el pasaje introductorio cuando, en referencia implícita al espacio, alude a la forma pura de las intuiciones sensibles: "la forma pura de las intuiciones sensibles en general, donde se intuye en ciertas relaciones toda la diversidad de los fenómenos, se hallará a priori en la mente" ( $K r V$, A21/B35; la cursiva es propia).7

Y a continuación nos hace ver que la figura y la extensión de un cuerpo pertenecen a la intuición pura; esta, en cuanto forma de la sensibilidad, tiene lugar en nuestra mente:

Así, al apartar de la representación de un cuerpo lo que el entendimiento piensa de él - sustancia, fuerza, divisibilidad, etc. - y al apartar igualmente lo que en dicha representación pertenece a la sensación —impenetrabilidad, dureza, color, etc.me queda todavía algo de esa intuición empírica, a saber, la extensión y la figura. Ambas pertenecen a la intuición pura y tienen lugar en la mente como mera forma de la sensibilidad, incluso prescindiendo del objeto real de los sentidos o de la sensación ( $K r V, \mathrm{~A} 21 / \mathrm{B} 35$; la cursiva es propia).

\footnotetext{
7 También es posible apreciar con mayor claridad que Kant se refiere a que el material sensible es intuido de manera ordenada en la nota que él mismo inserta al pie de página en A, inmediatamente después de la tesis que habla del espacio en cuanto "forma del fenómeno que hace que lo diverso del mismo pueda ser ordenado en ciertas relaciones". La nota al pie que el filósofo inserta dice que: "sea intuido como ordenado".
} 
El espacio es la forma de la sensibilidad; es a priori en cuanto a que antecede estructuralmente toda intuición externa, la hace posible. Se trata de un rasgo inherente a la sensibilidad de la especie humana, de ahí su carácter eminentemente subjetivo. Esto explica el argumento que se encuentra contenido en el cuerpo de la consecuencia (b). Para comprenderlo a cabalidad, es preciso añadir una premisa presupuesta en él: el espacio es la forma de la capacidad receptiva humana. El diagrama que muestra la estructura del argumento ubicado en el cuerpo de la consecuencia (b) referida a la subjetividad del espacio, con la inserción de la premisa implícita, es el siguiente:

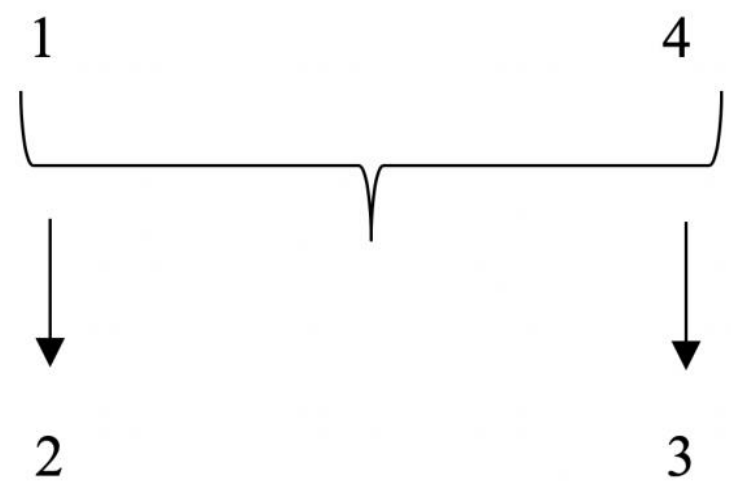

El (4) espacio es la forma de la capacidad receptiva humana.

De esta manera, a partir de la premisa implícita (4), en conjunto con la premisa (1) ("la receptividad del sujeto, cualidad consistente en poder ser afectado por los objetos, precede necesariamente a toda intuición de esos objetos"), se sigue que nos es posible comprender la naturaleza a priori del espacio (conclusión [2]) y el carácter relacional de este en cuanto intuición $a$ priori (conclusión [3]). El análisis de este argumento con base en el enlace que Kant establece entre la receptividad del sujeto y la tesis del espacio en cuanto forma de los fenómenos nos permite comprender por qué el espacio no es más que la condición subjetiva de la sensibilidad, como sustenta la presente consecuencia. Todo particular se presenta ante nuestra receptividad bajo una ordenación y disposición espaciales, es la manera humana de 
recibir el material sensible; el espacio es la condición subjetiva de la sensibilidad. 8

Ahora bien, la inclusión de la premisa implícita (4) permite entrever que bajo la óptica de que el espacio es trascendentalmente ideal, i.e., es condición de posibilidad de nuestra experiencia externa, la tesis epistemológica de la receptividad (nuestro conocimiento depende de que seamos afectados por los objetos) y la tesis de la naturaleza a priori del espacio en cuanto forma de los fenómenos (en cuanto orden de presentación de particulares) se implican mutuamente. Como veremos a continuación, precisamente a través del vínculo que existe entre ambas tesis, es posible apreciar con mayor nitidez que la idealidad trascendental del espacio en absoluto debilita, o incluso anula, el compromiso kantiano respecto de la realidad empírica del espacio en cuanto propiedad que corresponde necesariamente a los objetos físicos.

3. La tesis del carácter a priori del espacio en cuanto forma del fenómeno y la tesis de la receptividad: mutua implicación

Uno de los pasajes en los que es posible apreciar de manera más cristalina el vínculo de mutua implicación entre la TR y la TEF, se encuentra justamente en el parágrafo que sigue inmediatamente después de que Kant sostiene la subjetividad del espacio en la consecuencia (b).9 Vayamos a este nuevo parágrafo y observemos cómo es que la realidad empírica del espacio queda en pie al ir de la mano del idealismo trascendental:

Solo podemos, pues, hablar del espacio, del ser extenso, etc. desde el punto de vista humano. Si nos desprendemos de la única condición subjetiva bajo la cual podemos recibir la intuición externa, a saber, que seamos afectados por los objetos externos, nada significa la representación de espacio. Este predicado solo es

$8 \mathrm{Al}$ respecto Lazos señala que: "Que el espacio sea un orden de presentación de los particulares es algo que se puede afirmar al considerar las capacidades humanas para detectar relaciones espaciales $\mathrm{y}$, en ese sentido, vale solo desde el punto de vista humano: para decirlo provocativamente y no sin ambigüedad, la condición subjetiva es la condición humana (el mundo sub especie humanitatis)" (2014: 100).

9 En los Prolegómenos también podemos advertir con nitidez la mutua implicación que existe entre la tesis de la receptividad y la tesis del espacio en cuanto forma de los fenómenos, por ejemplo en la Observación I. En este pasaje, Kant señala que "el espacio no es otra cosa que la forma de todo los fenómenos externos, forma solo bajo la cual nos pueden ser dados objetos de los sentidos" (AA 04: 287) 
atribuido a las cosas en la medida en que estas se manifiestan a nosotros, es decir, en la medida en que son objetos de la sensibilidad. La forma constante de esa receptividad que llamamos sensibilidad es una condición necesaria de todas las relaciones en las que intuimos objetos como exteriores a nosotros y, si se abstrae de tales objetos, tenemos una intuición pura que lleva el nombre de espacio $(\mathrm{KrV}$, A27/B43).

La primera proposición es rotunda: la única manera en que podemos hablar de los objetos externos (los seres extensos) y del espacio es desde nuestra perspectiva humana; esta afirmación, como hemos visto, se sigue del carácter a priori del espacio en cuanto orden de presentación de particulares: recibimos la diversidad sensible del fenómeno bajo relaciones de adyacencia, la manera particular de recibir el material sensible constituye un rasgo estructural de nuestra sensibilidad (encuentra su asiento en el sujeto, $K r V$, B41); el espacio es la forma de la capacidad receptiva humana, es la única condición a través de la cual nos es posible (recibir) la intuición externa bajo el influjo que ejercen los objetos sobre nuestro aparato receptor. En este sentido, solamente desde el punto de vista humano podemos hablar de los objetos externos y del espacio. Podemos ver de manera más clara lo que aquí menciono en la oración condicional que el filósofo introduce enseguida de este primer aserto; en el antecedente de ella es posible apreciar la mutua implicación entre la tesis de la receptividad y la tesis del carácter a priori del espacio en cuanto forma de los fenómenos. Atendamos a esta relación: "Si nos desprendemos de la única condición subjetiva bajo la cual podemos recibir la intuición externa, a saber, que seamos afectados por los objetos externos, nada significa la representación del espacio" (KrV, A27/B43).

Para facilitar la lectura de este condicional, considero que la primera tarea es observar que "la representación del espacio" es el sujeto gramatical del consecuente. Este sujeto gramatical es definido en el antecedente por la función que cumple dicha representación en nosotros: "nada significa" si "nos desprendemos de la única condición subjetiva bajo la cual podemos recibir la intuición externa, a saber, que seamos afectados por los objetos externos". La representación del espacio es la única condición subjetiva en la que podemos recibir la intuición externa (es decir, es la manera en que se presenta ante nuestra receptividad todo particular, lo que refiere a la tesis del carácter a priori del espacio en cuanto forma del fenómeno) y la recepción 
de toda intuición externa solo tiene lugar si somos afectados por los objetos externos (lo que remite a la tesis de la receptividad). Al ser la forma de la capacidad receptiva humana la forma del sentido externo, el espacio es condición de posibilidad de la intuición externa; la manera en que recibimos esta es necesariamente espacial y ello implica ser afectado por los objetos, implica la tesis de la receptividad. Fuera de este marco, del papel que cumple la representación del espacio en cuanto condición de posibilidad de nuestra experiencia de objetos externos, nada es tal representación para nosotros, como afirma el consecuente del condicional que nos ocupa. En otras palabras, si perdemos de vista el papel que desempeña el espacio como condición a priori de nuestro conocimiento en virtud de las restricciones que impone la capacidad receptiva humana, la representación del espacio carece de significado.

Desde mi punto de vista, la clave para advertir que la TR y la TEF se implican mutuamente consiste en tener presente el carácter trascendental de la investigación kantiana en tanto que dicho estudio se ocupa de nuestro modo de conocer. Bajo el calificativo de 'trascendental' Kant caracteriza su propia indagación en cuanto dirigida a la facultad de conocimiento ( $c f r$. AA 04: 293), por lo que es totalmente explicable que en la cita que estamos analizando, fuera del papel que desempeña la representación del espacio en relación con el modo humano de conocer, esta nada signifique. En esa medida, afirmar que el conocimiento humano depende de que seamos afectados por los objetos - como sostiene la tesis de la receptividadimplica que la explicación de ello se debe a que la capacidad receptiva humana se encuentra estructurada de tal modo que toda intuición externa es recibida espacialmente, i.e., presupone la tesis de la anterioridad necesaria - en un sentido estructural- del espacio en cuanto orden de presentación de particulares. De la misma manera, la tesis del carácter a priori del espacio en cuanto orden de presentación de particulares presupone la forma espacial de nuestra receptividad $\mathrm{y}$, en función de este rasgo propio de nuestro modo de intuir, se sigue que solo podemos recibir la intuición externa si somos afectados por los objetos.

Observemos que la explicación tanto de la tesis epistemológica de la receptividad como del carácter a priori del espacio en cuanto orden de presentación de particulares se encuentra en la estructura de la capacidad receptiva humana, lo que en los términos que Kant emplea se traduce en la 
tesis acerca de que el espacio, al ser la forma de la receptividad ('la forma del sentido externo', 'la forma de los fenómenos', 'la forma de las intuiciones sensibles', 'la forma del fenómeno'), se encuentra a priori en nuestra mente. Tesis que, como señalé, se inscribe plenamente en la esfera de la investigación trascendental kantiana en torno a nuestro modo de conocer o, como señala el filósofo en los Prolegómenos, acerca de nuestra facultad de conocer.

Ahora bien, el que el espacio solo sea una condición subjetiva a partir de la cual es posible la intuición externa, i.e, que sea trascendentalmente ideal, en absoluto mina la realidad empírica de este en cuanto propiedad que pertenece "real y necesariamente al fenómeno", es decir, en cuanto propiedad que pertenece al objeto considerado en relación con nuestra forma de intuir; en la esfera de la investigación trascendental del sabio alemán, esta forma debe de buscarse "en el sujeto al que este [el fenómeno] se manifiesta" ( $K r V$, B55). En el seno de este estudio, el fenómeno es el objeto de nuestra sensibilidad, el objeto dado a nuestros sentidos externos: cuerpo situado espacialmente. De acuerdo con Kant, gracias al espacio podemos reconocer un objeto como 'externo'.10 Reconocer un cuerpo en cuanto objeto externo presupone necesariamente que es un objeto de la sensibilidad, un objeto dado a ella. Para Kant solo podemos hablar de objetos externos en la medida en que tales objetos "se manifiestan a nosotros", es decir, en la medida en que se trata de objetos de la sensibilidad, i.e., objetos que, en principio, tienen el poder de afectar nuestros sentidos: 'Este predicado ['objeto externo'] solo es atribuido a las cosas en la medida en que estas se manifiestan a nosotros, es decir, en la medida en que son objetos de la sensibilidad" (A27/B43).

Notemos cómo la noción misma de 'objeto externo', 'objeto de la sensibilidad', permite ver el compromiso kantiano frente a la realidad empírica del fenómeno; aquí el papel que juega la mutua implicación que existe entre la TR y la TEF es capital. Detengámonos un momento en la noción de objeto externo y pensemos qué significa esta para nosotros. En primera instancia, podemos decir que a través de ella nos referimos a un objeto que se presenta ante nuestra sensibilidad - ante nuestros órganos de los sentidos - ubicado en un plexo de relaciones espaciales respecto de

10 "Si las cosas son para nosotros objetos externos es solo gracias al espacio", afirma el filósofo alemán en A29. 
nosotros. Precisamente ese conjunto de relaciones de carácter espacial es la que define el objeto en cuanto cuerpo; esto porque para Kant un cuerpo se configura a través de relaciones entre sus partes (véase $K r V, \mathrm{~A} 283 / \mathrm{B} 339$ ) y, por ende, en cuanto externo, es decir, en cuanto ubicado fuera de la mente humana. Podemos tener experiencia espacial, podemos determinar las relaciones espaciales específicas que configuran un objeto externo $\mathrm{y}$, asimismo, las relaciones espaciales que existen entre este y nosotros gracias a que recibimos la diversidad sensible del fenómeno bajo una ordenación espacial y, a su vez, esto no ocurriría sin la presencia de objetos físicos que afectan nuestro aparato receptor, tal y como señala la tesis de la receptividad. En otras palabras, careceríamos de intuiciones externas que nos refieren inmediatamente a particulares sin la presencia de objetos físicos que afecten nuestra receptividad. La manera en que recibimos la diversidad sensible de toda intuición empírica11 es espacial, el espacio es la forma de la receptividad, es condición de posibilidad de nuestra experiencia espacial:

La forma constante de esa receptividad que llamamos sensibilidad es una condición necesaria de todas las relaciones en las que intuimos objetos como exteriores a nosotros y, si se abstrae de tales objetos, tenemos una intuición pura que lleva el nombre de espacio ( $K r V$, A27/B43).

Volvamos a esta cita y observemos cómo la idealidad trascendental del espacio, en cuanto condición subjetiva que hace posible nuestra experiencia espacial, en absoluto mina el compromiso realista del filósofo. Aquí es preciso centrar nuestra atención en las intuiciones externas: Kant parte de ellas y, bajo un ejercicio de abstracción, alude al espacio en cuanto 'intuición pura'. Esto corresponde plenamente con lo sustentado por el filósofo en el parágrafo introductorio. En el primer apartado, cuando Kant alude a la 'intuición pura', solo se refiere a la forma de la intuición empírica, no a una clase diferente de intuición.12 En este marco, si tenemos presente que para tener intuiciones sensibles requerimos ser afectados por

11 Recordemos que Kant habla de manera indistinta de la 'forma del fenómeno' y de la 'forma de las intuiciones sensibles' en el parágrafo introductorio.

12 No olvidemos que en el $\S 1$ el punto de inicio de Kant en la explicación sobre el espacio en cuanto intuición pura es la intuición empírica. Esto se aprecia, por ejemplo, en el pasaje en que el filósofo parte de la representación de un cuerpo y poco a poco aísla distintas representaciones hasta llegar a la figura y la extensión de este; propiedades que pertenecen al espacio en cuanto intuición pura (véase $K r V, \mathrm{~B} 35 / \mathrm{A} 21)$. 
los objetos, entonces el compromiso realista del filósofo es palmario en esta cita en la que, a su vez, habla del espacio en cuanto forma de la capacidad receptiva humana, i.e., en cuanto condición subjetiva de nuestra experiencia espacial. El realismo empírico de Kant en absoluto se ve opacado al ir de la mano del idealismo trascendental, sino que como he venido comentando - brilla junto a él.

Si nos ubicamos solo en el plano de la sensibilidad, a mi juicio las intuiciones empíricas $\longrightarrow$, de manera sencilla, las intuiciones- son, a diferencia de las sensaciones, el tipo de representaciones que revelan con mayor claridad el compromiso realista de Kant; esto, incluso, es aún más notorio en la mutua implicación que existe entre las tesis TR y TEF. Notemos el papel protagónico de las intuiciones en ambas tesis: la TR señala que careceríamos de intuiciones sin objetos externos que afectan a nuestros sentidos (lo que expresa el compromiso realista de Kant); a su vez, la TEF sostiene que la forma en que es recibida toda intuición es espacial (aserto que entraña el realismo kantiano en tanto que sin objetos externos en absoluto podríamos tener intuiciones ni, por tanto, podríamos mediante un ejercicio de abstracción hablar de la forma en que estas son recibidas; asimismo, recordemos que el componente material de las intuiciones, es decir, las sensaciones, corresponden a los efectos de los objetos externos sobre nosotros). La TR implica la TEF ya que el espacio es la forma en que es recibida toda intuición externa, es la condición bajo la cual somos afectados por los objetos; a su vez, la TEF implica la TR ya que no tendríamos intuiciones sin objetos externos que afectan a nuestra sensibilidad. En el núcleo de esta mutua implicación resplandece el realismo empírico en conjunción con el idealismo trascendental de Kant; esto, me parece, a partir del papel de las intuiciones en nuestra experiencia.

En suma, si tomamos en cuenta que para Kant (1) solo tenemos intuiciones si somos afectados por los objetos ( $K r V$, A19/B33); (2) las intuiciones refieren inmediatamente a tales objetos, "la intuición es el modo por medio del cual el conocimiento se refiere inmediatamente a dichos objetos" (a los objetos que han sido dados vía la sensibilidad, $\mathrm{KrV}$, A19/B33); y (3) que la explicación del carácter a priori del espacio en cuanto forma de las intuiciones, i.e., en cuanto orden de presentación de particulares, se encuentra en la constitución del sujeto ("la forma pura de las intuiciones sensibles en general, donde se intuye en ciertas relaciones toda 
la diversidad de los fenómenos, se hallará a priori en la mente", $K r V$, A21/B35), entonces, me parece que contamos con elementos necesarios para percatarnos del papel crucial del espacio en cuanto condición subjetiva, condición que hace posible nuestra experiencia de aquellas relaciones espaciales específicas bajo las cuales identificamos cualquier objeto como externo. Entre todas nuestras representaciones, solamente el espacio es condición de posibilidad de los objetos externos: "Exceptuando el espacio, no hay ninguna representación subjetiva y referente a algo exterior que pudiera llamarse a priori objetiva" ( $K r V$, A28/B44).

El espacio es una propiedad que "pertenece necesariamente al fenómeno o intuición de [los objetos externos]" aclara el filósofo a continuación de esta cita, en A29. Bajo este marco, el carácter subjetivo del espacio, en cuanto la manera humana de recibir el material sensible del fenómeno, permite identificar las propiedades espaciales específicas de los cuerpos — como la extensión y la figura - y, en esa medida, reconocer dicho objeto en tanto que externo.

Lo recién descrito marca la pauta para hacer una precisión indispensable: la tesis del espacio en cuanto forma del fenómeno, i.e., en cuanto orden de presentación de los particulares, únicamente señala que nuestra manera de recibir las sensaciones es espacial y que es a priori en tanto que, como vimos, es un rasgo estructural de nuestra receptividad a través del cual es posible tener experiencia espacial. Las sensaciones que, en especial, constituyen los elementos de la estructura, el lugar particular que ocupan dentro de ella y las relaciones entre estas, son a posteriori, provienen de los impactos de los objetos en nuestra capacidad receptiva y, en este sentido, dependen del mundo. 13

\footnotetext{
13 Sobre este tema la posición de Lazos es por completo clara: "Si bien el espacio es un orden de presentación que está presupuesto en toda percepción de objetos, la ubicación de los objetos y las relaciones espaciales que de hecho mantengan los objetos no están para nada dadas en la mente del sujeto. Puesto que la sensibilidad es receptiva, ella misma no puede nunca 'generar' los particulares mismos y su ubicación. La ubicación de los particulares, si bien presupone el espacio como un orden de presentación típicamente humano, solo puede provenir del impacto que tiene un trozo de mundo sobre nuestro aparato sensorial" (2014: 102). Por otra parte, esto mismo corresponde con lo que Isabel Cabrera señala acerca de que el carácter anticipatorio del espacio (en cuanto intuición a priori) de ningún modo determina el orden específico de los objetos; este es producto de la experiencia: "El espacio es anticipado solo como un ámbito de posibilidades y es la experiencia y, solo ella, la que nos dirá qué orden específico presentan sus objetos" (1994: 176).
} 
Con base en lo que he expuesto en el desarrollo de este apartado, el vínculo de mutua implicación que existe entre las tesis TR y TEF permite apreciar que la en apariencia 'descabellada' tesis kantiana de la subjetividad del espacio tiene su explicación — precisamente- en la estructura de la capacidad receptiva humana y, asimismo, que la alusión a ella corresponde plenamente con el propósito de la investigación trascendental que emprende el sabio de Königsberg, dirigida a la facultad humana de conocer. A su vez, hemos podido ver que la naturaleza eminentemente subjetiva del espacio en absoluto compromete la realidad empírica de este en cuanto propiedad que pertenece necesariamente al fenómeno - al objeto dado a nuestros sentidos - tal y como hemos visto en la presente sección.

\section{A manera de conclusión}

A partir de la reconstrucción que presento del argumento que aparece en el pasaje que corresponde a la segunda consecuencia que Kant deriva de la argumentación en torno al carácter a priori e intuitivo del espacio (consecuencia [b]), he mostrado que existe una relación de mutua implicación entre la tesis de la receptividad (TR) y la tesis del espacio en cuanto forma de los fenómenos, i.e., en cuanto orden de presentación de los particulares (TEF); y que esta relación se torna aún más evidente a partir del papel protagónico de las intuiciones en ambas tesis: la TR implica la TEF puesto que el espacio es la manera en que es recibida toda intuición externa, es la condición bajo la cual somos afectados por los objetos; del mismo modo, la TEF implica la TR ya que careceríamos de intuiciones sin la existencia de objetos externos que afectan a nuestra sensibilidad. A través de la mutua implicación entre ambas tesis es posible apreciar con mayor claridad que el idealismo trascendental kantiano respecto del espacio como forma de la intuición o forma del sentido externo es por completo compatible con la propuesta realista de Kant referida a la existencia del fenómeno en tanto que objeto dado a los sentidos. De lo expuesto en torno al espacio, en cuanto forma que contiene de manera a priori los principios que regulan las relaciones entre los objetos de la experiencia, es posible concluir - al menos parcialmente, ya que es preciso analizar el papel del tiempo en nuestro conocimiento empírico- que nuestra experiencia tiene un carácter indefectiblemente relacional: a través del espacio como la forma del sentido externo solo podemos tener representaciones de relación, de la 
relación del objeto con el sujeto. Ante el observador, el objeto se presenta bajo una ordenación y ubicación de carácter espacial. En el plano compartido entre el observador y el objeto de lo único que nos es posible tener conocimiento es de las propiedades relacionales de los objetos, como, por ejemplo, la figura y la extensión. Intentar penetrar en lo absolutamente interno del objeto para conocerlo escapa por completo a nuestras posibilidades humanas. No podemos sustraernos de la relación, del influjo que ejercen los objetos físicos sobre nuestro aparato receptor, sobre nuestros órganos sentidos, sobre nuestro cuerpo. Los límites y alcances de la experiencia incluyen, de manera ineludible, nuestra corporalidad.

\section{Referencias}

CABRERA, I.: "El espacio kantiano: interpretaciones recientes", Diánoia. Anuario de Filosofía 40 (1994) 143-176.

FALKENSTEIN, L.: Kant's Intuitionism. A commentary on the Transcendental Aesthetic, Toronto, University of Toronto Press, 1995.

KANT, I.: Gesammelte Schriften, Berlín, Königlichen Preißischen Akademie der Wissenschaften, Walter de Gruyter, 1900ss.

: Crítica de la razón pura, Madrid, Grupo Santillana, $2000\left(18^{\mathrm{a}}\right.$ ed.).

: Prolegómenos a toda metafísica futura que haya de poder presentarse como ciencia, Madrid, Ediciones Istmo, 1999.

LANGTON, R.: Kantian Humility. Our Ignorance of Things in Themselves, Oxford, Oxford University Press, 1998 [2001].

LAZOS, E.: Disonancias de la Crítica. Variaciones sobre cuatro temas kantianos, México, UNAM-IIF, 2014.

STRAWSON, P. F.: The Bounds of Sense. An Essay on Kant's Critique of Pure Reason, London, Routledge, 1966. 


\title{
La idealidad del tiempo, Gödel y la relatividad
}

\author{
GILBERTO CASTREJÓN 1
}

\begin{abstract}
Resumen
En la $K r V$ Kant plantea la idealidad del tiempo en términos de que no es algo que subsista por sí mismo. En este sentido, Gödel vio una reivindicación de Kant al encontrar algunas soluciones de las ecuaciones de campo de la relatividad. Pretendo llevar a cabo una actualización, a partir de la $K r V$, de la concepción kantiana del tiempo en Gödel, frente a críticas que consideran que este solo atendió a las 'A-series del tiempo', donde los eventos se ordenan en pasado, presente y futuro. La conclusión es que Kant sigue vigente, bajo ciertas condiciones, en la relatividad.
\end{abstract}

Palabras clave: tiempo, Kant, idealidad, Gödel, relatividad

\section{The ideality of time, Gödel and relativity}

\begin{abstract}
Kant poses the ideality of time in the $K r V$ to say that time is not something that subsists for itself. In this sense, Gödel approached a Kantian claim when he calculated some solutions of the relativity's field equations. I intend to update, from the $K r V$, the Kantian conception of time in Gödel, by paying attention to the critics that affirm that he just attended to the 'A-series of time', according to which the events are ordered in the sequence past, present, and future. My conclusion is that Kant remains in force, in some sense, through relativity.
\end{abstract}

Keywords: time, Kant, ideality, Gödel, relativity

\section{Introducción}

En el ámbito de la filosofía de la ciencia se considera a la Teoría General de la Relatividad (TGR) como la mejor teoría sobre el espacio y el tiempo. En

1 CICATA-Legaria, Instituto Politécnico Nacional (México). Contacto: gcastrejon@ipn.mx. 
este sentido, fue Kurt Gödel quien obtuvo ciertas soluciones de las ecuaciones de campo de Einstein, base matemática de la TGR, que posibilitaron especular sobre si realmente el tiempo es un 'ente del mundo', es decir, un ente objetivo, que existe independientemente de los objetos. Así, Gödel vinculó sus ideas con la filosofía de Kant.

En este trabajo, llevo a cabo primeramente una revisión de la concepción kantiana de la idealidad del tiempo, considerando que su fundamento estriba en que el tiempo no es algo que subsista por sí mismo, es decir, no es una substancia, ni una relación entre substancias. Una vez hecho esto, presento los principales conceptos de la TGR. De aquí, desarrollo las ideas de Gödel sobre el tiempo para, a su vez, atender a algunas críticas a este. Finalmente, ubico sus ideas frente a la filosofía de Kant, la cual, en ciertos aspectos, considero que sigue vigente.

\section{La idealidad del tiempo en Kant}

En términos generales, el carácter ontológico del tiempo se encuentra en la Exposición Metafísica ( $\mathrm{KrV}$, A31-32/B46-48), donde Kant desarrolla sus argumentos en cinco puntos, de los cuales los dos primeros se refieren a la condición a priori del tiempo:

El tiempo es una representación necesaria que sirve de fundamento de todas las intuiciones. Con respecto a los fenómenos en general, no se puede suprimir el tiempo mismo, aunque muy bien se puede sacar del tiempo los fenómenos. Por consiguiente, el tiempo está dado a priori ( $K r V$, A31/B46).

El punto tres lo ubica como posibilidad de toda experiencia, es decir: su representación no podría obtenerse de ninguna experiencia:

En esta necesidad a priori se funda también la posibilidad de principios apodícticos acerca de las relaciones del tiempo, o axiomas del tiempo en general [...] Estos principios valen como reglas bajo las cuales, en general, son posibles las experiencias; y nos instruyen antes de esta, y no mediante esta $(K r V, \mathrm{~B} 47)$. 
El punto cuatro sustenta la concepción del tiempo como intuición pura, pues toda representación del tiempo presupone una intuición pura a priori: "El tiempo no es un concepto discursivo o, como se suele decir, [un concepto] universal; sino una forma pura de la intuición sensible [...] Pero la representación que solo puede ser dada por un único objeto es intuición" ( $K r V$, A32). Finalmente, el punto cinco habla de la infinitud del tiempo, lo que sustenta asimismo que no puede ser concepto, pues toda "representación originaria tiempo debe ser dada como ilimitada" ( $K r V$, A32).

Resulta pertinente señalar que la idealidad del tiempo está ya presente en la Exposición Metafísica, si atendemos a que los argumentos de Kant, contenidos en los cinco puntos señalados, pueden presentarse en la siguiente estructura argumentativa:2

i) ¿Qué puede ser el tiempo? ¿Una substancia? ¿Una relación entre substancias? ¿O una condición subjetiva de representación? Lo que tiene que ver con las dos teorías sobre la naturaleza del tiempo vigentes en la época de Kant: la de Newton y la de Leibniz; siendo la última posibilidad la del propio Kant.

ii) ¿Cómo podríamos hacernos con la representación del tiempo? Si el tiempo fuera una substancia o una relación entre substancias, entonces obtendríamos la representación del tiempo mediante la experiencia. Pero a su vez, el tiempo es a priori.

iii) Ahora bien, dada su condición a priori, y no discursiva, no es posible obtener una representación del tiempo por medio de la experiencia. De esto último se concluye, simultáneamente:

iv) La idealidad: 'el tiempo no es una substancia ni una relación entre substancias'; y a su vez, la subjetividad: 'el tiempo es una forma subjetiva de representación'.

\footnotetext{
2 Efraín Lazos (2014) lleva a cabo una lectura de la exposición metafísica del espacio, donde plantea que, precisamente, el argumento sobre dicha exposición puede considerarse como una reductio, un dilema destructivo y tal que la estructura del argumento es análoga a como se presenta en los cuatro puntos (74-81). En este caso, he considerado que, efectivamente, la exposición metafísica sobre el tiempo también puede presentarse con dicha estructura, lo que permite separar la idealidad del tiempo de su subjetividad. Este último sentido es el que precisamente ha despertado diversas controversias sobre el carácter ontológico del tiempo.
} 
Así, Kant está estructurando un conjunto de argumentos que dan cuenta de la condición ontológica del tiempo: este no es una substancia ni una relación entre substancias, sino más bien una condición subjetiva de representación, una forma pura de la sensibilidad. En este sentido, mediante la estructura argumentativa de un 'dilema destructivo', Kant deduce simultáneamente el carácter subjetivo del tiempo y su idealidad. Ni la idealidad depende de la subjetividad, ni esta última depende de la primera. Llega asimismo —en la sección "Conclusiones a partir de los conceptos precedentes"- a plantear la 'idealidad transcendental del tiempo': 3

Le denegamos al tiempo toda pretensión de realidad absoluta, aquélla, a saber, por la que él, aun sin tener en cuenta la forma de nuestra intuición sensible, sería inherente a las cosas de manera absoluta, como condición o como propiedad. Tales propiedades, que corresponden a las cosas en sí, no pueden nunca sernos dadas por los sentidos. En esto consiste, pues, la idealidad trascendental del tiempo, según la cual este, si se hace abstracción de las condiciones subjetivas de la intuición sensible, no es nada, y no puede contarse entre los objetos en sí mismos ( $\sin$ la relación de ellos con nuestra intuición) ni como subsistente ni como inherente (KrV, A36/B52).

De lo anterior, el fundamento de la 'idealidad del tiempo' se refiere a que este no es ni una substancia, ni una relación entre substancias, es decir, no es un 'objeto' que subsista por sí mismo. Kantianamente: solo conocemos a los objetos como fenómenos y el tiempo es una condición para 'conocer temporalmente a dichos objetos'. Cabría aquí la pregunta: ¿el orden temporal es un orden propio del mundo? y, si fuera el caso, ¿cómo podríamos tener noción de modos temporales en los fenómenos, tales como la simultaneidad, el cambio o la sucesión? El orden temporal lo pone la sensibilidad humana. Esto es, el tiempo, como forma de la sensibilidad, hace posible la ordenación de los fenómenos. Aunque, ¿cómo es que podemos

3 Lisa Shabel (2010: 108) considera que el argumento de la idealidad del tiempo se desenvuelve similarmente al de la idealidad del espacio: "Esta es la tesis de Kant de la idealidad trascendental del espacio (la cual se aplica también para el tiempo), la cual él expone inmediatamente al final de las exposiciones Metafísica y Trascendental, en una sección titulada: 'Conclusiones a partir de los conceptos"" ["This is Kant's thesis of the trascendental ideality of space (which holds also for time), which he states immediately upon concluding the Metaphysical and Trascendental Expositions, in a section entitled 'Conclusions from the above concepts"']. 
ordenar dichos fenómenos? En la Deducción Trascendental4 Kant nos da una explicación de cómo los conceptos puros del entendimiento (categorías) pueden referirse a priori a objetos; es decir, está presentando un criterio de objetividad del conocimiento humano. Construimos un orden temporal de los fenómenos mediante la 'acción' de las categorías de relación, 5 el esquematismo6 y las analogías de la experiencia.7 Cabe señalar que las analogías de la experiencia constituyen tres principios que fundamentan la posibilidad de constituir objetos de experiencia. "Ellas nos muestran que ciertos principios son requeridos en orden para fundamentar determinaciones temporales acerca de objetos" (Guyer 1987: 207). Así las cosas, la manera en que, temporalmente, se ordenan los fenómenos, depende de la experiencia. Es decir, en la experiencia ordenamos temporalmente los fenómenos. El carácter temporal de los fenómenos es algo que se presenta en la experiencia. Ahora bien, aceptando el criterio kantiano de 'objetividad temporal', cabría esperar que: las relaciones pasadas, presentes o futuras (Aseries del tiempo8), así como las de antes, ahora y después (B-series del tiempo9), correspondan a series temporales de la experiencia del mundo. Asimismo, la subjetividad del tiempo implica que el mundo es temporal y que, a su vez, el orden temporal del mundo es algo que puede conocerse.

4 "Llamo a la explicación de la manera como conceptos pueden referirse a priori a objetos, la deducción trascendental de ellos, y la distingo de la deducción empírica, que muestra la manera como un concepto ha sido adquirido por experiencia y por reflexión sobre esta, y que por tanto no concierne a la legitimidad, sino al hecho por el cual se ha originado la posesión" ( $K r V$, A85).

5 De la relación: De inherencia y subsistencia, de causalidad y dependencia, de comunidad. "Las categorías, por medio de la intuición, no nos suministran tampoco conocimiento alguno de las cosas, salvo solo mediante la aplicación posible de ellas a la intuición empírica; es decir, ellas sirven solo para la posibilidad del conocimiento empírico. Pero este se llama experiencia. Por consiguiente, las categorías no tienen ningún otro uso para el conocimiento de las cosas, salvo solo en la medida en que estas puedan ser tomadas como objetos de una posible experiencia" $(\mathrm{KrV}, \mathrm{B} 148)$.

6 "Para relacionar las categorías a la experiencia, ellas deben cada una tener un 'esquema' o ser 'esquematizadas'. Hablando en general, el esquema de una categoría es una interpretación de la categoría que hace su aplicación a la experiencia fácil de captar" (Dicker 2004: 66). En palabras de Kant, el esquematismo "trata de la condición sensible solo bajo la cual pueden ser empleados conceptos puros del entendimiento" ( $K r V$, A136/B17).

7 Las analogías de la experiencia constituyen tres principios que fundamentan la posibilidad de constituir objetos de experiencia. "Ellas nos muestran que ciertos principios son requeridos en orden para fundamentar determinaciones temporales acerca de objetos" (Guyer 1987: 207).

8 Una A-serie de tiempo debe entenderse como un 'flujo' que va del pasado, pasando por el presente, al futuro. Implica que el tiempo 'contiene' una transición o sucesión, que este se mueve de 'tiempo en tiempo'. Asimismo, implica concebir una línea abierta de tiempo, causal en términos kantianos, pues este va del pasado al futuro.

9 Las B-series de tiempo se refieren a que todos los eventos son ontológicamente posibles, es decir, todos son reales. Esto implicaría una identidad y unicidad para cada instante de tiempo; por algo los eventos pueden agruparse en antes, ahora y después, lo cual puede resultar contrario a la idea de que 'el tiempo fluye', propia de las A-series. Para muchos autores, las B-series son las que más se adaptan a la idea de tiempo derivada de la TGR. 
Cabe aclarar que se afirma el 'orden temporal del mundo', pero no que exista el tiempo como un ente del mundo. La anterior afirmación sustenta lo que kantianamente sería la idealidad del tiempo: no es una substancia, ni una relación entre substancias.

Hablar de propiedades como el orden temporal, la 'dirección del tiempo' y el 'paso del tiempo' [passage], es compatible con las A-series del tiempo,10 a la vez de con el modelo de objetividad kantiano vinculado a la noción de tiempo, como se ha visto. Sin embargo, uno de los inconvenientes es que lo anterior resulta controversial con el 'carácter geométrico del tiempo',11 como es común en la TGR; aspecto más compatible con las Bseries del tiempo. Aun así, la idealidad del tiempo, como la he caracterizado a la sazón de Kant, juega un rol fundamental en las ideas de Gödel.

\section{Conceptos básicos de la Teoría General de la Relatividad (TGR)}

La TGR constituye la base de la cosmología moderna. En términos generales, se cree que dicha teoría ha contribuido a configurar una idea precisa sobre lo que son el espacio y el tiempo físicos, en términos de la entidad espacio-tiempo. Esta teoría le atribuye una estructura geométrica intrínseca y objetiva al espacio-tiempo y, asimismo, "la distribución de la materia influye en la geometría del espacio-tiempo, pero la distribución de la materia no determina la geometría del espacio-tiempo" (Maudlin 2014: 198). Lo anterior está relacionado con las ecuaciones de campo de Einstein, base matemática de la TGR.

\footnotetext{
10 En términos kantianos, la "sucesión temporal" puede identificarse en el argumento de la "segunda analogía de la experiencia", específicamente en el Principio de la sucesión temporal según la ley de la causalidad: "Todas las alteraciones suceden según la ley de la conexión de la causa y el efecto" ( $\mathrm{Kr} V$, B232). Ella precisamente es compatible con la sucesión temporal sustentada en las A-series temporales.

11 Hablar del 'carácter geométrico del tiempo' es referirse a cómo la estructura de la variedad diferenciable $M$ (tres dimensiones espaciales y una temporal), que es una estructura geométrica, define una especie de 'tiempo curvo'. En otras palabras, hay ciertos espacio-tiempos asociados a aspectos epistémicos de la TGR donde existen líneas temporales cerradas, como en el caso de las especulaciones de Gödel. Cabe señalar aquí que un aspecto epistémico de la TGR es que un objeto masivo curva la dimensión del tiempo y las tres dimensiones del espacio. En la sección cuarta se verá con más detalle esta idea.
} 
Así, tomando como base una "explicación de la gravedad, con relación a la curvatura del espacio-tiempo", Einstein (2005: 435-445) propuso los siguientes principios, 12 (véase Hacyan 2013; Wald 1984):

i) El espacio-tiempo corresponde a una variedad riemanniana13 $M$ de dimensión 4 (con tres dimensiones espaciales y una temporal), esto es, una 'variedad diferenciable' 14 cuya métrica,15 en forma general, se expresa por $d s 2=\sum 14 g_{\mu v} d x_{\mu} d x_{v}$. En dicha variedad está definida localmente una métrica lorentziana (la de la relatividad especial).

ii) Principio de equivalencia. Los campos gravitacionales 16 son indistinguibles, es decir, no pueden distinguirse de las fuerzas ficticias que aparecen en todo sistema de referencia17 acelerado. La aceleración gravitacional depende únicamente del campo gravitacional; por algo, en la presencia de dichos campos, un cuerpo describe una geodésica, 18 es decir, un campo gravitacional curvo al espacio-tiempo,19 y de ahí la trayectoria del cuerpo al moverse.

12 De manera análoga, la relatividad especial se sustenta en dos principios: i) la equivalencia de todos los marcos inerciales y ii) la constancia de la velocidad de la luz. Sobre la base de estos dos principios es posible derivar las transformaciones de Lorentz, un conjunto de ecuaciones que relacionan un grupo de coordenadas con otro grupo de coordenadas.

13 En términos generales, una variedad riemanniana corresponde a una generalización del espacio euclidiano en la cual se generaliza la métrica. Por ejemplo: $R 2$, el plano, es una variedad diferenciable. $R 3$, el espacio tridimensional, también sería una variedad diferenciable.

14 Una variedad diferenciable es una variedad topológica (variedad de Riemann) tal que pueden extenderse sobre esta las nociones del cálculo diferencial, ya definidas en espacios euclidianos. En la variedad diferenciable pueden definirse funciones diferenciables, a la vez que campos de tensores diferenciables.

15 Una métrica corresponde a una 'función distancia' que mide la distancia entre dos elementos de un conjunto. En el caso de espacios geométricos, la métrica es una función que define la distancia entre dos puntos. En $R_{2}$ (plano cartesiano), por ejemplo, la 'función distancia' entre el punto $P\left(x_{l}, y_{1}\right)$ y el punto $Q\left(x_{2}, y_{2}\right)$ es $d(P, Q)=\left[\left(x_{2}-x_{1}\right) 2+\left(y_{2}-y_{1}\right) 2\right]^{1 / 2}$.

16 Un campo gravitacional corresponde a un cúmulo de fuerzas en una cierta distribución espaciotemporal que representa a la gravedad. Es una cantidad física que puede medirse en una región y que depende de la masa de un objeto.

17 Los sistemas de referencia son usados en física como una convención para situar a un 'observador' y que este pueda medir ciertas cantidades físicas como la posición, la velocidad, la aceleración, etc. Pueden considerarse sistemas de referencia inerciales (en reposo) o en movimiento. La representación gráfica de un sistema de referencia puede hacerse mediante un sistema de coordenadas, como el plano cartesiano.

18 La geodésica es la línea más corta que une a dos puntos del espacio. En el caso de los espacios geométricos a los que se refiere la TGR, las geodésicas serían 'líneas' curvas.

19 En diversa literatura sobre relatividad se presenta esta parte de la teoría en términos de que la presencia de materia-energía constriñe la estructura del espacio-tiempo; por algo este se curva. 
iii) Principio de covarianza. Las leyes de la física son las mismas en todos los sistemas de referencia, ya sea inerciales o acelerados. Todos los sistemas de referencia son indistinguibles y equivalentes.

De aquí podemos remitirnos a las ecuaciones de campo, las cuales corresponden a un conjunto de diez ecuaciones en derivadas parciales no lineales que, en términos generales, describen la gravedad como el resultado de la curvatura del espacio-tiempo debido a la presencia de materia y energía, o del campo gravitacional. Las ecuaciones de campozo son:

$R \mu v-(1 / 2) g \mu v R=\left(8 \pi G / c_{4}\right) T \mu v(1)$

$R \mu v$ : Tensor de Ricci.

$g \mu v$ : Tensor métrico $\left(d s 2=\sum \mu, v=03 g \mu v d x_{\mu} d x_{v}\right)$.

$T \mu v$ : Tensor energía-momento.

$G$ : Constante gravitatoria.

$R$ : Curvatura escalar.

$c$ : Velocidad de la luz.

$\mu, v=0,1,2,3$.

i) El Tensor de curvatura de Ricci $R \mu v$ es una magnitud tensorial,21 con 10 componentes, combinación de las componentes del tensor de Riemann. Este último está conformado, en un espacio de 4 dimensiones, por 20 componentes linealmente independientes. A su vez, el tensor de Riemann determina la estructura del espaciotiempo.

20 En la versión de las ecuaciones de campo que involucra lo que se conoce como 'constante cosmológica': $\Lambda$, en el lado izquierdo de las ecuaciones de campo, se suma al término: $\Lambda g_{\mu v}$. La constante cosmológica fue incluida por Einstein con la finalidad de obtener una solución de las ecuaciones de campo que diera un universo estático.

21 Una magnitud tensorial caracteriza propiedades o comportamientos físicos que son modelados mediante un conjunto de números en una matriz (arreglo rectangular de números). Los números de la magnitud tensorial pueden cambiar de acuerdo a la elección de un sistema de referencia distinto al inicial y que puede estar en movimiento y en distinta dirección. 
ii) $R$ es la curvatura escalar. Corresponde a la traza invariante de la curvatura de Ricci, con respecto a una métrica específica.

iii) $T \mu \nu$ es el tensor de energía-momento, el cual contiene la información de la presencia, la densidad y la distribución de la energía y la materia en cada punto del espacio-tiempo $(M)$.

iv) El tensor métrico $g \mu v$, asociado a la métrica, precisamente define la estructura del 'campo gravitacional' (es muy común en la literatura sobre la TGR asociar tal tensor métrico a las propiedades de un campo gravitacional), es decir, contiene la información correspondiente a cada punto del espacio-tiempo $(M)$.

De forma compacta, puede presentarse a las ecuaciones de campo como:

$$
G \mu \nu=8 \pi k T \mu \nu(2)
$$

Curvatura del espacio-tiempo=Densidad energética de materia.

En tal teoría, los efectos de la gravedad definen la curvatura del espaciotiempo, la variedad diferenciable $M$. Dicha variedad constituye a su vez un espacio semi-euclidiano, con tres dimensiones del espacio y una dimensión del tiempo. Basta decir que, de acuerdo a la TGR, la presencia de materia curva en el espacio-tiempo y la estructura geométrica de este, al curvarse, hace que los cuerpos describan geodésicas en su movimiento. Esto es: un objeto masivo curva la dimensión del tiempo y las tres dimensiones del espacio, acorde a las ecuaciones de campo de Einstein. Cada solución de las ecuaciones de campo define un cierto espacio-tiempo, con una estructura geométrica intrínseca. Asimismo, una solución de dichas ecuaciones permitirá establecer condiciones observables, las que son verificadas por medio de los test, es decir, una verificación experimental.

Ahora bien, si hay ausencia de materia: 


$$
R \mu \nu-(1 / 2) g \mu \nu R=0(3)
$$

Esta nulidad no implica que el espacio-tiempo pueda ser plano; en el vacío (ausencia de materia), el tensor de curvatura de Ricci es cero en todas partes, es decir, todas sus componentes son cero. Lo que sí podría implicar que el espacio-tiempo sea plano es que las 20 componentes del tensor de Riemann sean cero. Además, dado que en el lado derecho de las ecuaciones de campo tenemos al tensor de energía-momento $T \mu \nu$, puede entenderse que mientras más materia y energía haya, mayor será la curvatura. Cabe aclarar que la distribución de materia y energía no determina la estructura geométrica del espacio-tiempo, únicamente la constriñe, ya que si $T \mu \nu=0$, una solución de las ecuaciones de campo resulta ser el espacio-tiempo de Minkowski de la relatividad especial, pero no es la única solución de las ecuaciones para este caso.

A su vez, para encontrar una solución de las ecuaciones de campo se deben considerar condiciones de contorno, esto es, condiciones en ciertas regiones del espacio-tiempo, dado que, por ejemplo, el espacio-tiempo es más curvo en regiones cercanas a una estrella y la curvatura va desvaneciéndose a la distancia de la estrella, en cuyo caso podría considerarse un espacio-tiempo asintóticamente plano.

De todo lo anterior puede identificarse que, dado el aspecto geométrico del espacio-tiempo, la dimensión temporal también se ve afectada por la presencia de materia, por lo que surge la cuestión de si cualquier espacio-tiempo curvo resulta compatible con las B-series temporales y, a su vez, con las A-series temporales. Principalmente, en toda solución de las ecuaciones de campo, debe aceptarse que el tiempo fluye y va del pasado al futuro, pasando por el presente; lo que también sustenta la idea de líneas temporales abiertas, es decir, que el tiempo solo fluye del pasado al futuro: idea intuitiva que tenemos del tiempo y, al mismo tiempo, ad hoc al modelo de objetividad temporal kantiano (ver sección 2), acorde asimismo con la noción de tiempo cósmico universal.22 ¿Será entonces el concepto de tiempo, en Kant, compatible con el concepto de tiempo que se deriva de la TGR?

22 El que se considera como tiempo objetivo, que define una línea temporal abierta, la cual va del pasado al futuro y es independiente del tiempo propio de cada sistema de referencia o sistema coordenado. 
Gödel se dio a la tarea de analizar lo anterior, entre otros aspectos. Pero a su vez, tuvo la intuición, dadas las soluciones a las ecuaciones de campo que él obtuvo, de que en la TGR la noción de tiempo que más se deriva de esta posee rasgos kantianos.

\section{Las ideas de Gödel}

El tratamiento que Gödel dio al problema del tiempo en el contexto de la TGR está referido a unas soluciones que obtuvo de las ecuaciones de campo.

La TGR es la base de la cosmología moderna y ciertas soluciones de las ecuaciones de campo se considera que representan la forma del universo. Así, dichas soluciones atienden a lo siguiente: 'Principio cosmológico', a gran escala, i) el universo es espacialmente homogéneo, y (ii) el universo es espacialmente isotrópico (el mismo para cualquier observador y en cualquier dirección).

En este sentido, en su artículo "Un ejemplo de un nuevo tipo de soluciones cosmológicas de las ecuaciones einstenianas del campo gravitatorio" (2006a), Gödel encuentra una solución de las ecuaciones de campo donde se observa un espacio-tiempo que no cumple completamente con el principio cosmológico, ya que el universo de Gödel: i) es homogéneo, ii) es infinito, iii) tiene una curvatura constante, iv) es estacionario (no admite expansión) y v) no da cuenta del desplazamiento hacia el rojo del espectro de la luz. Asimismo, se considera: i) que cada punto del espacio-tiempo es un evento y ii) que dos eventos A y B están unidos por un intervalo temporal I(A,B)23 (o espacial).

23 En la relatividad especial se define el intervalo relativista invariante por $\mathrm{I}(\mathrm{A}, \mathrm{B})=\left[(T(\mathrm{~A})-T(\mathrm{~B}))_{2}-\right.$ $\left.(X(\mathrm{~A})-X(\mathrm{~B}))_{2}-(Y(\mathrm{~A})-Y(\mathrm{~B}))_{2}-(Z(\mathrm{~A})-Z(\mathrm{~B}))_{2}\right]^{1 / 2}$, y en forma diferencial es $d I=\left(d T_{2}-d X_{2}-d Y_{2}-d Z_{2}\right)^{1 / 2}$; para la

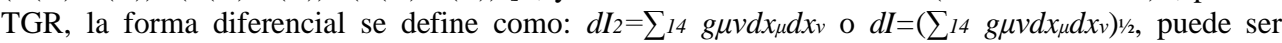
también del lado izquierdo $d s$ o $d s 2$, como generalmente se usa en la notación. Ahora bien, un intervalo temporal, desde el origen de un sistema de coordenadas, en relatividad especial, y un evento A es tal que $\mathrm{I}(\mathrm{A}, 0)=\left[(T(\mathrm{~A})-T(0))_{2}-(X(\mathrm{~A})-X(0))_{2}-(Y(\mathrm{~A})-Y(0))_{2}-(Z(\mathrm{~A})-Z(0))_{2}\right]_{1 / 2}$, es lo que se llama un 'intervalo cero', para todos los eventos (puntos) A, y es tal que $\mathrm{I}(\mathrm{A}, 0)=0$; y habría que aclarar que, como dice Maudlin (2014: 122): "Las distancias entre los puntos en un diagrama de espacio-tiempo no se corresponden de forma directa con los intervalos entre los eventos representados". 
Si $\mathrm{I}(\mathrm{A}, \mathrm{B})<0$, tipo tiempo (no hay simultaneidad). El orden temporal es invariante, digamos que $\mathrm{A}$ precede a $\mathrm{B}$ en todos los marcos de referencia. Ambos eventos están causalmente conectados.

Si I(A,B)>0, tipo espacio (no hay relación causal). No puede distinguirse si A precede a $\mathrm{B}$ o viceversa.

De lo anterior:

T1: En el universo de Gödel son posibles las líneas de universo de tipo temporal, en donde $\mathrm{A}$ es anterior a $\mathrm{B}$ (pasado de $\mathrm{B}$ ), mientras que en otra línea A es posterior a B (pertenece al futuro de B).24 Esto es debido a la geometría del espacio-tiempo, solución de las ecuaciones de campo que Gödel encontró. Una analogía de este universo puede verse en un espacio curvo de dimensión 2, que sería la superficie de una esfera, donde existen líneas cerradas (geodésicas) que van del polo norte, pasando por el polo sur y llegando al mismo polo norte. Si consideramos que tales líneas representan la 'coordenada temporal'; y a su vez, la línea del ecuador sería un ejemplo de la 'coordenada espacial'. Con la analogía, dada la línea temporal cerrada, ¿qué puntos sobre dicha línea temporal pueden considerarse pasado? ¿Cuáles presente, cuáles futuro?

T2: A su vez, existen líneas cerradas de tiempo, por lo que puede concebirse que no existe un tiempo absoluto, un tiempo cósmico universal, a diferencia de lo que se observa en ciertas soluciones de las ecuaciones de campo, basadas en el principio cosmológico. 25 Para encontrar soluciones a las ecuaciones de campo, se supone un tiempo cósmico universal, con lo que se da por hecho que existe un pasado y un futuro, se supone también que el tiempo 'fluye' en una única dirección (del pasado al futuro).

Todo lo anterior podría parecer que entra en contradicción con la idea kantiana del tiempo vinculado a la segunda analogía de la experiencia,

24 Para el caso de si $\mathrm{I}(\mathrm{A}, \mathrm{B})>0$.

25 Retomando la analogía de la superficie de la esfera, como un espacio-tiempo curvo de dimensión 2, se considera que los espacio-tiempos curvos que atienden al principio cosmológico son aquéllos cuya topología (forma) obedece a un tipo paraboloide hiperbólico que se asemeja a la superficie de una silla de montar. En tal superficie, sea cual sea la dirección que se asocie a la coordenada temporal, esta corresponde a una parábola que no es una curva cerrada. 
el Principio de la sucesión temporal según la ley de la causalidad: "Todas las alteraciones suceden según la ley de la conexión de la causa y el efecto" $(K r V$, B232). Aquí, Kant nos proporciona un criterio de la sucesión temporal objetiva, en la experiencia. Sin embargo, cabe aclarar que lo que está en juego no es el criterio de objetividad de la epistemología kantiana. Desde los avances de las dos grandes teorías de la física moderna, la mecánica cuántica y la relatividad, parece que la primera teoría 'viola' el principio de la primera analogía de la experiencia, a la vez que el principio de causalidad, y la relatividad, entonces, el 'principio de la sucesión temporal', entre otros aspectos. A su vez, dichos avances han traído a colación el que se pueda plantear la pregunta: ¿cómo puede constituirse una experiencia de fenómenos que no atienden al modelo kantiano, siendo que las teorías de la física moderna han posibilitado llevar a cabo dichas experiencias? Los problemas derivados de esta última cuestión rebasan los alcances del presente artículo. Regresando a Gödel, a pesar de que hasta aquí pareciera que sus resultados contradicen a Kant, para el autor no es así.

En su artículo "Una observación sobre la relación entre la teoría de la relatividad y la filosofía idealista" (2006b), Gödel obtiene las consecuencias filosóficas del primer artículo mencionado, para lo cual, basta señalar que: i) el autor entiende por filosofía idealista aquella que niega la realidad objetiva26 del tiempo y, por ende, la del cambio.27 Ejemplo: la filosofía de Kant. Esta afirmación puede resultar una tanto controversial, pues pareciera que Gödel entiende a Kant como un 'fenomenista', tal que concebiría que nuestra experiencia temporal de los fenómenos no es objetiva, sino una apariencia, aspecto por lo demás inconsistente con la filosofía kantiana del conocimiento. Lo que está en juego en la interpretación de Gödel no es ni un cuestionamiento de dicha filosofía ni una mala interpretación de Kant, sino el hecho de que en la TGR pareciera

${ }_{26}$ Por 'realidad objetiva' hay que entender uno de los postulados básicos de todo realismo científico: existe una realidad externa a nosotros, y las teorías de la ciencia dan cuenta fiel de esta. Lo que en el caso del tiempo implicaría que la TGR da cuenta de la realidad objetiva del tiempo.

27 L. Nathan Oaklander (2004: 20) señala que el problema del cambio enraíza dos aspectos básicos: i) por un lado, el cambio requiere 'similaridad', igualdad [sameness], es decir, una cosa que cambia debe ser una y la misma antes y después del cambio; si no es así, tendríamos dos cosas con propiedades distintas; y ii) el cambio debe requerir diferencia [difference], es decir, si algo está cambiando, ese algo debe tener una propiedad y posteriormente una propiedad distinta e incompatible: una manzana cambia de verde a roja, pero ¿permanece siendo una y la misma cosa? A su vez, se debe introducir al tiempo. Como se ha mencionado, muchos autores consideran que las Bseries de tiempo son las que mejor se adaptan a la TGR, con lo que resulta controversial la idea de cambio en dicho contexto. 
que con la idea de tiempo no nos estamos refiriendo a algún 'ente en el mundo', algo objetivo que existe, del cual podemos dar cuenta. Todo esto estaría a su vez vinculado a un realismo científico respecto a la condición de verdad de una teoría como la TGR; específicamente a si tal teoría resuelve el problema sobre la naturaleza del tiempo. Dicho problema no es tratado en el presente trabajo. ii) Con todo lo anterior, para Gödel podría concluirse que: el tiempo es no objetivo, es decir, no existe substancialmente, ni como una relación entre substancias. Lo que nos resta es vincularlo a la filosofía de Kant.

Gödel parte del análisis de la simultaneidad en la relatividad especial, lo que para él implica una relatividad de la sucesión temporal, ya que en su modelo puede darse que si el suceso A es causalmente anterior a $\mathrm{B}$, para un observador,28 para otro observador puede que sea lo contrario. Esto es, A y B no son simultáneos, e incluso no puede afirmarse que A ocurrió antes que $\mathrm{B}$, desde la perspectiva de distintos observadores.

En este último sentido, el argumento de Gödel es que el cambio solo es posible a través de lapsos de tiempo (estratos de 'ahoras' que existen sucesivamente).29 Pero debido a la relatividad de la simultaneidad, no es posible, entonces, establecer dichos lapsos de tiempo. Así, concluye, en primera instancia, que cada observador tiene su sistema de estratos de 'ahoras', por lo que no es posible aceptar que exista un sistema de lapsos de tiempo privilegiado, en contradicción con los modelos que consideran un 'tiempo cósmico universal' y en concordancia con las soluciones que él obtuvo de las ecuaciones de campo.

Recordemos que se pueden obtener ciertas soluciones de las ecuaciones de campo donde los tiempos locales de todos los observadores concuerdan con un tiempo universal (el 'tiempo cósmico'), como es común entenderlo en los textos sobre relatividad, pues, debido a la concordancia de las soluciones de las ecuaciones de campo con respecto a las observaciones, no hay razones para abandonar la suposición de un tiempo cósmico

\footnotetext{
28 Por observador no debe entenderse aquí un 'sujeto cognoscente'. Un 'observador' puede ser un reloj colocado en una 'línea de mundo' que mide un intervalo temporal.

29 Parecería que con esta concepción lo que se está haciendo es declarar que existen entidades temporales intrínsecas, lo cual de nuevo nos conduce a una especie de substancialización del tiempo. Así lo han interpretado autores como Nathan Oaklander (2004). Resulta más pertinente entender que Gödel se está refiriendo a 'propiedades temporales emergentes'.
} 
universal. Con todo, para Gödel, lo anterior puede ponerse en cuestión debido a las distintas soluciones de las ecuaciones de campo, en especial a las que él encontró, donde se muestra la posibilidad de universos rotatorios (estáticos y homogéneos). Asimismo, por lo ya dicho sobre la simultaneidad y los lapsos de tiempo, en su modelo no es posible definir un tiempo global para los distintos observadores locales (véase $T 1$ y T2). Además, en los universos rotatorios es posible hacer un viaje de ida y vuelta, es decir, es posible viajar a cualquier región del pasado, presente y futuro y volver al mismo punto. Sin embargo, esto puede conducir a absurdos lógicos.

Así, del conjunto de conjeturas anteriores Gödel extrae las siguientes conclusiones: i) no hay razones suficientes para admitir un lapso de tiempo objetivo, principalmente por las consecuencias sobre la posibilidad de los universos rotatorios. ii) Sin embargo, nuestro universo no puede llegar a representarse como el que se muestra en las soluciones del primer artículo, puesto que el universo en el que vivimos está en expansión, y hay corrimiento hacia el rojo. Aunque también hay soluciones para universos en expansión, y en estos puede que tampoco exista un tiempo absoluto. iii) Debido a la compatibilidad de las leyes de la naturaleza, para el caso de universos donde no se puede definir un tiempo absoluto, es posible traer a la luz ciertas consecuencias sobre los universos donde sí se puede definir un tiempo absoluto, pues implica establecer que un tiempo absoluto está transcurriendo y que la existencia o no de un lapso de tiempo objetivo depende del modo particular en que tanto la materia y su movimiento están distribuidos en el universo. Así, el tiempo objetivo sería una consecuencia contingente de la distribución fáctica de la materia en el universo; 30 algo que emerge y, a su vez, pertenece al 'orden temporal del mundo', en términos de cómo 'experimentamos' dicho orden, pero que no da cuenta de la existencia del tiempo como algo que subsiste por sí mismo.

30 Cabe aquí una precisión dada por Tim Maudlin (2014: 250): "En un cierto sentido es obvio que cualquier geometría del espacio-tiempo puede hacerse de manera que sea coherente con la ecuación de campo de Einstein. Tomamos una métrica arbitraria, calculamos el tensor de curvatura einsteiniano, y entonces usamos la ecuación de campo para definir el tensor de estrés-energía. Así que cuando juzgamos que algunas geometrías 'no son físicas' nos basamos en que consideramos que algunos tensores de estrés-energía no son físicos. Una condición estándar, la llamada condición de energía débil, esencialmente exige que en los marcos de Lorentz locales la densidad de la energía local no sea negativa [...] Por lo tanto, el intento de encontrar un escenario físico plausible para la formación de curvas cerradas de tipo tiempo significa encontrar una que satisfaga condiciones de energía razonables, que dé como resultado una solución estable y que no involucre curvas cerradas de tipo tiempo que ya se encuentren en las condiciones iniciales”. La cuestión aquí sería: ¿las soluciones de Gödel cumplen con las condiciones especificadas por Maudlin? 
Entre otras cosas, el trabajo de Gödel deja claro que en la TGR puede que no sea posible deducir un concepto de tiempo lineal (que va del pasado al futuro, pasando por el presente y, a la vez, posee una dirección) y que pueda considerarse una representación de un tiempo objetivo, dadas las soluciones a las ecuaciones de campo que él encontró. De ello se entendería que la naturaleza objetiva del tiempo31 resulte ser un aspecto controversial de la realidad. ¿El tiempo existe? ¿Es algo que fluye? Gödel entendió que la idea de tiempo, derivada de la TGR, tiene más que ver con la idealidad del tiempo en Kant (véase sección 2): 'el tiempo no es una substancia ni una relación entre substancias, un ente que existe en sí mismo’.

Sin embargo, parecería que las ideas de Gödel solo atienden a una concepción del tiempo inserta en lo que se ha dado en llamar A-Teorías del tiempo, que ordenan las series temporales en pasado, presente y futuro, lo que implica un 'flujo' del tiempo; a la vez de que ciertos autores lo ubican como concibiendo que solo existe el ahora. ¿Será el caso de que, efectivamente, Gödel solo es compatible con las A-Teorías del tiempo; con el presentismo?32

El tiempo, a la sazón de Kant, tiene una realidad empírica. Propiedades temporales de los objetos de experiencia como la permanencia, la sucesión y la simultaneidad son 'experimentadas', gracias a como Kant lo explica en las analogías de la experiencia, pero ¿existe el tiempo como algo independiente de esos objetos de experiencia, esto es, de los fenómenos? Cuando a lo sumo, por ejemplo, el concepto de 'simultaneidad', derivado de la relatividad especial, no es el mismo para Kant, eso no implica que los hallazgos de la TGR muestren una superación de la filosofía kantiana, como ya las ideas de Gödel nos han podido demostrar. En todo caso, hay que entender a Gödel en términos de que la TGR no da cuenta del problema de la naturaleza del tiempo; más bien, dicha teoría nos muestra solo el aspecto relativo del tiempo.

31 Entiéndase 'naturaleza objetiva del tiempo' en términos de que pareciera que la TGR es la teoría de la física que da cuenta de la naturaleza del tiempo.

32 El presentismo es la concepción metafísica sobre la naturaleza del tiempo que postula que lo único que existe es el presente. 


\section{Críticas a las ideas de Gödel}

Las conclusiones de Gödel y su interpretación sobre la filosofía idealista han sido objeto de ciertas críticas, sobre todo de aquellos que consideran que, tanto en la relatividad especial como en la TGR, sí se puede tener una idea del tiempo objetivo.

\subsection{Nathan Oaklander}

Nathan Oaklander (2004) ubica a Gödel en la tradición de McTaggart (1908),33 ya que le adjudica la concepción de que el tiempo es ideal, en el sentido de que es una ilusión que no representa nada en la realidad objetiva. El autor lleva a cabo su crítica interpretando que Gödel solo considera lo que se conoce como A-Teorías del tiempo, tal que los eventos en el tiempo son ordenados en términos de pasado, presente y futuro (A-series, Apropiedades). Ello implica una 'tensión temporal', es decir, un 'temporal becoming' ['devenir'].34 De lo anterior, según Oaklander, puede Gödel argumentar: i) si la relatividad es cierta (que todo indica que sí) y, ii) como los universos de Gödel son posibles, entonces, iii) la concepción en términos de A-Teorías del tiempo resulta ser falsa (en concordancia con McTaggart por ejemplo), lo que lo lleva a concluir que, iv) el tiempo es una ilusión.

Para Oaklander, Gödel deja de lado las B-Teorías del tiempo, según las cuales los eventos pueden ordenarse como en una red que distingue entre eventos anteriores, posteriores y simultáneos (B-series, B-propiedades). Le atribuye a Gödel que este, al tomar en consideración solo las A-Teorías del tiempo, está 'espacializando al tiempo'. La pregunta es: ¿acaso no tanto la relatividad especial como la TGR lo hacen implícitamente al postular la entidad espacio-tiempo? Para Oaklander las B-Teorías del tiempo toman las series de tiempo como 'genuinas posibilidades', es decir, las relaciones temporales son primitivas e inanalizables,35 y de manera tal que las

\footnotetext{
33 McTaggart (1908: 457) distingue entre series A y series B del tiempo, de tal forma que: "En pro de la brevedad hablaré primero de las series de posición que corren del lejano pasado a través del cercano pasado, al presente, y desde el presente al cercano futuro, y al lejano futuro. Las series de posición que corren del antes al después las llamaré las B series" ["For the sake of brevity I shall speak of the series of positions running from the far past through the near past to the present, and the from the present to the near future and the far future, as the A series. The series of positions which runs from earlier to later I shall call the B series"].

$34 \mathrm{El}$ problema del becoming ha llegado a ser muy robusto en la literatura sobre la naturaleza del tiempo, está obviamente asociado al problema del cambio.

35 Oaklander (2004: 25) da una cita de C. D. Broad donde este define lo que entiende por 'relación temporal': "Las características temporales están entre lo más fundamental de nuestra experiencia de objetos, y por tanto no pueden ser definidos. Debemos comenzar por admitir que en ciertos casos
} 
diferencias entre las relaciones temporales habrán de ser diferencias irreductibles, cualitativamente hablando. Sin embargo, en atención a esto: ¿cómo ordenamos los eventos temporales en cualquier teoría de la física? ¿No acaso como eventos simultáneos, o que han sucedido antes, o después uno con respecto al otro? ¿Cómo estamos a su vez seguros de que tenemos una idea objetiva del tiempo? Creo que la experiencia tendría una respuesta. Y, asimismo, ¿dónde quedan ciertas propiedades temporales como la causalidad, que precisamente permite establecer una diferenciación entre eventos, entre las relaciones temporales? Por lo que, ¿la causalidad no tendría cabida en la relatividad especial, en la TGR?

Cabe señalar que, físicamente hablando, se considera una línea temporal causal en la TGR,36 dado que esto permite establecer soluciones de las ecuaciones de campo de Einstein, es decir, modelos de universos posibles. Si no fuera el caso: ¿cómo podría a su vez postularse un 'tiempo cósmico universal', una línea temporal objetiva? Las B-Teorías del tiempo tienen sustento en la TGR, las A-Teorías del tiempo, también; por algo se habla de un 'tiempo cósmico universal', noción que las ideas de Gödel pone en duda a partir del conjunto de soluciones que él obtuvo. Como ya se mencionó en la sección 3, 'el aspecto geométrico del tiempo', propio de la TGR, permite sustentar relaciones temporales complejas como las de las BTeorías. Sin embargo, dado el principio cosmológico: ¿no acaso las BTeorías son incompatibles con la línea temporal causal del tiempo? Puesto que dichas B-Teorías permiten sustentar que las propiedades temporales son meramente relacionales, ¿cuál sería entonces una línea temporal objetiva?

juzgar que un evento experimentado es después que otro, en la misma inmediata forma como podemos juzgar que vemos que un objeto es la razón de otro [...] Sobre estas relaciones de antes y después, las cuales inmediatamente reconocemos, todo adicional conocimiento del tiempo es construido" ["Temporal characteristics are among the most fundamental in the objects of our experience, and therefore cannot be defined. We must start by admitting that we can in certain cases judge that one experienced event is later than another, in the same immediate way as we can judge that one seen object is to the right of another [...] On these relations of before and after, which we immediately recognize, all further knowledge of time is built"]. Lo curioso de esta concepción es que, si las relaciones temporales son primitivas e inalcanzables, y solo poseemos experiencias que nos permiten juzgar en términos de antes y después, por ejemplo, ¿cómo es entonces que podemos asimismo juzgar sobre un 'tiempo objetivo' en nuestras teorías físicas?

36 Stephen Hawking y George Ellis en su libro The Large-Scale Structure of Space-Time (1973: 189192) afirman: "El espacio-tiempo satisface lo que llamaremos condición de cronología: a saber, que no hay curvas cerradas de tiempo" ["That space-time satisfices what we shall call the chronology condition: namely, that there are no closed timelike curves"]; lo que en términos generales implica una condición de causalidad en la dirección del tiempo, puesto que como los mismos autores mencionan más adelante: "En soluciones físicamente realistas, las condiciones de causalidad y cronología son equivalentes" ["In physically realistic solutions (de las ecuaciones de campo), the causality and chronology conditions are equivalent"]. 
Las B-Teorías del tiempo tienen sustento en la TGR, dados los aspectos estructurales y topológicos de la 'variedad espacio-tiempo' (ver sección 3). Sin embargo, la postulación del 'tiempo cósmico universal' que se adecua a la idea del tiempo, propia de las A-Teorías, es precisamente lo que le permite a Gödel especular sobre si realmente el tiempo es un ente objetivo y no más bien algo ideal, a la sazón de Kant. Aspectos como el de la 'flecha del tiempo', el cambio, etc., resultan ser controversiales en las BTeorías vinculadas a la TGR; de aquí que las ideas de Gödel siguen sosteniéndose en cuanto al aspecto ideal del tiempo.

\subsection{R. T. W. Arthur}

Una crítica interesante es la llevada a cabo por R. T. W. Arthur (2008), donde el autor acusa a Gödel de no haber distinguido entre el 'tiempo propio' 37 y el 'tiempo coordenado'.38 Según Arthur, al referirse Gödel al 'tiempo de los observadores' 39 está solo considerando al tiempo coordenado y deja de lado al tiempo propio, el cual resulta ser objetivo y fundamental. Por ello, ejemplificando la noción de tiempo propio a partir de una versión de la paradoja de los gemelos en la relatividad especial, el autor llega a la conclusión de que las ideas de Gödel, en cuanto a la no objetividad del tiempo, no se sostienen.

37 El autor (Arthur 2008: 218) menciona que la noción de tiempo propio fue introducida por Minkowski, en su famoso artículo de 1908: "Si en un punto $P(x, y, z, t)$ en el espacio-tiempo imaginamos una línea de mundo corriendo a través del punto, la magnitud correspondiente al vector tiempo $d x, d y, d z, d t$ establecido como libre a lo largo de la línea es

$$
d \tau=\left[c 2 d t 2-d x_{2}-d y_{2}-d z 2 c\right] 1 / 2 / c
$$

El tiempo propio es ahora definido como la integral de esta cantidad a lo largo de la línea de mundo en cuestión. Introduciendo el concepto, Minkowski escribió: "La integral de esta cantidad, tomada a lo largo de la línea de mundo desde un espacio que comienza en el punto $P_{0}$ al punto final variable $P$ "' ["If at any pointin spacetime we imagine a worldline running through that point, the magnitude corresponding to the timelike vector $d x, d y, d z, d t$ laid off along the line is

$$
d \tau=\left[c 2 d t_{2}-d x_{2}-d y_{2}-d z 2 c\right] 1 / 2 / c
$$

Proper time is now defined as the integral of this quantity along the worldline in question. Introducing the concept, Minkowski wrote: 'The integral $\tau=\int d \tau$ on this quantity, taken along the worldline from any fixed starting point $\mathrm{P}_{0}$ to the variable endpoint $P$, we call the proper time of the substantial point at $P$ "'].

38 "El problema con la formulación de Gödel, como espero ser claro en este momento, es que falla en apreciar la degeneración del tiempo: un lapso de tiempo no está representado en la teoría de la relatividad por la función del tiempo coordenado, más bien por el tiempo propio" ["The problem with Gödel formulation, as I hope should be clear by this juncture, is that it fails to appreciate the degeneracy of time: time lapse is not represented in relativity theory by the time co-ordinate function, but by proper time"] (Arthur 2008: 224).

39 "Precisamente Gödel acababa de descubrir soluciones de las ecuaciones del campo gravitatorio de la relatividad general que determinan un modelo de universo en el que es imposible encajar los tiempos locales de los observadores particulares en un tiempo cósmico y en el que el tiempo pierde su carácter absoluto. En ese universo gödeliano es posible viajar por el tiempo hacia adelante y hacia atrás" (ápud Gödel 2006: 385-386). 
El problema con la crítica de Arthur es que parece que equipara 'observador' a 'sujeto en un sistema de referencia', y de ahí interpreta la concepción que Gödel tiene de la filosofía kantiana. Físicamente, por ejemplo, un 'observador' puede ser el reloj que se mueve por una línea de mundo y mide un tiempo, a diferencia de un sujeto colocado en un sistema de referencia inercial. Además, la idea de 'tiempo propio' presupone una línea temporal, un 'devenir', donde el tiempo corre de un pasado a un futuro, ¿no es esto básico en las A-Teorías del tiempo, las cuales son precisamente las teorías que Gödel pone en entredicho dadas las soluciones de las ecuaciones de campo que él encontró?

Si bien Gödel habla de observadores y de marcos de referencia, su idea es coherente con la noción de algo así como 'tiempo perceptivo', a la vez de con la del tiempo propio en la relatividad especial. El tiempo al que se refiere Arthur es el tiempo medido por un reloj en una línea de mundo. Si un observador (dígase el gemelo A) describiera dicha línea de mundo, su percepción temporal sería equivalente a la medida por un reloj que lo acompaña en su movimiento y, asimismo, la percepción temporal de otro observador (gemelo B) en reposo, sería equivalente a la medida por su propio reloj. ¿Serían ambas 'percepciones temporales' compatibles con el tiempo propio? Si puede hablarse de 'tiempo coordenado' y de 'tiempo propio', ¿no se está, en un cierto sentido, relativizando el tiempo?

Cabe aclarar que el tiempo propio es un cálculo matemático, que se obtiene atendiendo a propiedades de la variedad espacio-tiempo cuatridimensional y, a su vez, dicha noción debe aceptar el 'pasaje del tiempo', más acorde a las A-Teorías del tiempo.

Ahora bien, ¿puede decirse que la noción de tiempo postulada por la TGR atiende al hecho de que las relaciones temporales, sean cuales sean estas, son explícitamente representadas por los eventos físicos, independientemente de los observadores, estos últimos entendidos en el sentido de lo que es descrito coherentemente por nuestra experiencia? Si la respuesta es afirmativa, entonces conllevaría afirmar a su vez que nuestra experiencia del tiempo es no objetiva, lo que en cierto sentido estaría en concordancia con la idea de que la TGR niega la realidad física configurada por la física newtoniana, y, de ahí, rechazar el modelo de ciencia kantiano. Pero, asimismo, como nuestras experiencias temporales permiten tener noción de series temporales tipo pasado, presente y futuro (A-Teorías del 
tiempo), y de las series de tipo antes, simultáneo y después (B-Teorías del tiempo), entonces: ¿cómo podemos ordenar los eventos en una flecha temporal, a su vez, causalmente? ¿Cómo es que podemos discriminar entre un tiempo coordenado y un tiempo propio, entre un tiempo de los observadores y un tiempo cósmico, y, a su vez, postular que hay un tiempo objetivo, más allá de nuestra experiencia? Finalmente, ¿la idea de tiempo es algo que proviene de nuestras experiencias al ordenar temporalmente los fenómenos o es algo inherente a nuestra mente, en el sentido trascendental kantiano? Si el tiempo no fuera algo objetivo, ¿cómo puede servir de criterio para la realidad de las cosas?

Antes de pasar a las conclusiones, cabrían aquí los siguientes puntos: i) si las ideas de Gödel son pertinentes y el tiempo es trascendentalmente ideal, a la sazón de Kant, entonces: ii) puede ser que el tiempo no exista 'sobre' y 'en' las entidades físicas, es decir, que las cosas no posean propiedades temporales. iii) Quizá el tiempo solo sea 'algo' que emerge de los fenómenos. iv) Al ser presupuesto por las teorías físicas, el tiempo de nuestra experiencia no se refiere al 'tiempo físico', puesto que nuestra experiencia temporal no se adecúa a la noción de tiempo derivada, por ejemplo, de la TGR. v) Si (i) es cierto, entonces el tiempo no existiría independientemente de nuestra experiencia. vi) Pero si (i) es falso y existe un tiempo objetivo, entonces, ¿cómo es que tendríamos noción de un tiempo más allá de nuestra experiencia, como en las teorías físicas? Según Kant, no podríamos ir más allá de nuestra experiencia. vii) Finalmente, ¿el tiempo es trascendentalmente ideal solo si las A-Teorías del tiempo y las B-Teorías del tiempo son compatibles? ¿Es la TGR la teoría que logra lo anterior?

La idea de tiempo derivada de la TGR parece más bien reivindicar la concepción kantiana, puesto que parece no dar respuesta a la cuestión: ‘¿el tiempo es un ente del mundo?' Es posible que Gödel tenga razón al vincular las consecuencias filosóficas de sus resultados en el contexto de la TGR con la filosofía kantiana. 


\section{Conclusiones: Gödel y la filosofía kantiana}

Aquí es posible retomar de nuevo a Gödel 40 y reformular sus ideas: si el tiempo objetivo (como entidad de la realidad) puede ser postulado en las teorías, en los modelos teóricos, y dicha noción no se adecúa a nuestra experiencia común, a la experiencia de observadores en marcos inerciales, entonces debe decirse que 'el tiempo subjetivo' quizá no se refiera al mundo físico, como lo deja ver la TGR. Aunque, en tal teoría existen distintas nociones de tiempo;41 entonces, ¿realmente el tiempo es algo independiente de la mente? Resulta curioso que las ideas de Kant sobre el tiempo parecen reivindicarse por la TGR, a diferencia de lo que algunos filósofos de la ciencia han creído.42

Ahora bien, aceptando que la representación de un evento, en términos de un 'punto espaciotemporal', representa una realidad y las 'líneas de mundo' (líneas temporales), un 'cambio en el tiempo', ¿cada punto espacio-temporal representa un instante de tiempo distinto y real? ¿Hay una noción clara del 'ahora', del presente, en la relatividad especial, en la TGR? Esto nos llevaría a indagar alrededor de la naturaleza del tiempo en términos metafísicos acerca de si solo existe el presente (presentismo) o solo el presente y futuro (posibilismo) o el conocido eternalismo.43

Quizá, en términos kantianos, sea más factible decir que:

40 Cabe aclarar que no existen condiciones experimentales para verificar la pertinencia de las soluciones a las ecuaciones de campo que Gödel encontró. Sus ideas se insertan en el ámbito especulativo.

41 "Hay muchas distintas nociones de tiempo empleadas en GTR: tiempo coordenado t, tiempo propio $\mathrm{S}$, tiempo de los relojes $\mathrm{T}$, tiempo cosmológico $\mathrm{tFr}$, tiempo asintótico de Poincaré... Los últimos dos se refieren solamente a la descripción de soluciones especiales de las ecuaciones de Einstein. Ellas son irrelevantes en una discusión sobre la ontología del tiempo, porque una diferente ontología para diferentes soluciones de la misma teoría es ciertamente insatisfactoria. Los tiempos de relojes son simplemente las lecturas de ciertas variables físicas, las cuales pueden ser localmente empleadas como la variable independiente por coveniencia" ["There are many distinct notions of time employed in GR: coordinate time t, proper time S, clock times T, cosmological time tFr, asymptotic Poincare' timey. The last two refer to the description of special solutions of the Einstein field equations only. They are irrelevant in a discussion of the ontology of time, because a different ontology for different solutions of the same theory is certainly unsatisfactory. Clock times are simply the readings of certain physical variables, which can be locally employed as the independent variable for convenience"] (Rovelli 2006: 34).

42 En este sentido, puede consultarse a autores clásicos como Reichenbach (1920 [1965]) o Schlick (1923).

$43 \mathrm{El}$ eternalismo es la concepción metafísica del tiempo que plantea que todos los eventos temporales existen, el llamado 'Universo de bloque', y por tanto, el universo está en constante expansión, con lo cual, las diferencias entre pasado, presente y futuro solo son diferencias de perspectiva. 
Si el tiempo es solo una forma de percepción, si solo se encuentra en los fenómenos, en las cosas para nosotros, si es solo una variable de las ecuaciones de la física, entonces el tiempo circular de Gödel, el Eterno Retorno y las máquinas del tiempo no son conceptos contradictorios. No conducen a ninguna paradoja en el mundo de las cosas en sí, porque allí no fluye el tiempo (Hacyan 2004: 198).

Resulta más efectivo afirmar, parafraseando a Hao Wang (1995), que el espacio-tiempo cuatridimensional es 'natural' para el mundo físico, pero no resulta ser un sistema coordenado natural para la mente. Por tanto, el tiempo solo es un marco natural de referencia, en el sentido kantiano, por lo que, a su vez, permite llevar a cabo un ordenamiento de los fenómenos. Lo que queda finalmente es su condición tanto ideal como subjetiva.

Gödel entendió que desde la relatividad de Einstein no era posible aceptar una concordancia entre la idea intuitiva de tiempo (la experiencia de este) y lo que a partir de dicha teoría se entiende por 'tiempo objetivo'. Simplemente, Gödel mostró que la idea de tiempo lineal, más ad hoc con nuestra idea intuitiva, no se puede deducir de la TGR.

La relatividad, para Gödel, no capta la esencia del tiempo intuitivo, porque cuando esta llega al tiempo, nuestras intuiciones nos traicionan. 'El tiempo, tal como nos lo presentamos a nosotros mismos', decía, 'simplemente no encaja con los hechos. Llamarlo tiempo subjetivo es solo un eufemismo'. Este era, para Gödel, el punto de intersección entre el idealismo de Kant y el idealismo temporal implícito en la física de Einstein (Yourgrau 2007: 176).

Para Kant, el tiempo es no objetivo, es decir, no es un ente del mundo. Como vimos en la sección 2, el punto medular de la idealidad del tiempo es la idea de que este no es ni una substancia ni una relación entre substancias. Pero no es que el tiempo esté sobre las substancias, sobre los objetos, ni que sea algo que nosotros ponemos sobre estos. El tiempo es la forma del sentido interno que permite ordenar los fenómenos, un orden tal que posibilita la presentación temporal de los particulares. La TGR, en un cierto sentido, elimina la noción de un tiempo absoluto y el concepto de simultaneidad absoluta; de ahí que para Gödel esto sea una evidencia de que el tiempo no tiene una realidad objetiva, que sea un ente que exista (Hacyan 2006). 
Todas las problemáticas implícitas que giran en torno a la naturaleza del tiempo, ya sea por vía científica (mecánica newtoniana, relatividad especial o general, termodinámica, mecánica cuántica), ya sea en su sentido metafísico (presentismo, posibilismo, eternalismo, etc.) dan un tratamiento del tiempo con distintos 'matices ontológicos'; entonces, ¿puede hablarse de una unicidad en el concepto de tiempo?

A juicio de Kant, el tiempo no existe, y no existe porque no es un 'objeto externo'. Si fuera un objeto, se podrían establecer condiciones para constituirlo, ¿no sería esto una especie de reificación?

Por lo que hemos visto, ¿por qué el tiempo no es una entidad cuya experiencia sea similar a la experiencia de cualquier otra entidad de la física? ¿Por qué la noción de tiempo no es una y la misma en mecánica clásica, en la relatividad especial, en la TGR, en mecánica cuántica? Cabe aquí una afirmación de Kant:

El tiempo no es algo que subsista por sí mismo, o que sea inherente a las cosas, como determinación objetiva, y que por tanto permanezca, si se hace abstracción de todas las condiciones subjetivas de la intuición de ellas; pues en el primer caso, aun sin objeto efectivamente real, sería algo que sería efectivamente real ( $K r V$, A33).

Idealidad y subjetividad del tiempo sustentan la condición ontológica de este en clave kantiana.

La TGR ha permitido configurar una idea, como lo pensaba Gödel, quizá más cercana al carácter relativo del tiempo, pero no ha resuelto el problema sobre qué es el tiempo, sobre su naturaleza.

La idealidad del tiempo ha de entenderse en términos de que este no es una substancia, ni una relación entre substancias, por lo que no es algo que exista. Entonces, ¿queda aún lugar para Kant? Las consecuencias filosóficas que Gödel extrajo de sus soluciones a las ecuaciones de campo de la TGR parecen reivindicar al filósofo de Königsberg. 
Referencias

ARTHUR, R. T. W.: "Time Lapse and the Degeneracy of Time: Gödel, Proper Time and Becoming in Relativity Theory", en DIEKS, D. (ed.): The Ontology of Spacetime II, Paises Bajos, Elsiever, 207-227, 2008.

DAINTON, B.: Time and Space, Londres, McGill Queen's University Press, 2010.

DICKER, G.: Kant's Theory of Knowledge, Oxford, Oxford University Press, 2004.

DORATO, M.: "Kant, Gödel and Relativity", en GARDENFORS, P.; KIJANIA-PLACEK, K.; WOLENSKI, J. (eds.): Proceedings of the invited papers for the 11 th International Congress of the Logic Methodology and Philosophy of Science, Dordrecht, Synthese Library, Kluwer, 329-346, 2006.

EINSTEIN, A.: Einstein. Obras esenciales, Barcelona, Crítica, 2005.

GÖDEL, K.: Obras completas, Madrid, Alianza Editorial, 2006.

GUYER, P.: Kant and the Claims of Knowledge, Nueva York, Cambridge University Press, 1987.

HACYAN, S.: Física y Metafísica del espacio y el tiempo, México, Fondo de Cultura Económica, 2004.

: "On the Trascendental Ideality of Space and Time in Modern Physics”, Kant-Studien 97 (2006) 382-395.

: Relatividad para estudiantes de física, México, Fondo de Cultura Económica, 2013.

HAWKING, S. W.; ELLIS, G. F. R.: The Large-Scale Structure of SpaceTime, Cambridge, Cambridge University Press, 1973.

KANT, I.: Crítica de la razón pura, México, Fondo de Cultura Económica, 2008.

: Theoretical Philosophy 1755-1770, Nueva York, Cambridge University Press, 1992.

: Prolegómenos a toda metafísica futura que haya de poder presentarse como ciencia, Madrid, Istmo, 1999. 
LAZOS, E.: Disonancias de la Crítica. Variaciones sobre cuatro temas kantianos, México, IIF/UNAM, 2014.

MARKOSIAN, N.: “Time”, Stanford Encyclopedia of Philosophy, 2010, http://plato.stanford.edu/archives/win2010/entries/time/.

MAUDLIN, T.: Filosofía de la física I. El espacio y el tiempo, México, Fondo de Cultura Económica, 2014.

McTAGGART, J. E.: "The Unreality of Time", Mind: A Quarterly Review of Psychology and Philosophy 17 (1908) 456-473.

OAKLANDER, L. N.: The Ontology of Time, Nueva York, Prometheus Books, 2004.

REICHENBACH, H.: The Theory of Relativity and A Priori Knowledge, Berkeley, CA, University of California Press, 1965.

ROVELLI, C.: "The Disappearance of Space and Time", en DIEKS, D. (ed.): The Ontology of Spacetime, Paises Bajos, Elsevier, 25-36, 2006.

SHABEL, L.: "The Trascendental Aesthetic", en GUYER, P. (ed.): Kant's Critique of Pure Reason, Cambridge, Cambridge University Press, 93-117, 2010.

SCHLICK, M.: Space and Time in Contemporary Physics: And Introduction to the Theory of Relativity and Gravitation, Oxford, Oxford University Press, 1923.

SKLAR, L.: Space, Time, and Spacetime, Berkeley, CA, University of California Press, 1977.

STEIN, H.: "Newtonian spacetime”, Texas Quarterly 10 (1967) 174-200.

WALD, R. M.: General Relativity, Chicago, IL, University of Chicago Press, 1984.

WANG, H.: "Time in Philosophy and in Physics from Kant and Einstein to Gödel”, Synthese 102, 2 (1995) 215-234.

YOURGRAU, P.: The Disappearance of Time, Cambridge, Cambridge University Press, 1991. : Un mundo sin tiempo, Barcelona, Tusquets, 2007. 


\title{
Synthetische und analytische Einheit der Apperzeption. Über ein nach wie vor aktuelles und missverständliches Problem der Kritik der reinen Vernuft
}

\author{
CARSTEN OLK 1
}

\begin{abstract}
Inhaltsangabe
Die vorliegende Abhandlung versucht den grundlegenden Unterschied zwischen synthetischer und analytischer Einheit des Selbstbewusstseins deutlich zu machen. Inwiefern die synthetische als ,kollektive“ und allein objektive Verbindung ermöglichende von der analytischen und bloß ,distributiven“ Bewusstseinseinheit unterschieden werden muss, wird insbesondere mit einer Analyse des Problems der ,Meinigkeit' von Vorstellungen zu untersuchen sein. Das Problem der Verwechslung beider Bewusstseinsarten, das mit Blick auf einige wenig beachtete Forschungsarbeiten eigentlich schon als gelöst gelten könnte, manifestiert sich leider immer wieder in der Kant-Rezeption. So hält sich bis heute hartnäckig die These von der analytischen Einheit der Apperzeption als eigentlich höchstem Punkt der Transzendentalphilosophie, trotz Kants ausdrücklichem Hinweis, dieser sei allein die synthetische Einheit der Apperzeption.
\end{abstract}

Schlüsselwörter: Synthetische und analytische Einheit des Selbstbewusstseins, objektive Verbindung, kollektive und distributive Einheit des Bewusstseins, Meinigkeit von Vorstellungen

\section{Unidad sintética y analítica de apercepción. Sobre un problema conocido y ambiguo de la Crítica de la razón pura}

\begin{abstract}
Resumen
El presente trabajo intenta aclarar la fundamental diferencia entre la unidad sintética y analítica de la autoconciencia. En qué medida se debe diferenciar la union sintética de la conciencia, como 'colectiva' y condición de una síntesis objetiva, frente a la unidad analítica y meramente 'distributiva', es lo que se investigará mediante un análisis del problema de la Meinigkeit. El problema de la confusión existente entre estos dos tipos de conciencia (que podría ser considerado como resuelto en vistas a ciertos trabajos a los que se ha prestado poca atención) aún se manifiesta en la recepción de Kant. Así, obstinadamente se acepta la tesis de que la unidad analítica de la apercepción es el punto más alto de la filosofía
\end{abstract}

1 Universität Trier. Kontakt: olkc@uni-trier.de. 
transcendental, a pesar de las indicaciones de Kant de que esta es exclusivamente la unidad sintética de la aperceción.

Palabras clave: unidad sintética y analítica de la autoconciencia, unidad objetiva, unidad colectiva y distributiva de la conciencia, Meinigkeit

\section{Einleitung: Der höchste Punkt der Transzendentalphilosophie}

Der berühmte $\$ 16$ der B-Deduktion handelt, so dürfte klar sein, von der synthetischen Einheit der Apperzeption. Dieses ursprüngliche Selbstbewusstsein hat die wesentlichen Eigenschaften, einfach und einheitlich $\mathrm{zu}$ sein, mithin nichts Mannigfaltiges in sich $\mathrm{zu}$ enthalten, sondern Mannigfaltiges $\mathrm{zu}$ vereinheitlichen; die Eigenschaft der Einheitlichkeit ist daher im doppelten Sinne zu verstehen als numerische Identität einerseits, andererseits eben im Sinne eines Vermögens zur Vereinheitlichung. Es ist durch diese letztere Eigenschaft weiterhin gekennzeichnet als wesentlich verbindendes und gegenstandsbestimmendes Selbstbewusstsein, das einheitliche Erkenntnis, mithin Erfahrung, überhaupt erst ermöglicht.2 Denn damit alle meine - im Gemüt und empirischen Bewusstsein gegebenen Vorstellungen »insgesamt meine Vorstellungen «3 $(K r V, \mathrm{~B} 135)$ sind, d. h. alle zusammen und »collectiv, d. i. als Gesamtheit« in mir vereinigt werden, müssen sie in einem, numerisch identischen Selbstbewusstsein vereinigt werden können. Andernfalls stünden die Vorstellungen lediglich »fragmentarisch" als eine »Stoppelung der Warnehmungen« $(O P$, AA 22: 611) in einem »an sich zerstreut[en]« $(K r V$,

2 Eine ausführliche Auseinandersetzung mit den Charakteristika der ursprünglich-synthetischen Einheit der Apperzeption findet sich in Olk (2016: 47ff., sowie 203ff.). Über den zentralen Unterschied von synthetischer und analytischer Einheit der Apperzeption und Reflexion hat bereits Kugelstadt (1998: 78ff., 101ff., 241ff., 278ff., 313ff.) sowie in seinem Aufsatz „Inwiefern kann bei Kant von analytischer Einheit des Selbstbewußtseins überhaupt die Rede sein?" (Kugelstadt 2008: 407-418), ausführlich gesprochen. Es kann nur als höchst unglücklicher Umstand gewertet werden, dass diesen wegweisenden Arbeiten bis heute nicht die Beachtung geschenkt wurde, die sie verdienen. Andernfalls würden sich nicht, wie in Punkt 2 bemerkt, immer noch so viele grobe Missverständnisse in der Rezeption finden.

3 Kantzitate werden im Folgenden unmittelbar im Text nachgewiesen, wobei im Falle der 1. (A) und 2. (B) Auflage der Kritik der reinen Vernunft gemäß der Originalpaginierungen zitiert wird. In allen anderen Fällen wird unter Hinzufügung von Siglen, Band und Seitenzahl nach der Akademieausgabe (AA) zitiert. Bsp: $O P$, AA 21: 325. Hervorhebungen Kants sind durchgängig gesperrt, eigene hingegen kursiv gesetzt. 
B133) empirischen Bewusstsein, d. h. einem jederzeit »vielfärbige[n] verschiedene[n] Selbst« (KrV, B134) beisammen: »Das Bewußtsein seiner selbst, nach den Bestimmungen unseres Zustandes, bei der innern Wahrnehmung ist bloß empirisch, jederzeit wandelbar, es kann kein stehendes oder bleibendes Selbst in diesem Flusse innrer Erscheinungen geben « $(K r V$, A107). Damit erweist sich die synthetische Apperzeption samt ihren anderen Eigenschaften als transzendental und zugleich als der »höchste Punkt, an dem man allen Verstandesgebrauch, selbst die ganze Logik, und nach ihr, die Transzendental-Philosophie heften muß« $(K r V$, B134, Anm.).

So viel zunächst zum scheinbar Offensichtlichen. Ein Blick selbst in die neuere Forschungsliteratur offenbart jedoch, dass das hier nur grob Skizzierte nicht so selbstverständlich ist, wie man bei Lektüre der Kritik der reinen Vernunft vermuten könnte. So wird vor allem der - mehr als nachträgliche Ergänzung wirkende und später näher zu beleuchtende Satz der Identität des Bewusstseins in den Vorstellungen zum Anlass genommen, entgegen allen vorigen Kantischen Ausführungen die analytische Einheit der Apperzeption zum Dreh- und Angelpunkt der Transzendentalphilosophie zu erheben. Warum diese Vertauschung fatal für ein Verständnis der Kantischen Theorie des Selbstbewusstseins ist; worauf das Missverständnis und die Verwechslung beider Arten von Selbstbewusstsein beruht und welche eindeutige Unterscheidungsmöglichkeit es zur Vermeidung von Missverständnissen gibt; das soll nun, auch mit den von Kant in der Einleitung in die Kritik der Urteilskraft etablierten zwei Momenten von Reflektieren überhaupt, untersucht werden.

2. Zum Problem der Bestimmung des ursprünglichen Selbstbewusstseins in der Rezeption

Die Verwechslungen von synthetischer und analytischer Einheit des Selbstbewusstseins sind weit über die Kant-Forschung hinaus zahlreich. Es kann hier allerdings nur bei einer Auswahl bleiben, die das grundlegende Missverständnis bezüglich der Differenz von synthetischer und analytischer Bewusstseinseinheit offenlegt. Herbert J. Paton lässt der analytischen Einheit des Bewusstseins eine Funktion der objektiven Verbindung allein durch Vergleichung mehrerer ähnlicher Dinge zukommen: »Kants 
Behauptung ist, dass der Begriff mehr leistet als nur die Vereinigung verschiedener Objekte - und zwar auf die Weise der Analysis und Abstraktion unter Begriffe hinsichtlich ihrer gemeinsamen Eigenschaften « ["Kant's contention is that thought does more than unite different objectsby methods of analysis and abstraction under concepts of their common characteristics"] (Paton 1976: 285). Er intendiert dabei fälschlich eine bloß subjektiv-synthetische Einheit, die aber nichts anders als genau diese logische vergleichende Einheit des analytischen Selbstbewusstseins ist. Aus diesem Grunde spricht Paton der synthetischen Einheit lediglich die Funktion der Einheit verschiedenen Vorstellungen in einer Anschauung, während die analytische Einheit anzusetzen sei als Einheit, die verschiedenen Begriffen in einem Urteil Einheitlichkeit verschaffe (vgl. ebd: 288). Dass aber die Verbindung in einem Urteil seinem Inhalt nach gerade eine gegenstandsbestimmende, weil den Begriff erweiternde Synthesis erfordert, die folglich nur durch synthetische Einheit des Selbstbewusstseins geleistet werden kann, kommt Paton nicht in den Sinn. Das Missverständnis beruht gerade auf einem falschen Verständnis dessen, was bei Kant ein conceptus ist. Unter einem Begriff versteht Kant nämlich nicht bloß den conceptus als communis, sondern speziell Begriffe als synthetische, d. i. der »Actus des Verstandes [...] sich synthetische Begriffe von Dingen zu machen« (Refl, AA 16: 548), wodurch das bloß formale Urteil in Beziehung auf die Anschauung gerade inhaltlich erfüllt gedacht wird.

Gerhard Schönrich sitzt einem noch viel gravierenderen Missverständnis auf, wenn er behauptet, dass jede »synthetische Verbindung in ihrer Möglichkeit auf der analytischen Einheit « beruhe, weil ansonsten ein »unendlicher Regreß in der Frage nach der Verbindung dieser Verbindung « (Schönrich 1981: 307) entstehe. Diese Frage stellt sich jedoch nicht, weil gerade die synthetische Bewusstseinseinheit als ursprüngliches Selbstbewusstsein unhintergehbar ist und durch seine Einheitlichkeit und Einfachheit die Synthesis ermöglicht, wie umgekehrt die Synthesis diese Eigenschaften gewährleistet. Die analytische Reflexion hingegen würde, da sie objektiv niemals irgend etwas zusammenfügt und vereinigt, die Frage nach einer Verbindung aller Vorstellungen nicht lösen können; zudem würde auf Ebene der analytischen Reflexion die Frage nach der Verbindung der vorausgehenden Analysis nicht beantwortet werden können. 
Martin Bunte (2016: 169ff., 194f.) weist zwar ganz richtig die synthetische Einheit des Selbstbewusstseins als höchsten Punkt der Transzendentalphilosophie aus, ebenso wie er das ursprüngliche Ich denke hierbei richtig als ,Reflexionsbegriff' bezeichnet aufgrund der relationalen Tätigkeit des Denkens »in Beziehung auf das Subjekt des Gedankens selbst « (ebd: 213). Denn das Ich denke, das stellt er überzeugend heraus, wird als »Vehikel aller Begriffe überhaupt « $(K r V$, A341/B399) wie alle Verstandesbegriffe »a priori vor der Erfahrung und zum Behuf derselben gedacht « und enthält somit nichts weiter, »als die Einheit der Reflexion über Erscheinungen, in so fern sie notwendig zu einem möglichen empirischen Bewußtsein gehören sollen« $(K r V$, A310/B366f. $)$. Jede spezifische Verknüpfungsfunktion der Kategorie drückt ja letztlich auch nur die synthetische Einheit der qualitativen Einheit des Selbstbewusstseins aus. Er bringt aber durch eine Unterscheidung einer bloß formalen und dynamischen Apperzeption unnötige Schwierigkeiten in die Debatte (Vgl. etwa Bunte 2016: 192f.), die schon im Ansatz zu vermeiden wäre, wenn man sich klar macht, dass die reine Apperzeption als formale Bedingung des Denkens von Gegenständen ebenso die dynamische Einheit in der reinen Synthesis gewährleisten muss. Vielleicht kommt er deshalb später zu dem zweifelhaften Ergebnis, Kants Beweisstruktur in der transzendentalen Deduktion, mit der die transzendentale Apperzeption als notwendige und hinreichende Bedingung aller Erkenntnisse ausgewiesen wird, sei falsch, da nur einige Verknüpfungen, nicht aber alle Verknüpfungen der Apperzeption Erkenntnisse von Gegenständen lieferten. Hier differenziert Bunte nur unzureichend die unterschiedlichen Weisen der Objektbeziehung und missversteht, dass Kant in keiner Weise alle Verknüpfungen der Apperzeption Gegenstandserkenntnis bewirken, sondern nur diejenigen, die unter Bedingungen kategorialer Verknüpfung stehen. Dass also nur einige Verknüpfungen von Vorstellungen zu Erkenntnissen werden, ist ein geschenktes Argument, wenn man bedenkt, dass rein logische Verknüpfungen ebenfalls durch die Apperzeption »vermittelst analytischer Einheit « (KrV, A79/B105) geleistet werden. Die sehr formallogisch konzipierte Arbeit unterscheidet jedoch überhaupt nicht weiter zwischen den verschiedenen Arten des Selbstbewusstseins.

Suzanne Dürr etwa spricht zunächst ganz richtig die synthetische Einheit als höchstem Punkt der Transzendentalphilosophie an, identifiziert dann aber gerade an der Sache vorbei das Ich denke mit der analytischen 
Einheit, als ursprüngliches Selbstbewusstsein »im prägnanten Sinne, d. h. im Sinne eines sich denkenden Selbstverhältnisses « (2018: 303f.). Offenbar rührt auch hier das Missverständnis daher, dass man in der analytischen Einheit einen bloßen inhaltsleeren Begriff im Sinne der einfachen »und für sich selbst an Inhalt gänzlich leere[n] Vorstellung: Ich « (KrV, A345f./B404) zu erblicken glaubt, obschon dies bereits in der A-Auflage, in der noch keine analytische Einheit des Selbstbewusstseins auftaucht, lediglich das Charakteristikum der synthetischen Einheit ist, für die Verbindung des Mannigfaltigen selbst nichts Mannigfaltiges sein zu dürfen. Analytische Einheit wird in diesem Zusammenhang gerne auch als zeitlose Einheit der Apperzeption verstanden, was natürlich schon deshalb eine fehlerhafte Zuordnung ist, weil das verbindende Ich denke der Zeit ebenso enthoben ist. Mit dem Ich denke wird jedoch durch einen Begriff (d. i. Kategorien, die nur im Sinne eine Fichteschen Genesis des Bewusstseins wieder durch das Ich denke bedingt sind) auf das verbindende Ich der Apperzeption rekurriert, das sich als Form aller Vorstellungen nicht mehr weiter einholen lässt, dadurch aber mitnichten zur analytischen Einheit wird. Da wir keine andere »Art der Begriffe, als die Kategorien« ( $K r V$, A287/B343) haben, um uns (als Ich samt Vermögen) zu denken, ist ursprüngliches Selbstbewusstsein immer als synthetisches gedacht. Das bedeutet, auch in dem Moment, da ich mich selbst denke, bestimme ich mich bzw. mein Vermögen zu denken durch den Begriff, in der Weise der Synthesis, als denkendes, d. i. verbindendes und selbstbewusstes Ich. Der sich hier manifestierende Zirkel ist nur scheinbar, über seine Auflösung kann hier jedoch nicht weiter gesprochen werden.

3. Zwei Arten der Identität des Selbstbewusstseins - Zwei Arten der Reflexion

Schaut man sich zunächst den bloßen Wortlaut dieses Satzes im $§ 16$ an, werden vor allem zwei Dinge ersichtlich: Einmal das Verhältnis zwischen synthetischer und analytischer Einheit des Bewusstseins sowie eine entsprechende Zuordnung des Begriffs der Identität:

Also nur dadurch, daß ich ein Mannigfaltiges gegebener Vorstellungen in einem Bewußtsein verbinden kann, ist es möglich, daß ich mir die Identität des Bewußtseins in diesen Vorstellungen selbst vorstelle, d. i. die analytische Einheit 
der Apperzeption ist nur unter der Voraussetzung irgend einer synthetischen möglich $(K r V, \mathrm{~B} 133)$.

Augenscheinlich wird hier die analytische Einheit der Apperzeption als abgeleitete und nicht-ursprüngliche Einheit ausgewiesen, wobei die Identität des Bewusstseins gerade für diese abgeleitete Bewusstseinseinheit geltend gemacht wird. Könnte also der Grund der Verwechslung in einem Missverständnis mit Blick auf den Begriff der Identität liegen?

In der Tat ist es diese Identität in den Vorstellungen, die fälschlich mit der zuvor im $\$ 16$ etablierten »durchgängige $[n]$ Identität der Apperzeption« identifiziert wird. Letztere ist Eigenschaft und innere Bestimmung allein der synthetischen Apperzeption, denn nur diese (zunächst von aller Zeitlichkeit enthoben betrachtete, später auch zeitlich sich erstreckende) durchgängige synthetische Einheit »enthält eine Synthesis der Vorstellungen, und ist nur durch das Bewußtsein dieser Synthesis möglich « $(K r V, \mathrm{~B} 133)$. Umgekehrt hängt auch die Synthesis von der Einheit, d. h. der numerischen Identität dieses Selbstbewusstseins ab.4 Der Satz der Identität des Bewusstseins in den Vorstellungen ist folglich nicht mit dem Satz der Identität des (einen) Bewusstseins zu verwechseln; in erstem ist nämlich keine durchgängige Identität des »stehende[n] und bleibende[n] Ich (der reinen Apperzeption)« (KrV, A123; vgl. auch A107) und alle Vorstellungen begleitenden Ich denke gedacht. Würde es diesen Satz also nicht geben, es hätte vermutlich nie eine Diskussion darüber gegeben, ob nicht doch die analytische Einheit des Selbstbewusstseins als ursprüngliches Selbstbewusstsein deklariert werden müsse.

Wie schon eingangs erwähnt, können meine Vorstellungen nur in einem synthetischen Bewusstsein meiner selbst alle insgesamt zusammenstehen, d. h. nur so sind »die mannigfaltigen Vorstellungen « auch »insgesamt meine Vorstellungen« $(K r V, \mathrm{~B} 132 \mathrm{f}$.). Somit müssen also alle Vorstellungen prinzipiell zur einen »allbefassenden reinen Apperzeption«, als dem »Correlatum aller unserer Vorstellungen « $(K r V$, A123) gehören, sofern aus ihnen Erkenntnisse werden sollen. Folglich wird die subjektive Erscheinung durch synthetische, kategoriale Bestimmung zum Objekt der Erfahrung gemacht, d. h. die subjektiven Vorstellungen in Objekte

4 Zur ausführlichen Beweisführung siehe Olk (2016: 47ff., Anm. 75, sowie 58ff., Anm. 88, 89). 
verwandelt, indem eine objektive Verbindung in den Vorstellungen nach synthetischer Einheit des Selbstbewusstseins gedacht wird.5 Was aber hat es nun mit der die Identität des Bewusstseins in den Vorstellungen auf sich, die bisher nur in negativer Abgrenzung zur durchgängigen synthetischen Identität analysiert wurde?

Ein Blick ins Spätwerk vermag eine erste Antwort auf die Frage zu geben: Im Opus Postumum unterscheidet Kant, hier mit Blick auf zwei Momente der Reflexion, einen analytischen von einem synthetischen Gebrauch eines Begriffs: »Analytisch allgemein ist ein Begriff durch den eines in Vielem, - synthetisch aber wodurch Vieles in einem als zusammen unter einen Begriff gebracht wird« (OP, AA 21: 247). Während die synthetische Reflexion des Mannigfaltigen darin besteht, auch ungleichartige Erkenntnisstïcke zusammen in einem Bewusstsein synthetisch zu vereinigen, indem »Vieles in einem als zusammen « gedacht wird, denkt die analytische Reflexion »eines [ein Bewusstsein] in Vielem « (OP, AA 21: 247), nicht synthetisch-kollektiv, sondern analytischdistributiv — was gleich noch näher zu erläutern sein wird. In allen Fällen der synthetischen Reflexion geschieht diese also nach »einem [synthetisch, C.O.] gemeinschaftlichen Grunde der Einheit « ( $K r V$, A78/B104), folglich nicht durch eine analytisch »gemeinschaftliche Funktion des Gemüts « $(K r V$, A109). Diese Art der synthetischen Reflexion ist also allein das Charakteristikum der synthetischen Einheit der Apperzeption. Sie bringt ihre eigene durchgängige Identität in die Vorstellungen, dadurch dass sie viele, auch ungleichartige Vorstellungen in sich, d. h. in einem synthetischkollektiven Bewusstsein gegenstandkonstitutiv $\mathrm{zu}$ vereinen vermag und gerade nicht als ein je identisches Bewusstsein in den Vorstellungen auftaucht. 6 In concreto bedeutet dies die Verbindung der im inneren Sinn gegebenen Vorstellungen durch eine bestimmte Reflexionsform, d. i. die auf die Anschauung bezogene Kategorie. Während im Fall der synthetischen

5 Im Opus Postumum spricht Kant mit Blick vor allem auf die materiellen Gegenstände und die in diesem Zusammenhang geltend zu machenden ursprünglichen bewegenden Kräfte der Anziehung und Abstoßung davon, dass der »auf äußere Erscheinungen angewandte Verstand « letztlich beabsichtigt, »empirische Vorstellungen als Warnehmungen in Erfahrungen von der Beschaffenheit der Phänomene der Materie in Raum und Zeit zu verwandeln « (OP, AA 21: 162; vgl. auch 172, 477).

6 Vgl. ferner Deppermann (2001: 133), der zeigt, warum das Begleiten des Selbstbewusstseins, insofern es durch die Zeit mit allen Vorstellungen zugleich ist, zunächst immer auf ein synthetisches

Bewusstsein verweist. Dieses Zugleich ist übrigens nicht im Sinne einer Wechselwirkungsbestimmung zu verstehen, als ein gedachtes Zugleichsein der Bestimmungen zweier Substanzen im Raume, sondern besagt, dass die Vorstellungen »in Gemeinschaft (communio) der [reinen] Apperzeption stehen « $(K r V$, A214/B261). 
Reflexion das Subjekt sich jederzeit, der Identität der Funktion“ der Synthesis bewusst sein muss und somit jederzeit die durchgängige »Identität seiner Handlung vor Augen « hat, macht die »Identität seiner selbst in der Mannigfaltigkeit seiner Vorstellungen $\ll(K r V$, A108) wesentlich nur die analytische Reflexion aus.

Der spezifischen Art der (analytisch- oder synthetischgemeinschaftlichen) Reflexion auf Seiten der Vorstellungen entspricht dem Gesagten zufolge auf Subjektseite immer eine Bezogenheit auf die analytische oder synthetische Bewusstseinseinheit. Letztere muss aber prinzipiell immer vorausgehen, wenn einheitliche Erkenntnis, mithin Erfahrung, möglich sein soll. Diese Differenz wird sodann auch durch die Kantische Unterscheidung der beiden Momente von Reflektieren überhaupt sowie der damit einhergehenden Differenzierung von bestimmender und bloß reflektierender Urteilskraft deutlicher. Denn die beiden Momente von ,Reflectiren (Überlegen) ${ }^{\star}$ bestehen darin, „gegebene Vorstellungen entweder mit anderen, oder (besser gesagt und, C.O.) mit seinem Erkenntnisvermögen, in Beziehung auf einen dadurch möglichen Begriff, zu vergleichen und zusammen zu halten « (EEKU, AA 20: 211).7 Das bedeutet, es werden einmal die Vorstellungen untereinander und dann auch zugleich mit dem spezifischen Erkenntnisvermögen zusammengehalten und verglichen; entweder also synthetisch-gemeinschaftlich vermittelst der Kategorie verglichen und zusammengehalten und somit - mit Blick auf das Erkenntnisvermögen — nach synthetischer Einheit des Bewusstseins und in einer Apperzeption zusammengedacht oder analytisch-gemeinschaftlich auf bloße Gleichheit und Identität in diesen Vorstellungen hin verglichen, und

7 Inwiefern die weitere Bestimmung Kants an dieser Stelle, die ,reflektirende Urteilskraft ${ }^{\star}$ sei diejenige, »welche man das Beurtheilungsvermögen « (EEKU, AA 20: 211) nennen könne, zu kurz greift, führt Kugelstadt (1998: 112) mit Blick auf die bestimmende Urteilskraft vor. Auch diese ist nämlich ein Beurteilungsvermögen, weil sie in ihrer Bestimmung zugleich eine Überlegung (Reflexion und Beurteilung) darüber anstellen muss, wie und auf welche Weise (durch welches Schema als Vermittlungsfunktion) die Kategorie zur Bestimmung auf das Mannigfaltige der Anschauung angewendet werden kann. Dazu ist neben der bestimmenden als empirischer Urteilskraft, die den Fall zur Regel sucht, jederzeit die bestimmende in Form der transzendentalen Urteilskraft erforderlich, insofern diese (auf rein formaler Ebene) reflektiert, d. h. beurteilt, welche Kategorie zu welchem zeitlichen Modus passt und dadurch die objektive Bestimmung eines Gegenstandes möglich macht. So kann »der rein intellektuelle Inhalt« etwa des Substanzbegriffs, »als seine logische Bedingung des Denkens «, nicht »unter zeitlichen Bedingungen willkürlich in das Schema etwa des Größenbegriffs « transformiert werden, denn die Zahl ist »sowenig (mit dem Bewußtsein ihrer synthetischen Einheit verbundene) reine zeitliche Darstellung der logischen Vorstellung vom nur als Subjekt und für sich und nicht als bloße innere Bestimmung eines Subjekts Existierenden, wie umgekehrt das Beharrliche nicht reine Darstellung des Gedankens von demjenigen ,Ding' sein kann, das ,mit vielen zusammen“ [synthetisch] einerlei, d. i. eine ,Größe‘ ist« (vgl. ebd: 112f.). 
zwar nach analytischer Einheit des Selbstbewusstseins. Allein die erste Art der synthetischen Vergleichung kann dabei als eine objektive Verbindung gelten, weil hier das zu verbindende Teilmannigfaltige untereinander durch die Einheit der Kategorie insgesamt zusammengedacht wird, d. i. nur hier liegt veritable Verbindung im Objekt vor, während im zweiten Fall die zu verbindenden Teile objektiv getrennt bleiben, sie nur auf mögliche Gleichheit hin verglichen und daher allenfalls subjektiv-synthetisch8 vereinigt werden. Im Falle synthetischer Reflexion enthält jede Form der objektiven Vereinigung von gegebenem (anschaulich) Mannigfaltigen in Raum und Zeit (Größenbestimmungen, Bestimmungen objektiver Relationen) einen quantitativen Aspekt, insofern es um die Vereinigung aller Vorstellungen geht. Diese synthetische Einerleiheit, alle Vorstellungen zusammen und insgesamt $\mathrm{zu}$ vereinigen, lässt sich denken als eine Bestimmung der Vorstellungen gemäß der Kategorie der Allheit bei der Bestimmung des gleichartigen Raum- und Zeitmannigfaltigen.

Die beiden unterschiedlichen Reflexionen, die im eigentlichen Sinne als zwei komplementäre Reflexionsarten zu verstehen sind, lassen sich wie folgt veranschaulichen: Mit Blick auf die Größenkategorie wird ein Zahlbegriff, etwa der Sechs, so gebildet, dass die in der reinen Synthesis nach und nach gesetzten und sodann reproduzierten Einheiten untereinander durch die Kategorie der Allheit, welche nichts anderes ist als »die Vielheit als Einheit betrachtet « $(K r V, \mathrm{~B} 111)$, so verglichen und zusammengehalten werden, dass daraus die Zahl Sechs entspringt. Die nach und nach gesetzten Einheiten werden also durch die Funktion des reinen Verstandesbegriffs der Allheit in der reinen Synthesis zu einer Zahl zusammengesetzt und zugleich alle zusammen und insgesamt im Objekt verbunden gedacht, was also objektive Zahl- bzw. Größenverhältnisse hervorbringt.9 Diese gedachte synthetische Reflexion kann man am besten anhand einer nach oben

\footnotetext{
8 Bereits Heidegger (1929: 15) stellt fest: »Nun ist jedes Urteil als solches schon ein ,ich verbinde‘: nämlich Subjekt und Prädikat. Als Urteile sind auch die ,analytischen' Urteile schon synthetisch, wenngleich der Grund der Einstimmigkeit der Subjekt-Prädikat-Verbindung lediglich in der Subjektvorstellung liegt«.

9 Man kann demnach sagen, es werde der objektive ,Gegenstand' der Zahl Sieben hervorgebracht, insofern darunter die Zahl als eine objektive mathematische Relation verstanden wird, d. h. keine bloß subjektive Vorstellung; das reine Mannigfaltige wird also so bestimmt, dass daraus die ,objektive Zahl entspringt. Gleichwohl wird die eigentliche Verbindung im Objekt erst durch die Relationskategorien, insbesondere durch die Substanzkategorie, gedacht, insofern erst hier das Dasein des Gegenstandes nach der inneren realen Relation sowie den beiden äußeren (einseitigen oder wechselseitigen) realen Relationen bestimmt wird.
} 
geöffneten geschweiften Klammer10 veranschaulichen: Die — in der sukzessiven reinen Synthesis jeweils nach und nach gesetzten - Einsen werden durch Subsumtion unter die Kategorie der Allheit (zu der hin die geschweifte Klammer verläuft) zur Zahl (dem synthetischen Begriff) Sechs verbunden, mithin wird »Vieles in Einem als zusammen unter einen Begriff« (OP, AA 21: 247) gebracht. Genau diese Synthesis »des [hier reinen] mannigfaltigen $z u$ einer Anschauung Gegebenen « ist aber erfordert, damit diese »mir gegebenen Vorstellungen« $(K r V, \mathrm{~B} 135)$, die zwar schon »Beziehung [...] auf Einheit der Apperzeption« ( $K r V$, B145, Anm.) haben, alle »unter« $(K r V, \mathrm{~B} 135)$ dieser synthetischen Einheit stehen. Anders ausgedrückt: Dieses Darunterstehen ist nur möglich, indem sie erst »durch eine Synthesis « $(K r V, \mathrm{~B} 136)$ unter diese synthetische Apperzeption gebracht werden. Insofern erweist sich, wie erwähnt, die synthetische Einheit der Apperzeption allein als transzendentale und objektive (vgl. $K r V$, B139f.).

Inwiefern das Bewusstsein der Einheit der Synthesis, mithin die Bezogenheit aller Vorstellungen auf die synthetische Einheit zugleich einer Vereinigung der Vorstellungen untereinander entspricht, dazu kann das $»[\mathrm{~d}]$ as Wort Begriff [...] selbst« (KrV, A103) bereits Aufschluss geben. Denn »dieses eine Bewußtsein ist es, was das Mannigfaltige, nach und nach Angeschaute, und dann auch Reproduzierte, in eine Vorstellung vereinigt « ( $K r V$, A103). Anders gesagt: Die Funktion des Verstandes besteht darin, die reine Synthesis der Einbildungskraft »auf Begriffe $\mathrm{zu}$ bringen« $(\mathrm{KrV}$, A78/B103). Es ist hier die Funktion als »Einheit der Handlung, verschiedene Vorstellungen unter einer [synthetisch-]gemeinschaftlichen zu ordnen « $(K r V$, A68/B93) gemeint, folglich diese Funktion des reinen Verstandesbegriffs auf die reine Synthesis der Einbildungskraft bezogen gedacht, d. i. die synthesis speciosa (vgl. $K r V$, B151ff.). Das bedeutet, in dieser figürlichen Synthesis geben die Begriffe »dieser reinen Synthesis Einheit « $(K r V$, A79/B104) und ermöglichen so die Erkenntnis des Gegenstandes, wie das Zahlbeispiel verdeutlichen sollte. In diesem Akt der Zusammensetzung, Zusammenfügung und des Zusammendenkens, das im Spätwerk von Kant auch unter dem Ausdruck »cogitabile ut dabile« (OP, AA 22: 98; vgl. auch 23, 115) thematisch wird, ist das Mannigfaltige bzw. die »synthetische Einheit der Warnehmungen a priori [...] gedacht

10 Diese äußerst treffende Symbolisierung für die synthetische Einheit als geschweifte Klammer geht, ebenso wie die gleich noch für die analytische Einheit zu thematisierende Symbolik des Fächers, auf Kugelstadt (1998: 259f, sowie 2008: 412) zurück. 
(cogitabile) und zugleich [uneigentlich] gegeben (dabile)« (OP, AA 22: 377), d. h. gedacht und zugleich angeschaut und somit als vollständig bestimmter (formaler oder empirischer) Gegenstand gegeben. Hierdurch ist folglich die qualitative Einheit des Bewusstseins »in jedem Erkenntnisse eines Objektes«,11 d. h. auf Objektseite, ausgedrückt durch die

Einheit des Begriffes, welche man [ebenso wie die Einheit der Apperzeption] qualitative Einheit nennen kann, so fern darunter nur die Einheit der Zusammenfassung des Mannigfaltigen der Erkenntnisse gedacht wird, wie etwa die Einheit des Themas in einem Schauspiel, einer Rede, einer Fabel (KrV, B114).

Diese zeitlich bezogenen, »synthetische[n] Begriffe von Dingen« (Refl, AA 16: 548) sind zwar conceptus, werden in der Kritik aber nicht explizit von den conceptus communes unterschieden, was ein weiter Grund für die Vertauschung von synthetischer und analytischer Bewusstseinseinheit ist.

Die auf diese conceptus communes allein zu beziehenden analytische Einheit hingegen ist ein bloß objektiv-vergleichendes, nicht aber objektivverbindendes Selbstbewusstsein. Sie vergleicht durch eine andere und sich erst anschließende Reflexion die (jederzeit verbindbaren) gegebenen Vorstellungen auf bloße Gleichheit hin. Im Falle der Zahl Sechs stellt sie jede einzelne der sechs Einheiten als je gleichermaßen zur Zahl sechs gehörig fest. Sie »hängt« damit zwar »allen gemeinsamen Begriffen, als solchen, an « (KrV, B133, Anm.), jedoch nur als gemeinsamen an, d. h., sie subsumiert verschiedene Vorstellungen analytisch unter einen abstrakten

11 Dass mit dieser qualitativen Einheit, die auch ungleichartige Erkenntnisstücke vereinigt, in keiner Weise eine quantitative Einheit (vgl. Bunte 2016: 227) gemeint sein kann, nur weil sie alle Vorstellungen in einem Bewusstsein prinzipiell begleiten können muss, was somit einen quantitativen Aspekt beinhaltet, liegt schon daran, dass diese Einheit höher steht (vgl. $K r V, \mathrm{~B} 131)$ und jede spezifische Verbindung, damit also auch alle gleichartigen Erkenntnisstücke, mithin alle spezifischen quantitativen Verhältnisse, ermöglicht. Jede quantitative Einheit des gleichartig Mannigfaltigen setzt zunächst nur die spezifische Verbindungfunktion der Kategorie der Größe (Vielheit oder Allheit) voraus, worin aber jene qualitative synthetische Einheit ebenfalls gedacht ist. So werden bei partikulären Urteilen rein quantitativ gerade nicht alle Dinge in die Sphäre der Bestimmung eingeschlossen; innerhalb der durch die Kategorie der Vielheit materialiter erfassten unbestimmte Menge (»Auf der Wiese stehen viele Schafe«) wiederum müssen alle Vorstellungen in der qualitativen Einheit zusammenstehen, damit ein zusammenhängendes Urteil überhaupt möglich wird. Ferner ist es für die qualitative Einheit der Apperzeption charakteristisch, dass sie nicht alles im Gemüt gegebene Mannigfaltige auch tatsächlich zur Einheit bringt, sondern gerade nur einige Vorstellungen vermittelst kategorialer Reflexion bestimmt und damit gleichsam illuminiert. 
Begriff, einen ,conceptus communis' 12 (KrV, B134, Anm.) wobei der Begriff nun als vielen anderen Vorstellungen gemein gedacht und das Moment der möglichen jeweiligen Verbindung mit verschiedenen anderen Begriffen ausgeblendet wird.

In einer solchen analytischen Reflexion ist der conceptus als gleicher und identischer Teilbegriff damit in vielen Vorstellungskomplexen enthalten, mithin ist damit das vergleichende analytische Bewusstsein meiner selbst in den Vorstellungen bezeichnet. Man kann sich diese analytische Reflexion am besten dadurch veranschaulichen, dass man sich einen nach oben zusammenlaufenden und nach unten sich öffnenden Fächer vorstellt; hierbei wird der einzuteilende Begriff der Einheit (die Zahl bzw. Bedingung der Zahl Eins, nicht im Sinne der Kategorie der Einheit, welche eine Verbindung ausdrückt) unter allen Strängen des Fächers jeweils als Eins je gleich und identisch distribuiert, d. i. in den Vorstellungen gedacht als je identisches und damit gleiches Bewusstsein (,Eine jede Eins'). Der conceptus communis ist wiederum eine ,Beschaffenheit', die »als Merkmal irgend woran angetroffen « $(K r V, \mathrm{~B} 133$, Anm. $)$ werden kann, und zwar als analytisch ,gemeinschaftliches Merkmal', das »in einer unendlichen Menge von verschiedenen möglichen Vorstellungen« $(K r V, \mathrm{~B} 40)$ enthalten sein kann.

Während jedoch die Einheit in den Vorstellungen untereinander dadurch gestiftet wird, dass das Subjekt vermittelst der synthetischen Einheit der Apperzeption die Verstandeseinheit unter Zeitbedingungen (synthetisch-zeitlich) denkt, bleiben im Fall der analytischen Vergleichung vermittelst analytischer Einheit die einzelnen Einheiten objektiv getrennt. Zwar gehören sie, als je gleiche Einheiten, gewisser Maßen dennoch zu

12 Ein weiteres, hier nur kurz zu skizzierendes Problem besteht in der Frage, ob ein conceptus communis - wie ein synthetischer Begriff — erst gebildet werden muss. Im Falle empirischer Gattungsbegriffe muss augenscheinlich erst ein synthetischer Erfahrungsbegriff gebildet werden, damit er für alle Fälle je gleichermaßen gedacht werden kann. Aber auch im Falle der hier vorliegenden reinen Synthesis, da analytisch je gleichermaßen der - für sich bloße analytische Einheit ausdrückende - klare und gänzlich einfache Begriff der Eins gedacht wird, also ein Denken je gleichermaßen der Kategorie der Einheit, die als Grund aller Synthesis der Größe jeden synthetischen Zahlbegriff erst möglich macht, wird der conceputs erst gebildet, und zwar als conceptus communis, d. h. er gilt für jede einzelne Eins je gleichermaßen, was aber voraussetzt, dass mindestens zwei Einsen bereits objektiv zur Zahl Zwei verbunden werden können. Im Falle des klaren Begriffs findet zwar auch eine logische Reflexion auf Gleichheit hin statt, aber nicht eine solche, die zugleich mit Abstraktion verbunden ist und als verschiedenen Vorstellungen gemein gedacht wird. Vgl. dazu Olk (2016: 151ff., besonders Anm. 181, 183). 
einem Bewusstsein meiner selbst, aber nur dann und nach aller synthetischen Vereinigung als je gleiche. Damit sind sie gleichsam nur subjektiv-synthetisch in einem Bewusstsein verbunden, insofern sie ja dann alle auch in einem Bewusstsein vereinigt werden, jedoch objektiv und die Vorstellungen untereinander betreffend gerade nicht verbunden werden, sondern im analytischen Vergleichen und Zusammenhalten auf bloße Gleichheit hin, objektiv getrennt bleiben. Folglich kann erst nachträglich dann von einer jeden der verbundenen Vorstellungen gleichermaßen ,mein“ gesagt werden, so dass alle Rede von analytischer ,Meinigkeit" der Vorstellungen wesentlich keinen begrifflichen, sondern lediglich einen sprachlichen Unterschied ausmacht. Denn für andere gedachte analytische Einheiten, die auch nur unter Voraussetzung einer synthetischen als solche möglich werden (wie etwa eine jede der sieben zum Begriff der 7 verbundenen Einheiten nur durch diese Verbindung und nach ihr als je gleichermaßen zur 7 gehörig gedacht werden kann), gibt es schlichtweg kein eigenes Wort, wie dies beim Prädikat ,mein` aber gerade der Fall ist.

Um ein anderes Beispiel mit Blick auf die Relationskategorien und auf das Dasein der Gegenstände bezogen zu geben: Bei einem Auto machen nicht die je einzelnen Teile, d. h. das Fahrwerk, das Heck, das Dach, der Motor- und der Kofferraum, die Sitze, die Lampen und die Scheiben die Vorstellung des Autos je für sich aus, sondern nur alle zusammen und synthetisch-gemeinschaftlich machen sie die eine Vorstellung, den (Erfahrungs-)Begriff des ,Auto' aus — wobei jede Teilvorstellung für sich wiederum eine Substanz vorstellt, bei der das Prinzip synthetischer und analytischer Reflexion erneut angewandt werden kann. So besteht der Motor aus Schrauben, Gewinden, Antriebsketten und Zylindern, die alle zusammen den Motor ausmachen. Als dann bildbarer conceptus communis, mithin als empirischer Gattungsbegriff, kann der Erfahrungsbegriff des Autos (oder der des Motors, der Lampen etc.) dann auf je gleiche Fälle durch analytische Reflexion angewandt werden.

\section{Zusätzliches Prinzip der reflektierenden Urteilskraft}

Diese Variante der analytischen Reflexion, die nicht bloß die einzelnen Vorstellungen und Einheiten in der reinen Synthesis analytisch als je gleich 
denkt, sondern pointiert der Bildung empirischer Gattungsbegriffe dient, 13 setzt dabei immer ein zusätzliches Prinzip der bloß reflektierenden Urteilskraft voraus, wobei auf dieser dritten Stufe14 der Reflexion eine durchgängig zusammenhängende empirische Natur präsumiert wird.15 Während die bestimmende Urteilskraft im Suchen des Falles zur Regel bzw. im Suchen des passenden sinnlichen Modus der Kategorie ebenfalls reflektierend verfährt (vgl. Anm. 6), aber zugleich das Mannigfaltige (der Erscheinung) bestimmt, verfährt die bloß reflektierende Urteilskraft in ihrer Reflexion gerade nicht bestimmend; die Reflexion geschieht hier nur in Absicht auf den empirischen Gattungsbegriff im Sinne des Bemerkens von Ähnlichkeiten der Dinge, im oben genannten Beispiel das Bemerken ähnlicher Substanzen (also Autos), was allein analytisch zugeht.16 Im Falle eines Beurteilens der bloßen Gattungszugehörigkeit ist das Beurteilen eines bloßen Wiedererkennens von ähnlichen Fällen nach analytischer »Einerleiheit« (AA 29: 889). Das bedeutet, es werden die immer durch synthetische Vergleichung vermittelst des Exponenten der Analogie der Erfahrung und das Denken von Vielen in Einem gedachten objektiven empirischen Synthesen $(a+b)$ nun aufs Neue und untereinander nach der

13 Das bereits auf der Ebene der transzendentalen Grundsätze sich manifestierende Prinzip der analytischen Distribution geschieht nun auf Ebene des Empirischen nach zusätzlichem Prinzip der reflektierenden Urteilskraft als analytische Einheit der empirischen (Gattungs-)Begriffe, das bei der analytischen Reflexion auf bloße Gleichheit hin innerhalb der reinen mathematischen Synthesis (der Zahlerzeugung), aber auch der reinen objektiven Verknüpfung (Relationskategorien) augenscheinlich noch nicht thematisch war.

14 In seiner Untersuchung etabliert Kugelstadt (1998: etwa 74ff., 242ff., sowie 274ff.) in der Unterscheidung von bestimmender und bloß reflektierender Urteilskraft samt ihren Funktionen ein Drei-Stufen-Modell der Reflexion, das ausgehend vom bloß empirischen Begriff durch analytische Reflexion fortschreitet zum Erfahrungsbegriff durch synthetische Reflexion und beim empirischen Gattungsbegriff durch analytische Reflexion endet. In seinem Aufsatz von 2008 zeigt Kugelstadt ebenfalls, dass die analytische, logische Reflexion »in Absicht auf die analytische Einheit des conceptus communis als empirischen Gattungsbegriffs nach dem Prinzip der Urteilskraft« verfährt, wobei »gegebene Vorstellungen von Objekten untereinander auf analytische Einerleiheit als bloße Gleichheit in vielem hin verglichen werden, indem sie mit der Funktion des allgemeinen Urteils, einer Funktion der analytischen Einheit, zusammengehalten werden (logische Komparation und Reflexion [im engeren Sinne])« (Kugelstadt 2008: 410). Sie unterscheidet sich damit von der synthetischen, kategorial-bestimmenden Reflexion durch bestimmende Urteilskraft, im Zuge deren die Erscheinungen in einem Bewusstsein »aufs Neue untereinander, und zwar gerade durch Zusammenhalten mit der passenden dabei vereinigenden Kategorie des Verstandes, zusammengehalten und im Erfahrungsbegriff eines Objekts nach objektiv-synthetischer Einheit des Bewusstseins verbunden « (ebd: 411) werden.

15 Dabei bedarf die synthetische Ordnung der empirischen Synthesen, »als eine teils genuin empirische, durch kategoriale Reflexion der bestimmenden Urteilskraft in ihrem Materialen«, dieser Präsumtion der Urteilskraft nicht, die analytische »dann zusätzliche zwischen ihnen« freilich schon, wie Kugelstadt (1998: 261, Anm.) konstatiert. Zu den unterschiedlichen Arten der Präsumtion vgl. ebd: 128ff., besonders Anm. 177, 179 sowie Anm. 185., 208ff., 227ff., 290.

16 Vgl. Kugelstadt (1998: 177ff., 195ff., 206ff., 276 sowie 288f.). 
Präsumtion der reflektierenden Urteilskraft verglichen und unter den gemeinschaftlichen Gattungsbegriff $(\mathrm{A}+\mathrm{B})$ gebracht. Bei dieser Subsumtion wird also nicht wie bei der synthetischen unter die Analogien der Erfahrung (hin zum Erfahrungsbegriff) in Form einer synthetischen Bestimmung subsumiert, sondern durch Analogie- und Induktionsschlüsse weitere Fälle ausgemacht, die unter den Gattungsbegriff gehören. Bei der Subsumtion unter den Exponenten der Regel wird kein Fall zur Regel durch bestimmende Urteilskraft objektiv bestimmt, sondern nur subjektiv ein weiteres (gleiches) Ding als zum spezifischen empirischen Gattungsbegriff gehörig ausgemittelt. Die hier gedachte analytische Einerleiheit vieler, je gleicher für sich genommen objektiver empirischer Synthesen realisiert sich dabei in Form des allgemeinen Urteils wieder nach analytischer Einheit, wodurch alle Fälle nun wiederum »durch Reflexion [...] als identisch « (Refl, AA 16: 555) in einem Bewusstsein verbunden gedacht werden, also in einem abgeleiteten Sinne und nur subjektiv wiederum als Vieles in Einem. Diese subjektive Verbundenheit drückt aber objektiv jederzeit nur die distributive Einheit des analytischen Eines-in-Vielem-Denkens aus. Die Differenz synthetisch-kollektiver und analytisch-distributiver Einheit manifestiert sich an dieser Stelle erneut als zwei komplementäre Arten der Reflexion, indem gerade dieses kollektive Vieles in Einem $(a+b)$ dabei zugleich wieder distributiv als Eines identisch in vielem $(\mathrm{A}+\mathrm{B})$ gedacht wird. So gilt im Beispiel ,Alle Autos verfügen über eine Gangschaltung ‘ diese objektiv-synthetische empirische Regel für alle vorkommenden Fälle in der Welt, d. h. ein jedes Auto weist dieses Gattungsmerkmal auf. Oder, um ein anderes Bsp. zu machen: ,Alle Menschen sind sterblich', d. h. ein jeder der Gattung Mensch ist sterblich, d. h. ihm kommt das Gattungsmerkmal zu.17 Würde die Urteilskraft nicht diese empirische Regelmäßigkeit ganzer Klassen von Dingen als ein transzendentales, aber

${ }_{17}$ Die zu Beginn getroffene Unterscheidung und synthetischer und analytischer Allgemeinheit bzw. Gemeinschaftlichkeit bestätigt sich auch noch einmal mit Blick auf das von Kant bemühte Beispiel der Einheit des Themas in einem Schauspiel. Insofern nun jeder Akt analytisch je für sich genommen wird (der erste, zweite, dritte, vierte oder fünfte Akt je für sich) und nicht alle Akte im Verbund (als ein Schauspiel) nach synthetischer Einheit betrachtet werden, d. h. alle zusammen, enthält der conceptus, nun als communis, die Eins je gleich distribuiert unter sich (je ein einzelner Akt), bevor dann in einem nächsten Schritt — und wiederum nach aller synthetischen Reflexion und synthetischen Exposition der Erscheinung - analytisch der Begriff des Schauspiels aus einer Vielzahl von Theateraufführungen als gemeinschaftliches Merkmal extrahiert und zum conceptus communis als konkretem empirischem Gattungsbegriff, nach einem zusätzlichen und präsumierten Prinzip der reflektierenden Urteilskraft, erhoben werden kann, indem etwa von allen Unterschieden verschiedener Aufführungen abstrahiert wird. 
nur regulatives und subjektiv gültiges Prinzip voraussetzen, würde sich die Vielzahl der faktisch vorkommenden unterschiedlichen Arten von Dingen, etwa der spezifischen Kausalitäten, irgendwann nicht mehr überblicken lassen, so dass es fraglich wäre, ob es überhaupt eine Art regelmäßiger empirischer Erkenntnis, die freilich immer nur komparativ ist, geben kann.

Angesichts dieses Umstands leuchtet ein, warum das Prinzip der analytischen Reflexion hin zum empirischen Gattungsbegriff bereits die vollständige Bestimmung des Gegenstandes, insbesondere durch die auf das Dasein des Gegenstandes gehenden Relationskategorien, vermittelst der bestimmenden Urteilskraft, erfordert, die durch synthetische Exposition der Erscheinung (des Mannigfaltigen respektive des sinnlichen Begriffs dieses Mannigfaltigen) diese zum Gegenstand der Erfahrung macht. Ohne vorige Bestimmung eines Erfahrungsgegenstandes, mithin ohne die Erhebung des empirischen Begriffs zum Erfahrungsbegriff, würde sich späterhin keine Gleichheit der Dinge für alle Fälle aussagen lassen.

\section{Schlussbetrachtung}

Abschließend bleibt noch einmal zu konstatieren, dass der Begriff der Identität verschiedene Bedeutung in der Kantischen Philosophie hat. Abgesehen von der zeitlich-numerischen Identität des Gegenstandes, die immer nur eine durchgängige Identität nach bzw. von ursprünglich synthetischer Einheit ausdrückt, gibt es also eine Art von derivativer Identität, die nur der analytischen Einheit zukommt, und insofern ein eigenes Moment des Bewusstseins bzw. der Reflexion ausmacht. Während im ersten Fall das Subjekt sich jederzeit ,der Identität der Funktion“ der Synthesis bewusst sein muss, weshalb »das ursprüngliche Bewußtsein der Identität seiner selbst zugleich ein Bewußtsein einer eben so notwendigen Einheit der Synthesis aller Erscheinungen nach Begriffen, d. i. nach [synthetischen Grundsätzen als wiederum analytischen] Regeln « ist, besteht die »Identität seiner selbst in der Mannigfaltigkeit seiner Vorstellungen « $(K r V$, A108) im Bewußtsein analytischer Einheit. Deshalb kommt es bekanntlich auch nicht darauf an, ob »die Vorstellungen selbst identisch sind, und also eine durch die andere analytisch könne gedacht werden «, denn das »Bewußtsein der einen [ist] vom Bewußtsein der anderen doch immer $\mathrm{zu}$ unterscheiden», sondern nur »auf die Synthesis dieses (möglichen) Bewußtseins« $(K r V$, B131, Anm.) Dabei muss jede 
Vorstellung, die »als verschieden gemein gedacht werden soll«, als »in synthetischer Einheit mit anderen« Vorstellungen, die jederzeit »noch etwas Verschiedenes [außer ihr] an sich haben« (KrV, B133f., Anm.), verbindbar gedacht werden. Jede Vorstellung 18 muss also in prinzipiell möglicher synthetischer Einheit gedacht werden können, »ehe ich die analytische Einheit des Bewußtseins«, welche die Vorstellung »zum conceptus communis macht, an ihr denken kann« (ebd.).19

Die synthetische Einheit der Apperzeption kann damit allein als ursprüngliches Selbstbewusstsein gelten, die ihr entsprechende synthetische Reflexion allein ist gegenstandskonstitutiv, während die analytische Reflexion auf bloße Gleichheit hin keine Verbindung im Objekt denkt und somit die Vorstellungen objektiv getrennt bleiben. Es sei noch einmal herausgestellt, dass es sich bei der durchgängigen Identität des Selbstbewusstseins damit nicht um ein Identitätsbewusstsein handeln kann, das in den Vorstellungen liegt, sondern vielmehr um ein solches, in dem alle Vorstellungen vereinigt werden können. Ursprünglich ist also nicht das Bewusstsein des Einen in Vielem, sondern das Bewusstsein des Vielen in Einem. Dieses eine Bewusstsein des Vielen in Einem als zusammen drückt sich auf Seiten der Vorstellungen in Form einer der zwölf Kategorien, als synthetischer Reflexionsformen (die synthetische Einerleiheit des »vielen in einem $\ll)$ aus.

\footnotetext{
18 Dies bestätigt noch einmal den Befund, dass die analytische Bewusstseinseinheit eine nur derivative und abgeleitete, keine ursprüngliche Einheit des Selbstbewusstseins sein kann. Sie denkt einen Begriff, wie etwa »rot überhaupt « jederzeit nur als eine »Beschaffenheit«, die »als Merkmal irgend woran angetroffen « $(K r V, \mathrm{~B} 133$, Anm. $)$ werden kann, und zwar als analytisch »gemeinschaftliches Merkmal«, das «in einer unendlichen Menge von verschiedenen möglichen Vorstellungen« $(K r V, \mathrm{~B} 40)$ enthalten sein kann. Dass sie den Begriffen als solchen anhängt, bedeutet also keineswegs, dass sie die einzelnen Begriffe auch objektiv verbindet (respektive die einzelne Anschauung objektiv unter den synthetischen Begriff subsumiert) und diesen damit so anhängt, wie die vorauszudenkende synthetische Einheit.

19 Der Verstand kann also nur trennen, was er zuvor verbunden hat (vgl. $K r V$, B130). Um hier nochmal auf das erste Beispiel der Bildung spezifischer Größenbegriffe zurückzukommen: Gemäß der Kategorie der Allheit, nach der »ein Ding mit vielen zusammen einerlei, d. i. eine Größe« $(K r V$, B288) ist, werden dementsprechend nicht analytisch distributiv, sondern synthetisch gemeinschaftlich — dann wiederum auch analytisch gemeinschaftlich zu verstehende — je gleiche Teile vereinigt.
} 


\section{Literaturverzeichnis}

BUNTE, M.: Erkenntnis und Funktion (Kantstudien-Ergänzungshefte 189), Berlin/Boston, De Gruyter, 2016.

DEPPERMANN, A.: „Eine analytische Interpretation von Kants ,ich denke““, Kant-Studien 92 (2001) 129-152.

DÜRR, S.: „Das Prinzip der Subjektivität überhaupt“: Fichtes Theorie des Selbstbewusstseins (1794-1799), Jena, Wilhelm Fink Verlag, 2018.

HEIDEGGER, M.: Kant und das Problem der Metaphysik, Frankfurt am Main, Vittorio Klostermann, 1998, 1929 (6 ed).

KUGELSTADT, M.: Synthetische Reflexion. Zur Stellung einer nach Kategorien reflektierenden Urteilskraft in Kants theoretischer Philosophie (Kantstudien-Ergänzungshefte 132), Berlin/New York, De Gruyter, 1998.

: „Inwiefern kann bei Kant von analytischer Einheit des Selbstbewußtseins überhaupt die Rede sein?", in RHODEN, V. (e.a.) (Hrsg.): Recht und Frieden in der Philosophie Kants. Akten des X. Internationalen Kant-Kongresses. Bd. II/2: Sektionsbeiträge (Kants theoretische Philosophie), Berlin/New York, De Gruyter, 2008, 407-418.

OLK, C.: Kants Theorie der Synthesis. Zu einem grundlegenden Gedanken der kritischen Philosophie (Kantstudien-Ergänzungshefte 192), Berlin/Boston, de Gruyter, 2016.

PATON, H. J.: Kant's Metaphysic of Experience. A Commentary on the First Half of the "Kritik der reinen Vernunft", I. New York, George Allen, 1976.

SCHÖNRICH, G.: Kategorien und transzendentale Argumentation. Kant und die Idee einer transzendentalen Semiotik, Frankfurt am Main, Suhrkamp, 1981. 


\title{
En defensa de la actualidad de una Crítica de la razón pura
}

\author{
ALEJANDRO LANCHAS SÁNCHEZ
}

\begin{abstract}
Resumen
Propondremos aquí una lectura del texto "Las anticipaciones de la percepción", donde se demuestra el principio trascendental (matemático) que fundamenta la posibilidad del conocimiento real del objeto de la sensación, como contenido en una percepción, en la medida en que este posee una magnitud intensiva, un grado. Con esto se trata de apuntar hacia una defensa de la necesidad de una $\mathrm{KrV}$ frente a las críticas contemporáneas que, tanto desde la ciencia como desde la propia filosofía, anuncian su pretendida inactualidad.
\end{abstract}

Palabras clave: Kant, anticipación, percepción, sensación, juicio

\section{In defence of the contemporaneity of the Critique of pure reason}

\begin{abstract}
Here I will propose a reading of the text "Anticipation of perception". This text demonstrates the Transcendental (Mathematical) Principle which lays the foundations of the possibility of real knowledge of the object of sensibility. The object of sensibility is contained within perception, since perception has intensive magnitude. The purpose of this reading is to make a defense of the necessity of the Critique of pure reason against its contemporary critics (from science to philosophy).
\end{abstract}

Keywords: Kant, anticipation, perception, sensation, judge

\section{Introducción. Sobre la pretendida inactualidad de la Crítica}

¿Es posible hablar de actualidad cuando nos referimos a una obra como la Crítica de la razón pura? Es un lugar común en el debate filosófico contemporáneo el rechazar la obra kantiana denunciándose en ella una

1 Universidad Complutense de Madrid. Contacto: alanchas@ucm.es. 
pretendida inactualidad por encontrarse sometida a las exigencias epistemológicas de su época. Nuestra defensa de dicha actualidad va a consistir en mostrar que, pese al abandono de su contexto y sus presupuestos, todavía seguimos siendo interpelados por el contenido filosófico. Dicho contenido forma parte de un proyecto de miras muy superiores y puede estudiarse con independencia de una lectura netamente historicista del texto. Lo que nosotros defendemos, por tanto, es la actualidad de su filosofía.

Para los detractores, parece que Kant es un pensador oxidado y mal envejecido que, por haber aceptado rigurosamente los presupuestos epistemológicos de la física newtoniana y haber edificado una ontología (si bien de corte más 'modesto') destinada a legitimar los mismos, es totalmente incompatible con el actual desarrollo científico y epistemológico. Kant, de acuerdo con estas lecturas,

\begin{abstract}
definió el espacio y el tiempo tal como él los conocía, como la forma de nuestra intuición mental (Anschauung) [...] No diré que la idea de Kant era totalmente errónea, pero sí sin duda excesivamente rígida y exigía ser modificada a la luz de nuevas posibilidades, como, por ejemplo, la de que el espacio puede ser (y probablemente es) cerrado sobre sí mismo, aunque sin límites, y la de que dos acontecimientos pueden suceder de tal modo que cualquiera de ellos cabe ser considerado como previo (esta es la faceta más novedosa de la Teoría Restringida de la Relatividad de Einstein) (Schrödinger 1985: 62).
\end{abstract}

Gilles Deleuze, en su apuesta por una ontología de la inmanencia (que niega de raíz una separación entre un contenido filosófico y un contenido científico) se alinea con estos críticos de Kant y considera que el gran defecto de la $K r V$ encuentra su germen en que,

en el mismo momento en que le niega al espacio, como al tiempo, una extensión lógica, continúa reconociéndoles una extensión geométrica, al tiempo que reserva la cantidad intensiva para una materia que llena una extensión en determinado grado. [...] El espacio como intuición pura es cantidad intensiva; y la intensidad como principio trascendental no es simplemente la anticipación de la percepción sino el origen de una génesis cuádruple, la de las extensiones como esquemas, la de la extensión como magnitud extensiva, la de la qualitas como materia que ocupa la extensión, la del quale como designación del objeto (2009: 346). 
Hemos presentado aquí dos visiones que, tanto desde la ciencia como desde la filosofía, 2 ponen de manifiesto el problema de la denunciada inactualidad de la obra kantiana. Frente a ello, de lo que se trata aquí es de mostrar la vigencia de la misma; y nos ocuparemos de ello entrando a comentar de raíz el texto al que alude el propio Deleuze: "Las anticipaciones de la percepción".

\section{Las anticipaciones de la percepción}

\subsection{Origen del problema de "Las anticipaciones de la percepción"}

¿Cuál es el interés de este texto que nos parece actual? Aunque nuestra búsqueda sea la de una actualidad en su filosofía, sería ingenuo cerrar los ojos a que el campo de operaciones de Kant es el de la experiencia objetiva del conocimiento natural físico-matemático de la filosofía moderna.

Y esta, si bien no abandonó la noción de la forma material de la que hablaban los escolásticos, había reducido la materia a cantidad favoreciendo la conversión del mundo de los sentidos en favor de la especulación matemática. Como consecuencia, nos encontramos en un panorama donde la proyección matemática de la cosa como un movimiento extenso en espacio y tiempo va a tener como consecuencia que lo dado en el trato cotidiano se conciba como mero material y que se desintegre en la multiplicidad de sensaciones. De acuerdo con Heidegger:

Cuanto más se impuso la visión que considera las cosas como mero aspecto, según forma, situación y extensión (Demócrito y Platón), tanto más debió destacarse

\footnotetext{
2 En este sentido, es interesante tener en cuenta lecturas como la de Friedman (1992), que apuestan por una posición intermedia en tanto que Kant, siendo un teórico de la ciencia de su tiempo y funcionando dentro de los límites de esta, tiene algo que decir en la historia de la ciencia. De acuerdo con Peláez Cedrés (2007), la postura apuesta por defender el a priori relativizado, inspirado en el $a$ priori kantiano, pero con la peculiaridad de ser transformable. De este modo, dentro de ámbitos y teorías de la física matemática, como por ejemplo la mecánica newtoniana y la teoría de la relatividad, son entendidas como conformando una entidad asimétrica. Vemos aquí la diferencia del autor con Kant y al mismo tiempo el interés que supone el filósofo alemán para este. Ha abierto la posibilidad de producir principios a priori en teorías sucesivas y quizás incompatibles. "Para Kant, el recurso a la intuición no es un defecto, sino un rasgo esencial de la demostración matemática. Si la filosofía de Kant tiene alguna virtud, es esta: lo bien que se ajusta al estado de las ciencias matemáticas de su tiempo, un logro que no ha podido igualar la posteridad. Es por construcción que el geómetra exhibe ciertos objetos, lo cual lo exime de probar su existencia. Por otra parte, los axiomas y postulados que ofrece Euclides eran insuficientes para probar tal cosa. Lo anterior explica la necesidad de las figuras en la geometría elemental. Y Kant lo único que hizo fue idear el marco teórico correspondiente a tal "estado de cosas"” (Peláez Cedrés 2007: 54).
} 
frente a las relaciones situacionales lo sensorialmente dado, aquello que llena las distancias y los lugares. En consecuencia los datos sensoriales - color, tono, presión, choque - se transformaron en los elementos primeros y verdaderos de los cuales se componen las cosas (1975: 160).

Kant, en el tratamiento de este problema se adhiere al uso del concepto metafísico de realidad propio de los tratados de Baumgarten y de la tradición metafísica medieval y moderna; para este, el carácter fundamental de la realitas es el de la determinación. 'Realidad', en este contexto, proviene de realitas; y realis significa algo que pertenece a la res, que mienta a la cosa. Así, 'realidad' significa la totalidad de determinaciones esenciales de una cosa, o las partes integrantes de la misma. En este sentido, el ser real mismo, la existencia, era algo que se agregaba a la esencia, de tal modo que la existencia misma se comprendió como una realidad. La realitas es una determinación positiva relativa a la esencia verdadera de una cosa y puesta como tal. El concepto contrario sería el de la determinación del objeto con respecto a aquello que le falta. Dicho contrario es, por tanto, negación.

Hasta aquí tenemos la deuda de Kant con su tiempo. Aparentemente, lo actual se encuentra en el objeto y lo defendido se encuentra en el procedimiento y en los presupuestos. El tema, como decimos, puede ser salvado y tanto la epistemología como la metafísica de nuestro tiempo se interesarían por él. Nuestra apuesta va a consistir en poner el foco de atención precisamente en sus procedimientos y presupuestos para así sacar a la luz lo fundamental e interesante de la filosofía kantiana. ¿En qué consiste dicho procedimiento? Martínez Marzoa lo presenta de la siguiente manera:

Así, pues, por lo mismo por lo que se busca evitar que lo válido sea lo empírico, se tiende también a eliminar cuanto más mejor las consecuencias del incómodo estado de cosas consistente en que el ius sea un Facktum, la cosa del pensar algo con lo que nos encontramos y el pensar mismo epagogé (1992: 27).

Se trata, por tanto de sacar a la luz un modo de proceder de corte fenomenológico. Un modo de proceder que no persigue encontrar en la filosofía un fundamento de lo empírico, sino que más bien rastrea un contenido filosófico. Dicho contenido podrá, posteriormente, tener 
funciones organizadoras, estructuradoras, limitadoras y alentadoras (de hecho, un pilar básico en Kant es entender la profunda afinidad para este entre su modo de entender la metafísica y su modo de pensar lo jurídico). Pero, en todo caso, será un contenido con el que nos tendremos que topar en una búsqueda. La actualidad kantiana es la de una doctrina de las formas de la experiencia. Hablar de formas y de un 'encontrarse' apela a una pluralidad de suyo originaria. A la resignación, al menos para nosotros, seres finitos, del sueño de conquistar un principio desde el que derivar el resto de lo cognoscible. De una diversidad, por tanto, de sentidos del ser.

2.2. El lugar de "Las anticipaciones de la percepción" en la $K r V$. Principio matemático y principio dinámico

"Las anticipaciones de la percepción" se presenta en la $\mathrm{KrV}$ como el segundo de los Principios trascendentales del entendimiento inmediatamente a continuación de los Axiomas del entendimiento. Tanto estos como los primeros serán los llamados 'principios matemáticos'.

Los principios del uso matemático serán, pues, incondicionalmente necesarios, es decir, apodícticos, mientras que los del uso dinámico, si bien conllevarán igualmente el carácter de una necesidad a priori, solo la conllevarán bajo la condición del pensar empírico en una experiencia, es decir, solo mediata e indirectamente $(K r V, \mathrm{~A} 160 / \mathrm{B} 199)$.

De este modo, podemos ver cómo la diferencia entre principios matemáticos y dinámicos está en que los primeros son principios para (hacer posible) la síntesis de lo homogéneo en la experiencia (y lo homogéneo es siempre magnitud, quantum, ya sea extensiva - axiomas, cantidad, forma del fenómeno - ya sea intensiva - anticipaciones, grado, realitas o contenido del fenómeno-), mientras que los segundos hacen posible la síntesis de lo heterogéneo en la experiencia, ya sea que se trate de la existencia de los fenómenos en sí (enlace sustancia-accidentes, causa-sus efectos, substancias en relaciones causales de influencia recíproca analogías-), ya sea que se trate de la relación de los modos posibles de dársenos los fenómenos a nosotros (como contingentes, como efectivamente reales o como necesarios - postulados-). 
Nos referimos, pues, a aquellos principios en los cuales el juicio de determinación se produce mediante un concepto aplicado directamente sobre una intuición, esto es, aquellos principios relativos precisamente a la esencia de la cosa. Esto implica, por tanto, un conocimiento producido en atención a que el fenómeno se nos presente como dado. Frente a estos principios se encuadrarían los dinámicos, que hacen referencia a la estancia de las cosas, a su existencia, a su presencia objetiva. Mientras que los primeros, de acuerdo con Kant, poseerán una certeza intuitiva, los segundos se caracterizarán por una certeza meramente discursiva. Es importante en esta distinción tener en cuenta lo que se nos advertía ya en la estética trascendental:

\footnotetext{
La diferencia entre una representación clara y otra confusa es puramente lógica y no afecta a su contenido. [...] Esta receptividad de nuestra facultad cognoscitiva se llama sensibilidad y es completamente distinta del conocimiento del objeto en sí mismo, aun en el caso de que pudiera penetrarse hasta el fondo de dicho fenómeno. [...] Tal diferencia no afecta solo a la forma de la claridad o confusión, sino al origen y contenido de los conocimientos ( $K r V$, A43/B61).
}

De este modo, como podemos ver, la diferencia que hay entre estos dos tipos de conocimiento no es meramente de grado o de claridad, sino que se trata de una diferencia trascendental, una diferencia relativa a la procedencia del conocimiento y a la especificidad material de los mismos.

Por otra parte, tomaremos como punto de partida una nueva distinción: mientras en los axiomas de la intuición se consideraba a los fenómenos meramente por su forma (la de lo dado en una intuición, de lo que se encuentra contenido entre los moldes del tiempo y el espacio), aquí se atiende a los fenómenos en tanto que contenido de una percepción, esto es, teniendo en cuenta que no meramente ocupan una extensión en el tiempo y en el espacio, sino que 'lo llenan'. Lo que esto significa es que estamos enfrentándonos a una forma de determinar los fenómenos que atiende a los mismos en tanto en que pueden ser contenidos de una percepción y en tanto que producen una determinada afección en un sujeto teniendo, por tanto, una intensidad, que es lo determinable a la manera en que la materia lo es con respecto a la forma. 
Y esto se traduce, en nuestra lectura que pone el foco en el contenido filosófico de la investigación, en dos modos trascendentales, distintos pero complementarios, de recaer sobre lo mismo. Antes teníamos el concepto de intuición y sus axiomas. Ahora tenemos el concepto de percepción y sus anticipaciones.

\title{
2.3. El concepto de la percepción
}

¿Qué es una percepción?

\begin{abstract}
Percepción equivale a tener conciencia empírica de aquello lo cual al tiempo tenemos una sensación. Así, el fenómeno, en cuanto objeto de la percepción no es sin más una intuición pura como el tiempo y el espacio, sino que incluye a la vez algo material relativo a algún objeto en general, es decir, lo real de la sensación en tanto que mera representación subjetiva, que solo nos hace conscientes de que el sujeto está afectado y que nos referimos a un objeto en general ( $\mathrm{KrV}$, A166-167/ B207-208).
\end{abstract}

Una percepción es una manera de captar un fenómeno en la que este se muestra como dado frente a un observador, en el que se muestra como saliendo al encuentro de una manera tal que sea algo otro distinto del sujeto que conoce. Una captación que, además, tendrá en cuenta un material relativo a algún objeto en general, esto es, un carácter 'sensacional', netamente empírico. Y ¿cómo explica Kant este carácter de 'llenado' o de afección? Si atendemos al texto, esta representación subjetiva implicada en la percepción nos conduce a tener en cuenta dos aspectos presentes en el conocimiento: el sujeto y el objeto. Las anticipaciones de la percepción, como podemos ver, tienen la peculiaridad de que ponen en evidencia, tal como insiste el propio Kant, la existencia de un sujeto que está siendo llenado por el contenido de una representación subjetiva, cuya raíz procede de un objeto en general. De este modo, lo anticipado en la percepción es algo objetivo, una propiedad de la cosa que hace a la cosa ser lo que es y le permite ser aprehendida por un sujeto.

Dicho de otro modo, lo peculiar de "Las anticipaciones de la percepción" es que pone el foco de atención en el carácter trascendental del juicio sacándolo a la luz. Se presenta el abecé de la experiencia cotidiana sin por ello hipostasiar para la naturaleza sus exigencias (como pretenderían los críticos de Kant), en el seno de un debate en torno a los principios 
matemáticos del entendimiento. Así, nos encontramos con que en el espacio entre lo puro y lo empírico hay algo, un vacío, un campo abierto en el que es posible que lo dado varíe entre el extremo de un estímulo pleno y el vacío del ámbito espacio-temporal, de acuerdo a cuya variación resulta posible establecer una cuantificación. Y, como más adelante podremos ver, este espacio de llenado se presentará bajo la forma de una anticipación. Esto puede sonar extraño pero, sin embargo, antes de incidir en este aspecto anticipativo o activo de la receptividad, es preciso advertir que el contenido material de la sensación se experimentará siempre como la posibilidad de una modificación gradual desde la conciencia empírica hasta llegar a la conciencia pura, una modificación donde desaparece completamente lo real, quedando tan solo una conciencia perfectamente formal (a priori) de la variedad en el espacio y el tiempo. Y será esto lo que implicará la posibilidad de una síntesis que genere la magnitud de la sensación, desde su comienzo como intuición pura $=0$, hasta una magnitud cualquiera. Así, lo peculiar de esta magnitud es que no atiende a la pura extensión del fenómeno, sino que es el resultado de una síntesis previa del entendimiento que sale en busca de la sensación para darle un número, con lo que, consiguientemente, la sensación obtendrá una magnitud intensiva. En correspondencia con esta magnitud hay que asignar a todos los objetos de la percepción (en la medida en que esta contenga sensación) un grado de influencia sobre el sentido. 3

\footnotetext{
3 Es interesante anotar la importancia del texto en el estudio comparado de la filosofía posterior. En Hegel, la cuestión de los límites de la percepción ha evolucionado. Si pensamos en el análisis hegeliano de la percepción o tomar por verdadero en la Fenomenología del espíritu, nos encontramos con que lo interesante de dicho análisis frente al kantiano está, en primer lugar, en que existe desde el primer momento la pretensión de alcanzar un fundamento último de la realidad. Y al constatarse, la insuficiencia para el investigador de dicho fundamento tendrá que evolucionar a un modo más especulativo del conocer que es el entendimiento. Para Hegel, la conciencia se encontraría con una dialéctica entre la división de la cosa en una pluralidad de determinaciones: esta sal blanca, que también es cúbica, que también es sólida, etc; y la unidad de ser una cosa como tal. Esta unidad, de hecho, es postulada por la propia conciencia y recibe el nombre de sofistería porque es incapaz de encontrarla como tal en la cosa misma. Se teje una red entre las propiedades, pero somos incapaces de explicar el motor de tales propiedades, quedándonos sin más en un registro de las mismas. El paso al entendimiento en la Fenomenología del espíritu vendría exigido porque la mera percepción no puede producir un contenido valedero más allá de constatar la división de la cosa en una infinidad de propiedades. Cuando confronta el contexto científico y filosófico al que hemos hecho referencia se encuentra con que el material universal que hay en juego está todavía demasiado vinculado a lo sensible $\mathrm{y}$, por ello, la conciencia tendrá que renunciar a este y necesitará poder tratar con un universal incondicionado, basando en ello su paso al entendimiento. "La percepción, entendida como lo mediado, no es tan solo en el sentido de lo necesariamente obtenido como resultado de la mediación desde la certeza sensible, sino también, al mismo tiempo, en el sentido de lo emplazado en el medio, y esto significa: su objetividad absoluta sería unilateral, así pues, no captada de una manera
} 
En este estudio pretendemos mostrar lo transgresor que es el concepto kantiano de anticipación. De un lado, se propone un contenido ontológico a la base del contenido de las sensaciones y, de otro, se renuncia a acceder a un principio que sea motor de lo real. El concepto kantiano de anticipación apuntará a una ontología de corte más organicista y jurídico, porque lo que pone en evidencia es una constitución (algo indispensable en cualquier ordenamiento jurídico, ser más que un ordenado conjunto de leyes, sino disponer de principios que permitan la interpretación y la orientación). No persigue una fusión completa sino una estructuración, una mesura, un principio.

A nadie se le escapa que, al menos aparentemente, nos encontramos inmersos en una sibilina contradicción en la medida en que parecemos afirmar al mismo tiempo que una síntesis previa genera la magnitud de la sensación, desde su comienzo como intuición pura $=0$, hasta una magnitud cualquiera y, al mismo tiempo, que esto es lo que nos permite probar que en toda sensación podrá cuantificarse un, lo repetimos, grado de influencia sobre el sentido recogido en una magnitud. ¿En qué manera se puede anticipar algo del fenómeno en tanto que contenido de una percepción y en qué medida puede hacerse sin que esto implique una petición de principio? Ya hemos anticipado muy fugazmente cómo en Hegel esta cuestión se resuelve en un modo dialéctico de proceder. Veremos cómo plantea Kant el problema, apostando, como hemos venido insistiendo, en la cuestión de los límites.

\subsection{El concepto de anticipación}

¿Por qué Kant escoge el nombre de 'anticipación'? Anticipación, prolepsis, es un término que alude a un a priori de lo empírico pero en el modo de una actividad, la actividad de prevenir. La anticipación, así, viene a ser lo real - esto es, lo objetual- del fenómeno en tanto que contenido de una percepción entendida en los términos ya comentados. De lo que se tata con la anticipación es de señalar la separación entre un contenido que puede ser dicho con anterioridad a una experiencia y a otro que no puede ser anticipado y que tiene que darse siempre en el seno de esta, y que en todo caso será lo que perciba el sujeto empírico. Nos encontramos en uno de esos momentos clave de la $K r V$ en los que sale a la luz la abismal brecha entre lo

absoluta si en este momento solo quisiéramos tomarla atendiendo al lado de la certeza sensible y su procedencia absolvente" (Heidegger 2006: 119). 
empírico y lo trascendental. Aquí surge la 'realidad', eso determinable en la intuición empírica como correspondiente a la sensación. Pero también la 'negatividad', que será lo correspondiente a la falta de aquella. Esta sensación, además, en tanto que se da como afectando a un sujeto que anticipa algo como real en lo sensible, tiene siempre lugar en un momento y de una sola vez, sin que podamos proceder a construirlo mediante la adhesión gradual entre partes.

Tratemos de explicarlo:4 uno puede construir una extensión de dos metros si suma dos extensiones de un metro y un metro. En cambio, si dispone de un cubo de una temperatura de 4 grados centígrados y otro de dos, y procede a juntarlos, en ningún caso se alcanzará una temperatura de 6 grados, sino que, por el contrario, los dos cubos tenderán a alcanzar una temperatura intermedia. Será el propio Kant quien lo formulará de esta manera:

\begin{abstract}
Llamo magnitud intensiva a aquella que únicamente aprehendemos como unidad y en la que solo podemos representar la multiplicidad por aproximación a la negación $=0$. Así, toda realidad en el campo del fenómeno posee magnitud intensiva, es decir, un grado ( $K r V$, A168/B210).
\end{abstract}

A fin de cuentas, la intensidad no es otra cosa que aquello que podemos cuantificar en una cualidad. Captar una magnitud extensiva implica captar paso a paso la extensión, al modo de un recorrer parte a parte una suma de fracciones que componen una totalidad. Por el contrario, en el caso de la intensión, como por ejemplo la aprensión de un brillo, de lo que se trata es de atender a la fuerza de ese brillo, al cuánto brilla, a la coloración. De esta manera, la magnitud intensiva se capta inmediatamente como unidad y, precisamente por ello, tendremos que admitir de la multiplicidad que le pertenece solo se le presenta acercando algo intensivo hasta cero. Las multiplicidades individuales de la magnitud intensiva surgen más bien de la limitación de la unidad de un quale, siendo ellas mismas a la vez un quale, $\mathrm{y}$

\footnotetext{
4 En definitiva, podemos ver cómo el punto central se encuentra en mostrar que a través de la sensación se obtienen cualidades. ¿Dónde se produce dicha obtención? En el instante. Ya anunciamos antes cómo la clave de este principio está en su carácter homogéneo, es decir, en la síntesis de lo homogéneo. Sin embargo, es fundamental destacar aquello en lo que venimos insistiendo y es en que no se trata de una síntesis meramente de agregación, porque con lo que tratamos no es con una magnitud extensiva, sino una intensiva (Klemme 1998: 259).
} 
así sucesivamente. Y es a tales unidades a lo que llamamos grados. En un tono fuerte, lo que hay es un escalamiento desde los tonos más débiles hasta el mismo porque las multiplicidades de la unidad de una extensión son en cada caso unidades particulares de una multiplicidad. Esto implica, en todo caso, que

las posiciones presuponen siempre las intuiciones a limitar o a delimitar: si partimos de meras posiciones o de componentes que pudieran darse con anterioridad al espacio o al tiempo no podremos componer ninguno de los dos. Teniendo en cuenta que la síntesis (de la imaginación productiva) generadora de estas magnitudes representa un progreso temporal cuya continuidad suele designarse con el término fluir (correr), podemos también calificar estas magnitudes como fluyentes ( $K r V$, A170/B212).

Pues bien, pese a las diferencias que podamos encontrar entre ellas, hay algo que podemos decir en defensa de la unidad, y es el hecho de que ambas son compatibles y pueden ser coordinadas en una única experiencia, precisamente en la medida en que ambas pertenecen a lo relativo al fenómeno (frente a los principios dinámicos que nos aportan conocimiento relativo a lo pensado del fenómeno en una conciencia), lo cual además nos permitirá considerarlas como magnitudes continuas, esto es, magnitudes fluyentes, en tanto que son quanta continua y que no puede darse parte de forma alguna que no esté comprendida entre unos límites. Y esta idea va a resultar fundamental para proscribirnos de derivar de aquí la causalidad o cualquier suerte de un puro estar absoluto en el tiempo, lo cual, insistimos, solo sería válido si atendiésemos a la pura pensabilidad del fenómeno en tanto que inscrito en una conciencia. La modificabilidad afecta únicamente a ciertas determinaciones de los fenómenos que solo la experiencia puede mostrarnos.

\section{Conclusión}

¿Cuáles son, entonces, las verdaderas implicaciones de esta particular modificabilidad preceptiva? Hemos dejado claro que no es posible en ningún caso la posibilidad de una experiencia pura del tiempo o del espacio, como no sea la practicada en los axiomas de la intuición, en tanto que ateniendo exclusivamente a la pura forma del darse del fenómeno como 
extensivo. En esta ocasión, dado que no tenemos ahora ante nosotros cosa alguna de la que servirnos, como no sean los conceptos puros básicos de toda experiencia posible — los de la sensibilidad misma - no podremos anticipar, sin lesionar la unidad del sistema, la ciencia universal de la naturaleza, por ser esta una ciencia edificada sobre determinadas experiencias básicas. Es decir, nunca podemos derivar prueba alguna de un espacio o de un tiempo, vacíos, a partir de la experiencia, pues en todo caso contamos con intuición sensible que solo puede operar con fenómenos, cuyo aspecto sea el de lo ya dado en la intuición.

En una palabra: de lo trascendental no podemos derivar lo empírico. Pero resulta que lo único que aquí se pretende es simplemente mostrar, partiendo de un principio del entendimiento puro, que la naturaleza de nuestras percepciones posibilita semejante tipo de explicación, y que se yerra al suponer la realidad fenoménica como igual en virtud de su grado y como distinta en virtud simplemente de la agregación y de la magnitud extensiva de esta. Se yerra cuando se pretende incluso afirmar esto a priori basándose en un principio del entendimiento. De este modo, no es posible olvidar cómo la cualidad de los fenómenos es siempre meramente empírica, pues "lo real correspondiente a las sensaciones en general solo representa, en oposición a la negación $=0$, algo cuyo concepto contiene en sí un ser y no significa más que la síntesis realizada en una conciencia en general" ( $\mathrm{KrV}$, A176/B218). Podemos, pues, prescindir por completo de la magnitud extensiva del fenómeno y, no obstante, representarnos en la mera sensación, en un momento, una síntesis del entendimiento uniforme desde 0 hasta la conciencia empírica dada. Introducir las magnitudes intensivas como algo relativo a un contenido anticipado de la percepción, a diferencia del de las magnitudes extensivas, como un contenido axiomático de la intuición, supone, como ya hemos dicho, organizarlos y diferenciarlos en niveles complementarios pero no imbricables, por lo cual aquí la intensión no se construye a raíz de la extensión, ni viceversa. Es verdad que en ambos casos lo que está a la base de cada una no es la otra, sino la concreta aplicación de un juicio; de un juicio sintético a priori. Es verdad que en ambos casos podemos producir magnitudes de las cuales, como ya apuntábamos, solo podemos conocer a priori una única cualidad, a saber, la continuidad. Y, sin embargo, resulta que de toda cualidad (esto es, de lo relativo a lo real de los fenómenos) no podemos conocer a priori más que la cantidad intensiva, esto es, que posean un grado. 
Como dirá Kant al cerrar este apartado, el resto queda para la experiencia. ¿Qué significa esto? Poner un límite. ¿Pero qué clase de límite? ¿Se trata de un límite absoluto que niega el conocimiento a priori sobre el mismo contenido empírico (más allá, por supuesto, de poder afirmar que a toda sensación le pertenece, por ser tal, un grado)? O, por el contrario, ¿se trata de un límite que, poniendo punto final a nuestra incursión, nos permite asomarnos al exterior y alzar la vista hacia el vasto campo de lo empírico, en clave trascendental?

Este cierre va a ser clave para terminar de matizar nuestra tesis en la medida en que si aquí, que es donde nos ocupamos de los principios puros del entendimiento (los cuales son constitutivos, esto es, aportan un conocimiento y lo hacen en el orden del ser), se demuestra cómo el proyecto kantiano, lejos de hipostasiar la física newtoniana para construir un mundo cuyos parámetros metafísicos estarían planteados a la medida del hombre y de su recepción del mundo, resulta ocuparse precisamente de lo contrario. Entonces, se vuelve necesario su lugar de primer orden en la filosofía contemporánea y en la teoría de la ciencia de primer nivel.

¿Qué significa la frase con la que se cierra el texto según la cual "[t]odo lo demás queda para la experiencia" ( $K r V$, A176/B218)? Pues esto, contrariamente a lo que pueda parecer, implica que todavía hay algo que podemos decir de la misma. No se tratará de un conocimiento constitutivo, sí de uno regulativo, en tanto que nos servirá precisamente para orientarnos más allá de lo que a priori pueda ser determinado. De esta manera, un tanto wittgensteiniana, lo que más nos interesa del texto no es tanto lo que dice, como lo que no puede decir.

Y si no puede decirlo aquí, tal vez sea porque tenga que decirlo en otro sitio. Al dejar el resto para la experiencia, Kant está ganando un espacio para lo que será el campo de operaciones de las ideas de la razón. Es esto precisamente lo que garantiza que el hombre no será nunca la medida del mundo, sino que el ser humano descubre que es Razón y que es Razón que puede usarse, Razón que puede configurar sentido, y que ese saber encuentra restricciones, fuertes obstáculos para volverse contenido proposicional; y el sujeto, desde el momento en que reconoce ese obstáculo, se constituye como sujeto y, de este modo, damos con una antropología que no quiere centrar la mirada, que no se presenta de facto, postulándose de iure. 
Referencias

ARIAS-ALBISU, M.: "El esquema trascendental de las categorías de la cualidad", Signos Filosóficos 13, 26 (2011) 87-113.

DELEUZE, G.: Diferencia y repetición, Buenos Aires, Amorrortu, 2002.

FRIEDMAN, M.: Kant and the Exact Sciences, Cambridge, MA, Harvard University Press, 1992.

HEGEL, G. W. F.: Fenomenología del espíritu, Madrid, Gredos, 2010.

HEIDEGGER, M.: La pregunta por la cosa. La doctrina kantiana de los principios trascendentales, Barcelona, Orbis, 1975.

: La Fenomenología del espíritu de Hegel, Madrid, Alianza, 2006.

KANT, I.: Prolegómenos a toda metafísica futura que haya de poder presentarse como ciencia, Madrid, Istmo, 1999.

: Crítica de la razón pura, Madrid, Gredos, 2010a.

: Crítica del juicio, Madrid, Gredos, 2010b.

KLEMME, H. F.: „Die Axiome der Anschauung und die Antizipation derWahrnehmung“, MOHR, G.; WILLASCHEK, M. (eds.): Immanuel Kant. Kritik der reinen Vernunft, Berlín, Akademie, 247-266, 1998.

MARTÍNEZ MARZOA, F.: De Kant a Hölderlin, Madrid, Antonio Machado, 1992.

PELÁEZ CEDRÉS, A. J.: "Reconsiderando a Friedman, Richardson y lo $a$ priori constitutivo", Ideas y valores 131 (2006) 51-72.

SCHRÖDINGER, E.: Ciencia y humanismo, Barcelona, Tusquets, 1985.

VIGO, A. G.: “Determinación y reflexión”, Anuario Filosófico 37, 3 (2004) 749-795. 


\title{
Substancia, cambio y materia en las Analogías de la experiencia de la Crítica de la razón pura de Kant
}

\author{
JACINTO RIVERA DE ROSALES 1
}

\begin{abstract}
Resumen
En el artículo se exponen en diez momentos los conceptos de substancia, cambio y materia que aparecen en la Analítica transcendental de la Crítica de la razón pura de Kant, como categorías y esquemas y su funcionamiento en las Analogías de la experiencia. Se muestra cómo la categoría, en general, y la substancia, en particular, en su idealidad transcendental, son una estrategia para ordenar y objetivar el mundo fenoménico. Se afirma que también el cambio es necesario $a$ priori y que tanto el cambio como lo permanente son finitos y limitados, así como todos los fenómenos, lo cual nos llevaría a la afirmación de que lo enteramente permanente es la materia, la materia transcendental; pero esta no es un objeto sensible, de modo que la realidad empírica de la sustancia son los objetos sensibles que relativamente permanecen en el espacio-tiempo. Por último, la materia se presenta constituida por fuerzas y, dado que en ella no hay nada simple, podemos decir que la substancia no es sino un campo de fuerzas.
\end{abstract}

Palabras clave: Kant, substancia, materia, cambio, analogías de la experiencia, Crítica de la razón pura

\section{Substance, change, and matter in the Analogies of experience of Kant's Critique of pure reason}

\begin{abstract}
The article exposes in ten moments the concepts of substance, change and matter that appear in the transcendental Analytics of Kant's Critique of pure reason, as categories and schemes and its functioning in the Analogies of experience. It shows how the category, in general, and also that of substance, in particular, in their transcendental ideality, are a strategy to order and objectify the phenomenal world. It is affirmed that change is also necessary a priori, that both change and the persistent are finite and limited, as well as all appearances. That would lead us to the affirmation that the entirely persistent is matter, transcendental matter, but this is not a sensible object; so that the empirical reality of the substance is the sensible objects that relatively persist in space-time. Finally, matter is constituted
\end{abstract}

1 UNED. Contacto: jrivera@fsof.uned.es. 
by forces, and, since there is nothing simple in it, we can say that substance is nothing but a field of forces.

Keywords: Kant, substance, matter, change, analogies of experience, Critique of pure reason

Este artículo tiene por tema el concepto de substancia [Substanz], pero también subsidiariamente los de cambio [Wechsel] y materia [Materie] relacionados con ella, que están tratados en la Analítica transcendental y, sobre todo, en las Analogías de la experiencia de la Crítica de la razón pura. Desde que los latinos tradujeron el concepto griego de hypóstasis y la categoría aristotélica de ousía por substantia, este término-concepto ha tenido un largo e intenso recorrido a lo largo de la historia de la filosofía.

En la $\mathrm{KrV}$ (Crítica de la razón pura) hay, principalmente, dos momentos a considerar respecto a la substancia. En primer lugar, tenemos la Analítica transcendental, en donde se estudia la substancia como primera categoría de relación, su esquema y su funcionamiento, en la primera de las Analogías de la experiencia. Aquí nos explica Kant su significado objetivo o fenoménico. En segundo lugar, hay que tener en cuenta la Dialéctica transcendental, empezando con los Paralogismos, pues allí se ponen límites ontológicos a la categoría de substancia considerando que no es aplicable al 'Yo pienso' o a la 'Apercepción transcendental', dado que el sujeto transcendental no tiene el modo de ser de lo substante, sino que es una acción ideal, lógico-transcendental. Esto pone en tela de juicio las críticas contemporáneas al denominado 'sujeto moderno', nivelando así las propuestas filosóficas de la modernidad en relación con la subjetividad, igualándolas todas ellas a la res cogitans cartesiana. El Yo transcendental de Kant no es una substancia,2 una res, ni inmanente ni transcendente al mundo, ni una mónada pensante, pero tampoco un modo de una única substancia, como proponía Spinoza. Él es la acción ideal de conocer el mundo; su unidad no es la cuantitativa de la substancia, sino la cualitativa

2 El Yo pienso o autoconciencia no es substante porque no es intuición ( $K r V$, B278: 421-422; véase, por ejemplo, Olk 2018). 
de la acción transcendental, que unifica tanto la multiplicidad de cada uno de los objetos como la de toda la experiencia $(K r V$, B132-136), la cual está en continua expansión siguiendo el hilo conductor de la relación recíproca.

En la segunda de las Antinomias de la razón pura encontramos la tesis que defiende

que todas las cosas del mundo son entes simples; que la composición es solo un estado externo de ellas; y que, aunque nunca podamos sacar enteramente de este estado de enlace las substancias elementales (Elementarsubstanzen) y aislarlas, la razón debe pensarlas, sin embargo, como los primeros sujetos de toda composición, y por tanto, como entes simples anteriores a esta ( $K r V$, A436/B464).

Pero según el idealismo transcendental no hay en el mundo fenoménico nada simple en sí mismo, sino que todo está extendido en la ilimitada multiplicidad de lo sensible espacio-temporal, de modo que todos los fenómenos son magnitudes extensivas [extesive Größe] ( $K r V$, B202-203; A162-164/B203-204) como partes extra partes. Incluso en el Capítulo III de la Dialéctica transcendental, "El ideal de la razón pura", aparece la idea de Dios como la idea de "un sustrato transcendental", "la idea de un todo de la realidad (omnitudo realitatis)" ( $K r V$, A575-576/B603-604), al que no puede llegar el conocimiento objetivo, que únicamente alcanza lo condicionado espacio-temporal-causal.

Este artículo no aborda los temas señalados de la Dialéctica y se limita a la presentación que de la substancia hace la Analítica transcendental de la Crítica de la razón pura, para ceñirse al espacio otorgado a un artículo y dado que ahí se ponen las bases de lo que Kant piensa con ese concepto o categoría. Articularé esta exposición en los diez puntos principales que dan cuenta del significado de la substancia en Kant.

1.

La substancia aparece en la tabla de las categorías como la primera de las categorías de relación. Estas son categorías dobles y, en concreto, la de substancia va acompañada por la de accidente $(K r V$, A80/B106; A186/B229-230). Las otras categorías de relación son las de causa y efecto y la de relación recíproca entre las substancias. 
Estas categorías de relación vienen sistemáticamente tras las de cantidad y las de cualidad. Gracias a estas dos primeras, son delimitadas regladamente por la imaginación transcendental y pensadas o llevadas a concepto la forma y la materia sensibles del fenómeno, respectivamente, configurándose de ese modo cada uno de los objetos en su singularidad. Por medio de las categorías de cantidad y sus esquemas se les delimita a los objetos en su espacio y su tiempo y, en virtud de las categorías de cualidad y sus esquemas, son comprendidos en la conciencia reflexiva como reales los contenidos empíricos de cada uno de los fenómenos.

Tras esta operación de delimitación e interpretación cuantitativa y cualitativa de cada uno de los fenómenos, comienza la labor de ponerlos en relación los unos con los otros con el fin, primero, de situarlos entre sí en el espacio y en el tiempo común a ellos, o sea, en el espacio y el tiempo objetivo, y, segundo, de establecer sus relaciones de dependencia, de heteronomía, de unos respecto de los otros. Esa es la labor de las categorías de relación, sus esquemas y sus principios, que trabajan basándose también en las de cantidad y las de cualidad, de modo que gracias a ellas se va construyendo un nexo, una interconexión entre todos los fenómenos, una experiencia unificada con todos ellos, una "natura formaliter spectata" $(K r V, \mathrm{~B} 165)$.

\footnotetext{
Por naturaleza (en sentido empírico) entendemos la interconexión de los fenómenos según su existencia, según reglas necesarias, es decir, según leyes. Hay, por consiguiente, ciertas leyes que son a priori y que hacen, ante todo, posible una naturaleza; las empíricas solo pueden tener lugar y ser descubiertas por medio de la experiencia y como consecuencia de aquellas leyes originarias según las cuales la experiencia misma es, ante todo, posible. Nuestras analogías exponen, pues, propiamente la unidad de la naturaleza y la interconexión de todos los fenómenos ( $K r V$, A216/B263).
}

Y es aquí, primer punto, donde aparece la categoría de substancia, colocada como la primera entre las categorías de relación y presentada como la base o sustrato que hace posible el establecimiento y objetivación de las relaciones entre los fenómenos. 
2.

Una categoría, también la de substancia, es una regla de síntesis de la multiplicidad sensible que sigue el sujeto cognoscente para ordenar e interpretar el mundo sensible de manera objetiva, es decir, reglada y no arbitraria ni caóticamente (en cuyo caso no sería posible conocimiento alguno) y, por tanto, de manera intersubjetiva, válida para todos los objetos $\mathrm{y}$ todos los seres humanos. El idealismo transcendental propone que esas reglas no son dadas al sujeto cognoscente por los objetos concretos, pues si dependieran de ellos, podrían entonces aparecer objetos que no estuvieran en el espacio ni en el tiempo, que carecieran de causa, que no permanecieran ni cambiaran, etc., lo cual resulta imposible, pues en ese caso no lograríamos dar con ellos.

Esas reglas son formas creadas por el sujeto transcendental. Son cuestiones que plantea el sujeto desde sí, desde su espontaneidad, a los fenómenos sensibles a los que estos han de responder: qué espacio ocupan, qué tiempo, cuál es su causa, qué interrelación guardan, etc. No se basan en una experiencia particular, sino que estructuran todo el conocimiento empírico, al igual que la gramática lo hace con todo uso del lenguaje, sin poder dar razón de por qué esas reglas y no otras (facticidad de la forma) (Prol., AA 04: 322-323). Son preguntas o acciones ideales regladas del sujeto, pues solo así, nos dice Kant, esas idealidades logran tener una validez universal y necesaria para todo objeto y todo sujeto, y no puede ocurrir que un objeto no las cumpla $(K r V$, B3-6), porque entonces no sería un objeto para nosotros o no lo comprenderíamos objetivamente, no sabríamos situarlo, ordenarlo dentro de la experiencia.

Además, hemos de tener en cuenta que los objetos no son capaces de ofrecernos y traspasarnos conceptos, idealidades, algo de lo que carecen, sino que únicamente pueden causar efectos físicos. Pero el conocimiento es una elaboración ideal que el sujeto hace de la realidad: cuando yo conozco un objeto, por ejemplo un árbol, no lo transformo realmente, no lo riego, ni lo podo, ni lo corto, ni lo traslado de lugar, ni lo quemo, etc., sino que lo introduzco en el ámbito ideal del conocimiento. Solo así logra el sujeto enterarse de la realidad del mundo y que sea algo para él; el conocimiento o conciencia es un ámbito ideal abierto por la autoconciencia, no por los objetos. Tenemos, por tanto, en segundo lugar, que la categoría de substancia, como las demás, es en última instancia una idealidad, no una ley 
óntica de objetos en sí, sino una necesidad transcendental de la comprensión objetiva del mundo, una estrategia subjetiva para la ordenación e interpretación de la experiencia, para "deletrear" los fenómenos y "poderlos leer como experiencia" (Prol., AA 04: 312; véase también $K r V$, A314/B370-371). Fuera de ahí, las categorías tienen solamente un significado lógico, pero en modo alguno objetivo (Prol., AA 04: 324, §39).

3.

En consecuencia, la idealidad transcendental implica y requiere a su vez de un realismo empírico, algo dado sensiblemente, para llegar a ser conocimiento, pues, en caso contrario, nos quedamos con meras idealidades vacías, sin alcance objetivo; también ocurre eso con la categoría de substancia. Más aún, ni el 'Yo pienso' ni sus idealidades transcendentales serían si los objetos del mundo no respondieran en modo alguno de manera positiva a ellas, por lo menos en una medida suficiente para el manejo de la objetividad ( $K r V$, BXIIIss.), pues son acciones y formas de objetivación. Son modos de elaborar y ordenar objetivamente la experiencia sensible dada y de conocer el mundo, a fin de que el Yo sepa de él. Por ejemplo, todas las teorías sobre las múltiples partículas subatómicas llegan a ser válidas cuando estas son de algún modo físicamente detectadas; en caso contrario, la teoría o idea sobre esa partícula queda en mera hipótesis aún vacía, sin validez objetiva.

Por eso mismo, dichas formas o idealidades transcendentales no se darían sin lo dado en la experiencia sensible, sin un mundo real al que conocer. Las reglas no son dadas por los objetos, pero no serían sin una respuesta positiva del mundo $\mathrm{y}$, en ese sentido, se puede decir que también dependen de los objetos. Sin embargo, i) estos no pueden ser llamados cosas en sí en sentido transcendental porque responden a nuestras preguntas, a nuestras formas de conocer y, en ese sentido, la forma que muestran es dependiente de las nuestras, de nuestras preguntas, y no sabríamos si pudieran responder a otras, o sea, a otros seres cognoscentes que procedieran con otras formas transcendentales (facticidad de las formas, sobre todo del espacio-tiempo). ii) En las cosas conocidas, el tiempo y el espacio, así como las categorías, son tan empíricamente reales como transcendentalmente ideales ( $K r V$, A28/B44; A35-36/B52); si no fueran ideales, el Yo no podría elaborar la objetividad del mundo y enterarse, pero 
si no correspondieran a la realidad empírica de los objetos, entonces esas formas no tendrían validez objetiva $\mathrm{y}$, a la postre, desaparecerían junto con el sujeto del conocimiento. Por eso, iii) cuando vamos más allá de la experiencia preguntándonos por lo incondicionado - por el alma como substancia simple e inmortal, o por el mundo como totalidad o por Dios-, entonces, nos quedamos únicamente con meras idealidades que no alcanzan a proporcionarnos conocimiento de lo real debido a la ausencia de eso real. Esto es lo que estudia Kant en la Dialéctica transcendental.

Hablando en absoluto, podría ocurrir que el mundo no existiera; eso no sería contradictorio puesto que la existencia no se encuentra en el orden de los conceptos, sino que es la posición absoluta de la cosa con todos sus predicados posibles, como ya aclarara Kant en su escrito "El único fundamento de prueba posible para una demostración de la existencia de Dios" (AA 02: 72-77) y vuelve a explicar en la Crítica de la razón pura desmontando el argumento ontológico sobre la existencia de Dios ( $\mathrm{KrV}$, A597-601/B625-629). La categoría modal de existencia es diferente a la categoría modal de posibilidad. Requiere, además, el que algo sea dado empíricamente. Pero si el mundo no existiera en modo alguno, en ese caso nosotros, en cuanto sujetos cognoscentes, tampoco existiríamos, pues el yo transcendental no es una substancia transcendente que pudiera ser sin mundo.

Si bien las formas transcendentales no son empíricas, tampoco son formas divinas que pudieran crear material y mágicamente su propio mundo. En absoluto, el mundo podría ser de otra manera, de otra forma, y la reflexión transcendental parte de la facticidad de las formas a priori, en contra de un racionalismo. Pero, dado que existimos como seres cognoscentes, entonces, podemos afirmar con fundamento, en contra del escepticismo, que el mundo existe y que objetivamente es así como lo conocemos, al menos en una medida suficiente para manejarnos en él, siendo nuestra tarea el ir ampliando ese conocimiento constantemente. Aunque el conocimiento empírico del mundo está o debe estar en continuo progreso, este se hace siempre sobre la base de las estructuras transcendentales a priori, como necesidades de comprensión y ordenación de la experiencia. No podríamos decir, por ejemplo, que todo en el mundo está determinado, sino únicamente en la medida en que, mediante las categorías de causalidad y de determinación recíproca, encontremos la causa 
de un fenómeno, y en la medida en que esa causa explique (siempre de modo parcial) ese fenómeno. Las categorías de relación son regulativas, no nos proporcionan el objeto en la intuición (al contrario de lo que ocurre con las categorías de cantidad y cualidad), sino que ofrecen la regla para su búsqueda ( $K r V$, A161-162/B201). El conocimiento real está siempre in fieri, en el continuo espacial-temporal-causal.

También puede darse que existan estados caóticos del mundo, como parece ser que ocurre en los agujeros negros, o como sería antes del big bang. Nada responde entonces a algo permanente $\mathrm{y}$, por consiguiente, el conocimiento objetivo sería ahí imposible.3 La categoría de substancia no dice que habrá siempre algo permanente en el mundo, como si fuera un decreto divino, sino que el sujeto necesita que haya siempre algo permanente para que sea posible el conocimiento objetivo y (añadiría) la acción real del sujeto y el sujeto mismo. La categoría, también la de substancia, es una exigencia transcendental, no una ley óntica. Con ello, entendemos lo dado y buscamos regularidades, que son reales, constitutivas y no simplemente 'como sí', que es lo que ocurre con la finalidad en la naturaleza, pues esta no es objeto de la intuición. Siempre buscamos permanencia, cambio y dependencia y, en la medida en la que lo encontramos, tenemos conocimiento objetivo. Pero es muy posible que ignoremos más de lo que sabemos. Una categoría sola sin nada dado empíricamente no es un conocimiento objetivo: "Pensamientos sin contenido son vacíos, intuiciones sin conceptos son ciegas" ( $K r V$, A51/B75).4 Eso mismo ocurre con la categoría de causalidad, que no nos da la causa en la intuición, sino que nos pone a su búsqueda, pero solo tiene significado objetivo cuando se encuentra empíricamente la causa. En consecuencia, no podemos decir que todo está determinado, pues la totalidad no es objeto de experiencia, dado que toda experiencia empírica real es limitada y el conocimiento empírico está siempre in fieri en el continuo espacio-temporal-causal. Las categorías sin experiencia empírica son formas sin contenido objetivado, vacías, tareas sin realizar.

\footnotetext{
3 "No pretendo con esto negar el espacio vacío; pues él siempre puede estar allí donde las percepciones no alcanzan y no hay, por consiguiente, conocimiento empírico de la simultaneidad; pero entonces no es objeto alguno para toda nuestra experiencia posible" ( $K r V$, A214/B261).

4 "El entendimiento y la sensibilidad, en nosotros, solo enlazados pueden determinar objetos. Si los separamos, tenemos intuiciones sin conceptos o conceptos sin intuiciones; en ambos casos, representaciones que no podemos referir a ningún objeto determinado" ( $K r V$, A258/B314).
} 
También la categoría de substancia, en tercer lugar, requiere su realismo empírico.

4.

"Ahora bien, aquello que conecta lo múltiple de la intuición sensible es la imaginación, que depende del entendimiento en lo que respecta a la unidad de la síntesis intelectual de ella, y depende de la sensibilidad en lo que respecta a la multiplicidad de la aprehensión" ( $K r V$, B164). Es el esquema de la imaginación transcendental el que hace posible asignar una realidad sensible a lo demandado por las categorías. La categoría no se aplica directamente a lo empírico, sino a través de las formas a priori de la sensibilidad, o sea, del espacio y el tiempo. Eso mismo ocurre con la categoría de substancia, al contrario de lo que quería Hume, que la aplicaba a la impresión como último criterio de realidad y exigía que una impresión permaneciera y estuviera siempre presente para poderla designar como substancia y concederle a esta realidad; pero, al no encontrarla, descalificaba esta categoría. 5 La necesidad no está en la impresión, en lo empíricamente dado, pues ello nos ofrece solo el caso, no la necesidad, sino que esta se sitúa en la exigencia transcendental de comprensión expresada en las formas a priori.

Pues bien, la aplicación o uso objetivo de la categoría pasa, según Kant, por una operación o traducción imaginativa del contenido lógico de la categoría en el espacio y en el tiempo como formas a priori de la sensibilidad. En el Esquematismo transcendental nos ofrece Kant una traducción únicamente temporal de las categorías, de modo que "el esquema de la substancia es la permanencia [Beharrlichkeit] de lo real en el tiempo" ( $K r V$, A144/B183), "pues solo esta permanencia es el fundamento por el cual aplicamos al fenómeno la categoría de la substancia" ( $\mathrm{KrV}$, A184/B227; véase también Prol., AA 04: 335, §48) dado que toda modificación la predicamos de lo permanente. Lo substante en el fenómeno es algo que dura [dauert] en el tiempo. Esta permanencia sensible del objeto corresponde [correspondiert] en el fenómeno al tiempo considerado como

5 "La representación de algo permanente en la existencia no es lo mismo que la representación permanente, pues esta puede ser transitoria y cambiable, como todas nuestras representaciones, incluida la de la materia, y referirse sin embargo a algo permanente que, por tanto, ha de ser una cosa exterior y distinta de todas mis representaciones" ( $K r V$, BXLI, nota). Aquí se distinguen los objetos externos de las representaciones del sentido interno. 
permanente y siempre el mismo en su incesante fluir; y como el tiempo mismo, en cuanto forma de la intuición, al ser ilimitado, no puede ser percibido, es la substancia fenoménica, en cuanto que es lo sensiblemente permanente, lo que hace posible la percepción del tiempo permanente $(K r V$, B225-226) y con ello también los otros dos modos del tiempo: la sucesión y la simultaneidad, 6 es decir, la determinación y objetivación de lo que cambia y de lo que es a la vez [die Folge und das Zugleichsein], aunque para esas otras dos determinaciones del tiempo se precisen además otros elementos: "lo permanente es el sustratum de la representación empírica del tiempo mismo, y únicamente a partir de este sustrato es posible toda determinación temporal" ( $K r V$, A183/B226).

Pero tras la escritura del pasaje denominado "Refutación del idealismo", Kant comprende que toda permanencia requiere asimismo espacio en donde permanecer, mientras que el tiempo empírico siempre fluye, y que es por consiguiente esa permanencia espacial o materia $(\mathrm{KrV}$, B277-278), con su temporalidad propia, a saber, la de los objetos externos o del sentido externo, la que hace posible determinar objetivamente la temporalidad propia y diferente de las representaciones del sentido interno. Justamente de esa distinción de temporalidades de los objetos externos, que puede ser permanente, y de las representaciones del sentido interno, siempre sucesivas y dependientes de la atención [Aufmerksamkeit] ( $K r V$, B156-157, nota), parte la argumentación de la primera de las Analogías de la experiencia ( $K r V$, A182/B225-226). 7 Lo permanente es necesariamente un fenómeno espacio-temporal. Por eso concluye que, para asignar realidad objetiva a las categorías, que era de lo que justamente trataba el Esquematismo transcendental y que hubiera tenido que reescribir, no basta con el tiempo del sentido interno, como él había creído y señalado en ese lugar, sino que se requieren además intuiciones externas y espaciales $(\mathrm{KrV}$, B291) y la temporalidad propia de los objetos. Y así,

\footnotetext{
6 "Los tres modi del tiempo son permanencia, sucesión y simultaneidad. Por eso, tres reglas de todas las relaciones temporales de los fenómenos [...] precederán a toda experiencia y la harán ante todo posible" (KrV, A177/B219).

7 La necesaria distinción entre la aprehensión subjetiva (sentido interno) y la temporalidad objetiva de los objetos externos ( $K r V$, B219; A189-191/B234-236; A194-199/B239-244; B258), que también habrán de ser ligadas para la unidad de la experiencia, de modo que "deberé derivar la sucesión subjetiva de la aprehensión, de la sucesión objetiva de los fenómenos" (KrV, A193/B238).
} 
para suministrar algo permanente en la intuición que corresponda al concepto de substancia (y para mostrar de ese modo la realidad objetiva de este concepto), necesitamos una intuición en el espacio (materia) ya que solo el espacio está determinado de modo permanente, pero el tiempo, y con él todo lo que está en el sentido interno, fluye incesantemente ( $K r V$, B291; véase también $K r V$, A381).8

Lo permanente nos dirige a algo exterior y espacial, lo que Kant denomina materia, "objeto del sentido externo [...] extensión impenetrable e inanimada" ( $K r V$, A848/B876), y no puede quedarse en una mera impresión del sentido interno, que era lo que exigía Hume: "el concepto de una materia como substancia es el concepto de algo móvil en el espacio" (MAN, AA 04: 543). Y lo mismo se puede decir de la simultaneidad, el esquema de la categoría de relación recíproca, que requiere igualmente el espacio, a saber, que dos o más objetos ocupen diferentes espacios para que puedan ser a la vez.9 Y eso ocurre también con la segunda categoría de relación, la causalidad, pues es la que determina la temporalidad sucesiva de los objetos externos y extensos.

Cuarta idea: la categoría de substancia es aplicable a lo sensible permanente en el espacio-tiempo, sobre lo que inhiere los cambios, sus cambios o accidentes, y esa es su interpretación, aplicación o traducción objetivante, su posible realismo empírico.10 Esa permanencia o duración del fenómeno u objeto es obra de la imaginación, que recorre la multiplicidad sensible y la sintetiza en una unidad ( $K r V$, A77/B102) que mantiene también las diferencias, la conciencia de las diferentes partes del espacio, los distintos momentos del tiempo y las diferencias cualitativas en esa extensión y temporalidad; y el objeto responde positivamente a esa acción subjetiva. Es ella la que implementa en el espacio-tiempo-cualidades lo exigido por la categoría de substancia ( $K r V$, A183/B226). Lo permanente que corresponde a la substancia es recorrido y elaborado por el sujeto mediante la síntesis imaginativa de la multiplicidad sensible de un objeto y

8 Me he extendido más sobre este importante asunto en mi artículo de 2013.

9 Esto lo reconoce Kant ya en la formulación de la Tercera Analogía de la experiencia ( $\mathrm{Kr} V$, A211/B256), aunque después en su explicación no tiene en cuenta ese elemento necesario a priori. "Diferentes tiempos no son simultáneos, sino sucesivos, así como diferentes espacios no son sucesivos, sino simultáneos" (KrV, A31/B47).

10 "De hecho, la proposición de que la substancia es permanente es tautológica. Pues solo esa permanencia es el fundamento de por qué aplicamos al fenómeno la categoría de substancia, y se tendría que haber demostrado que en todos los fenómenos hay algo permanente del que lo cambiante no es otra cosa que una determinación de su existencia" ( $K r V, \mathrm{~A} 184 / \mathrm{B} 227)$. 
reconocido reflexivamente gracias al concepto o categoría de substancia. Estas síntesis, tanto la figurada de la imaginación o esquema imaginativo como la intelectual de la categoría (concepto, entendimiento y Juicio) ( $K r V$, B151-152), son actos de espontaneidad del sujeto transcendental, sin cuya espontaneidad o acción no lograría comprender nada, y no están en la impresión ni en la percepción [Wahrnehmung], que contienen, por el contrario, una pura multiplicidad en yuxtaposición azarosa $(K r V$, B218219).

Y aquí podemos diferenciar diversos sentidos del concepto de substancia. En sentido lógico, la substancia es el sujeto último de predicación que no puede convertirse a su vez en predicado (véase $K r V$, A147/B186; A242-243/B300-301; B149, 288-289, 410).11 Desde la perspectiva ontológica o según los modos de ser, la substancia es el substrato o soporte de sus accidentes o estados [Zustände], pero no en el sentido de que el accidente sea algo de por sí, sino "solo la manera como está determinada positivamente la existencia de una substancia" ( $K r V$, A187/B230). Transcendentalmente se exige que esa existencia se dé sensiblemente en el espacio-tiempo y, en concreto, como algo que permanece y dura, mientras que los accidentes cambian, pues lo permanente sería el soporte o el substrato de los cambios en el mundo. Eso permanente aparece entonces física u ónticamente como un objeto $\mathrm{y}$, en concreto, como un objeto externo del mundo, es decir, como un cuerpo material, pues en el sentido interno solo hay un fluir constante de representaciones, no hay ahí nada que permanezca, como ya lo había hecho constar Hume al decir que ninguna impresión permanece; por tanto, en ese ámbito no encontramos ninguna substancia, pues para la substancia se necesita también el espacio. De ahí que para la determinación temporal del sentido interno y de sus representaciones sea preciso contar con su relación con los objetos extensos del sentido externo y su temporalidad ordenada según la categoría de causalidad, como Kant muestra en su "Refutación del Idealismo" ( $\mathrm{KrV}$, B277-278, 291; A381).

11 La categoría de substancia la deduce Kant de los juicios categóricos $(K r V, \S \S 9,10)$. 
5.

En la Analítica transcendental de los principios se ponen en funcionamiento sintético las formas estudiadas anteriormente en la Crítica: las formas puras de la sensibilidad, las categorías y sus esquemas. Con ellas se forman los primeros juicios o principios del ente en cuanto objeto. De esa manera, se pone en ejercicio también la categoría de substancia y su esquema y se determina con más precisión su significado objetivo y su alcance.

En los dos primeros principios, a saber, en los axiomas de la intuición y en las anticipaciones de la percepción se estudian las síntesis transcendentales y regladas de la forma espacio-temporal y del contenido o realidad sensibles de cada uno de los fenómenos. Pero no habría una unidad de la experiencia, necesaria para la unidad del sujeto y su orientación objetiva, si estos fenómenos estuvieran aislados unos de otros o se relacionaran sin regla alguna. Si estuvieran aislados, el sujeto viviría en varios mundos no conectados entre sí sin saber moverse de uno a otro ni, por tanto, tampoco actuar en ninguno de ellos. $\mathrm{Y}$ si se relacionaran azarosamente, no podríamos orientarnos en la experiencia ni saber a qué atenernos, pues estaríamos sin discernir qué ocurre ni qué va a suceder o qué hacer con cada uno de esos fenómenos. Es preciso, por tanto, que ellos formen una trama, una red de conexiones y ligazones, de sucesiones regulares y de simultaneidades, o sea, es necesario para el sujeto, para su conocimiento y su acción, que los objetos estén conectados entre sí y que lo estén no azarosamente, sino por medio de reglas o conceptos, gracias a los cuales pueda él, primero, situarlos en el espacio y tiempo objetivos y, segundo, establecer sus dependencias, sus leyes naturales, con las que poder predecirlos, dominarlos, usarlos, o bien evitarlos, defenderse, etc. A ese principio básico y transcendental, como condición de posibilidad de la experiencia objetiva en general, llega el Juicio en la formulación general del contenido de las tres Analogías de la experiencia: "La experiencia es posible solo mediante la representación de una conexión necesaria de las percepciones" $(K r V, \mathrm{~B} 218)$.

Ahora bien, para situar los fenómenos en el espacio y el tiempo objetivos no podemos recurrir al espacio y al tiempo absolutos, porque estos no son percibidos $(K r V, \quad$ B219; B225; A183/B226; B233, 257; 
A200/B245),12 repite Kant en cada una de las tres analogías (aunque él ahí habla todavía solo del tiempo), pues todo lo percibido ha de ser limitado, recorrido y unificado (sintetizado) por la imaginación. Por consiguiente, solo podemos colocarlos espacial y temporalmente relacionándolos unos con otros, es decir, "los fenómenos mismos deben determinarse unos a otros sus lugares en el tiempo" ( $K r V$, A200/B245; véase también $K r V$, A214/B261) y el espacio mediante su relación dinámica (con influjos físicos) y según una regla universal. Así, decimos que el Sol está a tantos kilómetros de la Tierra o que la toma de la Bastilla tuvo lugar 1789 años después del nacimiento de Cristo. Y eso ocurre en las tres Analogías de la experiencia, o sea, para los tres modos del tiempo.

Por consiguiente, en quinto lugar, podemos decir que la substancia, en cuanto permanencia, es necesaria para poder percibir y objetivar los fenómenos cambiantes o las alteraciones y que ambos, lo que permanece y lo cambiante, son determinados entre sí, el uno por contraposición con el otro, pues "todo cambio presupone, simplemente para ser percibido como tal, algo permanente en la intuición" ( $K r V$, B292); toda conciencia requiere distinción y contraposición. Lo permanente es el substrato de todo cambio ( $K r V$, A183-184/B227) y "es lo único que puede representar la unidad del tiempo, a saber, la identidad del substrato, solo en el cual tiene integral unidad todo cambio. Esta permanencia, empero, no es más que la manera de representarnos la existencia de las cosas (en el fenómeno)" ( $\mathrm{KrV}$, A186/B229). Substancia es, en consecuencia, un fenómeno u objeto o cuerpo que permanece, aunque modificándose [verändert],13 mientras que sus accidentes o determinaciones [Bestimmungen] cambian [wechseln]

\footnotetext{
12 "El lugar temporal en cada caso y la relación temporal de un objeto nunca puede construirse a priori a partir del puro decurso del tiempo, es decir, nunca pueden ser expuestos ni presentados intuitivamente", aclara Heidegger (1987: 182). Preocupado sobre todo por el tiempo, Heidegger no toma nota de la necesaria presencia del espacio en las Analogías de la experiencia. Paul Guyer pone en duda "que nosotros no podamos conocer que el tiempo mismo es permanente a partir de la pura intuición del tiempo, aunque ese cambio tiene lugar en el tiempo y, por consiguiente, el tiempo no cambia" (2006: 106). Pero el problema no es saber que siempre estará el tiempo en toda objetivación, algo que se analiza en la Estética transcendental y en las categorías de cantidad, su esquema y su principio o Axiomas de la intuición, sino que no podemos percibirlo objetivamente como tal, pues es ilimitado, y solo en los objetos se delimita y adquiere una realidad empírica.

13 Así la definía también Christian Wolff: "El sujeto permanente y modificable se dice substancia" ["Subjectum perdurable et modificabile dicitur Substantia"] (1736: §768). Es una definición que le resulta a Kant evidente: "De hecho, la proposición 'la substancia permanece' es tautológica" ( $K r V$, A184/B227). Como ha sido numerosas veces advertido, las definiciones que recoge Kant del término de substancia tienen origen aristotélico, pero su significado se ve profundamente transformado desde su interpretación transcendental.
} 
(KrV, A187/B230-231) y se suceden los unos a los otros. Gracias a esa permanencia sensible, logramos situar en el espacio y el tiempo los fenómenos que cambian, pues no podemos recurrir al tiempo y al espacio absolutos para proceder a esa determinación porque no son percibidos.

La substancia en Kant no es la esencia de las cosas [das Wesen der Dinge], sino que es un momento de la misma. Esta esencia del fenómeno o realitas es expresada de la manera más estricta por las categorías de cualidad, su esquema y su principio. $\mathrm{O}$ bien, podemos pensar que la esencia de los fenómenos está constituida por las tres primeras clases de categorías, las de cantidad, las de cualidad y las de relación, pues la modalidad no aporta nada al contenido del objeto, sino a su relación con el sujeto transcendental, limitando las categorías a su uso empírico ( $\mathrm{KrV}$, A74/B99100; A219/B266-267; A233-235/B286-287). Sin embargo, podemos incluir también las categorías de modalidad, por cuanto que expresan la relación fenoménica con el sujeto transcendental.

6.

La permanencia es necesaria para captar el cambio. Pero ¿por qué es necesario el cambio? Kant no lo justifica. Más aún, piensa que toda modificación [Veränderung] es a posteriori, de modo que no cabría decir nada de ella a priori ( $K r V$, A171/B213), pues "el cambio es un concepto que solo puede extraerse de la experiencia" $(K r V$, B3).14 De igual modo, la posibilidad del movimiento [Beweglichkeit] de la substancia-materia en el espacio es un predicado empírico (MAN, AA 04: 482, 482; Prol, AA 04: 295).15 No habría por tanto una necesidad transcendental de que hubiera cambio ni modificación, ni en consecuencia de que hubiera accidentes ni movimiento, sino que lo único que existe es la constatación empírica de que se da.

Mas si no es transcendentalmente necesario el cambio, ¿por qué lo va a ser la permanencia, si son conceptos correlativos y además se ha

14 Este tema no es abordado por los investigadores kantianos.

15 "Al igual que en el caso de la categoría de sustancia esquematizada (permanencia de lo real en el tiempo) y el mero concepto de materia (ocupación del espacio) de la $K r V$, la categoría de sustancia no esquematizada (algo que es sustrato de propiedades) y el concepto empírico de la materia (algo movible en el espacio) de MAN tienen diferentes significados, aunque la materia es lo que le da realidad objetiva a la categoría en la intuición empírica" (Hall 2011: 98-99). 
argumentado justamente que la permanencia es necesaria porque sin ella no se puede captar el cambio, es decir, se ha hecho depender del cambio la necesidad de la permanencia? El cambio es exigido a contrario por la propia categoría de substancia, pues si es verdad que sin lo permanente no sería posible percibir el cambio, también es cierto la inversa: sin cambio no sería posible percibir lo que permanece. La duración de la substancia implica también la presencia de cambios, pues significa que "gracias a lo permanente la existencia recibe, en diversas partes sucesivas de la serie temporal, una cantidad que se llama duración" ( $K r V$, A183/B226) la cual no sería perceptible sin diferenciación sensible de momentos sucesivos del tiempo en virtud de cambios objetivos regidos y reglados por la ley de causalidad.

Yo diría que, trascendentalmente, son necesarios ambos, tanto la permanencia como el cambio, como es necesaria su contraposición para la conciencia y el conocimiento. La necesidad de la permanencia se expresa en la categoría de substancia en cuanto categoría, y la necesidad del cambio, por su parte, en la categoría de accidente, que también es una categoría, pues las categorías de relación son necesariamente duales. Ellas no unen o sintetizan elementos homogéneos [Verbindung, conjuctio] sensiblemente dados, como ocurre con las categorías de cantidad y de cualidad, sino elementos diferentes en su existencia, o sea, son conexiones [Zusammensetzung, compositio] de dos o más fenómenos y señalan "la síntesis de lo múltiple en la medida en que sus elementos se pertenecen necesariamente unos a otros, como por ejemplo el accidente es representado como enlazado a priori a alguna substancia, o el efecto a la causa, que por tanto son también representados enlazados como heterogéneos y sin embargo a priori" ( $K r V$, B201, nota), y no de manera puramente empírica. Las dos categorías, la de substancia y la de accidente, como todas las categorías, 16 son actos originarios del sujeto transcendental, que sintetizan regladamente el mundo fenoménico y señalan igualmente necesidades transcendentales en vistas a la ordenación e interpretación de la experiencia.

16 Las cuatro clases de categorías incluyen tres, y "la tercera categoría, en todos los casos, surge del enlace de la segunda de su clase con la primera. [...] Pero no se piense que por ello la tercera categoría es un concepto meramente derivado, y no un concepto primitivo del entendimiento puro, pues el enlace de los conceptos primero y segundo, para producir el tercero, requiere un acto particular del entendimiento que no es idéntico al ejercido con el primero y el segundo" $(\mathrm{KrV}, \mathrm{B} 110$ 111). 
Por consiguiente, es asimismo necesario que en el mundo de los fenómenos se dé el cambio al igual que la permanencia.17

Kant afirma que el tiempo permanece mientras que son los fenómenos los que cambian en el tiempo; pero, como el tiempo en cuanto tal no es percibido, es necesaria una visualización de esa permanencia mediante la substancia fenoménica. Pero, también nos dice que las partes o momentos del tiempo son todos sucesivos ( $K r V$, A183/B226), y esta sucesión de momentos temporales no podría ser captada empíricamente si todo permaneciera sin cambio alguno, sino únicamente si hay cosas que cambian de un momento del tiempo a otro. Por consiguiente, tiene que haber cambio en los fenómenos. Ese es el método de la reflexión transcendental: "todo aquello sin lo cual sería imposible la experiencia de los objetos, es necesario en relación con los objetos de la experiencia" ( $\mathrm{rrV}$, A213/B259-260; véase también $K r V$, A216-217/B263-264; A346347/B405).

En la primera categoría de relación se establece que debe haber permanencia y cambio; pero es en la segunda, en la de causalidad, donde se decreta la categoría o ley que rige y objetiva el cambio o sucesión temporal de los objetos: el efecto no puede ser anterior a su causa, pues la existencia de aquel depende de esta.18 En consecuencia, las categorías de causa y efecto exigen que haya cambio y modificación, pues sin ello no habría causalidad, ni por tanto establecimiento de la sucesión objetiva de los fenómenos, ni conocimiento objetivo del mundo, ni concienciaautoconciencia.

También se puede aducir que, si la extensión y la realidad de cada fenómeno ha de ser limitada para ser intuida, como lo exponen los dos primeros principios, los axiomas de la intuición y las anticipaciones de la

\footnotetext{
17 Ambos son fenómenos del sentido externo, lo que permanece y lo que cambia en el mundo sensible de los objetos interpretado categorial e imaginativamente, con un cambio regido por la ley de la causalidad y con una temporalidad diferente a la de las representaciones del sentido interno (véase Rivera de Rosales 2013). Eso es lo que, creo, no ha comprendido Georg Sans en su artículo de 2005, que identifica el cambio de los estados de las substancias con la sucesión de la aprehensión de la multiplicidad en el sentido interno $(712-713,718,723)$, lo cual contradice lo que Kant señala con su ejemplo de la visita a una casa $(K r V$, A190ss./B235ss.). Si no percibiéramos lo permanente, al igual que no percibimos el espacio y el tiempo absoluto (en cuanto formas a priori de sensibilidad), tampoco podríamos percibir el cambio ni la simultaneidad.

18 "Esta regla [...] es que en aquello que precede ha de encontrarse la condición bajo la cual el acontecimiento siempre (es decir, necesariamente) sigue" (KrV, A200/B246).
} 
percepción, entonces también ha de ser limitado en el tiempo y, por tanto, tiene que aparecer y desaparecer, y eso es el cambio.

Si no hubiera cambio no existiría el sentido interno, que consiste en un fluir temporal de representaciones.19 Pero si no hubiera un sentido interno, no sería entonces comprendido el objeto externo como externo, no habría conciencia de ello en cuanto tal por falta de distinción y contraposición, la vida interna del espíritu quedaría parada, congelada, petrificada y con ella el mundo y el Yo transcendental.

Por último, si "todo interés es, al fin y al cabo, práctico" 20 y la libertad "es la piedra angular de toda la construcción de un sistema de la razón pura, incluso de la especulativa",21 como nos dice Kant en la Crítica de la razón práctica, entonces podemos afirmar la necesidad transcendental del cambio y del movimiento para que sean posibles la realización de la libertad y de sus fines en el mundo. Sin cambios no habría acción libre capaz de modificar el mundo según sus fines, ni por tanto libertad, la cual no es una substancia transcendente que pudiera ser sin mundo, sino una acción de transformación del mundo. No habría, por tanto, moral, ni conciencia, ni sujeto. La naturaleza no puede tener influencia sobre la libertad, pero la libertad ha de tenerla sobre la naturaleza y realizar en ella sus fines ( $K U$, Introducción II) y por tanto ha de ser posible modificarla.

Luego, sexta idea, tiene que haber cambio y, en consecuencia, la permanencia no puede ocuparlo todo, no debe ser absoluta: sin cambio no habría conciencia ni libertad. La substancia fenoménica es, también por eso, necesariamente finita y modificable.

7.

La permanencia no es absoluta, pero tampoco puede ser absoluto el cambio. $\mathrm{Si}$ se diera un cambio absoluto, si de pronto cambiara radicalmente todo sin que nada permaneciera, o sea, sin que hubiera ninguna continuidad, se

\footnotetext{
19 "Nuestra aprehensión de lo múltiple del fenómeno es siempre sucesiva, y es, por consiguiente, siempre cambiante" (KrV, A182/B225).

${ }_{20}$ "Todo interés es, al fin y al cabo, práctico, y el interés mismo de la razón especulativa es solo condicionado y únicamente está completo en el uso práctico" (KpV, AA 05: 121).

21 "El concepto de libertad, en cuanto que su realidad es probada por una ley apodíctica de la razón práctica, constituye la piedra angular de todo el edificio de un sistema de la razón pura, incluso de la especulativa" $(K p V, 05: 3-4)$.
} 
produciría un corte en el mundo de la experiencia y se rompería su unidad: la unidad del tiempo, del espacio y de la causalidad y, con ello, también la unidad de la conciencia. Suponiendo que pudiéramos sobrevivir, pasaríamos de un mundo a otro sin puente ni transición, mágicamente, sin orientación alguna ni identidad de la conciencia ni continuidad del yo empírico, pues habría un instante vacío en donde no habría experiencia alguna.22 "El principio general de las tres analogías [de la experiencia] se basa en la necesaria unidad de la apercepción [o "Yo pienso" o sujeto transcendental] con respecto a toda conciencia empírica posible (de la percepción) en todo tiempo" ( $K r V$, A177/B220). Ni siquiera podríamos ser conscientes de ese cambio absoluto, pues "es lo permanente lo que hace posible la representación del tránsito de un estado a otro y del no ser al ser" ( $K r V$, A188/B231).23

Entonces, séptima conclusión, siempre ha de haber algo real que permanezca en el espacio-tiempo,24 sin lo cual no habría experiencia ni sujeto transcendental; y esa es, propiamente dicha, la exigencia expresada en la categoría de substancia y en la primera de las analogías de la experiencia. Ese 'siempre' y ese 'permanecer' es lo que aquí se añade a lo real [Realität] o realitas cualitativa, o sea, a lo presentado como real en la categoría de cualidad y las anticipaciones de la percepción, en donde ya se apunta que lo material es lo real que ocupa distintos espacios ( $\mathrm{KrV}$, A174/B216). En la categoría de substancia se añade que siempre ha de haber alguna realitas espacio-temporal fenoménica que se dé con cierta permanencia o duración ( $K r V$, B225).

8.

La exigencia transcendental expresada en la categoría de substancia es que siempre algo permanezca o dure en la experiencia, que no todo cambie, así como la expresada en la categoría de accidente es que siempre algo cambie y que no todo permanezca igual. Ahora bien, ningún cuerpo permanece

22 Un tiempo vacío no es objeto de percepción ( $K r V$, A186/B229; A188/B231).

23 Paul Guyer se pregunta: “¿Por qué no podríamos percibir un objeto (no permanente) en un estado siendo seguido por un objeto diferente (no permanente) en un diferente estado en el siguiente momento del tiempo?" (2006: g107). Podríamos, pero sobre la base de que otros objetos permanezcan de modo que no se corte la ligazón y unidad de la experiencia.

24 Ese 'siempre' de tiempo, de espacio y de materia corresponden a las tres magnitudes absolutas de la mecánica de Newton. 
siempre debido a su finitud espacio-temporal-real, cuantitativa y cualitativa, según los dos primeros principios (Axiomas de la intuición y Anticipaciones de la percepción) y por interacciones con los otros objetos que pueden destruirle (causalidad y relación recíproca).

Más aún, si antes veíamos que ni la permanencia ni el cambio pueden ser absolutos, ahora añadimos que ningún cuerpo permanece absolutamente. Nada es absoluto en el fenómeno, pues todo objeto es finito en su cantidad y su cualidad, además de serlo en su interrelación con los otros. Todo lo que permanece no lo hace en relación al espacio ni al tiempo absolutos, dado que estos no pueden ser percibidos, como ya se ha señalado, y únicamente mediante la relación de unos fenómenos con otros puede determinarse sus modos de tiempo: permanencia, sucesión, simultaneidad. En la categoría de substancia lo que se requiere es que a algún fenómeno se le pueda considerar como permanente en relación a otros; en el proceso de objetivación se considera que los objetos cambian y permanecen relativamente a otros fenómenos, o sea, en mutua relación de unos fenómenos con otros, de modo que lo que cambia más lentamente o mucho más lentamente puede servir de objeto permanente, o sea, de substancia para la percepción y determinación de otros, y a la inversa. Los cuerpos, como diría Platón, no cumplen a la perfección con lo exigido por las ideas, aquí tampoco con las exigencias transcendentales expresadas en el concepto o categoría, que es universal y abstracto porque en él se manifiesta y se toma conciencia de la regla en cuanto regla, aunque sí lo hacen respecto a las exigencias expresadas en la imaginación transcendental, que trabaja con lo concreto.

Por tanto, si la substancia solo puede ser modificada [verändert] en sus accidentes, pero no aparecer y desaparecer [wechseln] $(K r V$, A187/B230-231), si la substancia no puede nacer ni perecer $(K r V$, A205206/B251), podríamos pensar que en última instancia la exigencia transcendental e ideal expresada en la categoría de substancia apunta no a algo permanente que puede ser distinto en cada caso, sino a algo concreto y real siempre permanente en el espacio-tiempo del mundo sensible, como soporte último de todo cambio, y eso es la materia, que Kant llega a llamar "materia transcendental" ( $K r V$, A143/B182), que sería algo así como la materia prima aristotélico-escolástica, pero pensada como una exigencia transcendental objetivante. En ese caso solo habría una substancia y todos 
los fenómenos del mundo serían sus diversos estados o accidentes. De la permanencia de la substancia, pensada esta vez con la implacable universalidad del concepto, de manera absoluta (no mediante simple analogía y con el 'más o menos' de la imaginación que tiene que habérselas con lo concreto), se desprende la estricta conservación de su cantidad. Desde esa perspectiva podríamos decir que la materia ni se crea ni se destruye, solo se transforma, como dice la ley química de la conservación de la materia de Lomonósov-Lavoisier, y eso es lo que piensa Kant en definitiva en relación con la substancia.25 Pero entonces parece ser que solo pudiera haber en el fondo una única substancia, pues todos los objetos del mundo sí que aparecen y desaparecen, aumentan y disminuyen, y duran o permanecen relativamente.

Octava idea: la substancia fenoménica puede apuntar en última instancia a la materia universal de todos los objetos materiales, que experimenta modificaciones en el espacio-tiempo y que sería el último substrato de todo lo que existe y cambia en él. Relativamente, es decir, en la relación de unos fenómenos con otros, hay muchas substancias, muchos objetos en el mundo sensible que pueden ser, y de hecho son, tomados como substancias y permanentes en relación con los otros. Por ejemplo, esta mesa es considerada como una substancia en relación con el color, con sus partes, con sus defectos, con su lugar, etc. Desde esa perspectiva, hay pluralidad de substancias y tiene sentido hablar así y aplicar de ese modo la categoría de substancia para ordenar los fenómenos. Pero se podría afirmar también que, en último término, lo apuntado por la exigencia de permanencia expresada en la categoría de substancia hace relación a la materia única y universal de la que están hechas todas las cosas del mundo, las cuales serían modificaciones de ella, y habría entonces una sola substancia.

Ambos usos o niveles en el uso del concepto de substancia son aceptados por Kant, pues "la materia es divisible hasta el infinito y en concreto en partes que son igualmente materia" (MAN, AA 04: 503), de modo que los objetos son también materia que se mueven en el espaciotiempo con sus propiedades o accidentes:

\footnotetext{
25 "En todo cambio de los fenómenos permanece la substancia, y el quatum de ella no se acrecienta ni disminuye en la naturaleza [...] Y como ella no puede cambiar en la existencia, entonces tampoco su quantum en la naturaleza puede aumentarse ni disminuirse" ( $K r V$, B224-225; véase también $K r V$, A185/ B228; A277-228/B279-280; Principios metafísicos de la ciencia de la naturaleza III [AA IV: 541-542]).
} 
El concepto de una substancia significa el último sujeto de la existencia, es decir, aquello que no pertenece a su vez meramente como predicado de la existencia de otro. Ahora bien, la materia es el sujeto de todo lo que puede ser contado en el espacio para la existencia de las cosas, pues fuera de ella no puede ser pensado ningún otro sujeto salvo el espacio mismo [...]. Por consiguiente, la materia en cuanto lo movible en el espacio es la substancia en él. Pero justamente de igual manera todas las partes de ella habrán de llamarse substancia, y por tanto asimismo materia, en la medida en que (so fern) se puede decir de ellas que son sujetos y no meros predicados de otras materias. Y ellas son sujetos si son movibles y por tanto también algo existente en el espacio fuera de la relación con otras partes que estuvieran al lado (MAN, AA 04: 503),26

o sea, en la medida en que se pueden mover como una unidad independiente en el espacio. En el "so fern" ("en la medida en que") se puede ver cómo la categoría de substancia es una estrategia transcendental de objetivación y ordenación, no una ley óntica de cosas en sí.27

Ahora bien, esa materia transcendental como tal ha sido pensada solo desde la universalidad de la categoría y desde el concepto de permanencia en cuanto concepto, sin mediar la necesaria acción concreta de la imaginación ( $K r V$, A181/B223-224) y sus empíricas restricciones espaciotemporales, las que vemos, por ejemplo, en el tratado de lo sublime estético $(K U, \S 26)$. Aunque se puede entender que Kant afirma que la necesidad de permanencia expresada en la categoría de substancia "está enlazada inseparablemente con la necesidad de haber sido siempre" ( $K r V$, A185/B229), es decir, con la existencia de un substrato idéntico que permanece siempre y gracias al cual se podría representar la unidad del tiempo objetivo ( $K r V$, A185-186/B228-229), debido justamente a esa ilimitación en la que es pensada dicha materia transcendental, ella no puede convertirse en un objeto fenoménico, no logra ser en realidad un fenómeno sensible, no más que el tiempo y el espacio ilimitados en cuanto tales, ni por tanto hacer perceptible y asegurar la unidad del tiempo de todos los objetos,

\footnotetext{
26 "En toda materia, lo que se mueve en el espacio es el último sujeto de todos los accidentes inherentes a la materia, y la cantidad de lo que se mueve exterior a los otros es la cantidad de la substancia" (MAN, AA 04: 541-542). "No tenemos nada permanente que pudiéramos poner, como intuición, bajo el concepto de una substancia excepto la materia" $(K r V, \mathrm{~B} 278)$.

27 "Lo que puede valer como sustancia permanente queda abierto, como corresponde al carácter regulativo del principio. Esto únicamente puede ser descubierto por medio de la experiencia. Lo permanente ha de ser, en efecto, algo real" (Thöle 1998: 275). Puedo tomar un río, una piedra o un árbol como substancias, o bien los puedo pensar como accidentes de la Tierra en cuanto substancia permanente.
} 
o sea, el que todos ellos comparten un único tiempo objetivo.28 Esa materia se hace sensible en la forma de objetos concretos, únicamente ellos son percibidos y, por tanto, solo a partir de estos y de su relación entre sí determinadas por las tres categorías de relación, sus esquemas y sus principios (las Analogías de la experiencia) se puede determinar objetivamente los modos del tiempo y su unidad en la experiencia.29 En consecuencia, el uso más adecuado de lo expresado en la categoría de substancia es referirla a los múltiples objetos sensibles.30 Es lo que ocurre en la tercera Analogía de la experiencia, donde se estudia la simultaneidad de las diversas substancias fenoménicas u objetos externos, que se ordenan entre sí en el espacio-tiempo mediante su relación recíproca: "Todas las substancias, en la medida en que pueden ser percibidas en el espacio como simultáneas, están en universal relación recíproca" ( $K r V$, B256). Aquí se habla de "una multiplicidad de substancias como fenómenos" ( $K r V$, A212/B258); son substancias relativas, a saber, relativamente a otros fenómenos que cambian más rápidamente, y eso es lo propio de lo fenoménico.31

\footnotetext{
28 De modo contrario piensan Henry E. Allison (1992: 310ss., 321ss.) y Andree Hahmann (2010: 590), y también Bryan Hall (2011). Cuando Kant habla de la identidad del substrato ( $\mathrm{KrV}$, A186/B229) o que permanece el mismo en los cambios ( $K r V$, B225), podría entenderse también que en cada caso ha de haber siempre algo que permanezca idéntico, pero no necesariamente que eso idéntico y permanente sea el mismo en todos los casos. $\mathrm{O}$ cuando Kant afirma "que el nacer o perecer de la substancia mismo no tiene lugar" ( $K r V$, B233), pues eso daría lugar a romper la unidad del tiempo, se puede entender que siempre hay algo que permanece en cada cambio, y eso que en cada caso permanece es lo que en ese momento se toma como substancia.

29 "Experiencia es un conocimiento empírico, es decir, un conocimiento que determina un objeto mediante percepciones. [...] Entonces la determinación de la existencia de los objetos en el tiempo solo puede ocurrir mediante el enlace de ellos en el tiempo en general" ( $K r V$, B218-219).

30 "Por tanto, en todos los fenómenos, lo permanente es el objeto mismo, es decir, la substancia (phaenomenon)" (KrV, A183/B227).

31 Esta dualidad de perspectivas según las cuales habría, según una, solo una substancia, y desde la otra se verían una gran multiplicidad de ellas, tanto como objetos, ha sido muy discutida en la literatura secundaria y considerada a veces como una contradicción; véase por ejemplo Andree Hahmann (2010), quien defiende la necesidad transcendental de esa materia absolutamente permanente como fundamento de la unidad de la experiencia dado que el tiempo como tal no puede ser percibido; pero yo diría que tampoco lo es esa materia universal. Martín Arias-Albisu (2011) propone tomar los objetos relativamente permanentes de nuestra experiencia sensible como substancias, que Arias denomina substancias1 siguiendo a Jonathan Bennet, las cuales serían accidentes o modos de existir de la materia como única substancia absolutamente permanente o substanciaz. Yo diría que la contradicción se resuelve también si consideramos a la substancia no como una ley óntica de cosas en sí, sino como una estrategia de ordenación de los fenómenos, como una categoría transcendental de relación que nos pone a la búsqueda de aquel fenómeno que pudiera cumplir el esquema de una manera suficiente para la ordenación de los fenómenos, y que encuentra diversos niveles de aplicación. De hecho, Kant no ve problemático utilizar el término de substancia en singular y en plural en una misma frase: "la magnitud de la materia en relación con la substancia no es otra cosa que el conjunto de sustancias de las que se compone" (MAN, AA 04: 542).
} 
Yo diría que no es transcendentalmente necesario que una substancia permanezca siempre, absolutamente, pues eso no es constatable sensiblemente, sino que siempre haya algo sensible que permanezca para que no haya corte y discontinuidad en la experiencia con tiempo y espacio vacíos. Pero eso no impide que la ciencia pueda operar con la idea regulativa de que todo lo material no sea sino modificaciones de una misma materia o energía en distintas variaciones, agrupaciones, composiciones, complejidades, etc.; ella sigue en el camino de descubrir nuevas partículas de materia-energía cada vez más pequeñas, en dirección a ese substrato absolutamente permanente o materia última, si es que eso tiene sentido en algo que siempre está en proceso.32 Todo lo que lleva la marca de lo 'absoluto', como sería en nuestro caso una materia única absolutamente permanente, sobrepasa a la imaginación y está fuera del ámbito del entendimiento y del Juicio, sino que es propiamente una idea o exigencia de la razón y no tiene una función constitutiva de la objetividad, a lo sumo regulativa.

9.

Ahora bien, aquí estamos hablando de la materia fenoménica, la que se encuentra en el espacio y en el tiempo de los objetos. Pero en el espacio y el tiempo no hay nada simple, ningún punto absolutamente indivisible, nada que no puede verse como compuesto. Por tanto, en principio, todo lo que pertenece a la intuición en cuanto elemento sensible del conocimiento "no contiene más que meras relaciones, relaciones de lugares en una intuición (extensión), de cambio de lugar (movimiento) y leyes por las cuales se determina ese cambio (fuerzas motrices)" ( $K r V$, B66-67; véase también Nachträge zur $K r V$, AA 23: 37. Carta de Kant a Kiesewetter del 9 de febrero de 1790). La materia es exterioridad y multiplicidad, partes extra partes, y carece de partes simples (segunda Antinomia) que pudieran permanecer siempre de manera invariable, pero tampoco configura una totalidad concreta o cuerpo inmodificable e indestructible, sino que en principio ella

\footnotetext{
32 "La idea de Kant no es que cualquier cosa que casualmente llamamos substancia sea permanente, sino que tanto en la vida cotidiana como en la investigación científica debemos suponer que hay algún tipo de cosa que perdura a través de todo cambio, aunque tal vez solo la ciencia pueda decirnos qué es eso, y tal vez incluso la ciencia nunca llegue a una teoría final de lo que es eso" (Guyer 2006: 108).
} 
es ilimitadamente divisible.33 Por consiguiente, "las determinaciones interiores de una substantia phaenomenon en el espacio no son más que relaciones, y ella misma es únicamente un conjunto de meras relaciones" ( $K r V$, A265/B321; véase también $K r V$, A270ss./B326ss.; A283-286/B339342; A413/B440; Refl. 3921, AA 17: 345-346; 5982, AA 18: 415), afirma Kant polemizando con Leibniz y su concepto de mónada como substancia simple. Ella no puede contener nada interno, todo lo que llamamos ahí interno lo es de manera comparativa ( $K r V$, A285/B341). En la materia del fenómeno no hay nada incondicionado. Por eso puede tomar múltiples formas diferentes y ser configurada de ilimitadas maneras, lo que no podría ocurrir con elementos indivisibles, que serían siempre iguales a sí mismos, ni con cuerpos o totalidades inmodificables y eternas.

El sujeto pide que el mundo fenoménico sea modificable para introducir en él sus propias acciones consciente y libre, pero a la vez regido por leyes, pues solo así logra conocerlo, orientarse y saber cómo actuar sobre él para sus fines, y eso es precisamente lo expresado en las categorías de relación. Pero las leyes concretas, empíricas, han de ser descubiertas, porque las categorías de relación son discursivas y regulativas, no son intuitivas: ellas no nos proporcionan ya en la intuición el otro fenómeno conectado con el que tenemos delante (al contrario de lo que ocurre con las dos primeras clases de categorías, las de cantidad y las de cualidad, unidas a la aplicación de sus esquemas), pues la existencia (del otro fenómeno) no puede ser nunca deducida a priori, sino que únicamente nos indican qué tenemos que buscar, a saber, el otro elemento diferente aún no dado sensiblemente, pero necesariamente conectado con el que se nos presenta en la intuición, por ejemplo, la causa de un fenómeno o qué es lo que en él permanece o con qué otros objetos interactúa y cómo, y así poderlo también reconocer cuando lo hallamos, todo mediante analogías con otros casos. 34

\footnotetext{
33 "La materia es divisible hasta el infinito, y lo es en partes cada una de las cuales es a su vez materia" (MAN II, Teorema 4, trad. 78, AA 04: 503; véase también $K r V$, A525-526/B553-554).

34 Como la existencia de los fenómenos 'no se puede construir', al contrario de lo que ocurre en las analogías matemáticas, las Analogías de la experiencia "solo podrán referirse a la relación de la existencia, y no podrán suministrar más que principios meramente regulativos [...] no se podrá decir a priori cuál otra percepción, ni cuán grande, sino cómo está enlazada necesariamente con aquélla en lo que respecta a la existencia en este modo del tiempo [...] aunque tengo, por cierto, una regla para buscarlo en la experiencia y una señal para encontrarlo en ella $[\ldots]$ y como principio valdrá para los objetos (para los fenómenos) no constitutivamente, sino solo regulativamente" ( $K r V$, A179180/B221-222; véase también $K r V$, A162/B201-202). El concepto kantiano de esa analogía se puede ver en su Lógica (Log., AA 09: 133).
} 
Esas leyes concretas del mundo pueden ser muy diversas. Aunque Kant pensaba que Newton había puesto las bases de todas ellas, desde principios del siglo XX, la física, y también la química y la biología, nos han ido abriendo a mundos cada vez más extraños, con fenómenos que sorprenden y desafían nuestra imaginación y entendimiento, acostumbrados como estamos a movernos en nuestro reducido mesocosmos consciente. Ante esta diversidad, la compresión humana siempre tenderá e intentará llevar toda esa multiplicidad de fenómenos y leyes a un sistema abarcable y conectado o coherente, adecuado a nuestras capacidades de conocimiento y necesario para la unidad de la experiencia, según explica Kant, en su Crítica del Juicio, mediante la teleología como principio transcendental regulativo para la comprensión de la naturaleza. Conforme nos alejamos del mesocosmos, el mundo se nos hace más extraño. Pero siempre hemos de buscar leyes. Ahora, por ejemplo, la física de partículas está empeñada en unificar las cuatro fuerzas o interacciones fundamentales: la nuclear fuerte, la débil, la electromagnética y la gravitatoria.

Noveno punto: la substancia fenoménica o materia no es algo fijo, simple o indivisible, sino relacional $\mathrm{y}$, en principio, ilimitadamente modificable, aunque se exige transcendentalmente que lo sea según reglas o leyes, no arbitraria o caóticamente, pues esto último haría imposible la objetividad y la subjetividad. Es así que la subjetividad se da; entonces, podemos afirmar con fundamento que el mundo es así como lo conocemos, al menos en una medida suficiente.

10.

Aunque las substancias fenoménicas y la materia contengan meras relaciones y nada absolutamente interior, son sin embargo reales y "el primer substrato de todas las percepciones externas" ( $K r V$, A284/B340) y no meras idealidades o pura ilusión [Schein], sino fenómenos [Erscheinungen].

En primer lugar, no caemos en el engaño cuando aplicamos la categoría de substancia a los cuerpos físicos, pues estos permanecen de manera suficiente en relación con otros fenómenos y para nuestra percepción y la velocidad empírica de nuestro tiempo vital, de modo que es útil considerarlos permanentes e identificarlos como objetos singulares con vistas a ordenar otros fenómenos y a ellos mismos y orientarnos en el 
mundo objetivo. Son relativamente substancias. Y así decimos 'este árbol es una substancia', que es lo mismo que afirmar 'este árbol es un objeto' y lo tratamos como tal, no porque permanezca siempre lo mismo, pues nace y muere y está en continuo movimiento o cambio, pero sí conserva su unidad durante un tiempo y responde suficientemente a ese requerimiento transcendental en comparación con otros fenómenos, por ejemplo, su crecimiento o su cambio de color en otoño o los nutrientes que toma de la tierra.

Pero, sobre todo, en segundo lugar, la aplicación del concepto de substancia a los cuerpos físicos (o incluso a la materia como último soporte substancial del mundo fenoménico) queda justificada porque ellos presentan desde sí su propia realidad en el sentido de que no son creados ex nihilo por el sujeto, sino que a este le son dados (MAN, AA 04: 481), lo cual justifica el realismo empírico, o sea, que esas substancias no son meras idealidades. Esto queda consignado en la Estética transcendental, también en la categoría cualitativa de realidad [Realität], su esquema y su principio, categoría a la que la substancia añade el requisito de permanencia y de siempre. La substancia fenoménica no es mera relación en el sentido de que fuera solo idealidad, sino que consta de relaciones reales y exhibe una realitas propia, la cual es reconocida en la categoría de realidad, su esquema y su principio. Frente a esa realitas del fenómeno el sujeto se comporta pasivamente, le es dado y él no la crea, lo que muestra que el fenómeno exhibe cierta realidad desde sí, algo que Kant intenta pensar mediante los problemáticos conceptos de cosa en sí y de afección sensible (véase Rivera de Rosales 2018; 2011, Cap. 2).

Este modo de ser y de presentarse desde sí que tienen los objetos externos y materiales, que es lo que hace posible el realismo empírico de la substancia, lo comprende Kant a través del concepto de fuerza. La substancia fenoménica se nos manifiesta como fuerza desde sí capaz de ser causa. La "causalidad conduce al concepto de acción, esta, al concepto de fuerza, y por medio de ella al concepto de substancia" ( $K r V$, A204/B249). La acción [Handlung] es un criterio empírico suficiente para la sustancialidad, pues solo puede actuar lo que permanece haciendo que otra cosa cambie ( $K r V$, A205/B250-251). “Allí donde hay acción, y por tanto actividad y fuerza, allí hay también substancia, y únicamente en esta se ha de buscar el asiento de la fecunda fuente de los fenómenos" ( $K r V$, 
A204/B250). La substancia es la causa, pues el efecto hace relación a lo que cambia y aquello que cambia no puede ser la causa del cambio sino el efecto de lo que permanece. "La categoría de la substancia yace en el fundamento de todos los conceptos de cosas reales" (Prol., AA 04: 325, nota).

Kant defiende en sus Principios metafísicos de la ciencia de la naturaleza una concepción dinámica de la materia en línea con la tradición leibniziana, pues, según él, la materia está constituida por dos fuerzas motrices originarias, no deducibles de otras ni, claro está, creadas por el sujeto, y gracias a esas fuerzas la materia llena un espacio. Una es la fuerza expansiva o repulsiva, que se denomina también elasticidad, y la segunda es la fuerza de atracción, que limita la fuerza expansiva y mantiene el cuerpo en límites espaciales. Estas fuerzas físicas y su ocupación del espacio y del tiempo confieren el momento de realismo empírico a la unidad de la síntesis imaginativa con la que interpretamos un objeto y su unidad. "Conocemos a la substancia en el espacio solamente por fuerzas que actúan en él, ya para arrastrar a otras hacia allí (atracción), ya para impedir la penetración en él (repulsión e impenetrabilidad)" ( $K r V$, A265/B321). En ese sentido, hemos de ver una pluralidad de substancias fenoménicas como fuerzas que se mantienen en relación recíproca según el principio de acción y reacción (tercera ley de Newton).

Décimo y último momento: la substancia fenoménica y la materia son dinámicas, fuerzas, hoy se diría que son en el fondo energía. La materiafuerza o energía es el origen y la causa real de todos los fenómenos, tanto de los considerados como substancia como de sus accidentes. Además, dado que la materia-fuerza no cuenta con elementos simples,35 según se ha dicho, la substancia fenoménica se constituye como un campo de fuerzas, sin ningún elemento simple: esa es la conclusión final, no alejada de la física actual y de sus conceptos de campo - es lo que sugiere Michael Oberst (2017)-.

35 "Ni el tiempo ni tampoco el fenómeno en el tiempo consisten en partes que sean las mínimas [...] Ninguna diferencia de lo real en el fenómeno así como tampoco ninguna diferencia en la cantidad de los tiempos es la mínima" ( $K r V$, A209/B254). 
Referencias

ALLISON, H. E.: El idealismo trascendental de Kant: una interpretación y defensa, Barcelona, Anthropos, 1992.

ARIAS-ALBISU, M.: "La concepción objetiva de la substancia en la Crítica de la razón pura de Kant”, Estudios de Filosofía 44 (2011), 39-60.

GUYER, P.: Kant, Londres/Nueva York, Routledge, 2006.

HAHMANN, A.: „Wozu braucht Kant die Kategorie der Substanz?“, Deutsche Zeitschrift für Philosophie 58, 4 (2010) 579-594.

HALL, B.: "A Dilemma for Kant's Theory of Substance", British Journal for the History of Philosophy 19, 1 (2011) 79-109.

HEIDEGGER, M.: Die Frage nach dem Ding, Tübingen, Max Niemeyer, 1987.

JEFFREY, E.: Substance, Force and the Possibility of Knowledge: On Kant's Philosophy of Material Nature, Berkeley/Los Angeles, University of California Press, 2000.

KANT, I.: Gesammelte Schriften, Bd. 1-22, Preussische Akademie der Wissenschaften, 23, Deutsche Akademie der Wissenschaften zu Berlin, 24, Berlín, Akademie der Wissenschaften zu Göttingen,1900ss.

: Crítica de la razón pura, México, Fondo de Cultura Económica, 2009.

: Prolegómenos, Buenos Aires, Charcas, 1984.

: Principios metafísicos de la ciencia de la naturaleza, Madrid, Alianza, 1989.

OBERST, M.: „Kant über Substanzen in der Erscheinung“, Kant-Studien 108, 1 (2017), 1-18.

OLK, C.: „Ich, Selbstbewusstsein und der psychologische Paralogismus. Zur möglichen Bestimmung reflexiver Subjektivität und zur unmöglichen Bestimmung einer Ich-Substanz bei Kant", Kant-Studien 109, 2 (2018) 228248.

RIVERA DE ROSALES, J.: El punto de partida de la metafísica transcendental, Madrid, Xorki, 2011. 
: Heidegger and Kant's "Refutation of Idealism", en: Objectivity after Kant. Its Meaning, its Limitations, its Fateful Omissions, Hildesheim, Olms, 249-278, 2013.

: "Attempt to introduce the concept of body into the Critique of Pure Reason”, Estudos kantianos 5, 1 (2017) 231-251.

: "Kant y la cosa en sí", en: La razón y la vida, Madrid, Trotta, $533-543,2018$

SANS, G.: „Wie viel Substanz braucht Kant?“, Revista Portuguesa de Filosofia 61, 3-4 (julio-diciembre 2005) 707-730.

THÖLE, B.: „Die Analogien der Erfahrung“, en: Immanuel Kant. Kritik der reinen Vernunft, Berlín, Akademie Verlag, 266-296, 1998.

WOLFF, C.: Philosophie prima sive Ontologia, Fráncfort del Meno/Leipzig, Renger, 1736. 


\title{
La refutación kantiana del idealismo y el realismo ingenuo reconsiderado
}

\author{
MANUEl AMADO 1
}

\begin{abstract}
Resumen
En la breve sección de La crítica de la razón pura titulada "Refutación del Idealismo", Kant ofrece un argumento que pretende socavar al "idealismo problemático" según el cual la existencia de "objetos en el espacio por fuera de nosotros es dudosa e indemostrable". El objetivo de este texto es doble: primero, mostrar que la conclusión del argumento puede ser entendida de al menos dos maneras, una débil y una fuerte. Segundo, sugerir cómo la versión fuerte puede comprometer a Kant con una versión del realismo ingenuo que es compatible con su idealismo trascendental, contrario a lo que varios comentaristas sostienen.
\end{abstract}

Palabras clave: Kant, argumento trascendental, idealismo, realismo ingenuo, percepción

\section{Kantian refutation of idealism and naïve realism reconsidered}

\begin{abstract}
In the so-called "Refutation of Idealism", a brief section of the Critic of Pure Reason, Kant offers an argument against the "Problematic Idealism", the idea according to which "the existence of objects in space outside us" is "doubtful and indemonstrable". The objective of this paper is double: first, to show that the conclusion of this argument can be paraphrased in at least two ways, a weak and a strong readings. Second, to suggest how the strong reading entails a version of the so called naïve realism compatible with transcendental idealism, contrary to what some commentators have claimed.
\end{abstract}

Keywords: Kant, trascendental argument, idealism, naïve realism, perception

1 Universidad Nacional de Colombia. Contacto: megaskatos@gmail.com. 


\section{Introducción}

En la sección de La crítica de la razón pura titulada "Refutación del idealismo" ( $K r V$, B274-B279), Kant formula escuetamente un ataque en contra de lo que él considera una versión "razonable y filosóficamente rigurosa" del idealismo y que etiqueta como problemático. El presente texto procederá como sigue: en primer lugar, se expondrá en qué consiste el idealismo problemático y se dará cuenta de la estrategia argumentativa empleada por Kant para socavarlo; en segundo lugar, se revisarán críticamente las premisas y supuestos del argumento kantiano para exponer algunas de sus falencias. Finalmente, se mostrará cómo la conclusión del argumento kantiano puede entenderse de al menos dos formas y cómo estas pueden comprometer a Kant con una versión del así llamado realismo ingenuo: la tesis de que tenemos experiencia perceptual de objetos independientes de la mente.

\section{Dos tipos de idealismo}

Hay, según Kant, dos tipos de idealismo: el dogmático y el problemático. Aunque ambos ponen en entredicho la existencia de objetos fuera de nosotros, el dogmático niega dicha existencia y la considera imposible, mientras que el problemático solamente la considera dudosa o indemostrable. El ataque que esgrime Kant en su refutación se dirige solamente al idealismo problemático pues, dice, el dogmático ha sido refutado en otra parte de su obra.

La conclusión a la que pretende llegar Kant es que el idealismo problemático es falso, ya que no solo se puede demostrar que efectivamente existen objetos permanentes por fuera de nuestra mente, sino que tenemos experiencia de dichos objetos ( $K r V$, B275). Conforme a esto, la conclusión a la que quiere llegar Kant se puede dividir en dos afirmaciones separadas, una débil (CK1) y una fuerte (CK2):

CK1) Existen objetos permanentes fuera de nosotros.

CK2) Tenemos experiencia de objetos permanentes fuera de nosotros. 
CK1 y CK2 son afirmaciones diferentes, pues la primera no implica la segunda; es decir, comprometernos con que existan objetos fuera de nosotros no nos compromete con afirmar que tengamos experiencia de dichos objetos. Un ejemplo puede servir de ilustración: podemos admitir que existen los electrones $\mathrm{u}$ otras partículas subatómicas por fuera de nosotros, pero esto no implica admitir que tenemos experiencia de dichas partículas, simplemente no tenemos la capacidad ni los instrumentos para observarlas. De modo que Kant, además de tener que convencernos de CK1, nos debe una explicación de por qué también debemos aceptar CK2.

En lo que sigue intentaré reconstruir esquemáticamente la argumentación kantiana para defender CK1 y CK2.

\section{La refutación al idealismo}

\subsection{El argumento transcendental}

Como una suerte de preámbulo, Kant enuncia el rasgo general de su estrategia: la prueba consistirá en mostrar que la experiencia interna, que es indudable incluso para un escéptico del mundo exterior, solamente es posible si se supone la experiencia externa. El 'truco' de mostrar que algo ajeno a la experiencia interna es una condición necesaria que hace posible dicha experiencia se conoce como argumento trascendental. En términos amplios, el argumento trascendental de Kant puede exponerse así ( $\mathrm{KrV}$, B275-276):

R1) Si tenemos conocimiento de que nuestras experiencias están temporalmente ordenadas, entonces existen objetos permanentes fuera de nosotros.

R2) Tenemos conocimiento de que nuestras experiencias están temporalmente ordenadas.

Por tanto,

CK1) Existen objetos permanentes fuera de nosotros (Modus ponens R1, R2). 
La premisa R1 es justamente la que realiza la conexión entre la experiencia interna (indubitable para un buen cartesiano) y la experiencia externa (la experiencia del mundo exterior). Según Kant, el idealista problemático aceptará, sin ningún inconveniente, que tiene conocimiento de lo que ocurre en el interior de su mente; en particular, aceptará que tiene conocimiento de que sus experiencias tienen un orden o determinación temporal, o sea, la premisa R2. De esta forma, si Kant logra convencer al idealista problemático de la verdad de la premisa R1 logrará refutarlo, pues R1 y R2 implican necesariamente que existen objetos permanentes fuera de nosotros (CK1). Pero, ¿por qué R2 es algo que fácilmente aceptaría el idealista problemático? Y, lo más importante, ¿por qué tenemos que aceptar que R1 es verdad?

Empecemos por la respuesta a la primera pregunta. Mediante un desprevenido ejercicio introspectivo podemos darnos cuenta de que en nuestra mente ocurre una sucesión de experiencias: en el presente, podemos evocar imágenes de lo que estamos haciendo en este momento, de lo que hemos hecho momentos previos y aun de lo que hemos vivido en momentos del pasado muy alejados del momento presente. Aunque muchas de esas imágenes o experiencias no están fechadas (los recuerdos, por ejemplo, no aparecen con una fecha marcada), al momento de evocar sí somos conscientes de que las experiencias tienen un orden temporal: sabemos que esas imágenes se pueden ubicar en una línea de tiempo, que no todas ocupan el mismo lugar en esa línea y que unas aparecen antes y otras después. A este conocimiento de la ubicación de nuestras experiencias en una línea temporal es a lo que parece referirse Kant al decir que somos conscientes de la determinación temporal de nuestras experiencias internas $(K r V$, B275). Como este ordenamiento es algo que, aparentemente, podemos conocer a partir de una reflexión interna, parece entonces que incluso el idealista debe aceptar que tiene conocimiento de este ordenamiento: el idealista sabe, al menos en algunas ocasiones, que, por ejemplo, una de sus experiencias al esperar un autobús es anterior a su experiencia de viajar en el interior de este autobús, y es consciente de este orden temporal de experiencias incluso si no hay tal cosa como un autobús que exista por fuera de su mente. Similarmente, ahora mismo soy consciente de que tengo la experiencia de escribir esta oración. También soy consciente de que mi experiencia de leerla ahora es posterior, aun si el texto mismo realmente no existe por fuera 
de mi mente. De ahí que R2 sea algo que puede, en principio, aceptar el idealista.

Consideremos ahora la segunda pregunta: ¿qué razones tenemos para creer en R1 (si tenemos conocimiento de que nuestras experiencias están temporalmente ordenadas, entonces existen objetos permanentes fuera de nosotros)? Kant ofrece un breve argumento a favor de R1 ( $\mathrm{rrV}, \mathrm{B} 276-$ B278) que puede ser parafraseado como un clásico silogismo hipotético:

Q1) Si tenemos conocimiento de que nuestras experiencias están temporalmente ordenadas, entonces hay cosas permanentes en virtud de las cuales ordenamos temporalmente dichas experiencias.

Q2) Si hay cosas permanentes en virtud de las cuales ordenamos temporalmente dichas experiencias, entonces esas cosas permanentes son diferentes de nuestras experiencias.

Q3) Si esas cosas permanentes son diferentes de nuestras experiencias, entonces existen objetos permanentes fuera de nosotros.

Por tanto,

R1) Si tenemos conocimiento de que nuestras experiencias están temporalmente ordenadas, entonces existen objetos permanentes fuera de nosotros (Silogismo hipotético Q1, Q2 y Q3).

De todas las premisas a favor de $\mathrm{R} 1$, probablemente las más fácil de aceptar es Q2. Dado que la existencia de nuestras experiencias es bastante efímera (nuestras experiencias cambian cada vez que nos movemos, que parpadeamos, que vamos a dormir, y los recuerdos aparecen y se difuminan rápidamente), difícilmente podemos admitir que nuestras experiencias sean cosas permanentes. De ahí que Q2 sea verdad. No obstante, las premisas Q1 y Q3 son más difíciles de digerir. En la próxima sección discutiré con mayor detalle estas premisas.

Hasta el momento, la refutación kantiana del idealismo puede presentarse de forma esquemática así: 
Q1) Si tenemos conocimiento de que nuestras experiencias están temporalmente ordenadas, entonces hay cosas permanentes en virtud de las cuales ordenamos dichas experiencias.

Q2) Si hay cosas permanentes en virtud de las cuales ordenamos dichas experiencias, entonces esas cosas permanentes son diferentes de nuestras experiencias.

Q3) $\mathrm{Si}$ esas cosas permanentes son diferentes de nuestras experiencias, entonces existen objetos permanentes fuera de nosotros.

Por tanto,

R1) Si tenemos conocimiento de que nuestras experiencias están temporalmente ordenadas, entonces existen objetos permanentes fuera de nosotros (Silogismo hipotético, Q1, Q2 y Q3).

R2) Tenemos conocimiento de que nuestras experiencias están temporalmente ordenadas.

En consecuencia,

CK1) Existen objetos permanentes fuera de nosotros. (Modus ponens $\mathrm{R} 1, \mathrm{R} 2$ ).

Solo falta ver cómo Kant salta de la conclusión CK1 a la conclusión más fuerte:

CK2) Tenemos experiencia de objetos permanentes fuera de nosotros.

Lamentablemente, esta es la parte más débil, a mi juicio, de la refutación kantiana. Por una parte, no se encuentra en el texto una razón por la cual CK1 implique CK2; Kant solo afirma, sin más, que esta última es implicada por la primera: "la conciencia de mi propia existencia (en el tiempo) constituye, a la vez, la conciencia inmediata de la existencia de otras cosas fuera de mí" ( $K r V$, B276, énfasis añadido). Pero eso no parece ser cierto, como vimos con el ejemplo de los electrones: puedo aceptar que algo existe y esto no me obliga aceptar que tengo experiencia de él. Así, el 
argumento kantiano es válido hasta CK1, pero no hasta CK2. Por otra parte, no es claro por qué Kant necesita CK2 para refutar el idealismo: si lo que afirma el idealismo problemático es simplemente que no se puede probar que existen objetos externos, el argumento kantiano lograría su cometido al concluir CK1, sin el paso adicional a CK2. Finalmente, admitir, con CK2, que experimentamos objetos por fuera de la mente es algo que parece ir en contravía de la propia postura de Kant al respecto de la experiencia: según cierta interpretación del idealismo trascendental, tenemos experiencia de fenómenos, no de cosas en sí. Por el bien de la coherencia, parece mejor, por ahora, dejar el argumento hasta CK1 y posponer o abandonar la defensa de CK2. En la sección final, se discutirá una forma en la que Kant podría matizar CK2 a modo de hacerla compatible con una de las lecturas posibles del idealismo trascendental.

A continuación, revisaré críticamente algunas de las premisas del argumento kantiano a favor de CK1. Aunque el argumento, como vimos, es válido, creo que pueden hacerse algunos reparos con respecto a la verdad de sus premisas.

\subsection{El Descartes maligno, el diálogo interno y el Yo permanente}

Anteriormente se mencionó que R2 (tenemos conocimiento de que nuestras experiencias están temporalmente ordenadas) es algo que, para Kant, bien puede aceptar el idealista problemático de corte cartesiano, aquel que cree que la experiencia interna es indubitable. No obstante, hay una manera en la que un nuevo idealista problemático podría cuestionar la premisa R2 con viejos recursos cartesianos. La idea es como sigue.

Es evidente que creemos saber que nuestras experiencias tienen un orden temporal y que muchas veces creemos también saber cuál es ese orden. Mientras escribo esto, tengo el recuerdo de haber tomado un café en un día soleado y me parece que la experiencia de haber tomado ese café es anterior la experiencia de haber llegado a este lugar. Sin embargo, un espíritu maligno, tal vez el espíritu de Descartes, puede tener el poder de alterar mis recuerdos y hacerme creer que una experiencia tuvo lugar antes que la otra cuando, de hecho, fue todo lo contrario o, peor aún, puede hacerme creer que la experiencia tuvo lugar cuando realmente nunca ocurrió. Este Descartes maligno puede insertar falsos recuerdos a nuestra conciencia y, así, hacernos creer que nuestras experiencias tienen un orden temporal que en realidad no tienen. No tenemos razones, al menos no 
derivadas de la refutación kantiana, para pensar que este Descartes maligno no existe. En síntesis, puesto que no tenemos certeza de que nuestros recuerdos sean falsos, insertados, ni, consecuentemente, tenemos certeza del orden temporal de estas experiencias, debemos concluir que no tenemos conocimiento de que nuestras experiencias estén temporalmente ordenadas. Luego, la premisa R2 del argumento kantiano debe ser rechazada.

Hay varios caminos que podría tomar un kantiano para responder a esta réplica. Uno de ellos es intentar refutar a este nuevo idealista problemático, que podemos llamar superproblemático. Para ello, se debe mostrar la imposibilidad de la existencia del Descartes maligno descrito, algo que Kant no hace en la refutación original. Otra opción, quizás más simple, es reducir el alcance del argumento kantiano; es decir, mantener que el argumento trascendental expuesto solo se aplica al idealista problemático, no al superproblemático. En cualquiera de los dos casos, se deben hacer enmiendas al argumento original.

Supongamos que contamos con los elementos para bloquear la objeción anterior a la premisa R2. Hay, de todos modos, algunos reparos con las razones que tiene Kant para soportar la premisa R1. En la sección anterior afirmé que de las tres premisas que soportan $\mathrm{R} 1$, probablemente la más fácil de aceptar es Q2, las premisas Q1 y Q3 parecen algo más problemáticas. Veamos por qué.

De acuerdo con Q1, si tenemos conocimiento de que nuestras experiencias están temporalmente ordenadas, entonces hay cosas permanentes en virtud de las cuales ordenamos dichas experiencias. Es posible que lo que Kant tenga en mente con esta premisa es que para determinar el orden temporal de nuestras experiencias (cuál viene primero o cuál viene después), hacemos referencia a objetos que, suponemos, hacen parte del inventario del mundo exterior. Por ejemplo, recuerdo tener la experiencia de i) entrar a un café y ii) ordenar un cappuccino; recuerdo también iii) haber visto cómo lo preparaban, iv) lo servían, y finalmente v) cómo yo lo tomaba. Creo saber cuál fue el orden de esas experiencias: ocurren exactamente en el orden de i) a v) (con i) ocurriendo primero y v) al final). Probablemente, y este quizá sea el punto de Kant, mi seguridad al pensar que el orden es de i) a v) se debe, al menos en parte, a que asumo que todas esas experiencias ocurrieron en un mismo día, en un mismo lugar y con respecto a un mismo cappuccino; día, lugar y cappuccino que, de no ser 
reales (existentes por fuera de mi mente y lo suficientemente permanentes como para referirme a ellos), no me brindarían la seguridad de que el orden de mis experiencias es justamente el de i) a v). En otras palabras, si el día, el lugar y el cappuccino fueran ellos mismos experiencias o simples representaciones, no podría saber si el orden de mis experiencias es, efectivamente de i) a v): si el cappuccino es una simple experiencia o representación, el que ocurre en una experiencia sería diferente al que ocurre en otra, por ser diferentes experiencias. Y, como serían diferentes, no podría saber si la experiencia del cappuccino consumido fue anterior a la experiencia del cappuccino siendo preparado. En breve, parece que hay casos en los que tenemos que referirnos a objetos externos duraderos para afirmar que nuestras experiencias tienen un determinado orden temporal. De aquí que Kant mantenga algo como Q1.

Sin embargo, a pesar de que en el caso descrito debamos suponer que existen objetos externos permanentes fuera de nuestra mente para saber que nuestras experiencias tienen un determinado orden, no siempre es el caso que tengamos que referirnos al mundo externo para determinar el orden temporal de nuestras experiencias. Por ejemplo, cuando escuchamos una melodía es posible que determinemos el orden con que escuchamos determinados acordes que la componen; pero, no es obvio que debamos suponer que estos acordes, o la melodía misma, existen por fuera de nuestras cabezas. El diálogo interior, cuando conversamos con nosotros mismos o con otros de manera imaginaria, ofrece un ejemplo similar: podemos determinar qué parte del diálogo interno ocurrió antes y qué otra ocurrió después incluso si no suponemos que el diálogo, o los participantes en él, existen por fuera de nuestra mente. Por estos contraejemplos, la premisa Q1 no parece del todo cierta (Bennett [1966] construye otros contraejemplos para refutar la premisa Q1).

La premisa Q3 es algo más promisoria, siempre y cuando Kant coquetee con ciertos puntos de vista acerca del Yo, comúnmente asociados a Hume. Me explico: según Q3, si esas cosas permanentes (gracias a las cuales ordenamos temporalmente nuestras experiencias) son diferentes de nuestras experiencias, entonces existen objetos permanentes fuera de nosotros. Podemos aceptar que las experiencias mismas no pueden ser los objetos permanentes que busca Kant; no obstante, el hecho de que esas cosas permanentes no sean experiencias no implica que esas cosas estén 
fuera de nuestra mente. Esto porque hay otro posible candidato a objeto permanente que no es una de nuestras experiencias, pero tampoco está fuera de nuestra mente; a saber, el mismísimo Yo. Si nuestro Yo es diferente a nuestras experiencias y es lo suficientemente permanente como para poder referirnos a él, ¿por qué no puede ser en virtud del Yo que reconozco el orden temporal de mis experiencias?

No es evidente por qué Kant descartaría al Yo como posible objeto permanente en virtud del cual ordenamos nuestras experiencias, pero si se asume que el Yo es como lo describe Hume - o sea, un manojo o flujo de impresiones e ideas - es claro cómo el Yo no puede ser ese objeto permanente: como las experiencias no son el tipo de cosa permanente con respecto a las cuales puedo ordenar mis propias experiencias, si el Yo no es más que un flujo de experiencias, el Yo tampoco podrá ser ese objeto permanente.

De este modo, el Yo humeano puede ayudar a sustentar la premisa Q3, con la infortunada consecuencia de que al mismo tiempo debilita el argumento trascendental de Kant, pues el idealista problemático no tiene que adoptar una concepción humeana del Yo; podría también adoptar un concepto del Yo puramente cartesiano: un Yo sustancial, inmaterial y, sobre todo, permanente. Kant necesitaría una pequeña ayuda de Hume, la crítica del Yo cartesiano, para refutar al idealismo problemático.

\section{Kant y el realismo ingenuo reconsiderado}

Supongamos que Kant enmienda su argumento de tal forma que da cuenta de las objeciones recién expuestas. Aún hay una objeción fuerte a su argumento discutida por los comentaristas de su obra (Allison 1983; Dicker 2011; 2008; Guyer 1987; Robinson 2010; Strawson 1975). En términos generales, la objeción es que la conclusión del argumento de Kant, tanto en la lectura débil CK1 como en la lectura fuerte CK2, es incompatible con su renombrado idealismo trascendental. De modo que, según sus críticos, Kant deberá elegir, por el bien de la consistencia, entre su ataque al idealismo problemático y su renombrada tesis. En lo que resta de este texto, intentaré mostrar por qué Kant no enfrenta este dilema, si se acepta que Kant se compromete con una versión moderada del realismo ingenuo: la tesis de que tenemos experiencia de objetos independientes de la mente. 
De acuerdo con Dicker (2008: 100-104), hay varias formas de interpretar el idealismo trascendental: por una parte, tenemos una lectura metafísica y, por otra, una epistemológica.

Según la lectura metafísica, el espacio y el tiempo son parte del inventario de nuestra mente y, por tanto, dependen de ella. En esta lectura, hay una tajante diferencia entre las cosas en sí y las apariencias, pero esta diferencia puede entenderse, a su vez, de dos formas: en la lectura metafísica dual, las cosas en sí y las apariencias son dos cosas de un género completamente distinto, no son idénticas en ningún sentido. En la lectura metafísica de perspectiva, las cosas en sí son aquello que se nos presenta en la experiencia, pero no tienen todas las propiedades que en la experiencia parecen tener; en particular, no están en el espacio o en el tiempo, aunque así nos aparezcan.

La lectura epistemológica del idealismo trascendental no implica que las apariencias y las cosas en sí sean las mismas o diferentes; tampoco implica algún juicio existencial sobre las cosas en sí, pues considera que cualquier juicio al respecto es ininteligible. La lectura epistemológica solamente se compromete con una afirmación acerca de cómo percibimos y cómo conceptualizamos aquello que percibimos: tenemos percepciones como de objetos espacio-temporales, los conceptualizamos como independientes de nosotros y no tenemos otra forma de concebirlos que como los percibimos. De este modo, según la lectura epistemológica del idealismo trascendental, la pregunta acerca de si las cosas en sí son o no como las percibimos, o si existen independientemente de nuestra mente, no es inteligible o, al menos, no puede ser inteligiblemente resuelta.

La lectura epistemológica es ciertamente incompatible con CK2 (tenemos experiencia de objetos permanentes fuera de nosotros), pues CK2 no es una descripción de cómo percibimos, sino una descripción del objeto de nuestra experiencia: aquello acerca de lo que es la experiencia, no acerca de cómo luce. La lectura epistemológica tampoco es compatible con CK1, ya que creer en esta última implica mantener un compromiso con una afirmación acerca de la existencia de objetos por fuera de nuestra mente; compromiso que no puede ser inteligiblemente mantenido según la lectura epistemológica. La lectura epistemológica del idealismo trascendental no puede, en consecuencia, conciliarse con los propósitos de la refutación kantiana del idealismo. En otras palabras, si Kant mantiene la lectura 
epistemológica del idealismo trascendental, su refutación al idealismo no puede ser formulada inteligiblemente.

La lectura metafísica del idealismo trascendental no es, en apariencia, compatible con las conclusiones de la refutación kantiana: en estricto sentido, las cosas en sí no están por fuera de nosotros, pues esto implicaría que las cosas en sí satisfacen predicados espaciales, algo que no es cierto en la lectura metafísica del idealismo trascendental. Conforme a esta lectura, la existencia de las cosas en sí es más bien independiente de la nuestra.

Si Kant entiende 'por fuera de nosotros' como 'independiente de nosotros', la lectura metafísica dual es compatible con CK1 (existen objetos permanentes fuera de nosotros), pues la lectura metafísica dual se compromete con la existencia de cosas en sí y mantiene que estas son diferentes de nuestras experiencias e independientes de ellas. A pesar de la enmienda, la lectura metafísica dual seguiría siendo incompatible con CK2: en la lectura metafísica dual, las cosas en sí son diferentes a las apariencias y no son objeto de nuestra experiencia, ni directa ni indirectamente.

La única lectura del idealismo trascendental que resta por examinar es la lectura metafísica de perspectiva. Como intentaré mostrar, esta lectura es máximamente compatible con la refutación kantiana, pues es compatible con sus dos conclusiones.

De acuerdo con esta lectura, las cosas en sí son objetos posibles de nuestra experiencia; sin embargo, las experiencias que tenemos de ellas nunca son perfectamente verídicas: las experimentamos como teniendo propiedades espacio-temporales que, de hecho, no tienen. Al mantener esta lectura, Kant tendría que estar de acuerdo con la idea de que ninguna de nuestras experiencias de objetos es completamente verídica. Pero esta idea, por sí misma, no cuenta en contra de la lectura metafísica de perspectiva del idealismo trascendental ni de las dos consecuencias (CK1 y CK2) de la refutación al idealismo.

A primera vista, puede pensarse que la lectura metafísica de perspectiva no es compatible con la refutación al idealismo, ya que difícilmente puede atribuirse a Kant la idea de que si percibimos cosas en sí, las percibimos directamente o inmediatamente, como sugiere en su refutación y como mantiene el así llamado realismo ingenuo. Si Kant no es 
realista ingenuo, podría pensarse que es un realista indirecto; sin embargo, esto también es problemático. Esto porque leer el idealismo trascendental en términos del realismo indirecto socava el propósito de la refutación del idealismo: el realista indirecto deja abierta la posibilidad de que su experiencia de objetos no solo sea ilusoria, sino alucinatoria $\mathrm{y}$, por consiguiente, admite que nuestras experiencias de objetos externos pueden existir incluso si no existen objetos externos que las causen. De este modo, si Kant no es realista directo, ni realista indirecto, parece que no queda otra opción que considerar que su idealismo trascendental, incluso en la lectura metafísica de perspectiva, no se concilia con su refutación al idealismo.

Una salida a este problema está disponible. Es posible mantener que aunque nuestra experiencia es acerca de objetos independientes de nuestra mente que no son ellos mismos el contenido de nuestra experiencia, dicho contenido es objeto dependiente, en el sentido de Evans (1982). Que el contenido de la experiencia es objeto dependiente significa que si bien los objetos mismos no constituyen el contenido de mi experiencia (pues, el contenido está constituido por apariencias), el contenido de mi experiencia no puede existir sin que existan objetos independientes de mi mente.

Si interpretamos la refutación al idealismo como una defensa de la tesis de que la experiencia tiene un contenido objeto dependiente, el idealismo trascendental (en la lectura metafísica de perspectiva) es compatible con la refutación kantiana, tanto con CK1 como con CK2. Veamos por qué.

Una formulación más apropiada de ambas conclusiones de la refutación kantiana, a la luz de la tesis de la dependencia del objeto, sería la siguiente:

CK1* Existen objetos independientes de nuestra mente.

CK2* Tenemos experiencias como de objetos externos y el contenido de dichas experiencias depende de la existencia de objetos independientes de nuestra mente.

Ambas, CK1* y CK2*, son incompatibles con el idealismo problemático que busca combatir Kant y ambas son compatibles con el 
idealismo trascendental en la lectura metafísica de perspectiva: las cosas en sí y las apariencias son distintas, estas últimas serían propiamente los componentes del contenido de nuestra experiencia, mientras que las primeras serían la condición de posibilidad de la existencia del contenido de nuestra experiencia. Así, Kant no tiene que comprometerse con un realismo ingenuo puro, ni con un realismo indirecto que coquetea con el idealismo problemático, sino con lo que podríamos llamar un realismo ingenuo reconsiderado. De acuerdo con este realismo, tenemos experiencia de las cosas en sí, pero solo en el sentido en que los contenidos de mi experiencia, las apariencias, dependen de la existencia de cosas en sí. La tesis de la dependencia del objeto es compatible con la idea de que el espacio y el tiempo son parte del inventario mental, pues nuestras experiencias de cosas en sí, según esta tesis, serían necesariamente ilusorias: percibo las cosas como espacio-temporales cuando, de hecho, no lo son; pero no podría tener experiencias de objetos espacio-temporales de no ser por la existencia de objetos no espacio-temporales.

Aún persiste el problema del salto inferencial entre CK1* y CK2*, pero este problema es solo un problema de ausencia de pruebas, no de ausencia de coherencia, si la presente interpretación de la argumentación de Kant es correcta.

\section{Conclusiones}

Si la reconstrucción de la refutación kantiana del idealismo que he ofrecido hasta aquí es correcta, se puede señalar que, aunque la argumentación de Kant es válida al nivel de CK1*, sus premisas presentan ciertas falencias. En primer lugar, Kant debe limitar el alcance del argumento trascendental ante la amenaza del idealista superproblemático: el idealista que duda no solo del conocimiento del mundo exterior, sino del conocimiento del orden temporal de nuestras experiencias (R2). En segundo lugar, el argumento de Kant difícilmente puede afirmar que siempre que conocemos el orden temporal de nuestras experiencias lo hacemos en virtud de que nos referimos a objetos externos (Q1); hay otros casos, como las experiencias de melodías o el diálogo interno, en los que, aparentemente, conocemos el orden temporal de nuestras experiencias sin apelar a objetos externos. En tercer lugar, para que Kant pueda soportar confiadamente una de las premisas de su refutación (Q3), es probable que deba descansar en una 
concepción humeana del Yo según la cual el Yo no es más que un flujo de experiencias e ideas efímeras; de otro modo, un idealista problemático que asuma una concepción cartesiana del Yo, un Yo sustancial permanente, podría bloquear la refutación kantiana.

Aunque la argumentación de Kant presenta falencias, su refutación al idealismo es compatible con su idealismo trascendental, si se entiende en términos de la lectura metafísica de perspectivas y se asume que Kant se compromete con el realismo ingenuo reconsiderado: la idea de que las apariencias, aunque distintas de las cosas en sí, no pueden existir sin ellas y que la experiencia del mundo es, necesariamente, ilusoria — percibimos el mundo como espacio-temporal cuando, de hecho, no lo es.

Referencias

ALLISON, H.: Kant's Transcendental Idealism: An Interpretation, New Haven, NJ/Londres, Yale University Press, 1983.

BENNETT, J.: Kant's Analytic, Cambridge, Cambridge University Press, 1966.

DICKER, G.: “Kant's Refutation of Idealism”, Noûs 42, 1 (2008) 80-108. : "Kant's Refutation of Idealism: a reply to Chignell", The Philosophical Quarterly 61, 242 (2011) 175-183.

EVANS, G.: The Varieties of Reference, Oxford, Clarendon Press, 1982.

GUYER, P.: Kant and the Claims of Knowledge, Cambridge, Cambridge University Press, 1987.

KANT, I.: Crítica de la razón pura, Madrid, Taurus, 2013.

ROBINSON, D: “Kant's (Seamless) Refutation of Idealism”, The Review of Metaphysics 64, 2 (2010) 291-301.

STRAWSON, P.: Los límites del Sentido, Madrid, Revista de Occidente, 1975. 


\title{
La concepción kantiana de la verdad: Entre la correspondencia y la comunicación
}

\author{
ANA MARÍA ANDALUZ-ROMANILLOS 1
}

\begin{abstract}
Resumen
Este artículo estudia la teoría kantiana de la verdad atendiendo a dos criterios: la concordancia con el objeto y la comunicabilidad. Se intenta descubrir la posible conexión sistemática entre objeto e intersubjetividad. En la investigación se descubre en la Crítica de la razón pura la siguiente secuencia: la orientación de la verdad hacia la objetividad; la ecuación entre objeto y validez objetiva; la equivalencia de estos con la universalidad y la validez universal; y la perspectiva de la universalidad como una perspectiva de carácter intersubjetivo o participativo, que en algunos momentos parece acercarse al paradigma de la verdad como argumentación.
\end{abstract}

Palabras clave: concordancia, objeto, subjetividad, intersubjetividad, argumentación

Kantian conception of truth: Between correspondence and
communication

\begin{abstract}
This article studies Kant's theory of truth by following two criteria: the correspondence with the object and the communicability. It looks into the potential systematic connection between the object and the intersubjectivity. The research uncovers the following sequence in The Critique of Pure Reason: the orientation of truth towards objectivity; the equivalence between the object and the objective validity; their equivalence with universality and universal validity; and the perspective of universality as a perspective of intersubjective or communicative nature, which, at times, seems to approach the paradigm of truth as argumentation.
\end{abstract}

Keywords: concordance, object, subjectivity, intersubjectivity, argumentation

1 Universidad Pontificia de Salamanca. Contacto: amandaluzro@upsa.es. 


\section{Introducción}

En la Crítica de la razón pura no hay un desarrollo sistemático de la verdad, pero el problema de la verdad asoma a lo largo de las distintas partes que componen la obra; especialmente, la verdad entendida como concordancia con el objeto. Por otro lado, en la Crítica de la razón pura hay otros registros sobre la verdad: por ejemplo, la verdad como coherencia.2 Hay incluso una cierta concepción pragmatista de la verdad que aparece en distintos contextos.3 Por su parte, Putnam ve en Kant el origen de lo que él llama 'la perspectiva 'internalista' o 'realista interna' con respecto a la verdad" (1988: 69). Todos estos registros conectan a Kant con teorías de la verdad de la filosofía contemporánea. Además, Kant aduce como criterio extrínseco de la verdad la comunicabilidad.

En este trabajo voy a centrarme en dos criterios: el de la concordancia y el de la comunicabilidad. Voy a intentar mostrar que el idealismo trascendental kantiano se mueve entre estos dos paradigmas: el de la adecuación o concordancia y el de una razón participativa.

En principio, en el marco del idealismo trascendental, según el cual la realidad, tal como es en sí misma, es incognoscible para nosotros y la objetividad se funda en las condiciones de la subjetividad trascendental, se hace problemático afrontar la cuestión de la verdad desde la clásica noción de la adecuación (correspondencia, acuerdo, concordancia). Y, sin embargo, el concepto de verdad como adecuación o concordancia con el objeto está presente de manera explícita en numerosos lugares de la Crítica de la razón pura (KrV, A58/B82, A62/B87, A157/B197, A191/B236, A237/B296, A642/B670). Por otro lado, en la Crítica de la razón pura, así como en otros lugares de las obras críticas de Kant, asoma también el criterio de la

2 En este registro podría ubicarse el valor científico que Kant concede a la sistematicidad: "La completud y la articulación" de un sistema proporcionan "una prueba de la corrección o la autenticidad de todos los elementos cognoscitivos que entran en él" ( $K r V$, A65/B90). Citamos la Crítica de la razón pura por la primera y segunda edición originales: A y $\mathrm{B}$, respectivamente, según el modo habitual. Las referencias al resto de las obras de Kant remiten a la edición de la Academia (AA).

3 En el contexto de un comentario a los trascendentales de los antiguos (unun, verum, bonum), Kant habla de la verdad de un concepto en el sentido de verdad de las consecuencias: "En todo conocimiento de un objeto hay verdad respecto de las consecuencias. Cuantas más consecuencias verdaderas se desprendan de un concepto dado, tantos más serán los criterios de su realidad objetiva" $(K r V$, B114). Pero, sobre todo, podría hablarse de un criterio pragmatista a propósito del uso regulativo de las ideas de la razón; y, también, en el caso del Juicio reflexionante en la tercera Crítica. Igualmente, a propósito de la realización del bien supremo en el mundo, en el contexto de la filosofía práctica. 
intersubjetividad o comunicabilidad de la verdad ( $K r V$, A820-821/B848849; $L o g$, AA 09: 57; Refl, AA 16.3: 419; WDO, AA 08: 145). En esta otra perspectiva, el concepto de verdad parece orientarse hacia la idea de pretensión de intersubjetividad más propia del modelo contemporáneo de una teoría consensual de la verdad.

La hipótesis de la que parto es la de una posible conexión entre objetividad y pretensión de intersubjetividad: dado que no podemos medir nuestro conocimiento con los objetos en sí, a lo que apunta la noción de objeto es a la validez universal; ahora bien, la validez universal es, además de validez objetiva, esto es, basada en conceptos, validez para todos, validez intersubjetiva. Se trata, pues, de indagar si hay una conexión sistemática entre el problema del objeto y la intersubjetividad.4

Sin olvidar la bibliografía secundaria sobre el tema,5 este trabajo quiere ser ante todo una profundización en los textos kantianos desde el punto de vista de la mencionada conexión. Se estructura en dos partes: i) La verdad como concordancia con el objeto y ii) Verdad, intersubjetividad y el criterio de la comunicabilidad.

4 En realidad, esta hipótesis puede documentarse con el $\$ 19$ de los Prolegómenos a toda metafísica futura, donde Kant, reconociendo que el objeto no puede referirse al objeto en sí mismo, pues este no podemos conocerlo, hace "equivalentes" los conceptos de "validez objetiva" y "validez general necesaria (para todo el mundo)": "la validez objetiva y la validez general necesaria (para todo el mundo), son conceptos equivalentes, y si bien no conocemos el objeto en sí, al considerar un juicio como generalmente válido, y, por consiguiente, necesario, entendemos, pues, precisamente con esto que es válido objetivamente. Reconocemos por este juicio el objeto (aunque, por otra parte siga siendo desconocido como pueda ser en sí mismo), por el enlace generalmente válido y necesario de la observación dada" (Prol, AA 04: 298). Los juicios de la experiencia "no recibirán su validez objetiva del reconocimiento inmediato de los objetos (pues esto es imposible), sino solamente de la condición de la validez general de los juicios empíricos, los cuales [...] no se fundan jamás en las condiciones empíricas y, en general, sensibles, sino en un concepto puro del entendimiento. El objeto permanece siempre desconocido en sí mismo; pero si, por el concepto del entendimiento, es determinado como válido en general el enlace de las representaciones que le es dado por él a nuestra sensibilidad, será determinado el objeto por esta relación, y el juicio es objetivo" (Prol, AA 04: 298-299).

5 He aquí algunas referencias de autores que atienden a distintas formas de la verdad y a diversos criterios presentes en la Crítica de la razón pura. Sobre las diferentes clases de verdad (lógica, empírica, trascendental y metalógica), dependiendo del fundamento o "razón (Grund)" del juicio, es ya clásico el escrito de A. Schopenhauer, De la cuádruple raíz del principio de razón suficiente (1998: 158-164). Sobre las distintas formas de la verdad en Kant, véase también Palacios (1979) y Scheffer (1993); en la verdad como coherencia insiste Cabrera (1996); por su parte, Laserna (1985) se centra en la adecuación; Straulino (2016) destaca la centralidad de la verdad trascendental, como también Paek (2005); Masías (2015) pone en primer plano la intersubjetividad, al igual que Nenon (1981). 


\section{La verdad como concordancia con el objeto}

En la Crítica de la razón pura, en la Introducción a la "Lógica trascendental", Kant parte de la definición nominal de la verdad, según la cual esta consiste en la conformidad [Übereinstimmung] del conocimiento con su objeto [Gegenstande] ( $K r V$, A58/B82). La verdad así entendida no expresa otra cosa que el significado del nombre o término 'verdad'. Kant orienta el problema de la verdad más bien hacia la cuestión de los criterios de la verdad: "Se concede y se presupone la definición nominal de la verdad, a saber, como conformidad del conocimiento con su objeto. Pero se pretende saber cuál es el criterio general y seguro de la verdad de todo conocimiento" ( $\mathrm{Kr} V, \mathrm{~A} 58 / \mathrm{B} 82) .6$

En este punto, tanto en la Crítica de la razón pura como en la Lógica Jäsche, Kant toma en consideración un doble aspecto del conocimiento: el de su contenido o materia y el de su forma. Por contenido del conocimiento se entiende la relación de este a sus objetos. En cambio, la forma hace abstracción de toda relación a objetos.

La posición de Kant es que el criterio no puede ser universal si la conformidad se refiere al contenido del conocimiento, pues un criterio sería universal si tuviera validez para todos los conocimientos independientemente de la diversidad de sus objetos. Ahora bien, la verdad se refiere justamente al contenido del conocimiento, es decir, a la relación de este con sus objetos. Dicho de otro modo, conocimiento verdadero es conocimiento de objetos.

Es la lógica general la que hace abstracción de toda relación a objetos. Esta se refiere al conocimiento desde el punto de vista de la forma, prescindiendo de todo contenido. La lógica general debe exponer "unos criterios de verdad" ( $K r V$, A59/B84) en relación con las reglas del entendimiento, a las cuales debe conformarse todo conocimiento. Pero esos criterios "afectan solo a la forma de la verdad, esto es, del pensamiento, en general" ( $K r V$, A59/B84); es solo una verdad lógica, es decir, mera corrección y no verdad objetiva. La lógica no llega al contenido:

${ }_{6}$ Este enfoque viene a coincidir con el que aparece en la Introducción de la Lógica Jäsche: "Se trata aquí de la cuestión siguiente, a saber: si existe y en qué medida existe un criterio de verdad seguro, universal y útil en la aplicación. Porque tal es el sentido de la cuestión ¿qué es la verdad?’ (Log, AA 09: 50). 
aunque un conocimiento esté enteramente de acuerdo con la forma lógica, es decir, aunque no se contradiga a sí mismo, puede seguir estando en contradicción con su objeto. Por consiguiente, el criterio meramente lógico de verdad — la conformidad de un conocimiento con las leyes universales y formales del entendimiento y de la razón- constituye una conditio sine qua non, esto es, una condición negativa de toda verdad. Pero la lógica no pasa de aquí. Carece de medios para detectar un error que no afecte a la forma, sino al contenido ( $K r V$, A59-60/B84).

Queda, pues, pendiente la "verdad material (objetiva) del conocimiento" ( $K r V$, A60/B85), la cual afecta a los "juicios sobre los objetos" $(K r V, \mathrm{~A} 60 / \mathrm{B} 85)$.

De este modo, Kant va operando la equivalencia de verdad y objetividad. Dicha equivalencia se pone especialmente de manifiesto cuando presenta la Dialéctica como una lógica de la apariencia: cuando se convierte a la lógica general, que es solo un canon, en un órganon para la producción de afirmaciones objetivas, lo que se produce es una apariencia de verdad, esto es, un pensamiento vacío de objetos.

Pero la gran creación de la Crítica de la razón pura es la lógica trascendental. La diferencia entre la lógica general y la lógica trascendental está justamente en la referencia de esta segunda a objetos. Debido a dicha referencia a objetos, Kant presenta la lógica trascendental como una "lógica de la verdad" ( $K r V$, A62-63/B87). La lógica trascendental en su parte analítica trata de los conocimientos a priori del entendimiento; pero estos elementos solo fundan verdad si son aplicados a objetos de la experiencia sensible.7

Contenido, referencia a objetos, significa en este contexto, en general, materia del conocimiento, la cual es suministrada por la intuición empírica, frente a conceptos y principios puros del entendimiento. Por eso, cuando estos conocimientos puros se usan más allá de los límites de la

\footnotetext{
7 "En una lógica trascendental aislamos el entendimiento [...] y tomamos de nuestros conocimientos únicamente la parte del pensamiento que no procede más que del entendimiento. Ahora bien, el uso de este conocimiento puro se basa en la condición siguiente: que se nos den en la intuición objetos (Gegenstände) a los que pueda aplicarse. En efecto, sin intuiciones todo nuestro conocimiento carece de objetos y, consiguientemente, se halla enteramente vacío. La parte de la lógica trascendental que trata de los elementos del conocimiento puro del entendimiento y de los principios sin los cuales ningún objeto (Gegenstand) puede ser pensado es, pues, la analítica trascendental y constituye, a la vez, una lógica de la verdad. Pues ningún conocimiento puede estar en contradicción con ella sin perder, al mismo tiempo, todo contenido, esto es, toda relación con algún objeto (Objekt) y, consiguientemente, toda verdad" ( $K r V$, A62-63/B87).
} 
experiencia, se incurre en un uso dialéctico del entendimiento, que no produce verdad, sino falsa apariencia de verdad. Así pues, la Analítica trascendental pretende ser una lógica de la verdad.

Sin embargo, al mismo tiempo, puede notarse 8 que a la idea de objetos dados se añade la idea de que sin conformarse a los conceptos y principios del entendimiento ningún objeto puede ser pensado; y que son estos (es decir, los conceptos y principios del entendimiento) los que hacen posible la relación del conocimiento a algún objeto (siendo el término alemán correspondiente no Gegenstand, sino Objekt; si bien Kant no siempre utiliza el mismo criterio terminológico).

\subsection{Cambio de dirección en la adecuación y nueva noción de objeto}

Por tanto, vamos a intentar profundizar en el carácter especial que adquiere en el idealismo trascendental kantiano la noción de objeto; pues, además de los objetos dados en la intuición [Gegestand], Kant habla también del objeto [Objekt], en el sentido de algo constituido por el sujeto trascendental a partir de la diversidad dada en los objetos de la intuición; es decir, el objeto, en tanto que objeto de conocimiento, aparece como algo constituido [Objekt], lo cual puede conferir a la noción de adecuación, presente en la idea kantiana de verdad, un carácter especial. Veámoslo.

El punto de partida es la diversidad de la sensibilidad a priori, esto es, la multiplicidad de representaciones de objetos intuida según las condiciones a priori de nuestra receptividad, el espacio y el tiempo; dicha diversidad constituye la materia de los conceptos del entendimiento, sin la cual estos quedarían desprovistos de todo contenido. A su vez, la multiplicidad de representaciones tiene que ser reunida de un modo determinado para hacer de ella un conocimiento; a este acto es al que Kant denomina "síntesis" ( $K r V$, A77-78/B103), que lleva a cabo la imaginación. Pero esta síntesis de lo diverso de la intuición aún no es conocimiento. Para conocer un objeto se requieren los conceptos del entendimiento, los cuales dan unidad a esa síntesis ( $K r V$, A76-80/B102-106). En el conocimiento de un objeto intervienen, pues, la diversidad de la intuición sensible, la imaginación y el entendimiento ( $K r V$, A78-79/B104).

Pero este planteamiento implica que los objetos de la intuición sensible han de conformarse a los conceptos trascendentales del

8 Véase el final del pasaje citado en la nota 7. 
entendimiento o condiciones de unidad de este. En efecto, la justificación de dicha conformidad constituye justamente lo que Kant denomina deducción trascendental de las categorías (KrV, A90/B122-123). Así, la noción de la verdad como conformidad ocupa, en realidad, el centro mismo de la Analítica crítica.

Kant toma el término "deducción" en el sentido jurídico de la demostración del derecho o pretensión de algo; en este caso, la pretensión de los conceptos a priori del entendimiento de referirse "a unos objetos (Objekte) que no han tomado de la experiencia" ( $K r V$, A85/B117). Dichos conceptos "se refieren a sus objetos (Gegestánde) sin haber tomado nada de la experiencia para representárselos" ( $K r V$, A86/B118). Como es sabido, Kant demuestra la legitimidad de una pretensión tal poniendo de relieve que sin la conformidad de la diversidad de la intuición sensible a los conceptos transcendentales del entendimiento no sería posible la experiencia misma por lo que a su forma se refiere, entendiendo por ello el conocimiento de objetos en general, esto es, la subsunción de lo diverso de la intuición bajo conceptos, que es la única condición bajo la cual podemos conocer algo como objeto.

Pero dicha deducción se sustenta sobre un cambio en la dirección de la adecuación, conformidad o concordancia del conocimiento con sus objetos, cambio de dirección que procede de la revolución copernicana, tal como fue presentada en el Prólogo a la segunda edición y que, junto con la reducción fenoménica del conocimiento, constituye la base de la deducción. Solo a través de los conceptos a priori del entendimiento puede algo ser pensado como objeto, en general; por tanto "todo conocimiento empírico de los objetos ha de conformarse forzosamente a esos conceptos, ya que, si dejamos de presuponerlos, nada puede ser objeto (Objekt) de la experiencia" ( $K r V$, A93/B126). Las categorías son entendidas por Kant como "conceptos de un objeto (Gegenstande) en general" ( $\mathrm{KrV}$, A95/B128).9

Así pues, Kant acepta la idea de la adecuación, pero opera un giro en la dirección de la misma: a diferencia de lo que sucede con los conceptos empíricos, en el caso de los conceptos a priori del entendimiento son ellos los que hacen posible el objeto [Objekt].

9 En virtud de ellas, las intuiciones empíricas quedan subsumidas en juicios, en calidad de sujetos del mismo (KrV, A 95/B128-129). 
Pero además de un cambio en la dirección de la concordancia, se produce una transformación en el significado de la noción de objeto (conocido); este deja de ser algo independiente del sujeto para tener como punto de referencia la subjetividad trascendental. Ello se pone de relieve a lo largo de la Deducción.

Conocimiento significa en el marco del idealismo trascendental conexión entre representaciones $(K r V, \mathrm{~A} 97)$; y dicha conexión remite siempre y en cada una de sus etapas a las condiciones aprióricas de nuestra subjetividad y a la espontaneidad de esta.10 De acuerdo con la versión de la Deducción de la primera edición, hay tres etapas: la síntesis de aprehensión en la intuición, que es lo que Kant suele llamar "percepción" o "conciencia empírica" ( $K r V$, B160); la síntesis de reproducción en la imaginación y la síntesis de reconocimiento en el concepto. Pues bien, es en esta tercera etapa cuando aparece propiamente el objeto. Kant mismo considera necesario clarificar "qué es lo que se entiende por la expresión 'objeto (Gegenstandes) de las representaciones"” ( $K r V$, A104).

En primer lugar, debido a la reducción fenoménica del conocimiento, el objeto de este deja de ser entendido como algo independiente del conocimiento.11 Pero Kant no renuncia por ello a la noción de 'objeto' ni a la idea de 'concordancia'.12 Lo que sí tiene lugar es un cambio en su significación: objeto significa ahora unidad de nuestras representaciones; dicha unidad "constituye el concepto de un objeto" ( $K r V$, A105). Y esta unidad es producida por "la unidad formal de la conciencia",13 según unas

10 Según la versión de la segunda edición: "no podemos representarnos nada ligado en el objeto (Objekt), si previamente no lo hemos ligado nosotros mismos" ( $K r V$, B130).

11 "Anteriormente hemos dicho que los fenómenos no son más que representaciones sensibles que, de igual modo, tampoco han de ser consideradas en sí mismas como objetos (Gegenstände) independientes de la facultad de representación. ¿Qué se quiere, pues, decir cuando se habla de un objeto (Gegenstände) que corresponde al conocimiento y que es, por tanto, distinto de él? Se ve fácilmente que tal objeto hay que entenderlo simplemente como algo en general $=\mathrm{X}$, ya que, fuera de nuestro conocimiento, no tenemos nada confrontable con ese mismo conocimiento, como correspondiente a él" $(K r V$, A104).

12 "Advertimos, empero que nuestro pensamiento de la relación conocimiento-objeto conlleva siempre en sí cierta necesidad, ya que el primer elemento es considerado como algo que se opone al segundo. Observamos, además, que nuestros conocimientos no se producen al azar o arbitrariamente, sino que se hallan determinados de una cierta forma, ya que, al tener esos conocimientos que referirse a un objeto, han de concordar necesariamente entre sí con respecto a este último, es decir, han de poseer la unidad que constituye el concepto de un objeto (Gegenstande)" (KrV, A104-105).

13 "Pero, dado que solo nos ocupamos de lo diverso de nuestras representaciones y dado que la X a ellas correspondiente (el objeto) (der Gegenstand) no es - por ser este objeto forzosamente distinto de todas nuestras representaciones - nada para nosotros, queda claro que la unidad necesariamente formada por el objeto solo puede ser la unidad formal de la conciencia que efectúa la síntesis de lo 
reglas que son las categorías del entendimiento ( $K r V$, A105-106). "El concepto de esa unidad es la representación del objeto $($ Gegenstand $)=\mathrm{X}$ " $(\mathrm{KrV}, \mathrm{A} 105)$.

Esa unidad formal de la conciencia es lo que Kant denomina "apercepción trascendental" ( $K r V$, A107), la cual constituye, a su vez, el fundamento de las categorías del entendimiento (que no son sino reglas de unidad) y el fundamento del objeto ( $K r V$, A108).

Con todo ello, Kant puede precisar "el concepto de objeto (Gegenstande) en general" en los siguientes términos:

Todas las representaciones tienen, en cuanto tales, su objeto propio y pueden, a su vez, ser objeto de otras representaciones. Los fenómenos son los únicos objetos que se nos pueden dar inmediatamente y lo que en ellos hace referencia inmediata al objeto se llama intuición. Pero tales fenómenos no son cosas en sí mismas, sino meras representaciones que, a su vez, poseen su propio objeto, un objeto que ya no puede ser intuido por nosotros y que, consiguientemente, puede llamarse noempírico, es decir, trascendental $=\mathrm{X}$. El concepto puro de este objeto trascendental (que, de hecho, es idéntico en todos nuestros conocimientos, $=\mathrm{X}$ ) es lo que pone en relación todos nuestros conceptos empíricos con un objeto, es decir, lo que les puede suministrar realidad objetiva. Este concepto no puede contener una intuición determinada y no afectará, por tanto, más que a la unidad que forzosamente tiene que haber entre la diversidad de un conocimiento, siempre que tal diversidad haga referencia a un objeto. Pero tal referencia no es más que la necesaria unidad de conciencia y también, consiguientemente, de síntesis de lo diverso, mediante la función que realiza el psiquismo y que consiste en unificar esa diversidad en una representación $(K r V, 108-109) .14$

El sometimiento de los fenómenos a la unidad de la conciencia, en la cual se fundan, a su vez, las categorías del entendimiento en cuanto reglas de dicha unidad, hace posible la realidad objetiva de nuestro conocimiento;

diverso de las representaciones. Decimos, pues, que conocemos el objeto (Gegenstand) cuando hemos producido la unidad sintética en lo diverso de la intuición" $(\mathrm{KrV}, 105)$.

14 También en la versión de la segunda edición hace Kant precisiones sobre la noción de objeto: "El entendimiento es, para decirlo en términos generales, la facultad de los conocimientos. Estos consisten en determinada relación que las representaciones dadas guardan con un objeto (Objekt). Objeto (Objekt) es aquello en cuyo concepto se halla unificado lo diverso de una intuición dada. Ahora bien, toda unificación de representaciones requiere unidad de conciencia en la síntesis de las mismas. Por consiguiente, es solo la unidad de conciencia lo que configura la relación de las representaciones con un objeto (Gegenstand) y, por ello mismo, la validez objetiva (objektive Gültigkeit) de tales representaciones" (KrV, B137). 
es decir, hace posible que el conocimiento de los fenómenos sea un conocimiento de objetos.15 Por eso, Kant escribe: "Las condiciones a priori de la experiencia posible en general son, a la vez, condiciones de posibilidad de los objetos (Gegenstände) de experiencia" ( $K r V$, A111).

Pues bien, en la sección tercera de la Deducción (en la versión de la primera edición) Kant identifica expresamente "verdad" con "validez objetiva" ( $K r V$, A125). De acuerdo con el discurso de la Deducción, validez objetiva o "realidad objetiva" ( $K r V$, A110) significa relación de nuestras representaciones empíricas a objetos; y los objetos se constituyen como tales en virtud de la relación de las representaciones a la unidad de la conciencia,16 de acuerdo con los conceptos a priori del entendimiento, que no son más que reglas de dicha unidad.17 Así pues, Kant sitúa el fundamento último del objeto y, por tanto, de la validez objetiva y de la verdad, en la unidad de la conciencia o "conciencia trascendental" ( $K r V$, A117, nota de Kant).

Es verdad que en la Analítica de la Crítica de la razón pura la noción de realidad objetiva aparece enfocada en dos sentidos que vienen a corresponderse con los dos elementos del conocimiento en Kant: los conceptos a priori (categorías), mediante los cuales los objetos [Gegenstande] son pensados, y las intuiciones, por medio de las cuales dichos objetos son dados $(K r V, \mathrm{~B} 146)$.

15 "Dado que esa unidad ha de ser considerada como unidad necesariamente a priori (de lo contrario, el conocimiento carecería de objeto), la referencia a un objeto (Gegenstand) trascendental, es decir, la realidad objetiva (objektive Realität) de nuestro conocimiento empírico, se basará en una ley trascendental según la cual, si los fenómenos han de proporcionarnos objetos (Gegenstände), tienen que someterse a las reglas a priori que unifican sintéticamente dichos fenómenos, reglas sin las cuales no es posible relacionar los fenómenos dentro de la intuición empírica. Es decir, la realidad objetiva de nuestro conocimiento se basará en la ley según la cual, en la experiencia, esos fenómenos han de estar sometidos a las condiciones de indispensable unidad de apercepción, al igual que, en la simple intuición, lo han de estar a las condiciones formales de espacio y tiempo: son esas condiciones las que hacen posible el conocimiento" ( $K r V$, A109-110). Cabe apreciar que en la versión de la Deducción de la primera edición Kant hace uso del término Gegenstand, a diferencia de lo que sucede en la versión de la segunda edición, donde al objeto, en el nuevo sentido, suele referirse con la expresión Objekt. 16 Según un pasaje de la versión de la segunda edición, "La unidad sintética de la conciencia es [...] una condición objetiva de todo conocimiento. No es simplemente una condición necesaria para conocer un objeto (Objekt), sino una condición a la que debe someterse toda intuición para convertirse en objeto (Objekt) para mí. De otro modo, sin esa síntesis, no se unificaría la variedad en una conciencia" $(K r V, \mathrm{~B} 138)$.

17 Como es sabido, la conexión de las intuiciones empíricas con los conceptos a priori del entendimiento la lleva a cabo la imaginación (consúltese la mencionada sección tercera de la Deducción, de la primera edición). 
Por un lado, Kant habla de realidad objetiva en el sentido en el que venimos exponiendo, esto es, como relación de lo diverso de la intuición a la unidad de la apercepción, por medio del entendimiento y de acuerdo con las categorías. Por tanto, en este primer sentido, la noción realidad objetiva se aplica a la diversidad de representaciones dadas: estas devienen objetos en virtud de su relación con la unidad de la conciencia.

Pero en la versión de la Deducción de la segunda edición, donde Kant presta también atención a la vertiente material del conocimiento (véase a partir de $K r V$, B145) y no solo a la formal o apriórica, la noción de realidad objetiva amplía su significación en un sentido complementario, por así decirlo. En esta perspectiva, la "realidad objetiva" [objektive Realität] se plantea a propósito de los conceptos a priori del entendimiento; y en este caso significa "aplicación de estos a objetos (Gegenstände) dados en la intuición" $(K r V, \mathrm{~B} 150) .18$

Los objetos de la experiencia sensible o de la intuición empírica dotan de contenido a los conceptos a priori: "Si no pudiésemos asignar al concepto la intuición correspondiente, tendríamos un pensamiento atendiendo a su forma, pero carente de todo objeto (Gegenstand), sin que fuera posible conocer cosa alguna a través de él" ( $K r V$, B146). Dicho contenido se refiere a la realidad [Realität] y a la existencia [Dasein] o realidad efectiva [Wiklichkeit] de los objetos de la intuición empírica, a la cual accedemos a través de la sensación.19 Dicho de otro modo, sin la

18 Una aplicación que lleva a cabo el Juicio [Uteilskraft], tal como se establece en la Analítica de los principios. En este contexto del problema de la aplicación de las categorías a los fenómenos o subsunción de estos bajo las primeras, Kant vuelve a hacer sinónimas las expresiones validez objetiva y verdad: "El entendimiento y el Juicio tienen [...] el canon de su uso objetivamente válido - $y$, consiguientemente, verdadero- en la lógica trascendental y pertenecen, por tanto, a su parte analítica" (KrV, A131/B170).

19 "La intuición sensible es, o bien intuición pura (espacio y tiempo), o intuición empírica de lo inmediatamente representado, a través de la sensación, como real (wirklich) en el espacio y en el tiempo. Mediante la determinación de la primera podemos obtener conocimientos a priori de objetos (en las matemáticas), pero solo en cuanto a su forma, en cuanto a fenómenos. El que pueda haber cosas que hayan de ser necesariamente intuidas en esa forma queda sin decidir. Consiguientemente, ningún concepto matemático es, por sí mismo, ningún conocimiento, a no ser que supongamos la existencia de cosas que únicamente pueden sernos presentadas según la forma de dicha intuición pura sensible. Ahora bien, las cosas en espacio y tiempo solo se dan en la medida en que son percepciones (representaciones acompañadas de una sensación) y, por tanto, solo mediante una representación empírica" ( $K r V$, B147). A mi modo de ver, dicho contenido se refiere también al contenido quiditativo, pues en el capítulo sobre el esquematismo, cuando trata del esquema correspondiente a la realidad [Realität] como una de las categorías de la cualidad, Kant apela igualmente a la sensación ( $K r V$, A143/B182-183). Es decir, el contenido se refiere tanto a la realidad [Realität], en el sentido de las categorías de la cualidad, de los objetos de la experiencia, como a su existencia [Dasein; Wirklichkeit], en el sentido de las categorías de la modalidad. En ambos casos se apela a la sensación. 
intuición empírica, los conceptos del entendimiento no nos proporcionan conocimiento de 'cosas reales'.20

Ahora bien, esta segunda dirección de la noción de realidad objetiva no impide que la transformación operada en la noción de objeto (el objeto como Objekt) siga siendo central.

\subsection{La verdad transcendental}

Dicha centralidad se pone de manifiesto en el hecho de que la noción de verdad que salta a primer plano es la noción de 'verdad trascendental': "Todos nuestros conocimientos residen en la experiencia posible tomada en su conjunto, y la verdad trascendental (transzendentale Wahrheit), que precede a toda verdad empírica y la hace posible, consiste en la relación general con esa experiencia" ( $K r V$, A146/B185). Experiencia significa aquí el sometimiento de la variedad de los fenómenos a la unidad de la apercepción, de acuerdo con las reglas universales de las categorías. $21 \mathrm{La}$ adecuación de los fenómenos a dichas reglas de conexión o a dicha experiencia es lo que Kant llama verdad trascendental.

Es la primera vez que aparece en la Crítica de la razón pura la noción de verdad trascendental; y el pasaje está situado casi al final del capítulo sobre el esquematismo. No es casualidad que la verdad trascendental aparezca ubicada aquí, pues el esquematismo constituye una de las dos partes de la doctrina trascendental del Juicio [Urteilskraft], que es la facultad de aplicar las categorías a los fenómenos o de subsumir estos bajo las primeras. Por eso, la cuestión de la concordancia de los objetos sensibles con las categorías salta aquí a primer plano: "La filosofía trascendental debe [...] exponer las condiciones bajo las cuales pueden

\footnotetext{
20 "Las categorías no tienen, pues aplicación, en relación con el conocimiento de las cosas (Dinge), sino en la medida en que estas sean asumidas como objetos (Gegenstände) de una posible experiencia ( KrV, B147-148). "[M]ás allá de nuestra intuición sensible [...] se trata [...] de conceptos vacíos de objetos (Objekten), de los que ni siquiera podemos juzgar, a través de esos conceptos, si son posibles (möglich) o no; son simples formas del pensamiento sin realidad objetiva (objektive Realität), ya que no tenemos a mano intuición alguna a la que aplicar la unidad sintética de la apercepción, único contenido de estas formas. Con tal aplicación podrían determinar algún objeto (Gegenstand). Solo nuestra intuición sensible y empírica puede darles sentido y significación (Sinn und Bedeutung)" ( $K r V$, B148-149).

21 "las categorías [...] sirven tan solo para someter los fenómenos a unas reglas universales de síntesis tomando como base una unidad necesaria a priori (en virtud de la necesaria unificación de toda conciencia en una apercepción originaria) y para adecuar así tales fenómenos a una completa conexión en una experiencia" ( $K r V, \mathrm{~A} 146 / \mathrm{B} 185)$. El párrafo en el que aparece la expresión verdad transcendental sigue justamente a este pasaje.
} 
darse objetos (Gegenstände) concordantes (in Übereinstimmung) con tales conceptos" (KrV, A136/B175).

Dichas condiciones no son sino los esquemas de los conceptos del entendimiento. Los esquemas trascendentales indican "las condiciones sensibles que hacen posible el uso de las categorías" ( $K r V$, A136/B175); o dicho de modo complementario, las condiciones según las cuales los objetos sensibles [Gegenstände] pueden concordar con las categorías del entendimiento.

El esquema - escribe Kant- es el "fenómeno o concepto sensible de un objeto (Gegenstandes) concordante (Übereinstimmung) con la categoría" ( $K r V$, A146/B186). Y también, "los esquemas de la sensibilidad son los que realizan las categorías" ( $K r V$, A146/B185-186).

En virtud de los esquemas, en tanto que determinaciones del tiempo, lo diverso de la intuición empírica es reducido a la unidad del sentido interno; de este modo, al guardar una cierta afinidad con el concepto puro del entendimiento, lo empírico puede ser subsumido bajo este y, con ello, es también reducido, indirectamente (es decir, por medio del concepto), a la unidad de la apercepción ( $K r V$, A145/B185). Es así, es decir, gracias a los esquemas, como los conceptos puros del entendimiento pueden referirse a objetos [Objekte].22 Y esto es lo que Kant llama experiencia: el sometimiento de los fenómenos a las reglas de conexión universales del entendimiento, las cuales tienen su fundamento en la apercepción trascendental ( $K r V$, A145/B185). A mi modo de ver, experiencia y objeto (en el sentido de Objetk o concepto de objeto) son términos intercambiables.

Y a la relación de los conocimientos con dicha experiencia (o con el objeto así entendido) es a lo que Kant denomina verdad trascendental.23 Por tanto, los esquemas del entendimiento vienen a ser el mecanismo por medio del cual tiene lugar una verdad tal, pues es el medio que enlaza lo empírico con los conceptos a priori; y por medio de estos, con la apercepción pura,

\footnotetext{
22 "En consecuencia, los esquemas de los conceptos puros del entendimiento constituyen las verdaderas y únicas condiciones que hacen que tales conceptos se refieran a objetos (Objekte) y, consiguientemente, que posean una significación" ( $K r V$, A145/B185). Gracias a los esquemas los conceptos puros del entendimiento no se quedan en meras funciones lógicas o intelectuales, sino que llegan a ser conceptos de objetos, en general ( $K r V$, A147/B186-187).

23 No debe olvidarse que Kant acepta el concepto de verdad como concordancia del conocimiento con el objeto; y que en el idealismo trascendental el objeto se ha transformado de Gegentand en Objekt.
} 
haciendo así posible la experiencia o el objeto (como Objekt), sin el cual no cabe hablar de verdad.

En la Analítica trascendental de la Crítica de la razón pura hay algunos lugares más en los que asoma la cuestión de la verdad. No me es posible atender aquí a estos otros desarrollos; simplemente los dejaré indicados.

Así, en el capítulo segundo de la Doctrina trascendental del Juicio, la verdad se plantea como una cuestión estrechamente ligada a la posibilidad de los juicios sintéticos. Las nociones de verdad y de síntesis a priori vienen a ser equivalentes; ambas tienen en común el elemento de la concordancia con el objeto, el cual, a su vez, es constituido por la referencia del objeto al sujeto trascendental.

Por otro lado, la cuestión de la verdad vuelve a aparecer en el marco de los principios del entendimiento puro, tanto a propósito de las analogías de la experiencia, como de los postulados del pensar empírico. En este marco se pone de manifiesto que el objeto (a diferencia de lo que sería un mero juego subjetivo de representaciones), es hecho posible por el sometimiento de los fenómenos a las reglas del entendimiento, en tanto que condiciones formales de la experiencia; y que la verdad no es sino la concordancia del conocimiento con el objeto así entendido ( $K r V$, A191/B236); conformidad que constituye lo que Kant llama verdad trascendental ( $K r V$, A222/B269).

Haciendo un balance de lo conseguido, Kant escribe que

[las] reglas del entendimiento no solo son verdaderas a priori, sino que constituyen incluso la fuente de toda verdad, es decir, de la concordancia de nuestro conocimiento con objetos, ya que contiene en sí el fundamento de posibilidad de la experiencia, considerada esta como conjunto de todo conocimiento en el que se nos puedan dar objetos ( $K r V$, A237/B296).

A su vez, todo ello tiene su fundamento último en la apercepción trascendental: todo cuanto pueda convertirse en "objeto para mí" ( $K r V$, A177/B220) ha de someterse a la unidad trascendental a priori de la apercepción ( $K r V$, A237/B296). 
3. Verdad, intersubjetividad y el criterio de la comunicabilidad

No hay duda del gran protagonismo que Kant confiere al sujeto, protagonismo que, en lo que se refiere al problema que nos ocupa, tiene como consecuencia un giro, tanto en lo que concierne a la dirección de la adecuación, como en lo que se refiere a la noción misma de objeto. $\mathrm{La}$ verdad, entendida como concordancia con el objeto, tiene su fundamento, igual que este, en la conciencia trascendental.

Pues bien, llegados a este punto, cabe preguntarse si esa conciencia trascendenal, fundamento del objeto y de la verdad, nos encierra en nosotros mismos o tiene más bien un alcance intersubjetivo. Y, de acuerdo con los lugares en los que Kant presenta la comunicabilidad como criterio de verdad, (citados más atrás y que volveremos a mencionar) cabe preguntarse también: ¿está la verdad necesitada de confrontación intersubjetiva?

Veamos, en primer lugar, la primera cuestión. En relación con ella voy a destacar dos modos de presentar la conciencia trascendental.

En el discurso de la Deducción trascendental - y este es un primer modo de presentar la conciencia trascendental- Kant contrapone la identidad del yo al carácter disperso de las representaciones empíricas. Estas no son nada para nosotros mientras no sean "incorporadas" a la conciencia; solo "dentro de esta", en la medida en que formen parte de "una misma conciencia", pueden estar "ligadas entre sí" ( $K r V$, A116). Desde luego, si la conciencia trascendental se considera desde este punto de vista (es decir, contraponiéndola al carácter disperso de las representaciones empíricas), entonces la interpretación estaría más bien en la línea de un inmanentismo y un solipsismo, pues lo que se destaca frente a la dispersión de las representaciones empíricas es la mismidad, identidad, permanencia y unicidad de la conciencia; así como la pertenencia de las representaciones a una misma conciencia ( $K r V$, A116, A117 nota de Kant, A122), que Kant no duda en presentar como un "yo fijo y permanente" ( $K r V$, A123); incluso llega a presentar a los objetos, en tanto que fenómenos, como "determinaciones de mi yo idéntico" $(K r V, \mathrm{~A} 129)$.

Ahora bien, ¿es incompatible esta perspectiva con la posibilidad de que este yo tenga también un alcance intersubjetivo, y que este (en tanto que intersubjetivo) tenga un papel en la verdad? 
Hay un segundo aspecto (o argumento) que podría jugar a favor de un carácter intersubjetivo del sujeto trascendental; e incluso a favor de una equivalencia entre objetividad e intersubjetividad. Dicho aspecto - que conlleva una segunda manera de presentar la subjetividad trascendental - es el de la ecuación que se opera en la Analítica trascendental entre objeto y validez objetiva, por un lado, y validez universal, por el otro. Así, Kant contrapone la validez objetiva de la unidad trascendental de la conciencia a la validez meramente subjetiva, en el sentido de privada, de la conciencia empírica:

La unidad trascendental de la apercepción es aquella que unifica en un concepto del objeto toda la diversidad dada en una intuición. Por ello se llama objetiva, y hay que distinguirla de la unidad subjetiva de la conciencia [...] Solo la primera unidad posee validez objetiva. La unidad empírica de apercepción [...] solo tiene validez subjetiva. Unos ligan la representación de cierta palabra a una cosa, otros a otra; la unidad de la conciencia no es, en lo empírico, necesaria y universalmente válida en relación con lo dado $(K r V$, B139-140).

La unidad trascendental de la conciencia es objetiva en el sentido de que hace posible el objeto (o concepto del objeto); y este tiene validez universal, en tanto que se funda en la unidad trascendental de la conciencia. Sin embargo, en tanto que contrapuesta a la validez privada de la conciencia empírica, ¿qué puede significar validez universal sino validez intersubjetiva o validez para todos? Es cierto que aquí la universalidad se refiere al objeto más que a la conciencia misma: pero el objeto es hecho posible por la relación de lo diverso de la intuición con la unidad de la conciencia, tal como se mostró en la primera parte del trabajo; es decir, el origen y fundamento último del objeto es la unidad de la conciencia. Dicho de otro modo, la universalidad del objeto parece presuponer la 'universalidad de la conciencia’;24 y la universalidad de la conciencia podría interpretarse en el

24 En la Crítica del Juicio, en el segundo momento del Juicio estético que es el de la universalidad, Kant distingue entre universalidad lógica, que descansa en el concepto del objeto, y universalidad estética, que es solo subjetiva; es decir, no se refiere a los objetos que caen bajo un mismo concepto, sino solo a "la esfera total de los que juzgan". Ahora bien, "un juicio de valor universal objetivo es siempre también subjetivo, es decir, que cuando alguno vale para todo lo que está encerrado en un concepto dado, vale también para cada uno de los que se representan un objeto mediante ese concepto" ( $K U, \S 8$ AA 05: 215). Precisamente, uno de los aspectos que nos desvela la "Crítica del Juicio estético" es la universalidad de la subjetividad. 
sentido de 'intersubjetividad'; pues, ¿qué puede significar una perspectiva de universalidad sino la perspectiva de 'todos los demás'?

La ecuación entre objeto y validez universal se pone también de manifiesto en el discurso de Kant sobre la noción de juicio [Urteil], en el $\$ 19$ de la Analítica trascendental. Un juicio expresa la relación de las representaciones dadas con la apercepción originaria ( $K r V$, B141-142). "A ello apunta la cópula 'es' de los juicios” $(K r V, 141)$, frente a una relación de representaciones entre sí, propia de la imaginación reproductiva.25 Esto segundo no tiene una validez objetiva, sino subjetiva o privada. Pero, ¿por qué la relación de las representaciones a la unidad de la conciencia es fundamento de validez objetiva, frente a validez privada? ¿No será porque esa conciencia es una conciencia dotada de universalidad, es decir, intersubjetiva?

En suma, ¿cabría pensar que en el idealismo trascendental kantiano el objeto, la objetividad y, por tanto, la verdad, tienen su fundamento o condición de posibilidad en la intersubjetividad, y no solo en un yo entendido como identidad consigo mismo? A mi juicio, los pasajes en los que hemos basado nuestro segundo argumento sobre la conciencia trascendental hablan a favor de una articulación entre la objetividad y la intersubjetividad; entre la verdad como concordancia con el objeto y la universalidad de la conciencia o intersubjetividad, sin la cual no cabe hablar de validez objetiva.

La otra pregunta que nos hacíamos es si la verdad está necesitada de confrontación intersubjetiva. En relación con esta pregunta cabe destacar que uno de los aspectos que Kant mismo toma en consideración respecto a la verdad es la comunicabilidad de la misma; alude a este aspecto tanto en la Crítica de la razón pura como en otros lugares de su obra. Así, en la sección tercera de "El canon de la razón pura", titulada "La opinión, el saber y la creencia", Kant presenta la comunicabilidad como criterio extrínseco de la verdad de un juicio. Demos paso a su análisis.

En esta sección, Kant enfoca la cuestión de la verdad desde el punto de vista del sujeto que formula el juicio; introduce, en este sentido, la

25 "De acuerdo con tales leyes (con las asociativas), únicamente podría decir: 'cuando sostengo un cuerpo siento la presión del peso', pero no: 'el mismo cuerpo es pesado'; esta última proposición indica que las dos representaciones se hallan combinadas en el objeto (Objekt), es decir, independientemente del estado del sujeto, no simplemente que van unidas en la percepción (por muchas veces que esta se repita)" (KrV, B142). 
expresión "tener algo por verdadero".26 En esta perspectiva distingue entre "convicción” y "persuasión":

El tener algo por verdadero (das Fürwahrhalten) es un suceso de nuestro entendimiento, y puede basarse en fundamentos objetivos, pero requiere también causas subjetivas en el psiquismo del que formula el juicio. Cuando este es válido para todo ser que posea razón, su fundamento es objetivamente suficiente y, en este caso, el tener por verdadero se llama convicción (Überzeugung). Si solo se basa en la índole especial del sujeto, se llama persuasión (Überredung) $(\mathrm{KrV}$, A820/B848).

En este pasaje, y en coherencia con la tesis que venimos manteniendo de la concepción de la objetividad como validez intersubjetiva, Kant parece identificar, sin más, fundamentos 'objetivos' con 'validez para todos',27 frente a validez privada. El tener algo por verdadero se llama convicción si puede ser tenido como verdadero por todos; en tal caso se basa en fundamentos objetivos; y se llama convicción, frente a la mera persuasión, que tiene solo una validez privada.

De esa validez universal o validez para todos, que Kant identifica con validez objetiva o fundamentos objetivos (o viceversa, de ese fundamento objetivo de algo, que Kant identifica con validez intersubjetiva), deriva, a mi modo de ver, la afirmación de que la comunicabilidad de un juicio constituye un criterio extrínseco de su verdad. En efecto, según los pasajes a los que nos estamos refiriendo, "la verdad descansa en la concordancia con el objeto y, consiguientemente, los juicios formulados por cualquier entendimiento y relativos a dicho objeto tienen que coincidir" ( $K r V, \mathrm{~A} 820 / 848)$; por eso, la concordancia de todos en el juicio prueba que este es válido para todos, que estos concuerdan con el objeto y, por tanto, dicha concordancia o consenso es criterio de la verdad del juicio:

26 "Tener por verdadero" hace referencia al estado del sujeto; por eso, también usa como expresión sinónima "validez subjetiva del juicio" (KrV, A822/B850).

27 De todos modos, no niego una cierta ambigüedad: por un lado parece que fundamentos objetivos y validez para todos se identifican; pero, por otro lado, podría también pensarse que es por basarse en fundamentos objetivos por lo que algo puede tener validez para todos. Me inclino por la primera interpretación porque, de acuerdo con la indagación llevada a cabo en este trabajo, no veo que la objetividad en Kant pueda interpretarse de otro modo que como validez universal y, por tanto, intersubjetiva. 
El criterio para saber si el tener por verdadero es convicción o mera persuasión es, por tanto, externo y consiste en la posibilidad de comunicarlo y en comprobar su validez para toda razón humana. En este último caso parece al menos que la causa de la concordancia de todos los juicios residirá, a pesar de la diversidad de los sujetos entre sí, en la comunidad de fundamento, es decir, en el objeto; al concordar todos con él, queda demostrada la verdad del juicio $(K r V$, A820821/B848-849).

Ciertamente, el fundamento de la verdad del juicio sigue siendo la concordancia de este con el objeto; y es este fundamento, que en Kant queda articulado con la validez para todos, el que hace posible la comunicabilidad del juicio o coincidencia de todos los demás con el mismo. Pero no es menos cierto que a la cuestión del fundamento (constitución o condición de posibilidad) de la verdad se añade en estos pasajes la perspectiva intersubjetiva y comunicativa de todos los demás. Es decir, se añade el criterio (aunque sea extrínseco) de tener en cuenta "el entendimiento de otros" ( $K r V$, A821/B849), al menos para distinguir la mera persuasión de la convicción. Más que de un solipsismo, se trata ahora de un carácter participativo de la razón. 28

Este carácter participativo de la verdad aparece también en la Lógica Jäsche, en la sección VII de la Introducción, dedicada a la verdad: "Una característica externa o una piedra de toque externa de la verdad es la comparación de nuestros propios juicios con los de otros [...] La incompatibilidad de otros juicios con el nuestro ha de ser considerada [...] como una característica externa del error" (Log, AA 09: 57).

Como "piedra de toque para descubrir errores" o como "prueba para juzgar la corrección”, también menciona Kant, aquí mismo, el "entendimiento común" [sensus communis] (Log, AA 09: 57), así como sus tres máximas; entre ellas, la de situarse en el punto de vista de los otros o "modo de pensar ampliado".29

28 Comparto la opinión de quienes se oponen a considerar el yo kantiano como un yo solipsista (un ejemplo de dicha oposición es Granja [2010: 72-92, 214; véase también Masías [2015]). Otra cosa es que Kant no llegue a un yo intersubjetivo, al menos de modo directo, por la vía de una reflexión trascendental, algo que, como pone de relieve Cortina (1991: 21), lleva a cabo Apel en su transformación de la filosofía kantiana. Por otro lado, incluso aceptando (como es el caso del presente trabajo) el alcance intersubjetivo del yo kantiano, las diferencias con el a priori de la comunidad de comunicación de Apel son obvias desde varios puntos de vista (véase Apel 1985: 149-169).

29 "Las reglas universales y las condiciones para evitar los errores en general son: 1) el pensar por sí mismo, 2) pensarse en la posición de otro, y 3) pensar en todo momento de acuerdo consigo mismo. 
De acuerdo con la Reflexión 2565, la verdad necesita de confrontación intersubjetiva:

Dado que consideramos como necesario informar a los demás acerca de nuestros juicios, entonces no tenemos que ser únicamente comunicativos, sino también participativos. La propensión a la comunicación que guía a nuestro entendimiento se encuentra en nosotros tan solo porque debemos verificar nuestros propios juicios a través de otros (Refl, AA 16.3: 419).

Según la Reflexión 2566, los otros son interlocutores:

La inclinación comunicativa de la razón es equitativa solo bajo la condición de que esté vinculada a la vez a la participativa. Los otros no son aprendices, tampoco son jueces, sino colegas, en el gran consejo de la razón humana y tienen votum consultativum, y unanimitas votorum est pupila libertatis. Liberum veto (Refl, AA 16.3: 419).

A la comunicabilidad del pensamiento como condición de posibilidad de la corrección de este alude también Kant en el escrito de 1786 Qué significa orientarse en el pensamiento: “ihasta qué punto y con qué corrección pensaríamos, si no pensáramos, por decirlo así, en comunidad con otros a los que comunicar (mitteilen) nosotros nuestros pensamientos y ellos los suyos a nosotros!" (WDO, AA 08: 145).

Pero, ¿por qué es la comunicabilidad de un juicio y el ponerse en el punto de vista de los demás un criterio externo de su verdad? A mi parecer, lo que justifica esta posición es la tesis que venimos manteniendo sobre la articulación de objetividad e intersubjetividad; esto es, el hecho de que la subjetividad es universal. Compartimos una misma subjetividad y, por tanto,

La máxima de pensar por sí mismo se puede llamar modo de pensar ilustrado; la máxima de trasladarse en el pensamiento a puntos de vista ajenos, modo de pensar ampliado, y la máxima de pensar siempre de acuerdo consigo mismo, modo de pensar consecuente o franco" (Log, AA 09: 58). Estas mismas máximas aparecen en otros varios lugares (KU, AA 05: 294-295; Anthr, §40 AA 07: 201, §59, AA 07: 228). Sobre la máxima de la Ilustración, pensar por sí mismo, como «piedra de toque de la verdad», puede verse también un pasaje de Qué significa orientarse en el pensamiento. En ese pasaje la máxima de pensar por sí mismo o servirse de la propia razón como piedra de toque de la verdad consiste en someter lo que se admite a la prueba del principio de la universalización (WDO, AA 08: 146, nota de Kant). Nótese que, de acuerdo con este comentario, el problema de la verdad guarda relación con el concepto kantiano de 'ilustración' y con el 'principio de universalización'. 
compartimos las reglas a priori que hacen posible el objeto; por tanto, la confrontación del propio juicio con el de los demás sería el signo externo de su concordancia con el objeto (esto es, de la verdad del juicio). Esta línea de argumentación podría documentarse con la Reflexión 2564:

\begin{abstract}
Puesto que la validez universal de nuestros juicios indica la verdad objetiva30 para cualquier razón, se sigue (que el juicio de otros sea un criterio externo de verdad) la necesidad de una razón participativa, que se opone al egoísmo; por lo mismo el derecho de dar a conocer los propios juicios y la lealtad como el motivo impulsor de las ciencias. Un entendimiento y una voluntad participativas son buenas siempre; un entendimiento sano y correcto va siempre unido a la honradez, o al menos a la inversa (Refl, AA 16.3: 418).31
\end{abstract}

En esta perspectiva, cabe afirmar que la verdad, al menos desde el punto de vista del reconocimiento de la misma, está necesitada de confrontación con los demás.

Por todo lo expuesto, creo que puede aceptarse que Kant deja abierta una cierta perspectiva dialógica, es decir, la necesidad del diálogo y la argumentación. Podríamos citar en esta línea esos pasajes de la Doctrina del método en los que Kant presenta "la crítica de la razón pura como el verdadero tribunal de todos sus conflictos" ( $K r V$, A751/B779). Al uso dogmático de la razón opone Kant un uso "polémico" ( $K r V$, A739/B768) o crítico, basado justamente en la consideración de todos como interlocutores (KrV, A739-740/B766-767). Igualmente, podríamos traer aquí pasajes relativos al uso público de la razón, tanto en la Crítica de la razón pura como en otros escritos. 32

En pasajes como esos la verdad ya no es solo cuestión de objetividad, sino también de argumentación. En este punto es pertinente citar a Habermas, para quien la verdad no es cuestión de objetividad, sino de

\footnotetext{
30 Nótese de nuevo la identificación entre objetividad y validez universal.

31 Puede observarse que a la objetividad se unen en este texto elementos o motivos también de carácter moral, como la honradez.

32 "También forma parte de esa libertad el exponer a pública consideración los propios pensamientos y las dudas que no es capaz de resolver uno mismo, sin por ello ser tachado de alborotador o de ciudadano peligroso. Esto entra ya en el derecho originario de la razón humana, la cual no reconoce más juez que la misma razón humana común, donde todos tienen voz" ( $K r V$, A752/B780). Uso público de la razón significa para Kant la libertad de exponer y someter al examen del mundo el propio pensamiento sobre algo (WA, AA 08: 40).
} 
argumentación; justamente, reprocha a las teorías trascendentales de la verdad el haber pasado "por alto la distinción entre objetividad y verdad" (2011: 133). Según su teoría discursiva o consensual de la verdad, "solo puedo [...] atribuir un predicado a un objeto si también cualquiera que pudiera entrar en discusión conmigo atribuyese el mismo predicado al mismo objeto [...] La condición para la verdad de los enunciados es el potencial asentimiento de todos los demás" (2011: 121). Por supuesto, las diferencias con Kant son obvias: para Kant, es la concordancia de todos con el objeto lo que funda el consenso; es decir, el fundamento del consenso potencial es la objetividad. Pero, en todo caso, el consenso potencial, si bien no es para Kant lo que constituye la verdad, sí es un criterio extrínseco de la misma, esto es, para conocer si algo es verdadero; posición que, a mi juicio, deriva de la conexión que establece la Crítica de la razón pura entre objetividad y validez universal o intersubjetiva.

\section{Conclusión}

En relación con la verdad, he podido descubrir en la Crítica de la razón pura la siguiente secuencia: la orientación de la verdad hacia la objetividad; el giro de esta y de la concordancia con el objeto hacia la subjetividad trascendental; la ecuación entre objeto y validez objetiva; la equivalencia de estos con universalidad o validez universal; y la perspectiva de la universalidad como una perspectiva de carácter intersubjetivo o participativo; carácter participativo que parece congruente con ciertos pasajes de las obras de Kant en los que la comunicabilidad se presenta como criterio extrínseco de la verdad.

Mi objetivo era fundamentalmente descubrir la posible conexión sistemática entre la cuestión de la concordancia con el objeto y la intersubjetividad. Creo haber hallado el punto central de esta articulación en el alcance intersubjetivo de la conciencia trascendental, la cual constituye el fundamento del objeto y de la concordancia con este. He argumentado sobre el alcance intersubjetivo de la conciencia trascendental y su conexión con el problema del objeto en la segunda parte del trabajo. Hablo incluso de una suerte de equivalencia entre objetividad e intersubjetividad, equivalencia que tiene su base, a mi juicio, en la identificación entre el objeto y la validez universal, frente a la validez privada. Kant piensa la validez objetiva como 
validez universal, frente a la validez privada $\mathrm{y}$, por tanto, como validez intersubjetiva.

Compartimos una misma subjetividad y, así, compartimos las reglas a priori que hacen posible el objeto; por tanto, la confrontación del propio juicio con el de los demás sería el signo externo de su concordancia con el objeto; esta es una de las grandes posiciones de este trabajo.

Respecto al consenso (coincidencia de los demás en el juicio; o, en general, necesidad de comparar nuestros juicios con los de los demás, en tanto que interlocutores, o comunicabilidad), lo que se afirma en el trabajo es que el consenso no es un criterio constitutivo de la verdad, sino un criterio extrínseco para conocer si algo es verdadero. Lo que es constitutivo de la verdad es la concordancia con el objeto; pero como el fundamento del objeto está en la subjetividad, que es universal o intersubjetiva, el consenso puede ser tenido como criterio extrínseco de la verdad. Con ello, creo haber desarrollado, al menos en parte, la articulación de la objetividad e intersubjetividad; y creo haber justificado en esta articulación la consideración del consenso como criterio extrínseco de verdad.

En suma, situar el fundamento de la objetividad en la subjetividad universal o común a todos es coherente con la caracterización del consenso como criterio extrínseco de la verdad. Y haciendo del consenso criterio extrínseco de la verdad, Kant se está abriendo al actual paradigma dialógico o argumentativo de la verdad; al menos, en el siguiente sentido: aunque el consenso no es constitutivo de la verdad, esta sí tiene un 'alcance participativo'; si no hay un asentimiento potencial de todos, no cabe hablar de verdad. El consenso no es criterio, pero sí es indicio de verdad.

Esa articulación entre objetividad e intersubjetividad podría abrir a la filosofía crítica a la justificación de dos formas de verdad: la verdad como concordancia con el objeto, propia del entendimiento, "el territorio de la verdad" ( $K r V$, A235/B294), y la verdad como argumentación entre interlocutores válidos y el potencial asentimiento de todos. En realidad, la argumentación y el potencial consenso son fundamentales en los textos kantianos sobre la ilustración y en su filosofía política. Y, por otro lado, la exigencia del consenso potencial no remite sino al 'principio de la 
universalización', como eje central en uno y otro caso.33 Por eso, me atrevo a formular la sugerencia de que tal vez haya en Kant más de un sentido de verdad, cosa que sería coherente con su doctrina central de los usos de la razón.34 De hecho, una de las preguntas que suscita la presente indagación es: ¿hay en Kant una 'verdad práctica'? Cuestión que abordaremos en una ulterior investigación.

\section{Referencias}

APEL, K.-O.: La transformación de la filosofía. II. El a priori de la comunidad de comunicación, Madrid, Taurus, 1985.

CABRERA, I.: "Verdad y Juicio reflexionante en Kant", Dianoia 42 (1996) 81-90.

CORTINA, A.: "Introducción: Karl Otto Apel. Verdad y responsabilidad", en APEL, K.-O.: Teoría de la verdad y ética del discurso, Barcelona, Paidós, 9-33, 1991.

GRANJA, D. M.: Lecciones de Kant para hoy, Barcelona, Anthropos, 2010.

\footnotetext{
33 He aquí dos pasajes en ese sentido. Este primero, al que aludimos ya en la nota 29, se refiere al concepto kantiano de Ilustración: "Pensar por sí mismo significa buscar en uno mimo (es decir, en su propia razón) la suprema piedra de toque de la verdad; y la máxima de pensar siempre por sí mismo es la ilustración [...] Servirse de la propia razón no quiere decir otra cosa que preguntarse a sí mismo en todo lo que debe admitir: es factible convertir en principio universal del uso de la razón el fundamento por el que se admite algo, o aun la regla que resulta de lo que se admite?" (WDO, AA 08: 146, nota de Kant). Este segundo es relativo a su filosofía política, concretamente, a la idea kantiana del contrato originario, que algunos consideran como la cuarta formulación del imperativo categórico: "se trata de una mera idea de la razón que tiene, sin embargo, su indudable realidad (práctica), a saber, la de obligar a todo legislador a que dicte sus leyes como si estas pudieran haber emanado de la voluntad unida de todo un pueblo, y a que considere a cada súbdito, en la medida en que este quiera ser ciudadano, como si hubiera expresado su acuerdo con una voluntad tal. Pues ahí se halla la piedra de toque de toda ley pública" (TP, 08: 297).

${ }_{34}$ Con los usos de la razón podría también ponerse en relación una noción de la verdad como espacio de razones, más bien que de objetividad: es el caso del propio método o camino que sigue Kant para acceder a realidades suprasensibles como la libertad o la existencia de Dios (es decir, el método trascendental: tener que admitir algo como condición de posibilidad de algo otro que no cabe rechazar). En esta perspectiva de la verdad como espacio de razones podríamos también articular la creencia ( $K r V$, A822/B850), que es un modo de tener por verdadero, insuficiente objetivamente, a diferencia del saber, pero subjetivamente suficiente. En tanto que guía de acción u orientación ( $\mathrm{KrV}$, A824/B852-A832/B860, la creencia podría interpretarse en la línea de las teorías 'pragmáticas' de la verdad ( $K r V$, A824/B852, A832/B860); en este sentido, véase también, a propósito de la creencia moral o fe racional, WDO, AA 08: 142. Sobre la creencia en Kant, consúltese Tenreiro (2017: 212 241).
} 
HABERMAS, J.: "Teorías de la verdad", en: Teoría de la acción comunicativa: complementos y estudios previos, Madrid, Cátedra, 113-158, 2011.

KANT, I.: Gesammelte Schriften, Bd. 1-22, Preussische Akademie der Wissenschaften, 23, Deutsche Akademie der Wissenschaften zu Berlin, ab 24, Akademie der Wissenschaften zu Göttingen, Berlín, Walter der Gruyter, 1910ss. (AA)

: Anthropologie in pragmatischer Hinsicht (Anth), AA 07.

: Beantwortung der Frage: Was ist Aufkärung? (WA), AA 08.

: Kritik der reinen Vernunft $(K r V), \mathrm{A} / \mathrm{B}$.

: Kritik der Urteilskraft $(K U)$, AA 05.

: Logic $(\log )$, AA 09.

: Prolegomena zu einer jeden künftigen Metaphysik (Prol), AA

04.

: Reflexionen zur Logik (Refl), AA 16.3.

: Über den Gemeinspruch: Das mag in der Theorie richtig sein, taugt aber nicht für die Praxis (TP), AA 08.

: Was heisst sich im Denken orientiren? (WDO), AA 08.

: En torno al tópico: «Tal vez eso sea correcto en teoría, pero no sirve para la práctica», en KANT, I.: Teoría y Práctica, Madrid, Tecnos, 368, 1986.

: Antropología en sentido pragmático, Madrid, Revista de Occidente, 1991.

: Qué significa orientarse en el pensamiento?, Madrid, Universidad Complutense, 1995.

: Lógica. Un manual de lecciones (Edición original de G. B. Jäsche). Acompañada de una selección de Reflexiones del legado de Kant, Madrid, Akal, 2000.

: Qué es Ilustración (1784), en KANT, I.: Ensayos sobre la paz, el progreso y el ideal cosmopolita, Madrid, Cátedra, 21-31, 2005.

: Crítica del Juicio, Madrid, Tecnos, 2007. 
: Crítica de la razón pura, Madrid, Gredos, 2010a.

: Prolegómenos a toda metafísica futura, Madrid, Gredos, 2010b.

LASERNA, M.: "La teoría de la verdad en Kant", Ideas y Valores 34, 6667 (1985) 21-36.

MASÍAS, C. A.: La intersubjetividad en Kant, Tesis de Maestría, Universidad Panamericana, México, 2015.

NENON, T. J.: „Konsensus und Objektivität. Hat Kant sein Position aus der Kritik der reinen Vernunft nachträglich revidiert?“, en FUNKE, G. (ed.): Akten des 5. Internationalen Kant-Kongresses, Bonn, Bouvier Verlag, 171178, 1981.

PAEK, S. C.-H.: "Kant's Theory of Transcendental Truth as Ontology", Kant-Studien 96 (2005) 147-160.

PALACIOS, J. M.: El idealismo trascendental: teoría de la verdad, Madrid, Gredos, 1979.

PUTNAM, H.: Razón, verdad e historia, Madrid, Tecnos, 1988.

SCHEFFER, T.: Kants Kriterium der Wahrheit. Anschauungsformen und Kategorien a priori in der Kritik der reinen Vernunft, Berlín/Nueva York, Walter de Gruyter, 1993.

SCHOPENHAUER, A.: De la cuádruple raíz del principio de razón suficiente, Madrid, Gredos, 1998.

STRAULINO, S.: "La noción kantiana de verdad trascendental", Revista de Estudios Kantianos 2 (2016) 126-145.

TENREIRO, V.: Creer en el otro: La motivación moral a partir de Kant y Levinas, Madrid, Ápeiron Ediciones, 2017. 


\title{
Die konzeptualistische und die nicht-konzeptualistische Interpretation der Kooperationsthese
}

\author{
SOPHIA MADDALENA FAZIO 1
}

\begin{abstract}
Inhaltsangabe
Anhand der sogenannten Kooperationsthese wird in diesem Beitrag Kants kognitiver Dualismus innerhalb der (nicht-)konzeptualistischen Debatte untersucht. Ausgehend vom minimalen Empirismus wird McDowells Kritik an der Rechtfertigungsfunktion der Anschauung erläutert. McDowells konzeptualistische Interpretation des kantischen Vermögensdualismus wird der nichtkonzeptualistischen Interpretation Hannas gegenübergestellt, um die Kohärenz beider Positionen zum transzendentalphilosophischen Erkenntnismodell zu hinterfragen. Auf der Basis von Kants Bestimmung des Begriffes als allgemeine Vorstellung (repraesentatio generalis) mit einem Inhalt und einem Umfang wird schließlich eine dritte Deutung des von Kant vertretenen Vermögensdualismus vorgestellt.
\end{abstract}

Schlüsselwörter: Vermögensdualismus, Kooperationsthese, Konzeptualismus, Non-Konzeptualismus, minimaler Empirismus, representatio generalis

\section{La interpretación conceptualista y no conceptualista de la tesis de cooperación}

\begin{abstract}
Resumen
De la mano de la así llamada tesis de la cooperación se investiga en esta contribución el dualismo cognitivo kantiano dentro del debate (no-)conceptualismo. Partiendo de un empirismo mínimo, McDowells explica la función de justificación de la intuición. La interpretación conceptualista de McDowell del dualismo de facultades kantiano se contrapone a la interpretación no-conceptualista de Hannas, para indagar la coherencia de ambas posiciones frente al modelo de conocimiento de la filosofía trascendental. Sobre la base de la determinación kantiana del concepto como representación general (repraesentatio generalis) con un contenido y una extensión se representa, finalmente, una tercera interpretación del dualismo de facultades sostenido por Kant.
\end{abstract}

Palabras clave: dualismo de facultades, tesis de cooperación, conceptualismo, noconceptualismo, empirismo mínimo, representatio generalis

1 Friedrich-Wilhelms-Universität Bonn. Kontakt: sophia.m.fazio@gmail.com. 
In der berühmten Kooperationsthese [togetherness principle]2 aus der Kritik der reinen Vernunft — »Gedanken ohne Inhalt sind leer, Anschauungen ohne Begriffe sind blind « $(K r V, \mathrm{~B} 75)$ — wird das Verhältnis der zwei Grundvermögen der Erkenntnis plakativ zusammengefasst. Der von Kant vertretene kognitive Dualismus ist unter historischem Gesichtspunkt eine revolutionäre Neuerung gegenüber der Leibnizschen und Wolffianischen rationalistischen Schule und seine interpretativen Folgen sind in der Entwicklung des gesamten Deutschen Idealismus zu sehen. Allerdings ist diese Textstelle in der gegenwärtigen Forschung immer noch im Zentrum der Diskussion und zwar in der von John McDowell eingeleiteten Debatte über eine konzeptualistische und nicht-konzeptualistische Auffassung der Erkenntnistheorie. In diesem Zusammenhang besteht das Ziel dieses Beitrags in der Erläuterung und in der kritischen Auseinandersetzung mit der Interpretation des Vermögensdualismus in Kants theoretischer Philosophie innerhalb dieser Debatte. Im ersten Teil wird eine kurze Einführung zum (Non-)Konzeptualismus im Allgemeinen gegeben, um im zweiten Teil — ausgehend von Kants Kooperationsthese — die konzeptualistische und die nicht-konzeptualistische Auffassung des Vermögensdualismus zu erläutern sowie deren Kohärenz zum Gesamtwerk der Kritik der reinen Vernunft systematisch zu umreißen. Im letzten Teil wird ein alternativer Interpretationsansatz vorgestellt.

1. Die Debatte um eine (nicht-)konzeptualistische Auffassung der Erkenntnistheorie Kants

McDowell stellt in der Monographie Mind and World den von Kant eingeführten kognitiven Dualismus in Frage, indem er den sinnlichen Vorstellungen sowohl ihre epistemische Funktion als Materie der Erkenntnis als auch ihre ontologische Unabhängigkeit von den Verstandesformen abspricht.

Die epistemische Bezugnahme des Geistes - die Vernunft3 im Sinne Kants - weist nach McDowell eine normative Geltung auf, da sie in einer Handlung in der Form eines Sprechaktes erfolgt. Der Sprechakt drückt

2 Der Ausdruck togetherness principle wurde von Robert Hanna eingeführt, um die kognitive Wechselwirkung der zwei Grundvermögen der Erkenntnis zu bezeichnen (vgl. Hanna 2005: 255).

3 In diesem Zusammenhang wird unter Vernunft das Vermögen apriorischer Erkenntnis im weiten Sinne verstanden, das als oberes Erkenntnisvermögen den Verstand einschließt (vgl. KrV, B863, B731). 
eine Überzeugung über die Beschaffenheit der Dinge aus, die auf der Verantwortung beruht, die Welt zu beschreiben, wie sie tatsächlich ist (vgl. McDowell 1996: xi-xii). Aus der Verantwortung, die Welt angemessen zu beschreiben, folgt die Angabe einer Rechtfertigung, die es ermöglicht, zwischen wahren und falschen Aussagen zu unterscheiden.

In diesem Zusammenhang wendet sich McDowell gegen den minimalen Empirismus, nach welchem die Wahrnehmung als ein solches Rechtfertigungskriterium dienen kann (vgl. McDowell 1996: xii). Sinnliche, bloß mannigfaltige Vorstellungen können seines Erachtens kein Wissen rechtfertigen, weil sie nicht dem normativen Kontext des logischen Raumes der Gründe [space of reasons] angehören. Beruhend auf Wilfrid Sellars versteht er unter dem logischen Raum der Gründe die Einheit aller epistemischen Rechtfertigungen von Wissen (vgl. Sellars 1997: 76). McDowell stimmt mit Sellars überein, dass die normative Relation zwischen Begründetem und Begründer nur begrifflicher Natur sein und damit in der Form eines Urteils bestehen kann (vgl. McDowell 1996: xv). Daraus folgt, dass die Wahrnehmung ihre Rechtfertigungsfunktion nur unter der Bedingung erfüllen kann, dass begriffliche Fähigkeiten in der Rezeptivität tätig sind. Im Kontext der theoretischen Philosophie Kants bedeutet dies, dass bloß sinnliche Vorstellungen - die Anschauungen kein Wissen, sei es a priori oder a posteriori, begründen können. Erst in ihrer Wechselwirkung mit den Kategorien können sie ihre epistemische Funktion als Materie der Erkenntnis erfüllen.

Nach McDowell kommen in der Wahrnehmung und in der Erkenntnis dieselben begrifflichen Formen - die Kategorien nach Kant vor. Der Unterschied zwischen subjektivem und objektivem Wissen besteht darin, dass — während beim Wahrnehmen die Verstandesformen auf passive Weise mit dem Gegebenen hervortreten - sie im Rahmen einer Erkenntnis spontan auf das Gegebene a priori oder a posteriori bezogen sind (vgl. McDowell 2009: 12). Aufgrund des passiven Charakters der Rezeptivität weisen Wahrnehmungsurteile nach McDowell keine doxastische Geltung auf. In der Erfahrung werden die Dinge beschrieben, wie sie dem Subjekt erscheinen, da nicht bestimmt werden kann, welche Vorstellungen durch Affektion im Gemüt entstehen. Erst am Ende des Erkenntnisprozesses kann das Subjekt die normative Entscheidung treffen, ob die Dinge so sind, wie sie ihm sinnlich gegeben wurden. 
Auf dem epistemischen Modell McDowells beruht die philosophische Strömung des Konzeptualismus innerhalb der analytischen Philosophie des Geistes, dessen Grundthese darin besteht, dass die Sinnlichkeit, unabhängig vom begrifflichen Vermögen, keinen Zugang zu den Gegenständen der Erfahrungswelt hat und dass jede epistemisch relevante sinnliche Vorstellung begrifflich bestimmt sein muss, um bewusst vorgestellt $\mathrm{zu}$ werden. Der Nicht-Konzeptualismus besteht in der Gegenthese, dass sinnliche Vorstellungen, unabhängig vom Verstandesvermögen, Objekte unmittelbar darstellen und dass sie im Gemüt bewusst vorkommen können.

\section{McDowell Interpretation der Kooperationsthese}

Nach McDowell steht die Kooperationsthese im Einklang mit seiner konzeptualistischen Auffassung des Vermögensdualismus. Die Strategie seiner Argumentation besteht in der Ablehnung der These, dass der erste Satzteil — »Gedanken ohne Inhalt sind leer« — als eine bloße Tautologie $\mathrm{zu}$ verstehen sei, in der aus der Inhaltslosigkeit der Gedanken auf ihre Leerheit geschlossen wird. Es ist nämlich trivial $\mathrm{zu}$ behaupten, dass in einem leeren Gedanken nichts gedacht wird, da seiner Auffassung nach ein Gedanke per definitionem aus dem durch ihn Gedachte besteht (vgl. McDowell 1996: 4). Kant bezieht sich also an dieser Stelle nicht auf die vom Verstand spontan hervorgebrachten begrifflichen Vorstellungen, deren Inhalt entweder gegeben oder gedacht wird, sondern auf diejenigen Gedanken, die auf passive Weise in der Wahrnehmung hervortreten. Dies wird laut McDowell vom zweiten, ergänzenden Teil der Kooperationsthese bestätigt, in der Kant der bloßen sinnlichen Vorstellungen, die in der Wahrnehmung nicht begrifflich erfasst werden, Blindheit zuschreibt. In diesem Sinne möchte Kant im ersten Satzteil der Kooperationsthese hervorheben, dass in der Wahrnehmung die Gedanken qua begriffliche Vorstellungen mit dem Gegebenen in der Einheit einer Anschauung gegeben werden müssen, um die sinnlichen Inhalte $\mathrm{zu}$ befähigen, eine Erkenntnis zu rechtfertigen. Würden die in der Wahrnehmung hervortretenden Gedanken nicht auf passiver Weise mit dem sinnlichen Input hervortreten, würden sie sich nicht von den im spontanen Denken tätigen begrifflichen Vorstellungen unterscheiden, die allein betrachtet ein leeres Gedankenspiel bilden. 
Im zweiten Teil der Kooperationsthese - »Anschauungen ohne Begriffe sind blind « — wird auf die Anschauungen als bloß sinnliche Vorstellungen Bezug genommen, die aufgrund ihres unmittelbaren Charakters nicht zum logischen Raum der Gründe gehören und somit keine Erkenntnis begründen können. Die epistemische Funktion der Anschauung besteht darin, den Wirklichkeitsbezug einer Erkenntnis zu ermöglichen; wird jedoch das in ihr enthaltene Mannigfaltige nicht von Begriffen begleitet, kann sie ihre Funktion nicht ausüben und ist damit unter epistemischem Gesichtspunkt völlig irrelevant.

McDowells Interpretation stimmt aus mehreren Gründen mit Kants transzendentalphilosophischen Prämissen nicht überein. In erster Linie wird die im $§ 1$ der „Transzendentalen Ästhetik“ sowie in der Einleitung zur „Transzendentalen Logik“ erläuterte dichotomische Unterscheidung der Erkenntnisquellen stark relativiert, weil der Verstand nicht nur für die synthetische Einheit des Mannigfaltigen der Anschauungen in einem Begriff, sondern auch für die sinnliche Einheit der gegebenen Empfindungen in einer Anschauung zuständig ist. McDowells Konzeptualismus ist außerdem zu dem in der Kritik der reinen Vernunft unternommenen Isolationsverfahren nicht kohärent, nach welchem die epistemische Leistung der Sinnlichkeit von derer des Verstandes abgesondert werden kann (vgl. $\mathrm{KrV}, \mathrm{B} 36)$.

Abgesehen von der Inkohärenz zum Primärtext, ist es unklar, wie die Begriffe die anschauliche Einheit eines Mannigfaltigen bestimmen können. Die Einheit der Anschauung beruht nach Kant auf den reinen Anschauungsformen - Raum und Zeit - die sich laut der „Transzendentalen Ästhetik“ von den Begriffen ihrem Wesen nach unterscheiden. Während die Formen der Anschauung eine Einheit des Mannigfaltigen im Sinne eines Totum bilden, besteht die begriffliche Verbindung des Mannigfaltigen aus einem Compositum. Da im Rahmen einer Einheit als Totum das räumliche und das zeitliche Ganze die Bedingung der Möglichkeit dessen voneinander unselbständigen Teilen ist, sind Raum und Zeit singuläre Vorstellungen, aus denen qualitativ gleichartige, zur selben Einheit gehörende Raum- und Zeitabschnitte vorgestellt werden. Begriffe hingegen schaffen die Einheit eines Compositum, die aus einem Aggregat von heterogenen, wechselseitigen 
Teilvorstellungen besteht, die anhand eines gemeinsamen Merkmals vereinigt sind (vgl. $K r V$, B39, B47).

Im Zusammenhang der „Transzendentalen Analytik“ missachtet McDowell die Unterscheidung zwischen Denken und Erkennen. Er behauptet nämlich, dass leere Gedanken nicht als Gedanken identifiziert werden können, weil in ihnen nichts gedacht wird. Kategorien als Begriffe eines Gegenstandes überhaupt weisen jedoch nach Kant keinen wirklichen Inhalt auf, da sie das Denken der synthetischen Einheit des Mannigfaltigen anhand einer bestimmten logischen Funktion in Urteilen vorstellen (vgl. $K r V$, B104-105).

Kant würde allerdings zustimmen, dass das bloße Mannigfaltige nicht zum Raum der Gründe gehört. Da sinnliche Vorstellungen keiner Erkenntnis in der Form eines Urteils entsprechen, haben sie nach Kant keinen Wahrheitswert. Die negative Bedingung der Wahrheit besteht nämlich in der Einhaltung der formalen Regeln des Denkens, die das Verhältnis der Vorstellungen aufeinander in einem Urteil unter logischem Gesichtspunkt festlegt (vgl. $K r V$, B350). Die positive Bedingung der Wahrheit, verstanden als die objektive Realität der Erkenntnis eines Gegenstandes, besteht in dessen Möglichkeit der Erfahrung, die wiederum vom Verstand bestimmt wird, weil sie unter den notwendigen Bedingungen der synthetischen Einheit eines Mannigfaltigen überhaupt steht (vgl. $\mathrm{KrV}$, B194-195).

\section{Hannas Interpretation der Kooperationsthese}

Robert Hanna als Hauptvertreter des Nicht-Konzeptualismus hält am dichotomischen Verhältnis der zwei Vorstellungsarten fest. Seiner Meinung nach ist Kants Kooperationsthese nicht als Aussage über die Beschaffenheit der in Begriffen eingebundenen Anschauung zu verstehen, sondern als Bedingung für die Bildung einer Erkenntnis zu deuten. Dieser Interpretation gemäß, kann aus der Notwendigkeit der Wechselwirkung der zwei Grundvermögen zum besonderen Zweck der Erkenntnis nicht ausgeschlossen werden, dass Anschauungen und Begriffe unter ontologischem Gesichtspunkt unabhängig voneinander im Gemüt bestehen und dass sie unter epistemischem Gesichtspunkt eine wesensspezifische Funktion ausüben können. 
Um den ersten Teilsatz der Kooperationsthese zu verstehen, muss nach Hanna berücksichtigt werden, dass Begriffe, allein betrachtet, die Form der Erkenntnis bilden, d.h. die Art und Weise der Verarbeitung eines Gegebenen durch das erkennende Bewusstsein. Wird ihnen keinempirischer Inhalt als Materie gegeben, liefern sie nur ein subjektives Gedankenspiel: »unter "leere Gedanken” versteht Kant weder „falsche Begriffe“ noch „bedeutungslose Begriffe“: vielmehr meint er „nich objektiv gültige Begriffe“" (Autorenübersetzung) ["“"empty concept' for Kant does not mean either 'bogus concept' or 'meaningless concept': rather it means 'concept that is not objectively valid"'] (Hanna 2005: 257). Ein Beispiel für solche leere Begriffe sind nach Hanna die Noumena, also Begriffe die keine Korrespondenz in der Erfahrung haben und daher nicht objektiv gültig sind. Wird als Beispiel dafür der Begriff ,Seele' analysiert, wird es deutlich, dass er eine Substanz bezeichnet, die als denkende und wollende gedacht wird und damit kein wirkliches Prädikat aufweist. Die Seele ist als ein solcher Gedanke in der Form eines Begriffes möglich, sie kann aber nicht erkannt werden, weil ihre Entsprechung in der Erfahrung dem erkennenden Subjekt nicht sinnlich gegeben werden kann.

Blinde Anschauungen bezeichnen sinnliche Vorstellungen, die aufgrund ihrer Wechselwirkung mit den Begriffen nicht diskursiv erfasst werden und demzufolge unerkannt bleiben. Obwohl die Erscheinungen als unbestimmte Gegenstände der Wahrnehmung nicht objektiv erkannt werden, findet nach Hanna ein Bezug zu den sinnlichen Gegenständen statt, da sie mit Bewusstsein wahrgenommen werden. Die These, dass Wahrnehmungen im Gemüt mit Bewusstsein vorgestellt werden können, wird dadurch bewiesen, dass die Menschen Gefühle haben können, ohne dass sie diese artikulieren können oder dass sie von ihren Gefühlen zum Handeln bewegt werden, ohne dass es rational erklärbar ist (vgl. Hanna 2005: 257).

Der Vorteil von Hannas Interpretation besteht darin, dass sowohl die Irreduzibilität als auch die Isolierbarkeit beider Erkenntnisquellen bewahrt bleiben. Durch die Anschauungen wird ein Gegenstand wahrgenommen und durch die reinen Begriffe wird ein Gegenstand gedacht, ohne dass die spezifische Funktion des jeweiligen Vermögens vom anderen übernommen wird oder dass ein Vermögen an der Funktion des anderen beteiligt ist. Trotz der Annahme einer Wechselwirkung zum Zweck der Erkenntnis 
schränkt Hanna die epistemische Funktion der reinen Verstandesbegriffe ein: Die Kategorien sind weder für den Objektbezug noch für das bewusste Vorstellen der Anschauungen zuständig, sondern lediglich für die Bildung der Erkenntnis eines Gegenstandes in diskursiver Form.

Nach dem von Hanna vertretenen Inhalts-Non-Konzeptualismus [content Non-Conceptualism] unterscheiden sich die zwei Vorstellungsarten anhand ihrer ontologischen Beschaffenheit; dies hat zur Folge, dass der Verstand als Begriffsvermögen nicht in der Lage ist, sinnliche Inhalte ihrem Wesen nach in der Erkenntnis angemessen zu bestimmen. Aus diesem Grund kann es laut Hanna, rogue objects' geben, d.h. Anschauungen die vom Verstand nicht erkannt werden können (vgl. 2011: 407). Die Annahme, es gäbe ,rogue objects', widerspricht der Hauptthese der Transzendentalphilosophie, nach welcher die Kategorien als Bedingung der Möglichkeit der Erfahrung gleichzeitig die Bedingung der Möglichkeit aller Gegenstände der Erfahrung sind (vgl. KrV, B197).

\section{Alternativer Interpretationsvorschlag}

Anschauungen und Begriffe qua Vorstellungen sind Modifikationen des Zustandes des Gemüts, die eine bestimmte Art der Bezugnahme des Subjektes auf die Welt wiedergeben, jeweils als sinnliches und als denkendes Subjekt (vgl. KrV, B376-377). Allerdings weder Anschauungen noch Begriffe allein liefern nach Kant eine Erkenntnis, verstanden in diesem Zusammenhang als objektive und bewusste Vorstellung eines Gegenstandes: »Ohne Sinnlichkeit würde uns kein Gegenstand gegeben, und ohne Verstand keiner gedacht werden« $(K r V$, B75). Auf der epistemischen Ebene der Anschauung ist die Erscheinung unbestimmt, weil die kausale Wirkung auf die rezeptive Fähigkeit des Subjektes eine willkürliche Mannigfaltigkeit anschaulicher Vorstellungen bildet, die nicht in der objektiven Einheit eines Gegenstandes erfasst ist. Auch die vom Verstand gedachten Begriffe stellen keinen einzelnen Gegenstand dar, sondern eine Klasse von Gegenständen, die dasselbe Merkmal aufweisen. Das Erkennen eines Gegenstandes besteht in der Subsumierung eines sinnlich gegebenen Merkmals unter die von einem Begriff dargestellte Klasse von Gegenständen, die dieses Merkmal aufweisen (vgl. $\mathrm{KrV}$, B266). 
»Begriffe ohne Inhalt sind leer« — Wie Kant in der Logik näher erläutert, können Begriffe als ,repraesentatio generalis ' in höhere und niedere Vorstellungen anhand ihres Umfangs und ihres Inhalts geordnet werden. Der Umfang besteht in der Menge von Gegenständen, die unter einen Begriff anhand des gemeinsamen Merkmals fallen und die damit durch ihn gedacht werden können. Der Inhalt betrifft die Funktion eines Begriffes als Erkenntnisgrund eines Gegenstandes und besteht in der Menge von Merkmalen, die im Begriff enthalten sind und durch welche der Gegenstand erkannt wird. Umfang und Inhalt stehen in einem umgekehrten Verhältnis der Wechselwirkung: Umso genauer ein Begriff durch anschaulichen Inhalt spezifiziert ist, umso geringer ist die Menge der Gegenstände, die durch ihn vorgestellt werden kann (vgl. Logik, AA 9: 9596).4 Dies bedeutet, dass Gedanken ohne Inhalt Begriffen entsprechen, deren Umfang durch keinen sinnlichen Inhalt bestimmt wird, weil kein wirkliches Prädikat als gemeinsames Merkmal einer Klasse von Gegenständen gegeben wird. Ein leerer Begriff enthält kein einziges Merkmal, das die unter ihm vorgestellten Gegenstände gemeinsam haben können. Der Umfang leerer Begriffe ist also so allgemein, dass keine wirklichen Gegenstände unter ihnen fallen können.

»Anschauungen ohne Begriffe sind blind « — Ihnen fehlt der Bezug zum Gegenstand, weil sie eine bloße Modifikation des Gemüts sind. Im Rahmen der bloßen Sinnlichkeit wird kein Gegenstand erkannt, weil er nur als kausale Ursache der sinnlichen Affizierung bestimmt wird. Das Mannigfaltige der Anschauung bildet den Inhalt der Erkenntnis, verstanden als das sinnliche Merkmal eines möglichen Gegenstandes, der durch die kategoriale Synthesis auf ein Objekt oder eine Klasse von Objekten als deren Erkenntnisgrund bezogen wird. Die Bezugnahme einer Anschauung auf die objektive Vorstellung einer Klasse von Gegenständen wird durch ein Urteil vollzogen, in dem das sinnliche Merkmal eines möglichen Gegenstandes an der Prädikatstelle auf einen allgemeinen Begriff an der Subjektstelle bezogen wird, der mehrere Vorstellungen anhand desselben

\footnotetext{
4 Das Prädikat qua gemeinsames Merkmal einer Klasse von Gegenständen kann von der Sinnlichkeit unmittelbar gegeben werden oder in der Form eines Begriffes verallgemeinert sein. In beiden Fällen wird der sinnliche Bezug zum Gegenstand vorausgesetzt: »Da keine Vorstellung unmittelbar auf den Gegenstand geht, als bloße die Anschauung, so wird ein Begriff niemals auf einen Gegenstand unmittelbar, sondern auf irgend eine andre Vorstellung von demselben (sie sei Anschauung oder selbst schon Begriff) bezogen« $(K r V$, B93). Zum Zweck der Untersuchung des Vermögensdualismus wird hier der Fall untersucht, in dem das Merkmal unmittelbar gegeben wird.
} 
Merkmals in sich vereint (vgl. $\mathrm{KrV}$, B93-94). Blinde Anschauungen stellen also sinnliche Inhalte dar, die keinen Umfang aufweisen, weil sie ihre Funktion als Erkenntnisgrund einer Gegenstandklasse nicht erfüllen können.

\section{Fazit}

Es wurden eine konzeptualistische und eine nicht-konzeptualistische Interpretation der Kooperationsthese verglichen und in den Kontext des transzendentalen Erkenntnismodells gebracht. McDowells Auffassung des kantischen Vermögensdualismus steht im Widerspruch zu dem in der Kritik der reinen Vernunft unternommenen Isolationsverfahren und $\mathrm{zu}$ der wesensspezifischen Verschiedenheit der zwei menschlichen Vorstellungsarten, die in der „Transzendentalen Ästhetik“ erläutert wird. Hannas Deutung bewahrt die Irreduzibilität und die Isolierbarkeit der zwei Grundvermögen der Erkenntnis, allerdings stellt sie die transzendentale Funktion des Verstandes als Bedingung der Möglichkeit aller Erfahrungsobjekte in Frage.

Der Vorteil der am Ende des Vortrags vorgeschlagenen Interpretation der Kooperationsthese besteht darin, dass die Notwendigkeit der Wechselwirkung der zwei Grundvermögen zum Zweck der Erkenntnis behauptet wird, ohne dass deren Irreduzibilität in Frage gestellt wird. Die Sinnlichkeit und der Verstand erfüllen eine spezifische epistemische Funktion: Während die Anschauungen den Inhalt der begrifflichen Erkenntnis ausmachen, indem sie sinnliche Prädikate möglicher Gegenstände liefern, bilden die vom Verstand spontan erzeugten Begriffe die Form der Erkenntnis, indem sie den sinnlich gegebenen Inhalt auf eine Gegenstandsklasse beziehen und ihn damit einen Umfang verleihen. Eine solche Deutung der Kooperationsthese lässt zu, dass sowohl der Verstand als auch die Sinnlichkeit ihre eigenen apriorischen Formen haben, da die von den Kategorien hervorgebrachte gegenständliche Einheit nicht die räumliche und zeitliche Einheit der Anschauung betrifft. Die von der Sinnlichkeit und vom Verstand hervorgebrachten Erkenntnisanteile stehen schließlich nicht im Widerspruch zu Kants Isolierbarkeitsthese, da das Mannigfaltige der Anschauung und der Gedanke eines Gegenstandes überhaupt jeweils als Inhalts- und formstiftende Elemente einer Erkenntnis einzeln vorgestellt werden können. 


\section{Literaturverzeichnis}

HANNA, R.: "Kant and Nonconceptual Content", European Journal of Philosophy 13, 2 (2005) 247-290.

: "Kant's Non-Conceptualism, Rogue Objects, and the Gap in the B-Deduction”, International Journal of Philosophical Studies 19, 3 (2011) 399-415.

KANT, I.: Gesammelte Schriften, Bd. 1-22, Preussische Akademie der Wissenschaften, 23, Deutsche Akademie der Wissenschaften zu Berlin, 2429, Berlin, Akademie der Wissenschaften zu Göttingen, 1900ff.

MCDOWELL, J.: Mind and World. With a New Introduction by the Author, Cambridge, MA/London, Harvard University Press, 1996 (3 ed.).

: Having the World in View. Essays on Kant, Hegel, and Sellars, Cambridge, MA/London, Harvard University Press, 2009.

SELLARS, W.: Empiricism and the Philosophy of Mind, Cambridge, MA/London, Harvard University Press, 1997. 


\title{
Geist im sinnlichen. Eine Deutung der transzendentalen Ideen im Ausgang von Kants Anthropologie
}

\author{
MARGIT RUFFING 1
}

\begin{abstract}
Inhaltsangabe
Kant verwendet ,Geist‘ im Kontext metaphysischer Reflexion sehr vorsichtig, um sich von überschwänglicher Spekulation abzugrenzen. Dennoch macht die Definition von „Geist in ästhetischer Bedeutung“ als „das belebende Princip im Gemüthe“ (KU, AA 05: 313) deutlich, dass es zum einen eine Bedeutung gibt, die vom Ästhetischen, d.h. der Sinnlichkeit, ausgeht, zum anderen eine Verwandtschaft mit der Seele besteht, die Kant in der Anthropologie in pragmatischer Hinsicht metaphorisch als Organ des inneren Sinnes bezeichnet. ,Geist" steht für das rein Vernünftige des physischen Menschen, das sich durch das und am Sinnlichen zeigt. Wie sich das ausdrückt, soll die Analyse des Vernunftbegriffes, Geist` zeigen.
\end{abstract}

Schlüsselwörter: Geist, Seele, Sinnlichkeit, Vernunftbegriff

\section{Espíritu sensorial. Una interpretación de las ideas transcendentales al final de la antropología kantiana}

\begin{abstract}
Resumen
Kant usa el término 'espíritu' en el contexto de la reflexión metafísica de forma muy cautelosa para poder contraponerse a la especulación exacervada. No obstante, la definición de "espíritu en sentido estético" como "el principio vivificador del ánimo" ( $K U$, AA 05: 313) evidencia que existe un significado que, por un lado, parte de lo estético, es decir, de la sensibilidad y, por otro, tiene un paretesco con el alma, la cual es descrita por Kant metafóricamente en la Antropología en sentido pragmático como el órgano del sentido interno. 'Espíritu' quiere decir lo puramente racional del hombre físico, que se muestra mediante y en lo sensible. Cómo esto se manifiesta, es lo que debe mostrar el análisis de concpeto racional de 'espíritu'.
\end{abstract}

Palabras clave: espíritu, alma, sensibilidad, concepto de razón

1 Johannes Gutenberg-Universität Mainz. Kontakt: mruffing@uni-mainz.de. 
Ende 2018 ist unter dem Titel Die Aktualität des Geistes ein Sammelband erschienen, der, so der Untertitel, „Klassische Positionen nach Kant“" vorstellt (vgl. Noller; Zwenger 2018: 9-11): ,Ausgangspunkt der Beiträge“, die sich mit dem Begriff des Geistes bei Denkern der klassischen deutschen Philosophie wie Schelling und Hegel, aber auch Jacobi und Hölderlin über Humboldt, Nietzsche, Cassirer und Simmel bis zu Adorno befassen, soll Kants Philosophie sein, in dessen Werk der Begriff des Geistes allerdings »keine zentrale systematische Rolle ein[nimmt]《 (Noller; Zwenger 2018: 10f.), wie die Herausgeber Jörg Noller und Thomas Zwenger in ihrer „Einführung“ einräumen. Die im gleichen Kontext gelieferte Begründung leuchtet zwar ein — von Kant werde die »problematische Vieldeutigkeit des Wortes ,Geist', ebenso wie die Tendenz, den Geist zu verflüchtigen oder zu etwas Dinglichem zu reduzieren [verhandelt]« (vgl. Noller; Zwenger 2018: 11). Unter Erwähnung der kritischen Begriffsverwendung in den Träumen eines Geistersehers und der »lebensweltlichen« Interpretation des »Phänomen[s] Geist « in der Anthropologie in pragmatischer Hinsicht weisen die Herausgeber darauf hin, dass hier ein Geistbegriff entworfen wurde, der ein »interessiert[es] und belebt[es]« Verhältnis des Menschen zur Welt charakterisiert, und der geeignet ist, von nachkantischen Denkern differenziert, analysiert und in ein philosophisches System integriert $\mathrm{zu}$ werden (vgl. Noller; Zwenger 2018: 11). Der Band wird dann auch mit Thomas Zwengers Beitrag eröffnet, der — schon im Titel — die Frage nach dem »Geist als Grundbegriff einer kritischen Philosophie?« stellt, durch »Überlegungen zu Kants Vernunftverständnis« beantwortet werden soll (Zwenger 2018: 12). Langer Überlegungen zu Kants Philosophiebegriff kurzer Sinn: ,Geist' wird ausschließlich als Bestandteil des menschlichen Gemüts, als zufällige »Eigenschaft des konkreten, empirischen menschlichen Vernunftwesens « aufgefasst und kann daher »nicht in die kantische Transzendentalphilosophie gehören« (2018: 31). Mit dieser Einschätzung wird der Geistbegriff bei Kant auf das Empirische festgelegt; warum er dann eine solch ausgezeichnete Bedeutung für nachkantische Denker erlangen konnte, wird aus dem Fazit dieses Beitrags nicht klar, auch wenn ihm insofern zuzustimmen ist, als ,Geist' selbst in Kants Spätwerk und das heißt nicht nur in der Anthropologie, sondern auch im Opus postumum - nicht als philosophischer Strukturbegriff der Transzendentalphilosophie bedeutsam geworden ist. 
Doch die Analyse der Verwendung des Begriffes ,Geist' in Kants Gesamtwerk zeigt, dass ihre Vielseitigkeit nicht nur die Polysemie des Begriffes in der deutschen Sprache ausschöpft, sondern eine für das kantische Denken spezifische Bedeutung und Bedeutsamkeit erhält: Der Geistbegriff belegt und erläutert das Lebendigsein der Vernunft, die Art und Weise, wie sie sich in der sinnlichen Welt von uns Vernunftwesen erfahren lässt. Und damit geht es um eine wesentliche Ergänzung innerhalb des Interpretationsspektrums des kantischen Vernunftbegriffes - ganz im Sinne der Herausgeber des erwähnten Sammelbandes, und auch dem Thema des IV. Kongresses der SEKLE gemäß, das der Aktualität der reinen Vernunft gewidmet ist.

Es soll im Folgenden gezeigt werden, dass der Begriff ,Geist ${ }^{\star}$ bei Kant immer dort Verwendung findet, wo es darum geht, das Zusammenwirken von Denken (des Verstandes und der Vernunft) und Sinnlichkeit zum Ausdruck zu bringen, wo ein dynamisches und belebendes Tätigsein der Erkenntnis ermöglichenden Gemütsvermögen vorkommt; ein Zusammenwirken, das nicht in der naturgesetzlichen Erklärung, auch nicht in den philosophischen Termini zur Beschreibung von Bewusstsein aufgeht. Die Gründe für ein solches inneres Geschehen im Gemüt liegen nach Kant in der praktischen Vernunft und können hier nicht weiter vertieft werden. Es ist diese geistige Gemütsverfassung selbst, die uns interessiert: Sie ist nicht nur eine der Bedingungen theoretischer Reflexion, die zu einem Urteil führt, sondern auch Gegenstand einer Philosophie der Moral. Der Sache nach gehört sie insofern zu einer philosophischen Anthropologie, als wir Begriffe wie ,Geist“ (und ,Seele') brauchen, um uns als Vernunftwesen zu verstehen.

Eine Umschreibung der ,geistigen Gemütsverfassung ' findet sich in einem Brief an Marcus Herz (gg. Ende 1773), in dem Kant sich über den Grund der Moralität äußert. Aus dem, was er schreibt, lässt sich schließen, dass er grundsätzlich die Möglichkeit ,intellectualer' Vorstellungen annimmt, die an sich selbst,wohlgefallen', ,Bewegkraft haben' und unmittelbar mit den ,Triebfedern des Willens` in Beziehung stehen. Es heißt hier:

Es kan aber ein bloßer reiner Verstandesbegrif die Gesetze oder Vorschriften desjenigen was lediglich sinnlich ist nicht angeben weil er in Ansehung dieses vollig unbestimmt ist. Der oberste Grund der Moralität muß nicht blos auf das 


\begin{abstract}
Wohlgefallen schließen lassen er muß selbst im höchsten Grade wohlgefallen den er ist keine blos spekulative Vorstellung sondern muß Bewegkraft haben und daher ob er zwar intellectual ist so muß er doch eine gerade Beziehung auf die erste Triebfedern des Willens haben (Br, AA 09: 145, 9-16).
\end{abstract}

Wir finden bei Kant außer dem hier gemeinten Gefühl der Achtung (für das moralische Gesetz der Vernunft) auch anderenorts Annahmen solcher Vorstellungen, die ,wohl gefallen' und Bewegkraft haben: Es gibt gefühlsartige Erfahrungen eigentlicher ,Humanität', die das SelbstVerständnis, also auch erkenntnishaftes Bewusstsein, fördern. In der Kritik der Urteilskraft gibt es solche Vorstellungen bekanntermaßen: den Genius, das Genie betreffend, aber auch im Kontext des Gefühls des Erhabenen. In der Anthropologie in pragmatischer Hinsicht begegnen wir dem ,Geistesgenuß' (Anth, AA 07: 157). Bevor mit Bezugnahme auf die genannten Schriften der Aspekt des ,bewegenden“ und unmittelbar im Gemüt wirkenden Geistes schwerpunktmäßig behandelt wird, sollen einige kurze Ausführungen $\mathrm{zu}$ Kants Verwendung des Geistbegriffs aus vorkritischer Zeit und Vorlesungsnotate vorgestellt werden, die das Bedeutungsspektrum des Begriffes und seinen Bedeutungswandel aufzeigen. Anfangs noch die traditionelle Bedeutung des Begriffes ,Geist ${ }^{\star} /$,Geister ${ }^{6}$ kritisch analysierend, verleiht Kant ihm im Laufe der Entwicklung der Transzendentalphilosophie eine spezifische Bedeutung, die sich am deutlichsten im Spätwerk und Opus postumum zeigt, wo vom ,Geist des Menschen`die Rede ist.

\title{
1. Kants vorkritischer Geist-Begriff
}

In den Träumen eines Geistersehers fragt Kant, mit deutlich metaphysikkritischem Unterton, »ob es Geister gebe« und stellt fest, dass er ja noch nicht einmal wisse, »was das Wort Geist bedeute «. Er geht nun daran, die »versteckte Bedeutung « des Begriffes »auszuwickeln«, indem er den »schlecht verstandenen Begriff«, den er »selbst oft gebraucht [...] oder andere [hat] brauchen hören«, »an allerlei Fälle der Anwendung « prüft (TS, AA 02: 320). Das Ergebnis der Untersuchung (vgl. TS, AA 02: 350ff.) ist bekannt: »[A]lle Theorien von der muthmaßlichen Natur geistiger Wesen und ihrer Verknüpfung mit uns « sind gegenstandslos, im wahrsten Sinne des Wortes, weil sie kein Objekt haben, über das man etwas wissen kann. Dass 
es überhaupt zu der »Vernunftidee von Geistern« (TS, AA 02: 350) und einer philosophischen Lehre darüber gekommen ist, erklärt Kant aus der Hoffnung, »daß man noch auf irgend eine Art nach dem Tode übrig sei« (TS, AA 02: 350). Die Frage, »wie eine immaterielle Natur in einem Körper und durch denselben wirksam sei« (TS, AA 02: 350f.), hat ihren Platz auch in metaphysischen Theorien über die Seele, wird aber nicht beantwortet. Geister lassen sich nicht nachweisen, ihre Existenz ist nicht widerspruchsfrei denkbar und schon gar nicht sinnlich erfahrbar. Kant schließt seine Untersuchung mit der Feststellung ab, dass sich nun aufgrund seiner Analyse die philosophische Einsicht ergeben habe, dass es keine Geisterlehre als Teilbereich von Metaphysik geben kann, weil erwiesen ist, dass man über sie nichts wissen, sondern bestenfalls meinen kann. Kant kommentiert den »philosophischen Lehrbegriff von geistigen Wesen « auf eine Weise, die auch die Ergebnisse der Kritik der reinen Vernunft kennzeichnet: Es handelt sich nämlich um einen negativen Begriff, der , vollendet', d.h. vollständig durchdacht werden kann, indem er

\footnotetext{
die Grenzen unserer Einsicht mit Sicherheit festsetzt und uns überzeugt: daß die verschiedene Erscheinungen des Lebens in der Natur und deren Gesetze alles seien, was uns zu erkennen vergönnt ist, das Principium dieses Lebens aber, d.i. die geistige Natur, welche man nicht kennt, sondern vermuthet, niemals positiv könne gedacht werden, weil keine data hiezu in unseren gesammten Empfindungen anzutreffen seien, und daß man sich mit Verneinungen behelfen müsse, um etwas von allem Sinnlichen so sehr Unterschiedenes zu denken, daß aber selbst die Möglichkeit solcher Verneinungen weder auf Erfahrung, noch auf Schlüssen, sondern auf einer Erdichtung beruhe, zu der eine von allen Hülfsmitteln entblößte Vernunft ihre Zuflucht nimmt (TS, AA 02: 351f.).
}

Die Analyse des falschen Gebrauchs zeigt zwar schon, dass es sich bei der geistigen Natur um ein Lebensprinzip handelt; man kann sie aber nicht erkennen, weil zu Erkenntnis Empfindungsdata, also Erfahrung, erforderlich sind. Es bleibt also nur die Funktion der Verneinung, »um etwas von allem Sinnlichen so sehr Unterschiedenes zu denken«, das man als ein »nichtmaterielles Vernunftwesen« bezeichnen könnte.

Kants frühe Auseinandersetzung mit dem traditionellen philosophischen Lehrbegriff ,Geist ${ }^{\star}$ geht in seine Metaphysik-Vorlesungen ein, und findet dort verschiedentlich Erwähnung, z.B. bei Herder (1762- 
1764) als Exempel für das ,intellectuelle Dichtungsvermögen“, dem in der Philosophie und Mathematik willkürliche Definitionen und Hypothesen geschuldet seien: »Geist, ist kein Erfahrungs- auch kein abstrahirter Begriff «(V-Met/Herder, AA 28: 70).

Im Abschnitt über Rationale Psychologie der Metaphysik-Vorlesung L1 (Mitte der 1770-er) führt Kant mit seinen Studenten offensichtlich ein Gedankenspiel durch, das den philosophischen Lehrbegriff des Geistes im Unterschied zu tierischen und menschlichen Seelen didaktisch verwendet, um vor Hirngespinsten zu warnen. Kurz das Ergebnis: »[D]enkende vernünftige Wesen, mit Bewußtseyn ihrer selbst, die immateriell sind « können problematisch angenommen, aber nicht apodiktisch bewiesen werden. Und: »Sie [geistige Wesen] sind kein Gegenstand des äußern Sinnes; also sind sie nicht im Raume. Weiter können wir hier nichts sagen; sonst verfallen wir in Hirngespinste. Der Begriff von thierischen Seelen und von höhern Geistern ist nur ein Spiel unserer Begriffe« (V-Met-L1/Pölitz, AA 28: 223). Es sind zweifelsohne Wesen vorstellbar, die lediglich einen äußeren Sinn haben, das bestätigt auch die Erfahrung - Kant nennt sie tierische Seelen. Wesen, die ausschließlich einen inneren Sinn haben würden, lassen sich zwar auch vorstellen, aber es bleibt bei philosophisch und psychologisch unbrauchbarer Spekulation jenseits aller Erfahrung. Der Abschnitt endet mit der Feststellung: »Wenn wir uns Wesen vorstellen, die sowohl einen innern als äußern Sinn haben; so sind das menschliche Seelen $\ll(V-M e t-L 1 / P o ̈ l i t z$, AA 28: 223).2

\section{2. ,Geist' in den Kritiken}

Es versteht sich von selbst, dass ein solcher Begriff des Geistigen, des Geistes, geistiger Wesen der bestehenden Lehren, von einer an ihre Grenzen geratenen, hilflosen Vernunft spekulativ bis zum Wahn überhöht, für die kritische Philosophie unbrauchbar ist. Einen anders definierten

\footnotetext{
2 Der Begriff der Seele steht demnach für das Geistige am Menschen, dessen Natur die Freiheit ist: Der nächste Abschnitt dieser Vorlesungsnachschrift behandelt dann das, was man über die menschliche Seele problematisch äußern kann, wobei der ,commercio' mit dem Körper gegeben ist, und der letzte Abschnitt beweist die Unsterblichkeit der Seele aus der Freiheit: »Wenn wir nun aus der Nothwendigkeit dieses göttlichen Wesens auf die Unsterblichkeit der Seele schließen wollen, so können wir a priori aus der göttlichen Natur solches nicht erkennen; denn sonst müßte die Seele ein Theil der göttlichen Natur seyn. Wenn ich es also aus der Natur des Wesens der Seele nicht erkennen kann, was bleibt dann übrig? Antwort: Freiheit; denn Natur und Freiheit sind nur das, was an einem Wesen erkannt werden kann«(V-Met-L1/Pölitz, AA 28: 238).
} 
,theoretischen' Sinn legt Kant dem Geistbegriff noch nicht bei, er verwendet ihn bestenfalls dem populären Verständnis gemäß als Synonym des von ihm bevorzugten Begriffs ,Denkungsart'. Folgerichtig taucht ,Geist ${ }^{6}$ in der Kritik der reinen Vernunft auch nur marginal in der Vorrede und in zwei Fußnoten auf.3

In der Kritik der praktischen Vernunft spricht Kant in Bezug auf den »obersten Grund der Moralität«, dem er im Brief an Herz von 1773 im Gegensatz zu bloßen Verstandesbegriffen »Bewegkraft« zuspricht, vom »Geist des Gesetzes« selbst. Diesen setzt er hier mit der »unmittelbaren« Vorstellung des Gesetzes gleich, als der einzigen Vorstellungsart, die eine moralische Gesinnung bewirken kann (vgl. $K p V$, AA 04: 151f.). Dazu findet sich eine vergleichbare Stelle aus der Religionsschrift, wo Kant das Befolgen des Gesetzes dem Geiste nach von dem »dem Buchstaben nach « unterscheidet und definiert: »[D]er Geist des moralischen Gesetzes besteht darin, daß dieses für sich allein zur Triebfeder hinreichend sei« $(R G V$, AA 06: 30). Diese Verwendung des Begriffes ,Geist ${ }^{\star}$ — nur noch im Singular - rekurriert nun offensichtlich auf eine andere Bedeutung, der zufolge (auch noch dem heutigen allgem. Sprachgebrauch entsprechend) Geist für das Rationale, das denkende, erkennende Bewusstsein steht, im Unterschied zur empfindenden Seele. Es kommt aber noch ein Bedeutungsmoment hinzu, das als metaphorisch gelten kann: Denn der Geist des Gesetzes als dessen unmittelbare Vorstellung ist ja offensichtlich etwas anderes als der bloße Begriff des Gesetzes, den man auch haben kann, ohne die Wirkkraft dieser Vorstellung zu erfahren.

Auch wenn Kant unter ,Geist' hier das verstehen würde, was als Definition nach seiner kritischen Analyse des Lehrbegriffs metaphysischer Theorien als Definition übriggeblieben ist, müsste der Terminus ,Geist des Gesetzes' metaphorisch aufgefasst werden. Denn das Moralgesetz ist keins der »denkende[n] vernünftige[n] Wesen mit Bewußtseyn ihrer selbst, die immateriell sind «(V-Met-L1/Pölitz, AA 28: 222), sondern das einzige als unbedingt vorgestellte Faktum der Vernunft des Menschen, der wiederum ein an seinen Körper gebundenes, denkendes vernünftiges Wesen mit Bewusstsein seiner selbst ${ }^{\star}$ ist.4 — Auch ohne die Interpretation der

3 In den Vorreden der ersten und zweiten Auflage der Kritik der reinen Vernunft (vgl. A22, Fn./B43) und einer Fußnote B504.

4 Der Geist des Gesetzes kann andererseits vor dem Hintergrund der Postulatenlehre der 2. Kritik und der Religionsschrift als der Moralgesetz-gebende Gott gedeutet werden, der Kant zufolge 
spärlichen Stellen zu übertreiben, lässt sich feststellen, dass die theoretischen Begriffe der spekulativen Vernunft nicht mehr zureichen in der Beschreibung einer reinen Philosophie der praktischen Vernunft. Die Durchführung einer potentiell auch anwendbaren Moralphilosophie aus apriorischen Prinzipien erfordert Begriffe, die etwas verständlich machen, was in der Spannung zwischen dem Gebiet des Sinnlichen und dem des Übersinnlichen mit jeweils spezifischen Gesetzen paradox klingt (beispielsweise: Nötigung aus Freiheit). Das könnte auch ein Grund dafür sein, dass Kant im Bereich der praktischen Philosophie mehrfach auf Metaphern zurückgreift — wie ,Stimme der Vernunft' oder ,Gerichtshof des Gewissens ‘ - um den Lesern in Analogie zu sinnlicher Erfahrung den immateriellen Geist des Moralgesetzes näher zu bringen, dessen Wirkung und Bewegkraft als möglich und sogar wirklich angenommen werden muss, aber nicht erklärt und begriffen werden kann.

Wenden wir uns nun der der dritten Kritik zu, deren Aufgabe Kant explizit darin sieht, dazu beizutragen, die »Kluft zwischen dem Gebiete des Naturbegriffs, als dem Sinnlichen, und dem Gebiete des Freiheitsbegriffs, als dem Übersinnlichen« ( $K U$, AA 05: 176) zu überwinden, indem sie »den Übergang von der Denkungsart nach den Principien der einen zu der nach Principien der anderen möglich macht« (ebd.). Wir haben es hier, wo es explizit darum geht, die Vernunft in ihrer systematischen Einheit zu begreifen, wieder mit theoretischer Philosophie zu tun. Es ist die Kritik der Urteilskraft, in der der Begriff ,Geist' am häufigsten vorkommt. Ich habe die relevanten Passagen zusammengestellt und kommentiere sie kurz.

Im $\S 43$ „Von der Kunst überhaupt“ (KU, AA 05: 304) ist von den ,freien Künsten“ die Rede, Kant erläutert hier den Unterschied von Kunst und Kunsthandwerk, freiem und auftragsgebundenem Schaffen von Kunstprodukten. Er stellt abschließend fest, »[d]aß aber in allen freien Künsten dennoch etwas Zwangsmäßiges, oder, wie man es nennt, ein Mechanismus erforderlich sei«. Andernfalls nämlich würde der ,Geist', der das Kunstwerk belebt und dazu auch »in der Kunst frei sein muß«, »gar keinen Körper haben und gänzlich verdunsten« ( $K U$, AA 05: 304). Als ,Zwangsmäßiges` oder Mechanismus, der dem Geist Körper gibt und ihn daran hindert, sich zu verflüchtigen, nennt Kant für die Dichtkunst bspw.

vernünftigerweise als einziges ,denkendes vernünftiges Wesen mit Bewusstsein seiner selbst, das immateriell ist" angenommen werden kann. 
Sprachrichtigkeit, Sprachreichtum, Vers- und Silbenmaß, also die Form der Gestaltung betreffende Talente und Regeln. Kant erklärt in $\S 43$, also noch vor der Präsentation der Theorie der ästhetischen Idee und des Genies, dass zum Kunstwerk auch Kunstfertigkeit gehört. Es können Gestaltungsregeln erlernt werden, um das Kunstwerk zur Darstellung zu bringen. So wird am Kunstwerk dem Geist ein ,Körper' geschaffen, in dem er bleiben kann. Die metaphorische Ausdrucksweise scheint in diesem Zusammenhang auch dem Bedürfnis geschuldet, sich einem Publikum verständlich zu machen, das schon bestimmte Auffassungen über Kunst hat und Begriffe verwendet Geist —, ohne sich der eigentlichen, der philosophischen, Bedeutung der Sache bewusst zu sein.

Das lässt auch der Anfang des $§ 49$ über die Gemütsvermögen des Genies vermuten; er beginnt mit: »Man sagt«: Hier greift Kant ganz eindeutig den im zeitgenössischen Diskurs über Kunst üblichen Gebrauch des Geistbegriffes auf und nennt einige Beispiele für »gewisse[.] Producte[.], von welchen man erwartet, daß sie sich, zum Theil wenigstens, als schöne Kunst zeigen sollten« (KU, AA 05: 313) - es aber nicht tun, weshalb man von ihnen sage, dass sie ,ohne Geist' seien. Alle erwähnten ,Producte' ohne Geist haben etwas mit der Verwendung der Sprache, d.h. dem sprachlichen Ausdruck einer poetischen Kunstform (Gedicht, Geschichte, feierliche Rede) oder auch nur Konversation, zu tun. Als letztes nennt Kant dann noch die seinerzeit wohl nicht unübliche Beurteilung eines ,Frauenzimmers' als eines gefälligen Wesens ,ohne Geist'. Es folgt auf diese populäre Einführung Kants bekannte Definition von Geist, die erklärt, was es denn ist, was man an manchem sog. ,Kunstwerk' vermisst:

Geist in ästhetischer Bedeutung heißt das belebende Princip im Gemüthe. Dasjenige aber, wodurch dieses Princip die Seele belebt, der Stoff, den es dazu anwendet, ist das, was die Gemüthskräfte zweckmäßig in Schwung versetzt, d.i. in ein solches Spiel, welches sich von selbst erhält und selbst die Kräfte dazu stärkt (KU, AA 05: 313).

Es handelt sich also auch in ästhetischer Bedeutung um eine immaterielle Bewegkraft, ein das Lebendige, Belebende, Bewegende betreffende Prinzip. Im Falle der Erfahrung von Schönheit kommt noch ein ,Stoff' dazu, und die sozusagen ,energetisch neutrale', sich selbst erhaltende 
Bewegung wird als schwungvolles Spiel der Gemütskräfte beschrieben. Das belebende Prinzip ist hier allerdings keine ,unmittelbare Vorstellung' (wie die des Moralgesetzes), sondern ein Vermögen, ein Können - die Kunst , Vorstellungen darzustellen, die unmittelbar wirken. Es sind besondere Vorstellungen der Einbildungskraft, die Kant ,ästhetische Ideen' nennt. Eine solche ästhetische Idee ist dadurch ausgezeichnet, dass sie »viel zu denken veranlaßt, ohne daß ihr doch irgend ein bestimmter Gedanke, d.i. Begriff, adäquat sein kann, die folglich keine Sprache völlig erreicht und verständlich machen kann« (KU, AA 05: 314). Es sind also Vorstellungen, die das intellektuelle Vermögen des Menschen berühren und anregen, sich aber sprachlich nicht als ,Gedanke' ausdrücken lassen, d.h. nicht in einem Begriff aufgehen, sondern etwas über ihn hinaus, ohne sprachliche Entsprechung, vermitteln. Denken und innerlich Anschauen (Einbildung) sind bei der Belebung der Seele durch Geist beteiligt. Eine besonders gelungene ,Vereinigung' von Verstand und Einbildungskraft in der Darstellung der ästhetischen Idee durch den Künstler bewirkt Schönheit am Produkt und verleiht damit auch diesem Geist, der wiederum die Gemütskräfte des Betrachters — dessen Verstand und Einbildungskraft in Schwung und zum freien Spiel bringt. Das ist es, was Kant ,Genie“ nennt; das Besondere daran ist die Weise, wie in der ästhetischen Idee Vorstellungen der Einbildungskraft und Begriff in der Darstellung zusammenkommen, indem nämlich ohne Begriff zum Begriff hinzu ,gedacht', zugleich aber auch gefühlt wird. Das eigentlich Belebende ist dieses Gefühl, das zwar mit einem sprachlichen Ausdruck verbunden, aber durch diesen nicht adäquat und vollständig wiedergegeben werden kann:

[D]ie ästhetische Idee ist eine einem gegebenen Begriffe beigesellte Vorstellung der Einbildungskraft, welche mit einer solchen Mannigfaltigkeit der Theilvorstellungen in dem freien Gebrauche derselben verbunden ist, daß für sie kein Ausdruck, der einen bestimmten Begriff bezeichnet, gefunden werden kann, die also zu einem Begriffe viel Unnennbares hinzu denken läßt, dessen Gefühl die Erkenntniß-vermögen belebt und mit der Sprache, als bloßem Buchstaben, Geist verbindet ( $K U, \mathrm{AA} 05: 316)$.

Der Mannigfaltigkeit des (sinnlich) Gegebenen, die Kant im Kontext der theoretischen Erkenntnis thematisiert, entspricht hier eine Mannigfaltigkeit von Teilvorstellungen einer Idee, die sich auf einen 
,gegebenen Begriff' bezieht, aber nicht zum Erkenntnis mit Hilfe eines allgemeineren synthetisiert werden muss. Die Einbildungskraft macht vielmehr freien Gebrauch von diesen Teilvorstellungen, sie ist also spontan tätig, nicht rezeptiv, wodurch die ästhetische, einem Begriff beigesellte Idee zu diesem »viel Unnennbares hinzu denken läßt« (KU, AA 05: 314). Das Unnennbare ist nicht nur etwas zufällig Begriffloses oder subjektiv Unbegriffenes, sondern prinzipiell Unbegreifliches, nämlich ein Gefühl: ein die Erkenntnisvermögen belebendes Gefühl, das in den bloßen ,Buchstaben des sprachlichen Ausdrucks ,Geist' hineinbringt. Wenig später bezeichnet Kant das Vermögen des Genies selbst als Geist, wenn er sagt, dass »[z]ur schönen Kunst [...] Einbildungskraft, Verstand, Geist und Geschmack erforderlich sein [würden] «, in einer Fußnote ergänzt er: »Die drei ersteren Vermögen bekommen durch das vierte allererst ihre Vereinigung « $(K U, \mathrm{AA}$ 05: 320). Geschmack wird, neben der Urteilskraft im Allgemeinen, als »Disciplin (oder Zucht) des Genies « beschrieben, damit die gesetzlose Freiheit der Einbildungskraft, die ohne Anleitung nur »Unsinn« hervorbringen würde, durch die Urteilskraft dem Verstand (und dessen Gesetzmäßigkeit) angepasst wird. Bei allem Ideenreichtum und größter Originalität darf die Zweckmäßigkeit in der Darstellung einer ästhetischen Idee nicht verlorengehen (vgl. ebd.).

Zwei weitere Stellen aus der Kritik der Urteilskraft bringen die Nähe des wesentlich immateriellen und intellektuellen Charakters dessen, was Geist bezeichnet, zu Gefühl und Lust, d.h. wesentlichen Momenten der Sinnlichkeit, zum Ausdruck.

Zum ersten Mal ist in der 3. Kritik im $\S 42$ von ,Geist' an der Stelle die Rede, wo Kant »Vom intellectuellen Interesse am Schönen« $(K U$, AA 05: 298ff.) handelt. Interesse hat der Mensch zunächst im Ausgang von seinen Neigungen und Triebfedern, es gehört zu seiner sinnlichen Natur, Interesse(n) zu haben. Das einzige moralische Interesse (Kant fügt hinzu: sogenannte moralische Interesse), das der Mensch nicht als natürlichen Antrieb hat, sondern nehmen muss, ist das der Achtung fürs Gesetz. Nun gibt es aber auch ein ,intellektuelles Interesse', das so bezeichnet wird, weil es zwar einerseits ein unmittelbares, sinnlich basiertes Interesse ist, aber andererseits mit der »Denkungsart aller Menschen überein[stimmt], die ihr sittliches Gefühl cultivirt haben« (KU, AA 05: 299). Es hat demnach eine sinnliche Grundlage, ein Gefühl, das aber kultiviert, d.h. bewusst gepflegt 
ist, und mit der Achtung für das Vernünftig-Moralische einhergeht. Wenn nun ein Mensch mit solcher Denkungsart zudem Geschmack hat, d.h. das Vermögen über Kunstwerke zu urteilen, wird er, so Kant, die Naturschönheit der Kunstschönheit vorziehen. Der Grund: Im Schönen der Natur findet er »gleichsam Wollust für seinen Geist in einem Gedankengange [...], den er sich nie völlig entwickeln kann» (KU, AA 05: 300). Mit anderen Worten: Er genießt seinen eigenen Geist, seine vernünftige, freie Denkungsart, in einem von der ästhetischen Idee der Natur selbst bewirkten Denken, das sich grundsätzlich im Begriff nicht erschöpft; diese Idee ist die Zweckmäßigkeit der Natur. Hier kommt ein neuer Aspekt von Geist hinzu: der menschliche Geist, der sich in Betrachtung der Naturschönheit selbst fühlt und genießt.

Die zweite Textstelle enthält einen Begriff, der, soweit ich es herausfinden konnte, in Kants Schriften (die Vorlesungsnachschriften eingeschlossen) nur ein einziges Mal vorkommt: das »Geistesgefühl« ( $K U$, AA 05: 192). Er soll aber nicht übergangen werden, denn er findet sich an einer zentralen Stelle der Einleitung, in dem langen, letzten Satz des VI. Abschnitts, in dem begründet wird, warum die „Kritik der ästhetischen Urteilskraft" in zwei Teilen entwickelt werden muss: Das ästhetische Urteil ist nicht nur ein Geschmacksurteil über das Schöne, sondern auch ein Urteil, das »als aus einem Geistesgefühl entsprungenes, auf das Erhabene bezogen wird« (KU, AA 05: 192). Der entscheidende Unterschied zum Geschmacksurteil ist der, dass »die Empfänglichkeit einer Lust aus der Reflexion über die Formen « von Kunst- oder Naturdingen nicht nur die Zweckmäßigkeit von Objekten »gemäß dem Naturbegriffe« im Verhältnis zur reflektierenden Urteilskraft des Subjekts ausdrückt, sondern auch die des Subjekts »in Ansehung der Gegenstände, ihrer Form, ja selbst ihrer Unform« (KU, AA 05: 192). Es gibt also auch ein ästhetisches (Reflexions)Urteil »zufolge dem Freiheitsbegriffe«, das über das Erhabene. Dieses soll nun einem »Geistesgefühl« entspringen (KU, AA 05: 192). Kant braucht einen Begriff, der ausdrückt, dass das Erhabene Formlosigkeit und Unbegrenztheit darstellt, also wiederum etwas, was sich im Begriff nicht fassen lässt und $\mathrm{zu}$ dem etwas ergänzend hinzugedacht wird - den Vernunftbegriff der Totalität. Die ,Unform` der Gegenstände wird vom Betrachter als zweckwidrig angesehen, bewirkt aber dennoch ein spezifisches Wohlgefallen, das Kant »negative Lust« (KU, AA 05: 245) nennt, nämlich Bewunderung und Achtung. Die sinnlich erfassbare 
,natürliche“ Unangemessenheit (Unbegrenztheit, Zweckwidrigkeit) am Erhabenen bringt das Gemüt dazu, sich mit Ideen einer anderen Zweckmäßigkeit als derjenigen der Natur zu befassen, nämlich der der Freiheit, der wesentlichen Unabhängigkeit der Vernunft von Naturkausalität. Diese durch form- und maßlose sinnliche Naturgegenstände angeregte, an Vernunftideen gebundene Gemütsverfassung oder Gefühlslage ist das über die sinnliche Natur erhebende Geistesgefühl.

Insofern als in der kantischen Theorie der ästhetischen Idee und der daran anknüpfenden Lehre vom Genie ,Geist ${ }^{\star}$ nicht nur in ästhetischer Hinsicht definiert, sondern innerhalb der genannten Theoriestücke als relevanter Terminus verwendet wird, erhält der Begriff in der Kritik der Urteilskraft eine spezifische philosophische Bedeutung. In der „Kritik der ästhetischen Urteilskraft" spricht Kant dort von ,Geist", wo ein Übergang oder eine Verbindung zwischen Denken und Fühlen, Sinnlichkeit und Verstand zu benennen ist, etwas im Gemüt ist, was weder Gedanke noch bloße Wahrnehmung ist. In der Komplexität des Geschehens im Gemüt, der Wirkung der Gemütskräfte aufeinander und ihrem Spiel miteinander drückt sich — wie in der Moralphilosophie - ein besonderes Verhältnis von Natur und Freiheit aus. Dieses wird allerdings — anders als in der Moralphilosophie - nicht auf das Prinzip der praktischen Vernunft, das Moralgesetz und die Bedingungen seiner Möglichkeit und Anwendung, sondern auf das Prinzip der Urteilskraft, die Zweckmäßigkeit, hin ausgearbeitet und ausgelegt. Dazu gehört auch eine ,Erweiterung ' der Gesinnung durch die Erhebung über das Sinnliche, die als negative Lust vorgestellt wird.

\section{3. ,Geist' in Kants Anthropologie}

Kommen wir nun abschließend zur Anthropologie, die als pragmatische eine positive Variante des gefühlten vernünftigen Selbstverständnisses kennt, und als philosophische den Kreis zu einer transzendentalen Metaphysik schließen könnte, die Kant, wenn man Aufzeichnungen aus dem Opus postumum ernst nimmt, bis zum Schluss seiner philosophischen Reflexion vorschwebte. Auch in pragmatischer Hinsicht äußert sich Kant zum Kunstgeschmack (vgl. Anth, AA 07: 246), allerdings werden nur die »redenden Künste» berücksichtigt — »Beredsamkeit und Dichtkunst«, also Rhetorik und Poesie. Sie seien, so Kant, »auf eine Stimmung des Gemüths 
angelegt [...], wodurch dieses unmittelbar zur Thätigkeit aufgeweckt wird « (Anth, AA 07: 246). Da es in der Anthropologie in pragmatischer Hinsicht um die Kenntnis des Menschen geht, insofern er etwas aus sich machen kann, und in Hinsicht auf das, was er aus sich machen kann, ist die Betrachtung von Künsten der Sprache als Mittel der Gedankenmitteilung von Relevanz. Der Begriff ,Geist' wird in der ästhetischen Bedeutung aufgenommen, die bereits genauer betrachtet wurde; doch die populäre Darstellungsart der aus Vorlesungsinhalten entstandenen Anthropologie kann auf die komplexen abstrakten Analysen der theoretischen Kritik verzichten, ohne mit deren Ergebnis in Widerspruch zu geraten. Geschmack und Geist stehen hier als Bezeichnungen von verschiedenen Vermögen, deren Funktion Kant in wenigen Zeilen zusammenfasst wie folgt:

Geschmack ist ein bloßes regulatives Beurtheilungsvermögen der Form in der Verbindung des Mannigfaltigen in der Einbildungskraft; Geist aber das productive Vermögen der Vernunft, ein Muster für jene Form a priori der Einbildungskraft unterzulegen. Geist und Geschmack: der erste, um Ideen zu schaffen, der zweite, um sie für die den Gesetzen der productiven Einbildungskraft angemessene Form $\mathrm{zu}$ beschränken und so ursprünglich (nicht nachahmend) $\mathrm{zu}$ bilden (fingendi) (Anth, AA 07 [,Vom Kunstgeschmack“]: 246).

Mit Geist bezeichnet Kant hier das produktive Vermögen der Vernunft selbst; er ist die Vernunft insofern als er die ihr eigenen Begriffe, Ideen, hervorbringt. Die ästhetischen Ideen sind allerdings nicht regulativ wie die metaphysischen, sondern apriorische Form-Muster für das, was die Verbindung von Mannigfaltigem und Einbildungskraft hervorbringen kann — wobei auch die Einbildungskraft produktiv ist. Der Geschmack vermag $\mathrm{zu}$ beurteilen, welches Form-Muster der inneren Gesetzmäßigkeit der Einbildungskraft angemessen ist, er reguliert die Bildung des Produktes. Im Fall der ,redenden Künste" ist der Stoff, aus dem und in dem sich mit Geist und Geschmack die Idee bilden lässt, die Sprache selbst. Dass diese so bedeutsam ist, liegt daran, dass sie die »die vorzüglichste Art der Gedankenbezeichnung « ist, das »größte Mittel, sich selbst und andere zu verstehen«, so Kant in der gleichen Schrift (Anth, AA 07: 192f.). »Mangel« und »fehlerhafter Gebrauch« des Bezeichnungsvermögens führen $\mathrm{zu}$ Diskrepanz zwischen Sprache, d.h. Wortverwendung, und Begriff, d.h. Wortverständnis, »vornehmlich in Sachen der Vernunft« (Anth, AA 07: 
193). Der innere Zweck des Sprechens ist Gedankenmitteilung (daher auch das Wahrhaftigkeitsgebot bzw. Lügenverbot in der Metaphysik der Sitten). Wenn Kommunikation, also die Gedankenmitteilung durch Sprache, gelingt, und vielleicht sogar noch Geist zum Buchstaben hinzukommt, ist zudem ein Zweck des Menschseins erfüllt, der seine Vernunft lebendig und wirklich macht. Kant spricht in der Anthropologie vom »Geistesgenuß, der in der Mittheilung der Gedanken besteht « (Anth, AA 07: 158). Der findet insbesondere auch bei Gelegenheit des Umgangs mit anderen bei einer Tischgesellschaft statt, bei der durch eine gemeinsame Mahlzeit und guten Gesprächen sinnlicher und intellektueller Genuss zusammenkommen, mit Kant gesprochen »[d]ie Denkungsart der Vereinigung des Wohllebens mit der Tugend im Umgange« geübt und gepflegt wird, im $\S 88$ über »Das höchste moralisch-physische Gut « auch als »gesittete Glückseligkeit» beschrieben (Anth, AA 07: 277). Diese Denkungsart ist es, die »Humanität« ausmacht (Anth, AA 07: 277). In der Gemeinschaft mit anderen, die das intellektuelle Interesse teilen, d.h. die »Denkungsart von Menschen, die ein sittliches Gefühl cultivirt« (KU, AA 05: 299) haben, wird das belebende Prinzip des Gemüts, der Geist, ebenso wirklich wie in der Schönheit der Natur.

\section{Geist als Lebensprinzip des Menschen}

Aus einem Abschnitt aus der Verkündigung eines nahem Abschlusses eines Traktats zum ewigen Frieden in der Philosophie (1796) geht hervor, dass der späte Kant vom Geist des Menschen als der »idealen Person in uns «5 spricht, der mit der Seele in enger Verbindung steht und durch die Vernunft gegeben oder vermittelt wird, aber nicht mit ihr identisch ist. Geist ist nun das menschliche Lebensprinzip, das als solches von der Freiheit, nicht vom Sinnlichen ausgeht, und von dem auch ein Philosophieren ausgeht, das dieser Situation angemessen ist und sie angemessen zum Ausdruck bringt. In der Verkündigung spricht Kant von der »Hyperphysische[n] Grundlage des Lebens des Menschen zum Behuf einer Philosophie desselben«. Es heißt dort:

\footnotetext{
5 Auch in einer nachgelassenen Notiz zur Metaphysik der Sitten ist die Rede von Geist als der idealen Person; hier heißt es, dass wir »uns [...] die Idee von einem solchen Wesen [Seele als ,besonderes Subjekt im Menschen', von dem wir nicht wissen, ob es existiert] und unsere Pflicht in Ansehung unserer Selbst zu einer Pflicht gegen eine ideale Person (den Geist in uns) machen« (VAMS, AA 23: 416).
} 
Vermittelst der Vernunft ist der Seele des Menschen ein Geist (Mens, nous) beigegeben, damit er nicht ein bloß dem Mechanism der Natur und ihren technisch-praktischen, sondern auch ein der Spontaneität der Freiheit und ihren moralisch-praktischen Gesetzen angemessenes Leben führe. Dieses Lebensprincip gründet sich nicht auf Begriffen des Sinnlichen, welche insgesammt zuvörderst (vor allem praktischen Vernunftgebrauch) Wissenschaft, d.i. theoretisches Erkenntniß, voraussetzen, sondern es geht zunächst und unmittelbar von einer Idee des Übersinnlichen aus, nämlich der Freiheit, und vom moralischen kategorischen Imperativ, welcher diese uns allererst kund macht; und begründet so eine Philosophie, deren Lehre nicht etwa (wie Mathematik) ein gutes Instrument (Werkzeug zu beliebigen Zwecken), mithin bloßes Mittel, sondern die sich zum Grundsatze zu machen an sich selbst Pflicht ist (VNAEF, AA 08: 417).

Diese Passage bringt kurz und prägnant zum Ausdruck, dass es die Vernunft ist, die ,Geist" ermöglicht: zunächst zum praktischen Zweck einer Lebensführung, die der Freiheit und Moralität des Menschen entspricht. Zugleich begründet die Vernunft mit Geist eine Philosophie, deren Lehre anzunehmen Pflicht ist. Auf beeindruckende Weise ist hier in zwei Sätzen das gesamte Programm der kantischen Vernunft-Philosophie zusammengefasst; und mehr noch: Das Lebensprinzip ,Geist' wird explizit benannt, als für das dem Menschen angemessene moralische Selbstverständnis und philo-sophische Weltverständnis geltend.

Auch im 1. Konvolut des Opus postumum (1800) schreibt Kant dem »Geist des Menschen « Prinzipiencharakter zu; er skizziert in diesem Kontext bruchstückhaft ein »System der Transcendental / Philosophie, in drey Abschnitten«, und nennt drei Prinzipien:

Drey Principien: Gott, die Welt und der Begriff des sie vereinigenden Subjects welches in diese Begriffe synthetische Einheit bringt (a priori) indem die Vernunft jene transscendentale Einheit selbst macht [...] - Gott, die Welt, und Ich, Gott, die Welt, und der Geist des Menschen als das was die erstere verbindet (OP, AA 21: 23).

An anderer Stelle des Ersten Konvoluts (OP, AA 21: 29, §7-31, §8) heißt es: 
Gott u. die Welt, und der Geist des Menschen der beyde denkt [...] Es muß aber in diesem Verhältnisse ein Verbindungsmittel beyder [Gott und Welt, MR] zu einem absoluten Ganzen geben und das ist der Mensch der als Naturwesen, doch zugleich Persönlichkeit hat um das Sinnen Princip mit dem Übersinnlichen zu verknüpfen.

Der Begriff des Geistes begleitet Kants Denken von der Kritik am spekulativ-theoretischen Vernunftgebrauch über den praktischen bis zum Entwurf einer transzendentalphilosophischen Metaphysik. Person/Persönlichkeit, Ich, Geist sind die zentralen Begriffe, die den Menschen, das »vernünftige Sinnenwesen«, das »sinnlich-practische« und »denkende Wesen in der Welt« $(O P$, AA 21: 31, §9) als »Verbindungsmittel « zwischen Gott, der als höchstes Ideal als Person (OP, AA 21: 31, §6) und der Welt, die als Inbegriff aller Sinnenwesen gedacht wird, charakterisieren; und das nicht nur in theoretisch-metaphysischem Kontext, sondern auch praktischmoralisch, insofern der vernünftige Mensch, dem ,Geist' gegeben ist, als moralischer »Weltbewohner« zu leben in der Lage ist. Die Durchführung dieser Metaphysik Kants hätte letztlich eine ,Philosophie des Geistes hervor-gebracht. Dass zahlreiche Denker den Begriff des Geistes im Anschluss an Kant philosophisch aufgewertet, sogar als zentralen Systemoder Struktur-begriff verwendet haben, hat gute Gründe.

\section{Literaturverzeichnis}

BAUCH, B.: Immanuel Kant. 3. Aufl., Berlin/Leipzig, de Gruyter, 1923a.

KANT, I.: Gesammelte Schriften, Bd. 1-22, Preussische Akademie der Wissenschaften, 23, Deutsche Akademie der Wissenschaften zu Berlin, 2429, Berlin, Akademie der Wissenschaften zu Göttingen, 1900ff. : Briefwechsel (Br), AA 09, Brief an Marcus Hertz, AA 10, $143-$ 146.

: Träume eines Geistersehers (TS), AA 02.

: Kritik der reinen Vernunft $(K r V)$, AA 03; A/B.

: Kritik der praktischen Vernunft (KpV), AA 04. 
: Die Religion innerhalb der Grenzen der bloßen Vernunft (RGV),

AA 06.

: Kritik der Urteilskraft (KU), AA 05.

: Anthropologie in pragmatischer Hinsicht (Anth), AA 07.

: Verkündigung des nahen Abschlusses eines Tractats zum ewigen Frieden in der Philosophie (VNAEF), AA 08.

: Vorlesung Metaphysik Herder (V-Met/Herder), AA 28.

: Vorlesung Metaphysik L1/Pölitz (V-Met-L1/Pölitz), AA 28.

: Opus postumum $(O P)$, AA 21.

: Vorarbeit zur Metaphysik der Sitten (VAMS), AA 23.

NOLLER, J.; ZWENGER, T. (Hrsg.): Die Aktualität des Geistes. Klassische Positionen nach Kant und ihre Relevanz in der Moderne, Freiburg/München, Verlag Karl Alber, 2018.

ZWENGER, T.: „Der ,Geist“ als Grundbegriff einer kritischen Philosophie? Überlegungen zu Kants Vernunftverständnis“, in NOLLER, J.; ZWENGER, T. (Hrsg.): Die Aktualität des Geistes. Klassische Positionen nach Kant und ihre Relevanz in der Moderne, Freiburg/München, Verlag Karl Alber, 12 33, 2018. 


\title{
La deducción metafísica de las ideas a partir de las formas del silogismo
}

\author{
MARio PedRo Miguel CAIMI
}

\begin{abstract}
Resumen
Mostramos cómo las ideas de Dios, del Mundo y del Alma se originan en los prosilogismos que resultan de la concatenación ascendente de las formas de los silogismos categóricos, hipotéticos o disyuntivos. En la Disertación de 1770 Kant dice que el uso real del entendimiento consiste en la producción de conceptos puros. En la Dialéctica de la Crítica de la razón pura retoma ese pensamiento y sugiere que el uso real de la razón conduce a la producción de ideas. Procuramos aquí reconstruir ese proceso de producción de las ideas a partir de la actividad formal de la razón.
\end{abstract}

Palabras clave: razón, ideas, metafísica, dialéctica, prosilogismo, uso real

\section{The metaphisical deduction of the ideas from the forms of silogism}

\begin{abstract}
In this paper we show how the ideas of God, of the World and of the Soul originate in the prosyllogisms which result from linking categorical, hypothetical or disjunctive syllogisms, thus building series in progress towards their previous conditions. In the Dissertation of 1770 Kant states that understanding, in its real use, produces pure concepts. In the Dialectic of the Critique of Pure Reason he resumes this doctrine and suggests that the real use of reason leads to the generation of ideas. We intend to reconstruct this process of production of the ideas in the formal activity of reason.
\end{abstract}

Keywords: reason, ideas, metaphysics, dialectic, prosyllogism, real use

1 CONICET - Universidad de Buenos Aires. Contacto: mcaimi3@yahoo.com.

Una primera versión de la investigación de este tema fue publicada en 2012 (23-41) y fue expuesta oralmente en las universidades de Hagen (2018) y de São Carlos (2017). El presente texto contiene modificaciones importantes. Agradezco a quienes, al comentar las versiones anteriores, me hicieron ver la conveniencia de esas modificaciones. 


\section{Introducción}

Voy a llamar 'deducción metafísica', en este trabajo, a algo similar a la 'exposición metafísica' que, con respecto al espacio y al tiempo, se presenta en $K r V$, B38: a la demostración del origen a priori de ciertos conceptos (en nuestro caso, los conceptos puros de la razón). Aunque parezca superfluo para los conocedores del texto, es conveniente recordar que la deducción metafísica se distingue de la deducción transcendental, que es la explicación de cómo los conceptos a priori se refieren a objetos. La deducción metafísica de las categorías consistió en mostrar el origen a priori de ellas. Eso se hizo mostrando que las acciones propias del entendimiento, documentadas en la tabla de los juicios, eran las mismas acciones $\mathrm{u}$ operaciones por las que se producían todas las síntesis de las que el entendimiento era capaz: eran funciones fundamentales.2 De la tabla de los juicios se podía obtener, en consecuencia, la tabla de las categorías. De una manera semejante, procuraremos mostrar que las operaciones de la razón, que se encuentran documentadas en la tabla de los silogismos, son las mismas que dan origen a las ideas.

La deducción metafísica, así concebida, presupone la actividad (espontaneidad) de la razón, tal como la deducción metafísica de las categorías presupone la espontaneidad del entendimiento. Tanto este como la razón, precisamente por su espontaneidad, se distinguen de la sensibilidad, que es pasiva. Ya en 1770 concibe Kant esa espontaneidad. En la Dissertatio la denomina 'usus realis' del entendimiento. Muchos comentadores han interpretado (erróneamente, en mi opinión) ese 'uso real' como si fuera solamente la facultad de conocer las cosas tal como son en sí mismas. 3 Es cierto que en la Disertación se atribuye al entendimiento esa

2 Sobre la Deducción metafísica de las categorías y la bibliografía correspondiente véase Caimi (2000).

3 Así, entre otros, explica Klimmek (2005: 31) que un uso real de la razón se presenta cuando la unidad de la razón no consiste solamente en la unidad lógica de los conocimientos en un sistema, sino que significa la unidad de los objetos mismos. Lorini, por su parte, vacila y plantea la cuestión de si el uso real se refiere a los actos cognoscitivos o se refiere a las cosas conocidas mediante estos: "¿Estos intellectualia son cosas o son actos cognoscitivos?" ["questi intellectualia sono cose o atti conoscitivi?"] (2017: 186). Sala, en cambio, presenta una interpretación del uso real del intelecto cercana a la que nosotros exponemos aquí: "Tenemos aquí ante nosotros la tendencia a entender esos conceptos que se suelen llamar conceptos intelectuales, no como representaciones de esta o aquella $[\ldots]$ realidad, sino, más bien, como la operatividad propia del entendimiento humano" [»[W]ir haben hier vor uns die Tendenz, die sogenannten intellektuellen Begriffe nicht so sehr als Vorstellungen dieser oder jener [...] Wirklichkeit aufzufassen, sondern vielmehr als die dem menschlichen Verstand eigene Operativität«] (1978: 5). Sala desarrolla esta interpretación en un sentido peculiar y diferente del nuestro (1978: 12ss.). Sobre la adquisición originaria de los conceptos puros es fundamental el 
facultad. Pero también es cierto que no es a ella a lo que se refiere la expresión 'uso real'. En la Disertación se explica con claridad que el uso real del entendimiento es la facultad que este tiene de producir por sí mismo conceptos: "Conviene ante todo notar bien que los usos del intelecto, es decir, de la facultad superior del alma, son dos: de los cuales por el primero se dan los conceptos mismos, de las cosas o de sus relaciones, y este es el uso real" (MSI, §5, AA II: 393).4

En la Crítica de la razón pura encontramos la misma explicación de cierto uso de la razón (uso que podríamos llamar nosotros también 'uso real' de ella), que se refiere a la facultad que ella posee de producir, por sí misma, conceptos:

De ella [es decir, de la razón, MC], tal como del entendimiento, hay un uso meramente formal, es decir, lógico, en el cual la razón hace abstracción de todo contenido del conocimiento; pero también un uso real, en el cual ella contiene en sí misma el origen de ciertos conceptos y principios que ella no toma ni de los sentidos ni del entendimiento. La primera facultad ha sido hace ya mucho definida por los lógicos como la facultad de inferir de manera mediata (a diferencia de las inferencias inmediatas, consequentiis immediatis); pero la segunda, que genera por sí misma conceptos, no se llega a entender en virtud de ello (KrV, A299/B355).5

libro de Michael Oberhausen (1977). Este autor examina la expresión 'uso real', pero no desarrolla especialmente el análisis de ella.

4 "ante omnia probe notandum est, usum intellectus s. superioris animae facultatis esse duplicem: quorum priori dantur conceptus ipsi vel rerum vel respectuum, qui est USUS REALIS". Citamos según la traducción de Ceñal Lorente (1996).

5 »Es giebt von ihr wie von dem Verstande einen bloß formalen, d.i. logischen, Gebrauch, da die Vernunft von allem Inhalte der Erkenntniß abstrahirt, aber auch einen realen, da sie selbst den Ursprung gewisser Begriffe und Grundsätze enthält, die sie weder von den Sinnen, noch vom Verstande entlehnt. Das erstere Vermögen ist nun freilich vorlängst von den Logikern durch das Vermögen mittelbar zu schließen (zum Unterschiede von den unmittelbaren Schlüssen, consequentiis immediatis) erklärt worden; das zweite aber, welches selbst Begriffe erzeugt, wird dadurch noch nicht eingesehen«. El uso real de la razón, aquí mencionado, es análogo al que en MSI $\$ 6$ y $\S 8$ se menciona como uso real del intelecto. Mediante este usus realis el intelecto produce, por sí mismo, conceptos: "Por lo que toca a lo intelectual en sentido estricto, acerca de lo cual el uso del intelecto es real, [digo:] tales conceptos, tanto de los objetos como de sus relaciones, se dan por la misma naturaleza del intelecto, y no son abstraídos a partir de ejercicio alguno de los sentidos, ni contienen forma ninguna del conocimiento sensible en cuanto tal" (trad. de Ceñal Lorente 1996: 12) ["Quod autem intellectualia stricte talia attinet, in quibus usus intellectus est realis, conceptus tales tam obiectorum quam respectuum dantur per ipsam naturam intellectus, neque ab ullo sensuum usu sunt abstracti, nec formam ullam continent cognitionis sensitivae, qua talis"]. Tales conceptos resultan ser los conceptos puros del entendimiento, como se puede leer en MSI, AA II: 395: "Así, pues, no dándose en la metafísica principios empíricos, los conceptos en ella presentes no se han de buscar en los sentidos, sino en la misma naturaleza del intelecto puro, no como conceptos innatos, sino como abstraídos de las leyes connaturales de la mente (habida cuenta de su ejercicio con ocasión de la experiencia) y son por lo mismo adquiridos. Son de esta clase [los conceptos de] posibilidad, 
Este es el tema que nos proponemos desarrollar aquí: el origen de los conceptos puros de la razón, con la guía de las operaciones de ella en los silogismos.

Antes de presentar aquí nuestra hipótesis acerca de la deducción metafísica de las ideas a partir de las operaciones de la razón, conviene conocer la historia del problema del origen de las ideas, tal como esa historia se le presentó a Kant mismo.

2. Algunas observaciones acerca del problema del origen de las ideas en la filosofía pre-kantiana

El hecho de que se pueda demostrar que las ideas de la razón especulativa tienen origen en las operaciones lógicas de la razón, específicamente en las formas del silogismo, implica una novedad extraordinaria en la filosofía. Descartes había sostenido el origen divino de la idea de Dios ("la marca del artífice en su obra" [1897-1913: AT VII: 51]).6 Para Leibniz, no solo las tres grandes ideas de la metafísica especulativa, sino todas las ideas en general son una dotación que Dios da a cada alma singular. Malebranche7 y Spinoza (1925: II, prop. 1, demostración) entienden —cada uno a su modo - que las ideas son el contenido de la Mente divina; nosotros, mentes singulares, tenemos acceso a ellas de manera limitada según nuestra finitud.

Se ve, aquí, que la metafísica racionalista conecta las ideas, de diversas maneras, con lo sagrado e incluso con lo divino. Pero entonces viene Kant y nos demuestra que aquellas ideas que creíamos que tenían origen divino y que, por tanto, eran verdaderas y se referían a sus objetos correspondientes, son el mero resultado casi mecánico de la repetición de

existencia, necesidad, sustancia, causa, etc., con sus opuestos o correlativos; los cuales, no siendo nunca partes de ninguna representación sensible, no pueden ser de ningún modo abstraídos de ella" (trad. de Ceñal Lorente 1996: 13) ["Cum itaque in metaphysica non reperiantur principia empirica, conceptus in ipsa obvii non quaerendi sunt in sensibus, sed in ipsa natura intellectus puri, non tanquam conceptus connati, sed e legibus menti insitis (attendendo ad eius actiones occasione experientiae) abstracti, adeoque acquisiti. Huius generis sunt possibilitas, exsistentia, necessitas, substantia, causa etc. cum suis oppositis aut correlatis; quae cum nunquam ceu partes repraesentationem ullam sensualem ingrediantur, inde abstrahi nullo modo potuerunt"].

${ }_{6}$ "Et sane non mirum est Deum, me creando, ideam illam mihi indidisse, ut esset tanquam nota artificis operi suo impressa".

7 "De ahí se puede concluir que es en Dios, o en una naturaleza inmutable, donde se percibe todo aquello que se conoce por la inteligencia clara o la idea clara" (a. trad.) ["De là on peut juger que c'est en Dieu ou dans une nature immuable: que l'on voit tout ce que l'on connoît para lumiere ou idée claire"] (Malebranche 1976: 141). La fundamentación de la doctrina de la visión en Dios se encuentra en Malebranche (1965: 248ss.). 
ciertas formas lógicas. Por eso he dicho que la deducción metafísica de las ideas implica una novedad extraordinaria en la filosofía. Es casi una revolución dentro de esta.

Kant resume las mencionadas teorías racionalistas acerca del origen de las ideas, oponiéndolas a la tradición empirista:

En lo que respecta al origen de los conocimientos racionales puros, si son derivados de la experiencia, o si, independientemente de esta, tienen la fuente de ellos en la razón. Aristóteles puede ser considerado el jefe de los empiristas, y Platón el de los noologistas. Locke, que en tiempos más recientes siguió al primero, y Leibniz, que siguió al último [...], no pudieron tampoco, en este debate, llegar a ninguna decisión $(K r V, \mathrm{~B} 882)$.

\section{Una cuestión terminológica}

Antes de ir más adelante conviene prestar atención a una cuestión terminológica. $\mathrm{Ni}$ entre los racionalistas ni entre los empiristas de la Modernidad estaban fijados los términos técnicos para 'idea'. Aparecen, en este contexto, los términos 'idea' [Idee], 'representación' [Vostellung], 'contenido del alma o del espíritu' [Seelen= oder Geistesinhalt], 'percepción' [Wahrnehmung] e incluso 'sensación' [Empfindung]. De acuerdo con el Onomasticon philosophicum latinoteutonicum et teutonicolatinum (Aso et al. 1989: 164), la palabra latina idea se traducía, en la filosofía alemana del XVIII, como 'representación', 'concepto', 'imagen', 'concepto singular', 'figura', 'modelo'.8 Para Wolff, en su Metafísica alemana, 'idea' significa lo mismo que 'representación' [Vorstellung] (1997; véase Rumore 2007: 51). Solo después de que Kant fijara la nomenclatura en la 'escala' que figura en la Crítica de la razón pura, el problema general del origen de las representaciones se especificó como el problema particular del origen de las ideas (véase $K r V$, B376ss.).9 Esta cuestión terminológica incide de manera decisiva sobre el concepto de 'idea' en la filosofía de Leibniz y de Wolff.

Leibniz es quien da el paso decisivo al explicar la idea como una posibilidad de acción, en lugar de hacerlo como un contenido estático y fijo

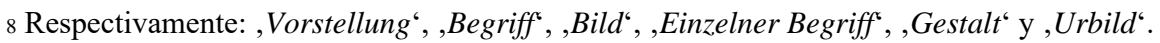

9 Sobre la historia de la escala de las representaciones véase Rumore (2007: 266ss.). Sobre el origen y el desarrollo del concepto de idea en Kant véase Hinske (1999: 119-132). 
del espíritu. Idea es, para Leibniz, la posibilidad de una acción por la cual la facultad representativa produce el pensamiento de una cosa.10 Christian Wolff adopta esta concepción leibniziana de las ideas. Wolff define las representaciones como alteraciones del estado del alma, producidas por la facultad representativa. Con esta explicación ofrecida por Wolf — según Paola Rumore - «La filosofía avanza, desde la concepción cartesiana de la idea [...], hacia la actividad dinámica propia de la representación leibniziana» (2007: 42).

4. El problema específico del origen de las ideas en la Crítica de la razón pura. Vacilaciones

Kant toma de la filosofía de Leibniz y de Wolff la concepción dinámica de las ideas a la que nos hemos referido antes.11 Está claro que en la filosofía crítica las ideas no pueden ser entendidas como accidentes de la substancia 'alma'. Pero tampoco se las puede entender como contenidos estáticos de la mente. Antes bien, llegamos a las ideas mediante la actividad del sujeto pensante (tal como Leibniz y Wolff lo establecieron).

Tal actividad del sujeto pensante, mediante la cual este produce las ideas, la ha concebido Kant de varias maneras. Michael Oberhausen ha encontrado, en la Crítica de la razón pura, un intento temprano de descubrir el origen de las ideas. Según ese pasaje de la Crítica citado por Oberhausen, el origen de las ideas ha de buscarse en el entendimiento (y no en la razón) y, más precisamente, en las categorías de relación. El texto de la Crítica dice:

Ahora bien, para poder enumerar estas ideas con precisión sistemática, según un principio, debemos observar primeramente que solo del entendimiento pueden surgir conceptos puros y trascendentales; que la razón no genera propiamente

\footnotetext{
10 "Una idea no consiste, para nosotros, en un acto de pensar, sino en una facultad, y decimos que tenemos una idea de una cosa aunque no pensemos en ella, con tal que podamos pensar en ella cuando se presenta la ocasión" (a. trad.) ["Idea enim nobis non in quodam cogitandi actu, sed facultate consistit, et ideam rei habere dicimur, etsi de ea non cogitemus, modo data occasione de ea cogitare possimus"] (Leibniz 1875-1890: VII, 263s.).

11 Yuichiro Yamane señala que la concepción kantiana del origen a priori de los conceptos puros se distingue de las concepciones de Locke y de Leibniz en que estos pensadores presuponen una facultad cognoscitiva otorgada por Dios, mientras que para Kant los conocimientos surgen en el sujeto humano gracias a una acquisitio originaria (véase 2010: 419).
} 
concepto alguno, sino que a lo sumo libera al concepto del entendimiento de las inevitables limitaciones de una experiencia posible $(\mathrm{Kr} V$, B435).12

Esta temprana 'deducción metafísica', según la cual el origen de las ideas está en el entendimiento y se niega a la razón la facultad de producir conceptos, coexiste en la Crítica de la razón pura con la deducción definitiva de las ideas, que dice que el origen de ellas está en la razón y que la tabla de las ideas se puede establecer siguiendo las formas lógicas de los silogismos.13

La concepción definitiva de la 'deducción metafísica' de las ideas queda fijada ya entre 1778 y 1783. Esos son, según Adickes, los años probables de redacción de la Refl. 5553. En esa reflexión se conectan las tres clases de silogismo con las tres ideas de la Metafísica especial. El texto dice: "Por tanto, todos los conocimientos de la razón serán paralelos a las tres clases de silogismos, y no será posible ninguno más" (Refl. 5553, AA XVIII: 222).14 El sistema de las ideas transcendentales consta de tres títulos «según las tres clases de silogismos» (Refl. 5553, AA XVIII: 223). Con ello, la deducción metafísica de las ideas toma su rumbo definitivo.

5. La deducción metafísica de las ideas a partir de las operaciones propias de la razón

El problema de la deducción metafísica de las ideas se resuelve de manera análoga a como se resolvió el problema de establecer la tabla de las categorías a partir del 'hilo conductor' suministrado por la tabla lógica de los juicios. El texto de los Prolegómenos confirma esa analogía: "La razón

12 »Um nun diese Ideen nach einem Princip mit systematischer Präcision aufzählen zu können, müssen wir Erstlich bemerken, daß nur der Verstand es sei, aus welchem reine und transscendentale Begriffe entspringen können, daß die Vernunft eigentlich gar keinen Begriff erzeuge, sondern allenfalls nur den Verstandesbegriff von den unvermeidlichen Einschränkungen einer möglichen Erfahrung frei mache«. Seguimos a Michael Oberhausen (1997: 231).

13 Oberhausen explica esta deducción temprana como un remanente de una redacción antigua de la obra. Sin embargo, la deducción de las ideas a partir de las categorías de relación sigue siendo válida: "El recurso a las formas del silogismo no convierte en obsoleto el anterior esbozo de una fundamentación de los conceptos de lo incondicionado en las conexiones de relación. Antes bien, ofrece un desarrollo ulterior de ese proyecto" (a. trad.) [»Der Rekurs auf die Schlussformen macht den früheren Entwurf einer Gründung der Begriffe des Unbedingten in den Relationsverhältnissen dabei nicht obsolet. Er stellt vielmehr eine Weiterentwicklung dieses gedankens dar«] (1997: 235).

$14 »$ Also werden alle Vernunfterkenntnisse den drey Arten der Vernunftschlüsse parallel seyn. und mehr derselben werden nicht moglich seyn«. Compárese Oberhausen (1997: 235). 
contiene en sí el fundamento de las ideas [...]. Estas últimas residen en la naturaleza de la razón tal como las primeras [es decir, las categorías, MC] residen en la naturaleza del entendimiento" (Prol, §40, AA IV: 328). Como si dijera que así como el uso lógico del entendimiento (la enunciación lógica de juicios) nos suministró el hilo conductor para el descubrimiento de los conceptos puros del entendimiento (véase $K r V$, A69/B94), así podemos esperar que el uso lógico de la razón nos conduzca a establecer la tabla completa de los conceptos puros de la razón.15 Esta analogía está expresada de manera todavía más clara y precisa en la Crítica de la razón pura cuando se trata de exponer el origen de las ideas: "la razón, por el mero uso sintético de la misma función de la que se vale para el silogismo categórico, necesariamente debe ir a parar al concepto de la unidad absoluta del sujeto pensante" (KrV, B392).

Es decir, el silogismo categórico conduce (como veremos) a la concepción de la idea del alma. De la misma manera se establece el origen de las demás ideas: la deducción metafísica tiene la misión de explicar

cómo el procedimiento lógico en el [silogismo] hipotético debe acarrear necesariamente tras sí la idea de lo absolutamente incondicionado en una serie de condiciones dadas; y finalmente, [cómo] la mera forma del silogismo disyuntivo debe acarrear tras sí necesariamente el supremo concepto de razón, de un ser de todos los seres (KrV, B392ss.).16

\footnotetext{
15 "Por analogía con los conceptos del entendimiento, podemos esperar que el concepto lógico suministre a la vez la clave del transcendental, y que la tabla de las funciones de los primeros suministre a la vez la guía genealógica de los conceptos de la razón” (a. trad.) [»Wir [können] nach der Analogie mit den Verstandesbegriffen erwarten [...], daß der logische Begriff zugleich den Schlüssel zum transscendentalen und die Tafel der Functionen der ersteren zugleich die Stammleiter der Vernunftbegriffe an die Hand geben werde«] ( $K r V$, A299/B356).

$16 »$ Wie das logische Verfahren in hypothetischen [Vernunftschluss] die Idee vom SchlechthinUnbedingten in einer Reihe gegebener Bedingungen, endlich die bloße Form des disjunctiven Vernunftschlusses den höchsten Vernunftbegriff von einem Wesen aller Wesen nothwendiger Weise nach sich ziehen müsse«. Contra esto afirma Nikolai Klimmek (2005: 51ss.) que de esta manera no obtenemos ideas, sino solamente clases de ideas. Por tanto, los conceptos de Dios, del Mundo y del Alma no serían propiamente ideas sino solo títulos o clases de ideas, análogas a aquellos títulos que se anteponen a las categorías en la correspondiente tabla (véase también Klimmek 2005: 24). El hilo conductor para el descubrimiento de las ideas no está, según Klimmek, en las formas lógicas de los silogismos, sino que hay que buscarlo en una "tricotomía de los campos de objetos de las posibles representaciones" (Klimmek 2005: 73). Esa tricotomía consiste en i) los estados del sujeto pensante y sintiente; ii) los objetos del pensamiento empírico; y iii) los objetos del pensar puro. Solo a partir de esos tres elementos, junto con las relaciones que ellos guardan con las categorías, resultan, según Klimmek, las ideas. Nosotros, empero, preferiríamos llamar predicables de las ideas a aquello que Klimmek denomina ideas (por analogía con los predicables de las categorías mencionados en $\mathrm{Kr} V$, B108). Si los entendemos como predicables, entonces los conceptos racionales de Dios, del Mundo y
} 
Todavía no está claro cómo es que de la forma de un silogismo puede surgir una idea. A ese proceso se alude al comienzo de la doctrina de la razón, cuando Kant ofrece una definición de la razón. Allí nos recuerda la definición lógica de la razón y añade la definición real de ella, que se basa en el ya mencionado uso real de la razón; esta definición real dice que la razón es una facultad de generar conceptos y principios. Una definición de orden superior abarca esas dos definiciones en una unidad; dice que la razón es la "facultad de los principios" ( $K r V$, A299/B356), donde 'principio' debe entenderse en sentido absoluto y no comparativo (véase B382 para el uso de la expresión 'absolut'). En sentido absoluto, los principios son conocimientos sintéticos por conceptos (véase $K r V$, B357); deben ser conocimientos absolutamente primeros; no pueden ser conocimientos derivados. De acuerdo con eso, se debe entender por "facultad de los principios" una facultad que instaura la "unidad sintética incondicionada de todas las condiciones en general" ( $K r V$, B391). Por tanto, la definición de la razón como "facultad de los principios" abarca tanto la actividad lógica de la razón, mediante la cual esta produce inferencias mediatas, como la actividad de ella por la cual genera ideas. Como veremos más adelante, esa generación de ideas se produce a través de un regreso en una cadena de silogismos, en dirección a un silogismo primero. Ese silogismo primero (en el orden lógico) contiene el principio al que se refiere la facultad de la razón, según la definición citada. La concatenación de silogismos se denomina ratiocinatio polysyllogistica (polisilogismo, o "cadena de inferencias de la razón", según la traducción de María Jesús Vázquez Lobeiras [2000: 171]). La cadena ascendente que se inicia en la conclusión de un silogismo y regresa hacia sus condiciones, conectando unos silogismos con los que los preceden y condicionan, se llama, en la Lógica, "prosilogismo" (Log, AA IX: 134).17 En el prosilogismo, la premisa mayor del silogismo inicial se reconoce como conclusión de un silogismo previo. La cadena de silogismos que así se establece forma un regreso que llamaremos 'regreso prosilogístico'; como veremos, solo por medio de un regreso polisilogístico (es decir, mediante un prosilogismo) puede la razón cumplir con la regla que manda encontrar "la unidad sintética incondicionada de todas las condiciones en general" ( $K r V$, B391). Solo por

del Alma conservarán su denominación de ideas y se conservará mejor la concordancia con el texto de la Crítica de la razón pura.

17 Sobre la historia de la terminología lógica kantiana véase el "Estudio preliminar" de María Jesús Vázquez Lobeiras en Kant (2000: 13-67). 
medio de ese regreso polisilogístico la razón puede cumplir lo que la definición le prescribe: ser la facultad de los principios. Dicho de otra manera: es propio de la naturaleza de la razón proseguir siempre un retroceso en la serie de las condiciones a través de una cadena de prosilogismos. Esa es la manera como la razón, de acuerdo con su definición, procura lo incondicionado.

En este proceso Rudolf Malter ha distinguido dos pasos. En el primero de esos pasos se establece que las premisas y la conclusión, en el silogismo, son juicios; es decir, que consisten en representaciones que están conectadas unas con otras según las tres clases de relación mencionadas en $K r V$, B391.18 En el segundo paso de la deducción metafísica se les aplica a estas relaciones el principio de la razón, a saber, el principio que prescribe encontrar la unidad sintética incondicionada de todas las condiciones. De allí resulta el "sistema de las ideas transcendentales" (Malter 1981: 185).

Estas indicaciones para la realización de la deducción metafísica de las ideas a partir del uso lógico de la razón no son suficientes, sin embargo, para determinar el camino que debe tomarse para encontrar los conceptos de la razón al final de las series de condiciones lógicas. Kant reconoce que

[S]ólo en la exposición completa se podrá explicar distintamente, cómo es que la razón, por el mero uso sintético de la misma función de la que se vale para el silogismo categórico, necesariamente debe ir a parar al concepto de la unidad absoluta del sujeto pensante; cómo el procedimiento lógico en el [silogismo] hipotético debe acarrear necesariamente tras sí la idea de lo absolutamente incondicionado en una serie de condiciones dadas; y finalmente, [cómo] la mera forma del silogismo disyuntivo debe acarrear tras sí necesariamente el supremo concepto de razón, de un ser de todos los seres; un pensamiento que a primera vista parece ser extremadamente paradójico ( $K r V$, B392ss.).19

18 La agrupación de los silogismos en tres clases según la relación de los conceptos en la premisa mayor está explicada en Logik §60, nota 1, AA IX: 122. Véase sobre eso Klimmek (2005: 20). $19 »$ Eben so wird sich auch nur in der völligen Ausführung deutlich machen lassen, wie die Vernunft lediglich durch den synthetischen Gebrauch eben derselben Function wie die Vernunft lediglich durch den synthetischen Gebrauch eben derselben Function, deren sie sich zum kategorischen Vernunftschlusse bedient, nothwendiger Weise auf den Begriff der absoluten Einheit des denkenden Subjects kommen müsse, wie das logische Verfahren in hypothetischen die Idee vom SchlechthinUnbedingten in einer Reihe gegebener Bedingungen, endlich die bloße Form des disjunctiven Vernunftschlusses den höchsten Vernunftbegriff von einem Wesen aller Wesen nothwendiger Weise nach sich ziehen müsse: ein Gedanke, der beim ersten Anblick äußerst paradox zu sein scheint«. 
Pero el filósofo se contenta con la indicación de que el camino que va del uso lógico al uso real de la razón (es decir, el camino que conduce a la generación de las ideas mediante las inferencias mediatas) es el camino de los prosilogismos. No hay otra indicación y la explicación se posterga para más adelante. Bien puede ser ése el motivo por el que los intérpretes se muestran descontentos y declaran, de varias maneras, que la deducción metafísica es fallida. En lo que sigue, antes de dedicarnos a la reconstrucción de los pasos lógicos de la deducción metafísica, examinaremos algunas de esas objeciones que los comentaristas han presentado.

\section{Algunas objeciones a la deducción metafísica de las ideas}

Los comentaristas han propuesto diversas objeciones a la deducción metafísica de las ideas. Será útil examinar algunas de esas reacciones críticas para poder evaluar más exactamente nuestro intento de reconstrucción.

Friedrich Paulsen niega toda validez a la deducción de las ideas a partir de las formas de los silogismos: "No es necesario demostrar que todo eso es un juego ocioso de una caprichosa precisión escolástica" (1924: 215).20 De manera similar, Adickes, Kemp Smith, Strawson y Bennet rechazan la deducción en su totalidad.21

Heimsoeth presenta objeciones diferenciadas acerca de la deducción de cada una de las ideas (1966: 45ss.). El resultado del prosilogismo categórico, a saber, "aquello que solo puede ser enunciado como sujeto y no como predicado", podría entenderse, según Heimsoeth, "como una substancia incondicionada solamente en el sentido de Spinoza (o de Hegel)" [»als unbedingte Substanz etwa im Sinne des Spinoza (oder Hegels)«] (1966: 45) y no como alma (sujeto del conocimiento). La obtención de la idea de Mundo mediante la serie de los prosilogismos hipotéticos constituye, según Heimsoeth, solo una parte de la tarea; la serie presentada en la Crítica es solo una entre muchas que tendrían que exponer otros aspectos de la idea, como, por ejemplo, "la cantidad de la totalidad del

$20 » \mathrm{Da}$ dies alles müßiges Spiel eines eigensinnigen scholastischen Scharfsinns ist, bedarf nicht der Ausführung«.

21 Según Oberhausen (1997: 241ss.), Klimmek (2005: 3) agrega los nombres de Riehl, de Schmucker y de Malzkorn. 
universo o la manera de su constitución (en división y composición)" [» [d]ie Größe des Weltganzen oder die Art seiner Gefügtheit (in Teilung und Zusammensetzung)«] (1966: 46; véase también Klimmek 2005: 24, 51, 73). Igualmente insatisfactoria es para Heimsoeth la deducción de la idea de Dios a partir del silogismo disyuntivo: "En este pasaje no se puede descubrir fácilmente que Kant haya aludido a la idea de Dios a partir de algo formal" [»Daß Kant hier, vom Formalen her, auf die Gottesidee zielt, wird man aus diesem Textstück nicht sogleich erraten können«] (1966: 47).

Oberhausen admite la validez de la deducción metafísica a pesar de las "deducciones forzadas y las contradicciones" que encuentra en ella. Pero opone una objeción semejante a las de Heimsoeth: duda de que el resultado de la deducción se pueda poner en relación con las ideas de una metaphysica specialis (1997: 245).

Camilla Serck-Hansen (2008) rechaza, por erróneo, el proceder lógico de la deducción metafísica, en especial en el caso de la idea del alma.22

Limitaremos nuestro examen de las objeciones a las que hemos presentado aquí; están en representación de muchas otras. Esperamos que nuestra reconstrucción de la deducción metafísica de las ideas pueda servir de respuesta a ellas.

\section{Ensayo de una deducción metafísica de las ideas de Dios y del Mundo}

Haremos ahora un ensayo de deducción metafísica de las ideas de Dios y de Mundo; es decir, intentaremos mostrar cómo es posible obtener esas ideas a partir, respectivamente, del silogismo disyuntivo y del silogismo hipotético.

7.1. Deducción de la idea de Dios a partir del silogismo disyuntivo

El silogismo disyuntivo, junto con el correspondiente prosilogismo, genera un concepto puro de la razón que introduce en la multiplicidad de los conocimientos una unidad colectiva; es decir, una unidad tal que reúne los conocimientos en un todo. Ese silogismo tiene, como es sabido, la forma siguiente:

22 Véase, sin embargo, la exposición que esta investigadora hace del origen de la idea de alma en su trabajo de 2011 (59-70, especialmente 62ss.). 
$O$ bien $\mathrm{A}(\mathrm{x})$, o bien $\mathrm{B}(\mathrm{x})$ (premisa mayor, propositio major); pero no es: $\mathrm{A}(\mathrm{x})$ (premisa menor, minor);

por tanto: $\mathrm{B}(\mathrm{x})$ (conclusión).

(Donde $\mathrm{A}(\mathrm{x})$ quiere decir: 'a $\mathrm{x}$ se le atribuye el predicado positivo $\mathrm{A}$ '; $\mathrm{B}(\mathrm{x})$ quiere decir: 'a $\mathrm{x}$ se le atribuye el predicado positivo $\mathrm{B}$ '; $\mathrm{y} C(\mathrm{x})$ quiere decir: ' $a x$ se le atribuye el predicado positivo C').

La premisa mayor resulta ser necesaria, si se la considera como la conclusión de un silogismo previo (en eso precisamente consiste el prosilogismo, es decir, el retroceso prosilogístico). Podemos expresar ese silogismo previo de la manera siguiente:

O bien $\mathrm{C}(\mathrm{x})$, o bien [o bien $\mathrm{A}(\mathrm{x})$, o $\mathrm{B}(\mathrm{x})]$;

pero no es: $\mathrm{C}(\mathrm{x})$

por tanto: o bien $\mathrm{A}(\mathrm{x}), \mathrm{o} \mathrm{B}(\mathrm{x})$.

A su vez, la premisa mayor de este silogismo se considerará necesaria desde el punto de vista de la razón, si esa premisa mayor es el resultado racional (la conclusión) de un silogismo disyuntivo previo que vendría a ser:

O bien $\mathrm{D}(\mathrm{x})$ o bien $\{\mathrm{o}$ bien $\mathrm{C}(\mathrm{x})$ o $[\mathrm{A}(\mathrm{x})$, o bien $\mathrm{B}(\mathrm{x})]$ \};

Pero no es: $\mathrm{D}(\mathrm{x})$

Por tanto: o bien $\mathrm{C}(\mathrm{x}) o[\mathrm{~A}(\mathrm{x}), \mathrm{o} \mathrm{B}(\mathrm{x})]$

La unidad colectiva absolutamente completa, buscada por la razón, se alcanzará, en el prosilogismo disyuntivo, cuando, mediante la prosecución de este procedimiento prosilogístico, se llegue a una premisa mayor que contenga en sí la disyunción completa de todos los predicados posibles, de modo que no quede ningún predicado que no se haya integrado a esa disyunción absolutamente completa. Dado que los predicados son la denominación de realidades, la disyunción completa, en la premisa mayor del supremo silogismo disyuntivo así elaborado, expresará la totalidad de las 
realidades predicables. Si ahora pensamos esa premisa como unidad sintética (es decir, si pensamos con un único concepto esa suma completa de todas las realidades), obtenemos la idea de la omnitudo realitatis. Esa totalidad de las realidades, concebida como un individuo, es el ideal de la razón pura (Heimsoeth 1966: 47). Hemos obtenido, así, la idea de Dios.

$\mathrm{Si}$, además, 'hipostasiamos' la premisa suprema, es decir, si concebimos la suma de todos los predicados como si se refiriera a una substancia efectivamente existente, entonces incurrimos en el uso dialéctico del concepto racional de Dios.

7.2. Deducción de la idea de Mundo a partir del silogismo hipotético23

Algo semejante ocurre con el silogismo hipotético y la idea de Mundo. Este silogismo tiene la forma:

\title{
Si $\mathrm{p}$, entonces $\mathrm{q}$ \\ Es el caso que p, por tanto, q.
}

$\mathrm{Si}$ buscamos, mediante un procedimiento prosilogístico, las condiciones que hacen necesaria esa premisa mayor, vemos que esa premisa mayor es la conclusión de un silogismo previo. Podemos expresar ese silogismo previo de la manera siguiente:

\author{
Si $\mathrm{n}$, entonces (si $\mathrm{p}$, entonces $\mathrm{q}$ ) \\ Es el caso que $\mathrm{n}$
}

\begin{abstract}
23 Parece que Kant, al tratar el silogismo hipotético, lo asimila a los modos ponens y tollens. Así en V-Lo/Busolt, AA XXIV, 677: "Los raciocinios hipotéticos tienen 2 modos: a) Modum ponentem. Allí concluyo de la verdad del antecedente a la afirmación del consecuente. b) Modum tollentem; aquí, de la supresión del consecuente concluyo la remoción del antecedente" [»Die Hypothetischen Ratiocinia haben 2 Modos: a.) Modum ponentem. Da schlüsse ich a veritate antecedentis ad consequentis positionem. b.) Modum tollentem; hier schliesse ich a remotione consequentis ad remotionem antecedentis «]. Así también en $V$-Lo/Wiener, AA 24, 940; en V-Lo/Dohna, AA 24, 776, donde solo la premisa mayor es una proposición condicional; en el mismo sentido $V$-Lo/Pölitz, AA 24, 589. Esto explica la forma que hemos dado a la deducción de la idea de Mundo. Esta podría obtenerse también como suma de las condiciones a partir de un silogismo hipotético de la forma habitual.
\end{abstract}


Por tanto, (si $\mathrm{p}$, entonces $\mathrm{q})$.

La continuación del procedimiento prosilogístico requiere que la premisa mayor de este nuevo silogismo sea, a su vez, la conclusión de un silogismo previo:

Si $\mathrm{m}$, entonces [si $\mathrm{n}$, entonces (si $\mathrm{p}$, entonces $\mathrm{q})]$

Es el caso que m

Por tanto, [si n, entonces (si p, entonces q)]

Eso, por su parte, nos lleva a más condiciones previas, en un regreso hasta una primera (o última) premisa que contiene en sí la serie completa de las condiciones de todos los silogismos hipotéticos posibles. En esa premisa alcanzaría su consumación la unidad de la razón. Si pensamos esa premisa como una unidad sintética (es decir, si concebimos con un único concepto la suma de todas las condiciones enlazadas unas con otras) obtenemos la idea de Mundo. De acuerdo con eso, la idea de Mundo es la que contiene en sí la representación de la serie completa (y por tanto, incondicionada) de las causas y los efectos. Es un todo que no es, a su vez, parte de ninguna otra cosa. Por tanto, también la idea de Mundo tiene su origen en un procedimiento lógico legítimo de la razón. Solo pierde su legitimidad si atribuimos existencia al objeto de esa idea. Ese uso ilegítimo de la idea se presenta cuando 'hipostasiamos' esa premisa, es decir, si concebimos esa serie completa de condiciones como si se refiriera a una substancia efectivamente existente. Entonces incurrimos en el uso dialéctico de la idea de mundo.

La diferenciación interna del concepto racional de Mundo mediante su conexión con las clases de categorías conduce (como lo han observado Heimsoeth, Oberhausen y Klimmek) a los conceptos racionales que intervienen en la Antinomia de la razón.

Hemos visto, así, cómo se originan las ideas de Dios y de Mundo en la naturaleza de la razón. 
7.3. Ensayo de una deducción metafísica de la idea del Alma a partir del silogismo categórico

La deducción de la idea de Alma presenta una dificultad mayor (véase la exposición del origen de la idea de alma en Camilla Serck-Hansen [2011: 62ss.]). Paulsen observa que las indicaciones ofrecidas en la Crítica de la razón pura acerca del origen de las ideas tienen validez solo para las ideas teológica y cosmológica, pero no para la psicológica (1924: 215). El mismo Kant señala la particular dificultad que tiene la deducción metafísica de la idea psicológica. 24

El prosilogismo categórico puede reconstruirse de la siguiente manera; el silogismo que forma el punto de partida es:

\section{Todo $\mathrm{M}$ es $\mathrm{P}$}

$\mathrm{S}$ es $\mathrm{M}$

Por tanto $\mathrm{S}$ es $\mathrm{P}$

El regreso conduce a un silogismo previo:

\section{Todo R es $\mathrm{P}$}

Todo $\mathrm{M}$ es $\mathrm{R}$

Por tanto, todo $\mathrm{M}$ es $\mathrm{P}$ (Esta es la premisa mayor del silogismo que formó nuestro punto de partida).

\footnotetext{
24 "por lo que toca a las categorías de la relación real entre los fenómenos, la categoría de substancia con sus accidentes no es apta para [ser] una idea trascendental; es decir, la razón no tiene ningún fundamento, con respecto a ella, para dirigirse regresivamente a condiciones. Pues los accidentes (en la medida en que son inherentes a una única substancia) están coordinados unos con los otros, y no constituyen serie alguna. Y con respecto a la substancia, no están propiamente subordinados a ella, sino que son el modo de existir de la substancia misma" [»was die Kategorien des realen Verhältnisses unter den Erscheinungen anlangt, so schickt sich die Kategorie der Substanz mit ihren Accidenzen nicht zu einer transscendentalen Idee; d.i. die Vernunft hat keinen Grund, in Ansehung ihrer regressiv auf Bedingungen zu gehen. Denn Accidenzen sind (so fern sie einer einigen Substanz inhäriren) einander coordinirt und machen keine Reihe aus. In Ansehung der Substanz aber sind sie derselben eigentlich nicht subordinirt, sondern die Art zu existiren der Substanz selber «] ( $\mathrm{KrV}, \mathrm{B} 441)$.
} 
A su vez, la premisa mayor de este nuevo silogismo (la que dice 'Todo $\mathrm{R}$ es $\mathrm{P}$ ') resulta ser la conclusión de un silogismo previo; y así sucesivamente.

\section{Dificultades}

Parecería que la deducción metafísica de la idea de Alma pudiera tomar el mismo camino que recorrimos con las ideas de Dios y del Mundo. Pero se presenta una objeción considerable: el regreso, en el prosilogismo categórico, conduce solo a un término medio de universalidad constantemente creciente. La creciente universalidad del término medio lo hace a este cada vez más apropiado para cumplir la función de un predicado. Por consiguiente, el regreso en el prosilogismo categórico nunca podrá llevarnos a la idea de un sujeto que no puede ser predicado (que era la meta de la deducción de la idea de Alma; véase Klimmek 2005: 25ss.; Serck-Hanssen 2008).

Para resolver esa dificultad, Klimmek (2005: 25ss.) recurre a un pasaje de Mellin, quien hace notar que el prosilogismo categórico podría construirse también de tal modo que la conclusión de cada silogismo de los que forman la serie sirviera como premisa menor (y no como premisa mayor) del silogismo siguiente (Mellin 1968: 719ss., especialmente 721). De acuerdo con eso, Klimmek presenta un ejemplo de prosilogismo en el que cada premisa menor es la consecuencia necesaria de un silogismo precedente. Comencemos por el silogismo categórico:

Todos los hombres son mortales

Caius es hombre

Caius es mortal

Con el regressus llegamos a la condición de la premisa menor:

Todos los jóvenes son hombres

Caius es un joven 
Caius es un hombre (Esta conclusión es la premisa menor del silogismo que formó nuestro punto de partida).

El regressus nos ha conducido al término medio 'joven', que tiene una extensión menor que el término 'hombre'. De esa manera podemos progresar hacia términos medios de extensión cada vez menor y así, según Klimmek, nos aproximaremos continuamente, cada vez más, a un concepto tal, que ya no pueda servir de predicado (2005: 27). Klimmek admite, sin embargo, que este regreso así ordenado se aproxima, por cierto, a un concepto último, pero no lo puede presentar nunca. No es posible, dice Klimmek, "que un concepto sujeto como ése se presente en un último y supremo juicio de la cadena silogística" (2005: 27). De manera que también aquí fracasa el intento de generar la idea de Alma mediante un prosilogismo categórico.

Eso nos pone en aprietos, pues si se renunciase a la deducción metafísica, se provocaría la caída de toda la Dialéctica transcendental, tanto en su sentido negativo como en su sentido positivo.25

\section{Propuesta de deducción de la idea de Alma}

Se puede pensar, sin embargo, una salida de este aprieto; esa salida consiste en advertir que el regreso prosilogístico no nos tiene que llevar a un primer concepto sino, más bien, a una proposición (a una primera premisa mayor). El propósito de la deducción metafísica de la idea de Alma no sería entonces encontrar un concepto que, siendo sujeto de la premisa mayor, no pudiera servir, a su vez, de predicado. El comienzo absoluto de la serie de silogismos categóricos no debería buscarse, entonces, en el sujeto de la primera premisa mayor, sino que estaría en esa premisa mayor entera.

$\mathrm{Si}$ eso es así, tenemos que encontrar esa premisa mayor absolutamente primera. Según la forma, la premisa mayor del silogismo categórico dice: Todo $\mathrm{M}$ es $\mathrm{P}$. El sujeto de esa proposición (el término medio M del silogismo categórico) deberá tener, una vez cumplido el

25 "La deducción metafísica de las ideas y, con ella, la Dialéctica, más que una etapa preliminar de la destrucción de la metafísica resulta ser un momento indispensable de la construcción de esta" [“A dedução metafísica das idéias e, com ela, a Dialética, mais do que etapa preliminar da destruição da metafísica, mostra-se como momento indispensável de sua construção"] (Licht dos Santos 2008: 154). 
regreso, la máxima universalidad. Con el aumento de la universalidad del concepto crece también su extensión. 26 El concepto que ha alcanzado su máxima extensión ve reducida al mínimo su comprensión, de modo que le resta solo su forma de concepto. Así, tenemos que la premisa mayor primera alcanzada mediante el prosilogismo categórico dice:

Un concepto en general (sin especificaciones internas que lo limiten) es $P$

o bien:

Todo concepto en general (si se hace abstracción de las especificaciones internas que puedan limitarlo) es $P$

También el predicado $\mathrm{P}$ de ese juicio categórico supremo y último debe ser llevado a su máxima extensión. Enunciado en su completa universalidad (haciendo abstracción de toda determinación que lo limite), $\mathrm{P}$ se puede formular como: 'Predicado de un sujeto'.

Con ello podemos enunciar la premisa mayor de la manera siguiente:

Todo concepto en general es (o puede ser) predicado de un sujeto.

Con eso se confirma la observación de Klimmek, que dice que el concepto que cumple la función de término medio, tomado en su máxima extensión, puede siempre servir como predicado (y no puede, por tanto, identificarse con el sujeto absoluto, que es el sujeto que no puede servir como predicado).

Pero podemos dar todavía un paso más, a saber, podemos efectuar una conversión de la proposición. En este caso presente es posible efectuar la conversión que, en la Lógica, se llama 'pura' [conversio simpliciter talis], pues ambos conceptos están tomados en su completa extensión $(\log , \S 52$,

26 Es decir, alcanzará la máxima posibilidad de su uso predicativo en juicios afirmativos universales. Así lo señala Klimmek (2005: 26): "La universalidad de un concepto se acrecienta juntamente con la posibilidad de su uso predicativo en juicios verdaderos afirmativos universales" [»die Allgemeinheit eines Begriffs [wächst] zusammen mit der Möglichkeit seines prädikativen Gebrauchs in wahren universell-bejahenden Urteilen«]. 
$\S 53$, AA IX: 118). Con la conversión de la proposición "Todo concepto en general es predicado de un sujeto" se obtiene: "Un sujeto tiene por predicados todos los conceptos en general" (o bien: puede tenerlos por predicados).

La proposición : "Un sujeto tiene por predicados todos los conceptos en general" se puede expresar de manera resumida diciendo: "Yo pienso todas las representaciones en general". Este es, según Kant, "el único texto de la Psicología racional", a saber, el Principio "del que ella debe derivar toda su sabiduría" ( $K r V$, B401). Por consiguiente, podemos admitir que el prosilogismo nos ha llevado a una última (o primera) premisa mayor, más allá de la cual no se puede ir.

$\mathrm{Si}$ ahora hipostasiamos esa premisa mayor (es decir, si la consideramos como descripción de un estado de cosas efectivamente existente), tenemos la afirmación de que hay un sujeto efectivamente existente del cual todos los conceptos se pueden enunciar como predicados suyos. Convendrá, para mayor brevedad, recurrir aquí al vocabulario de Leibniz. Según este, el sujeto al que se le pueden atribuir, como predicados suyos, todas las representaciones es la mónada (el Alma). Todo el universo está, como representación, contenido en la mónada (por eso, todo enunciado verdadero acerca de las substancias es una proposición analítica). La proposición que dice "Un sujeto tiene por predicados suyos a todos los conceptos en general" expresa precisamente ese estado de cosas.

Ese sujeto es, según Leibniz, la substancia o la mónada. Las mónadas que poseen conciencia de sí se denominan Almas. Por tanto, el prosilogismo categórico nos ha conducido finalmente al concepto racional 'Alma'.

10. Conclusión. Adquisición originaria de las ideas, preformación y epigénesis

En lo que precede hemos reconstruido una parte de la deducción metafísica de las ideas. En verdad, esa deducción tiene dos tareas, a saber: en primer lugar, tiene que mostrar el origen de las ideas en la razón pura; en segundo lugar, basándose en esa previa demostración del origen a priori de ellas, tiene que formular la tabla completa de las ideas. Una vez demostrado que las ideas se originan en las tres formas del silogismo, en el mismo acto 
queda resuelta también la segunda tarea, pues hay solo tres clases de relaciones de lo condicionado con su condición; esas relaciones quedan expresadas en las premisas mayores de los silogismos. Por tanto, solo serán tres las ideas que se puedan deducir de las formas del silogismo (Refl. 5553). La conexión de esas ideas con las cuatro clases de las categorías produce, después, una pluralidad de conceptos racionales puros a priori que podríamos llamar 'predicables de las ideas' (por analogía con los predicables de las categorías). Esos conceptos forman el fundamento de las antinomias.

De nuestra investigación resulta que no tenemos ideas innatas de Dios, ni del Mundo, ni del Alma. El origen de las ideas se puede ilustrar (por cierto, solo analógicamente) con una metáfora biológica de la que se ha servido Kant en relación con las categorías ( $K r V$, §27 B167) y que solo se explica en la Kritik der Urteilskraft ( $K U, \S 81$, AA V: 421ss.): Las ideas no residen, preformadas, en la mente (como, en opinión de los partidarios de la teoría de la preformación, el individuo completo está presente entero, desde la Creación, en los cuerpos de sus progenitores). Tampoco implanta Dios las ideas de manera inmediata en la mente, sino que son producidas por la potencia generatriz de la razón (tal como, en opinión de los partidarios de la teoría biológica de la epigénesis - sobre este concepto, véase Dupont 2007: 39-, se forma un cuerpo orgánico a partir de la materia inorgánica informe). Lo que genera las ideas es la espontaneidad de la razón. Si las ideas estuvieran preformadas en la mente o fueran implantadas en esta por Dios, tendrían que referirse a sus objetos de manera cierta e infalible (pues, de no ser así, Dios nos habría engañado al dárnoslas). Si, en cambio, son generadas por la razón, podrían ser quizá conceptos vacíos a los que no correspondiera objeto alguno. Para resolver esta última cuestión acerca de la posible vacuidad de las ideas se hace necesaria una deducción transcendental de ellas. Pero ése es otro tema que requiere otra investigación.

El reino de las ideas ha quedado desacralizado. Tal como lo anunciamos al comienzo de nuestra exposición, se ha producido, también aquí (como en toda la metafísica especulativa), una revolución análoga a la copernicana. No Dios, sino el sujeto racional humano es el responsable de las ideas de la metafísica. 
Referencias

ASO, K.; KUROSAKI, M.; OTABE, T.; YAMAUCHI, S.: Onomasticon philosophicum latinoteutonicum et teutonicolatinum, Tokio, TetsugakuShobo, 1989.

CAIMI, M.: „Einige Bemerkungen über die Metaphysische Deduktion in der Kritik der reinen Vernunft“, Kant-Studien 91 (2000) 257-282.

DESCARTES, R.: "Meditationes de Prima Philosophia", en ADAM, C.; TANNERY, P. (eds.): Oeuvres de Descartes, VII (A T VII), París, Vrin, IXVIII y 1-516, 1897-1913 [1996].

DUPONT, J.-C.: "Pre-Kantian Revival of Epigenesis. Caspar Friedrich Wolff's De formatione intestinorum (1768-69)", en HUNEMAN, P. (ed.): Understanding purpose. Kant and the Philosophy of Biology, New York, NY, Rochester, 37-49, 2007.

HEIMSOETH, H.: Transzendentale Dialektik. Ein Kommentar zu Kants Kritik der reinen Vernunft. Erster Teil: Ideenlehre und Paralogismen, Berlín, Walter de Gruyter, 1966.

HINSKE, N.: „Kants Anverwandlung des ursprünglichen Sinnes von Idee“, en: Idea. VI Colloquio Internazionale del Lessico Intellettuale Europeo, Roma, Edizioni dell' Ateneo, 317-327, 1990.

: 'Ricezione e trasformazione del senso originario di 'idea' in Kant”, en HINSKE, N.: Tra illuminismo e critica della ragione. Studi sul corpus logico kantiano, Pisa, Scuola Normale Superiore, 119-132, 1999.

KANT, I.: Lógica. Un manual de lecciones, Madrid, Akal, 2000.

: Dissertatio, Madrid, Consejo Superior de Investigaciones Científicas, 1996.

KLIMMEK, N. E.: Kants System der transzendentalen Ideen, Berlín/New York, NY, de Gruyter, 2005.

LEIBNIZ, G. W.: "Quid sit idea", en GERHARDT, C. I. (ed.): Philosophische Schriften von Gottfried Wilhelm Leibniz, VII, Berlín, Weidmann, 263-264, 1875-1890.

LICHT DOS SANTOS, P. R.: "Algumas observações sobre a Dialética Transcendental: o fim da Crítica da razão pura", Studia Kantiana 6/7 (2008) $135-179$. 
LORINI, G.: Fonti e lessico dell'ontologia kantiana. I Corsi di Metafisica (1762 - 1795), Pisa, Edizioni ETS, 2017.

MALEBRANCHE, N.: De la recherche de la vérité. III, Xe. éclaircissement, París, Vrin, 1976.

: "Que nous voyons toutes choses en Dieu”, en: De la recherche de la vérité. París, Rodis-Lewis, 1965.

MALTER, R.: „Der Ursprung der Metaphysik in der reinen Vernunft. Systematische Überlegungen zu Kants Ideenlehre“, en KOPPER, J.; MARX, W. (eds.): 200 Jahre Kritik der reinen Vernunft, Hildesheim, Gerstenberg, 169-210, 1981.

MELLIN, G. S. A.: „Prosyllogismus“, en: Encyclopädisches Wörterbuch der kritischen Philosophie, Jena/Leipzig, 719-726, 1797-1804 [1968].

OBERHAUSEN, M.: Das neue Apriori. Kants Lehre von einer ,ursprünglichen Erwerbung' priorischer Vorstellungen, Stuttgart, Frommann, 1997.

PAULSEN, F.: Immanuel Kant. Sein Leben und seine Lehre, Stuttgart, Fromman, 1924.

RUMORE, P.: L'ordine delle idee. La genesi del concetto di 'rappresentazione' in Kant attraverso le sue fonti wolffiane (1747-1787), Florencia, Le Lettere, 2007.

SALA, G. B.: „Der ,reale Verstandesgebrauch“ in der Inauguraldissertation Kants von 1770“, Kant-Studien 69 (1978) 1-16.

SERCK-HANSSEN, C.: "The Error of Reason. Rereading the First Paralogism". IV Congresso Kant da Sociedade Kant Brasileira, Porto Alegre, Brasil, 2008.

: „Der Nutzen von Illusionen. Ist die Idee der Seele unentbehrlich?“, en DÖRFLINGER, B.; KRUCK, G. (eds.): Über den Nutzen von Illusionen. Die regulativen Ideen in Kants theoretischer Philosophie, Hildesheim, Olms, 59-70, 2011.

SPINOZA, B.: "Ethica ordine geometrico demonstrata et in quinque Partes distincta in quibus agitur", en GEBHARDT, C. (ed.): Spinoza Opera. Im Auftrag der Heidelberger Akademie der Wissenschaften herausgegeben von Carl Gebhardt, 2, Heidelberg, Winter, 41-392, 1925. 
VÁZQUEZ LOBEIRAS, M. J.: "Estudio preliminar", en KANT, I.: Lógica. Un manual de lecciones, Madrid, Akal, 13-67, 2000.

WOLFF, C.: „Vernünftige Gedancken von Gott, der Welt und der Seele des Menschen, auch allen Dingen überhaupt", en: Gesammelte Werke, I. Abteilung: Deutsche Schriften Band 2.1., Hildesheim, Olms, 1997.

YAMANE, Y.: „Eine Studie zum kritischen Begriff ,a priori“ als ein Sachverhalt, der ,ursprünglich erworben' wird“, Kant-Studien 101 (2010) 413-428. 


\title{
The epistemological interpretation of transcendental idealism and its unavoidable slide into compatibilism
}

\author{
DANIEL DAL MONTE 1
}

\begin{abstract}
In this paper, I first defend Kant's critique of compatibilism. Kant rejects as semantic subterfuge a form of compatibilism that tries to assimilate a form of freedom within a deterministic causal series. I will address two major compatibilist theories: those that ascribe freedom based on reactive attitudes, and those that ascribe freedom based on some causal integration involving psychological drives of the agent. I then proceed to undermine the epistemological, or methodological, interpretation of transcendental idealism by showing how the only theory of freedom it can formulate is a compatibilist one.
\end{abstract}

Keywords: Kant, compatibilism, free will, methodological interpretation, transcendental idealism, determinism

\section{La interpretación epistemológica del idealismo transcendental y su inevitable desplazamiento hacia el compatibilismo}

\begin{abstract}
Resumen
En este artículo, defiendo primero la crítica de Kant al compatibilismo. Kant rechaza como subterfugio semántico una forma de compatibilismo que intenta asimilar una forma de libertad dentro de una serie causal determinista. Abordaré dos grandes teorías compatibilistas: las que atribuyen libertad sobre la base de actitudes reactivas, y las que atribuyen libertad sobre la base de alguna integración causal que involucra impulsos psicológicos del agente. Luego procedo a socavar la interpretación epistemológica o metodológica del idealismo trascendental al mostrar cómo la única teoría de la libertad que puede formular es una compatibilista.
\end{abstract}

Palabras clave: Kant, compatibilismo, libre albedrío, interpretación metodológica, idealismo trascendental, determinismo

1 Temple University Philadelphia. Contact: tuf42914temple.edu@temple.edu. 


\section{Introduction}

In the Critique of Practical Reason, Kant explicitly rejects compatibilist views of freedom. A compatibilist concedes that determinism is true but still tries to maintain the viability of freedom. Determinism need not fully undercut our freedom, the compatibilist argues, so long as we understand freedom in a certain way. Freedom, a compatibilist might say, is the ability to pursue what one wants, but not the ability to determine what one wants (see Schopenhauer 2013: 531). Deterministic causation, outside of our control, limits our desires, and so our freedom consists of acting on them but not in choosing them. Thomas Hobbes, for instance, wrote that the freedom of an individual consists of his finding "no stop, in doing what he has the will, desire, or inclination to do" (1985: II, Ch. 21). As long as there is no obstacle in the way of the individual's achievement of his wants, the individual is free, according to the compatibilist, although his desires are determined.

Kant, however, is clear that any attempt to refashion the notion of freedom to adjust to determinism diminishes it to the point that it is no longer freedom. The compatibilist, having already acknowledged the reality of determinism, cannot at the same time believe that freedom is a spontaneous, uncaused power to author events. The latter is the libertarian conception of freedom. A libertarian conception of freedom posits the will as the ultimate source of action. As Robert Kane puts it, "the ultimate source of our actions lies in us and not outside us in factors beyond our control" (2007: 5). If it is the source, the will cannot be the byproduct of causal powers acting in its environment.

The compatibilist concedes the reality of determinism. If there is freedom at all for the compatibilist, then, it can only be ensconced in a deterministic causal network that extends into the individual's environment. So, a libertarian conception of freedom, which defends a conception of freedom as the source of an action, is very different from the conception of the compatibilist. A compatibilist conception of freedom cannot allow freedom to be the source of action, since freedom is in fact, for the compatibilist, determined by pre-existing causes.

To call some action 'free' that is ultimately the product of deterministic causation, even if it finds its proximate origins in desires, or higher-order desires, is, for Kant, a kind of semantic trickery. Determinism, 
for Kant, means the absence of freedom, no matter how one may reset the conditions of freedom so that they conform to the presence of determinism. Kant writes,

If, as is admitted by these men themselves, these determining representations themselves have the ground of their existence in time and indeed in the antecedent state, and this in turn in a preceding state [...] these determinations may be internal and they may have psychological instead of mechanical causality [...] which may therefore bring with them psychological freedom [...] but nevertheless natural necessity $(\mathrm{Kp} V, 5: 96)$.

Kant caustically remarks that the so-called 'freedom' of the compatibilists is "nothing better than the freedom of a turnspit, which, when once it is wound up, also accomplishes its movements of itself" (1996: 5:97). In other words, compatibilist theories of freedom merely provide verbal window dressing for what are deterministic causal sequences. There are devices, such as clocks, that generate activity of their power, once they are prepared to do so by a human. But, the mere fact of being able to power their activity is not nearly enough to establish freedom for the clock. In the same way, the mere fact that one can act without constraint on a certain desire - and so is animated by one's psychological drives - is not enough to establish freedom, if that person is also at the same a product of deterministic causation.

Compatibilists exaggerate the difference between proximate and ultimate causation into one between freedom and determinism. The analogy with a turnspit is perhaps somewhat infelicitous, as a turnspit presumably does not have desires. Nevertheless, a human that is determined psychologically, is just as woodenly mechanistic as a turnspit. It does not matter, as far as establishing freedom, that there may be no obstacle in the way of the desires of this human, just as it would not matter if there are no obstacles in the way of a turnspit.

In this paper, I will first defend Kant's critique of compatibilism. I will then show how epistemological interpretations of Kant's transcendental idealism can only provide a basis for a compatibilist conception of freedom. I will proceed to do this by showing how epistemological interpretations presuppose an anti-realist attitude to both determinism and transcendental 
idealism. Once this presupposition is exposed as fallacious, I will prove that the best that epistemological interpretations can provide are compatibilist versions of freedom. The upshot is that epistemological interpretations end up clashing with Kant's explicit commitments as well as taking on all the weaknesses of compatibilist theories of freedom.

\section{Contemporary compatibilism and its problems}

In this section, I will defend Kant's rejection of compatibilism by identifying some problems with contemporary compatibilism. Compatibilism has grown in sophistication in the many decades that have passed since Kant. In fact, most contemporary philosophers are compatibilists (see Pereboom 2001: xvi). Differing argument styles defending compatibilism have emerged.

The major figure associated with one version I will describe is P.F. Strawson. This version holds that our notion of freedom is grounded in socalled 'reactive attitudes'. Freedom for Strawson consists of the mere psychological assumption behind these reactive attitudes, and not any ontological reality rooted in some special form of causation.

Strawson's reactive attitudes consist in human reactions such as praise, blame, admiration, and gratitude, all of which presuppose the idea that the person to whom we are reacting is free and therefore morally responsible. We do not, for instance, react to an object like a tree with the same kind of admiration with which we react to a human being. When we admire a human being, we admire them for qualities of which they are in some way the source - at least, there is the presupposition of sourcehood in the reactive attitude. The person is responsible for their admirable actions, whereas a tree is just the passive bearer of admirable properties (see Strawson 1982: 75).

Reactive attitudes are a permanent feature of human relationships, according to Strawson. Even if the scientific community were to prove that determinism is true, this would not undermine our reactive attitudes. The first step in Strawson's argument is, therefore, a psychological thesis that, regardless of how convinced we are of the truth of determinism, we will continue to praise, blame, and admire people as if they are morally responsible. The thesis is purely psychological because the reactive attitudes 
that characterize everyday interchanges with other human beings are independent of any kind of metaphysical facts about the nature of the person. It could turn out that a certain kind of ontological reductionism is true, such that all of the human behavior is understandable in terms of the DNA. Nevertheless, we would still regard people with blame when they err, as if it were they who erred, and we could not instead account for their misbehavior in terms of some biological predestination.

Strawson writes (1982: 81):

The human commitment to participation in ordinary interpersonal relationships is, I think, too thoroughgoing and deeply rooted for us to take seriously the thought that a general theoretical conviction might so change our world that, in it, there were no longer any such things as inter-personal relationships as we normally understand them.

The next step in Strawson's argument is normative. Because reactive attitudes are so deeply interwoven into the fabric of human life, efforts to square them with metaphysical postulates are merely academic. We do not need to ask whether our reactive attitudes, which presuppose the freedom and responsibility of individuals with whom we interact, are consistent with metaphysical reality. We need not preoccupy ourselves with arcane philosophical debates about whether or not we are really free. The presupposition that we are free is simply inextricably woven into our daily lives, and it will not change no matter how often we are chided by philosophers and/or scientists. Our reactive attitudes do not require an “external 'rational' justification” (Strawson 1982: 82).

I argue that Strawson has attempted to build a compatibilist account of freedom (see Pereboom 2001: 90). Freedom can exist along with determinism because we presuppose freedom in our reactive attitudes, even if we also accept the reality of determinism in our more speculative moments. Strawsonian freedom is not grounded in some ontological reality having to do with a special sort of causation. Instead, it is grounded in the pervasive social phenomenon of reactive attitudes. This sort of grounding of freedom, since it avoids questions of causation, is compatible with determinism. 
There is another broad category of argument for a compatibilist conception of free will. Derk Pereboom describes this second type of account as picking out "causal integrationist conditions" (2001: 100). Strawsonian compatibilism is distinctive in that it establishes a version of freedom that can exist regardless of any causal circumstances that might characterize the agent. Freedom amounts to a psychological stance that characterizes our intersubjective relationships. Since we retain this psychological stance independently of our ontological situation, it is needless to parse the kind of causation we may or may not be exercising.

\section{Causal-integrationist versions of compatibilism}

On the other hand, causal-integrationist compatibilism2 does concern itself with metaphysical aspects of the agent's causal situation. While accepting determinism, the causal integrationist compatibilist draws distinctions within the category of deterministic causation that are metaphysical in nature. These metaphysical distinctions are crucial to distinguish between free and unfree acts. Causal-integrationist accounts identify free actions as those that are integrated especially with the psychology of the agent.

For instance, A.J. Ayer articulates a conception of free action that emphasizes a specific role for the desires of an agent in the causal history of an action. Let us say an agent has a strong desire to take a course in the philosophy of mind. The agent acts freely only insofar as this desire leads to the action of the agent. If the agent's desire is the driving force behind the action of the agent, then the action is a free act. This could all be maintained while at the same time defending the view that the desires of the agent are themselves the product of deterministic causation.

If, on the other hand, the agent has a strong desire to take a course in the philosophy of mind, but his practically-minded parents distressed at the prospect of him wasting time on an impractical topic, coerce their son into taking a course on core accounting practices, then he is not acting freely. His strong desire to take a course on the philosophy of mind is not driving his behavior. Instead, his parents have intervened and so the agent is acting under constraint.

\footnotetext{
2 The terminology is derived from Pereboom (2001: 103).
} 
For a compatibilist like Ayer, freedom and necessity are not opposed. One can still act freely, even while one's desires are fully determined by external causes, so long as one's desires are the driving force behind one's actions. It is freedom and constraint that are opposed. One is not acting freely when one's behavior is being directed by external pressures against one's desires. "For it is not, I think, causality that freedom is to be contrasted with, but constraint [...] If I am constrained, I do not act freely" (Ayer 1982: 19). Ayer's account is a causal-integrationist account in the sense that it identifies freedom with a certain integration of one's action with one's psychology - in the case of Ayer, one is free when one's actions are integrated with one's desires.

Another causal-integrationist compatibilist account is that of Harry Frankfurt. A free action is for Frankfurt is one that results from a first-order desire that is in conformity with a second-order volition (1971: 5-20). Frankfurt gives a taxonomy of different desires. There are first-order desires, which take the form of $A$ wants to $X$, where $A$ is the agent and $X$ is some activity or object. First-order desires are desires for certain activities or objects-e.g. I want to take a philosophy course. Second-order desires are desires to have certain desires. They take the form $A$ wants to $X$, where $X$ is a certain desire. For example, I might desire to desire to take a philosophy course - in other words, I approve of my desire to take a philosophy course. The opposite may also be true: I may have a second-order desire to not want my first-order desire to take a philosophy course. Finally, there are secondorder volitions, which are a more serious form of second-order desire, in which the agent wants a certain desire to be part of his or her will. For example, not only do I want to want to take a philosophy course, I want to act on my desire to take a philosophy course (i.e. make it part of my will) (Frankfurt 1971: 13-15).

Free action for Frankfurt consists of a special causal integration understood in light of this taxonomy of desire. Free action occurs when an agent acts on a first-order desire that is in accordance with a second-order volition. That is, an agent acts freely when he acts on a first-order desiree.g. a desire to take a philosophy course - that is in accord with a secondorder volition - e.g. the agent wants the desire to take a philosophy course to be part of his or her will. An agent does not act freely when he or she acts according to a first-order desire-e.g. the desire to take a philosophy 
course - that is not in accord with a second-order volition-e.g. the agent does not want the first-order desire to take a philosophy course to be part of his or her will. Perhaps the agent is helpless to avoid the allure of philosophy, but wishes to rid himself of it because it is filling his mind with doubts!

\section{Criticism of contemporary compatibilism}

It is legitimate to ask if Kant would continue to maintain his adamant rejection of compatibilist accounts of freedom if he were to encounter them in the sophisticated form they have taken in contemporary philosophy. It is my view that Kant's criticisms still hold. In the second Critique, Kant writes, in reference to compatibilist solutions to the philosophical problem of free will, that "some still let themselves be put off by this subterfuge and so think they have solved, with a little quibbling about words, that difficult problem" $(K p V, 5: 96)$.

Kant's insight here, i.e. that compatibilist accounts of freedom do work that is merely semantic quibbling, is compelling. 'Freedom', according to some compatibilist accounts, is not an ability to override natural causality, rooted in a real metaphysical power that is exempt from natural causality. Instead, 'freedom' is refashioned to allow us to continue to believe in it in spite of our acknowledgment of uninterrupted determinism. Freedom consists of a mere psychological attitude or a mere harmonization between what we want and what we want to be part of our will.

Such semantic refashioning, though, attempts to solve the contradiction between freedom and determinism not by establishing a real reconciliation between the two realities but diluting the definition of freedom to make it compatible with determinism. Compatibility is achieved at the expense of losing any meaningful sense of freedom. After all, people manipulated by ingenious neuroscientists, whom no one would intuitively regard as free, are capable of having reactive attitudes, and of wanting what they want to be part of their will (see Pereboom 2001: 112).

Though the scope of this paper is too limited to provide an extensive treatment of compatibilist theories of freedom, I will provide what I think are some powerful justifications for Kant's rejection of it. These arguments against compatibilist versions of freedom are ultimately intended to build a 
case against epistemological interpretations of transcendental idealism. If all epistemological interpretations can give us are compatibilist versions of free will, then they are in severe tension with Kant's clear commitment against compatibilism, and also suffer from all the deficiencies of compatibilism which I here expose.

\section{Question-begging incompatibilist arguments}

The first problem with compatibilism I will identify is that at the heart of arguments for compatibilism is a fallacy of begging the question. To define freedom a certain way, as compatibilists do, and then to claim that freedom is consistent with determinism, amounts to begging the question. The original question compatibilists try to answer is whether freedom is compatible with determinism. Compatibilism amounts to a defense of an affirmative answer to this question. To answer this question affirmatively, though, by defining freedom in a way that is already compatible with determinism, is to assume what one is trying to prove. This is a central problem for both argument styles of compatibilism that I have mentioned. The point is therefore worth reemphasizing.

Begging the question is, of course, the logical fallacy of prejudging as true in the premises of one's argument that which one hopes to establish in the conclusion. The question for compatibilists is whether or not freedom and determinism are compatible. They set out to answer this question by assuming a definition of freedom that is already compatible with determinism. Therefore, compatibilist arguments assume what they are trying to prove.

So, Strawsonian compatibilism begins with the attempt to address the question of whether or not free will and determinism are compatible. That these two realities are compatible is what the argument for Strawsonian compatibilism seeks to prove. To prove compatibility, Strawsonian compatibilism adopts a definition of freedom - namely, a psychological version that consists of reactive attitudes - that already assumes that freedom is compatible with determinism. Other definitions of freedom-for instance, as an absolute causal spontaneity - could have been selected that would have shown the failure of compatibilism. But, the argument for 
Strawsonian compatibilism conveniently adopts a definition of freedom that will lead to a successful defense of compatibilism.

Similarly, Frankfurtian compatibilism argues for the compatibility of free will and determinism by presupposing in its premises a definition of free will that is compatible with determinism, when it could have selected other definitions of freedom.

The begging the question fallacy is common to both routes to compatibilism I have outlined. Moreover, each route to compatibilism errs in its ways. I will begin with the flaws unique to the compatibilist account of Strawson.

\section{Problems unique to the Strawsonian compatibilist}

As I said earlier, this compatibilist account moves from a psychological thesis, i.e. that theoretical considerations about determinism will not dislodge our reactive attitudes, to a normative thesis, i.e. that esoteric metaphysical exercises are superfluous and in dehumanizing. Contemplating ways in which human beings are determined warps our relationships with other people, such that we regard them as objects to be manipulated and managed. Strawson writes (1982: 82):

Finally, to the further question whether it would not be rational, given the general theoretical conviction of the truth of determinism, so to change our world that in it all these [reactive] attitudes were wholly suspended [...] it is useless to ask whether it would not be rational for us to do what it is not in our nature to (be able to) do.

Yet, this move from psychology to normativity does not really address the fundamental question of compatibilism, which is whether or not freedom and determinism can be reconciled. At best, Strawson's compatibilist account offers practical guidance. Even if determinism is true, we should not try to rid ourselves of the inevitable emotions of resentment, praise, and blame that characterize human relationships. But, compatibilism has to do more than merely offer practical guidance. Compatibilism is supposed to answer the question of whether freedom and determinism are reconcilable in a conceptual way. To merely recommend that it is best to 
move on from questions of the consistency of freedom and determinism, and just continue to interact with one another in the way that is most natural to us, leaves unanswered the philosophical and conceptual matter of whether or not freedom and determinism are compatible. Just the fact that we ought to maintain the status quo does not have any bearing on the issue of whether or not free will and determinism are conceptually compatible.

Strawson tries to dismiss the conceptual question of whether or not freedom and determinism can be reconciled as an example of overintellectualization. Reactive attitudes so deeply embedded in human relationships that it is erroneous to even attempt to evaluate these attitudes in terms of some metaphysical inquiry that is independent of them (1982: 78). But the question compatibilists try to answer requires a philosophical treatment that addresses the consistency of the concepts of freedom and determinism. Compatibilism already presupposes, therefore, the importance of the theoretical issues relating reactive attitudes and metaphysics that Strawson dismisses as a mere distraction from the commitments most fundamental to our nature. To say that reactive attitudes are a permanent feature of human society, and we are therefore just going to work within the framework they form, is practical guidance. This guidance does not answer the central question of compatibilism, which has to do with the logical consistency of freedom and determinism.

The normative recommendation, therefore, we get from Strawson has to do with how we ought to live our lives. But, the normativity that compatibilist theories are supposed to offer is theoretical, i.e. whether or not it is logical or consistent to believe in both freedom and determinism.

The mere fact that a belief in freedom, presupposed in the reactive attitudes, can persist even given determinism, does not mean that freedom is actually consistent with determinism. This is true even if we define freedom in a reductive way as a reactive attitude. If a thoroughgoing determinism is true, then the reactive attitudes that characterize human relationships are also determined. So, there is no question of the reactive attitudes not being there. It is not as if we are maintaining our presupposition of freedom even in the face of determinism. We could maintain-i.e. willfully and deliberately hold - our presupposition of freedom if determinism were not true. In such a case, we would be exercising judgment about whether the presupposition of freedom is viable or appropriate. 
If determinism is true, though, it just so happens, as an inevitable product of deterministic causation, that there are these reactive attitudes that presuppose freedom. And the mere presence of the presupposition of freedom that results from deterministic causation does not mean the former and the latter are consistent, in a theoretical sense. Beliefs that are the product of deterministic causation are not truth-sensitive, nor are they sensitive to the conditions of logical consistency. These beliefs just happen to characterize the subject and are not the product of a considered, free judgment.

The task of the compatibilist is to reconcile freedom and determinism, but it seems all that Strawson's theory does it to identify a cooccurrence. There is deterministic causation, and the presupposition of freedom in the reactive attitudes occurs because of deterministic causation. This co-occurrence is fully consistent with the idea that freedom, qua reactive attitude, is not conceptually/philosophically consistent with determinism.

\section{Problems with causal integrationist accounts}

I will now introduce criticisms of compatibilist accounts that identify causal-integrationist conditions. Harry Frankfurt writes, "It is only because a person has volitions of the second-order that he is capable both of enjoying and of lacking freedom of the will" (1971: 210). Volitions of the secondorder occur when someone desires that a certain desire constitutes his will (see Frankfurt 1971: 9). Those beings that lack second-order volitions do not arbitrate over which of their first-order desires are incorporated into their will, and it would be hard to characterize such a being as free. Such a being would be pulled along by its strongest first-order desire, whatever it happens to be.

Frankfurt's distinction between second-order volitions and firstorder desires is illuminating, and it captures some of the difference between situations in which we recognize someone as free, and situations in which we do not. For instance, we would say that someone who is a drug addict does not act freely because they are acting on a first-order desire to obtain drugs, but they lack a second-order volition to incorporate the first-order 
desire into their will. This person is acting against their will, and so not freely. But, Frankfurt's account is flawed.

First, as I stated earlier, such an account begs the question of whether or not freedom and determinism are compatible by defining freedom in a way that permits it to be compatible with determinism. There are other problems, though. One only has to extend the logic in Frankfurt's attempt at compatibilism to expose its flaws.

Let us say, along with Frankfurt, that a person who has a first-order desire to take drugs, but lacks a second-order volition to make this desire her will, is not free. Why exactly, one might ask, isn't such a person free? A reasonable answer is that they have not made their first-order desire their own, and so their will, which is based on their first-order desire, is not their own (see Frankfurt 1971: 14). The person is acting against her will, established in her second-order volition, and so is subject to some alien force. Derk Pereboom writes: "Like Ayer, Frankfurt can also be viewed as attempting to capture the intuition that for an agent to be morally responsible for an action is for it to be really his" (2001: 104). The firstorder desire is not representative of the person because she has not endorsed it with her second-order volition. We would view a person who is gripped by an overpowering first-order desire, which runs contrary to her secondorder volitions, as a pathetic victim, perhaps even pathological, rather than free. The first-order desire is alien and not her own because she condemns it with her second-order volition.

But, we need to take a deeper look at the second-order volition. If determinism is true, then this second-order volition is the product of deterministic causation beyond the person's control. If the first-order desire is not the person's own because they did not endorse it with a second-order volition, doesn't it follow that the second-order volition is not the person's own because they did not endorse it? Moreover, if the second-order volition is the product of deterministic causation, does it constitute genuine endorsement of the first-order desire? After all, can someone truly endorse something if they can't help but endorse it?

In sum, we can ask the same questions about the second-order volitions that we can about first-order desires if determinism is true. If one is not free if one is driven by a first-order desire one does not endorse, then 
it also follows that one is not free if one is driven by second-order volition, for a certain first-order desire, one did not endorse.

In the end, Frankfurt's distinction between the conflicted state in which first-order desires clash with second-order volitions, and an integrated state, seems arbitrary. Even in the integrated state, the person has not fully identified with their actions, given the fact that the second-order volition is the result of deterministic causation.

Even sophisticated contemporary accounts of compatibilism, then, of which Kant was unaware, remain vulnerable to the criticisms of compatibilism that Kant leveled in the second Critique. Compatibilist accounts of freedom try to dance around our reservations by redefining freedom in question-begging ways. Or, such accounts just accept the fact that attributions of freedom are not going away and then act as though some genuine resolution of the tension between freedom and determinism has been achieved.

The problems of contemporary compatibilism will also plague interpretations of Kant's theory of freedom that misrepresent it as a compatibilist account. I will now address a certain style of interpretation of Kant's transcendental idealism that inevitably leads to a misrepresentation of Kant's theory of freedom as compatibilist. Such a misrepresentation weighs down Kant's theory of freedom with all the problems of compatibilism I have just identified. There is also the considerable problem, of course, that Kant himself rejected compatibilism. No interpretation of his transcendental idealism that leads to compatibilism can avoid reconstructing Kant's central doctrine in a way that contradicts other explicit commitments in his work.

\section{Differing versions of Kant's transcendental idealism}

I will focus on two broad camps that have formed in the scholarship on the proper interpretation of Kant's transcendental idealism. There is a multitude of different interpretations of transcendental idealism, but they can be understood in terms of a spectrum of views that give different degrees of epistemological and metaphysical import to the central distinction of transcendental idealism, that between appearances and things in themselves. 
Kant believes that our mental faculties have a certain structure through which we receive impressions of the external world. Since these impressions are filtered through this cognitive structure, the appearance of a thing is different from the thing as it is in itself, independent of this structure (see $K r V$, Bxxvi).3

The two camps of interpretation I will address are epistemological interpretations of transcendental idealism and ontological interpretations. An epistemological interpretation sees the difference between appearances and things in themselves as merely epistemological. Appearances and things in themselves are not separate entities, nor are they even different properties of the same entity. The only appropriate way to differentiate between appearances and things is through epistemology. We can only cognize that which conforms to our cognitive structure, and so we can cognize appearances, but not things in themselves. "We can have cognition of no object as a thing in itself, but only insofar as it is an object of sensible intuition" ( $K r V$, Bxxvi).

Epistemological interpretations make this epistemological modesty about things themselves central while rejecting any kind of ontological separation between appearances and things in themselves.4 Henry Allison argues that positing an ontological distinction between appearances and things in themselves distracts from the 'epistemological thrust' of transcendental idealism, which indicates that there are cognitive structures that we bring to experience and that we cannot know reality apart from them. When we talk about the difference between appearances and things in themselves, we are not talking about two different things or metaphysically distinct aspects of a thing, but two ways of considering a thing. We can consider a thing as it appears, in conformity with our cognitive structures, and as it is independent of these cognitive structures (Allison 2004: 16).

Ontological interpretations can accept the epistemological differences between appearances and things in themselves, but for the things in themselves and appearances represent two distinct things, and not merely two distinct ways of considering things. The ontological interpretation

\footnotetext{
3 References to Kant's Critique of Pure Reason follow the customary practice of citing the pagination of the 1781(A) edition and the 1787(B) edition.

4 Incidentally, it seems that the difference in epistemic access between appearances and things in themselves has to do with a metaphysical difference. We cannot know things in themselves because they are not objects of perception that have conformed to our cognitive structures.
} 
agrees that we can only cognize appearances, but also affirms that there is an ontological difference between appearances and things in themselves. Karl Ameriks, for instance, writes (2003: 104),

The epistemic interpretation, in understanding transcendental idealism as the claim that human knowledge is governed by certain sensible conditions, does not insist on Kant's own stronger conclusion, which is that there are objects which in themselves have genuine ultimate properties [i.e. they are not mere modes of considering objects] that do not conform to those conditions.

I will now argue that it is the epistemological interpretation that precludes the possibility of transcendental freedom. Transcendental freedom is the ability to begin a series of events spontaneously, apart from the influence of prior causes. Kant writes, "A causality must be assumed through which something happens without its cause being further determined by another previous cause, i.e. an absolute causal spontaneity beginning from itself [...] hence transcendental freedom" ( $\mathrm{KrV}$, A446/B474). If the epistemological interpretation precludes transcendental freedom, then the best account of freedom it can offer is a compatibilist account. If all that we are left with is a compatibilist account of freedom, then we are left with the severe challenges for compatibilism I have already detailed. Compatibilism leaves us only with some semantic maneuvres that merely hide the truth that we are really no different from a machine that operates according to some built-in algorithm.

A key premise of my argument, that the best account of freedom that the epistemological theory can provide is a compatibilist one, is that there is a presupposition of anti-realism in the epistemological account of transcendental idealism that is false. Since the epistemological interpretation is allergic to any kind of ontological difference between appearances and things in themselves, there is the curious implication, when considering a human individual, that the person is neither free nor determined. Freedom and determinism pertain to different perspectives one might take on a person. But, neither one has a privileged ontological status. It is not as though one is really determined, and the consideration of oneself as free is merely a fiction. Nor is it the case that one is really free, and the appearance of oneself as determined is just that - an appearance that is an object of 
mental perception but does not exist independently of perception. This sort of definitive resolution of the question of freedom and determinism, in which the person is either really free or really determined, would betray the epistemological interpretation's commitment to avoiding any ontological distinction between appearances and things in themselves. Relegating one perspective as a mere appearance, and affirming another as an ultimate reality, is precisely the sort of stance taken by philosophers like Ameriks (i.e. genuine ultimate properties) that the epistemological interpretation rejects. Allison, therefore, reaches the following conclusion: "It must suffice to note that the illusion is not that we are free, or, for that matter, that we are causally determined. It lies rather in the assumption that we must really be one or the other in some ontologically privileged, context-independent sense" (2004: 49).

With the anti-realist presupposition, there is a way to reach a kind of incompatibilist account, though even this is unsatisfactory. But, once one undercuts the antirealism, there is no option left but compatibilism.

9. The two-aspect interpretation of transcendental idealism and its implications for transcendental freedom

There is a debate about the nature of the distinction between appearances and things in themselves in transcendental idealism. The debate hinges on whether or not there is an ontological difference between things in themselves and appearances, or if the difference between things themselves and appearances is merely a matter of which perspective one takes. A concrete illustration of the two positions might involve a radar and a sentence, respectively. The ontological theory sees appearances as if they were bright lights on a radar screen and things in themselves as if they were objects deep in the sea that people using the radar can never directly perceive (see Hartnack 2001: 27). The example shows how the ontological theory views things in themselves and appearances as different things. Whereas the bright lights are merely two-dimensional luminous points on a screen, the objects of which they are indicative are much larger threedimensional objects deep in the ocean.

As for the epistemological interpretation, a concrete illustration may involve a sentence spoken aloud. Let us say one does not know the language 
in which the sentence is spoken. The words are unintelligible. But, if someone does know the language, then the same sentence is intelligible. The example shows that the two-aspect theorist sees appearances and things in themselves not as ontologically distinct (the sentence is the same ontologically regardless of whether it is understood or not), but as relating to two different perspectives. One perspective includes the conditions for knowledge, whereas the other does not.

A two-aspect view cannot sustain ontological priority. That is, in the relationship between appearances and things in themselves, there cannot be one that has ontological priority, in the sense that it is more fundamental and capable of existence independent of the mind.

As I have noted, this rejection of ontological priority leads to an antirealism about free will. Allison refers to the work of Michael Dummett to develop his anti-realist view on free will. Dummett is an influential contemporary philosopher who developed an anti-realist theory that defined the notion of truth not in terms of some objective state of affairs, that is independent of what we can know, but in terms of evidence which we can know. Statements can only be true or false in terms of the evidence available to our perspective. They cannot be true or false independently of the limitations of this perspective. So, if we are debating about the characteristics of some person long dead of whom we have no evidence, whether or not that person was brave is neither true nor false, because there is simply no evidence related to that person from our perspective (see Dummett 1978: 146).

Applied to free will, anti-realism means that, from a deliberative perspective, in which we see ourselves as making decisions, we have evidence that we are free and so, from this perspective, we are free. From a theoretical perspective, in which we see ourselves from outside and subject to deterministic causality, we have evidence that we are determined. When we see ourselves as determined, we cannot at the same be free, since there can be no truth for the anti-realist beyond perspective. By the same token, when we see ourselves as free, we are not determined, because of the absence of evidence for determinism from the deliberative perspective.

The incompatibilist commitment that free will and determinism are contradictory is consistent on this anti-realist account. One could argue that, in this anti-realist account, freedom and determinism never coexist. They 
pertain to separate perspectives which one cannot take simultaneously. Since, in this anti-realist account, perspectives cannot be taken simultaneously, then the evidence peculiar to each perspective, for determinism and freedom, cannot coexist. Freedom and determinism are permanently separated in the anti-realist account, and it can, therefore, be consistent with the belief that freedom and determinism are incompatible.

It must be said, though, that an anti-realist free will, that merely exists from a certain perspective, sounds like a version of free will all too similar to the sort of semantically ornate versions of free will a compatibilist would create. Such a version of free will, that exists only from a certain perspective, is fully compatible with deterministic causation. I can take a certain perspective in which I intuit myself as free, but this does not mean that I am the source of my actions.5 The perspective could be an anti-realist one, which does not entail any objective reality independent of the perspective. Having transcendental freedom as a mere perspective, and not as an actual causal power, is fully compatible with determinism. Calling a person free, merely based on a perspective, is not a designation Kant would readily accept, as we have seen.

\section{Evaluation of the epistemological interpretation}

The anti-realism of the epistemological interpretation allows it to formulate a kind of incompatibilist version of freedom, in which determinism and freedom are understood as incompatible. The anti-realist interpretation affirms both freedom and determinism, but only from certain perspectives. Recall that Henry Allison advances the, I must say, bizarre view that the human person is neither free nor determined, in a context-independent sense. Christine Korsgaard, another prominent advocate of a nonmetaphysical interpretation of transcendental idealism, maintains equality of privilege between the two standpoints: "Both interests are rational and legitimate. And it is important that neither standpoint is privileged over the other-each has its own territory" (1996: 173). It is not as though I am really free, or really determined, in an absolute sense. Anti-realism saturates

5 Being the source of one's action, instead of the action being the product of alien forces internal or external to oneself, is accepted by some philosophers as a condition for free will. For instance, Roderick Chisholm conceived of an agent as a 'prime mover unmoved', having a nearly God-like ability to initiate new sequences of events without any determination from prior causes (see 1964: 32). 
the epistemological interpretation, such that both freedom and determinism are true only from a perspective, and not as objective facts regardless of what evidence one might have from a given perspective. So, in this antirealist version of the self, it seems there is no absolutely existing self.

Since freedom and determinism are true only from certain perspectives, and the perspectives, moreover, are mutually exclusive, it is not the case that the epistemological interpretation affirms a compatibilist position, in which freedom and determinism coexist. The ultimate aim for this paper, which I stated at the outset, is to show that the epistemological interpretation has no other option but a compatibilist conception of freedom. The route I will take to show this, then, is first to undermine the anti-realism of the epistemological interpretation. It is only in virtue of anti-realism that the epistemological interpretation can maintain an incompatibilist position, albeit a weak one that Kant would most likely find repellent. There are good reasons to reject both the idea that Kant was an anti-realist, and that antirealism about the person is a strong philosophical position. Without the antirealist assumption, I will show how incompatibilist versions of freedom are impossible for the epistemological interpretation.

11. The first argument against anti-realism: anti-realism cannot be applied to the thesis of the third antinomy

We know from the third antinomy in the transcendental dialectic of the first critique that it is transcendental realism that cannot resolve the contradiction between transcendental freedom and total determinism. Transcendental realism ignores the transcendental structures of the human mind. Therefore, the transcendental realist views experience as the reception of objects that exist independently of the mind, instead of consisting of appearances that conform to the conditions of possible experience associated with the mind, and so are dependent on the mind. "The transcendental realist therefore represents outer appearances [...] as things in themselves, which would exist independently of us and our sensibility" ( $K r V$, A369). If the transcendental realist sees a cup, therefore, she views her experience of the cup as consisting entirely in mind-independent properties. The experience of the cup is simply the reception of the cup as it is, apart from any observer. 
Transcendental realism drives a contradiction between free will and determinism because it posits both as mind-independent entities. Transcendental realism is therefore forced to try to fit together causality according to natural laws and transcendental freedom in the same series. This is not possible, because the two are contradictory. There cannot be both an uncaused, spontaneous cause and causality that only follows from previous events according to natural laws.

Kant applies his transcendental idealism to create two separate levels, appearances and things in themselves so that transcendental freedom and determinism can coexist. Transcendental idealism allows causality according to natural laws and transcendental freedom to exist in separate series. Causality according to natural laws is a mere appearance, which exists only insofar as it is an object of perception. Transcendental freedom, on the other hand, has an absolute existence that is independent of any perceptual faculty.

What is of particular interest, for this paper, is the issue of antirealism concerning the resolution of the contradiction between transcendental freedom and determinism. As I have noted, the epistemological interpretation applies anti-realism to both transcendental freedom and determinism. Neither are objective realities; both exist from mere perspectives, in which there is a warrant to believe in them that is exclusive to that perspective. 6

Transcendental realism fails to resolve the third antinomy because it refuses to incorporate anti-realism at all. Appearances for the transcendental realist are not appearances that only have a perspective-dependent existence, but are instead objectively existing facts. The epistemological interpretation is partially correct to apply anti-realism as the key to the resolution of the third antinomy.

However, the version of free will we get in the epistemological interpretation misapplies anti-realism in a way that clearly strays from Kant's commitments. Anti-realism ought not to be applied to transcendental freedom. For Kant, anti-realism applies only to appearances. It is appearances that exist only as objects of perception, and so they are

6 For an excellent comparison of Kant's transcendental idealism to contemporary anti-realism, see Lucy Allais (2003). 
appropriately understood, in an anti-realist way as existing only from a certain perspective and not objectively. "If we remove our own subject or even only the subjective constitution of the senses in general, then all constitution, all relation of objects in space and time, indeed space and time themselves would disappear, and as appearances they cannot exist in themselves, but only in us" ( $K r V$, A42/B59).

Things in themselves, on the other hand, are capable of existing independently of the mind. It would not be right to apply anti-realism to things in themselves. In fact, such an application would amount to a contradiction, since a thing in itself is by definition that which cannot be subjected to an anti-realist interpretation. Things in themselves refer to that aspect of things which is independent of perception. Kant in the Preface speaks of "things as objects of experience and the very same things as things in themselves" $(\mathrm{KrV}, \mathrm{Bxxvi)}$. When we consider a thing as a thing in itself, we are considering it as it is independent of experience. It is therefore contradictory to interpret a thing in itself in an anti-realist way, as if we could understand a thing in itself as something that exists only from a certain perspective.

Kant is clear that the third antinomy is a dynamical antinomy. The dynamical antinomies, which are the third and fourth antinomies, differ significantly from the mathematical antinomies, which are the first and second antinomies. The respect in which these two sets of antinomies differ is that, in the dynamical, there is a non-sensible intelligible element paired with a sensible appearance. In the mathematical antinomies, on the other hand, there are sensible appearances in both the thesis and the antithesis sections (see $K r V$, A531/B559).

So, in the third dynamical antinomy, we deal with the sensible appearance of empirical causality according to natural laws, but also the non-sensible intelligible reality of transcendental freedom, which cannot be included in any experience. In the first antinomy, one of the mathematical antinomies, we deal in both the thesis and the antithesis arguments with a sensible appearance, namely, the world (see $K r V$, A426/B454).

The significance of this disparity is great. Since appearances are part of both the thesis and the antithesis arguments in the mathematical antinomies, anti-realism can be applied to both. The mathematical antinomies are resolved by determining that both arguments are false. 
Neither of them is objectively true. So, we conclude the first antinomy with the position that the world is neither finite nor infinite in duration and magnitude. The world cannot have a determinate duration or magnitude, since, as a mere appearance, it does not exist as a whole. That is, the world does not have an absolute existence, and only exists as an object of perception. Any kind of determinate magnitude, whether finite or infinite, requires being able to exist independently from these perceptual faculties (see $K r V$, A522/B550).

Allison applies the same sort of solution to the third antinomy. But, this is erroneous. The third antinomy is a dynamical antinomy. This means that it includes a non-sensible element-in this case, transcendental freedom. As a non-sensible element, one cannot apply anti-realism to transcendental freedom. The way to solve the third antinomy is not by applying anti-realism to both parts of the argument, but by applying it only to one. In this scenario, both the thesis and the antithesis arguments of the third antinomy may be true (see $K r V$, A531/B559). There can be transcendental freedom, so long as we understand natural causality as existing only as an appearance.

Transcendental freedom cannot be an appearance, so it cannot be subjected to an anti-realist treatment. What Allison tries to do is to turn Kant into a Putnam-style anti-realist who gives no place to the notion of a thing in itself, that can exist independently of any perspective. A Putnam-style antirealist rejects the idea that anything can exist independently of a certain theory. Lucy Allais writes (2003: 373),

The rejection of 'theory-independent' reality has been important to Putnam, but Kant clearly believes in theory-independent reality, in his views about things as they are in themselves: the way things are as they are in themselves is entirely independent of us and our knowledge of them.

Kant's belief that there is an ultimate reality independent of any theory also is inconsistent with the idea that there cannot be one uniquely true theory. It is not as though what is real is a function of what theory one happens to adopt, and so there is a multiplicity of possible true theories. The idea that we are both free and determined, depending on the perspective one 
adopts, is rejected by Kant. There is an ultimate truth about the human person.

If transcendental freedom is to exist, then, it must exist as an objective, perspective-independent fact. If it exists, it would be thing in itself, and these are perspective-independent by definition. The epistemological interpretation begins to flounder once it acknowledges this. If the epistemological interpretation tries to develop an account of freedom based on its version of transcendental idealism, it first has to acknowledge that freedom cannot be subjected to an anti-realist treatment. It has to exist as a perspective-independent, absolute reality.

Causality according to natural laws also has to be given a place. However, the epistemological interpretation cannot simply give determinism a conditional, perspective-dependent reality, while permitting to transcendental freedom a mind-independent reality. This kind of distinction is an ontological one that the epistemological interpretation obviously rejects. Mind-dependent realities are ontologically different from absolute realities.

The only way, then, that the epistemological interpretation can affirm both the existence of natural causality and transcendental freedom is by treating them both as objective, perspective-independent facts. This is the only way to close the ontological distinction between natural causality and transcendental freedom.

Once the anti-realist interpretation of transcendental freedom is exposed as faulty, we have to understand it as a thing in itself. Determinism also would have to have, then, an absolute mind-independent status, to preserve the epistemological interpretation from an ontological distinction.

Of course, we know that this sort of participation in the same causal series, by causality according to natural law and transcendental freedom, is impossible. The only option is to somehow refashion one's understanding of transcendental freedom to make it compatible with determinism. One could perhaps understand transcendental freedom as a sort of harmony between one's second-order volitions and first-order desires. But, of course, this is the compatibilism that Kant rejects and which leaves one so deeply unsatisfied. 
12. Anti-realism subverts the grounding relationship between practical and transcendental freedom

The anti-realist solution to the free will problem we find in the epistemological interpretation cannot effectively frame the distinction between practical freedom and transcendental freedom, and the kind of relationship they have. This distinction can be parsed in terms of a distinction between a positive capacity for freedom and a negative condition having to do with the absence of necessitation by psychological drives. Transcendental freedom, that is, is the positive capacity for starting a new series of events from oneself.

By freedom in the cosmological (Kant arrives at the necessity of transcendental freedom through an argument for the necessity of a first cause) sense, on the contrary, I understand the faculty of beginning a state from itself, the causality of which does not in turn stand under another cause determining it in time in accordance with the law of nature (see $\mathrm{KrV}$, A533/B562).

Practical freedom is a mere negative attribute of not being necessitated by one's impulses/desires. Practical freedom means the human power of choice is affected by impulses, but not necessitated by them (see $K r V$, A534/B562).

The relationship between practical freedom and transcendental freedom, according to Kant, consists of the fact that practical freedom is grounded upon transcendental freedom. "It is especially noteworthy that it is this transcendental idea of freedom on which the practical concept of freedom is grounded" ( $K r V$, A533/B561). In other words, one can be independent of one's desires/impulses in virtue of the fact that one can initiate sequences of events from oneself. One's ability to initiate events from oneself gives one a veto power, as it were, over the desires and impulses that pressure one to act one way or another.

The united reality of practical freedom grounded on transcendental freedom presents a sort of reality that straddles the two worlds, so to speak, of appearances and things in themselves. On the one hand, there is transcendental freedom, which is necessarily outside of experience and its spatiotemporal framework. As an unconditioned cause, transcendental freedom cannot figure in experience. "Freedom in this signification is a pure 
transcendental idea, which, first, contains nothing borrowed from experience, and second, the object of which also cannot be given determinately in any experience" $(K r V$, A533/B561). At the same time, there is practical freedom, that seems to be within experience, since it has to contend with the desires/impulses that occur at particular times, in particular contexts.

There is no way the anti-realist version of free will in the epistemological interpretation can capture this sort of relationship between practical and transcendental freedom. In this epistemological version, we view ourselves as transcendentally free from a certain perspective, i.e. the deliberative perspective. In this perspective, we have abstracted from the epistemic conditions by which we come to represent objects to ourselves. Among these epistemic conditions are space and time. So, in the practical perspective, we have an absolute sovereignty over our decisions, and we are abstracted from the various desires that arise concerning a specific spatiotemporal location. The abstraction from these desires occurs because, in considering ourselves as transcendentally free, we are abstracting from the epistemic conditions of space and time.

Once we shift to the theoretical perspective, epistemic conditions are restored, and we see ourselves in space and time, as part of a causal network which determines us. In the theoretical perspective, transcendental freedom does not remain as a ground. It disappears since the anti-realist presuppositions of this account of free will mean that whatever lacks evidence in a given perspective does not have an objective existence. The epistemological interpretation presents transcendental freedom as something that is not verification-transcendent, i.e. capable of existing independently of the perspective in which it is verifiable (see Allais 2003: 376).

The idea that transcendental freedom just disappears once one considers oneself from the theoretical perspective, in the spatiotemporal framework, is not consistent with Kant's comments on the relationship between practical and transcendental freedom. Practical freedom, I have noted, is immersed in a temporal context, since it is immersed in the flux of desires. Our practical freedom makes us immune to necessitation by these desires. Practical freedom, then, is a kind of retention of transcendental freedom even amid the psychological pressures of desires and their necessarily temporal context. Practical freedom straddles two worlds. It is a 
capacity conferred by transcendental freedom, in the non-spatiotemporal world of things in themselves, that manifests itself in the spatiotemporal world of appearances, in which desires unfold over time.

This sort of picture is very different from the kind of picture we get in the anti-realist interpretation. In the anti-realist interpretation, once epistemic conditions are restored, and we see ourselves as an object in the spatiotemporal world, we are determined. The practical perspective is gone, and there can be no objective reality of our transcendental freedom independent from this perspective. It is far from clear, then, that we can have a sort of practical freedom, immune to the pressure of desire, once we shift perspectives and consider the self as an object in the empirical world. If transcendental freedom is not verification-transcendent, then it cannot ground practical freedom once we shift away from the deliberative, firstperson perspective.

Once one becomes aware of psychological drives operating in time, one has taken the theoretical perspective, in conformity with the epistemic conditions of time and space. According to the anti-realist epistemological interpretation, there is no transcendental freedom once one has taken the theoretical perspective. In this case, transcendental freedom cannot be a ground, as one views oneself from the theoretical perspective, for practical freedom.

The failure of anti-realism to properly frame the idea that practical freedom is grounded on transcendental freedom means it must be abandoned. Once it is abandoned, we acknowledge the possibility that transcendental freedom is perspective-independent. Determinism also is a characteristic of the person, as Kant's interest in defending transcendental freedom does not mean any compromise on determinism (see $\mathrm{KrV}$, A550/B578). But there can be no ontological distinction in the epistemological interpretation. So, if transcendental freedom is perspectiveindependent, determinism must also be so.

But, we know that transcendental freedom and determinism cannot exist in the same series, as two perspective-independent realities. This is why transcendental realism fails to resolve the third antinomy. The only 'solution', which ultimately fails, is to refashion transcendental freedom as a compatibilist version of freedom. 
13. The vacuity of the anti-realist perspectives

The epistemological interpretation is motivated by the alleged strangeness of certain implications of the ontological interpretation. One implication of the ontological interpretation is that we assume that appearances, which alone are cognizable, are caused by things that are outside the mind, which we cannot cognize. But, by restricting cognition to appearances, one prohibits oneself from making any claims to knowledge of what might exist independently of experience. So, one cannot assert the reality of things in themselves, as mind-independent grounds of experience. 7 There seems to be a contradiction, therefore, at the heart of transcendental idealism.

Another seemingly untenable implication is that, if we are aware only of a conditional mind-dependent reality, we can never have access to reality as it is in itself. We are therefore doomed to skepticism. We can never know the external world because knowledge means grasping the intrinsic predicates of things and not merely the way they appear to consciousness. 8

To avoid paradox and eternal entrapment in a mere illusion, we are supposed to adopt the anti-realist epistemological view. But, in the antirealist rendition of freedom, the two perspectives from which we view the person, either from within or from the outside, are vacuous. The perspectives have content only insofar as they have a certain meaning. But, they lack content to the extent that they refer to no aspects of things. Allison says explicitly that we are neither free nor determined (see 2004: 49). The perspectives have a certain conceptual content, but they are not rooted in any real aspect of the person, because there is no person independent of the perspectives.

So, the perspectives have psychological and conceptual content. We know what being free and determined mean. But, as far as having any ontological root in the person, these perspectives lack any. The perspectives are therefore vacuous. In the same way, I might take a perspective on one of Kant's books and see it as a black cat. This perspective has psychological/conceptual content but is vacuous insofar as it is completely disconnected from the ontology of the book.

7 This sort of objection has been around since Kant first came out with his ideas and is fairly easy to rebut. See Jacobi (1815: 304).

8 Henry Allison attributes this criticism to H.A. Prichard (see 1909: 71-100). 
Hoke Robinson provides an example of a vacuous perspective:

\begin{abstract}
Normally, a consideration of a thing under some aspect or respect $A$ would be vacuous if there is no sense in which the thing has, or is, $A$ : I can consider the Pietá as a great work of art, a lump of marble, an expression of religious faith, or a valuable commodity, but to consider it as a rocket or as a mathematical formula is just to be mistaken (1994: 421).
\end{abstract}

A vacuous perspective, then, is one that has no connection to the thing being considered. A vacuous perspective is merely psychological, without any point of anchor in the ontology of the thing being considered. There is some objectively existing thing that constrains the number of nonvacuous perspectives one might take on a thing. Seeing the Pietà as an expression of religious faith is not vacuous, because it highlights a real aspect of the work of art, i.e. that it elevates the mind to faith in a higher power. The perspective in which one sees the Pietà as an expression of religious faith has roots in the ontological reality of the work of art. But, seeing the Pietà as a mathematical formula is vacuous, since it has nothing to do with what this work of art actually is.

In the same way, one might challenge the anti-realist version of free will. We have two perspectives, neither of which correspond to any objective reality that is perspective-independent. We can conclude that there really is no objectively existing person. I am nothing more than mutually exclusive perspectives.

I see no reason that this view-that the self is just a mental phenomenon - is any less bizarre than the view that one can only know appearances and not ultimate reality, or that ultimate reality is something we cannot cognize but causes what we can cognize.

Moreover, one might take the approach of Robinson to vacuous perspectives, and apply it to the anti-realism of the epistemological interpretation. "Thus if the two considerations [of a thing as an appearance and as a thing in itself] are to be non-vacuous, we must ultimately deal with the aspects to which the considerations are directed" (Robinson 1994: 421). That is, to avoid a situation in which we are dealing with just two empty perspectives, having only a mental content and no roots in an extramental 
reality, we have to inquire into the aspects of things. We have to move from mere psychological considerations to ontological aspects.

If we try to root the two considerations in ontological aspects of things, we end up with compatibilism. Rooting considerations in ontological aspects is the only hope for providing some ontological credibility, i.e. nonvacuity, for the perspectives. So, the perspective from which one is determined, let us say, is rooted in an aspect of the self that is really determined.

If there is a determined aspect, then the only freedom the self can have is compatibilist. This is because there can be no ontological distinction, between the self as it appears and the self as it is independently of epistemic conditions, in the epistemological view. So, if there is a real aspect of determinism to the self, then freedom has to be within this aspect and, of course, this can only be compatibilist freedom.

If, on the other hand, one tries to posit a real aspect of freedom, then determinism cannot be a mere appearance. To designate freedom as a real aspect, and determinism as a mere appearance, that is purely mental and not ontological, amounts to making an ontological distinction between them. An epistemological view, of course, cannot tolerate this. So, again, we have to intermingle determinism with freedom, by making it also an ontological aspect. This intermingling can only mean that freedom is compromised and we end up with compatibilism.

\section{Conclusion}

In this paper, I surveyed compatibilist theories of free will and identified major flaws in these approaches. Then, I showed how an epistemological interpretation of transcendental idealism leads to an anti-realist conception of the human person, such that the person is neither free nor determined. I made the case, then, through a series of three arguments that the anti-realism about the person is untenable. Though the epistemological interpretation can present incompatibilism of sorts through its anti-realism, the untenability of anti-realism means that its only hope is a compatibilist theory. The epistemological interpretation, therefore, ends up twisting Kant's view of freedom into a compatibilist theory which is both deeply flawed and something that Kant surely would reject. 
References

ALLAIS, L.: "Kant's Transcendental Idealism and Contemporary AntiRealism", International Journal of Philosophical Studies 11, 4 (2003) 369392.

ALLISON, H.: Kant's Theory of Freedom, Cambridge, Cambridge University Press, 1990.

: Kant's Transcendental Idealism, New Haven, CT, Yale University Press, 2004.

: "From Transcendental Realism to Transcendental Idealism", in GARDNER, S.; MATTHEW, G. (eds.): The Transcendental Turn, Oxford, Oxford University Press, 20-34, 2015.

AMERIKS, K.: Interpreting Kant's Critiques, Oxford, Clarendon Press, 2003.

: "Review of Allison, Henry: Kant's Theory of Freedom." Ethics (1992): 655-657.

AYER, A. J.: "Freedom and Necessity", in WATSON, G.: Free Will, Oxford, Oxford University Press, 15-23, 1982.

CHISHOLM, R.: "Human Freedom and the Self", in WATSON, G. (ed.): Free Will, New York, NY, Oxford University Press, 1-15, 1964.

DUMMETT, M.: "Realism", in: Truth and Other Enigmas, Cambridge, MA, Harvard University Press, 145-165, 1978.

FRANKFURT, H.: "Freedom of the Will and Concept of the Person", Journal of Philosophy, 68 (1971) 5-20.

HARTNACK, J.: Kant's Theory of Knowledge, Indianapolis, IN, Hackett Publishing Company, Inc., 2001.

HOBBES, T.: Leviathan, London, Penguin Books, 1985.

JACOBI, F. H.: Werke, Leipzig, Gerhard Fleischer, 1815.

KANE, R.; FISCHER, J. M.; PEREBOOM, D.; VERGAS, M. (eds.): Four Views on Free Will, Cambridge, MA, Blackwell Publishing, 2007.

KANT, I.: Critique of Practical Reason, Cambridge, Cambridge University Press, 1996. 
Critique of Pure Reason, 1781(A) and 1787(B), Cambridge, Cambridge University Press, 1998.

KORSGAARD, C.: Creating the Kingdom of Ends, Cambridge, Cambridge University Press, 1996.

LANGTON, R.: Kantian Humility, Oxford, Clarendon University Press, 1998.

PEREBOOM, D.: Living without Free Will, Cambridge, Cambridge University Press, 2001.

PRICHARD, H. A.: Kant's Theory of Knowledge, Oxford, Clarendon Press, 1909.

ROBINSON, H.: “Two Perspectives on Kant's Appearances and Things in Themselves", Journal of the History of Philosophy 32, 3 (1994) 411-441.

SCHOPENHAUER, A.: "On Freedom of the Will”, in: ZUCKER, M.: The Philosophy of American History: The Historical Field Theory, Michigan, MI, Arnold-Howard Publishing Company, Inc, 520-540, 2013.

STRAWSON, P. F.: "Freedom and Resentment", in WATSON, G.: Free Will, Oxford, Oxford University Press, 72-93, 1982.

WATKINS, E.: Kant and the Metaphysics of Causality, New York, NY, Cambridge University Press, 2005.

WOOD, A.; GUYER, P.; ALLISON, H. (eds.): "Debating Allison on Transcendental Idealism”, Kantian Review 12, 2 (2007) 1-39. 


\title{
Estructura argumentativa, unidad temática y coherencia doctrinal en los Progresos de la metafísica de Immanuel Kant. Una revisión crítica de la edición de Friedrich T. Rink
}

\author{
MARCOS THISTED 1
}

\begin{abstract}
Resumen
A pesar de la importancia que la Kantforschung concede a los Progresos de la metafísica, los principales estudios dedicados a esta obra inconclusa y póstuma del filósofo crítico coinciden en considerarla como carente de una nítida unidad temática, afectada por severas anomalías en su estructura argumentativa y con diversas incoherencias desde el punto de vista doctrinal. A partir de una revisión crítica de la edición de los textos efectuada por el albaceas de Kant, Friedrich T. Rink —en la que, a su vez, se basa la edición académica de los Progresos-, nuestra contribución se propone indicar cuál sería la unidad temática de esta obra, identificar sus pilares argumentativos y, por último, establecer su coherencia doctrinal.
\end{abstract}

Palabras clave: metafísica, crítica, progreso

The metaphisical deduction of the ideas from the forms of silogism

\begin{abstract}
Despite the significance attributed by Kantian scholars to the Progress of Metaphysics, the major studies devoted to this unfinished, posthumous work by the critical philosopher agree that it lacks a clear thematic unity and that it shows severe anomalies in its argumentative structure, with various inconsistencies as regards doctrine. Based on a critical review of Friedrich T. Rink's edition of the writings, our contribution aims to show the possible thematic unity of this work, to identify its main argumentative lines and, finally, to establish its doctrinal consistency.
\end{abstract}

Keywords: metaphysics, critique, progress

1 Universidad de Buenos Aires. Contacto: marcosthisted@gmail.com. 


\section{Introducción}

Los Progresos de la metafísica tienen un lugar de relevancia asegurado en los estudios kantianos. Las razones de tal reconocimiento no son difíciles de comprender: en sus páginas inconclusas, Kant retoma el hilo de su reflexión sobre el problema de la metafísica, teniendo ahora la perspectiva privilegiada y la madurez conceptual que le ofrece la finalización de la 'síntesis crítica'.2

Ahora bien, este juicio favorable de la crítica especializada no alcanza a la memoria como conjunto: se refiere, más bien, a ciertos capítulos de la obra — especialmente, a la Sección Segunda, que contiene la renombrada doctrina de los estadios de la metafísica (Menzer 1911: 371374; Freyer 1912: 100-122; Wundt 1924: 375-400; Braun 1971: 139-203; Caimi 1989: 85-175; Grandjean 2008: 3-14)—, y a determinados conceptos —como, por ejemplo, el simbolismo y la analogía (Caimi 1989: 79-83); o la metafísica práctico-dogmática (Paulsen 1898: 255-257; Oesterreich 1906: 93-108; Heimsoeth 1949: 112-113, 128-135; Rovira 2001: 646-655; Caimi 1992: 259-286; Cunico 2008, 309-329)—. Es decir, concierne fundamentalmente a aquellos aspectos fragmentarios o parciales del escrito kantiano que, ya sea por su novedad, por su excepcionalidad, o tal vez por la madurez de su formulación, llamaron la atención de los estudiosos del idealismo transcendental, particularmente de aquellos que — siguiendo el camino iniciado por Friedrich Paulsen (1898: 255-257) y Max Wundt (1924: 375-400) — sondaron las regiones menos frecuentadas del corpus crítico en busca de textos que confirmaran lo que las tres Críticas dejarían solo traslucir: la existencia de un Kant metafísico. 3

Pero la buena suerte de las partes no se transmitió al todo. En efecto, considerados no ya como un mosaico de conceptos y de párrafos cargados de sugerencias metafísicas, sino como una obra dotada de una totalidad de sentido propia, los Progresos de la metafísica ha recibido más bien críticas

2 Los estudiosos de los Progresos de la metafísica han determinado con certeza, aunque no con exactitud, el lapso en el que Kant habría redactado los manuscritos publicados por su albaceas, Friedrich T. Rink, bajo el extenso título Sobre la cuestión propuesta por la Real Academia de Ciencias de Berlín como certamen para el año 1791: ¿Cuáles son los reales progresos que ha hecho la metafísica desde el tiempo de Leibniz y de Wolff en Alemania?: la tarea se habría iniciado no antes de 1792/1793 y habría culminado no después de 1795 (véase de Vleeschauwer 1974: 299-307; Manganaro 1977: 27-30).

3 A propósito de la relación entre el inicio de los estudios eruditos sobre los Progresos de la metafísica y la Wendung zur Metaphysik de inicios de siglo pasado, véase Manganaro (1977: 11$18)$. 
y objeciones severas, entre las que pueden destacarse las siguientes: en primer lugar, que la memoria carece de una estructura argumentativa sólida, probablemente debido a las anomalías filológicas de que adolece;4 en segundo término, que no es posible determinar con suficiente rigor su unidad temática; 5 tercero, que debido a su ambivalencia temática conviven en el texto doctrinas tan opuestas que resultan contradictorias entre sí.6

El principal objetivo de este artículo es ofrecer argumentos consistentes que pongan en cuestión este juicio negativo que pesa sobre los Progresos de la metafísica. Sostendremos, en efecto, que los textos redactados por Kant representan una verdadera obra, un totum dotado de una estructura argumental suficientemente sólida como para servir de base a un texto definitivo, con una unidad temática claramente delimitada y absolutamente coherente desde un punto de vista doctrinal (independientemente de los defectos característicos de toda obra inconclusa). Más aún, nos proponemos mostrar que tal juicio negativo no se debe a los manuscritos legados por Kant sino, fundamentalmente, a la deficiente tarea de edición a la que fueron sometidos posteriormente por parte del albaceas de Kant, Friedrich T. Rink.

Con este propósito, en primer lugar, estableceremos en qué consiste el problema filológico fundamental que afecta a los Progresos de la metafísica e indicaremos cuál fue el criterio elegido por el editor para abordar tal inconveniente, al mismo tiempo que explicaremos el misterio que envuelve la aplicación de dicho criterio. En segundo lugar, procederemos al análisis de algunos pasajes cruciales de las dos versiones existentes del capítulo introductorio de los Progresos, indicando previamente cómo consideramos que debe procederse en su exégesis,

4 Las principales anomalías filológicas de los Progresos de la metafísica consisten en la duplicación de todas sus secciones, el desorden de algunas de sus páginas más importantes y los huecos faltantes entre algunas de ellas (véase Vleeschauwer 1979). La mayor parte de los intérpretes de los Progresos considera que esta característica específica del texto basta para considerarla una obra carente de solidez argumentativa (Wundt 1924: 375-400; Langthaler 2010: 155-179; Thiel 2008: 154-163; von Herrmann 2004: 1-20; Hahmann 2009: 214-224).

5 La principal incógnita, aún no despejada por la crítica especializada, es la siguiente: ¿se proponía Kant presentar en los Progresos de la metafísica una original (y ciertamente premonitoria) concepción dialéctica de la historia de la filosofía (escandida en tres estadios), o más bien su objetivo era presentar los pilares fundamentales de un sistema de la metafísica, moldeado según el esquema heredado de la escolástica tardo-medieval y de la Schulmetaphysik (una metaphysica generalis u ontología y tres disciplinas especiales), pero fundado sobre el nuevo basamento crítico? (Wundt 1924: 375-400; Thiel 2008: 154-163; Han 1988).

6 Esta contradicción, sostiene Félix Duque (1987: LXVI) habría forzado a Kant a un prematuro abandono de la redacción de la memoria. 
habida cuenta de la singular naturaleza del texto al que nos enfrentamos. Reservamos la conclusión para llevar a cabo una evaluación retrospectiva del recorrido realizado.

2. Un problema filológico clave en la edición original de los Progresos de la metafísica: las dos versiones de la Introducción

De las numerosas anomalías filológicas que dificultan la comprensión de los Progresos de la metafísica, una se destaca entre todas: la existencia de dos versiones de la Introducción de la obra; una fue emplazada por Rink al inicio de la memoria kantiana (FM, AA 20: 259-265); la otra fue desplazada por el editor al primero de los Anexos (FM/Beylagen, AA 20: $315-320) .7$

El origen de esta duplicación del capítulo inaugural es bien conocido para los estudiosos de los Progresos de la metafísica: los tres fajos de texto entregados por Kant a su albaceas contenían en total dos versiones de cada uno de los capítulos que integraban la memoria que el filósofo había proyectado. 8 Esta tarea debió resultar relativamente sencilla para el caso de las dos secciones principales (en ambos casos, el grado de desarrollo es claramente disímil y funciona por sí mismo como criterio de distinción para determinar cuál de ellas debía incluirse como parte oficial de la memoria y cuál relegar a los Anexos), 9 pero no resultaba en absoluto evidente con respecto a la Introducción. En efecto, ambas versiones de este primer apartado habían sido objeto de una elaboración suficientemente cuidadosa por parte de Kant y no exhibían fisuras retóricas o argumentativas de

\footnotetext{
7 En la edición académica figuran los títulos Vorrede (FM, AA 20: 259-265) y Einleitung (FM, AA 20: 315-320) para designar una y otra versión del capítulo inaugural del texto kantiano. Ahora bien, solamente la segunda designación podría provenir de la pluma de Kant; la primera (Vorrede) parece un agregado posterior ya que no figura en la edición original de 1804 (Kant 1804: 7, 155). Seguimos, por ello, el consejo de Kant Vleeschauwer, quien sostenía que no debía darse importancia alguna a este distingo entre Vorrede y Einleitung (1979: 159). Por ello, nos referiremos indistintamente a la Introducción de los Progresos (diferenciaremos una y otra versión, como se verá más adelante, denominándolas respectivamente como 'Introducción oficial' e 'Introducción anexo').

8 Un análisis detallado de esta anomalía filológica se encuentra en de Vleeschauwer (1979: 158-164). 9 La Sección Primera elegida por Rink como oficial tiene quince páginas de desarrollo ( $F M$, AA 20: 265-280); mientras que la que fue relegada a los Anexos tiene tan solo dos páginas (FM/Beylagen, AA 20: 322-324). Análogamente, la Sección Segunda oficial ocupa otras quince páginas (FM, AA 20: 281-296), mientras que la versión arrumbada en los Anexos solo dos (FM/Beylagen, AA 20: 324326). Por el contrario, en el caso de la Introducción, la versión oficial tiene seis páginas ( $F M$, AA 20 : 259-265) y la versión relegada a los Anexos tiene cinco (FM/Beylagen, AA 20: 315-320); en ambas se aprecia una cuidada utilización retórica de los términos involucrados en la Preisfrage.
} 
relevancia. Por esta razón, para el caso de la Introducción, Rink decide relegar aquella versión que le parecía "en cierto modo, la más completa", por la que consideraba que se ajustaba más al conjunto de las restantes partes de la memoria, con el objetivo de evitar "una fusión forzada de varias elaboraciones" y una mayor "falta de concordancia", de la que ya adolecía el texto (FM, AA 20: 259.12-31).10

Si las declaraciones de Rink tienen algún valor de verdad, la versión de la Introducción que figura al inicio de la obra en todas las ediciones actuales de los Progresos de la metafísica (que para mayor comodidad llamaremos 'Introducción oficial'), debería ser coherente y relativamente armónica con el desarrollo del texto. Y, en cambio, la versión arrumbada en el primer Anexo (de ahora en más, 'Introducción anexo') debería ser, sí, la más completa pero se encontraría desarticulada con respecto al todo argumentativo de la memoria.

Pero algo extraño debió suceder en la aplicación de este razonable criterio ideado por Rink. En efecto, si el editor se hubiera atenido a él a rajatabla, la elección debería haber sido exactamente a la inversa: la que hoy funge como Introducción oficial (FM, AA 20: 259-264) debiera haber sido ubicada en los Anexos de los Progresos de la metafísica, ya que no hay ninguna relación evidente entre ella y el resto de la obra;11 y, por el contrario, la Introducción anexo se encuentra - como veremos - en notable armonía tanto desde un punto de vista retórico como argumentativo con el conjunto del texto.

Según creemos, esta inconsistencia entre la Introducción oficial y el resto de la memoria proyectada es responsable de la mayor parte de las valoraciones negativas que ha recibido el texto Progresos de la metafísica como obra (inconclusa, claro, pero dispuesta como un todo argumentativo que no puede ser desmembrado sin tener en cuenta el todo al que pertenece y del que depende el sentido de sus partes).12

10 Utilizamos la versión española de los Progresos de la metafísica (Caimi 2008). Para el texto original en alemán nos hemos guiado por la edición académica (Kant 1942: 253-351). Hemos controlado esta edición académica con la versión original de la memoria kantiana (Kant 1804).

11 Nos referimos específicamente al Tratado [Abhandlung] (FM, AA 20:265.1-12) y a las dos Secciones centrales de la obra [Erste Abteilung (FM, AA 20: 265-280) y Zweite Abteilung ( $F M$, AA 281-296)].

12 Este supuesto se encuentra presente, explícita o implícitamente, en los principales estudios sobre los Progresos de la metafísica (Wundt 1924; Han 1988; Duque 1987; Caimi 1989; Grandjean 2013). 
He ahí pues gran parte del misterio que pesa sobre la edición de este escrito póstumo de Kant: o bien Friedrich T. Rink insólitamente aplicó mal un criterio que era en sí mismo válido, o bien debió ocurrir un problema final en la manipulación del material que arruinó un trabajo razonablemente proyectado. Sea de ello lo que fuere, 13 el error resultó fatal y decisivo para la incomprensión de la estructura argumentativa de la memoria ideada por Kant y debe ser restañado. Con tal propósito, analizaré algunos aspectos de las dos versiones de la Introducción (anexo y oficial —en este orden-) de los Progresos de la metafísica.

\section{La Introducción de los Progresos de la metafísica y sus dos versiones}

\subsection{La Introducción anexo de los Progresos de la metafísica}

Antes de proceder al análisis del texto del capítulo introductorio de los Progresos de la metafísica conviene dedicar una breve reflexión a la función que cumple, en general, el primer capítulo en un escrito de características tan peculiares como es un Preisschrift. A diferencia de otro tipo de textos filosóficos de Kant, la primordial tarea de la Introducción de los Progresos de la metafísica consiste en explicitar el modo en que será interpretada la pregunta académica. Y mucho más en el caso de la desconcertante fórmula propuesta por la Academia de Ciencias de Berlín.14 Pero, en segundo término, se trata de traducir los términos de la enunciación de la Preisfrage al vocabulario propio del filósofo: ¿qué debía entenderse, desde la perspectiva crítica, por progreso, metafísica, real, etc.? Y, por sobre todas las cosas: ¿cómo esos términos pueden congeniar entre sí en una sola formulación?

Una vez resueltas estas dos cuestiones -interpretación de la Preisfrage; traducción al vocabulario crítico-, Kant pasa a la tercera tarea: la anticipación del modo en que esa pregunta, reformulada en el vocabulario

\footnotetext{
13 Cabe subrayar que los manuscritos redactados por Kant aún no han sido encontrados y que lo más probable es que hayan sido destruidos en el proceso mismo de la publicación de la memoria kantiana. 14 La pregunta académica rezaba: “¿Cuáles son los reales progresos que ha hecho la metafísica en Alemania, desde la época de Leibniz y Wolff?”. Como era tradición, la Academia de Ciencias de Berlín formuló en francés dicha consigna: "Quels sont les progrès réels de la Métaphysique en Allemagne depuis le temps de Leibnitz et de Wolff?". Existen suficientes registros de época que dan cuenta del desconcierto que generó la integración, en una sola fórmula, del concepto de metafísica (que vinculaba la discusión a la polémica entre el criticismo y el neowolffianismo) y del progreso de las disciplinas filosóficas (que conectaba la contienda con la discusión en torno a la reflexión metateórica sobre la historia de la filosofía) (von Eberstein 1794; 1799: 486-508).
} 
y el espíritu de la filosofía crítica, será abordada a lo largo de la obra. Esto se lleva a cabo en un pequeño texto que es, en rigor, una bisagra entre la Introducción y las dos secciones de la memoria, al que Kant denomina Tratado [Abhandlung] (FM, AA 20: 265).

Pasemos, ahora sí, sin más dilación, al análisis del texto de la Introducción anexo, que comienza del siguiente modo:

El problema de la Real Academia de las Ciencias contiene en sí implícitamente [stillschweigend] dos cuestiones:

I. Si la metafísica, desde siempre hasta inmediatamente después del tiempo de Leibnitz y de Wolff ha dado siquiera en general un solo paso [Schritt] en aquello en lo que consiste su fin propio, y el fundamento de su existencia; pues solo si eso ha sucedido se puede preguntar por los progresos [Fortschritte] ulteriores que haya realizado a partir de cierto momento.

IIda. Cuestión es: si sus presuntos [vermeyntlichen] progresos son reales [reell]. (FM/Beylagen, AA 20: 315.06-15)

Con sutil ironía, considera Kant en este pasaje inicial que la Preisfrage es, en rigor, una pregunta compleja. Las dos cuestiones que oculta deben ser correctamente elucidadas para ser respondidas, luego, cada una por separado.

La primera de estas cuestiones se anuncia con un peculiar juego de palabras, artilugio retórico que utiliza Kant para indicar una relación de precedencia desatendida por el dogmatismo leibnizo-wolffiano (y, en rigor, por todo dogmatismo): los pasos [Schritten] (hacia la metafísica) deben preceder a los progresos [Fortschritte] (de la metafísica).15 $\mathrm{Si}$ bien a la Academia le interesan solamente estos últimos —los Fortschritte der Metaphysik-, el filósofo crítico recuerda que su posibilidad depende de los pasos que les anteceden. Este juego de palabras - imposible de verter al castellano - lo utiliza Kant para introducir la relación, sello distintivo del criticismo, entre filosofía transcendental (que se encarga de los Schritten nach Metaphysik) y metafisica propiamente dicha (que trata sobre los Fortschritten der Metaphysik).

Se puede comprobar fácilmente, siguiendo esta clave de lectura, con la lectura del Tratado (FM, AA 20: 265-266) y del cuerpo central de la

15 En el Tratado Kant lo anuncia sin ambages, véase FM (AA 20: 265.8-10). 
memoria kantiana (FM, AA 20: 266-311) que Kant, efectivamente, ha dedicado la Sección Primera [Erste Abteilung] a una sintética presentación de la filosofía transcendental escandida en tres pasos hacia la metafísica;16 y ha consagrado la Sección Segunda [Zweite Abteilung] a una presentación originalísima del progreso de la razón pura en la metafísica propiamente dicha dividida en tres estadios.17

Es este pues el fundamento de la estructura de la memoria kantiana, que conecta a la Introducción, al Tratado, y a las dos Secciones de la memoria kantiana.

¿Qué ocurre, pues, con la segunda cuestión que menciona Kant en el pasaje inaugural de la Introducción anexo que hemos citado más arriba - a saber, aquella que se refiere a la discriminación entre un progreso efectivo, real, de la metafísica y otro que no es más que mera apariencia (FM/Beylagen, 20: 315.13-14)—?

Ante todo, notemos que se trata de un nuevo juego de palabras, esta vez más sutil y casi imperceptible. En efecto, Kant utiliza para referirse a la realidad de los progresos de la metafísica la voz alemana de procedencia latina 'reell' cuando, en rigor, hubiera sido esperable 'wirklich' (véase $F M$, AA 20: 315).18 Es posible que la formulación de la Preisfrage académica en francés motivara la excepcional elección terminológica por parte de Kant. Sin duda; pero sostenemos que, en todo caso, no es esa la única razón: una lectura atenta de los Progresos de la metafísica muestra que Kant utiliza el concepto de realidad objetiva [objektive Realität] con un fin claramente polémico, a saber, para discernir el progreso aparente del progreso real de la metafísica, según se trate —claro está— de la metafísica leibnizo-wolffiana

\footnotetext{
16 En la Sección Primera puede leerse que los tres pasos hacia la metafísica dados por la filosofía transcendental están representados (en este orden) por i) la distinción de los juicios en analíticos y sintéticos (FM, AA 20: 265.16-25); ii) la formulación de la pregunta "¿Cómo son posibles los juicios a priori?" ( $F M$, AA 20: 266.1-9), y iii) por el planteo del problema "¿Cómo es posible un conocimiento a priori a partir de juicios sintéticos?" (FM, AA 20: 266.10-22).

17 La Sección Segunda se divide en tres estadios de la metafísica que exponen sistemáticamente el progreso de la razón pura, del conocimiento de lo sensible al conocimiento de lo suprasensible: i) la Doctrina de la ciencia; ii) la Doctrina de la duda; y iii) la Doctrina de la sabiduría ( $F M$, AA 20 : 272.32-37, 273.1-10).

18 En este sentido, puede constatarse que, inclusive el propio Rink, al elegir el título para la memoria kantiana, adopta la fórmula "wirklichen Fortschritte" ("¿Cuáles son los verdaderos avances que la metafísica ha hecho desde la época de Leibniz y Wolf en Alemania?" ["Welches sind die wirklichen Fortschritte, die die Metaphysik seit Leibnitzens und Wolfs Zeiten in Deutschland gemacht hat?'], cursiva añadida).
} 
o de la metafísica crítica.19 En efecto, mientras que la primera no es capaz de mostrar ni la realidad objetiva de los conceptos de la metafísica general o 'conceptos de lo sensible' (porque desconoce la distinción crítica entre sensibilidad y concepto) (FM, AA 20: 281-286) ni tampoco la realidad objetiva de los conceptos de la metafísica especial o conceptos de lo suprasensible (FM, AA 20: 279-280, 296-310) (porque desconoce la distinción crítica entre uso teórico y uso práctico de la razón y, sobre todo, porque desconoce la diferencia entre el origen de los conceptos ontológicos en el entendimiento puro y el de los conceptos metafísicos en la razón pura); en cambio, el criticismo supera airoso ambas pruebas.

La elección de la voz reell en la enunciación de la segunda cuestión a ser tratada en los Progresos de la metafísica se ajusta claramente a la preocupación de Kant por indicar de qué modo se resolvería la contienda con el neowolffianismo, cuyo escenario había sido montado para la ocasión por la Academia de Ciencias de Berlín, en ese momento todavía fuertemente influida por Eberhard: el concepto de realidad objetiva.20

\subsection{La Introducción oficial de los Progresos de la metafísica}

Pero, entonces: la solución al problema que estamos tratando, a saber, la deficiente edición de los Progresos de la metafísica, ¿consistiría en aplicar correctamente el razonable criterio pensado por Rink? Esto equivaldría a invertir el orden en el que se encuentran actualmente ambas versiones de la Introducción de los Progresos. Procediendo de esta manera, es cierto, el lector tendría a su vista los rasgos estructurales de la memoria kantiana - la división de la obra en filosofía transcendental y metafísica propiamente dicha-, del mismo modo que podría captar más sencillamente la función polémica que desempeña en esta obra el concepto de realidad objetiva (contra el neowolffianismo).

\footnotetext{
19 La función polémica de este concepto crítico no era novedosa: ya en Über eine Entdeckung, nach der alle neue Kritik der reinen Vernunft durch eine ältere entbehrlich gemacht werden soll había utilizado Kant el concepto de realidad objetiva para impugnar la posición filosófica de Eberhard (ÜE, AA 08: 188-191, 193, 204).

20 El concepto de la realidad objetiva teórica de los 'conceptos de lo sensible' (es decir, de los conceptos puros del entendimiento) se fundamenta en la Sección Primera (FM, AA 20: 266-280) y es esgrimido como una crítica a la ontología o metaphysica generalis leibnizo-wolffiana al comienzo de la Sección Segunda, en el primer estadio de la metafísica (FM, AA 20: 281-285). El concepto de la realidad objetiva práctica de los 'conceptos de lo suprasensible' se fundamenta al inicio del tercer estadio de la metafísica (FM, AA 20: 293-301) y se utiliza como crítica a la metafísica especial en las restantes páginas de la Sección Segunda (FM, AA 20: 301-310; véase especialmente AA 20: 301.13 26; AA 20: 309.7-35; AA 20: 309.37-38, 310.19).
} 
Sin embargo, si solo se tratara de aplicar correctamente el criterio de Rink, se perdería de vista el papel relevante que desempeña, también, la Introducción oficial (FM, AA 20: 259-265). En efecto, esta segunda versión cumple una función relevante ya que nos ofrece una pre-comprensión del concepto más original de la memoria kantiana, aquel que responde, desde el punto de vista propiamente filosófico - y no ya polémico-, a la inquietud de la Academia de Ciencias de Berlín: la posibilidad de establecer una relación entre el 'progreso' y la 'metafísica'.

Analicemos este segundo asunto con un poco más de detalle. Del mismo modo que sucedía en la Introducción anexo (FM/Beylagen, 20: 315319), aquí, en la Introducción oficial, Kant dedica las páginas iniciales a la elucidación del sentido de la pregunta académica y a su asimilación a la filosofía crítica, destilando una vez más su filosa ironía contra la institución promotora de la contienda filosófica:

La Real Academia de las Ciencias desea que se enumeren los progresos de una parte de la filosofía, en una parte de la Europa culta, y además en una parte del corriente siglo.

Esta parece una tarea fácil de cumplir, pues concierne solo a la historia [Geschichte]; y así como los progresos [Fortschritte] de la astronomía y de la química, como ciencias empíricas, han hallado ya a sus historiadores, y los del análisis matemático o de la mecánica pura, realizados en el mismo país en el mismo período, hallarán también, si se quiere, pronto los suyos, así también parece que no fuera mayor la dificultad con la ciencia de que aquí se trata (FM, AA 20: 259.1-11).

Evidentemente, en esta versión de la Introducción no se refiere Kant ni a la relación entre filosofía transcendental y metafísica propiamente dicha ni a la realidad o apariencia del progreso en la metafísica.21 Aquí se aborda la consigna académica desde una perspectiva que podríamos denominar

21 En general, los estudiosos de los Fortschritte der Metaphysik suelen considerar ambas versiones de la Introducción como similares. Pero esto se debe a que no han reparado en la importancia que tiene la interpretación que Kant da de la pregunta académica. En la anterior versión de la Introducción analizada, Kant ironiza respecto de la posición dogmática de la Academia en filosofía (que no les permite reconocer la precedencia del problema de la pregunta por la posibilidad de la metafísica, antes de abordar el problema de la metafísica por sí mismo); ahora, en la segunda versión, Kant ironiza respecto de la posición ecléctica de la Academia con relación a la historia de la filosofía, que lleva a los académicos a ignorar las diferencias esenciales que hay entre la metafísica y las demás ciencias, creyendo que lo que es posible en estas (la redacción de la historia de la disciplina), es posible también en aquélla. 
metafilosófica: el problema consiste ahora en evaluar si corresponde poner en conexión - como lo exige la Academia- dos términos que son, en apariencia, antitéticos: el clásico concepto de metafísica y el moderno concepto de progreso.22

La reflexión de Kant parece nacer de la sospecha de estar frente a una analogía inapropiada: lo que vale para las ciencias fragmentarias empíricas — como la astronomía y la química - y que puede valer para las ciencias puras, pero fragmentarias - como la matemática y la mecánica pura-, no necesariamente se aplica, argumenta, a la metafísica, que es una ciencia fundada integralmente "en la crítica de toda la facultad pura de la razón" (FM, AA 20: 321). Por lo tanto, si el término progreso puede aplicarse a la "más antigua" de las ciencias ( $K r V$, BXIV), deberá ser en un sentido absolutamente diferente del que —ingenua o maliciosamenteespera la Real Academia de Ciencias de Berlín.23

Y, en efecto, el corazón de la respuesta kantiana al problema planteado por la Academia gira alrededor de esta tensión esencial entre metafísica y progreso. La metafísica es una ciencia integral en la que no hay progreso visible alguno, porque ni deja huellas ni tampoco tiene una meta sensible.24 Por lo tanto, la empresa propuesta por la Academia de Ciencias de Berlín parece desmesurada e, inclusive, inadecuada.

\footnotetext{
22 Sobre la vinculación del concepto de progreso con la historia de la filosofía en dicha época hay una extensa bibliografía. Es este el punto exacto de intersección entre el debate en torno al progreso de la metafísica y el debate en torno al método de escribir la historia de la filosofía, que abarca en general la segunda mitad del siglo XVIII alemán, pero que cobra particular vigor en la última década del siglo XVIII (Geldsetzer 1966) (en este sentido, es una confirmación fundamental la referencia a G. Fülleborn - una de las figuras descollantes del debate en torno al método de redactar historia de la filosofía, defensor del punto de vista crítico - en una de las 'Hojas sueltas' adosadas a la publicación académica de los Problemas [FM/Lose Blätter, AA 20: 343.9]).

23 Hay en esta obra póstuma de Kant dos conceptos de progreso en liza a lo largo de todo su desarrollo: uno, rechazado, el progreso histórico de la metafísica (en rigor: rechazado para el caso de la metafísica propiamente dicha, no para el caso de la historia 'filosofante' de la filosofía); otro, aceptado, el progreso dinámico, lógico-sistemático, de la facultad de conocimiento en el camino de su autocrítica. La doctrina de los estadios de la razón pura expone este segundo concepto de progreso. En ella vemos cómo la razón pura (en su sentido más amplio posible) progresa del conocimiento de lo sensible (primer estadio), al conocimiento de lo suprasensible (tercer estadio), siguiendo la guía de las antinomias de la razón pura que evitan todo exceso dogmático y que también le indican la vía del uso práctico como solución al problema del acceso crítico al conocimiento de lo suprasensible (segundo estadio) (FM, AA 20: 311).

24 Kant expresa esta idea mediante una conocida metáfora: la metafísica es "un mar sin orillas, en el cual el progreso no deja huella alguna y cuyo horizonte no contiene ninguna meta visible [sichtbares] con respecto a la cual se pueda percibir cuánto se ha acercado" (FM, AA 20: 259).
} 
Pero, luego de haber señalado la extrema tensión que subyace a los dos términos que integran la Preisfrage, Kant presenta cuál será la vía por la que intentará mostrar un resultado positivo: una osada alteración crítica de la definición de la metafísica de cuño neoplatónico: "[La metafísica] es la ciencia de progresar mediante la razón, del conocimiento de lo sensible al [conocimiento] de lo suprasensible" (FM, AA 20: 260).25

De este modo, la definición de la metafísica que Kant presenta aquí, en la Introducción oficial, anticipa cuáles son los tres estadios que recorre la razón pura, precedida por la filosofía transcendental, en su progreso: la doctrina de la ciencia (conocimiento de lo sensible, fenoménico), la doctrina de la duda (segundo estadio, tránsito de lo sensible a lo suprasensible, sin conocimiento objetivo alguno) y la doctrina de la sabiduría (tercer estadio, conocimiento de lo suprasensible, práctico). Solo de ese modo, progreso y metafísica son compatibles: la metafísica propiamente dicha no es sino el camino lógico-transcendental que recorre la razón, progresando desde lo sensible hasta lo suprasensible.

Es por esta razón que consideramos que el criterio de F. T. Rink, en sí mismo correcto aunque mal aplicado, puede y debe ser mejorado en vista a una reedición de los textos de los Progresos de la metafísica: no solo se trata de aplicarlo bien (priorizar la versión de la Introducción que sea más coherente y armónica con los restantes capítulos del texto kantiano), sino también de acompañarla de la otra versión, a modo de preservar la asombrosa trabazón argumentativa y la riqueza teórica de los Progresos de la metafísica. De esta manera, quedarían a la vista del lector las dos versiones de la Introducción, tal que fuera comprensible (es el aporte de la Introducción anexo) la estructura argumentativa (filosofía transcendentalmetafísica propiamente dicha) y el concepto polémico de realidad objetiva (que permite distinguir el progreso real del meramente aparente); pero también la otra versión (Introducción oficial) que brinda la clave de la

\footnotetext{
25 El texto en alemán expresa del siguiente modo esta definición de la metafísica: ella es »die Wissenschaft, von der Erkenntniß des Sinnlichen zu der des Übersinnlichen durch die Vernunft fortzuschreiten « (FM, AA 20: 260). Cabe destacar que la incorporación del verbo 'progresar' [fortschreiten] es elección deliberada de Kant, ya que en las Lecciones de Metafísica Dohna encontramos la formula clásica, proveniente de la tradición leibnizo-wolffiana, en la que figura 'ascender' [übersteigen]: “Ascender de lo sensible a lo suprasensible, de los phenomenis a los noumenis a los noumenis,es el gran problema, ante el cual fraason tantos filósofos" [»Von dem Sinnlichen zum Übersinnlichen, von den Phenomenis zu den Noumenis überzusteigen ist das große Problem woran so viele Philosophen scheiterten«] (V-Met/Dohna, AA 18: 618).
} 
solución al problema académico desde la perspectiva de la propia filosofía crítica.

$\mathrm{Y}$ es en este punto donde reside la originalidad y el aporte de los Progresos a la riqueza del problema de la metafísica en el Kant de la década de los 90 .

\section{Conclusiones}

Esbozaremos algunas conclusiones de la revisión crítica de algunos aspectos específicos - aunque fundamentales - de la edición de los manuscritos kantianos realizados por Friedrich T. Rink que aquí hemos emprendido. En primer lugar, ha quedado establecida cuál es la estructura argumentativa de la obra, a saber, la distinción y estrecha relación — sello distintivo del criticismo - entre la filosofía transcendental y la metafísica propiamente dicha: la eigentlich Metaphysik, para alcanzar el status de ciencia, debe ser precedida por una filosofía transcendental que establezca el uso legítimo de sus conceptos. La filosofía transcendental es un medio para la metafísica propiamente dicha en la que se encuentra el fin último de la razón. Este distingo conceptual es el que está por detrás del juego de palabras entre Schritte nach Metaphysik (los tres pasos de la filosofía transcendental en dirección a la metafísica) y Fortschritte der Metaphysik (los tres estadios de la metafísica en los que la razón pura progresa de lo sensible a lo suprasensible). Las dos secciones desarrollan resumida y sistemáticamente el aporte del criticismo en cada uno de los respectos indicados.

En segundo término, hemos podido identificar en qué consiste la unidad temática de los Progresos de la metafísica $-\mathrm{y}$, por lo tanto, de la obra en sentido propio del término-: la peculiar explicación de la relación entre progreso y metafísica. Este asunto es abordado ya sea desde el punto de vista polémico, como desde el punto de vista propiamente filosófico. En efecto, contra el neowolffianismo de Eberhard, se sostiene que hay un progreso real (propio del criticismo) y otro meramente aparente (propio del dogmatismo filosófico); la demarcación entre uno y otro está dada por el concepto de realidad objetiva. Así, solo el criticismo sale airoso de la prueba diseñada, ya que es el único capaz de exhibir en qué consiste la realidad objetiva de los conceptos ontológicos y metafísicos y de mostrar, de este modo, la realidad de sus progresos en la metafísica. 
Pero, por otra parte, en sentido propiamente filosófico $-\mathrm{y}$ en esto consiste, tal vez, el mayor aporte al estudio de la metafísica crítica que brinda el análisis de los Progresos de la metafísica-, el progreso de la metafísica no es otro que el avance lógico-sistemático de la razón pura a través de sus tres estadios correctamente delimitados (repitámoslo una vez más: doctrina teórico-dogmática de la ciencia, doctrina escéptico-metódica de la duda y doctrina práctico-dogmática de la sabiduría).

Por último, podemos rechazar terminantemente la sospecha de una contradicción doctrinal: la obra Progresos de la metafísica, entendida desde una mirada de conjunto, ni trata acerca de la historia de la metafísica ni tampoco se propone como la reedición de un sistema clásico de la metafísica sobre nuevo basamento crítico: más bien pretende dar cuenta de la pregunta académica que exige poner en relación al concepto clásico de la metafísica y el novedoso concepto de progreso (y, al hacerlo, sin duda, ofrece importantes observaciones sobre la cuestión de la historia de la filosofía y sobre la edificación de un sistema de la metafísica crítica). Es esa la tensión conceptual la que se resuelve a lo largo de la memoria kantiana.

La revisión del problema filológico que entraña la duplicación de la introducción de los Progresos de la metafísica representa, por ello, un primer paso dirigido a devolver a este texto de 1790 el lugar que le corresponde como una obra clave de la metafísica kantiana.

\section{Referencias}

BRAUN, L.: Histoire de l'histoire de la philosophie, París, Ophrys, 1973.

CAIMI, M.: La metafísica de Kant, Buenos Aires, Eudeba, 1989. Reimpreso como comentario introductorio en Kant, I.: Los progresos de la metafísica, México, FCE, VII-CLXXXVI, 2008.

: "Consideraciones acerca de la metafísica de Kant", Revista

Latinoamericana de Filosofía XVIII, 2 (1992) 259-286.

: „Kants Metaphysik. Zu Kants Entwurf einer metaphysica specialis“, en FUNKE, G. (ed.): Akten des 7.[Siebenten] Internationalen Kant-Kongresses, I, Mainz/Berlín, Bouvier, 103-126, 1991. 
CUNICO, G.: „Erklärungen für das Übersinnliche: physikotheologischer und moralischer Gottesbeweis (§§85-89)“, en HOFFE, O. (ed.): Immanuel Kant Kritik der Urteilskraft, Berlín, Akademie Verlag, 309-330, 2008.

DUQUE, F.: "Historia y metafísica: El frágil espejo móvil de la razón. Contribución al estudio de la Aetas kantiana: 1790-1797", en: Immanuel Kant: Sobre el tema del Concurso para el año de 1791 propuesto por la Academia Real de Ciencias de Berlín: ¿Cuáles son los efectivos progresos que la Metafísica ha hecho en Alemania desde los tiempos de Leibniz y Wolff?, Madrid, Tecnos, XI-CCXXX, 1987.

FREULER, L.: Kant et la métaphysique spéculative, París, Vrin, 1990.

FREYER, J.: Geschichte der Geschichte der Philosophie im achtzehnten Jahrhundert, Leipzig, Voigtländer, 1912.

FUNKE, G.: „Die Wendung zur Metaphysik im Neukantianismus des 20. Jahrhunderts“, en: LABERGE, P.; DUCHESNEAU, F.; MORRISEY, B.Morrisey (eds.): Actes du Congrès d'Ottawa sur "Kant dans les traditions anglo-américaine et continentale”, Ottawa, Éditions de l'Université d'Ottawa, 36-76, 1976.

GAWLINA, M.: Das Medusenhaupt der Kritik. Die Kontroverse zwischen Immanuel Kant und Johann August Eberhard, Berlín/Nueva York, de Gruyter, 1996.

GELDSETZER, L.: „Der Methodenstreit in der Philosophiegeschichtsschreibung 1791-1820“, Kant-Studien 56, 3 (1966) 519-527.

GRANDJEAN, A.: "Kant historien de la métaphysique. Progrès sans histoire", en ALMEIDA, G.; ROHDEN, V.; RUFFING, M.; TERRA, R. (eds.): Recht und Frieden in der Philosophie Kants. Akten des X. Internationalen Kant-Kongresses, IV, Berlín/Nueva York, 3-14, 2008.

: "Présentation", en: I. Kant, Les progrès de la métaphysique, París, Flammarion, 9-77, 2013.

GRAPOTTE, S.: "Validité et réalité objectives", Kant-Studien 96, 4 (2005) 427-451.

HAHMANN, A.: Kritische Metaphysik der Substanz: Kant im Widerspruch zu Leibniz, Berlín, de Gruyter, 2009. 
HAN, J.: Transzendentalphilosophie als Ontologie: Kants Selbstinterpretation der Kritik der reinen Vernunft und Kritik der praktischen Vernunft in seiner Schrift ,Welches sind die wirklichen Fortschritte, die die Metaphysik seit Leibnizens und Wolff's Zeiten in Deutschland gemacht hat?', Würzburg, Königshausen-Neumann, 1988.

HEIMSOETH, H.: La metafísica moderna, Madrid, Revista de Occidente, 1949 [1932].

HERRMANN, F. W.: „Die ,Kritik der reinen Vernunft“ als TranszendentalMetaphysik“, en: FISCHER, N. (ed.): Kants Metaphysik und Religionsphilosophie, Hamburgo, Meiner, 1-20, 2004.

HOLZ, F.: Kant et l'Académie de Berlin, Fráncfort del Meno /Bern/Cirencester, Publications Universitaires Européennes, 1981.

HUMPHREY, T.: “Translator's Introduction”, en: I. Kant, What Real Progress Has Metaphysics Made in Germany since the Time of Leibniz and Wolff?, Nueva York, Abaris, 11-43, 1983.

KANT, I.: Los progresos de la metafísica, Buenos Aires, Eudeba, 1989. Reedición en México, Fondo de Cultura Económica, 2008.

: Metafísica - Dohna, Salamanca, Sígueme, 2007.

: Über die von der Königl. Akademie der Wissenschaften zu Berlin für das Jahr 1791 ausgesetzte Preisfrage: Welches sind die wirklichen Fortschritte, die die Metaphysik seit Leibnitzens und Wolff's Zeiten in Deutschland gemacht hat?, Königsberg, Goebbels \& Unzer, 1804.

: Kant's gesammelte Schirften, XX, Berlín, Academia Prusiana de las Ciencias, 1942.

LANGTHALER, R.: „Zur Gottesthematik in der ,Preisschrift“ über die wirklichen Fortschritte in der Metaphysik. Das Gefüge der Ideen des ,Übersinnlichen in uns, über uns und nach uns““, en FISCHER, N. (ed.): Die Gottesfrage in der Philosophie Immanuel Kants. Forschungen zur europäischen Geistesgeschichte, Friburgo, Herder, 155-179, 2010.

LEHMANN, G.: „Einleitung“, en: Kant's gesammelte Schirften, XX, Berlín, Academia Prusiana de las Ciencias, 479-483, 1942.

LÜBBE, H.: „Philosophiegeschichte als Philosophie. Zu Kants Philosophiegeschichtsphilosophie“, en OEHLER, K.; SCHAEFFER, R. 
(eds.): Einsichten. Gerhard Krüger zum 60.Geburstag, Fráncfort del Meno, Klostermann, 204-229, 1962.

MANGANARO, P.: "Introduzione", en: Immanuel Kant, I progressi della metafisica, Napoles, Bibliopolis, 12-58, 1977.

MENZER, P.: Kants Lehre von der Entwicklung in Natur und Geschichte, Berlín, Reimer, 1911.

MICHELI, G.: Kant storico della filosofia, Padova, Antenore, 1980.

ÖSTERREICH, K.: „Kant und die Metaphysik“, Kant-Studien, Ergänzungshefte 2 (1906).

PAULSEN, F.: „Kant's Verhältnis zur Metaphysik“, Kant-Studien 4 (1899/1900), 413-447.

: Immanuel Kant. Sein Leben und seine Lehre, Stuttgart, Fromanns Verlag, 1898, [1904].

ROVIRA, R.: „Von der mannigfachen Bedeutung der Metaphysik nach Kant", en: VOLKER, G.; HORSTMANN, R.-P.; SCHUMACHER, R. (eds.), Kant und die Berliner Aufklärung. Akten des IX. Internationalen Kant-Kongress, 2, Berlín/Nueva York, de Gruyter, 646-655, 2001.

THIEL, K.: Kant und die „Eigentliche Methode der Metaphysik“, Hildesheim/Zürich/Nueva York, Olms, 2008.

VLEESCHAUWER, H. J.: "La Cinderella dans l'oeuvre kantienne", en: FUNKE, G.; KOPPER, J. (eds.): Akten des 4. Internationalen KantKongresses, 1, Mainz, de Gruyter, 297-310, 1974.

: "La Composition du Preisschrift d'Immanuel Kant sur les progrès de la métaphysique", Journal of the History of Philosophy XVII (1979) 143-196.

VON EBERSTEIN, W. L. G. F.: Versuch einer Geschichte der Logik und Metaphysik bey den Deutschen von Leibnitz bis auf gegenwärtige Zeit, Halle, Ruff, 1794 [1799].

WUNDT, M.: Kant als Metaphysiker, Hildesheim/Zürich/Nueva York, Olms, 1984 [1924]. 


\title{
Sentido y límites de la filosofía transcendental en el proyecto kantiano
}

\author{
SALVI TURRO
}

\begin{abstract}
Resumen
Partiendo de la (aparente) paradoja expresada en $K r V$, A801/B829, se intentará esclarecer la comprensión kantiana de la filosofía transcendental frente a las otras partes del sistema. A tal efecto, se situará el proyecto global de la $\mathrm{KrV}$ - tal como se especifica en el Canon de 178 - a la luz del concepto mundano de filosofía como teleologia rationis humanae y de su inserción en el horizonte histórico de la Bestimmung des Menschen de J. J. Spalding. Con ello, se ganará una comprensión del proyecto crítico alejada tanto de las lecturas epistemológicas como de las metafísico-fenomenológicas.
\end{abstract}

Palabras clave: Kant, Spalding, filosofía transcendental, sistema filosófico, filosofía moral

\section{Sense and boundaries of transcendental philosophy in the Kantian project}

\begin{abstract}
In the light of the (apparent) paradox expressed in $K r V$, A801/B829, this article aims to clarify Kant's understanding of transcendental philosophy as opposed to the other parts of the system. To that effect, the general project of the $\mathrm{KrV}$-as specified in the Cannon of 1781-will be situated within the context of Kant's mundane concept of philosophy as a teleologia rationis humanae and of its insertion in the historical horizon of J. J. Spalding's Bestimmung des Menschen. This approach will allow for a better understanding of the critical project distanced from both epistemological and metaphysico-phenomenological perspectives.
\end{abstract}

Keywords: Kant, Spalding, transcendental philosophy, kantian system, morals

1 Universitat de Barcelona. Contacto: salvi.turro@ub.edu. 
1. El lugar de la filosofía transcendental en la sistemática kantiana

Mi propósito es esclarecer las implicaciones del, cuanto menos, sorprendente pasaje de $K r V$, A801/B829 en relación con el conjunto del proyecto crítico y, en especial, a la comprensión de lo que se denomina filosofía transcendental. No me atrevo a pretender, como sostenía Kant, que sea posible "entender a un autor mejor de lo que él se ha entendido a sí mismo" (KrV, A314/B370);2 me bastará con entenderlo como él se entendió a sí mismo. $\mathrm{O}$, siendo más modesto aún y siguiendo su propio consejo, me bastará con entenderlo a partir de "la comparación de pensamientos que un autor expresa sobre su objeto, tanto en el discurso común como en sus escritos" ( $K r V$, A314/B370). Eso sí, si esta comprensión problematiza lecturas sedimentadas desde contextos e intereses históricos distintos del que se muestra en los textos kantianos, por muy tradicionales y consagradas que aquéllas puedan ser, habrá de reconocerse que, al menos, divergen de la cosa misma que constituía el horizonte y concepción filosófica del pensador de Königsberg.

El pasaje en cuestión ocupa un lugar estratégicamente capital en la $K r V$ : el paso a la temática moral en la segunda sección del Canon de la razón pura. Una vez desveladas las ilusiones dialécticas de la razón y establecida la necesidad de disciplinar su pretensión cognoscitiva, debemos concluir que "la intención última de la naturaleza sabiamente previsora al equipar nuestra razón" al "qué hacer si hay voluntad libre, Dios y un mundo futuro" - esto es, a lo que mueve su interés especulativo- solo puede “apuntar propiamente a lo moral” ( $K r V$, A800/B828). Si el entendimiento es la facultad canónica respecto al conocimiento, la razón lo será respecto a la moralidad. Pues bien, lo sorprendente radica en la advertencia formulada por Kant: a partir de ahora "fijaremos la atención en un objeto que es ajeno a la filosofía transcendental" ( $K r V$, A801/B829). Es decir, el tránsito al nuevo ámbito comporta una discontinuidad discursiva radical con todo lo anterior, pues significa abandonar la perspectiva transcendental adoptada hasta aquí en la obra. De hecho, esta afirmación no debería sorprender al lector, pues la definición de transcendental con que se abre la obra se refiere exclusivamente al ámbito cognoscitivo: "llamo transcendental a todo

2 Citamos las obras de Kant (1900ss.) según las abreviaturas de la Kantsforschungsstelle (Maguncia) referenciadas en la bibliografía final, indicando número de volumen y de página según la edición de la Academia, con la salvedad de la primera crítica que se cita, como es habitual, por la paginación de sus dos ediciones. 
conocimiento que se ocupa no tanto de objetos como de nuestro modo de conocer objetos en tanto que ha de ser posible a priori" $(\mathrm{KrV}, \mathrm{B} 26) .3 \mathrm{Sin}$ embargo, y como si Kant temiera que el lector hubiese olvidado aquella acotación, lo subraya con una nota al efecto:

Todos los conceptos prácticos se refieren a objetos de satisfacción o de disgusto - esto es, de placer o desplacer-y, por tanto, al menos indirectamente a objetos de nuestro sentimiento. Ahora bien, como este no es ninguna capacidad de representarnos cosas, sino que radica fuera de nuestra capacidad cognoscitiva, los elementos de nuestros juicios en tanto que se relacionan con el placer o el desplacer —y así con los juicios prácticos - no pertenecen al conjunto de la filosofía transcendental, que solo tiene que ver con conocimientos puros a priori (KrV, A801/B829).

De acuerdo con este cambio de perspectiva, Kant añade otra observación: para abordar la cuestión moral basta con el concepto de una "libertad práctica" que "puede probarse por la experiencia" ( $\mathrm{KrV}$, A802/B830). La discusión sobre la libertad en sentido transcendental se sitúa en la temática especulativa de la metafísica racional y, como ha sentenciado la Dialéctica, "la independencia de la voluntad [...] de todas las causas determinantes del mundo sensible parece oponerse a la ley natural y a toda experiencia posible y constituye así un problema" $(\mathrm{Kr} V$, A803/B831): problema tratado en la tercera antinomia y especulativamente irresoluble. Pues bien, a esa conclusión, nuestro texto contrapone la experiencia inmediata de la libertad: constatamos, en efecto, que "tenemos una facultad de sobreponernos a las impresiones de nuestra facultad sensible de desear mediante representaciones de lo que es, incluso de modo remoto, útil o prejudicial” ( $K r V$, A802/B830). Como esta capacidad de vencer los impulsos sensibles no depende de ninguna especulación transcendentalmetafísica — que, por su parte, ha dejado abierta como posible la libertad-, sino que remite a lo dado en un sentimiento inmediato, en lo que sigue "tratándose de lo práctico, podemos dejar de lado como totalmente indiferente la libertad transcendental" y "reconocer por la experiencia la libertad práctica como una causa natural" ( $K r V$, A803/B831). Basta con esto para definir y tematizar la noción de un "mundo moral" sometido a "leyes

3 La versión de la primera edición dice: "llamo transcendental todo conocimiento que no se ocupa tanto de objetos cuanto de nuestros conceptos apriori de los objetos" (KrV, A12). 
éticas" según la "libertad de los seres racionales" ( $K r V$, A808/B836): se abre así la parte constructiva de la $K r V$ en el capítulo del Canon.

Sin duda este pasaje plantea graves problemas de interpretación en el horizonte conjunto de la filosofía kantiana, sobre todo si no se tiene presente que el criticismo, más que un resultado acabado en 1781, es un proceso in fieri al menos hasta 1790 . Y, en efecto, algunas de las afirmaciones aquí efectuadas serán matizadas y corregidas posteriormente. No obstante, ¿cómo interpretar la tesis capital y de máxima relevancia conceptual según la cual la filosofía transcendental solo se refiere a la "capacidad cognoscitiva" en tanto que "capacidad de representación", mientras que los temas "prácticos" ( $K r V$, A801/B829) - ya sean morales o del sentimientoson ajenos a la perspectiva transcendental?, ¿se trata de una afirmación casual e inconsistente con el conjunto del proyecto crítico o, por el contrario, arroja luz sobre la comprensión última que Kant tiene de la filosofía y del papel que en ella juega su parte transcendental que, por tanto, no equivaldría en absoluto al conjunto del sistema filosófico? Sostendré aquí la segunda alternativa: ciertamente la lectio difficilior pero, a mi parecer, la única que permite entender la totalidad del proyecto crítico y, en especial, la función de los análisis epistemológicos (transcendentales) de la $\mathrm{KrV}$ en aquel horizonte conjunto. Comencemos por ocuparnos del aspecto sistemático o arquitectónico de la cuestión: en qué medida la distinción entre la temática transcendental y la moral articula las divisiones de la filosofía que aparecen en la obra kantiana desde 1781.

La primera sistemática del período crítico4 se ofrece en la Arquitectónica de la razón pura: "filosofía es el sistema de todo el conocimiento filosófico" ( $K r V$, A838/B866), siendo el conocimiento filosófico "por conceptos" y no "por construcción de conceptos" ( $K r V$, A837/B865). Una vez se ha distinguido su parte "propedéutica" ("crítica") y el conocimiento científico o "metafísica", se detallan las partes doctrinales de la ciencia filosófica resultante de la crítica $(K r V$, A841/B869): la "metafísica de la naturaleza" y la "metafísica de las costumbres" correspondientes al uso teórico de la razón -representaciones cognoscitivas - y al uso práctico — legalidad de la acción libre—. La

4 Dado nuestro objetivo, no entramos a considerar las sistemáticas anteriores a la primera Crítica - así, por ejemplo, las de la gestación de la obra en las importantes cartas a M. Herz de 1771 y 1772 - para centrarnos solo el período donde lo transcendental se ha definido plenamente. 
metafísica de la naturaleza se divide, a su vez, en "filosofía transcendental" y "fisiología de la razón pura" ( $K r V$, A845/B873): la primera se ocupa del concepto general de objeto y la segunda de las distintas regiones de objetos — esto es, la metafísica general (ontología) y las metafísicas especiales del wolffianismo- - Aplicando los resultados de la crítica, se indican seguidamente las partes transcendentes y doctrinalmente vacías de la metafísica escolar ( $K r V$, A846-850/B874-878). Obsérvese, pues: filosofía transcendental solo designa la parte de la filosofía teórica — ni siquiera toda ella- que versa sobre los principios cognoscitivos del objeto y, por tanto, en absoluto es competencia suya lo práctico. De hecho, ello ya se anticipaba en la Introducción de la obra: "aunque los principios supremos de la moralidad y sus conceptos fundamentales constituyen conocimientos a priori, no pertenecen a la filosofía transcendental" ( $K r V$, A14-15/B28-29). Distinción radical de ámbitos en clara continuidad con lo enunciado por nuestro pasaje, que, por tanto, lejos de ser una afirmación casual, se imbrica claramente en la sistemática de 1781.

El Prólogo de la Fundamentación de la metafísica de las costumbres se abre con una consideración sistemática. Aquí, la división de la filosofía no se hace en diálogo con Wolff sino con la tradición helenística: sus partes son física, ética y lógica. Si distinguimos lo formal de lo material, solo la lógica es conocimiento puramente formal. La filosofía es conocimiento material y sus objetos solo pueden ser dos (GMS, AA 04: 387): las leyes de la naturaleza ("física" o "doctrina de la naturaleza") o las de la libertad ("ética" o "doctrina de las costumbres"). Estas disciplinas materiales, a su vez, pueden contener elementos empíricos o puramente racionales: como en 1781, la parte pura (a priori) de la física y de la ética constituyen respectivamente la "metafísica de la naturaleza" y la "metafísica de las costumbres", mientras que sus partes empíricas configuran la "física empírica" y la "antropología práctica" (GMS, AA 04: 388). No se hace ninguna mención en este Prólogo a la filosofía transcendental: en parte porque, seguramente, se sobreentiende que el análisis del objeto en general que determina lo a priori de la física está incluido en la metafísica de la naturaleza; en parte porque el interés del texto radica en explicitar la problemática moral y, por tanto, el ámbito que en 1781 ya quedaba fuera de lo transcendental-cognoscitivo. Por el contrario, aparece repetidamente el término filosofía moral como equivalente a doctrina de las costumbres y compuesta, por tanto, por una parte pura y una aplicada: la fundamentación 
consiste precisamente en separar ambas y manifestar así la existencia de una "razón pura práctica" (GMS, AA 04: 389). Con ello, empero, Kant reinterpreta el contenido y función de la $\mathrm{KrV}$ : ahora parece referirla solo a la metafísica de la naturaleza - por tanto, solo a la filosofía teórica, como si no hubiera escrito el Canon-, con lo que abre el espacio para una "crítica de la razón práctica" (GMS, AA 04: 391) centrada solo en el principio de la moral. Este desplazamiento no hace más que reafirmar lo anticipado por nuestro pasaje: si la filosofía transcendental se circunscribe solo al ámbito teórico - ahora la totalidad de la $\mathrm{KrV}$-, la filosofía moral no tiene ninguna necesidad de referirse, ni siquiera nominalmente, a ella, y, desde luego, se constituye independientemente de los principios del objeto conocido.

La Crítica de la razón práctica no se ocupa temáticamente de la división del sistema filosófico. Desde su Prólogo e Introducción se evidencia, no obstante, la continuidad con lo planteado en la Fundamentación: la obra establecerá el principio puro de la filosofía moral de forma académica, frente al carácter expositivo más popular del ensayo de 1785. Igual que en la Fundamentación, en la $K p V$ no aparece ni en una sola ocasión la expresión de filosofía transcendental para calificar su desarrollo temático. A su vez, las escasas ocurrencias del término transcendental, doce en total,5 remiten siempre al significado establecido en la primera Crítica en el ámbito de los temas cognoscitivos o especulativos: como calificativo de la libertad en sentido metafísico, 6 como calificativo de facultades, términos o secciones de la primera crítica,7 o como calificativo de la perfección del ser supremo en su comprensión metafísica o de su estatuto como ideal de la razón.8 Nunca, por tanto, se dice ni atribuye lo transcendental al ámbito moral.

Las dos introducciones escritas a la Crítica del Juicio son, en parte, una revisión de la sistemática anterior en el marco de la distinción posterior a 1787 - de las capacidades de la mente (conocer, desear, sentimiento de placer) asociadas a las tres facultades superiores

5 Estadística obtenida a partir de la versión informatizada de la obra kantiana (Kant 2001).

${ }_{6}$ Cinco ocurrencias en $K p V$, páginas 3, 7, 29, 94, 97.

7 Tres ocurrencias en $K p V$, páginas 68, 90, 137.

${ }_{8}$ Cuatro ocurrencias en $K p V$, páginas 41, 113, 133, 139. 
(entendimiento, razón, Juicio).9 De entrada, se mantiene la continuidad: a partir de la definición de filosofía como "sistema del conocimiento racional por conceptos", si prescindimos de su parte meramente formal (lógica), el "sistema real de la filosofía" solo puede consistir en una filosofía teórica o de la naturaleza y una filosofía práctica o de las costumbres (EEKU, AA 20: 195). Pero se acentúa mucho más la contraposición entre ambas: entre el "territorio del concepto de naturaleza, como lo sensible, y el territorio del concepto de libertad, como lo suprasensible" hay un "abismo infranqueable", de modo que "no es posible transitar del primero al segundo" (KU, AA 05: 175-176). No obstante, si "ha de haber ciertamente un fundamento de la unidad de lo suprasensible que radica en la base de la naturaleza con lo que contiene el concepto de libertad", tiene que darse, al menos, un "tránsito" entre un modo de pensar y otro (KU, AA 05: 176): tránsito que, como se sabe, quedará vinculado al Juicio como facultad referida (de modo más o menos artificioso) al sentimiento de placer. De por qué sea necesaria aquella unidad entre la naturaleza y la libertad, nada se dice en el texto: sobre ello volveremos más adelante. En todo caso, de aquí resulta una tripartición peculiar de la filosofía: dos territorios propiamente dichos (naturaleza, libertad) y, no un territorio, sino un modo de pensar (reflexión) que apunta a la unidad de ambos.

En 1791 encontramos la última de las sistemáticas kantianas: la que ofrece el importante, aunque inacabado, escrito sobre los Progresos de la metafísica en Alemania desde los tiempos de Leibniz y Wolff, verdadero compendio del resultado conjunto de las tres Críticas. Ahora la filosofía, identificada con la parte doctrinal o "metafísica", "es la ciencia que avanza, mediante la razón, del conocimiento de lo sensible a lo suprasensible" (FM, AA 20: 260). Esto significa una nueva división tripartita. Su primera parte constituye una mera "ontología" o "gramática" de la experiencia, a la que se denomina —y solo a ella— "filosofía transcendental" (FM, AA 20: 260) y que viene definida, exactamente como en 1781, como "la doctrina de la posibilidad de todo conocimiento apriori en general" (FM, AA 20: 272). A ella sigue una "doctrina de la duda" como infructuoso intento de conocer lo suprasensible a partir del aparato categorial de lo sensible (FM, AA 20: 273, 281): claramente, la Dialéctica de 1781 y su conclusión escéptica. El

9 Es solo a partir de su carta a K. Reinhold del 28 de diciembre de 1787 (Br, AA 10: 513515) que Kant diferencia temáticamente estas tres capacidades, desde las cuales se justifica tanto el sentido de una tercera Crítica como su lugar en la (nueva) sistemática filosófica. 
tránsito a lo suprasensible solo puede darse a partir de los postulados de la razón práctica y la comprensión teleológica de la naturaleza en función del fin final (jurídico y moral) que constituye la destinación del hombre: se constituye aquí la "doctrina de la sabiduría" (FM, AA 20: 273, 281) que permite entender reflexivamente la unidad de lo real y es así el último resultado de la crítica como tal (Turró 1996: 207-233). Nótese, a su vez, que si bien esta sabiduría tiene un carácter discursivo o doctrinal —si queremos teórico - , su validez no la recibe de la filosofía transcendental principios del fenómeno-, sino exclusivamente de la posición práctica del sujeto (libertad, ley moral): por ello Kant califica su estatuto de "prácticodogmático" (FM, AA 20: 273, 293). Así, la culminación doctrinal de la crítica kantiana tampoco es parte de la filosofía transcendental, precisamente porque la reflexión teleológica que la sustenta remite, a través de la noción de fin final [Endzweck], a la moralidad (FM, AA 20: 307).

En suma, el recorrido diseñado por las sucesivas sistemáticas confirma el carácter nada casual — más bien, esencial — de lo afirmado en $K r V$, A801/B829: que en el tránsito al Canon —esto es, a la temática de la libertad, de la ley moral y, en último término, a la teleología ético-jurídica de los fines de la razón - "fijamos la atención en un objeto que es ajeno a la filosofía transcendental".

2. La filosofía transcendental a la luz de la dimensión cósmica de la filosofía Hasta aquí nos hemos referido a la sistemática filosófica desde una perspectiva "académica", esto es, "sin tener otro objetivo que la unidad sistemática del conocimiento o completud lógica del conocimiento" ( $\mathrm{KrV}$, A838/B866). Pero, como sabemos, para Kant la filosofía tiene otro sentido más originario — determinante de su misma función académica-: su sentido "mundano" en tanto que "referencia de todos los conocimientos con los fines esenciales de la razón humana (teleologia rationis humanae)", que hace del filósofo no un mero "artesano" dedicado a la construcción lógica de sistemas, sino un auténtico "legislador de la razón" $(\mathrm{KrV}, \mathrm{A} 838$ 839/B866-867). Porque esos fines han de ser realizados, el ser humano se define dinámicamente como el animal rationabile que ha de llegar a ser rationale (Anth, AA 07: 321), esto es, como un ser que ha de dar cumplimiento por sí mismo a lo que ha de llegar a ser. Dicho de otro modo, el hombre, "como única criatura racional sobre la tierra", se caracteriza por 
unas "disposiciones naturales" que no tienen otro fin que obligar "al uso de su razón" para desarrollarlas ( $I a G$, AA 08: 18). Pues bien, los fines de la razón configuran una "unidad sistemática", pero no por mera exigencia de consistencia lógica, sino porque sus "fines subalternos" se subordinan al "fin final" y este no es otro que la "destinación completa del ser humano" (KrV, A840/B869). Die ganze Bestimmung des Menschen no es una expresión casual. Como ha expuesto detalladamente R. Brandt (2007: 139177), con la temática de los fines de la razón y de la destinación del hombre, Kant se sitúa en la constelación mental y lingüística del neoestoicismo que domina la segunda ilustración berlinesa y, más en concreto, en el horizonte abierto por Die Bestimmung des Menschen de Johann Joachim Spalding. 10

El Leitmotiv de la obra de Spalding se formula así: “¿merece la pena el esfuerzo para saber por qué existo y qué debo ser según la razón?” (BestM, I/1: 45).11 Ni los goces sensibles ni el cultivo del espíritu satisfacen completamente las aspiraciones del hombre. Solo en la exigencia de "felicidad del género humano" encontramos "el objeto de mis esfuerzos más serios y de mi propia felicidad" (BestM, I/1: 107) y, con ello, "la regla del derecho y del orden moral" (BestM, I/1: 111); solo entonces podemos decir que "hago lo que debo hacer, soy lo que debo ser" (BestM, I/1: 125). El reconocimiento de mi destinación moral lleva a preguntarme por la causa de este "orden completo [...], de la regularidad en todas sus leyes, tanto de los cuerpos como de los espíritus" (BestM, I/1: 135) y la respuesta a tal cuestión abre el ámbito de la religión: ha de existir una divinidad que instaura un "gobierno moral" y un "plan por el que se rige el mundo" (BestM, I/1: 171, 173); a su vez, un mundo ordenado moralmente implica, que "yo estoy hecho para otra vida, el tiempo presente es solo el inicio de otra vida, es mi primera infancia en que soy educado para la eternidad" (BestM, I/1: 181). La destinación del hombre, pues, no radica en su dimensión sensible — ni como apetito, ni como conocimiento de la naturaleza - sino en la

\footnotetext{
10 La presencia de elementos estoicos, especialmente de Séneca, en la obra de Kant ha sido estudiada detenidamente por U. Santozki (2006) y el tema de la destinación del hombre de Spalding a Fichte por L. A. Macor (2013).

11 Citamos la obra de Spalding (2001ss.) según las abreviaturas referenciadas en la bibliografía final, indicando sección/volumen y página de la edición crítica. Die Bestimmung des Menschen se publicó en 1748 y alcanzó once ediciones (con adiciones a la versión original) hasta 1794, la última autorizada por el autor. Citamos aquí por la tercera edición (1763): especialmente relevante porque motivó la polémica entre las recensiones de M. Mendelssohn y T. Abbt, que llevaría al primero a la redacción del Fedón - referente dialógico de los Paralogismos de la razón de la $\mathrm{KrV}$-.
} 
moralidad, y es esta $-\mathrm{y}$ no la metafísica especulativa, como en el wolffianismo - la que abre el ámbito de la religión (existencia de Dios, inmortalidad): "el concepto de moralidad es más cercano a los sentimientos originarios e inmediatos de la naturaleza humana que el concepto de religión" de modo que "el camino a la convicción religiosa que parte del sentimiento moral es, sin duda, el más cierto y de mayor utilidad común" (AnHV, I/4: 212). Sin duda acordes que, pasando del tono menor al tono mayor, siguen sonando en la obra kantiana. El Canon de la $\mathrm{KrV}$ formula el sistema de fines o intereses de la razón en las tres conocidas preguntas por el saber, el actuar y el esperar ( $K r V$, A805/B833). Intereses sometidos a una jerarquización en la línea de Spalding: "la completa destinación del ser humano" solo se alcanza cuando respondemos al segundo y "la [parte] de la filosofía sobre ello se llama moral" ( $\mathrm{KrV}$, A840/B868). Incluso respecto al tercer interés de la razón, que como saber de un tiempo futuro "es a la vez práctico y teórico", lo práctico es "el hilo conductor para responder a lo teórico" ( $\mathrm{KrV}$, A806/B834), tal como los postulados de la segunda Crítica o la doctrina de la sabiduría de 1791 desarrollarán detalladamente. En este punto, es significativa la carta que el mismo Spalding dirigió a Kant el 2 de febrero de 1788 para agradecerle el envío de la recién publicada Crítica de la razón práctica. Después de admitir cordialmente la indudable superioridad del talento de Kant para "la profundidad de la especulación", Spalding confiesa que él, a pesar de la influencia recibida de Shaftesbury y Hutcheson, nunca pudo "reconciliarse del todo con el principio de la felicidad en la doctrina moral", aunque, precisamente por aquella influencia, tampoco fue capaz de elevarse "con completa distinción" a lo más "puro" de la consciencia moral ( $\mathrm{Br}$, AA 10: 527-528). Justamente la $K p V$, añade, muestra "el fundamento de la moral bajo una luz tan clara y venerable" que "ha colocado la virtud, en su belleza verdadera, simple y digna de profundo respeto, en tanto que derecho y conformidad a la ley, en el trono supremo que le corresponde, habiendo expulsado de él a aquel lisonjero usurpador [la felicidad]" ( $\mathrm{Br}$, AA 10: 528). Con esta autocrítica, Spalding reconoce su proximidad al planteamiento kantiano, admitiendo implícitamente que, al eliminar todo rastro de eudemonismo en el fundamento de la moral, el filósofo de Königsberg ha respondido mejor que él mismo a la pregunta por la destinación del hombre. No es de extrañar así que, en su última edición de la Bestimmung des Menschen, de 1794, Spalding incorpore vocabulario de 
la $K p V$ para matizar el eudemonismo de las ediciones anteriores (Macor 2013: 304-310).

Ahora bien, Kant no sostiene tan solo la primacía de lo moral sino que, por estar en juego tres intereses interconectados, deben ser compatibles también las respuestas a cada uno de ellos, pues en caso contrario la razón no constituiría una unidad sino que estaría escindida consigo misma. La interrelación de los tres intereses hace de ellos no una mera yuxtaposición, sino en cierto modo un todo orgánico, y recodemos que "un órgano que no haya de emplearse, una ordenación que no alcance su fin, es una contradicción en la doctrina teleológica de la naturaleza" (IaG, AA 08: 18). Siendo la razón la disposición con que la naturaleza nos ha dotado, la falta de armonía en las respuestas a sus tres intereses mostraría que la misma idea de una destinación del ser humano (como individuo y como especie) carecería de todo sentido. Kant utiliza en diversos lugares este argumento, pero es especialmente determinante en el paso del segundo al tercer interrogante: "si el bien supremo según reglas prácticas fuera imposible, entonces la ley moral que ordena fomentarlo, también sería fantástica y encaminada a un fin imaginario y vacío, con lo cual sería falsa en sí misma" ( $K p V$ AA 05: 114). Por el mismo motivo, cuando las introducciones a la $K U$ plantean el tránsito entre la naturaleza y la libertad, con la subordinación de la primera a la segunda, ello obedece a la necesaria unidad orgánica del sistema de intereses de la razón.

Pues bien, Kant, por su "profundidad especulativa", es mucho más consciente que Spalding de la tensión existente entre la dimensión cognoscitiva y la moral para llevar a buen puerto el tema de la destinación del hombre. Spalding reconoce ciertamente que "una tendencia natural irresistible al conocimiento opera dentro de mí y veo el amplio reino de la verdad como mi propiedad" (BestM, I/1: 71), pero entiende el saber como contemplación de "las flores dibujadas por la mano de la naturaleza, el bosque repleto de melodías, la clara luz del día que vierte vida y goce alrededor mío", todo lo cual, a modo de "anuncios de una clase todavía superior de belleza" (BestM, I/1: 67), apunta a la divinidad. Spalding se mueve aún en el horizonte de la continuidad entre el verum y el pulchrum de Shaftesbury y en el uso indiscriminado del finalismo leibniziano, omitiendo las consecuencias demoledoras para el viejo orden del mundo (Turró 2016: 59-78) que implica la nueva ciencia matemática de la naturaleza y sus 
consecuencias materialistas. Kant, con su buen conocimiento de la física newtoniana y con su progresivo alejamiento del racionalismo escolar y de la físico-teología popular, no puede ignorar este factum decisivo. La físicomatemática no solo destruye la imagen de un kósmos kalós kaí agathós y la armonía leibniziana "entre el mundo físico de la naturaleza y el reino moral de la gracia" (Monadología: $\$ 88$, a. trad.), sino que parece exigir, como reza la tercera antinomia, que "todo en el mundo acaece solo según leyes de la naturaleza" y, por tanto, que "no hay libertad" ( $K r V$, A445/B473). Pero si fuera así, no tendrían sentido alguno ni el segundo ni el tercer interés de la razón: se quebraría la unidad sistemática de los fines racionales y el hombre no tendría otro destino que la esquizofrenia existencial. Por esto, "el concepto de libertad [...] constituye la piedra angular del edificio entero de un sistema de la razón pura, incluida la especulativa" (KpV, AA 05: 3-4).

En el estado del saber en el siglo XVIII se daba, en efecto, una importante tensión desapercibida por Spalding: la oposición entre las consecuencias deterministas de la nueva ciencia y la libertad como condición de posibilidad de la moralidad. La primera posición parece firmemente fundada en una física que, aunque más tarde que la matemática, ha encontrado "el camino seguro de la ciencia" $(K r V, \mathrm{BX}-\mathrm{XII})$. La segunda viene exigida por el fin final práctico de nuestra razón. Sin eliminar esta oposición es imposible dar una respuesta coherente a la destinación del hombre y, en última instancia, a la misma naturaleza — esa "gran artista [que] llamamos providencia en vistas a la adecuación a fines del curso del mundo" (ZeF, AA 08: 360)—, al proveernos de razón, "sería sospechosa de practicar, en el caso del ser humano, un juego infantil" (IaG, AA 08: 19). Ante esta situación, si no queremos practicar el salto mortale de visionarios y exaltados — como Jacobi en 1785-, solo cabe una estrategia filosófica. Los Prolegómenos la expresan nítidamente: "suprimir las afirmaciones impertinentes del materialismo, naturalismo y fatalismo" y "proporcionar a las ideas morales un espacio fuera del campo de la especulación”, para así "esclarecer suficientemente nuestras disposiciones naturales" (Prol, AA 04: 363). Este es el horizonte conceptual último que determina el objetivo y la función de la crítica kantiana de la razón.

Desarrollar esta estrategia pasa necesariamente por disolver la oposición entre la física y la moral. Y, dada la primacía indudable del fin moral, ello solo puede efectuarse mediante un análisis epistemológico que 
impida interpretar la cosa conocida como una realidad que haga imposible la libertad. El análisis de nuestras facultades cognoscitivas para determinar lo que las constituye a priori es la filosofía transcendental. Por tanto, la filosofía transcendental tendrá por objeto elaborar una noción de realidad compatible con la libertad. La nota de $K r V$, A801/B829 no expresa otra cosa: mientras estamos en la filosofía transcendental nos movemos en el ámbito de la representación, cuando tratamos de los deseos, sentimientos o satisfacción — puesto todo ello bajo la rúbrica de lo práctico - nos las habemos más bien con la cosa misma. Con esta equiparación entre conocimiento y representación, frente a la peculiar inmediatez de lo práctico, el pasaje no hace más que retomar la doble dualidad que recorre la Estética y la Analítica transcendentales: la diferencia entre la afección y la cosa en sí, entre el estatuto fenoménico del conocimiento y del noúmeno.

Tal dualidad - supuesto y a la vez conclusión de la epistemología de la $\mathrm{KrV}$ - cumple la doble función exigida por aquella estrategia argumentativa. Por un lado, una función positiva en tanto que justificación de los supuestos de la nueva ciencia matemática de la naturaleza: como la labor sintética del entendimiento supone una síntesis categorial reglada de lo que siempre se nos da en la sucesión y orden necesarios del espacio-tiempo, la cosa conocida no es mera apariencia; el territorio de lo que se muestra sensiblemente [Erscheinung] y es conceptualizado intelectivamente [Phänomen] constituye la "isla de la verdad" (KrV, A294-295/B235-236). Por otro lado, una función restrictiva del estatuto de realidad de ese conocimiento: como las síntesis intelectivas dependen tanto del material sensible pasivamente recibido como de la legalidad impuesta por nuestro entendimiento, hay que reconocer que "permanece para nosotros completamente desconocido qué puedan ser los objetos en sí y separados de toda receptividad de nuestra sensibilidad" ( $K r V$, A42/B59), pudiéndose incluso afirmar —en clara anticipación a Schopenhauer- que "si suprimiéramos nuestro sujeto o simplemente la estructura subjetiva de los sentidos en general, todas las características y relaciones de los objetos en el espacio y en el tiempo, como el mismo espacio y tiempo, desparecerían" ( $K r V$, A42/B59).

Este resultado de la Estética y la Analítica es lo que expresa la nota de $K r V$, A801/B829 cuando sostiene que la capacidad cognoscitiva es solo re-presentativa: cuanto se presenta como fenoménicamente real nunca es 
toda la realidad, pues las síntesis espacio-temporales son iterables ad infinitum; y como solo puede dársenos cognoscitivamente cuanto es susceptible de aparecer en ese marco, queda abierta la posibilidad (pensable) de la realidad objetiva de la libertad. Esta conclusión — de hecho, "la distinción de todos los objetos en general en phaenomena y noumena" ( $\mathrm{rrV}$, A235/B294) — aporta los argumentos forenses al tribunal de la razón para condenar las pretensiones de toda metafísica especulativa y neutralizar con ello las consecuencias cosmológicamente destructivas de la nueva ciencia. Hasta aquí llega la filosofía transcendental: análisis y justificación del estatuto fenoménico del conocimiento científico (momento canónico) y consiguiente imposibilidad de conocer la realidad en sí desde aquel aparato categorial (momento disciplinar). En palabras de R. Brandt (2007: 171172): "transcendentales son aquellas determinaciones que inmediatamente (espacio, tiempo, categorías, yo pienso) o mediatamente (ideas de la razón) posibilitan la experiencia objetiva" y, por tanto, "la filosofía práctica de Kant no es parte alguna de la filosofía transcendental". Así las cosas, si hay un ámbito donde nos las habemos con algo que no es representación cognoscitiva y ese algo tiene que ver con la libertad, ipso facto abandonamos la perspectiva trascendental para ocuparnos del interés supremo moral y de la esperanza resultante. En suma, la parte transcendental de la $\mathrm{KrV}$ - "crítica transcendental del entendimiento" ( $K U$, AA 05: 179) se la denomina en 1790 — juega el papel propedéutico de fijar los límites del saber fenoménico para poder transitar adecuadamente a lo suprasensible-moral. No olvidemos que si la "isla de la verdad" ha de ser cartografiada exhaustivamente, no es tanto por el placer de hacerlo, sino para después poder "explorar exhaustivamente el mar y asegurarnos que podemos esperar algo en él" ( $K r V$, A236/B295), esto es, para dar satisfacción completa a los fines superiores de la razón como auténtica destinación del ser humano.

Sin duda, el modo en que nuestro pasaje transita del conocimiento a la moral será abandonado después por Kant. Que haya una experiencia inmediata (psicológica) de la libertad, aunque se dé al margen de los argumentos especulativo-metafísicos invalidados por la Dialéctica, contraviene una de las tesis centrales del análisis transcendental: aquella experiencia se da en el sentido interno y este no es más que la serie de afecciones que el sujeto tiene de sí mismo como fenómeno. La $K p V$ corrige, en parte, esta inconsistencia. Dado que, por el concepto mismo de ley, 
puede probarse que "libertad y ley práctica incondicionada se implican recíprocamente" ( $K p V$, AA 05: 29), de la consciencia de la ley moral se concluye la realidad objetiva de la libertad y así puede afirmarse que la "libertad es la única, entre las ideas de la razón especulativa, de cuya posibilidad sabemos apriori por más que no la intuyamos" ( $K p V$, AA 05: 4). Decimos que se corrige en parte la inconsistencia porque la consciencia de la ley también es caracterizada como algo "dado", solo que aquí se trata de un factum que, asemejándose a un "principio sintético a priori" pero "sin fundarse en intuición alguna, ni pura ni empírica", es "el único factum de la razón pura que nos la muestra como originariamente legisladora" ( $K p V$, AA 05: 31). Factum intelectivo del filósofo, pero que apela igualmente al "juicio que los hombres formulan sobre la legalidad de sus acciones" ( $K p V$, AA 05: 32), esto es, a la inmediatez (ajena a toda especulación) del "entendimiento común desprovisto de instrucción" ( $K p V$, AA 05: 27). En suma, el principio de la filosofía moral remite a una dación originaria que nos sitúa fuera de lo fenoménico: la consciencia del nuestro poder legislador es la "sentencia inapelable de la razón" [Machtspruch der Vernunft] (RL, AA 06: 281) a favor de la libertad y, por tanto, testimonio irrefutable de nuestra libertad nouménica.

Consiguientemente, la verdadera vertebración sistemática de la filosofía kantiana es impropiamente arquitectónica. Si el uso analógico de este término tiene un sentido mínimo, más allá de la mera formalidad de indicar que "los conocimientos no pueden constituir una mera rapsodia" (KrV, A832/B860), tal sentido remite al arte constructivo como primum analogatum: un edificio es ciertamente más que una yuxtaposición de materiales, pero no es una ordenación cualquiera de ellos, sino una que implica unos fundamentos y lo fundado sobre ellos. Pero las dos partes del sistema kantiano (filosofía transcendental y filosofía moral) no tienen ningún fundamento común $\mathrm{y}$, por tanto, no constituyen sensu stricto un único edificio: en la parte cognoscitiva el fundamento es la actividad sintética del entendimiento que, a través de los esquemas, produce los principios a priori del objeto de experiencia; en la parte práctica, el fundamento es la ley-libertad que determina la doctrina de la virtud y la del derecho, así como sus consecuencias reflexivo-teleológicas (postulados, filosofía de la historia). La filosofía transcendental, una vez fundamentado el conocimiento, se limita a dejar como posible otro ámbito, que solo el Machtspruch de la razón práctica consolida; en todo caso hay dos edificios, 
no uno solo. La ordenación global del sistema no se adecúa, pues, al símil arquitectónico, sino que apunta más bien a un modelo cartográfico (Turró 1999). En efecto, ya en el opúsculo de 1786 contra Jacobi, la tarea críticoracional es comparada a una labor de orientación, esto es, poder establecer un mapa del ámbito suprasensible. En la $K r V$ la metafísica de la naturaleza y de las costumbres remiten a la dualidad entre la isla y el océano circundante donde la ley moral viene a ser la brújula que permite su navegación. En las dos introducciones a la $K U$, la sistemática cartográfica es diáfana: dos territorios, un abismo entre ellos y la necesidad, si no de un puente, al menos de un tránsito. Y, finalmente, en los Fortschritte, la metafísica incorpora sin más la analogía territorial a su misma definición: ciencia del tránsito de lo sensible a lo suprasensible a través de las consecuencias de la ley moral.

\section{Insuficiencia de las lecturas epistemológicas del kantismo}

Tanto las sucesivas sistemáticas kantianas como el entramado conceptual que las sostienen muestran una dualidad de estatuto discursivo, de fundamentos y de territorios cartografiados en el proyecto crítico. Los Fortschritte lo resumen con precisión: si "la crítica de la razón atiende cuidadosamente a todos sus progresos" debe reconocerse que "gira sobre dos goznes: primero, la doctrina sobre la idealidad del espacio y el tiempo [...]; segundo, la doctrina de la realidad del concepto de libertad" (FM, AA 20: 311). La idealidad del espacio y el tiempo es el eje del análisis del conocimiento fenoménico y, en la medida que este análisis no se ocupa de las cosas en sí mismas, sino de las condiciones de nuestra representación de las cosas, constituye el ámbito exclusivo de la filosofía transcendental; pero, en este nivel, la tendencia natural de la razón a elevarse al incondicionadoabsoluto no obtiene satisfacción alguna. La realidad objetiva de la libertad da consistencia a la filosofía práctica y su sistema de fines (moralidad, republicanismo, federación de estados, cosmopolitismo, paz perpetua), dando así plena respuesta al segundo y supremo interés de la razón. Por su parte, la aplicación de estos fines moral-jurídicos a la reflexión teleológica da lugar a una doctrina de la sabiduría (postulados, filosofía de la historia, ético-teología) en que encuentra finalmente satisfacción el interés especulativo de la razón en los límites que le son propios (estatuto subjetivo-necesario, doctrina práctico-dogmática). Por tanto, no es desde la 
filosofía transcendental sino desde la filosofía moral desde donde se esclarece "la destinación completa del ser humano" ( $K r V$, A840/B868). Bestimmung des Menschen que, en continuidad con el interés prácticomundano y cosmopolita de la ilustración alemana desde Spalding, constituye la clave de lectura del conjunto de la obra crítica.

Si comparamos estos motivos y objetivos fundamentales del proyecto kantiano con lecturas de gran predicamento, sean de corte neokantiano, heideggeriano o analítico, el contraste es evidente. Por un lado, todas ellas - sin duda excelentes ejercicios de filosofía académica, tanto en el sentido kantiano como meramente institucional de la expresión- ponen el eje central de su interpretación en el problema del conocimiento o de la metafísica, como si el primer interrogante de la razón tuviera el primado jerárquico en el criticismo. Con ello, el núcleo fuerte del kantismo pasa a ser el tema de los juicios sintéticos a priori, de la deducción transcendental y las diferencias entre sus dos ediciones, del esquematismo, de la unidad lógica de la consciencia, de los principios del entendimiento, etc. Consiguientemente, el llamado método transcendental -expresión, por cierto, no utilizada por Kant -12 pasa a extenderse al conjunto de la obra crítica y de sus resultados doctrinales, con lo cual no solo se debilita la especificidad y primacía de lo práctico frente a lo transcendental, sino que la misma distinción discursiva y operativa entre ambas esferas se desdibuja. De este modo, los problemas de fundamentación o demarcación del conocimiento (neokantismo, filosofía analítica), o los de nuestra abertura ontológica al mundo (fenomenología, Heidegger) pasan a ser el criterio determinante de la aproximación al kantismo en detrimento de la pregunta

\footnotetext{
12 En efecto, como puede comprobarse mediante la edición informatizada (Kant 2001), en ninguna de las ocurrencias de Methode en la obra kantiana publicada, el término aparece con el calificativo transcendental. En el lugar más temático para la cuestión, la Lógica de 1800, se señalan los métodos científico, popular, sistemático, fragmentario, analítico, sintético, silogístico, tabular, acroamático (catequético), erotemático (dialógico o socrático), pero ni tan solo aparece el término transcendental (Log, AA 09: 148-149). En la Disciplina de la razón pura se distingue el método por construcción de conceptos (o matemático) del método por conceptos (filosófico), pero sin más alusión a lo transcendental que indicar que se inscribe en el segundo ámbito ( $K r V$, A713-721/B741-749). En la Historia de la razón pura se habla de método naturalista y científico, dogmático y escéptico, frente a los que se sitúa el "camino crítico", pero no, como sería de esperar, el transcendental ( $K r V$, A855856/B883-884). La única ocurrencia próxima a la expresión método transcendental no deja de ser paradójica: "nada podemos decir aquí sobre el método propio de una filosofía transcendental, dado que solo nos ocupamos aquí de una crítica del estado de nuestra facultad" (KrV, A738/B766).
} 
esencial por la destinación del hombre y el sistema de los fines racionales. Sin negar que aquellas cuestiones hayan sido ciertamente relevantes para el desarrollo de la filosofía académica del siglo XIX y del XX, como perspectiva desde la que aproximarse a Kant resulta enormemente desenfocada.

Estas interpretaciones podrían aducir a su favor el testimonio de Kant sobre la Deducción transcendental que se lee en el Prólogo de la primera edición de la $K r V$ : "no conozco investigaciones más importantes que las [allí] ofrecidas por mí, y que son las que más trabajo me han costado" ( $K r V$, AXVI). Y, sin duda, la filigrana conceptual que recorre el núcleo de la Analítica - lo que propiamente es filosofía transcendental, en el uso kantiano - es una de las más relevantes de la historia de la filosofía: no puede negarse que aún nos encontramos bajo la sombra de su Wirkungsgeschichte. Pero el alto nivel técnico y gran esfuerzo intelectual no hacen de estos capítulos el objetivo último del criticismo ni el interés primordial de la razón humana, esto es, la perspectiva desde la que Kant concibe la totalidad de su obra. Baste recordar otro pasaje, en este caso del Prólogo a la segunda edición: "tuve que suprimir el saber, para hacer lugar a la $f e "(K r V, \mathrm{BXXX})$. Afirmación que, leída a la luz de cuanto hemos expuesto, dice: tuve que limitar el saber a conocimiento representativo de fenómenos (filosofía transcendental), para acceder a la cosa misma en tanto que ley-libertad (filosofía moral) para, desde ella, elaborar la doctrina de la sabiduría capaz de responder a las preguntas especulativas vinculadas a la esperanza (orden del mundo). En este sentido, la filigrana conceptual de la deducción transcendental no deja de ser un instrumento 13 - si no, en términos postmodernos, una verdadera retórica - para poder esclarecer la situación del ser humano en un mundo que, leído como realidad en sí desde la físico-matemática, sería inmundo, pero que, merced a su reducción a fenómeno y al simultáneo Machtspruch de la razón práctica, puede ser reinterpretado reflexivamente como kalós kaí agathós, esto es, como lugar donde tiene sentido nuestra destinación y nuestra acción para realizarla. Por ello,

13 Carácter instrumental presente explícitamente en la cita de F. Bacon que encabeza la primera crítica: la filosofía transcendental a modo de novun organum "de hecho, conclusión y fin legítimo de un error interminable" ["revera sit infinits erroris finis et terminus legitimus"] ( $K r V$, BII). 
Del filósofo solo puede decirse que filosofa [en la medida que] se esfuerza por establecer los fines superiores y la destinación de su razón; cuando los ha alcanzado, se halla en el tempo de la sabiduría. El filósofo, como guía de la razón, dirige el ser humano hacia su destinación. Como artesano mejora nuestra intelección y ciencia, [aunque] la ciencia no es propiamente nuestra destinación. El filósofo, como guía de la razón, es un maestro de sabiduría; como artesano de la razón, es un maestro de ciencia. El uso de la razón en relación de sus fines es su aplicación más noble [...]. Wolff fue un filósofo especulativo, pero no arquitectónico ni guía de la razón. Propiamente no fue en absoluto un filósofo, sino un gran artesano de la avidez humana de saber (PhilEnz, AA 29: 8).14

Algo parecido podría decirse de las lecturas epistemológicas o metafísicas del proyecto crítico que, centrándolo solo en el momento transcendental, obvian ocuparse de la sabiduría acerca de la destinación del hombre: sus promotores "propiamente no son en absoluto filósofos, sino grandes artesanos de la avidez humana de saber".

\section{Referencias}

BRAND, R.: Die Bestimmung des Menschen bei Kant, Hamburgo, Meiner, 2007.

KANT, I.: Gesammelte Schriften, Berlín, Preussische Akademie der Wissenschaften, 1900ss.

: Anthropologie in pragmatischer Hinsicht (Anth), AA 07.

: Briefe $(\mathrm{Br})$, AA 10-13.

: Erste Einleitung in die Kritik der Urteilskraft (EEKU), AA 20.

: Fortschritte der Metraphysik (FM), AA 20.

: Grundlegung der Metaphysik der Sitten (GMS), AA 04.

: Idee zu einer allgemeinen Geschichte in weltbürgerlicher Absicht $(\mathrm{IaG})$, AA 08.

14 Kant impartió en diez ocasiones el curso titulado Enciclopedia filosófica entre 1767 y 1782. Los apuntes conservados no pueden datarse pero, dada la proximidad a lo expuesto en el Canon y la Arquitectónica de la razón de la $K r V$, deben proceder probablemente a las últimas exposiciones de 1779/80 o 1781/82. 
: Kritik der praktischen Vernunft (KpV), AA 05.

: Kritik der reinen Vernunft $(K r V)$, AA 03; A/B.

: Kritik der Urteilskraft (KU), AA 05.

: $\operatorname{Logik}(\log )$, AA 09.

: Metaphysische Anfangsgründe der Rechtslehre (RL), AA 06.

: Philosophische Enzyklopädie (PhilEnz), AA 29.

: Prolegomena zu einer jeden künftigen Metaphysik (Prol), AA

04.

: Zum ewigen Frieden $(\mathrm{ZeF})$, AA 08.

: Kant im Kontext 2000, Berlín, Karsten Worm InfoSoftWare,

2001.

MACOR, L. A.: Die Bestimmung des Menschen (1748-1800). Eine Begriffsgeschichte, Stuttgart-Bad Cannstatt, Frommann-Holzboog, 2013.

SANTOZKI, U.: Die Bedeutung antiker Theorien für die Genese und Systematik von Kants Philosophie. Eine Analyse der drei Kritiken, Berlín, De Gruyter, 2007.

SPALDING, J. J.: Kritische Ausgabe [SKA], Tubinga, Mohr Siebeck, 2001ss.

: An den Herrn Vicepresident und Abt Jerusalem (AnHV), I/4.

: Die Bestimmung des Menschen (BestM), I/1.

TURRÓ, S.: Tránsito de la naturaleza a la historia en la filosofía de Kant, Barcelona, Anthropos, 1996.

: "De la filosofía crítica a la filosofía com a ciència estricta", Convivium. Revista de Filosofia 12 (1999) 61-75.

: Filosofia i Modernitat. La reconstrucció de l'ordre del món, Barcelona, Edicions Univesitat de Barcelona, 2016. 


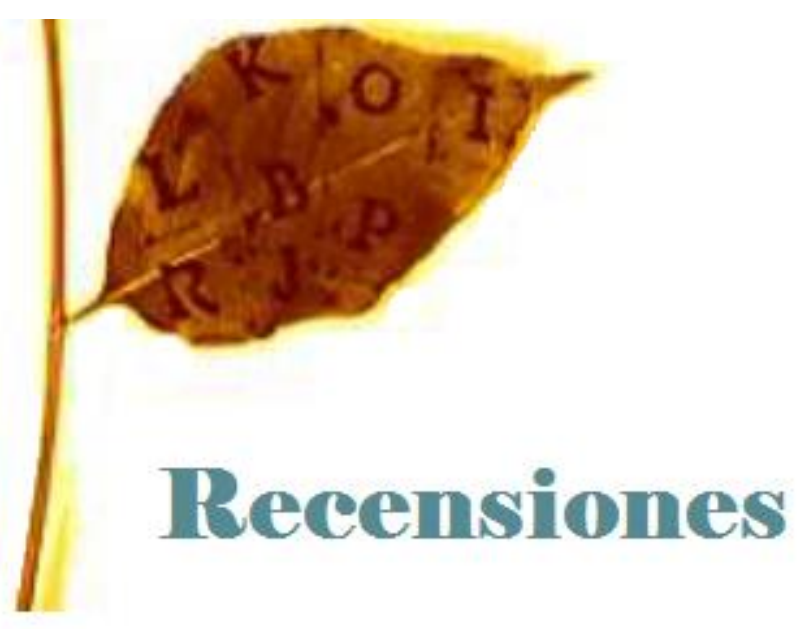




\title{
Gualtiero Lorini y Robert B. Louden (Eds.): Knowledge, Morals and Practice in Kant's Anthropology. Nueva York, Palgrave Macmillan, 2018, 171 pp. ISBN: 978-3-319-98726-2
}

\author{
NATALIA ANDREA LERUSSI
}

Knowledge, Morals and Practice in Kant's Anthropology es un libro editado recientemente por Gualtiero Lorini y Robert B. Louden sobre la antropología de Immanuel Kant. El libro consta de una introducción a cargo de los editores y nueve artículos (de reconocidos especialistas en el área), subdivididos en dos partes: i) Sources and Influences in Kant's Definition of the Knowledge Concerning the Human Being y ii) The Peculiarities of Anthropological Knowledge in Kant: Metaphysics, Morals, Psychology, Politics. El libro abre con un resumen de los antecedentes académicos de quienes escriben, seguido por una sección que informa del modo como se citan las diferentes obras de Kant, las ediciones y las traducciones adoptadas en el libro, y cierra con un útil índice de nombres y palabras. Se trata de una edición cuidadosa y cómoda para el lector.

Como indican los editores en la "Introducción" el objetivo del libro es desarrollar algunas tendencias adoptadas recientemente en la lectura de la antropología de Kant, así como ofrecer algunas innovaciones. Particularmente, buscan definir la especificidad y el aporte del sendero que abre la antropología de Kant; alternativo y complementario, según los editores, a la vía de la filosofía trascendental. Las tendencias remiten, por un lado, a las investigaciones que dan cuenta de esta disciplina desde las fuentes de la ilustración alemana y Rousseau y, por otro, a las lecturas 'internas' que dan cuenta de la originalidad del aporte de Kant y que inscriben su antropología dentro del gran proyecto crítico. En las páginas 2 3 los editores defienden la tesis según la cual la filosofía trascendental y la antropología se ocupan ambas, esencialmente, del 'sujeto humano'; la primera desde un punto de vista a priori y la segunda desde una perspectiva

1 CONICET - Universidad de Buenos Aires. Contacto: natalialerussi@gmail.com. 
a posteriori. De ahí que sostengan la relevancia que tiene la incorporación de los aportes de la antropología kantiana en cualquier comprensión adecuada de su filosofía trascendental. Esta tesis es muy importante. Ciertas lecturas canonizadas de la filosofía kantiana se han tomado demasiado en serio las pretensiones de Kant acerca de que lo trascendental está separado por un abismo de lo empírico y han desconsiderado, en consecuencia, solamente las fuentes que hablan a favor de lo contrario. Este libro considera, seriamente, aquellas otras fuentes y pone a la luz elementos que no pueden desconsiderarse si se pretende comprender la filosofía de Kant: el laboratorio desde el cual emergió, las tradiciones de las cuales Kant bebió, etc. Creo que las diferentes propuestas del libro colaboran a renovar y oxigenar el legado del filósofo.

En la primera parte, Sources and Influences in Kant's Definition of the Knowledge Concerning the Human Being, seis especialistas de la filosofía kantiana (Wilson, Favaretti Camposampiero, Goubet, Lorini y Lyssy) estudian la presencia, fundamentalmente, de Thomasius, Wolff, Crusius, Baumgarten, Meier, Lambert y Rousseau en la antropología de Kant.

En "Elucidations of the Sources of Kant's Anthropology" Holly Wilson introduce el debate acerca de las fuentes principales de las lecciones de antropología de Kant. Fundamentalmente, discute las tesis de Adickes y Brandt que enfatizan el vínculo que tendrían estas lecciones con la sección dedicada a la Psicología Empírica de la Metafísica de Baumgarten — se sabe que Kant usaba esta sección como manual para el dictado del curso de antropología - . La autora reconoce este vínculo, pero muestra la importancia que tiene la remisión a otro conjunto de fuentes. Incluso ya en sus primeras lecciones de 1772-1733 Kant refiere su antropología como un Weltkenntnis o Kenntnis des Menschen que en la lección de antropología "Friedländer" de mediados de los años 70 relaciona con un tipo de conocimiento 'pragmático', es decir, en los términos de Kant, a una doctrina de la prudencia. En este contexto, Wilson remite la concepción de lo pragmático en Kant a la tradición que se remonta a Thomasius, pasa por Johann Franz Budde, Andreas Rüdiger entre otros y llega a Christian August Crusius.

Jean-François Goubet propone en "Anthropology-A Legacy from Wolff to Kant?" remitir como una de las fuentes principales de la 
Antropología en sentido pragmático de Kant el tratamiento de la pneumatología de Wolff, en particular su psicología racional. Aunque, como se remarca al final del artículo, los proyectos de ambos autores son diferentes, la referencia a Wolff da cuenta del uso que hace Kant del hombre como animal racional, es decir, como animal que tiene entendimiento (autoconsciencia) y que tiene como destino la razón. Esto se ejemplifica mediante la definición de Wolff de hombre como individuo moral en tanto capaz de preservar memoria de sí mismo, capaz de decir 'yo' y que tiene una dimensión tanto teórica como práctica, la cuestión 'metafísica' del egoísmo, la perfección o perfectibilidad humana y la sabiduría.

"Anthropology from a Logical Point of View: The Role of Inner Sense from Jungius to Kant", de Matteo Favaretti Camposampiero, estudia la antropología como 'antropología del sentido interno' (tal y como Kant define la 'psicología racional' en el $\$ 89$ de la Crítica de la facultad de juzgar) e indaga sobre sus fuentes, entre las cuales se encuentra el 'sentido interior' (o reflexión) de Locke, pero, principalmente, el concepto de 'sentido interno' que se habría desarrollado en la tradición alemana, fundamentalmente, en Wolff y Lambert (pero que se remonta a Descartes, Jungius y Leibniz y tiene resonancias en Baumgarten y Crusius) con independencia del pensamiento de Locke. Lo que le interesa subrayar al autor es el vínculo entre la concepción implicada en esta tradición y su relación con la lógica de los conceptos. Kant habría detectado un error persistente en esta tradición (y que se encuentra todavía presente en el Kant pre-crítico) por el cual se confunde el sentido interno (apercepción empírica), la consciencia de sí en el tiempo, con la apercepción pura, la unidad pura de la conciencia, de la que no podemos tener sensación, sino solo concepto.

Gualtiero Lorini regresa a la cuestión planteada en el primer artículo del libro y pregunta, en "The Rules for Knowing the Human Being: Baumgarten's Presence in Kant's Anthropology", por el alcance de la influencia que pudo tener en su concepción antropológica el manual que usaba Kant en sus clases de antropología, la sección dedicada a la "Psicología Empírica" incluida en la Metaphysica de Baumgarten. A diferencia de Wilson, el autor considera no desdeñable la influencia de este texto para comprender la concepción antropológica de Kant, al menos en las secciones editadas como Didáctica, cuyo tema es el hombre como objeto del 
sentido interno. El autor muestra que, a diferencia de Wolff, Baumgarten defendía una concepción de la psicología empírica que enfatiza el acceso al alma que tiene la primera persona singular y, por lo tanto, entiende el alma como ‘yo' y una concepción de psicología racional en la que se buscaba determinar los principios racionales del conocimiento empírico. Estas ideas serían el marco para comprender el aporte antropológico kantiano.

En "Kant on the Vocation and Formation of the Human Being" Ansgar Lyssy desarrolla la inscripción de Kant, todavía no muy comprendida, según el autor, en una de las discusiones centrales de la ilustración alemana, a saber, la discusión en torno a la 'vocación del género humano' [Bestimmung der Menschheit] en la que fueron parte Spalding, Abbt, Mendelssohn, Kant, Schiller, Herder, Fichte y Reinhold. El aporte fundamental de este artículo es mostrar que la concepción histórica de Kant, su concepción del modo en que se desarrollan las diferentes disposiciones humanas a lo largo de la historia, es la respuesta del filósofo a la cuestión ('antropológica') de la vocación del hombre. Como Spalding, Kant incluye dentro de este proyecto no solo el desarrollo de la razón, es decir, la libertad, sino también el desarrollo de las disposiciones animales o sensibles, pero a diferencia de Spalding, la propuesta de Kant apunta a la especie humana en su conjunto y no solo al individuo.

En la Parte II, The Peculiarities of Anthropological Knowledge in Kant: Metaphysics, Morals, Psychology, Politics, Louden, Silva, Tommasi y Sánchez Madrid estudian el impacto que habría tenido la antropología kantiana en el así llamado 'período crítico' y, por lo tanto, los supuestos antropológicos de una diversidad de temas como la moral, la producción artística, la somatología, las enfermedades mentales, etc.

En "The Moral Dimensions of Kant's Anthropology" Robert B. Louden se detiene en la indicación de Kant, en una carta a Marcus Herz de fines de 1773, según la cual la antropología es 'la fuente de todas las ciencias de las costumbres' y, por lo tanto, atiende al uso que Kant le adscribe a la antropología como fundamento de la dimensión práctica, específicamente moral, del ser humano. Contra una fuerte tradición que niega la posibilidad de que una ciencia (empírica) del ser humano pueda fundar un ámbito expresamente trascendental, incluso en tensión con importantes fuentes kantianas, Louden explora esta interesante y novedosa vía, por lo demás, difundida en el marco de la ilustración. El autor ofrece 
argumentos que indican el sentido en el que la antropología del filósofo es o puede ser considerada una 'antropología moral', mostrando, por ejemplo, cómo en diferentes lugares de su obra Kant reconoce que hay ciertas 'normas-solo-para-humanos', es decir, normas 'no puras' que funcionan como imperativos categóricos. El conocimiento empírico del ser humano puede devenir 'antropología moral'. El artículo de Louden es valioso no solo por la tesis principal que defiende sino también por su 'estrategia de lectura': su propuesta disputa expresamente una lectura de Kant según la cual ciertas fuentes, pero no otras, definen lo que realmente Kant creyó.

Fernando M. F. Silva, en "Ein Spiel der Sinnlichkeit, durch den Verstand geordnet: Kant's Concept of Poetry and the Anthropological Revolution of Human Imagination", se ocupa de un tema muy desatendido por los estudios kantianos: la concepción kantiana de la poesía [Dichtkunst] - como un juego entre imaginación y entendimiento del que nacen imágenes y representaciones-, de su significado e importancia en las lecciones de antropología. La tesis principal que se defiende en el artículo es que la poesía tiene un rol central en la concepción revolucionaria que Kant tiene de la imaginación humana.

"Somatology: Notes on a Residual Science in Kant and the Seventeenth and Eighteenth Centuries", de Francesco Valerio Tommasi, estudia las menciones de Kant de la 'somatología' y su inscripción en el marco de los desarrollos de esta incipiente disciplina en los siglos XVII y XVIII. Se trata de una ciencia que nace en un contexto en el que la escolástica protestante intentaba suplantar la organización aristotélica de las ciencias. Marco en el cual nacería - este es un aporte muy interesante del artículo - la ontología, la psicología, la antropología, etc., en el siglo XVI. A diferencia de estas disciplinas, la somatología no tuvo éxito para instituirse como saber disciplinar, consecuencia, según el autor, de la ambigüedad de su objeto: la materia física, en general, pero también el cuerpo animal y el cuerpo humano.

Finalmente, Nuria Sánchez Madrid estudia la concepción kantiana de la enfermedad mental en el marco de su comprensión 'pragmática' de la disciplina antropológica en "Controlling Mental Disorder: Kant's Account of Mental Illness in the Anthropology Writings". La autora muestra cómo la perspectiva de Kant de las dolencias mentales se inscribe, en primer lugar, en la concepción general que Kant tenía de la mente, de la relación entre las 
facultades y de la exigencia de la unidad de la consciencia, así como también, en segundo lugar, en la concepción que tenía de la antropología como 'pragmática'; como disciplina que considera al hombre como capaz de actuar sobre la naturaleza y, por lo tanto, también sobre sí mismo. Según esta propuesta de lectura la 'terapia' de la enfermedad mental se debería buscar, según Kant, en el mismo sitio que le da su origen: así como la pérdida de sentido común coincide con el origen de la enfermedad mental, la interacción social puede prevenirla.

Knowledge, Morals and Practice in Kant's Anthropology es un bello libro del cual pueden sacar gran provecho no solo las personas que investigan la antropología kantiana, sino también aquellas otras que desean tener una comprensión más profunda, renovada y actualizada de la filosofía kantiana. 


\title{
Paula Órdenes y Anna Pickhan (Eds.): Teleologische Reflexion in Kants Philosophie. Weisbaden, Springer, 2019, 310 pp. ISBN: 978-3-658-23693-9
}

\author{
RAFAEL REYNA FORTES 1
}

Este libro está constituido por catorce artículos divididos, a su vez, en dos partes con tres capítulos cada una. Todos ellos están escritos o bien en lengua inglesa o bien en lengua alemana. La primera de las partes está dedicada al estudio sistemático de la tercera crítica kantiana en el marco provisto por las otras dos críticas. La segunda, en cambio, se ocupa de la dimensión teleológica de la facultad de juzgar. Por tanto, cabe señalar, de entrada, que en esta obra los autores se enfrentan con problemas de gran relevancia para la investigación kantiana. A continuación realizaré, a modo de síntesis, un breve sumario de aspectos centrales de cada una de las contribuciones.

La primera parte del libro es la que corresponde al estudio de la sistematicidad y la teleología de la razón. Courtney D. Fugate muestra en su artículo, el primero de la sección dedicada al problema del sistema de la razón y su teleología, que Kant alterna dos modelos teleológicos, a saber: el platónico y el hobbesiano. Echando mano de ambos modelos el autor enfrenta el abigarrado problema que plantea el intento de equilibrar las teorías expuestas en la primera y la tercera crítica. La segunda de las contribuciones la lleva a cabo Peter König, que se centra en un tema que si bien es cierto que reviste gran importancia, no es menos preciso decir que ha sido pasado por alto por gran cantidad de estudiosos. Se trata de la interpretación del sistema kantiano que ofrece la adecuada valoración del duodécimo parágrafo de la Analítica Trascendental. En dicho artículo se ofrecen soluciones muy concretas y, desde luego, razonables a los enigmas que dicho parágrafo trae consigo. El tercer y último trabajo lo realiza Paula Órdenes y ofrece una interpretación sobre el vínculo que existe entre la

1 Universidad de Málaga. Contacto: rafaelreynafortes@gmail.com. 
primera y la última crítica. Según tal interpretación, la estructura teleológica de la propia razón es la que permite y produce la unidad de carácter teleológico que se descubre y desarrolla en la tercera de las críticas.

El segundo de los temas afrontados en esta primera parte es el de la relación de la razón teórica con la ciencia natural. La profesora Brigitte Falkenburg desarrolla, en el primero de estos trabajos, la solución al problema que presenta mantener, por un lado, la imposibilidad de la metafísica, como hace Kant, y entenderla, al mismo tiempo como el fundamento de un saber que sirve a la humanidad como lo es la ciencia natural. La siguiente contribución es de Anna Pickhan y estudia el extraño concepto de cuerpo tal y como este es desarrollado en el Opus Postumum. En particular, en tal trabajo se da una explicación más que plausible del origen, en parte empírico y, también en parte, a priori del concepto de cuerpo y, con ello, asimismo del paso de una ciencia a priori de la naturaleza a una empírica. En tercer lugar, Anton Friedrich Koch elabora su trabajo a partir de tres conceptos de gran calado en la obra kantiana, a saber: intuición intelectual, entendimiento intuitivo y pensamiento especulativo. La atención a la trama conceptual que subyace a estos conceptos le permite al autor una explicación del concepto de fin natural.

La última de las temáticas expuestas en esta primera parte del libro está centrada en la dimensión práctica de la razón. Así, el primer trabajo, de Peter McLaughlin, ofrece un análisis de un concepto a menudo descuidado por los estudios kantianos como lo es el de la razón técnico-práctica. El objeto de este trabajo es ofrecer una solución al problema planteado por la alternativa determinismo y libertad. Al final de esta contribución, el autor muestra con un ejemplo claro los conceptos vinculados a esta temática y ofrece, por ello, una solución interesante a un problema de gran relevancia filosófica. La segunda contribución a este tema la lleva a cabo el profesor Fernando Moledo, quien analiza la idea kantiana de que el hombre constituye el fin de la creación. Según se muestra, son la autoconciencia, la libertad y la legislación moral de la que participa el hombre los elementos que le sitúan a este como fin de toda la creación.

La segunda parte del libro está dedicada a la facultad de juzgar teleológica. El primer tema abordado es el del principio de adecuación a fines [Zweckmäßigkeit]. Johannes Haag emplea los conceptos cardinales de adecuación a fines subjetiva y objetiva para explicar la característica 
fundamental del concepto de principio de adecuación a fines. En un segundo momento, Haag trae a colación el concepto libertad para mostrar la unidad de la crítica que se construye por el principio antedicho. En segundo lugar, el profesor Manuel Sánchez-Rodríguez elabora un estudio del concepto de adecuación a fines en comparación con el concepto leibniziano de armonía preestablecida. Según este trabajo, dicho principio podría explicarse en términos de la asunción crítica del mencionado concepto elaborado por Leibniz.

El siguiente tema que se aborda en la segunda parte es el de la interpretación kantiana de los organismos como fines naturales. El primer trabajo, realizado por Natalia Lerussi, intenta justificar la necesidad de pensar los seres organizados de acuerdo con términos teleológicos y lo hace por medio de la valoración de las características y los límites del entendimiento. Posteriormente, el trabajo de Georg Toepfer sitúa la posición kantiana en el marco de la discusión actual en torno a la teleología que, según defiende el autor, permite ser representada por dos modelos de explicación distintos, a saber: el cíclico o el lineal.

El último grupo de contribuciones, comenzando con el sexto capítulo de esta antología, está reservado a la discusión en torno a los conceptos de mecanicismo y finalismo. El primer trabajo, redactado por Jacinto Rivera de Rosales, busca explicar la antinomia consistente en la posibilidad de pensar al hombre tanto en términos de un mecanismo de la naturaleza como también en de adecuación a fines. Es decir, se le puede pensar, efectivamente, como una parte de la naturaleza, al mismo tiempo que puede ser concebida la naturaleza como adecuada a los fines del hombre. En último lugar, el trabajo de Daniel Schwab gira en torno al problema de la dialéctica de la facultad del juicio teleológica que consiste en afirmar, por un lado, que toda cosa material debe poder ser explicada de acuerdo a leyes mecánicas, mientras que, por otro lado, se afirma que algunos productos de la naturaleza no pueden ser explicados en tales términos.

En definitiva, se trata de un volumen que se ocupa de aspectos centrales tanto de la obra kantiana como de su importancia en el marco de discusiones filosóficas actualmente relevantes. 


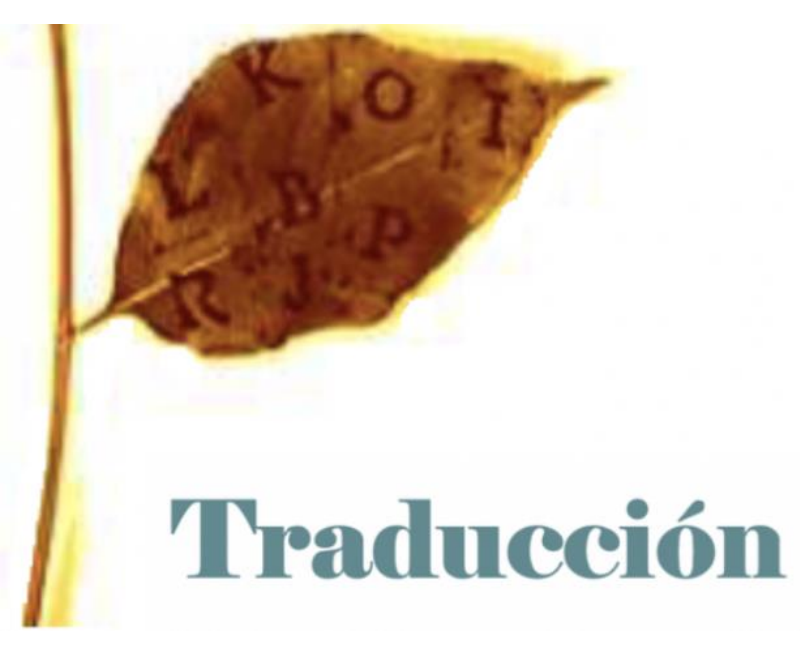




\title{
Los Aforismos sobre religión y deísmo de J. G. Fichte. Presentación, debates abiertos y traducción
}

\author{
MARÍA JIMENA SOLÉ1
}

\begin{abstract}
Resumen
Este artículo ofrece una presentación general y la traducción al español de uno de los documentos fundamentales para acceder al pensamiento de juventud de $\mathrm{J}$ G. Fichte. El texto, publicado póstumo bajo el título Aforismos sobre religión y deísmo, fue redactado por Fichte en 1790, luego de su estudio de la Crítica de la razón pura de Kant, pero antes del encuentro con la Crítica de la razón práctica, que motivó en él una profunda revolución interior. En la presentación general al texto, se abordan los debates que este fragmento ha motivado entre los especialistas, tanto respecto de las fuentes filosóficas del escrito — que refiere a la cuestión del supuesto spinozismo del joven Fichte-, como acerca del modo en que el texto debe ser interpretado.
\end{abstract}

Palabras clave: sentimiento, reflexión, religión, filosofía, escisión

\section{J. G. Fichte's Aphorisms on Religion and Deism. Presentation, open discussion and translation}

\begin{abstract}
This article offers a general presentation and the translation into Spanish of one of the fundamental documents to access Fichte's philosophical position during his youth. The text, published posthumously under the title Aphorisms on Religion and Deism, was written by Fichte in 1790, after his study of Kant's Critique of Pure Reason, but before the encounter with the Critique of Practical Reason, which motivated in him a deep inner revolution. The general presentation to the text addresses the debates that this fragment has motivated among specialists, both with respect to its philosophical sources-which refers to the question of the supposed Spinozism of the young Fichte-, and to the way in which the text must be interpreted.
\end{abstract}

Keywords: feeling, reflection, deism, philosophy, scission

1 CONICET - Universidad de Buenos Aires. Contacto: jimenasole@ filo.uba.ar. 
Fichte ha dejado valiosos documentos que permiten precisar el momento exacto en el que abrazó la posición kantiana y comenzó a desarrollar su propio sistema, la Doctrina de la Ciencia. Esos mismos documentos permiten conocer cuál era la posición a la que Fichte se había adherido hasta ese momento, y que dejaba atrás para siempre. En una carta a Weisshun, de septiembre de 1790, Fichte le comunica que desde que ha leído la Crítica de la razón práctica vive en un mundo nuevo, en el que principios que consideraba irrefutables se han venido abajo y en el que ha visto probadas cosas que creía imposibles de demostrar, entre ellas, el concepto de una libertad absoluta y del deber (GA, III.1: 167).2 En otra carta de ese mismo mes, dirigida a su prometida, Johanna Rahn, Fichte admite que sus disquisiciones acerca de la necesidad eran erróneas y le confiesa que en ese momento está "completamente convencido de que la voluntad humana es libre" (GA, III.1: 169, 174). Poco después, en otra epístola dirigida a Achelis, Fichte escribe: "a usted especialmente debo reconocerle que ahora creo de todo corazón en la libertad del hombre" (GA, III.1: 193). Según estos testimonios, hasta septiembre de 1790, Fichte había estado convencido de la imposibilidad de demostrar la libertad de la voluntad y, por lo tanto, también de la imposibilidad de fundar racionalmente una moral, basada en los conceptos de responsabilidad, deber y delito. A esto se añade el testimonio de Carl Fiedler, quien menciona que hacia comienzos de 1785 Fichte tenía la intención de escribir un ensayo sobre el fatalismo y la necesidad (GA, III.1: 9).

Si ese ensayo fue escrito, no ha sido conservado. En cambio, sí contamos con un fragmento en el que Fichte se ocupó del asunto del determinismo y que ha sido considerado por muchos especialistas como la expresión más temprana de las convicciones filosóficas que había abrazado durante su juventud. Se trata del fragmento titulado Aphorismen über Religion und Deismus [Aforismos sobre religión y deísmo], cuya traducción al español ofrecemos a continuación.

El fragmento, compuesto por 18 aforismos de diferente extensión, no fue redactado con el fin de ser publicado y permaneció inédito durante la vida de Fichte. En 1831, su hijo, Immanuel Hermann, lo incluyó en la segunda parte de un libro titulado Johann Gottlieb Fichte's Leben und

2 Citamos la obra completa de Fichte editada por la Bayerischen Akademie der Wissenschaften utilizando la sigla GA, indicando el tomo y la página. 
litterarischer Briefwechsel. En 1845, volvió a publicarlo en el tomo V de las Sämtliche Werke de su padre, que reúne escritos sobre filosofía y religión. 3 En la edición crítica de la Academia de ciencias bávara, el texto está incluido en el tomo II.1 (GA, II.1: 287-291).

El fragmento está fechado en el año 1790. Si bien probablemente no haya sido el propio Fichte quien anotó la fecha, se puede inferir, a partir de su contenido, que fue redactado ese año a finales del mes de julio. Esto se desprende del hecho de que Fichte hace referencia allí a la primera Crítica de Kant que, según se sabe, leyó a finales de julio de 1790; pero no hace referencia a la Crítica de la razón práctica que, como acabamos de señalar, motivó su conversión al kantismo y el abandono de sus convicciones deterministas y que, según sabemos, leyó a finales de septiembre de ese año (cfr. GA, III.1: 167). Fichte tenía, entonces, al momento de redactar estos aforismos, 28 años.

A continuación, antes de ofrecer nuestra traducción, a modo de presentación general del texto, analizaré brevemente su contenido y luego haré referencia a algunas de las discusiones a las que este fragmento ha dado lugar en la bibliografía especializada.

\section{Religión y deísmo; corazón y reflexión}

Tal y como el título anticipa, los Aforismos sobre religión y deísmo presentan dos posiciones que se revelan completamente heterogéneas, sin nada en común: la religión cristiana y el sistema del deísmo. La religión se basa en el sentimiento o el corazón. El deísmo se basa en la reflexión o especulación. Cada una de estas posiciones posee sus proposiciones fundamentales y ofrece al ser humano una concepción de Dios, de la libertad y del mundo completamente diferente y opuesto al de la otra.

El fragmento comienza investigando la naturaleza de la religión cristiana, a lo que dedica los primeros 12 aforismos. Fichte presenta la religión cristiana como un sistema. Las proposiciones fundamentales del cristianismo "se presuponen como admitidas" (af. 1)4 y a partir de ellas

\footnotetext{
3 Citamos esta edición de las obras de Fichte utilizando la sigla $F S W$, indicando tomo y página. ${ }_{4}$ Citamos los Aforismos sobre religión y deísmo según nuestra traducción al español, que se incluye a continuación, indicando la abreviatura af. y el número. En el cuerpo del texto de nuestra traducción se ofrece entre barras la paginación de las dos ediciones de las obras de Fichte, GA y FSW.
} 
"todo lo demás se sigue por medio de los más correctos argumentos, según la más clara conexión" (af. 2). En cuanto al contenido de estas proposiciones fundamentales, Fichte afirma que el cristianismo "considera a Dios únicamente en la medida en que Él puede tener relación con los seres humanos" (af. 3). No se ocupa de la esencia o de la existencia de Dios consideradas en sí mismas, sino que únicamente le interesa la divinidad en la medida en que se vincula con los hombres. Este Dios para el hombre responde a una exigencia del corazón humano, resultado de un requerimiento universal, y es diferente del Dios de la especulación. Este Dios del corazón, para satisfacer esos requerimientos, debe poseer determinadas características. El corazón exige "un Dios al que se pueda implorar, que sienta compasión y amistad" (af. 4); el ser humano requiere "un Dios con el que pueda comunicarse, con el que sea posible establecer una relación de mutua transformación" (af. 4).

Por eso, Fichte afirma que "al comienzo más y luego gradualmente cada vez menos" (af. 5) las religiones apelaron al antropomorfismo. Pero en la medida en que "la razón humana se elevó a un concepto consecuente de la divinidad" (af. 6), ya no fue posible pensar a Dios como un ser humano y se recurrió a lo que Fichte denomina "el sistema de la mediación" (af. 6), esto es, la introducción de figuras que funcionan como mediadoras entre los hombres y la divinidad. Jesús cumple con esta función de la mejor manera, ya que es, al mismo tiempo, divino y humano. A él se le atribuyen "todas las propiedades de Dios que pueden referirse al ser humano" (af. 7) y también "aquellas propiedades que el corazón de los seres humanos buscan en su Dios, sin que el entendimiento las encuentre en él: compasión, amistad afectuosa, flexibilidad" (af. 8).

La manera en la que el sentimiento humano experimenta su relación con la divinidad da origen a lo que Fichte considera la proposición fundamental de todas las religiones, incluido el cristianismo. Esta consiste en afirmar "que el pecado existe y que el pecador únicamente puede acercarse a Dios luego de determinadas conciliaciones" (af. 9). En la medida en que se basa en el sentimiento, no es demostrada racionalmente ni dice nada acerca de la realidad tal como es. Se trata del modo en que el corazón experimenta su situación de separación como resultado del pecado y la posibilidad de la reconciliación gracias a la muerte de Jesús. El sacrificio de Jesús puede ser pensado como propio por los cristianos que 
experimentan el requerimiento de una reconciliación (af. 10). El cristianismo presupone, por lo tanto, que los seres humanos son responsables de sus pecados y libres para buscar la conciliación con su creador. Ese concepto de libertad, de una voluntad que decide de manera incondicionada, también es, según Fichte, un concepto del sentimiento que la razón no puede demostrar (af. 15, nota). Por todo esto, Fichte concluye que "la religión cristiana parece destinada más para el corazón que para el entendimiento" (af. 12), y en la medida en que no pretende imponerse mediante razonamientos, "parece una religión de almas simples y buenas" (af. 12).

Fichte pasa entonces a analizar el deísmo, a lo que dedica principalmente los aforismos 15 y 16. Si se dejan de lado las exigencias del corazón y se procede únicamente con la reflexión, sostiene Fichte, de manera consecuente y sin preocuparse por los resultados de esta investigación, entonces necesariamente se arriba a una serie de afirmaciones, que expone a modo de un listado en el aforismo 15. La razón o reflexión enseña que existe necesariamente un ser eterno que produjo el mundo a través del pensamiento eterno y necesario, que cada cambio en este mundo es necesariamente determinado por una causa suficiente, que cada ser pensante y sintiente debe existir necesariamente del modo en que existe y que el pecado es un producto de la limitación necesaria que, en mayor o menor medida, caracteriza a los seres finitos. Fichte denomina a esta posición como el "sistema del puro deísmo" (af. 16) y su proposición fundamental es el principio de razón suficiente que establece que todo lo que sucede tiene una causa eficiente que da cuenta de su existencia y de la manera determinada en que existe. Dios es la primera causa de todo lo existente y existe, también, necesariamente de determinada manera.

Es claro que hay grandes diferencias entre el Dios demostrado racionalmente y el Dios del corazón. Fichte adelanta esta diferencia en el aforismo 4, donde sostiene que mientras el corazón exige un Dios que escuche las plegarias de los hombres, que se compadezca de sus males y que tuerza su voluntad en función de ellos, la especulación le ofrece un Dios "como un ser inmutable, incapaz de cualquier pasión" (af. 4), una divinidad "que no tiene ningún punto de contacto [...] con ningún ser finito" (af. 4). Así, tanto la posibilidad de una libertad de la voluntad, como la posibilidad de que el orden universal establecido pueda modificarse, quedan totalmente 
descartadas para la especulación. En un sistema del puro deísmo, lo que usualmente es considerado como pecado o falta, no es más que limitación; una limitación que es propia de todo ser finito, inevitable. Así, la especulación ofrece una visión del mundo que afirma de manera radical el determinismo universal y excluye la atribución de valores morales a los acontecimientos humanos o naturales. Sin embargo, Fichte considera que el deísmo "no tiene ninguna influencia perjudicial" (af. 16) para la moral. Lo único que hace, reconoce el autor, es impedir que el hombre tome parte de esos sentimientos agradables que produce la religión y, en cambio, genera cierta "inflexibilidad" (af. 16).

El desarrollo de los dos sistemas - la religión cristiana y el deísmo puro- desemboca así en la contraposición sentimiento-especulación. El sentimiento motiva requerimientos en los seres humanos, exigencias para la vida que deben ser satisfechas. Se trata del sentimiento universal, no de los sentimientos privados, individuales de cada ser humano. Se trata, pues, de un aspecto constitutivo de todo ser humano $\mathrm{y}$ es por eso que sus afirmaciones poseen validez universal, aunque sea meramente una "validez subjetiva" (af. 16). El resultado sistemático que satisface a estos requerimientos es la religión, y la que mejor lo hace es la religión cristiana. La especulación o reflexión también es presentada como una facultad común a todos los seres humanos, que investiga las esencias y las existencias de sus objetos tal como son en sí mismos - en el sentido que Fichte llama aquí "objetivo" (af. 3 y 7)— dejando de lado cualquier exigencia del corazón. El sistema que se construye sobre la base de los principios del conocimiento humano y mediante la deducción rigurosa de sus consecuencias es, pues, la filosofía.

Sentimiento y especulación son dos facultades humanas que no tienen nada en común, que producen edificios sistemáticos totalmente heterogéneos y que, por lo tanto, no deberían entrar en conflicto. Existe, según Fichte, un límite [Gränze] que separa ambas facultades y que debe ser respetado. Fichte señala que tanto los apóstoles como el máximo filósofo de la época, Immanuel Kant, han reconocido y respetado ese límite. Como se sabe, la Crítica de la razón pura sostiene la imposibilidad de conocer lo suprasensible. Así, la esencia de Dios, de la libertad y de las penas y castigos divinos quedan fuera del ámbito del conocimiento teórico ( $c f r$. af. 12). 
Pero reconocer el límite no implica que sea respetado siempre. Fichte dedica el aforismo 14 y la nota al aforismo 15 a examinar los casos en los que ambos puntos de vista se entremezclan. En primer lugar, el corazón se inmiscuye en la marcha de la reflexión, "cuando al comenzar a pensar se pone ya en la mira el objetivo al que se quiere llegar con el fin de que, en la medida de lo posible, la especulación y las afirmaciones de la religión coincidan" (af. 14). El resultado de esta operación es, dice Fichte, "una casa construida sobre el aire con materiales muy diversos y muy mal unidos" (af. 14). Fichte ofrece dos ejemplos. Primero, la "filosofía religiosa" que se encuentra en las obras de Christian August Crusius, a quien califica como un pensador "cobarde y dotado de escasa fantasía". Crusius (17151775) fue profesor de Teología en la Universidad de Leipzig, donde Fichte estudió, y sus obras tuvieron cierta popularidad en su época. Pasó a la historia como uno de los más sagaces enemigos de la filosofía de Leibniz y Wolff. Principalmente, criticó su adhesión irrestricta al principio de razón suficiente y el consecuente determinismo que de allí se sigue. Según Crusius, la voluntad es libre y la revelación y la razón pueden ser unificadas. El segundo ejemplo hace referencia a "los nuevos teólogos", a quienes considera "más valientes y más ocurrentes" que a Crusius, autores de una "religión filosófica, o un deísmo" (af. 14). El deísmo, tomado como una religión filosófica y no como el sistema del deísmo puro al que Fichte dedica este escrito, es denunciado en este pasaje como el intento de justificar mediante argumentos racionales las exigencias del corazón. Al igual que la filosofía religiosa, es una construcción incoherente, frágil y engañosa. Estas críticas pueden aplicarse también a la otra corriente teológica que era dominante hacia finales del siglo XVIII en Alemania: la neología. Como una reacción frente al deísmo, y también frente al ateísmo de los materialistas franceses, esta corriente representa un esfuerzo por reunir el cristianismo con la posición filosófica característica de la ilustración alemana. En efecto, la neología coincide con el deísmo en la postulación de la necesidad de que la religión sea racional; pero, a diferencia de aquel, no rechaza la revelación sino que se propone racionalizarla. Así pues, la neología fue la posición teológica defendida por personalidades como Ernesti, Sack, Spalding, Jerusalem y Semler, quienes sostuvieron la posibilidad de una completa racionalización del contenido de la revelación cristiana mediante el examen filosófico, histórico y filológico de la doctrina (véanse Allison 1966; Carvalho 2009: 16ss.; Sparn 2001). 
En segundo lugar, el corazón puede obstaculizar el ejercicio de la reflexión, estableciendo la proposición fundamental a partir de la cual se deduce todo lo demás, y hacerla pasar por una afirmación justificada especulativamente. Como ejemplo, remite al defensor de la libertad en la tercera antinomia de la Crítica de la razón pura, quien "había obtenido el concepto de la libertad de alguna otra parte (del sentimiento, sin duda) y que, en sus pruebas, no hace sino justificarlo y aclararlo" (af. 15, nota). En efecto, Fichte había afirmado la imposibilidad de sostener la libertad de la voluntad mediante la sola reflexión. Únicamente el sentimiento provee al ser humano de una idea de la libertad de su voluntad. De hecho, continúa Fichte, "en las cadenas argumentativas no modificadas que se siguen de las proposiciones fundamentales del conocimiento humano jamás hubiese llegado a un concepto de esa clase" (af. 15, nota). Un sistema filosófico que afirme la libertad de la voluntad no es más que otro castillo en el aire.

La religión se basa en el sentimiento o corazón. La filosofía - o sistema del deísmo puro- se basa en la especulación o reflexión. Mezclarlos conduce a incoherencias. Fichte insiste en la necesidad de reconocer y respetar el límite que se alza entre reflexión y corazón. Los últimos dos aforismos del fragmento abordan la contraposición entre sentimiento y reflexión. El aforismo 17 refiere a los instantes en que "el corazón toma venganza de la especulación" y se dirige al Dios de la reflexión, carente de compasión, "como si Él fuese a modificar su gran plan a causa de un individuo" (af. 17). Fichte habla aquí de los momentos de desesperación en los que el corazón humano, a pesar de la evidencia racional en contra, cree con fervor que las plegarias podrían ser escuchadas $\mathrm{y}$, ante el sentimiento del desagrado que el pecado ocasiona en la divinidad, anhela con apremio una reconciliación. La especulación puede construir un firme edificio sistemático en el que se demuestra todo de manera rigurosa sin aceptar nada que no esté fundado sobre los principios supremos del conocimiento humano. El ser humano que especula vive en un mundo en el que rige el determinismo universal, en el que Dios es la causa necesaria, eterna e inmutable del universo, en el que todos los eventos presentes, pasados y futuros tienen una explicación causal. Sin embargo, los resultados de esa construcción racional son tan contarios a las exigencias del corazón que este irrumpe en ese mundo racional para aniquilarlo en un solo instante. Por eso Fichte habla de la venganza del corazón, que se enfurece al ver que la razón no satisface sus anhelos. 
El ser humano experimenta un desgarramiento en su propio ser. “CCómo hay que tratar con un ser humano semejante?”, se pregunta Fichte en el último aforismo del fragmento. Todo ser humano siente, pero también especula. En cuanto que especula correctamente es inapelable; sus conclusiones son irrefutables, e incluso comprende las ventajas propias de la religión que su punto de vista racional le obligan a rechazar. En cuanto que siente, desea esas ventajas, quiere unirse a la divinidad, experimenta su libertad y quiere ser perdonado por sus pecados. Cuando siente, cancela la especulación. Cuando especula, debe acallar al corazón. "El único medio de salvación para él consistiría en llevar sus especulaciones más allá del límite" (af. 18), reconoce Fichte. La única vía que permitiría escapar del sufrimiento de la escisión, dice Fichte, implica avanzar con la razón más allá del límite. Intentar demostrar aquello que el corazón exige. El final del texto adquiere un tono desesperado en la repetición de un interrogante: ¿puede el ser humano reflexionar más allá del límite? Fichte no ofrece ninguna respuesta.

\section{El determinismo del joven Fichte}

Como mencionamos, Immanuel Hermann Fichte publicó este fragmento varios años después de la muerte de su padre. En el prólogo al tomo $\mathrm{V}$ de las Sämtliche Werke, presenta los Aforismos como la expresión sistemática de la postura determinista a la que su padre se había adherido durante su juventud. Afirma que cuando Fichte era estudiante de teología en Leipzig, las enseñanzas de sus maestros lo habían llevado a buscar respuestas en la filosofía, y continúa:

Fue entonces cuando la visión determinista del mundo le pareció como la más consecuente, aun si esta lo dejaba en una escisión (Zweispaltung) irreconciliable entre el entendimiento y el sentimiento; y Spinoza, cuyo sistema consideró luego como el único consecuente antes del descubrimiento del idealismo trascendental, le sirvió como modelo (Vorbild) para esa concepción filosófica. La manera en que él comprendió ese sistema en ese entonces, lo muestran ciertos pasajes de los Aforismos sobre religión y deísmo (\$15 y ss.), escritos en el año 1790, que por lo tanto hemos considerado aquí como un testimonio de su más temprana etapa en la historia de su formación (FSW, V: VI). 
Este breve pasaje del prólogo contiene dos afirmaciones que se transformaron en tópicos comunes de los estudios fichteanos posteriores. Por un lado, sostiene que los Aforismos expresan la posición determinista a la que Fichte se adhirió durante sus años de estudiante. Por el otro, establece que ese determinismo tiene su fuente principal en la doctrina de Spinoza.

Que Spinoza haya sido el modelo a partir del cual Fichte construyó su posición determinista es difícil de justificar a partir del análisis del texto. Tampoco existen documentos fehacientes para afirmar que en el momento de escribir los Aforismos Fichte hubiese estudiado los textos spinozianos y menos aún que se hubiese adherido a su doctrina. Sin embargo, la cuestión del spinozismo del joven Fichte dio lugar a diferentes especulaciones en las primeras biografías de Fichte.

Johann Heinrich Loewe sostiene, en una investigación publicada en 1862, que Fichte conocía a Spinoza desde su juventud a través de la lectura de las Cartas sobre la doctrina de Spinoza (1862: 247). Loewe se refiere al escrito publicado por F. H. Jacobi en 1785, y nuevamente en 1789, que desencadenó la llamada Pantheismusstreit, una polémica mantenida inicialmente entre Jacobi y Mendelssohn, pero que pronto involucró a los principales pensadores de la época y puso a Spinoza en el centro del debate filosófico (véase Scholz 1916; Timm 1974; Beiser 1987; Solé 2011).

Ludwig Noack ofreció, en una investigación publicada ese mismo año, una versión diferente. Según él, durante sus años de estudiante, Fichte estaba convencido de la inexistencia de la libertad, entendida como la indeterminación de la voluntad. Sus propias experiencias el encuentro casual con el noble que financió sus estudios, el flagelo de la pobreza que en esos años se agrava- le parecían confirmar el punto de vista del determinismo. Según Noack, Fichte descubrió que con esta convicción "se encontraba completamente de acuerdo con la visión de Spinoza" (1862: 30). Este descubrimiento habría sucedido hacia 1785, cuando Fichte visitó a un predicador sajón cerca de Leipzig y le comunicó sus convicciones deterministas. Entonces el pastor "le entregó bienintencionadamente al joven spinozista para que leyera un libro que había aparecido unos treinta años antes, cuyo título era La ética de Spinoza, refutada por el conocido sabio Christian Wolff (Fráncfort, 1744)" (Noack 1862: 31). El objetivo del pastor, afirma Noack, era que Fichte encontrara - gracias a la refutación wolffiana- el camino para salir del error del determinismo spinozista y 
regresar a una creencia más sensata y coherente con la religión. Fue así que el joven ávido de conocimiento accedió al pensamiento de Spinoza, a quien hasta ese momento únicamente conocía por su mala fama como el ateo más difícil de comprender y más sagaz. La lectura de la Ética generó, según este biógrafo, un gran impacto: "Y al igual que diez años antes lo había hecho Goethe a sus veinticinco años, captó en ese momento Fichte, que aún no tenía ni veinticinco años, el espíritu de ese gran hombre tan difamado, con una fuerza que lo afectó profundamente" (Noack 1862: 31).

Al igual que el joven Goethe, el joven Fichte habría experimentado el impacto del encuentro con Spinoza antes de la publicación de las Cartas sobre Spinoza de F. H. Jacobi - texto que puso a Spinoza y su doctrina en el centro del debate y provocó lo que se conoce como el Spinozarenaissance en Alemania- Sin embargo, continúa Noack, el efecto de este encuentro fue muy diferente para ambos. Mientras que el joven poeta vio en Spinoza un modelo ético, un sabio libre de pasiones que lo llevó a ver en él a un auténtico cristiano, el joven estudiante de teología, en cambio, fue impactado de otra manera:

Lo que a Fichte en ese entonces le atrajo de Spinoza fue, por un lado, la tenaz consecuencia (Folgerichtigkeit) con la que Spinoza refutaba la presunta libertad humana y colocaba nuestras acciones en la cadena infinita de causas eficientes necesarias. Por otro lado, le atrajo la manera en que explicaba al alma humana como activa en la comprensión de la verdad y como pasiva en la comprensión de lo falso, la determinación de la voluntad por medio de la razón y de la intuición (Einsicht) y, por lo tanto, la manera en que establecía una armonía entre el orden universal y necesario del mundo y la verdadera virtud. Finalmente, lo impactó su explicación del conocimiento adecuado supremo o la intuición correcta de Dios como amor intelectual de Dios universo como la fuente de nuestra paz y nuestra felicidad (Noack 1862: 32).

Así, según Noack, Fichte admitió los resultados de la filosofía de Spinoza - al menos en relación con su doctrina de Dios - con tranquilidad y desapasionadamente y fortaleció su afirmación del determinismo universal a medida que fue profundizando en el estudio de esta doctrina. Sin embargo, "el estudio de la doctrina spinoziana dejaba en su interior cierta insatisfacción" (Noack 1862: 33). En efecto, a pesar de su afirmación de la 
existencia de un destino inconmovible, el joven no estaba completamente reconciliado con esta idea.

También Xavier Léon apela a la experiencia de vida del joven Fichte para explicar su adhesión al determinismo. Según Léon, Fichte había aprendido el peso que tienen las circunstancias y las fatalidades en nuestro destino. La visión determinista parecía imponerse a —aunque convivía con- la certeza interior de su propia libertad. León hace referencia al libro de C. F. Hommel, un profesor de Derecho de la Universidad de Leipzig, a partir del cual Fichte habría delineado los contornos de su determinismo. El libro se titula Alexander von Joch. Über Belohnung und Strafe nach türckischen Gesetzen [Recompensa y castigo según las leyes turcas], publicado en 1770 y nuevamente en 1772. La tesis principal de Hommel consiste en que la creencia en la libertad es una ilusión, pues la voluntad es el resultado de un mecanismo regido por las leyes de asociación de la imaginación y el entendimiento. De este modo, sostiene León, el joven estudiante de teología se transformaba en un filósofo y fue, según él, por aquella época, que Fichte entró en contacto con la doctrina de Spinoza:

Un día, el día en que venía de pronunciar su primer sermón en un templo cerca de Leipzig, tuvo una larga conversación acerca de este tema tan serio con el pastor del lugar, un discípulo del filósofo Wolff. Le expuso sus dudas acerca de la realidad del libre arbitrio y su creencia en el determinismo universal, única posición conciliable con la omnipotencia de Dios. «Pero usted es spinozista», le respondió el hombre, un poco escandalizado. Y para convencer a Fichte de su herejía le puso en sus manos un libro, viejo, de más de treinta años, que había ido a buscar al fondo de su biblioteca: la Ética de Spinoza refutada por el célebre filósofo Christian Wolff. La refutación de Wolff le pareció tan pobre a Fichte, aunque era apenas un estudiante, que lejos de apartarse del spinozismo le fortaleció la convicción de que la doctrina de Spinoza era la verdadera. Y aunque no podemos precisar la fecha exacta en la que Fichte estudió directamente el Tratado teológicopolítico y la Ética, podemos afirmar que la filosofía de Spinoza ejerció una influencia singular en la formación de su pensamiento. Fichte aprendió de Spinoza el sentido moral y religiosa del problema filosófico, la unidad pura del primer principio, la inteligibilidad perfecta al mismo tiempo que universalmente necesaria de las cosas, la realidad absoluta de toda existencia relacionada con su esencia eterna. Moralismo, monismo, racionalismo, panteísmo, de esta cuádruple enseñanza recibida de Spinoza, el espíritu de Fichte llevará para siempre la marca; y cuando llegue el día en que, bajo el impulso de la Crítica, se transforme en el apologista de la libertad, será todavía en relación a la Ética que la Doctrina de la Ciencia se caracterizará como un «spinozismo invertido» (Léon 1922: 55-56). 
Léon conecta de esta manera las convicciones juveniles de Fichte con el desarrollo posterior de su sistema, acusado por Jacobi en 1799 como una forma de spinozismo invertido en el contexto de la Polémica del ateísmo (véase Rivera de Rosales; Cubo 2009).

Contra la afirmación de Immanuel Hermann Fichte, que apuntaba a vincular el determinismo expuesto los Aforismos con la doctrina de Spinoza, algunos especialistas han señalado que esa posición posee otras fuentes filosóficas. Willy Kabitz fue el primero en sostener, en una investigación publicada en 1902 sobre la historia del desarrollo de la Doctrina de la Ciencia, que Fichte expresa convicciones deterministas antes de conocer las Cartas sobre la doctrina de Spinoza de Jacobi (1902: 2-7) y que la fuente de su posición parece ser Leibniz, a quien conocía a través de las obras de Crusius, Wolff o Platner (1902: 13ss.). En esa misma línea, Hermann Nohl sostiene que la visión fatalista se inicia en los años de estudiante universitario en Leipzig, donde asiste a las clases de K. F. Hommel -a quien también había hecho referencia Xavier Léon-. Nohl señala que Fichte menciona la obra de Hommel Alexander von Joch. Über Belohnung und Strafe nach türckischen Gesetzen [Recompensa y castigo según las leyes turcas] en diferentes oportunidades, por lo que se puede suponer que le sirvió como fuente de su determinismo (1911: 373ss.).

En un artículo publicado en 1978, Reinhard Lauth parece haber puesto fin a las discusiones en torno a la cuestión del spinozismo de Fichte. Lauth muestra que según todos los documentos conocidos hasta el momento, Fichte menciona a Spinoza por primera vez en 1793 y afirma que seguramente este no hubiese sido el caso si ya en 1785-1786 hubiese sido tan fuertemente impactado por el spinozismo, como afirma Noack.5 Lauth sostiene que la imaginación de este biógrafo ha hecho frecuentemente violencia a la realidad y señala que no hay garantía histórica de lo que afirma acerca del descubrimiento del spinozismo por parte de Fichte. Supone que Noack ha adornado con su imaginación el hecho de que Fichte, quien en 1785 era preceptor de la familia von Hähnel en Elbersdorf, escribió al pastor Karl Gottlob Fiedler, de Dittersbach, que deseaba visitarlo el 2 de febrero y en esa misma carta expresaba ciertas concepciones deterministas.

\footnotetext{
5 La primera mención explícita a Spinoza en una obra publicada por Fichte la encontramos en la "Reseña de Creuzer" de 1793, en la que se refiere de manera indirecta a la refutación del "panteísmo spinozista" incluida en el libro reseñado (GA, I.2: 7-14). Existe una traducción al español de Vicente Serrano (2014).
} 
La carta de Fichte se ha extraviado ( $c f r$. GA, III.1: 1). La respuesta de Fielder, que sí se conserva y a la que hicimos referencia al comienzo de este artículo, no menciona a Spinoza ni a Wolff, sino que habla de la necesidad como el ídolo de Fichte; se declara dispuesto a leer un estudio que Fichte deseaba escribir para exponer su punto de vista y lo remite a Crusius, que había mostrado que determinación y necesidad se encuentran muy alejadas la una de la otra ( $c f r$. Lauth 1978: 28).

En cuanto a las fuentes de la posición determinista expuesta en los Aforismos, si bien no hay documentos que permitan dirimir la cuestión de manera definitiva, los especialistas sostienen que lo más probable es que Fichte se haya basado en ciertos elementos de la escuela Leibniz-wolffiana. Probablmente, estos elementos le llegaron a través de K. F. Hommel, a quien ya hicimos referencia. Hommel fue su profesor en la Universidad de Leipzig y había publicado bajo el pseudónimo Alexander von Joch, el mencionado libro Über Belohnung und Strafe nach türckischen Gesetzen [Recompensa y castigo según las leyes turcas], donde rechaza el libre albedrío y expone una visión determinista basada en ciertos elementos de la filosofía de Leibniz ( $c f r$. Nohl 1911: 11ss.; Wildfeuer 1997b; Preul 1969: 121ss.). En esta misma línea, Ivaldo sostiene que si es posible detectar algunos aspectos de su posición similares a la posición de Spinoza, esto se debe a que ciertos motivos spinozistas estaban muy difundidos en el medio filosófico de su época (1992: 4ss.).

\section{Interpretaciones en pugna}

Más allá de las discusiones acerca de sus fuentes y posibles influencias, los Aforismos sobre religión y deísmo han dado lugar a diferentes interpretaciones. Como ya adelantamos, muchos especialistas aceptan, siguiendo la afirmación de Immanuel Hermann en el prólogo al tomo $\mathrm{V}$ de las Sämtliche Werke de Fichte, que el fragmento constituye la expresión fehaciente de ese determinismo al que se adhirió durante su juventud (véase, por ejemplo, Gueroult 1930: I, 38; López Domínguez 1995: 35; Ivaldo 1996: 13).

En su exhaustivo estudio sobre la época pre-kantiana del pensamiento de Fichte, Reiner Preul ha discutido esta lectura, señalando que se trata de una interpretación simplista del texto que no toma en cuenta el 
otro concepto desarrollado allí, también fundamental para el pensamiento fichteano: el concepto de sentimiento o Gefühl (Preul 1969: 6ss.). Preul interpreta el fragmento como el esfuerzo de Fichte por reunir ambos puntos de vista $-\mathrm{y}$ ambas visiones del mundo - en una misma subjetividad, a pesar de que este intento revele la imposibilidad de que esa coexistencia sea armónica (1969: 113ss.).

Contra esta lectura, Wildfeuer ha reivindicado la interpretación según la cual los Aforismos expresan el determinismo del joven Fichte, pero sostiene que esa posición determinista no coincide con lo que Fichte presenta allí como el sistema del deísmo puro. En su obra Praktische Vernunft und System [Razón práctica y sistema] (1997a) muestra que las dos posiciones presentadas en los Aforismos —el determinismo y la religiónpresuponen un sistema de referencia único que garantiza la posibilidad de que ambas coexistan. Ese sistema único es, según Wildfeuer, una forma del determinismo que, si bien no es mencionado explícitamente en el texto, debe ser presupuesto si se pretende comprender la propuesta fichteana de una religión que subsiste junto a un deísmo puro sin refutarse ni anularse mutuamente (1997a: 164ss).

Frente a estas dos posiciones, surge en la bibliografía especializada una tercera propuesta: la de ver en el joven Fichte un defensor del sentimiento, de la certeza inmediata no racional basada en la constitución afectiva del ser humano. En esta línea, Vicente Serrano afirma, en Metafísica y filosofía transcendental en el primer Fichte (2004), que Fichte se revela en sus fragmentos tempranos como un lector de Rousseau, quien priorizaba el sentimiento sobre la especulación. Serrano afirma entonces que el verdadero problema para Fichte consiste en encontrar la manera de justificar la prioridad de lo práctico por sobre lo teórico, lo cual se traduce, según su lectura, en una adhesión al punto de vista del corazón en los Aforismos (cfr. 2004: 22-23).

Por nuestra parte, hemos defendido otra alternativa (cfr. Solé 2016; 2017). Creemos que los Aforismos no constituyen la declaración fichteana de su adhesión al determinismo ni tampoco al punto de vista del sentimiento. Según nuestra lectura, el texto no se limita a exponer dos posiciones contrapuestas - la posición religiosa, que afirma la libertad de la voluntad, y la especulativa, que la niega - como sistemas que no se contradicen por estar basados en principios opuestos. Fichte sostiene, en 
primer lugar, que la mezcla de ambos puntos de vista es inaceptable. 6 Esa es, según nuestra interpretación, la primera tesis del fragmento. Pero además, Fichte muestra la necesidad de buscar una posición superadora, ya que es igualmente imposible adherirse a un sistema sin experimentar la escisión. Nuestra propuesta es que los Aforismos no constituyen un texto aporético — como es leído por algunos especialistas (cfr. Preul 1969: 121; Wildfeuer 1997b: 64)—, sino que las preguntas que quedan abiertas y que no obtienen respuesta implican una toma de posición, expresan la necesidad de buscar un nuevo punto de vista, un sistema que no intente combinar religión y especulación, sino que logre subsanar la escisión en la que estos abandonan al ser humano. Esa posición superadora resultará ser la Doctrina de la Ciencia, que modifica los términos del planteo antagónico y supera la escisión a través de la reconciliación de la libertad y la filosofía: el primer sistema de la libertad.

\section{Referencias}

ALLISON, H.: Lessing and the Enlightenment, Michigan, University of Michigan Press, 1966.

BEISER, F.: The Fate of Reason. German Philosophy from Kant to Fichte, Cambridge, Harvard University Press, 1987.

CARVALHO, M.: "Introducción histórica", en: RIVERA DE ROSALES, J.; CUBO, Ó. (eds.): La polémica sobre el ateísmo. Fichte y su época, Madrid, Dykinson, 13-134, 2009.

FICHTE, J. G.: Gesamtausgabe der Bayerischen Akademie der Wissenschaften, Stuttgart/Bad Cannstatt, Frommann-Holzboog, 1962ss., [GA].

: Sämtliche Werke, V, Berlín, Verlag von Veit und Comp, 1845. Reedición: Berlín, De Gruyter, 1971 [FSW].

: „Skeptische Betrachtungen über die Freiheit des Willens mit Hinsicht auf die neuesten Theorien über dieselbe“, Jenaer Allgemeine Literatur-Zeitung 303 (1793) 201-205.

${ }_{6}$ En esta misma línea, Heimsoeth sostiene que los Aforismos presentan frente a frente dos sistemas inconciliables ( $c f r$. 1931: 25; véase también Carvalho 2009: 84). 
: Johann Gottlieb Fichte's Leben und litterarischer Briefwechsel, II, Sulzbach, Seidelschen Buchhandlung, 1831.

: Querelle de l'Athéisme suivie de divers textes sur la religion, París, Vrin, 1993.

GAUDIO, M.; SOLÉ, M. J.; FERREYRA, J. (eds): Los caminos cruzados de Spinoza, Fichte y Deleuze, Buenos Aires, RAGIF, 2018.

GAWLICK, G.: "Deismus", en: SCHNEIDERS, W. (ed.): Lexicon der Aufklärung, München, Beck, 81-82, 2001.

GUEROULT, M.: L'évolution et la structure de la doctrine de la science chez Fichte, París, Les Belles Lettres, 1930.

HEIMSOETH, H.: Fichte, Madrid, Revista de Occidente, 1931.

IVALDO, M.: "La idea de la filosofía trascendental en la primera Doctrina de la ciencia", en: LÓPEZ DOMÍNGUEZ, V. (ed.): Fichte 200 años después, Madrid, Editorial Complutense, 11-24, 1996.

JACOBI, F. H.; MENDELSSOHN, M.; WIZENMANN, T.; KANT, I.; GOETHE, W.; HERDER, G.: El ocaso de la Ilustración. La Polémica del Spinozismo, Bernal, Editorial de la Universidad de Quilmes/Prometeo, 2013.

KABITZ, W.: Studien zur Entwicklungsgeschichte der Fichteschen Wissenschaftslehre, Berlín, Reuter \& Reichard, 1902.

LAUTH, R.: "Spinoza vu par Fichte", Archives de Philosophie 41 (1978) $27-48$.

LERUSSI, N.; SOLÉ, M. J. (eds.): En busca del Idealismo. Las transformaciones de un concepto, Buenos Aires, RAGIF, 2016.

LÉON, X.: Fichte et son temps, París, Armand Colin, 1922.

LÓPEZ DOMÍNGUEZ, V.: Fichte: acción y libertad, Madrid, Ediciones Pedagógicas, 1995.

LOEWE, J. H.: Die Philosophie Fichtes nach dem Gesamtergebnisse ihrer Entwicklung und in ihrem Verhältnisse zu Kant und Spinoza, Stuttgart, Wilhelm Nitzschke, 1862. 
NOACK, L.: Johann Gottlieb Fichte nach seinem Leben, Lehren und Wirken zum Gedächtnis seines hundertjährigen Geburtstages, Leipzig, Wignad, 1862.

NOHL, H.: „Miscellen zur Fichtes Entwicklungsgeschichte und Biographie“, Kant-Studien 16, 4 (1934) 373-381.

PHILONENKO, A.: "Traduction et commentaire de la lettre à F.A. Weisshuhn: fragment de 1790", Revue de théologie et de philosophie 41 (1991) 229-248.

PREUL, R.: Reflexion und Gefühl: Die Theologie Fichtes in seiner vorkantischen Zeit, Berlín, De Gruyter, 1969.

RIVERA DE ROSALES, J.; CUBO, Ós. (eds.): La polémica sobre el ateísmo, Fichte y su época, Madrid, Dykinson, 2009.

SCHRADER, W. (comp.): Anfänge und Ursprünge. Zur Vorgeschichte der Jenaer Wissenschaftslehre. Fichte Studien 9, Amsterdam/Atlanta, Rodopi, 1997.

SCHOLZ, H.: Die Hauptschriften zum Pantheismusstreit, Berlín, Verlag von Reuther \& Richard, 1916. Reedición: Waltrop, Hartmut Spenner, 2004.

SERRANO, V.: Metafísica y filosofía transcendental en el primer Fichte, Valencia, Universidad Politécnica de Valencia, 2004.

: "Reseña de Creuzer", Revista de Estud(i)os sobre Fichte [Web], 2014. http://ref.revues.org/565.

SOLÉ, M. J.: Spinoza en Alemania (1670 - 1789). Historia de la santificación de un filósofo maldito, Córdoba, Brujas, 2011.

: "Especulación, sentimiento y escisión en el joven Fichte. Análisis de sus Aforismos sobre religión y deísmo", Veritas. Revista de Filosofía y Teología 35 (2016) 59-80.

: "Fichte frente a Spinoza: la Doctrina de la ciencia como vía de reconciliación", Contrastes. Revista Internacional de Filosofía XXII, 1 (2017) 155-171.

SPARN, W.: „Neologie“, en: SCHNEIDERS, W. (ed.): Lexicon der Aufklärung, München, Beck, 287-288, 2001. 
TIMM, H.: Gott und die Freiheit. Studien zur Religionsphilosophie der Goethezeit. I. Die Spinozarenaissance, Fráncfort del Meno, Klostermann, 1974.

WILDFEUER, A. G.: Praktische Vernunft und System. Entwicklungsgeschichtliche Untersuchungen zur ursprünglichen KantRezeption Johann Gottlieb Fichtes. Spekulation und Erfahrung, Stuttgart/Bad Cannstaat, Frommann-Holzboog, 1997a.

: „Vernunft als Epiphänomen der Naturkausalität. Zu Herkunft und Bedeutung des ursprünglichen Determinismus J. G. Fichtes“, en: SCHRADER, W. (comp.): Anfänge und Ursprünge. Zur Vorgeschichte der Jenaer Wissenschaftslehre. Fichte Studien 9. Amsterdam/Atlanta, Rodopi, 61-82, 1997b. 


\section{J. G. FICHTE}

/FSW 2/GA 287/

\section{Aforismos sobre religión y deísmo (fragmento)1}

Del año 17902

\section{/FSW 3/}

1) La religión cristiana está construida sobre algunas proposiciones que se presuponen como admitidas. Más allá de ellas, no hay ninguna investigación.

2) Para determinar exactamente el contenido de esta religión, primero hay que investigar esas proposiciones. A partir de ellas, todo lo demás se sigue por medio de los más correctos argumentos, según la más clara conexión. La colección de estas proposiciones sin la más mínima mezcla de razonamiento filosófico, sería un canon de esta religión.

3) Esta considera a Dios únicamente en la medida en que Él puede tener relación con los seres humanos. Acerca de su existencia objetiva, 3 las investigaciones se suspenden.

4) Parece que es un requerimiento universal4 para el ser humano, buscar en su Dios ciertas características que le impidan el ingreso al ámbito de la

1 [Einige] Aphorismen über Religion und Deismus. Entre barras, en el cuerpo del texto se incluye la paginación de ambas ediciones, indicando en cada caso la sigla correspondiente.

Esta traducción al español fue realizada originalmente para el uso de los doctorandos que asistieron al seminario de posgrado "Spinoza en el Idealismo alemán" (que dictamos junto con la Dra. Sandra Palermo en la Facultad de Filosofía y Letras de la Universidad de Buenos Aires en 2015) y luego fue revisada para el uso de los estudiantes del Seminario de grado "Spinoza-Fichte-Deleuze: Caminos cruzados" (que dictamos junto con los Dres. Mariano Gaudio y Julián Ferreyra también en la Facultad de Filosofía y Letras de la UBA, en 2016). Agradezco a estudiantes y colegas la lectura y los comentarios, que enriquecieron esta traducción.

2 No se sabe si la fecha fue añadida por el editor o se encontraba en el manuscrito original. Sin embargo, se admite que es correcta. Al respecto, véase la breve presentación del texto que acompaña esta traducción.

3 Objectives Daseyn.

4 Allgemeines Bedürfniß. Traducimos Bedürfnis por requerimiento, para evitar la traducción usual por necesidad, término que remite principalmente sentido de necesidad lógica. 
especulación.5 La especulación le mostrará a Dios como un ser inmutable, incapaz de cualquier pasión; pero su corazón6 exige un Dios al que se pueda implorar, que sienta compasión y amistad. Aquélla se lo muestra como un ser que no tiene ningún punto de contacto con él ni con ningún ser finito; pero el ser humano quiere un Dios con el que pueda comunicarse, con el que sea posible establecer una relación de mutua transformación.

5) Las religiones anteriores a Jesús, incluso la judía, al comienzo más y luego gradualmente cada vez menos, se sirvieron del antropomorfismo para satisfacer esos requerimientos del corazón. /FSW 4/

6) Este medio fue suficiente solo hasta que la razón humana se elevó a un concepto consecuente de la divinidad. En una religión para todos los tiempos y pueblos, el antropomorfismo ya no tenía lugar. En la religión cristiana, que pretendía ser eso mismo, se eligió el sistema de la mediación. $7^{*}$

* En las religiones paganas, los dioses menores, especialmente los penates, lares, etcétera, eran mediadores personales entre los seres humanos y los Dioses superiores. Ya que luego de la venida de Jesús la humanidad volvió a hundirse, surgieron durante la época de los papas numerosos mediadores bajo la forma de santos. Esto es una prueba, según mi opinión, de que este requerimiento se funda en lo más propio de la humanidad que no especula.

7) A Jesús se le atribuyen todas las propiedades de Dios que pueden referirse /GA 288/ al ser humano. Él es puesto como el Dios de los seres humanos. Por lo demás, acerca de la esencia objetiva8 de Jesús, las investigaciones se suspenden.

8) A Jesús también se le atribuyen aquellas propiedades que el corazón de los seres humanos buscan en su Dios, sin que el entendimiento las encuentre en él: compasión, amistad afectuosa, flexibilidad.9 Según el punto de vista de los apóstoles: él es tentado en todas partes, para aprender a ser misericordioso, 10 y otras afirmaciones similares.* Acerca de la manera en

5 Speculation.

6 Herz.

7 System der Mittlerschaft.

8 Objective Wesen

9 Beweglichkeit.

10 Hebreos IV, 15-16: "Nuestro sumo Sacerdote no se queda indiferente ante nuestras debilidades, por haber sido sometido a las mismas pruebas que nosotros, pero que, a él, no lo llevaron al pecado. Por 
que esta delicada humanidad coexiste junto con las propiedades divinas, las investigaciones otra vez se suspenden.

* Consideraciones acerca del destino de Jesús desde este punto de vista, como modelo y representación del Dios humano de los hombres, arrojarían una nueva luz sobre la religión en su totalidad y le otorgarían una nueva fecundidad a los hechos más insignificantes de la vida de Jesús.

9) Una proposición fundamental11 de las antiguas religiones y también de las más nuevas, en la medida en que las conozco, es la siguiente: que el pecado existe y que el pecador únicamente puede acercarse a Dios luego de determinadas conciliaciones.12 Esto prueba, otra vez, que esta proposición se encuentra fundada en el sentimiento universal 13 de la humanidad que no especula.

10) La religión cristiana presupone esta proposición como una proposición del sentimiento14 sin plantearse la cuestión del cómo ni la de su validez objetiva. Quien se hace cristiano no requiere ninguna otra reconciliación.15 A través de la religión fundada /FSW 5/ por medio de la muerte de Jesús, se le abre, a todo aquel que cree sinceramente, el camino a la gracia de Dios. El que siente el requerimiento de un sacrificio para la reconciliación, 16 considera entonces la muerte de aquél como la propia. Esto es, según mi parecer, lo que dicen los apóstoles.17

11) Si nos basamos en estas proposiciones, todo en la religión parece tener la más clara coherencia. Pero si vamos más allá con nuestra investigación, nos enredamos en interminables dificultades y contradicciones.*

* Incluso Pablo parece haber traspasado esta frontera del cristianismo en sus cartas a los romanos con sus sutiles investigaciones acerca de la elección de la gracia.

lo tanto, acerquémonos con confianza al Dios de bondad; él tendrá piedad de nosotros y nos recibirá en el momento oportuno" (GA, II.1: 288).

11 Grundsatz.

12 Aussöhnungen.

13 Allgemeinen Empfindung.

14 Empfindungssatz.

15 Versöhnung.

16 Versöhnopfers.

17 Romanos V, 10: "Y si fuimos reconciliados con Dios por la muerte de su Hijo cuando éramos enemigos, con mucha mayor razón ahora, reconciliados, su vida nos salvará"; Efesios II, 16: "Destruyó el odio y los reconcilió con Dios, por medio de la cruz, haciendo de los dos un solo cuerpo" (cfr. GA, II.1: 288). 
12) Estos primeros principios fundamentales de la religión se basan más en sentimientos 18 que en convicciones: en el requerimiento de unirse con Dios, /GA 289/ en el sentimiento19 de su caída en el pecado y su culpabilidad, etcétera. Así pues, la religión cristiana parece destinada más para el corazón que para el entendimiento. No pretende imponerse mediante demostraciones; quiere ser buscada por un requerimiento. Parece una religión de almas simples y buenas. - "Los fuertes no requieren del médico, sino solamente los enfermos"; "He venido a llamar a los pecadores al arrepentimiento",20 y otras afirmaciones similares. Así se explica la oscuridad, que los envuelve y debía envolverlos. Así se explica que no fueran utilizados medios sumamente posibles para lograr un convencimiento imperioso, como por ejemplo la aparición de Jesús ante toda la nación judía luego de su resurrección, el anhelado signo del cielo,21 y otros similares.

13) Es notable que en los primeros siglos, apóstoles iletrados hayan suspendido sus investigaciones exactamente en el mismo sitio donde el pensador más grande del siglo XVIII, Kant,22 seguramente sin tener esto en cuenta, establece el límite 23 de la investigación acerca de la esencia objetiva de Dios, de la investigación de la libertad, la imputación, la culpa y la pena.

14) Cuando se sobrepasa este límite, sin dejarle a la investigación el camino libre; cuando al comenzar a pensar se pone ya en la mira el objetivo al que se quiere llegar /FSW 6/ con el fin de que, en la medida de lo posible, la especulación y las afirmaciones de la religión coincidan, entonces el resultado es una casa construida sobre el aire con materiales muy diversos y muy mal unidos. En las obras de Crusius, 24 cobarde y dotado de escasa fantasía, esto aparece como una filosofía religiosa. En las de los nuevos

\footnotetext{
18 Empfindungen.

19 Gefühl.

20 Mateo IX, 12-13: "Pero Jesús los oyó y dijo: «Los sanos no necesitan médico, sino los enfermos. Aprendan lo que significa esta palabra de Dios: Yo no les pido ofrendas, sino que tengan compasión. Pues no vine a llamar a hombres perfectos sino a pecadores»" (cfr. GA, II.1: 289).

21 Mateo XII, 38: "Entonces algunos maestros de la Ley y fariseos le dijeron: «Maestro, queremos que nos hagas un milagro.» Pero él contestó: «Esta raza perversa e infiel pide un milagro, pero solamente se le dará el signo del profeta Jonás»"; Lucas XI, 29: "Como la gente se juntaba en mayor número, Jesús empezó a decir: «Los hombres de hoy son una gente mala; piden una señal, pero señal no tendrán. Solamente se les dará la señal de Jonás»"; Mateo XXVII, 41-42: "Los jefes de los sacerdotes, los jefes de los judíos y los maestros de la Ley lo insultaban, diciendo: «Ha salvado a otros y no puede salvarse a sí mismo: que ese rey de Israel baje ahora de la cruz y creeremos en él»" (cfr. GA, II.1: 289).

22 Immanuel Kant (1724-1804).

23 Gränze.

${ }_{24}$ Christian August Crusius (1715-1775).
} 
teólogos, más valientes y más ocurrentes, aparece como una religión filosófica, o un deísmo,25 que como deísmo no sirve de mucho. Además, esta clase de obras generan la sospecha de que sus autores no realizan muy honestamente su trabajo.

15) Si se avanza con la reflexión 26 siempre hacia adelante, sin mirar hacia la derecha ni hacia la izquierda, sin preocuparse por el sitio al que se arribará, entonces me parece que con seguridad* se llega a los siguientes resultados:

/GA 290/ a) Hay un ser eterno, cuya existencia y cuya manera de existir es necesaria.

b) Según y a través del pensamiento eterno y necesario, este ser produjo27 el mundo.

c) Cada cambio en este mundo es determinado por una causa suficiente necesariamente tal como es. La primera causa de cada cambio es el pensamiento originario de la divinidad. 28

d) Asimismo, cada ser pensante y sintiente debe existir necesariamente del modo en que existe. Ni su actuar ni su padecer pueden ser de otra manera que como son, sin contradicción. /FSW $7 /$

e) Lo que el sentimiento humano universal llama pecado, es producido por la limitación necesaria, mayor o menor, de los seres finitos. Se dan efectos necesarios en la situación de estos seres, que son tan necesarios como la existencia de Dios e igualmente imposibles de eliminar.

* Sé que los filósofos que llegan a otros resultados, los demuestran con igual rigor. Pero también sé que de vez en cuando, en las cadenas demostrativas se guardan para sí mismos sus conclusiones y comienzan una nueva cadena con nuevos principios, que han encontrado en alguna otra parte. Este es el caso, por ejemplo, del sagaz defensor de la libertad en las antinomias kantianas,29 quien había obtenido el

25 Esta es la primera aparición del término deísmo en el cuerpo del texto. Aquí el sentido de este término se vincula con la mezcla no deseada entre el punto de vista del sentimiento y de la reflexión. Muy distinta será la acepción que Fichte le atribuye en los aforismos 15 y 16, donde habla del "sistema puramente deísta".

26 Nachdenken.

27 Entstand.

28 Urgedanke.

29 Kant, I., Kritik der reinen Vernunft, Riga, 1781, I.2, parte 2, parágrafo 2, libro 2 (Referencia tomada de GA, II.1: 290). 
concepto de la libertad de alguna otra parte (del sentimiento, sin duda) y que, en sus pruebas, no hace sino justificarlo y aclararlo, ya que en las cadenas argumentativas no modificadas que se siguen de las proposiciones fundamentales del conocimiento humano, por el contrario, jamás hubiese llegado a un concepto de esa clase.

16) Este sistema puramente deísta30 no contradice a la religión cristiana, sino que le deja toda su validez subjetiva. No la falsea, ya que en ningún lugar entra en colisión con ella. No tiene ninguna influencia perjudicial, más que en aquél que desatiende por completo una influencia por demás beneficiosa para la moralidad. No se opone a que se la venere como la mejor religión popular31 ni a que sea recomendada con la más sincera efusión a aquellos que la requieren, cuando se posee poca coherencia32 pero se posee sentimiento.33 Pero produce una cierta inflexibilidad e impide a la propia persona participar de los sentimientos gratos que provienen de la religión.

17) Sin embargo, puede haber ciertos instantes en los que el corazón toma venganza de la especulación, en los que se dirige con un anhelo ardiente al Dios reconocido como carente de compasión, como si Él fuese a modificar su gran plan a causa de un individuo. Puede haber ciertos instantes en los que /GA 291/ el sentimiento de una ayuda visible, de una atención casi incuestionable a las plegarias, destruye todo el sistema; y cuando se extiende el sentimiento del desagrado de Dios frente al pecado, puede haber instantes en los que surge el anhelo apremiante de una reconciliación.

18) ¿Cómo hay que tratar con un ser humano semejante? En el campo de la especulación parece imbatible. No hay que ofrecerle pruebas de la verdad de la religión cristiana. Pues las admite únicamente en la medida en que es

30 Aquí aparece la segunda mención al deísmo, como "sistema puramente deísta" que ya no es, como el deísmo mencionado en el aforismo 14, una mezcla del sentimiento y la reflexión, sino que se trata de un sistema completamente especulativo, sin mezcla de principios o proposiciones que provengan de las exigencias del corazón. Este sistema consiste en la afirmación de los puntos enumerados en el aforismo 15 y por lo tanto afirma el determinismo universal, la existencia necesaria de una divinidad no personal, la inexistencia del pecado como culpa moral. Esta posición que Fichte denomina "sistema del puro deísmo", no coincide con el deísmo entendido como la posición teológica a la que adhirieron, entre otros, Locke, Hume, Tindal, Rousseau y Voltaire, y que sostiene que los principios fundamentales de la religión, como la existencia de Dios entendido como un creador inteligente y bueno, la inmortalidad del alma y la eternidad de las penas, pueden ser demostrados racionalmente. Acerca del concepto de deísmo, véanse Allison 1966; Carvalho 2009: 16ss.; Gawlick 2001.

31 Volksreligion.

32 Consequenz.

33 Empfindlichkeit. 
posible demostrárselas, pero alega que le es imposible recurrir a ellas. Es capaz de comprender las ventajas que rehúye de esta manera. Puede desearlas con el anhelo más ardiente, pero le es imposible creer. El único medio de salvación para él consistiría /FSW 8/ en llevar sus especulaciones más allá del límite. ¿Pero es capaz de hacerlo cuando quiera? ¿Es capaz de hacerlo, en la medida en que se le ofrece la prueba irrebatible del carácter engañoso de estas especulaciones? ¿Puede hacerlo, en la medida en que este modo de pensar se encuentra entrelazado con él, ya sea por naturaleza, ya con el sesgo completo de su espíritu?34

34 Ganzen Wendung seines Geistes. 


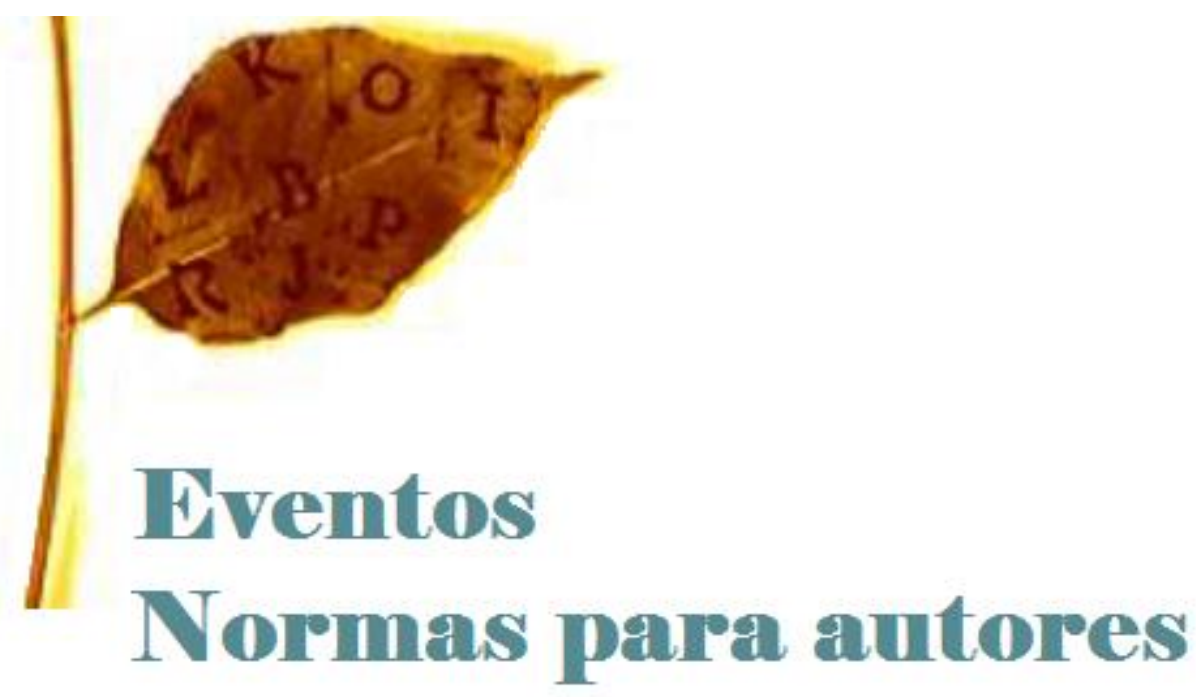




\section{Normas para autores}

La revista publica trabajos redactados en lengua castellana, alemana, inglesa y portuguesa y referidos a cualquiera de los ámbitos relativos a la filosofía kantiana o en los que la presencia de esta tenga una relevancia significativa. Las contribuciones deben ser originales y su extensión no podrá superar los 80.000 caracteres con espacios. Las reseñas no excederán los 16.000 caracteres con espacios.

\section{Encabezado}

El texto será precedido por título (Times New Roman, 14 puntos), un resumen (máx. 100 palabras, Times New Roman, 10 puntos) y hasta cinco palabras clave (Times New Roman, 10 puntos, separadas por comas), tanto en la lengua propia del artículo como en inglés (si la lengua empleada en el trabajo es el castellano) o en castellano (si el trabajo está redactado en inglés, alemán o portugués).

\section{Estilo}

\subsection{Cuerpo de texto}

Los textos serán redactados en Times New Roman, 12 puntos, interlineado múltiple 1,15, con espaciado posterior de 6 puntos, con párrafos justificados y sangrados $(1,25 \mathrm{~cm})$ en primera línea siempre que no se trate del párrafo que da comienzo a una sección.

\subsection{Citas}

Las referencias relativas a una cita textual aparecerán en cuerpo de texto, indicando entre paréntesis autor y año seguido de dos puntos y número de página, según el modelo:

...tal y como indica el naturalista inglés (Darwin 1871: 32 )... / ...tal y como indica el naturalista inglés Darwin (1871: 32)... / “...todo apuntaba en esa dirección” (Autor1; Autor2; Autor3 2018: 15) / “...todo apuntaba en esa 
dirección" (Autor1 et al. 2018: 15) / Autor et al. (2018) ha explicado que “...todo apuntaba en esa dirección” (15).

Ello no excluye que se abra una reflexión complementaria, si así se estima oportuno, en nota a pie de página, a 9 puntos, Times New Roman, justificado, interlineado sencillo. Cuando se indique que parte de la cita ha sido omitida se emplearán tres puntos entre corchetes [...]. Si la cita es en lengua distinta a la del artículo, se tratará de buscar su traducción en alguna edición en castellano y se añadirá entre corchetes la cita en la lengua original (en caso de que no se disponga de una traducción, el autor indicará que la misma ha sido elaborada por él mismo mediante la abreviatura a. trad., o bien en una nota a pie de página si todas las traducciones son propias); por ejemplo

“...todo apuntaba a dicha interpretación" [“...All leads us in that direction"] (Autor 2017: 18; 1995: 20) / “...todo apuntaba a dicha interpretación" (a. trad.) [“...All leads us in that direction”] (Autor 1995: 20)

Cuando las citas textuales superen los 4 renglones se colocarán aparte, a 10 puntos, en un párrafo justificado y sangrado en primera línea a 1,25 cm.

Citaciones kantianas

En el caso de obras de Kant, en cuerpo de texto y nota se aludirá a ellas empleando las abreviaturas establecidas por la Kant-Forschungsstelle de Maguncia. Las abreviaturas se hallan publicadas en su página web (http://www.kant.uni-mainz.de/), pestaña 'Kant-Studien', sección 'Hinweise für Autoren'.

Ejemplo:

(SF, AA 07: 83)

$(K r V, \mathrm{~A} 158 / \mathrm{B} 197)$

\subsection{Apartados}

Los encabezados de los apartados y subapartados se indicarán mediante la siguiente numeración: $1,1.1,1.1 .1 \ldots$ etc., sin cursiva ni negrita, a Times 
New Roman, 12 puntos. La enumeración de listados empleará los indicativos i), ii), iii), etc. Cada apartado irá separado del anterior por un espacio en blanco.

\subsection{Uso de las comillas, guiones, corchetes y cursiva}

Comillas altas o inglesas (“"): para citas textuales, ej. "todo apuntaba en esa dirección”; para títulos de artículos, capítulos de libro, noticias, posts, entradas en una web, entradas en enciclopedia, título de ponencia..., ej. En el tercer capítulo "La verdad y la mentira" / Así lo demostró en su artículo "La recepción de los colores".

Comillas simples (' ’): para añadir énfasis a una palabra o expresión, ej. Esa 'verdad' era muy relativa.

Corchetes ([ ]): para la traducción de palabras extranjeras, ej. Cuando Heidegger habla de Stimmung [estado de ánimo], está refiriéndose a...

Cursiva: reservada para palabras o expresiones en lengua distinta a la del manuscrito, así como para títulos de libro, revistas, periódicos, películas, páginas web, blogs, congresos..., ej. Así lo describe Kant en la Crítica de la razón pura / La noticia apareció en El país / La revista Evolutionary Anthropology se encargó de la publicación... / Como apunta la autora en su web Ver para creer...

\subsection{Notas a pie}

Los números indicativos de las notas a pie de página (que en ningún caso se colocarán al final del documento, sino al final de cada página) deben encontrarse después de los signos de puntuación.

\subsection{Referencias bibliográficas}

Las referencias bibliográficas completas aparecerán al final de la contribución, en un apartado ad hoc bajo el título Bibliografía o Referencias, según corresponda, por orden alfabético aplicado a los apellidos de los autores. En el caso de que varias publicaciones del mismo autor coincidan en el mismo año, se las distinguirá con letras (1999a, 1999b).

Citas de libros

MORENO, J.: Los retos actuales del darwinismo. ¿Una teoría en crisis?, Madrid, Síntesis, 2008. 
DARWIN, C.: The Descent of Man and Selection in Relation to Sex, Londres, John Murray, 1871, 1882 (2 $2^{\mathrm{a}}$ ed.).

: El origen del hombre y la selección en relación al sexo, trad.

Julián Aguirre, Madrid, EDAF, 2006.

Capítulos de libro

KINSBOURNE, M.: "Integrated field theory of consciousness", en MARCEL, A.; BISIACH, E. (eds.): Consciousness in Contemporary Science, Oxford, Oxford University Press, 1988, 35-78.

ROS VELASCO, J.: "Introduction", en: Feminism. Past, Present, and Future Perspectives, Nueva York, Nova, 2017, 1-16.

Artículos

TINBERGEN, N.: "On aims and methods of Ethology", Zeitschrift für Tierpsychologie 20 (1963) 410-433.

MARTIN, S.: "Recepciones de la despersonalización”, Retos 12, 3 (2015) 103-115.

Recursos de internet

LEMOS RODRÍGUEZ, R.: “Conoce los beneficios del aburrimiento", La mente maravillosa (Web), 2015, https://lamenteesmaravillosa.com/conoce-los-beneficios-del-aburrimiento/.

CAMPOS DÍEZ, A.: "Cómo vencer al aburrimiento sin moverse del sofá", El país (online), 2015, https://elpais.com/elpais/2015/02/19/buenavida/1424345312_592437.html.

FLORES, Y.: “Aburrido. ¿Qué hacer contra el aburrimiento?”, El blog de Yes (Blog), 2017, http://www.elblogdeyes.com/aburrido-que-hacer-contrael-aburrimiento/.

ARCHILA, A.: "El aburrimiento", Youtube (Clip de video), 2016, https://www.youtube.com/watch?v=0NXrkHpIFn4.

\section{Revisión}

Cada autor/a revisará detenidamente que de su envío haya sido eliminado cualquier indicio que pudiera denotar su identidad. En el caso de que se 
aluda a publicaciones propias, se sustituirá todos los datos por la indicación [Datos eliminados para favorecer la anonimidad del envío]. Del mismo modo, se cuidará de que el documento no contenga información sobre la autoría en sus propiedades informáticas.

\section{Envío}

Los trabajos deberán ser enviados a través de la plataforma virtual:

https://ojs.uv.es/index.php/REK/

Es aconsejable que los autores revisen los artículos publicados previamente para una mejor adaptación a las normas de estilo o que usen la plantilla disponible en la web de la revista.

\section{Instructions for contributors}

The journal publishes papers in Spanish, German, English, and Portuguese, dealing with Kantian philosophy or with issues raised in it. Contributions must be original and should not exceed 25 pages $(80,000$ characters with spaces). Reviews should not exceed 5 pages $(16,000$ characters with spaces).

\section{Heading}

The text will be headed by title (Times New Roman, 14 points), abstract (max. 100 words, Times New Roman, 10 points) and keywords (max. 5, Times New Roman, 10 points, separated by commas) in both the language in which the work is written and English (if written in Spanish) or Spanish (if written in English, German, or Portuguese). 
2. Style

\subsection{Body text}

The text will be written in Times New Roman, 12 points, multiple spacing 1,15 , line spacing after 6 points, justified paragraphs, first line intended $(1,25 \mathrm{~cm})$, as long as it is not the paragraph with which the section starts.

\subsection{Quotes}

The textual quotes will appear in the text self, by referring to author and year followed by colon and page number. For example:

...so as pointed out by the British naturalist (Darwin 1871: 32)... / ...as so pointed by the British naturalist Darwin (1871: 32) / "... all leads us to that direction" (Autor1; Autor2; Autor3 2018: 15) / "... all leads us to that direction" (Autor1 et al. 2018: 15) / Autor et al. (2018) explained that "all leads us to that direction" (15).

If considered suitable, a further discussion in a footnote is not excluded ( 9 points, Times New Roman, justified, simple space). To indicate that a part of the quoted text has been omitted three points will be used in brackets [...]. If the quote is in a different language, the author should look for a translation, adding the original quote in brackets. If no translation is available, the author will indicate that it has been drawn up by himself by the abbreviation a. trans. or in a footnote if all translations have been made by the author.

"...All leads us in that direction" ["...todo apuntaba a dicha interpretación"] (Autor 2017: 18; 1995: 20) / “...All leads us in that direction" (a. trans.) [“...todo apuntaba a dicha interpretación”] (Autor 1995: 20)

When quotations exceed 4 lines will be placed apart, 10 points, in a justified paragraph and $1,25 \mathrm{~cm}$. 


\section{Kantian quotes}

The citation of Kantian texts will employ the abbreviations established by the Kant-Forschungsstelle Mainz (see website http://www.kant.unimainz.de/, 'Kant-Studien', section 'Hinweise für Autoren').

Example:

(SF, AA 07: 83)

$(K r V, \mathrm{~A} 158 / \mathrm{B} 197)$

\subsection{Sub-headings}

The headings of the sections and subsections shall be indicated by the following numbers: 1, 1.1, 1.1.1., etc., without italics nor bold, Times New Roman, 12 points. To enumerate the elements of a list: i), ii), iii), etc. Each sub-heading will be separated from the previous by a space.

\subsection{Quotation marks and italics}

Inverted commas (" "): literary quotes, e.g. "all leds us in that direction"; titles of papers, book chapters, news, posts, communications... e.g. In the third chapter "The truth and the lie" / That was pointed in his paper "Color perception".

Single quotes (' '): to add emphasis to a word or expression, e.g. This 'truth' is relative.

Brackets ([ ]): to translate words in other language, e.g. Heidegger is talking about the Stimmung [mood]...

Italics: to foreign words and titles of books, journals, diaries, movies, websites, blogs, conferences... e.g. This is what Kant says in his Critique of pure reason / The piece of news published in the New York Times... / The journal Evolutionary Anthropology published... / As the author point in her web Looking for knowledge...

\subsection{Footnotes}

The indicative numbers for footnotes (which in any case will be placed at the end of the document, but at the end of each page) must meet after punctuation. 


\subsection{References or Bibliography}

The complete references will be indicated (in alphabetic order of the name of the authors) at the end of the contribution, in a section entitled Bibliography or References. Should different publications of an author be edited in the same year, they will appear with subscript characters (1999a, 1999b).

\section{Books}

MORENO, J.: Los retos actuales del darwinismo. ¿Una teoría en crisis?, Madrid, Síntesis, 2008.

DARWIN, C.: The Descent of Man and Selection in Relation to Sex, London, John Murray, 1871, 1882 (2 $2^{\mathrm{a}}$ ed.).

: El origen del hombre y la selección en relación al sexo, trans.

Julián Aguirre, Madrid, EDAF, 2006.

Book chapter

KINSBOURNE, M.: "Integrated field theory of consciousness", in MARCEL, A.; BISIACH, E. (eds.): Consciousness in Contemporary Science, Oxford, Oxford University Press, 1988, 35-78.

ROS VELASCO, J.: "Introduction", in: Feminism. Past, Present, and Future Perspectives, New York, Nova, 2017, 1-16.

Papers

TINBERGEN, N.: "On aims and methods of Ethology", Zeitschrift für Tierpsychologie 20 (1963) 410-433.

MARTIN, S.: "Recepciones de la despersonalización”, Retos 12, 3 (2015) 103-115.

Internet resources

LEMOS RODRÍGUEZ, R.: "Conoce los beneficios del aburrimiento", La mente maravillosa (Web), 2015, https://lamenteesmaravillosa.com/conoce-los-beneficios-del-aburrimiento/.

CAMPOS DÍEZ, A.: "Cómo vencer al aburrimiento sin moverse del sofá", El país (online), 2015, https://elpais.com/elpais/2015/02/19/buenavida/1424345312_592437.html. 
FLORES, Y.: “Aburrido. ¿Qué hacer contra el aburrimiento?”, El blog de Yes (Blog), 2017, http://www.elblogdeyes.com/aburrido-que-hacer-contrael-aburrimiento/.

ARCHILA, A.: "El aburrimiento", Youtube (Videoclip), 2016, https://www.youtube.com/watch?v=0NXrkHpIFn4.

\section{Revision}

Each author will make sure that all indication of identity has been removed. In case of quotation of the author's own publications, the reference will be replaced by the sentence "[Reference removed to guarantee anonymous review]". The author will take care that the file does not include personal information within its digital properties.

\section{Sending}

Contibutions should be uploaded to:

https://ojs.uv.es/index.php/REK/

It is advisable that the authors review the previously published articles or use the provided template to better adaptation to the style rules. 